
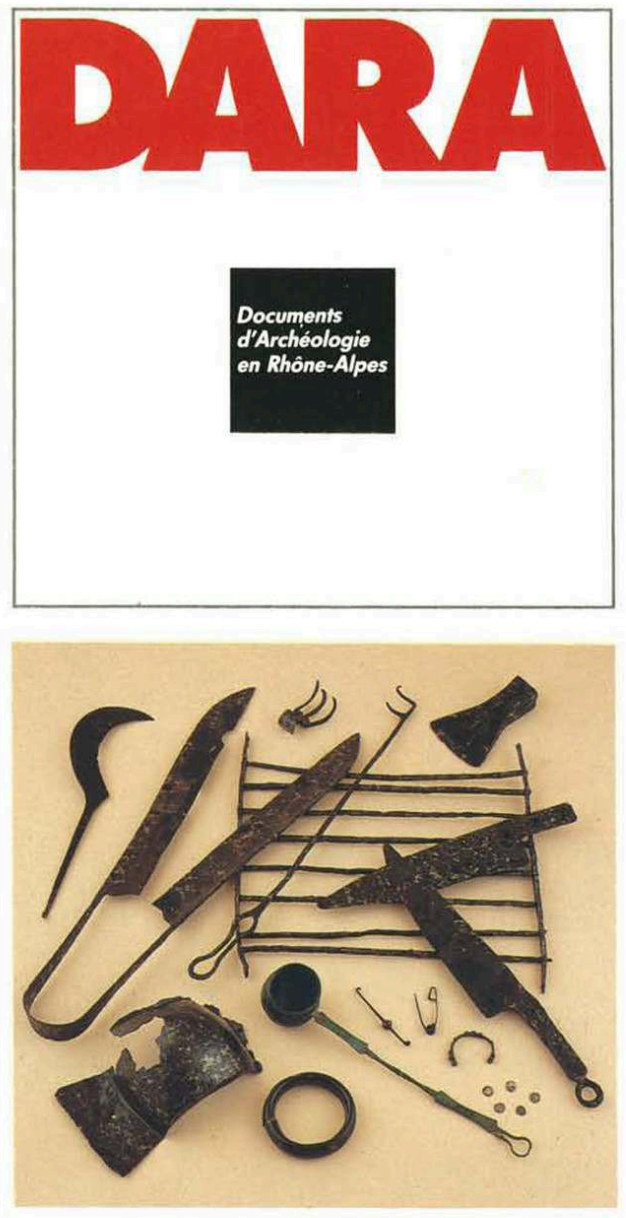

UN DÉPÔT D'OBJETS Gaulois À LARINA

HIÈRES-SUR-AMBY - ISÈRE Franck PERRIN 


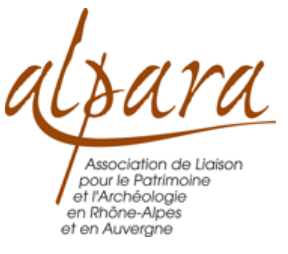

Alpara

\section{Un dépôt d'objets gaulois à Larina}

Hières-sur-Amby, Isère

Franck Perrin

DOI : 10.4000/books.alpara.1596

Éditeur : Alpara

Lieu d'édition : Lyon

Année d'édition : 1990

Date de mise en ligne : 2 juin 2016

Collection : DARA

EAN électronique : 9782916125237

\section{OpenEdition Books}

https://books.openedition.org

\section{Édition imprimée}

EAN (Édition imprimée) : 9782906190085

Nombre de pages : 176

\section{Référence électronique}

PERRIN, Franck. Un dépôt d'objets gaulois à Larina : Hières-sur-Amby, Isère. Nouvelle édition [en ligne] Lyon : Alpara, 1990 (généré le 28 juin 2022). Disponible sur Internet : <http://books.openedition.org/ alpara/1596>. ISBN : 9782916125237. DOI : https://doi.org/10.4000/books.alpara.1596.

Ce document a été généré automatiquement le 12 janvier 2021. Il est issu d'une numérisation par reconnaissance optique de caractères.

(C) Alpara, 1990

Conditions d'utilisation :

http://www.openedition.org/6540 
La simple mention du nom des Allobroges suffit à évoquer le puissant peuple gaulois qui occupait l'actuel Dauphiné et avait pour capitale Vienne en Isère. Mais s'ils entrent très tôt dans l'Histoire grâce aux auteurs grecs et latins, leur culture matérielle et leur mode de vie nous restent très mal connus. Le présent ouvrage prend donc un relief tout particulier puisqu'il constitue l'une des rares publications récentes consacrées à un site gaulois dans cette région.

Le camp de Larina est surtout connu aujourd'hui pour son habitat de l'Antiquité tardive et du Haut Moyen-Âge, bien que la présence humaine depuis l'âge du Bronze y ait été révélée dès le siècle dernier. Pour la période de l'âge du Fer, autour de laquelle est centré ce volume, la nature de l'occupation du site restait énigmatique : habitat de hauteur fortifié ? sanctuaire?

L'analyse exhaustive des mobiliers découverts dans une faille de la falaise qui limite le site, tente d'apporter des éléments de réponse. La comparaison de cet ensemble exceptionnel qui rassemble à la fois des objets de parure, des outils agricoles, artisanaux et domestiques, des armes, des monnaies... avec des ensembles similaires provenant d'autres sites conduit l'auteur à suggérer que nous pourrions être en présence d'un de ces vastes dépôts d'objets -sacrifiés ou non - que l'on trouve disséminés dans l'ensemble de l'aire celtique. Les spécificités du gisement l'amènent à envisager une interprétation nouvelle et inattendue du Camp de Larina à l'âge du Fer.

Enfin, l'inventaire détaillé des objets et leur situation dans le contexte de la Protohistoire régionale, permettent de dégager la place culturelle et économique des Allobroges à la veille de la conquête césarienne: contacts avec Marseille, affinités avec le Plateau Suisse, particularismes locaux.

Die bloBe Erwahnung des Namens der Allobrogen geniigt, um das mächtige gallische Volk heraufzubeschwören, das das heutige Dauphiné bewohnte, und dessen Hauptstadt Vienne an der Rhône war. Wenn auch dieser Volksstamm dank den griechischen und lateinischen Autoren in die Geschichte friih einging, so bleibt uns dessen Kultur und Lebensweise ziemlich unbekaant. Diese Tatsache verleiht dem jetzigen Werk seinen besonderen Wert, um so mehr als es eine der weinigen neuen Veroffentlichun Die bloBe Erwahnung des Namens der Allobrogen geniigt, um das mächtige gallische Volk heraufzubeschwören, das das heutige Dauphiné bewohnte, und dessen Hauptstadt Vienne an der Rhône war. Wenn auch dieser Volksstamm dank den griechischen und lateinischen Autoren in die Geschichte friih einging, so bleibt uns dessen Kultur und Lebensweise ziemlich unbekaant. Diese Tatsache verleiht dem jetzigen Werk seinen besonderen Wert, um so mehr als es eine der weinigen neuen Veroffentlichungen ist, die einer gallischen Ansiedlung in dieser Gegend gewidmet ist. Das Lager bei Larina ist heute bekannt, vor allem als Wohnlage in der spaten Vorzeit und in hohem Mittelalter, obwohl wir bereits seit dem letztzen Jahrhundert wissen. daB der Mensch schon in der Bronzezeit hier anwesend war. Was die Eisenzeit betrifft, um die es in diesem Werk vorwiegend geht, so blieb der Zweck der Ansiedlung noch ratselhaft : hohe Festung oder Heiligtum ? Die ausfiihrliche Untersuchung des in einer Felsenspalte am Rand der Siedlung entdeckten Mobiliars bemüht sich einige Antworten zu geben. Der Vergleich dieser auBergewöhnlichen Menge von Schmuck, Münzen, Agrar- sowie Haus- und Flandwerkzeugen mit anderen Funden in anderen vergleichbaren Lagern läBt den Autor vermuten, daB es sich hier um eines dieser reichhaltigen Lager von Gegenständen handelt - ob aufgeopfert oder nicht ? - die wir hier und da auf dem gallischen Gebiet und in der Keltischen Welt zerstreut finden. Die Eigentümlichkeiten der Lagerstatte führen zu einer neuen, unerwarteten Deutung des Lagers bei Larina in der Eisenzeit. Das ausfiihrliche Inventar der Gegenstände, sowie deren Lage in der regionalen der Allobrogen zu bestimmen, kurz vor Caesars Einmarsch : Beziehungen zu Marseille. Verbundenheit mit der Schweizerischen Hochebene, lokale Eigenarten.gen ist, die einer gallischen Ansiedlung in dieser Gegend gewidmet ist. Das Lager bei Larina ist heute bekannt, vor allem als Wohnlage in der spaten Vorzeit und in hohem Mittelalter, obwohl wir bereits seit dem letztzen Jahrhundert wissen. daB der Mensch schon in der Bronzezeit hier anwesend war. Was die Eisenzeit betrifft, um die es in diesem Werk 
vorwiegend geht, so blieb der Zweck der Ansiedlung noch ratselhaft : hohe Festung oder Heiligtum ? Die ausfiihrliche Untersuchung des in einer Felsenspalte am Rand der Siedlung entdeckten Mobiliars bemüht sich einige Antworten $\mathrm{zu}$ geben. Der Vergleich dieser auBergewöhnlichen Menge von Schmuck, Münzen, Agrar- sowie Haus- und Flandwerkzeugen mit anderen Funden in anderen vergleichbaren Lagern läBt den Autor vermuten, daB es sich hier um eines dieser reichhaltigen Lager von Gegenständen handelt - ob aufgeopfert oder nicht ? - die wir hier und da auf dem gallischen Gebiet und in der Keltischen Welt zerstreut finden. Die Eigentümlichkeiten der Lagerstatte führen zu einer neuen, unerwarteten Deutung des Lagers bei Larina in der Eisenzeit. Das ausfiihrliche Inventar der Gegenstände, sowie deren Lage in der regionalen der Allobrogen zu bestimmen, kurz vor Caesars Einmarsch : Beziehungen zu Marseille. Verbundenheit mit der Schweizerischen Hochebene, lokale Eigenarten.

The Allobroges: the name itself conjures up the powerful people of Gauls who occupied what is now the Dauphiné, and whose capital was Vienne, in Isère. While they appear early on in History, thanks to Greek and Roman authors, their material culture and their way of life remain largely unknown to us. The present work therefore takes on particular prominence, as it is one of the few recent publications dealing with a gaul site in that area. The Camp of Larina is especially known today for its settelements of late Antiquity and of the Early Middle Ages, although the presence of humans since the Bronze Age was testified as early as the 19 th century. As for the Iron Age, the period which this volume focuses on. the type of settlement remained an enigma: fortified heights? Sanctuary? A thorough analysis of the objects found in a rift in the cliff that borders the site tries to offer some elements of an answer. The study of this exceptional collection, which includes ornemental objects, agricultural, domestic and craftmen's tools, weapons, coins, compared with other sites having revealed similar collections, leads the author to suggest that this site may be one of the large stores of objects (sacrificial or not) wich can be found scattered all over the Gaul territory and the Celtic world. The specific features of the findings lead him to view a new, unexpected interpretation of the Camp of Larina in the Iron Age. Finally, the detaile inventory of the objects and their place in the context of regional Protohistory give us an insight into the cultural and economic importance of the Allobroges just before the caesarian conquest : contacts with Marseilles, connections with the Swiss Plateau, local particularities.

La sola menzione del nome degli Allobrogi basta ad evocare il potente popolo gallico che occupava l'attuale Delfinato la cui capitale era Vienne nell'Isère. Tuttavia, se tale popolo entra prestissimo a fare parte della storia tramite i racconti degli autori greci e latini, la sua cultura materiale ed il suo modo di vivere sono a noi poco noti. Di conseguenza, la presente opera assume un carattere di particolare rielevo in quanto costituisce una delle poche pubblicazioni recenti dedicate ad un'insediamento gallico nella regione. Il campo di Larina è noto oggi sopratutto per il suo habitat della tarda antichità e dell'primo medievo, benché la presenza umana dall'età del Bronzo vi sia stata rivelata fin dallo scorso secolo. Per quanto riguarda il periodo dell'età del Ferro intorno al quale è imperniato questo volume, il tipo di occupazione del sito rimaneva enigmatico : habitat di altezza fortificato ? santuario ? L'analisi esauriente del suppellettile scoperto in una faglia della falesia che limita lil terreno tenta di addurre elementi di risposta. Il confrontro tra questo insieme eccezionale che raccoglie oggetti di ornamento, arnesi agricoli. artigianali e domestici, armi, monete... ed insiemi simili portati alla luce in altri scavi archeologi conduce l'autore a suggerire che potrebbe trattarsi di uno di quei vasti depositi di oggetti sacrificati o no - sparsi per il territorio gallico ed il mondo celtico. Le caratteristiche specifiche del suppellettile lo portano il oltre a proporre uno nuova ed inattesa interpretazione del campo di Larina nell'età del Ferro. Infine, l'inventario particolareggiato degli oggetti nonchè la loro valutazione all'interno del contesto protostorico della regione permettono di mettere in evidenza 
l'importanza culturale ed economica degli Allobrogi alla vigilia della conquista cesariana : contatti con Marsiglia, affinità con l'Alto piano svizzero, particolarismi locali. 
SOMMAIRE

\section{Avant-propos}

Introduction

Chapitre 1. Le plateau de Larina: les découvertes

Michel Feugère, Brigitte Fischer, Katherine Gruel et Roger Collot

Contexte archéologique

Historique des recherches sur le plateau

Les documents lateniens du plateau

La céramique

Une parure en verre

Les monnaies

Le coin monétaire gaulois

L'occupation du plateau à l'âge du Fer

\section{Chapitre 2. Le site de La Chuire}

Jean-Paul Morel, Brigitte Fischer, Patrice Méniel et Henri Duday

Les données de terrain

Les découvertes de la grotte

Les découvertes de la faille

\section{Chapitre 3. Synthèse}

Chronologie du site

Nature du gisement

Le site et son contexte culturel

Index des lieux de conservation et des données typométriques

Bibliographie

Crédits illustrations 
NOTE DE L'ÉDITEUR

À Catherine 


\section{Avant-propos}

1 C'est un exceptionnel ensemble d'objets métalliques et céramiques découverts à Larina, sur la commune de Hières-sur-Amby, près de Lyon, qui a éveillé l'attention du personnel de la Direction des Antiquités Historiques de Rhône-Alpes. A la demande de J. Lasfargues, alors directeur des Antiquités, un inventaire fut réalisé par nos soins. Devant les nombreuses interrogations que suscitaient ces objets, une recherche plus approfondie nous conduisit à rédiger, sous la direction de Venceslas Kruta, directeur d'étude à la IV ection de l'Ecole Pratique des Hautes Etudes, Paris, Sorbonne. un mémoire, soutenu en 1988. Sa disponibilité de tous les instants et ses constants encouragements ont permis une étude dont la publication devait constituer l'aboutissement : j'espère avoir été digne de sa confiance.

2 Le premier manuscrit fut confié par l'éditeur à P. Arcelin et J.-P. Guillaumet, chercheurs au CNRS : chacun à leur manière, ils ont su dynamiser un texte dont l'élaboration a été suivie de bout en bout par M. Vaginay, alors ingénieur de la Direction. Qu'ils trouvent ici l'expression de notre sincère reconnaissance. Cette étude s'est ensuite progressivement enrichie des contributions de spécialistes - universitaires et chercheurs au CNRS-; leur collaboration a permis la critique de diverses hypothèses, incitant ainsi à la recherche de nouvelles interprétations, mais elle a surtout permis de mettre en lumière la capacité d'ouverture sur l'extérieur du site de Larina, entre le IXe et le $\mathrm{I}^{\text {er }}$ siècle av. n. è. Cette vitalité est le reflet de sa nature géographique, la moyenne vallée du Rhône, artère aux multiples ramifications située entre Méditerrannée et Europe intérieure, qui fut explorée dès les années 70 par A. Bocquet, G. Chapotat, Ch. Lagrand. Ce volume ne sera, nous l'espèrons, que le premier pas d'un renouveau de la recherche sur l'âge du Fer.

3 Sa réalisation a été rendue possible grâce au concours et au soutien de nombreuses personnes, professionnels de l'archéologie ou plus simplement particuliers sensibles au passé. Ma reconnaissance va à $M$. Pin, maire de Hières-sur-Amby et président de la Maison du Patrimoine et à P. Porte, conservateur des fouilles et directeur de cette structure, pour les facilités accordées lors des recherches de terrain et de l'étude de la collection aujourd'hui exposée à Hières. Dans l'avenir germera peut-être le projet d'une fouille de grande envergure de la faille de La Chuire, avec des moyens adaptés à l'ampleur de la tâche. Je n'oublierai pas J. Lasfargues, conservateur du musée de la civilisation gallo-romaine de Lyon et F. Leyge, conservateur adjoint, qui ont témoigné 
d'une efficacité stimulante face à cette collection actuellement répartie entre plusieurs musées. Ainsi le musée de Lyon est à l'origine de la restauration du métal effectuée par M.-C. Depassiot et V. Langlet, au laboratoire du centre d'études et de recherches archéologiques de Vienne, dirigé par R. Lauxerois. Fruit d'une étroite collaboration, à laquelle j'associe $\mathrm{G}$. Chapotat, la mise en évidence de productions originales de l'art celtique constitue un acquis non négligeable qu'il conviendrait de renforcer en poursuivant ce type d'investigation.

4 Je ne manquerai pas de remercier ici pour leur aide technique $H$. Ducasse et ses collaborateurs du Centre de Recherches Archéologiques de Sophia-Antipolis ainsi que J. Burnouf, responsable des fouilles de la ligne $\mathrm{D}$ du métro de Lyon et son équipe de publication. Une attention particulière à C. Plantevin, V. Bel. J. Bellon, V. Guichard et J. Vital pour leur aide discrète et efficace et à tous les fouilleurs bénévoles: C. Bellon, R. Carbonnel, M.-A. Carron, R. Convert, D. Hote, E. de Nattes, P. Richard et F. Thiériot. Enfin il convient de rappeler que sans l'Abbé François Nicollet $\dagger$, J.-C. Chausse, J.-P. Pélatan $\uparrow$. Ch. Revellin, amateurs éclairés qui ont su découvrir le site et en souligner l'intérêt auprès de la communauté scientifique, cette étude n'aurait pu exister.

1- Le Camp de Larina et la faille de La Chuire : vue des falaises dominant le village de Hières-surAmby

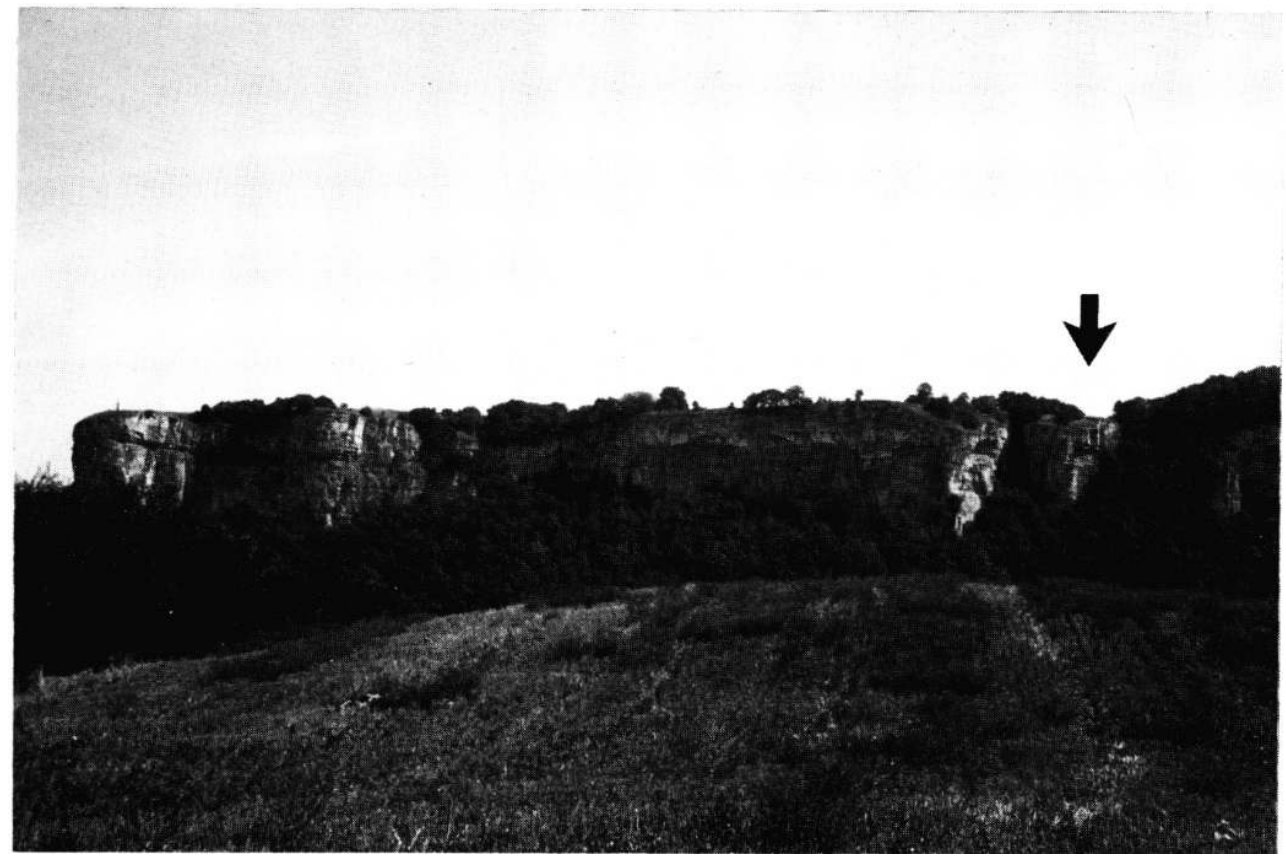




\section{Introduction}

2- La Gaule d'après César : localisation du Camp de Larina, des Allobroges et des principaux peuples gaulois

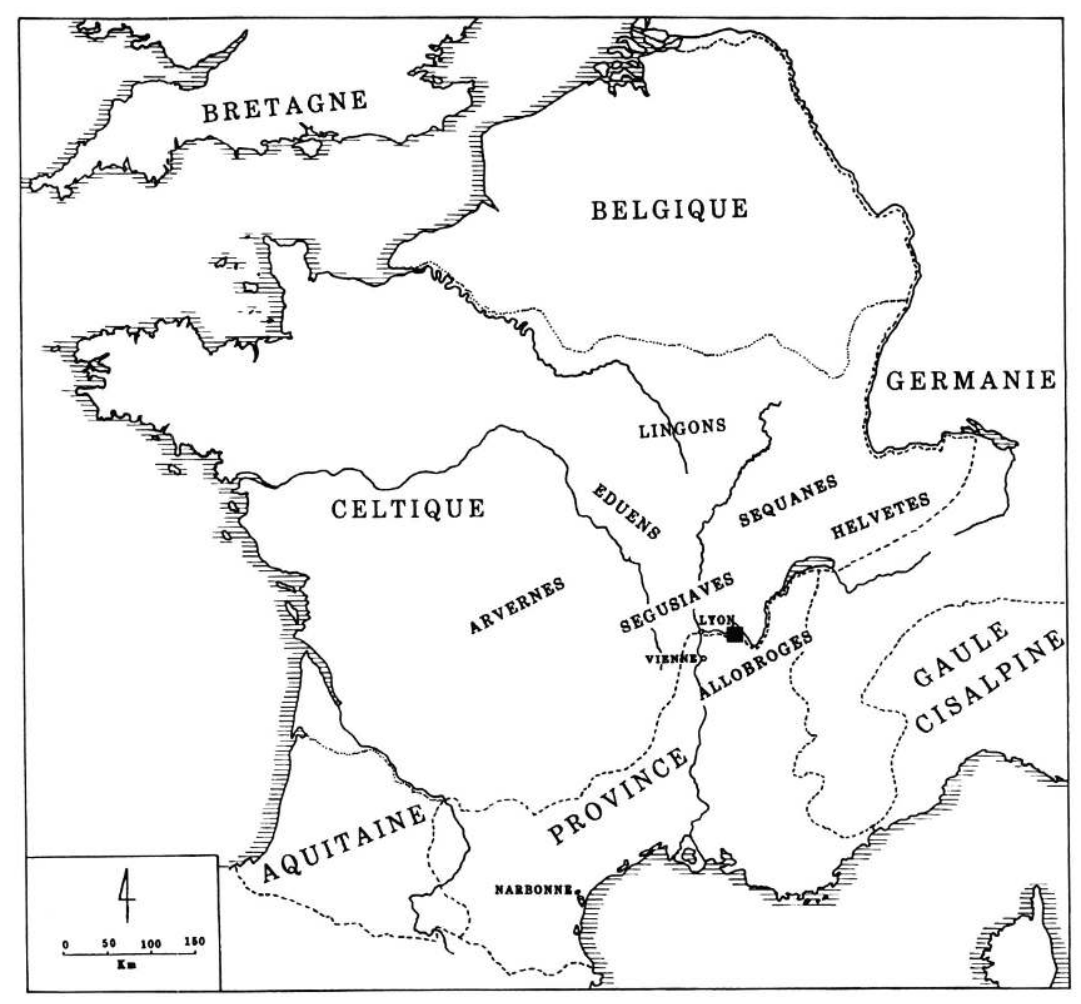

1 Les premières mentions de l'ethnie celtique allobroge apparaissent dans les textes concernant la deuxième guerre punique, relatée par les auteurs grecs et latins des époques républicaine et impériale (Barruol 1975). A la fin du IIIe siècle av. n. è., le passage de l'expédition militaire d'Hannibal dans le Sud de la Gaule est l'occasion pour les auteurs antiques de décrire l'attitude des différents peuples portant des noms celtiques vis-à-vis des Carthaginois (Volques, Cavares...). Par la suite, le comportement belliqueux des Allobroges (fig. 2) à l'égard du peuple romain fournira aux commentateurs antiques la matière à de multiples mentions. Mais si ce peuple, qui 
occupait l'actuel Dauphiné, est bien connu par la philologie, son approche à partir de l'analyse des vestiges archéologiques reste cependant très lacunaire.

Dès le XIXe siècle pourtant, un certain nombre de découvertes sont rapportées à l'âge du Fer, en particulier par le savant E. Chantre, puis signalées par J. Déchelette dans son Manuel. Il s'agit de sépultures assez exceptionnelles (tombes à char de la Côte-SaintAndré et de Saint-Romain-de-Jalionas, Isère) qui cependant ne feront l'objet que de brèves relations dans la littérature archéologique. Au début du XXe siècle, le Grenoblois H. Müller signale plusieurs découvertes datables du second âge du Fer et publie la sépulture de guerrier de Voreppe qui demeure l'ensemble funéraire le mieux décrit de l'époque de La Tène en Dauphiné (Müller 1913). Il faut attendre les années 1970 pour voir la parution des deux principaux ouvrages concernant l'âge du Fer en pays allobroge : «L'Isère pré-et protohistorique » de $\mathrm{A}$. Bocquet et «Le matériel de La Tène III découvert sur la colline de Sainte-Blandine à Vienne (Isère)» de G. Chapotat (Bocquet 1969 a; Chapotat 1970). Depuis peu, les découvertes et le réexamen de collections anciennes se multiplient et permettent une première esquisse du peuplement du pays allobroge au second âge du Fer (structures et niveaux d'habitats de Vénissieux dans le Rhône et de Vienne ; redécouverte des sépultures de Saint-Romainde-Jalionas) (fig. 3).

3. Le territoire des Allobroges et les découvertes de l'âge du Fer

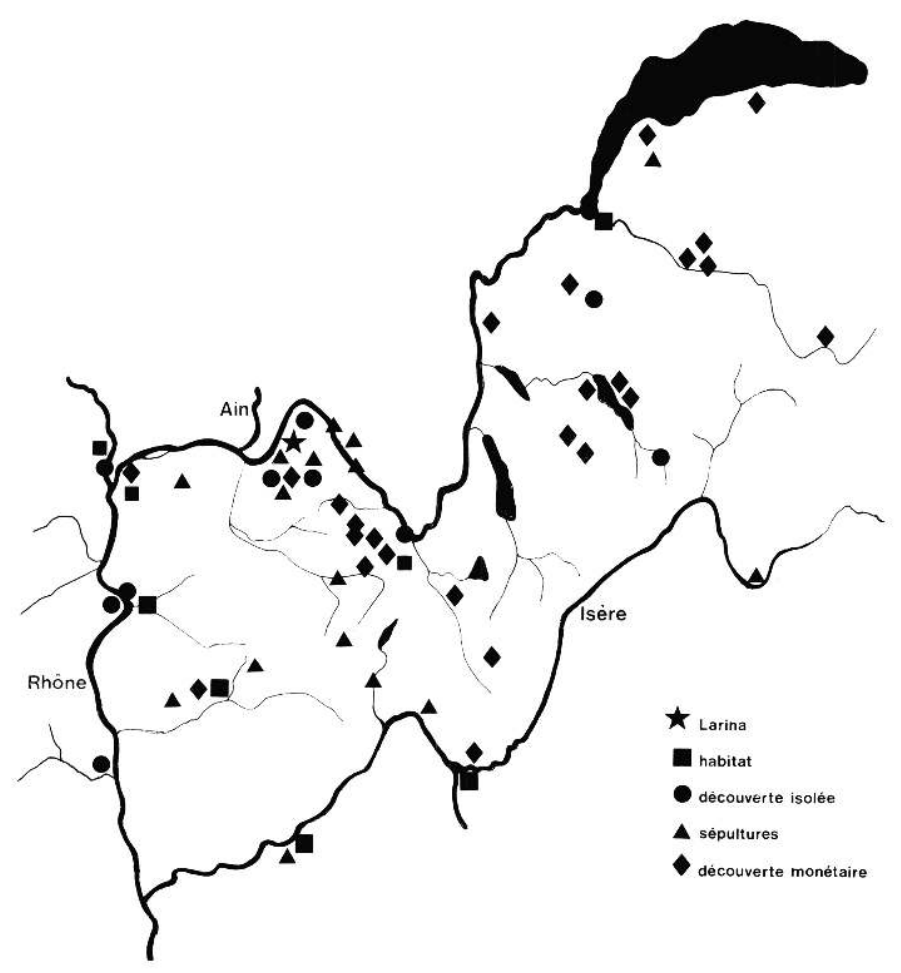

Cette époque est principalement attestée par des découvertes funéraires, plus particulièrement par des sépultures de guerriers. Les habitats sont mal localisés ou encore trop peu étudiés : les rares sites connus sont le plus souvent des gisements de hauteur (oppidum de Rochefort, de Saint-Loup et de Plan en Isère) dont les occupations sont mal datées; l'existence de vestiges de La Tène sur des sites gallo-romains laisse entrevoir des occupations pré-augustéennes (Revel-Tourdan, Isère). Il faut mettre à 
part le cas de Vienne qui a livré depuis longtemps des témoins de La Tène dans le lit du Rhône, sur une hauteur dominant la ville moderne et dans celle-ci (Feugère 1982; Pelletier 1966; Chapotat 1970). De même, il faut distinguer le site de Genève (Suisse), mentionné dans les Commentaires de César sur la Guerre des Gaules, dont la connaissance vient d'être tout récemment renouvelée par l'archéologie (Bonnet 1989).

4 Cet état de la connaissance qui privilégie les contextes funéraires au détriment des habitats est certainement dû à l'histoire de la recherche archéologique régionale, marquée par la trouvaille en 1888 du char de la Côte-Saint-André (Chapotat 1962). Ce bilan, qui tend à se modifier rapidement au gré des découvertes récentes, montre que le Dauphiné à l'âge du Fer se rapproche des régions alpines et même du Plateau Suisse où la majeure partie des structures appartenant au second âge du Fer est de type funéraire. La situation est similaire pour les périodes antérieures; le premier âge du Fer est surtout connu à partir de découvertes funéraires (nécropoles de Rochefort, d'Ornon, du Mont-de-Lans en Isère) ; quant à l'âge du Bronze final, c'est surtout par des trouvailles en grottes (sépulcrales ou non) que cette époque a pu être appréhendée (Bocquet 1969 a). En pays allobroge sur le territoire français, seul un secteur a fait l'objet d'une succession de travaux archéologiques et de trouvailles fortuites: il s'agit de la région de l'Isle Crémieu (fig. 4), principalement du site fortifié de hauteur du Camp de Larina à Hières-sur-Amby et plus spécialement d'un des ses gisements : La Chuire (fig. 1). 


\title{
Chapitre 1. Le plateau de Larina : les découvertes
}

\author{
Michel Feugère, Brigitte Fischer, Katherine Gruel et Roger Collot
}

1 Le site protohistorique de La Chuire est un des gisements archéologiques actuellement reconnus à l'intérieur d'un ensemble de parcelles délimitées par une levée de terre artificielle : le Camp de Larina.

2 Ce dernier est situé en Bas-Dauphiné, dans une région circonscrite par les premiers reliefs des Alpes du Nord, la bordure est du Massif Central et le couloir rhodanien, et l'extrémité méridionale du Jura. Localisé au nord du département de l'Isère, à une trentaine de kilomètres à l'est de l'agglomération lyonnaise et du confluent RhôneSaône, le Camp de Larina se trouve sur la bordure ouest d'un plateau jurassique calcaire dénommé l'Isle Crémieu. Celui-ci, de forme triangulaire et d'une surface d'environ deux cents kilomètres carrés, est bordé - comme son nom l'indique - par plusieurs cours d'eau : à l'est, au nord et à l'ouest par le Rhône; au sud par la Bourbre, la Save et des zones marécageuses, résidus d'un ancien cours du Rhône. 


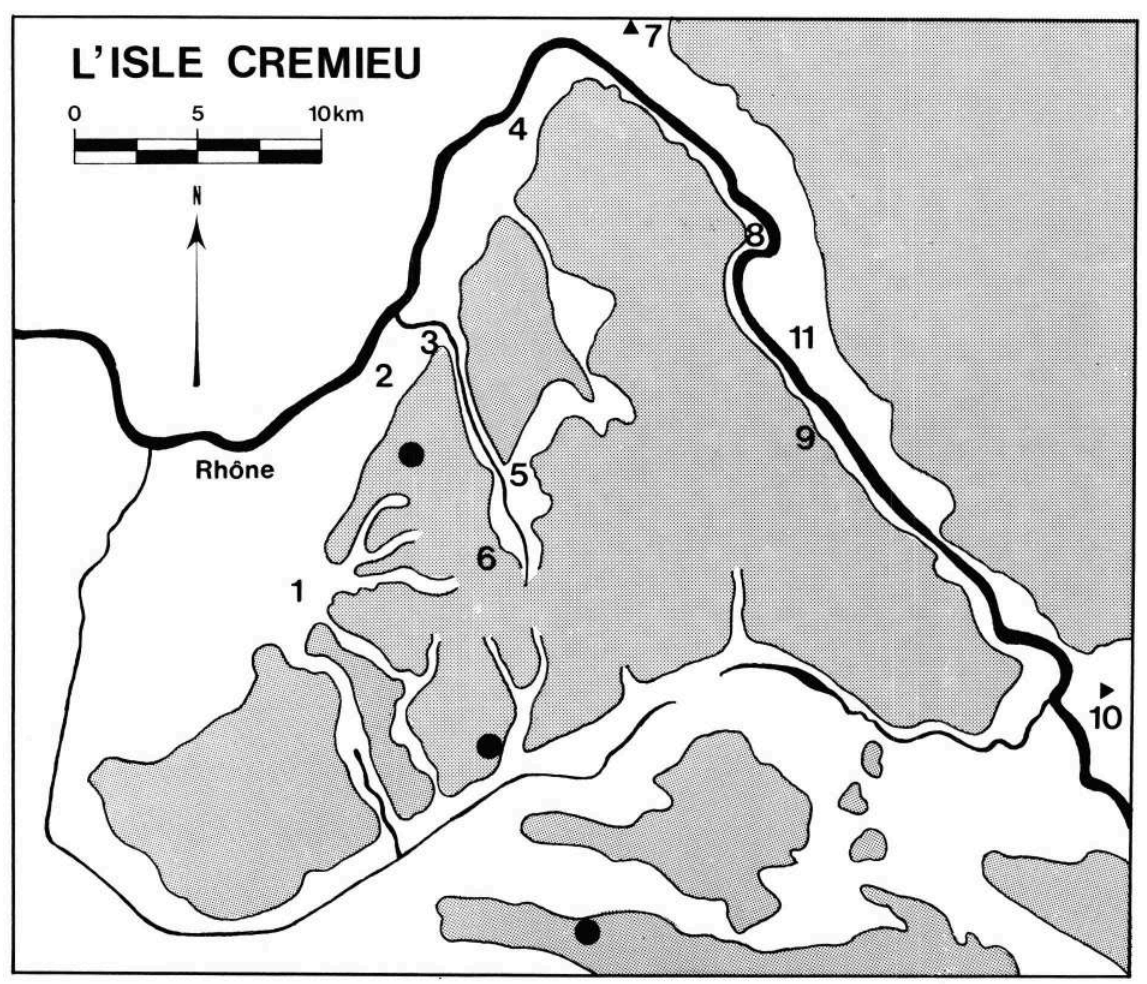

3 Le Camp de Larina est situé à l'extrémité d'un éperon, en partie détaché du plateau de Crémieu par une étroite vallée : le Val d'Amby. Actuellement, le site est partagé entre la commune de plaine de Hières-sur-Amby et la commune de hauteur d'AnnoisinsChatelans ; il domine ainsi d'environ deux cents mètres le cours du Rhône, distant d'un kilomètre et dont il est séparé par la tourbière d'Hières, et le confluent de l'Ain et du Rhône situé actuellement à quelques kilomètres ${ }^{1}$. De plus, il est localisé tout à la fois, au débouché de la haute vallée du Rhône, au moment où le fleuve quitte les reliefs du Jura pour se diriger vers la Saône, et en aval de la rupture de charge de Sault-Brenaz, où des rapides interdisent toute navigation. Le franchissement du fleuve face au Camp de Larina est autorisé par l'existence de gués. Dans le prolongement de ceux-ci, le Val d'Amby permet la traversée du plateau, et par là, l'accès à la vallée de l'Isère et aux cols alpins.

4 Les ressources naturelles de ce terroir sont des plus faibles. A quelques exceptions près, la majeure partie des terres du plateau de Crémieu est actuellement peu rentable, tant pour l'agriculture, que pour l'élevage. Les nombreux marais de cette région ont cependant pu constituer de multiples blachères pour le bétail (Bravard 1987 : p. 159). Les ressources minérales sont peu variées, cependant quelques galeries d'extraction du minerai de fer sont connues, certaines ayant été notablement exploitées au XIXe siècle. En fait, le principal attrait du Camp de Larina est certainement sa situation privilégiée, contrôlant la circulation sur le Rhône et surplombant une région dominée par la présence de l'eau (Porte 1980 ; Bravard 1987). 


\section{Contexte archéologique}

5 Le Camp de Larina n'est pas le seul site protohistorique de l'Isle Crémieu (pour l'âge du Bronze cf. Bocquet 1969 a). De nombreuses découvertes, principalement de l'âge du Fer, ont été faites depuis le XIXe siècle, tant sur le plateau, que sur l'étroite zone circonscrite par le cours du Rhône et les reliefs (fig. 4).

$6 \quad \mathbf{n}^{\circ} 1$ : Crémieu-La Levrettière-(Isère).

De la commune de Crémieu proviennent plusieurs objets datables de l'âge du Fer; les conditions de leurs découvertes sont inconnues. Il s'agit d'une part, d'un fragment de poignée d'épée en bronze du Hallstatt C (Bocquet 1969 a : p. 235) et d'autre part, d'une épée incomplète en fer, appartenant probablement aux phases $C$ ou D de La Tène. La lame de cette arme (longueur $663 \mathrm{~mm}$ ) montre sur une face les marques de deux repliements successifs; le premier est visible sur le premier tiers de l'objet, le second sur le dernier tiers. Ce mode de destruction implique l'utilisation d'un support rigide et anguleux (poteau carré ou objet métallique tranchant) et semble moins fréquent que les torsions réalisées manuellement ou à l'aide d'un support circulaire qui donnent à l'objet un profil curviligne. L'épée est actuellement droite et a sans doute été dépliée lors de sa découverte. Bien que sans contexte connu, cette arme provient probablement d'une sépulture de guerrier du second âge du Fer (Bocquet 1971 : p. 101).

7 Dans les environs de Crémieu, un petit trésor monétaire a été découvert peu avant 1867 : un statère et un quart de statère (B. N. 5315 et 5317) attribués aux Ambarres (?) sont encore conservés (Loriot 1988 : p. 44).

$\mathrm{n}^{\circ} 2$ : Vernas/Saint-Romain-de-Jalionas (Isère).

En 1818, la découverte d'un ensemble d'objets protohistoriques est signalée. Le mobilier est ensuite conservé dans une collection privée et ce n'est que très récemment qu'il a pu être inventorié (Guillaumet 1986: p. 12) et confronté à des notes manuscrites relatant la fouille. Le mobilier comprend de l'armement (épées, lances, boucliers), de nombreuses pièces de char et de harnachement, un ensemble de vaisselle en bronze (seau, situle, patelle), quelques parures, de l'outillage et des bronzes figurés de type italique. Il s'agirait d'une (ou de plusieurs) sépulture (s) à incinération sous tumulus de La Tène D (Chantre 1880: p. 44; Raynard 1819: p. 192). La redécouverte de cet ensemble funéraire a conduit à une nouvelle étude des tumuli conservés entre le cours du Rhône et les falaises de l'Isle Crémieu. Ces sépultures jalonnaient vraisemblablement un axe de circulation qui conduit aux abords du Camp de Larina, puis aux gués qui permettent le franchissement du Rhône. La fouille de l'un d'entre eux a permis d'observer une inhumation de guerrier de type aristocratique (parures en or, vaisselle en bronze) datable de l'extrême fin du Bronze final ou du tout début de l'âge du Fer (Verger 1988).

$9 \mathbf{n}^{\circ} 3$ : Hières-sur-Amby, Camp de Larina et faille de La Chuire (Isère).

$10 \mathbf{n}^{\circ} \mathbf{4}$ : La Balme-les-Grottes (Isère).

La grotte de La Balme a livré une importante série de céramiques datables du Bronze final dans un contexte qui semble funéraire. Le second âge du Fer est attesté par quelques parures dont un fragment de fibule de schéma La Tène $\mathrm{II}^{2}$.

$11 \quad \mathbf{n}^{\circ} 5$ : Optevoz (Isère).

En 1931, l'exploitation d'une carrière a permis la découverte d'une épée dans son 
fourreau à entrée droite et d'une pointe de lance. Il s'agit assurément d'une sépulture à incinération datable de La Tène D 1 (Millier 1931 : p. 67 : Bocquet 1970 : p. 174).

$\mathrm{n}^{\circ} 6$ : Siccieu-et-Carisieu (Isère).

En 1929, des travaux agricoles permirent la découverte de deux ciseaux en bronze et de sept pointes de flèches en bronze, de type gréco-scythe (Snodgrass 1964 ; Kleemann 1955 : p. 147 ; Sulimirski 1961 : p. 793). La seule mention de cette trouvaille indique que ces armes et ces outils proviennent d'un tas de pierres (Bocquet 1969 b).

13 Il n'est guère aisé de fixer une datation pour ces armes largement répandues durant la protohistoire méditerranéenne et dont la forme est encore connue à l'époque galloromaine (Erdmann 1976: p. 56-10). En Gaule, des armes offensives grecques (flèches, javelots) sont connues aux VIe-IVe siècles av. n. è. dans la périphérie du comptoir phocéen de Marseille et jusqu'en Languedoc (Arcelin 1982: p. 104-105). Quelques exemplaires sont signalés au nord du Camp de Larina jusqu'au val de Loire (Primas 1974 : p. 36 ; Millotte 1963 : p. 333 : Anonyme 1987 a : p. 16). D'autre part, plusieurs découvertes proviennent du domaine celtique occidental (Sievers 1984: Taf. 110) et oriental (Benadik 1983: p. 85; Dusek 1966: Tav. LXV1I1). Ces objets ont vraisemblablement circulé par deux axes différents (Danube, Rhône) pour parvenir dans le domaine hallstattien; rien ne permet de dire si ces flèches faisaient partie de panoplies d'archer (arc et carquois) ou si elles ont circulé isolément. L'association de ces flèches à des ciseaux en bronze indique une datation haute dans le premier âge du Fer et évoque le cas particulier d'un dépôt d'artisan bronzier (ou éventuellement une sépulture sous tumulus). La situation géographique du dépôt de Siccieu et la rareté des pointes de flèches à triples ailerons en Italie (ex. de Cumes et de Catania) indiquent que ces objets proviennent certainement du domaine massaliote; quelques exemplaires découverts dans les Hautes-Alpes et la Drôme constituent les intermédiaires entre Marseille et le dépôt de Siccieu-et-Carisieu (Millier 1904 : pl. 1, nº 6 ; Guillot 1966 : fig. 7, $n^{\circ} 1$ ). Leur présence en Gaule intérieure n'en demeure pas moins curieuse dans la mesure où il s'agit d'armement grec et on peut se demander si ces objets ne trahissent pas une présence physique de Grecs (ou d'indigènes fortement hellénisés) (ChausserieLaprée 1984 : p. 26-31).

\section{$n^{\circ} 7$ : Ambérieu - Grotte du Gardon-(Ain).}

Outre des céramiques du Bronze final, cette cavité a livré dès 1957 des vases d'importation d'origine provençale : fragment d'anse d'amphore à pâte micacée, d'anse de forme haute en céramique peinte "pseudo-ionienne» et céramique grise monochrome. Le gisement a été aussi fréquenté durant le second âge du Fer, puisque une fibule de schéma La Tène II en provient (Bornatico 1957 : p. 34 ; Treffort 1986 : p. $100)$.

$15 \mathbf{n}^{\circ} 8$ : Montalieu-Vercieu - Chamboux-(Isère).

Très récemment, les travaux d'aménagement du cours du Rhône ont permis d'observer trois sépultures à incinération de l'âge du Fer. Le mobilier (fibule en fer, bracelet d'enfant) permet de dater ces tombes de la seconde moitié du Ve siècle av. n. è. (Vital 1986).

$16 \quad \mathbf{n}^{\circ} 9$ : Mépieu - Champoulaillier-(Isère).

En 1970, des labours ont détruit entre sept et dix sépultures à incinération en fosse datables de La Tène D1 et peut-être même de la phase antérieure. Le mobilier, hors contexte, comprend de l'armement (épées dans leurs fourreaux pliés, umbo, lance), de la parure (fibule de Nauheim et de schéma La Tène II en fer, bagues, anneau de 
ceinture) (Anonyme 1986 a : p. 24). Le mobilier de cette nécropole rappelle celui des sépultures de Montmort (Côte-d'or) (Guillaumet 1976).

$\mathrm{n}^{\circ} 10$ : Les Avenières-Pont d'Evieu-(Isère).

Découverte en 1959, dans un bras du Rhône, d'un casque en bronze (Cucherat 1960 : p. 41-43) analogue à l'exemplaire de Belleville (Rhône) provenant de la Saône (Gallay 1972 : p. 311-313). Ces casques, du type de Mannheim (RFA), appartiennent à une série de découvertes le plus souvent aquatiques. Les trouvailles d'armes (épées dans leur fourreaux, lances, casques) dans les fleuves ont suscité de nombreuses interprétations, faute d'une connaissance suffisante des contextes archéologiques: en dernier lieu on peut les rapprocher des rites militaires grecs pratiqués lors de la traversée d'un fleuve (Brunaux 1987) ; le même rituel est mentionné dans la littérature médiévale galloise, dans le Mabinogi relatant les aventures de Kulhwch et Olwen (Loth 1979: p. 110). Cependant, toutes ces mentions ne concernent que les épées et non les casques; la présence de ces derniers dans le lit des fleuves ne s'explique donc pas nécessairement de la même manière que l'armement offensif. Il faut toutefois noter que le toponyme du lieu de la découverte indique sans doute l'existence d'un gué, permettant de franchir le Rhône.

\section{$n^{\circ} 11$ : Briord-Les Plantées-(Ain).}

La fouille de la nécropole gallo-romaine des Plantées a livré plusieurs fibules de schéma La Tène II attribuables aux phases $\mathrm{Cl}$ et $\mathrm{C} 2$ du second âge du Fer et dont on connaît des parallèles dans les nécropoles du Plateau Suisse. Certains exemplaires sont intacts et leur état de conservation pourrait indiquer un contexte funéraire à incinération (Perraud 1971 : p. 43-46).

De ce bref inventaire, on peut surtout retenir l'importance des découvertes funéraires qui entourent le Camp de Larina et l'Isle Crémieu. La plupart de ces découvertes sont anciennes et mal documentées, mais il semble bien que l'on ait surtout affaire à des tombes isolées et à de petites nécropoles datées du second âge du Fer. La majorité de ces tombes comprend de l'armement indiquant des sépultures de guerriers. Si l'incinération est le seul rite reconnu, les structures funéraires sont de deux types: tumulaire à Vernas pour une sépulture aristocratique de La Tène $\mathrm{D}$; en fosse pour les autres découvertes. La situation observable dans la région de Crémieu n'est pas sans rappeler celle de l'oppidum de la Enge à Berne (BE. Suisse), également cerné de tombes du second âge du Fer (Wyss 1975 : p. 83). Dans l'état actuel des recherches, hormis le Camp de Larina, aucun habitat strictement de La Tène n'a été repéré dans l'Isle Crémieu (cf. néanmoins Chastel $1988:$ p. 135).

\section{Historique des recherches sur le plateau}

La connaissance du Camp de Larina se heurte à deux problèmes. D'une part, il s'agit d'un site qui a fait l'objet de recherches archéologiques précoces, associant à la destruction des structures repérées, inhérente à la fouille archéologique, une publication très partielle des résultats. D'autre part, le site a été en partie détruit par le développement de carrières pour l'extraction de lauzes, et en partie recouvert par d'importants remblais provenant de cette activité. Ces derniers masquent et protègent une surface importante du site (fig. 5). Paradoxalement, c'est la structure anthropique la mieux conservée et la plus visible (le ou les remparts) qui a le moins fait l'objet de recherches, alors qu'elle a nécessairement conditionné la vie des occupants du site. 
5- Le Camp de Larina et la faille de La Chuire : emplacements des carrières, des reliefs et des découvertes protohistoriques

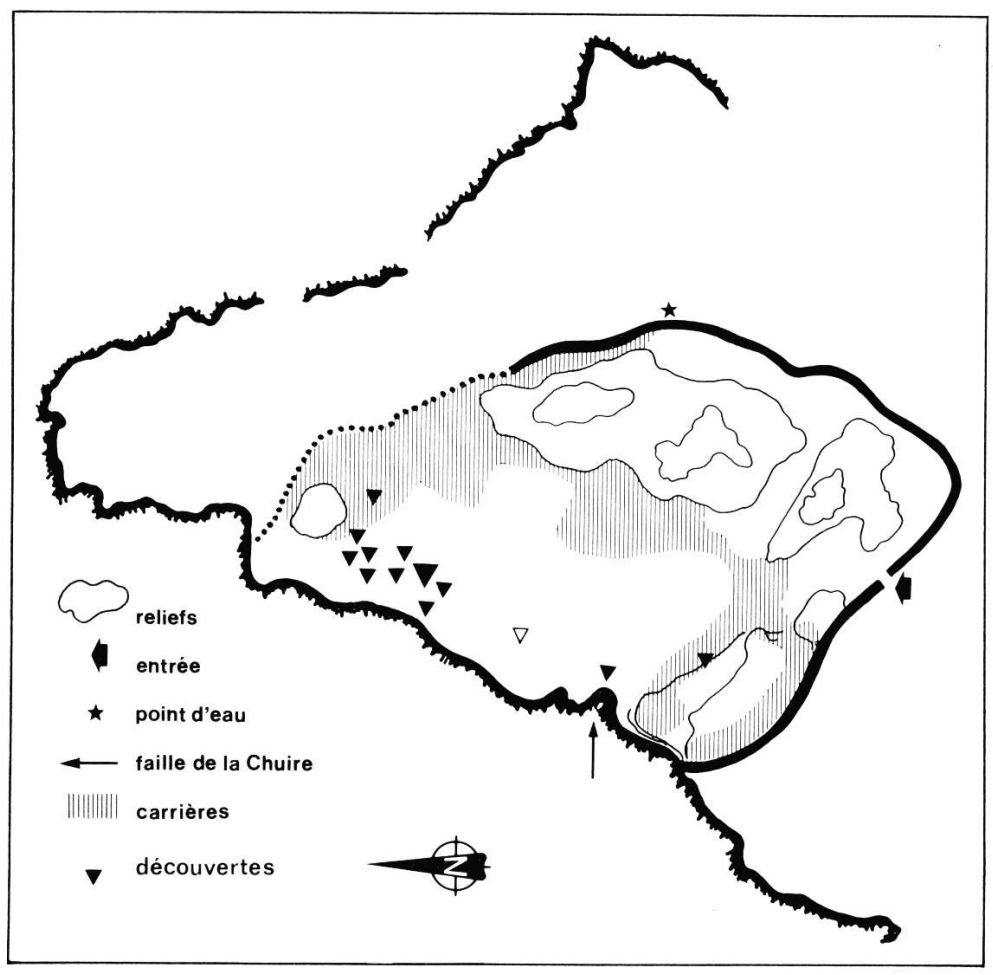

Les premières recherches sur le site de Larina ont débuté dès la seconde moitié du XIXe siècle (1866) sous l'impulsion du scientifique E. Chantre. Celui-ci, âgé alors d'une vingtaine d'années, n'a laissé que des relations imprécises et contradictoires de ces premières recherches; de plus, la majeure partie du mobilier exhumé a disparu. Dans une première publication datée de 1880, il signale avoir fouillé une série de " tumulus » situés «au milieu du Camp» recouvrant des sépultures par inhumation avec un entourage de lauzes soigneusement jointes. Le mobilier archéologique associé comprend «des poteries» et "des débris d'armes en fer ». Il attribue ces tombes à «l'époque gauloise ». Par ailleurs, il mentionne la fouille «d'une sépulture " située à l'extérieur du Camp qui aurait livré trois bracelets en bronze, ainsi que des « anneaux ou des bagues ». A la fin de sa vie, en 1923, il publiera un article de synthèse sur ses travaux et précisera sa première description. Il aurait fouillé deux niveaux successifs de sépultures: le plus récent comprenant des sépultures par inhumation avec un entourage de lauzes associées à de l'armement et de la céramique qu'il attribue à «l'époque burgonde». Quant au niveau inférieur, il semble correspondre à une nécropole gallo-romaine (à incinération ?) (Chantre 1880 : p. 44 ; Chantre 1923).

A partir de ces deux publications, il semble possible d'établir que E. Chantre a fouillé une nécropole présentant un niveau ancien galloromain et un niveau récent attribuable au Haut Moyen-Âge, comprenant des sépultures d'individus armés. Quant à l'âge du Fer, rien ne permet d'affirmer la présence de tombes de cette époque à l'intérieur du Camp et, au contraire, de récents travaux (Verger 1988: p. 231) ont montré que les tertres encore visibles à l'intérieur du site n'étaient que des résidus de moraines glaciaires et non des tumuli recouvrant des sépultures. Dans le peu de mobilier conservé provenant des fouilles de $\mathrm{E}$. Chantre, il existe pourtant quelques objets attribuables au 
second âge du Fer, en particulier deux amulettes (Pélatan 1986: p. 68) à décor zoomorphe en relief ${ }^{3}$.

Dès les années 1950, le développement des carrières va détruire un certain nombre de structures archéologiques et renouveler ainsi l'intérêt pour le site de Larina. Vers 1950, une nécropole du Haut Moyen-Âge peut être observée ainsi que les vestiges d'un bâtiment cultuel. Dans les années 1970, plusieurs fosses présentant des traces de combustion ont pu être repérées dans un front de taille, une sera fouillée. Le mobilier céramique livré par ces structures est attribuable au Bronze final. Ces fosses étaient creusées dans un niveau qui a livré quelques éléments attribués au Néolithique moyen permettant ainsi de situer chronologiquement l'occupation initiale du site de Larina. D'autres travaux ont mis en évidence la présence de mobilier protohistorique en divers points du plateau, mais ne sont que trop incomplètement publiés pour être utilisés (Pélatan 1986 : p. 8-71).

Plus récemment, il a été possible de fouiller en extension un remarquable ensemble de bâtiments de l'Antiquité tardive. La fouille des niveaux de sols et des remblais a mis en évidence la présence, en position déplacée, d'un certain nombre d'objets datables du second âge du Fer et de l'époque gallo-romaine. En ce qui concerne les documents laténiens, il s'agit pour l'essentiel de fibules de schéma La Tène III, de monnaies celtiques et marseillaises, de tessons d'amphores italiques et de céramiques campaniennes. Plusieurs prospections de surface (Travaux P. Porte) ont permis la découverte de nouveaux objets laténiens tous datables de La Tène $D$ (monnaies, fibules, simpulum, céramiques) et de céramiques gallo-romaines. D'autre part, la présence de blocs monumentaux en divers points du site ou dans sa périphérie et le réemploi d'inscriptions dans les fortifications ont permis de déduire l'existence à l'époque galloromaine d'un bâtiment d'importance sur le site (Porte 1980).

Les différents documents publiés sur le site, en particulier les études les plus récentes (Porte 1980 ; Pélatan 1986) permettent de décrire sommairement le Camp de Larina. Celui-ci est délimité par une levée artificielle enserrant dans son état actuel une surface d'environ 21 hectares présentant des reliefs marqués. Le site peut se diviser en deux parties : à l'ouest une zone basse, plane et partiellement en culture; à l'est une zone haute de surface irrégulière où le substrat affleure en de nombreux endroits. La jonction de ces deux parties est partiellement détruite par des carrières. L'alimentation en eau est assurée par une unique source-La Fontaine de la Vie-située à l'extérieur du site.

Dans leur état actuel, les fortifications de Larina atteignent 950 mètres de longueur tout en présentant de nombreuses différences dans leurs dimensions et leurs modes de construction. Les parties les plus massives montrent une levée de terre et de blocs calcaires rapportés de plus de 10 mètres de hauteur et surmontée par une construction à parements en pierres sèches. Plusieurs structures quadrangulaires (tours, bastions ?) sont accolées contre la face interne du rempart. Enfin, cette construction présente par endroits des traces de mortier et des réemplois de blocs galloromains. Tout porte à croire que l'on a affaire à une construction protohistorique en partie remaniée, et il est pour l'instant impossible de déterminer l'aspect primitif de cette structure et les évolutions du plan d'ensemble. L'état présent montre une extension maximale des fortifications en utilisant les défenses naturelles des falaises. (en appui sur un à-pic) bien attesté dans le Sud de la France, dès le VIe siècle av. n. è. 
(Arcelin 1985 : p. 1315). Dans la moyenne vallée du Rhône, les sites de Saint-Saturnin (Donzère, Drôme) et de Jastres (Lussas, Ardèche) sont également établis sur des rebords de plateau (Lefèbvre 1985 : p. 100-101 Odiot à paraître). En France septentrionale, seuls quelques sites ont adopté ce type de fortification par exemple, La Cité d'Affrique (Messein Meurthe-et-Moselle) (Buchsenschutz 1984: p. 213). Le Camp de Larina ne possède qu'une entrée connue ; elle est située au sud de celui-ci. L'accès carrossable antique reliant la plaine du Rhône au plateau devait sans doute passer par le vallon de l'Amby.

\section{Les documents lateniens du plateau}

\section{Les objets métalliques}

Plusieurs objets laténiens ont été découverts dans le Camp de Larina. Hors de tout contexte cohérent, ils proviennent soit des niveaux d'habitat du site du Bas-Empire, soit des parcelles cultivées qui longent le côté ouest du site.

\section{Le simpulum}

$\mathrm{n}^{\circ}$ 1. Fragment de simpulum (louche) en bronze (fig. 6). Un index des lieux de conservation et des données typométriques des objets décrits dans ce volume se trouve p. 158

6- Simpulum en bronze découvert hors contexte sur le plateau de Larina

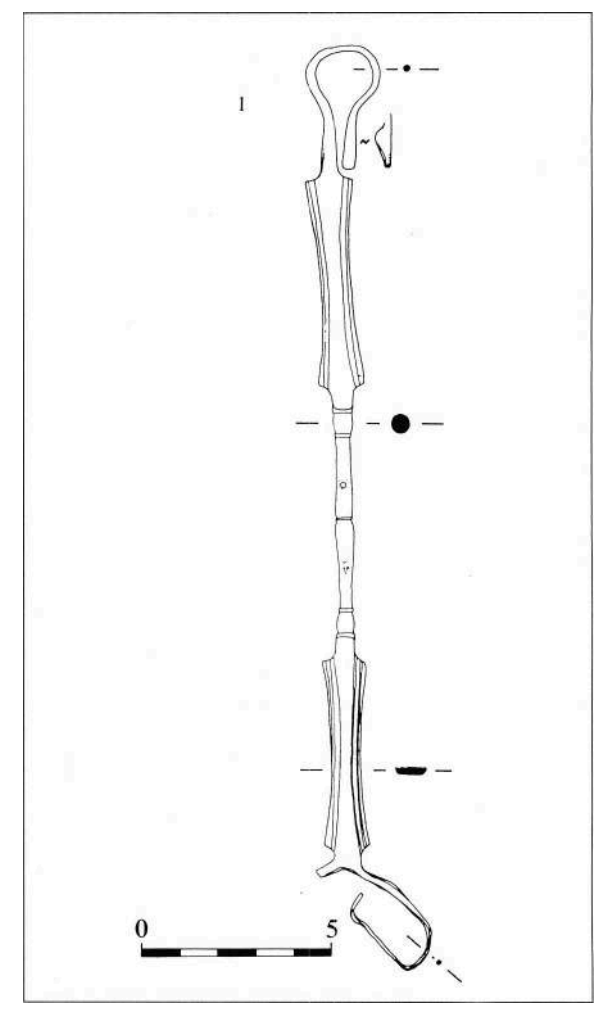

30 La partie conservée concerne le manche, long de $216 \mathrm{~mm}$ et constitué principalement de deux parties plates, légèrement évasées à leurs extrémités, cannelées et séparées par une tige moulurée, de section ronde. Le sommet du manche forme un crochet effilé, tandis que la base se prolongeait, à l'origine, par deux fines tiges formant un anneau 
d'environ 5 à $7 \mathrm{~cm}$ de diamètre; l'une de ces tiges manque, l'autre est tordue et incomplète (fig. 7).

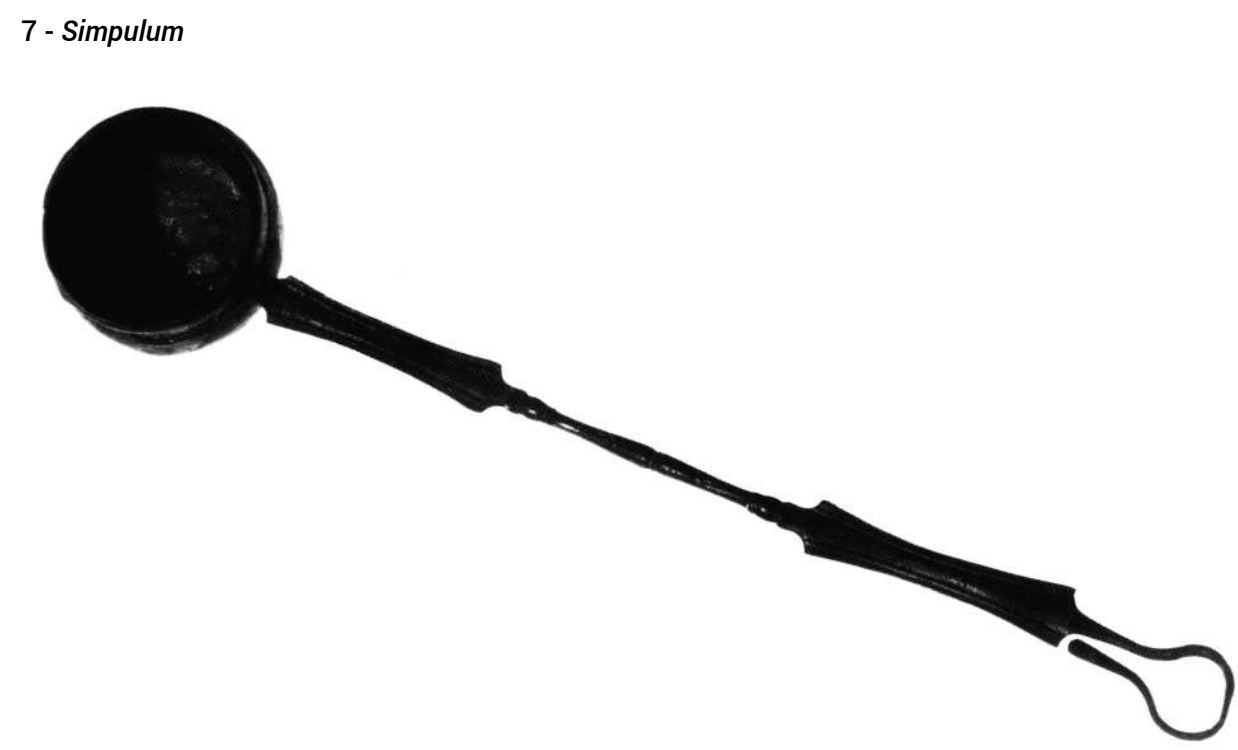

RECONSTITUTION CERA DE VIENNE du Fer en Italie (Ridgway 1979 : p. 436) ; quelques exemplaires contemporains ont été découverts en Gaule, dans le domaine ibérique, à Mailhac, Couffoulens (Aude), SaintJulien-de-Pézenas (Hérault) (Solier 1976: p. 68-69). En Gaule interne, les simpula sont plus rares: un puisoir est par exemple attesté dans une tombe de Magny-Lambert (Côte-d'Or) datée aux environs de 700 av. n. è. Comme dans les sépultures méridionales, il s'agissait d'une tombe d'homme possédant un équipement guerrier. D'autres exemplaires de même chronologie sont connus dans des contextes funéraires aristocratiques à Conliège (Jura) et à Savigné (Gros-Guignon, Vienne) (Roulière-Lambert 1987 ; Gomez de Soto 1988: p. 65). La plupart des exemplaires découverts sur le territoire français sont cependant datables de la fin du second âge du Fer.

impulum de Larina, par comparaison avec les exemplaires complets, appartient au type de Pescate, défini par J. Werner dans son étude sur les vases en bronze de la fin de l'âge du Fer (Werner 1954 : p. 43-73). Ce type de simpulum se caractérise par le mode de fixation de la vasque, disparue sur l'exemplaire de Larina. A l'origine, celle-ci était située dans le même plan que le manche, retenue au niveau du col par deux fines tiges formant un anneau. Les simpula de type Pescate se distinguent ainsi des simpula italiques classiques, d'une seule pièce et dont la vasque forme un angle droit avec le manche. Le type de Pescate est bien représenté en Italie, notamment en Italie du Nord ${ }^{4}$.

La relative abondance de cette forme en Slovénie et en Dalmatie (Todorovic 1972 : pl. III, IV, XXVIII, XXXII, XXXVI), régions directement en contact, par la plaine vénète, avec le Trentin-Haut Adige, renforce l'hypothèse d'une production cisalpine. En revanche, le type de Pescate est beaucoup plus rare au nord des Alpes, en Europe Centrale $^{5}$ et en Gaule. Il s'agit vraisemblablement de vases fabriqués en Italie du Nord, dans des ateliers qui restent à localiser : de plus, compte tenu du fait que le motif qui orne le manche de Larina se retrouve sur quelques simpula à vasque perpendiculaire, on ne peut douter de leur origine commune ${ }^{6}$. Pourtant, ces deux formes, bien que 
contemporaines, ne répondent pas nécessairement à la même fonction si l'on considère à la fois la rareté et la répartition du type de Pescate en Gaule (fig. 8). En effet, alors que les simpula italiques à vasque perpendiculaire ont clairement été introduits, à partir du littoral méditerranéen, avec les cargaisons de vin et de céramiques à vernis noir, les simpula de type Pescate connaissent à la fois une diffusion très occidentale et une faible représentation littorale.

8- Répartition des simpula du type de Pescate en Gaule

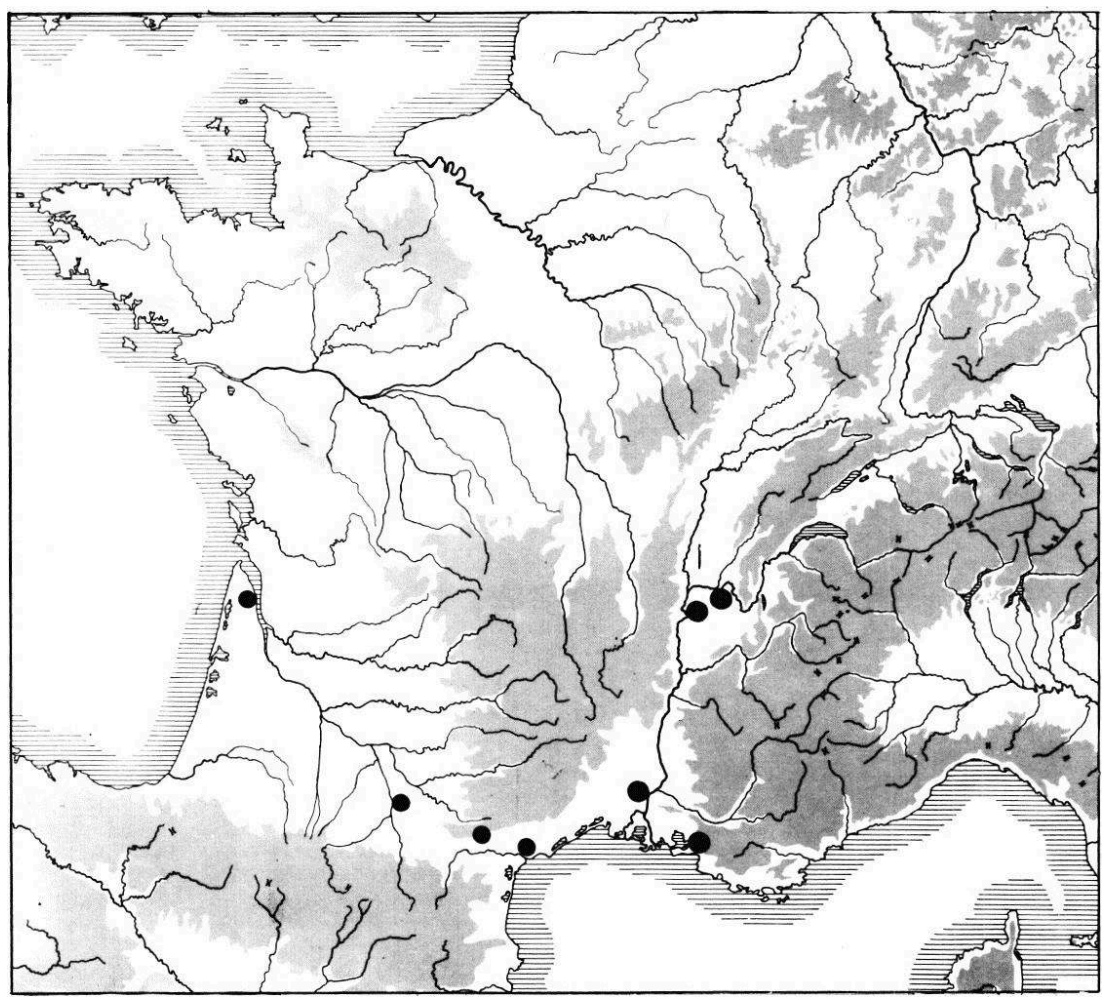

Chronologiquement, les repères restent rares. L'épave de Spargi a dû sombrer à la fin du IIe siècle av. n. è. . L'exemplaire du Musée de Berlin porte une estampille (L. HEL. CAT.), dont E.-R. Knauer souligne qu'elle doit être postérieure à l'époque où les tria nomina deviennent officiels à Rome, soit l'époque de Sylla (Knauer 1969: p. 54-58). Quant au site de La Cloche (Les Pennes-Mirabeau. Bouches-du-Rhône), il a été occupé durant la première moitié du Ier siècle av. n. è, jusqu'à sa destruction brutale, peut-être en 49 av. n. è. Le simpulum de Larina est donc datable de La Tène Dl, soit entre le troisième quart du IIe siècle av. $n$. è. et le milieu du Ier siècle av. $n$. è. et il s'agit sans doute d'une importation, arrivée en Transalpine par la voie des cols. Régionalement, le simpulum n'est pas isolé, puisque outre le fragment de Vienne, le mobilier de Vernas Saint-Romain-de-Jalionas comprend plusieurs récipients et des bronzes figurés de type nord-italique ${ }^{8}$.

M.F.

\section{Les parures vestimentaires}

Il s'agit essentiellement de fragments de fibules en bronze, datables du second âge du Fer (fig. 9). 
9-Parures de La Tène découvertes hors contexte sur le plateau de Larina

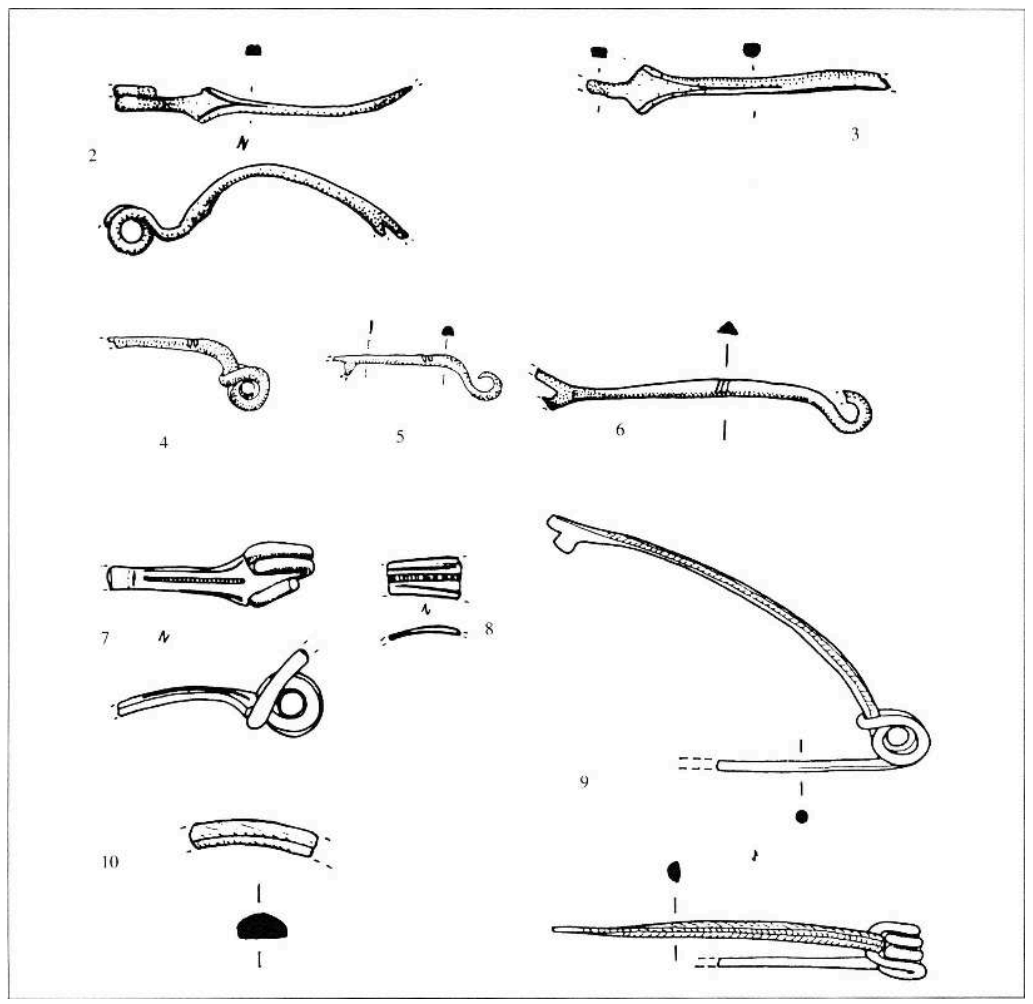

2-9. Fibules en bronze : 10. Bracelet en verre

L'arc s'élargit à l'approche du ressort pour former deux ailettes ornées de deux incisions en $\mathrm{V}$ se réunissant sur le milieu de l'objet. Ce dernier est très déformé, particulièrement au niveau du ressort.

La tête de l'arc s'élargit à l'approche du ressort pour former deux ergots, points de départ de deux incisions qui se fondent en une sur l'arc. Le départ du ressort est dans le même plan que l'arc et montre une section rectangulaire : cet aspect pourrait indiquer qu'il s'agit d'une fibule abandonnée en cours de fabrication.

Ces deux fibules appartiennent au type de Lauterach, connu surtout de la Bourgogne au Plateau Suisse et daté de La Tène D. $\mathrm{n}^{\circ} 4$. Fibule de schéma La Tène III.

Le ressort compte 2 x 2 spires et une corde interne; l'arc de section semi-ovalaire est orné de deux incisions transversales. $\mathrm{n}^{\circ}$ 5. Fibule de schéma La Tène III.

Même type que l'exemplaire précédent.

41 Ces fibules miniatures se rapprochent du type Feugère $5 \mathrm{~b} 4$ (Feugère $1985 \mathrm{a}$ : p. 180) des exemplaires proches figurent dans le mobilier du sanctuaire de Martigny (VS, Suisse), ainsi qu'à Bâle-Gasfabrik (Suisse) (Rey-Vodoz 1986 : p. 156 ; Furger-Gunti 1980 : p. 50). Leurs dimensions réduites laissent penser qu'il pourrait s'agir de fibules d'enfant, c'est du moins l'hypothèse proposée à partir des exemplaires de Martigny. On peut cependant remarquer la grande rareté de ces exemplaires miniatures sur les sites du second âge du Fer. Il est possible que ces objets aient été refondus 
systématiquement, car devenant rapidement inadaptés en raison de leurs dimensions, ou alors transmis d'un individu à un autre toujours pour les mêmes raisons. Leur faible taille explique également que ces parures ne figurent pas dans les contextes funéraires où elles seraient systématiquement détruites par la chaleur de l'incinération qui est la pratique dominante à la fin de l'âge du Fer. Toutefois, la miniaturisation de certains objets métalliques caractérisant aussi divers contextes cultuels (Tisserand 1980; Barruol 1985 ; Michelucci 1978 : p. 207-220) et funéraires de la fin du Ier siècle av. n. è. et de l'époque galloromaine (Ferdière 1987 : p. 47-48), il pourrait tout aussi bien s'agir d'ex-votos.

$42 \mathrm{n}^{\circ}$ 6. Fibule de schéma La Tène III.

L'arc de section triangulaire est orné de trois incisions transversales formant des chevrons.

43 Si cette fibule appartient au type Feugère $5 b 2$, elle est cependant très proche par sa décoration d'une fibule de type Feugère $5 \mathrm{~b} 3$ (section losangique de l'arc) provenant de Sainte-Blandine (Feugère $1985 \mathrm{a}$ : p. 180 ; Chapotat 1970 : pl. V, n² 2).

$44 \quad \mathrm{n}^{\circ}$ 7. Fibule de schéma La Tène III.

La tête de l'arc est décorée d'un trémolo encadré par deux incisions et délimité par trois incisions transversales.

45 Cette fibule appartient au type Feugère $5 a 31$ connu par cinq exemplaires dans le mobilier de Sainte-Blandine et par une douzaine d'exemplaires découverts dans le Sud de la Gaule, le plus fréquemment sur la rive gauche du Rhône; le ou les ateliers ayant produit cette forme sont probablement localisés dans le sud-est de la Gaule (Feugère 1985 a : p. 217 et 223), peut-être même pour certains en territoire allobroge. $\mathrm{n}^{\circ}$ 8. Fibule de schéma La Tène III.

Fragment d'arc orné d'un trémolo longitudinal encadré par deux incisions.

47 Trop fragmentée pour être identifiée assurément, cette fibule appartient néanmoins soit au type Feugère 5a 31, soit au type 5a 33 (Feugère $1985 a$ : p. 204).

$48 \mathrm{n}^{\circ}$ 9. Fibule de schéma La Tène III.

L'arc de section ovale est orné de quatre incisions longitudinales; les espaces obtenus sont décorés de séries d'incisions transversales.

Cet exemplaire appartient au type Feugère $5 b$ (Feugère $1985 a:$ p. 220). Il peut être rapproché d'un fragment de Bibracte (Saône-et Loire) (Guillaumet $1984:$ pl. 10, n 54).

Toutes ces fibules sont datables de La Tène $\mathrm{D}$ et appartiennent à des types connus en Gaule interne, et pour certains en Gaule méridionale. A l'exception des fibules miniatures, tous ces modèles figurent dans le mobilier découvert sur la colline SainteBlandine.

\section{La céramique}

51 Le site a livré, lors des fouilles de l'habitat du Bas-Empire et à l'occasion de prospections de surfaces, des fragments d'amphores italiques (30 individus recensés) et quelques tessons de céramiques italiques à vernis noir (cf. la céramique a vernis noir par J. P. Morel p. 113) D'autre part, l'ensemble de la céramique provenant des habitats de l'Antiquité tardive fait actuellement l'objet d'une étude ${ }^{9}$ qui montre la forte présence de céramique non tournée très fragmentée dans les remblais gallo-romains et 
mérovingiens; cet aspect du site n'étant pas étudié ici, seules quelques remarques préalables à une étude globale sont possibles.

Les remblais gallo-romains ont livré 30000 tessons attribuables aux époques protohistoriques : le nombre peut paraître très élevé, mais le calcul effectué a pris en compte tous les fragments de céramiques. La quasi-totalité de ce lot consiste en des tessons informes, de petites dimensions (souvent moins de $3 \mathrm{~cm}$ ) dont les surfaces sont très altérées et les cassures émoussées. L'examen des formes identifiables montre une nette prédominance des céramiques de la fin du Bronze final. La céramique tournée de La Tène semble très peu présente, mais il faut tenir compte de la très mauvaise conservation des tessons ${ }^{10}$.

\section{Une parure en verre}

Hormis les fibules, les parures ne sont que peu attestées à ce jour sur le site : seul un fragment de parure annulaire en verre a été mis au jour.

$\mathrm{n}^{\circ}$ 10. Fragment de bracelet en verre.

Cette parure, de couleur bleue, appartient au type Haevernick 2 (Haevernick 1960).

Ce type de parure caractéristique de La Tène D apparait à Nages (Les Castels, Gard) dans le dernier quart du IIe siècle av. n. è. pour rester en usage jusqu'à la fin du Ier siècle av. n. è. Sur ce site languedocien, les exemplaires bleus ne sont connus que vers les années 100-70 av. n. è. (Feugère 1989).

\section{Les monnaies}

Parmi le matériel recueilli sur le plateau de Larina figurent 60 monnaies. Le lot le plus riche a été trouvé dans des remblais, lors de recherches effectuées sur l'habitat mérovingien (cf. p. 15) ; quelques monnaies ont été découvertes lors de prospections de surfaces ${ }^{11}$.

\section{Les émissions de narbonnaise}

\section{Monnaies massaliotes}

\section{Oboles}

$57 \mathrm{n}^{\circ}$ 11. Pièce fourrée, qui présente au droit une tête à gauche (= g.), grènetis au pourtour. Le revers est divisé en 4 cantons, 2 d'entre eux renferment les lettres $M$ et A. Poids (= P) $=0,35$ gramme $(=$ g.).

$\mathrm{n}^{\circ}$ 12. La tête qui, normalement, orne le droit, est très incomplète. On distingue seulement la coupe du cou, une partie du visage et de la chevelure. Revers semblable au précédent. $\mathrm{P}=0,45 \mathrm{~g}$. $\mathrm{n}^{\circ}$ 13. Exemplaire fourré, oxydé, surtout au droit. Cette face est décorée d'une tête à g., dans un grènetis. Revers identique aux précédents. $\mathrm{P}=0,31 \mathrm{~g}$.

$60 \mathrm{n}^{\circ}$ 14. La tête du droit est tournée à droite. Le revers est identique aux précédents. $\mathrm{P}=$ $0,45 \mathrm{~g}$. 
$61 n^{\circ}$ 15. Au droit, tête tournée à g. Les traits du visage aussi bien que le rendu de la chevelure évoquent fortement le style des monnaies arvernes. Revers: on voit le premier canton de la pièce occupé par un grand $M$ et le début du deuxième canton, dans lequel on aperçoit une haste oblique du A et l'amorce de la barre horizontale. $\mathrm{P}=$ $0,48 \mathrm{~g}$.

$62 \mathrm{n}^{\circ}$ 16. Le droit est orné d'une tête à g., dont le dessin paraît celtique. Au revers, on ne voit qu'un seul canton, dans lequel est gravé un grand $\mathrm{M}$ aux extrémités bouletées. Cette pièce est en bas argent. Elle doit comporter beaucoup de cuivre et d'étain, qui lui donnent un aspect proche de celui du bronze. $\mathrm{P}=0,39 \mathrm{~g}$.

$63 \mathrm{n}^{\circ} 17$. Au droit, tête d'Apollon à gauche. Le revers présente une roue à quatre rayons, entre lesquels on voit les lettres $\mathrm{M}$ et $\mathrm{A} . \mathrm{P}=0,60 \mathrm{~g}$.

$\mathrm{n}^{\circ}$ 18. Le droit est identique au précédent. Le revers est divisé en deux cantons. L'un comporte la moitié de la lettre $M$, l'autre renferme un caractère hybride entre le $\mathrm{M}$ et le A. La chevelure du droit n'a pas la belle ordonnance du numéraire de Marseille. La mauvaise épigraphie du revers semble confirmer l'hypothèse d'une imitation locale. $\mathrm{P}=$ $0,57 \mathrm{~g}$.

\section{Bronzes au taureau cornupète}

65 Ces monnaies présentent au droit la tête d'Apollon à droite (d.), au revers un taureau chargeant à droite, sur une ligne de sol. Au-dessus de l'animal : MA $\Sigma \Sigma$ A, en dessous, à l'exergue : LIETSN.

$\mathrm{n}^{\circ}$ 19. Pièce fragmentaire. $\mathrm{P}=1,74 \mathrm{~g}$.

$67 \mathrm{n}^{\circ} 20$. Aucune inscription n'est visible sur cet exemplaire. $\mathrm{P}=1.73 \mathrm{~g}$.

$68 \mathrm{n}^{\circ} 21$. Exemplaire en mauvais état. $\mathrm{P}=1,28 \mathrm{~g} \cdot \mathrm{n}^{\circ} 22$. Pièce également en mauvais état. $\mathrm{P}$ $=1,22 \mathrm{~g}$.

\section{Monnaies des Volques Arecomiques}

$n^{\circ} 23$. Ce petit bronze est en très mauvais état. On devine au droit une tête à d., seule la coupe du cou est nette. Le revers est orné d'un personnage debout. Il s'agit vraisemblablement d'une monnaie de type LT VI, 2677 (La Tour 1892). P = 0, 65 g.

\section{Monnaie de Nîmes}

$\mathrm{n}^{\circ}$ 24. Demi-as de Nîmes en bronze, de type LT VII, 2837. $\mathrm{P}=6,49 \mathrm{~g}$.

\section{Monnaies au cheval galopant des Cavares}

71 Ces espèces en argent présentent au droit une tête laurée à g., au revers, un cheval au galop à gauche. Au-dessus de son dos on peut voir un motif qui a été interprété tantôt comme une épée, tantôt comme un rameau.

$n^{\circ} 25$. Au revers de cette monnaie, on peut voir l'inscription VOL au-dessus du dos du cheval, une rouelle à quatre rayons se trouve sous son ventre. Fin grènetis au pourtour. Type Deroc VIII, 173. P = 2,09 g. (Deroc 1983). $\mathrm{n}^{\circ} 26$. Cet exemplaire correspond au type Deroc VI, 129-140. $\mathrm{P}=2,05 \mathrm{~g}$. 
$74 n^{\circ}$ 27. Au droit, on ne distingue que l'arrière d'une tête laurée à gauche. Grènetis. Le cheval du revers est doté d'une crinière perlée; sous le ventre de l'animal, légende VO(L). Type Deroc VIII, 153. P = 1, $97 \mathrm{~g}$.

$n^{\circ} 28$. Au revers de cet exemplaire, le corps du cheval est effacé, on ne voit que ses pattes. Sous son ventre, roue centrée à cinq rayons. Type Deroc VIII, 174. $\mathrm{P}=1,95 \mathrm{~g}$. L'inscription VOL. qui figure normalement au-dessus du dos, est invisible sur cet exemplaire.

$n^{\circ} 29$. Cette petite pièce en bronze présente au droit une tête laurée identique à celle des espèces précédentes. Le revers, illisible, ne permet pas d'identifier le type. Cette monnaie cavare pèse $1,70 \mathrm{~g}$.

$\mathrm{n}^{\circ}$ 30. Monnaie fourrée, très oxydée. Au revers, la légende VOL est visible au-dessus du cheval ; sous son ventre, une roue à quatre rayons. Type Deroc VIII, 171-172. P = 1,54 g. $n^{\circ}$ 31. Exemplaire fragmentaire, en très mauvais état. $P=1,44 \mathrm{~g}$.

$\mathrm{n}^{\circ}$ 32. Pièce fourrée, très oxydée. Type Deroc VI. 130. $\mathrm{P}=1.71$ g. (fig. 10).

10- Monnaie au cheval galopant attribuée aux Cavares (argent fourré)

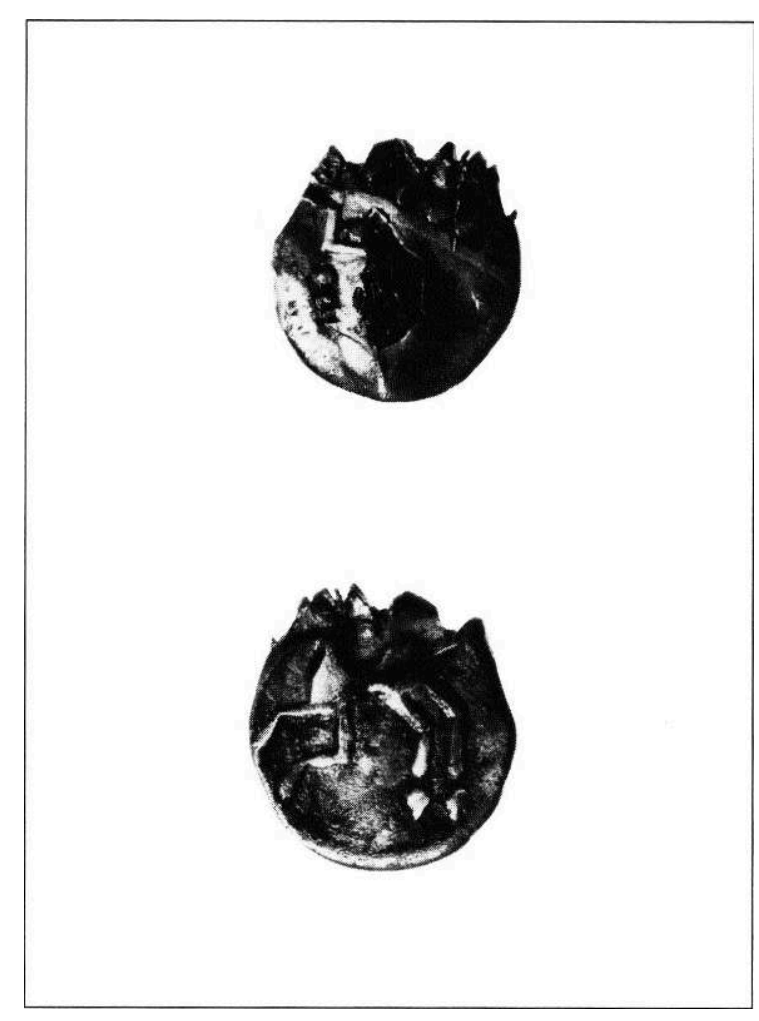

\section{Monnaies à l'hippocampe des Allobroges}

Ce numéraire d'argent est orné au droit d'une tête casquée à gauche. Le revers présente un hippocampe à gauche. Les deux faces offrent un grènetis périphérique. $\mathrm{n}^{\circ}$ 33. Cet exemplaire présente au droit une tête casquée à droite. Fin grènetis au pourtour. Au revers, un hippocampe également à droite. Cette orientation est très rare. Type Deroc IX, 189 ; P = 2, 25 g. Il s'agit là d'une pièce de la classe I de A. Deroc. Ces espèces, qui constituent l'émission de tête, ont un poids moyen de 2, 40 - 2, $30 \mathrm{~g}$. 

est perlée. A côté, on voit l'amorce d'une autre image de revers. Type Deroc IX, 190. P = $1,81 \mathrm{~g}$. 198. $\mathrm{P}=1,39 \mathrm{~g}$.

11- Monnaie à l'hippocampe des Allobroges (argent fourré)

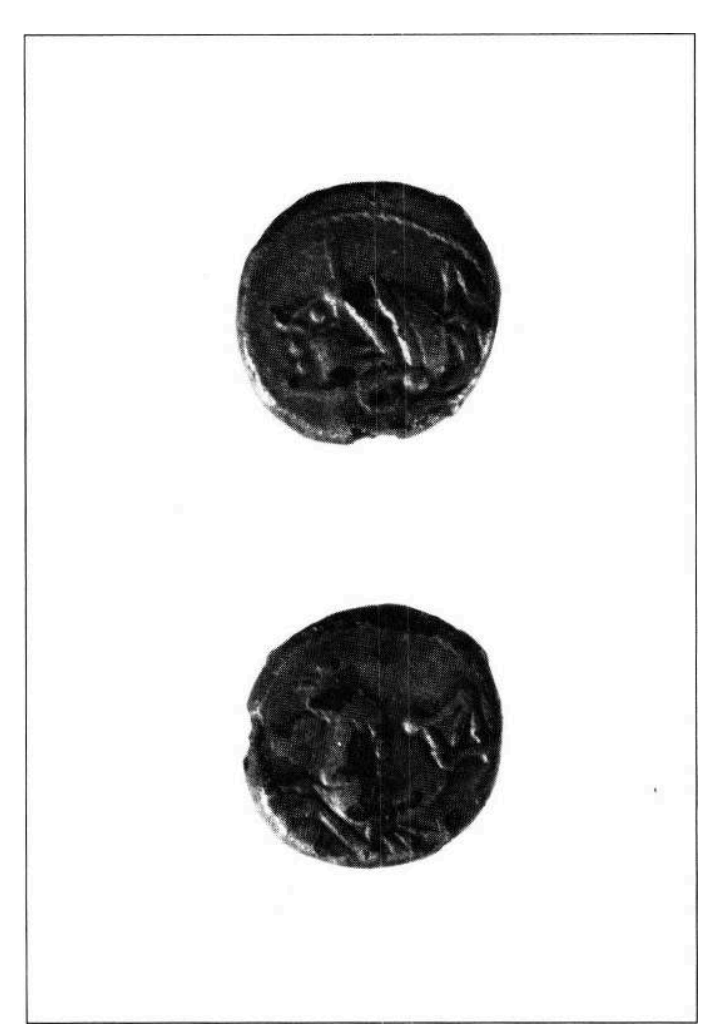

$\mathrm{n}^{\circ}$ 34. Au droit, tête à g., mais le type est décentré, on ne voit que l'arrière de cette tête. Au revers, hippocampe à gauche. Type Deroc IX, 195. $\mathrm{P}=2,18 \mathrm{~g}$.

$\mathrm{n}^{\circ} 35$. La tête du droit est d'un dessin très flou. $\mathrm{P}=2,04 \mathrm{~g}$.

$\mathrm{n}^{\circ}$ 36. Au revers, l'hippocampe est tourné à droite. Dans ce monnayage, la tête et l'animal sont normalement dirigés du même côté. Le phénomène observé ici (la tête à g.) est exceptionnel. $\mathrm{P}=1,96 \mathrm{~g}$. Deroc : classe IV.

$\mathrm{n}^{\circ}$ 37. Pièce de type Deroc IX, 198. $\mathrm{P}=1,85 \mathrm{~g}$.

$\mathrm{n}^{\circ} 38$. Monnaie de même type et de même poids que la précédente.

$n^{\circ} 39$. Au revers, cette pièce est ornée de l'avant d'un hippocampe à droite ; sa crinière

$\mathrm{n}^{\circ}$ 41. Pièce fourrée, très oxydée. Type Deroc IX, 195. P = 1,85 g. (fig. 11).

$n^{\circ}$ 42. Type Deroc IX, 196. $\mathrm{P}=1,74 \mathrm{~g}$.

$\mathrm{n}^{\circ}$ 43. Pièce fourrée, très oxydée, en particulier au revers. Type Deroc IX, 198. $\mathrm{P}=1,81 \mathrm{~g}$.

$\mathrm{n}^{\circ} 44$. Contrairement aux autres espèces qui constituent ce numéraire, cet exemplaire est entièrement fait de bronze, on ne remarque aucune trace d'argent en surface. Type identique à la monnaie précédente : Deroc IX, 198. $\mathrm{P}=1,42 \mathrm{~g}$.

$93 \mathrm{n}^{\circ}$ 45. Pièce fourrée, recouverte d'une mince pellicule d'argent. Type Deroc IX. 195. $\mathrm{P}=$ $1,97 \mathrm{~g}$. 


\section{Monnaies au cavalier de la vallée du Rhône}

\section{Les numéraires de gaule chevelue}

\section{Monnaies des Lingons}

$\mathrm{n}^{\circ}$ 51. Cette petite pièce d'argent présente au droit une tête casquée à gauche. Au revers, cheval au galop à gauche. Des lettres et des symboles divers, répandus dans le champ constituent la légende Kaletedou. $\mathrm{P}=1,76 \mathrm{~g}$.

$\mathrm{n}^{\circ}$ 52. Monnaie fourrée. Au revers, une rouelle à quatre rayons, forme une partie de la légende. Type LT XXXII, 8178. $\mathrm{P}=1,47 \mathrm{~g}$.

\section{Monnaies des Sénons}

$n^{\circ}$ 53. Une face de ce potin offre une tête stylisée, échevelée à d. ; sur l'autre, on voit un cheval à g., surmonté d'un globule, un deuxième globule se trouve devant le poitrail de l'animal, le troisième sous son ventre. Type LT XXX, 7417. P = 3, $67 \mathrm{~g}$.

103 C'est aux Sénons que l'on attribue traditionnellement ces espèces, mais leur dispersion ne permet pas de connaître avec sûreté le peuple émetteur.

\section{Les monnaies inédites}

$\mathrm{n}^{\circ}$ 54. Une petite pièce d'argent allié présente un droit illisible. Le revers est orné d'un cheval galopant, à gauche, sa crinière est perlée ; une grande esse est visible au-dessus de son dos. Divers motifs parsèment le champ. Grènetis au pourtour. La complexité et la finesse des décors sont remarquables. $\mathrm{P}=0,76 \mathrm{~g}$.

$\mathrm{n}^{\circ}$ 55. Le droit de cette monnaie est également illisible. Au revers, on voit un cheval à g. à crinière perlée, une volute se déroule au-dessus de son dos. $\mathrm{P}=0,64 \mathrm{~g}$.

\section{Les monnaies indéterminables}

$\mathrm{n}^{\circ} 56$. Petit bronze. Au droit, tête casquée à droite. Le revers est illisible; $\mathrm{P}=2,28 \mathrm{~g}$.

$\mathrm{n}^{\circ} 57$. Petit bronze fruste. $\mathrm{P}=1,52 \mathrm{~g}$. 
$\mathrm{n}^{\circ}$ 58. Petite monnaie de bronze qui présente des traces d'argent en surface. La forte oxydation des deux faces ne permet pas l'identification. $\mathrm{P}=1,23 \mathrm{~g}$.

$n^{\circ} 59$. Petit bronze dont une face est totalement illisible, sur l'autre, on ne voit qu'un fin grènetis. $\mathrm{P}=1,00 \mathrm{~g}$.

$\mathrm{n}^{\circ}$ 60. Le droit de ce petit bronze paraît orné d'une tête à droite; fin grènetis au pourtour. Le revers est illisible. $\mathrm{P}=0,98 \mathrm{~g}$.

$113 \mathrm{n}^{\circ}$ 62. Minuscule pièce de bronze, également dépourvue de décor. Module : 0, $5 \mathrm{~cm} . \mathrm{P}=$ $0.19 \mathrm{~g}$.

$114 \mathrm{n}^{\circ}$ 63. Bronze fragmentaire. Sur une face, on devine une tête à d., aucun motif n'est visible sur l'autre face. $\mathrm{P}=1,70 \mathrm{~g}$.

$115 \mathrm{n}^{\circ}$ 64. Petit bronze fragmentaire, rien n'est visible au droit, le revers semble présenter un quadrupède à $\mathrm{d}$. $\mathrm{P}=0,64 \mathrm{~g}$.

$116 \mathrm{n}^{\circ} 65$. Monnaie de bronze très oxydée. $\mathrm{P}=1,45 \mathrm{~g}$.

B.F.

\section{Le coin monétaire gaulois}

En juillet 1987, J.-R Guillaumet et S. Verger (Verger 1988, p. 231) entreprirent la fouille de deux levées de terre à l'intérieur de l'oppidum, dans sa partie nord. Ces buttes, longtemps considérées comme de possibles tumuli étaient en fait d'origine glaciaire. Cependant, dans les couches de surface, aux abords de la butte la plus méridionale, l'un de nous, R. Collot, a mis au jour un coin monétaire gaulois en parfait état de conservation.

118 Cette découverte porte à dix le nombre de coins monétaires gaulois publiés à ce jour. A la recension effectuée par L.-R Delestrée et A. Duval (Delestrée 1977), il faut en effet ajouter un coin monétaire découvert à La Lagaste dans l'Aude (Sciau 1982) et un nouveau coin trouvé à Corent dans le Puy de Dôme (Malacher 1987). Il est probable que d'autres coins monétaires restent non identifiés parmi les objets métalliques dans les dépôts de fouilles ou les musées.

Description :

$\mathrm{n}^{\circ}$ 66. Coin monétaire en bronze.

Ce coin en bronze, de forme tronconique, pèse $86,9 \mathrm{~g}$. Il a une hauteur totale de $28 \mathrm{~mm}$. Le diamètre de la partie "matrice » atteint $24 \mathrm{~mm}$. Celui de la partie frappée, dont la surface est très irrégulière, mesure environ $14 \mathrm{~mm}$. Il porte à sa base la gravure inversée et en creux des revers du type au cheval galopant à gauche, de la vallée du Rhône (fig. 12). Il s'identifie avec la classe II de Deroc (Deroc 1983 : p. 6) : cheval libre galopant à gauche, crinière représentée par un grènetis; audessus du cheval, un rameau ou une épée; cercle plein au pourtour; anépigraphe. Il est illustré par les monnaies de la Bibliothèque Nationale de Paris : BN 2637 à 2644 et 2893 à 2895 (La Tour 1892, LT 2895, pl. VII). 


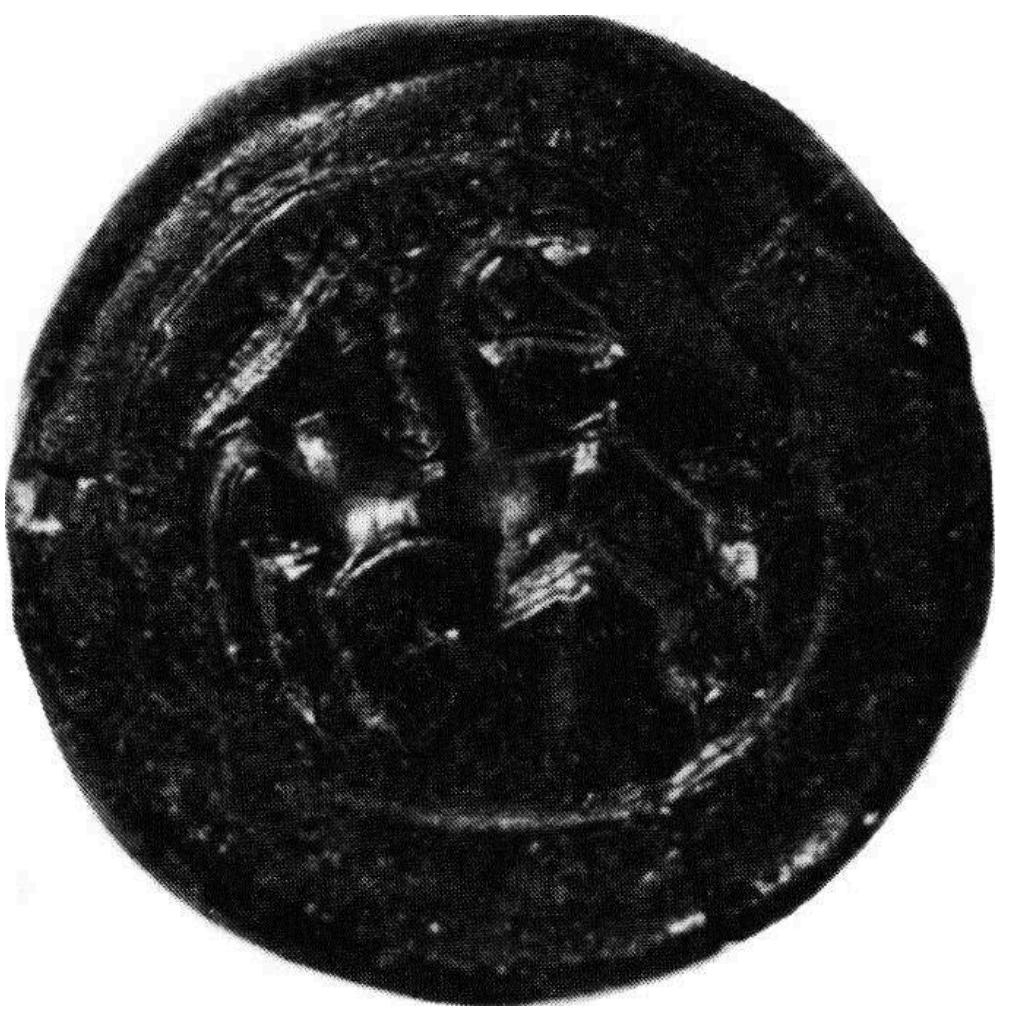

121 Il a donc été fabriqué pour frapper des monnaies d'argent d'un module de 13 à $15 \mathrm{~mm}$ et d'un poids moyen de $2,3 \mathrm{~g}$ à $2,4 \mathrm{~g}$. Il s'agit là d'un coin frappant, c'est-à-dire de celui que le monnayeur tient en main et sur lequel il frappe avec un marteau et non pas d'un coin d'enclume encore appelé coin de droit ou coin dormant. Il faut se l'imaginer, à l'origine, inséré en force dans un manchon de fer (Gruel 1987 : p. 67-74).

L'examen attentif de ce coin entraîne deux remarques :

- le diamètre de la partie gravée du coin est nettement supérieur au module moyen des monnaies qu'il est destiné à frapper (Deroc 1983 : pl. VI, VII, n 125 à 152). C'est là une confirmation d'une observation courante sur l'ensemble des monnayages gaulois.

- l'examen de l'état actuel de la gravure est plus surprenant. L'aspect très acéré des angles conduit à penser qu'il n'a pas ou peu servi. Le relief n'est pas du tout émoussé, soit que l'objet soit neuf, soit qu'il ait été regravé juste avant sa perte...

\section{Techniques de gravure}

L'observation de l'image agrandie montre que le graveur a utilisé deux techniques différentes pour obtenir cette matrice en creux: d'une part, il a procédé par enlèvement de métal à l'aide de gouges : les traces en sont particulièrement visibles sur la patte antérieure droite du cheval. Le cercle périphérique a été tracé au stylet. D’autre part, il a utilisé un poinçon circulaire pour obtenir, par simple enfoncement, les points constituant la crinière perlée, l'œil et les six perles du rameau (ou épée). Déjà l'étude de la gravure du coin de Saint-Symphorien-d'Arcelles nous avait conduit à admettre l'usage de poinçons pour certains détails (Gruel 1986). Aucun poinçon de détail n'a cependant été découvert ou identifié comme tel à ce jour... En revanche. Cl., J. et J. Fournier ont publié récemment un objet de bronze qui présente un type monétaire en 
relief qu'ils interprètent comme un poinçon de coin (Fournier 1989: p. 119-122). La gravure d'un coin par enfoncement de métal présente l'avantage de ne pas affaiblir la matrice qui doit ensuite supporter les chocs de la frappe. Cependant, si l'on admet l'utilisation d'un poinçon général du coin, il faut envisager une reprise et une finition de la gravure en creux par enlèvement de métal afin d'obtenir les angles aigus du relief que l'on observe sur les coins découverts. L'identification des monnaies par coin monétaire montre en général des différences notables dans les proportions de l'image monétaire reproduite à partir de coins différents de même type, ce qui permet d'affirmer que cet usage d'un poinçon général pour la fabrication des coins reste exceptionnel, peut-être le fait de faux monnayeurs (?).

\section{Datation, circulation et attribution des monnaies au cheval galopant}

L'étude des facies des trésors permet de conclure à la contemporanéité de circulation, dans la vallée du Rhône, des monnaies au bouquetin (classe II et III de Deroc), de celles à l'hippocampe et de celles au cheval galopant tant anépigraphes qu'avec la légende VOL. A. Deroc place leurs émissions au début du premier siècle av. n.è., avant la frappe des monnaies au cavalier. L'attribution du type au cheval galopant est en revanche plus controversée. A. Deroc (Deroc 1983 : p. 46) propose à juste titre d'attribuer la frappe de ces monnaies aux Cavares en raison de la concentration des pièces isolées sur leur territoire (Deroc 1983 : p. 112, fig. 7, carte $\mathrm{n}^{\circ} 4$ )... Il est donc curieux de noter que les deux coins monétaires au type du cheval galopant actuellement connus proviennent du territoire allobroge. Le premier a été trouvé avant 1870, c'est le coin dit de Moirans (Isère); bien que sa provenance reste inconnue, on le considère comme venant probablement de la région de Grenoble; il appartient aux collections du musée de Grenoble (Vallier 1879; Delestrée 1977 : p. 47 ; Deroc 1983: p. 11 et 54, note 59). La découverte d'un coin à Larina n'implique pas, à l'évidence, l'existence d'un atelier monétaire sur le site. En effet, les monnaies de ce type sont très minoritaires dans le faciès monétaire du site (cf. B. Fischer p. 21). Bien que leur état de conservation ne permette pas d'être formel, aucune des monnaies de ce type trouvées à Larina ne semble frappée avec ce coin. Comment expliquer la présence en territoire allobroge de ces coins dits cavares? Il faut probablement les mettre en relation avec la diffusion des trésors contenant des monnaies de même type. Or leur distribution géographique est sensiblement différente de celle des pièces isolées et nettement centrée sur l'Isère. A. Deroc (Deroc 1983: p. 46) explique ce phénomène par les révoltes successives des peuples de la vallée du Rhône contre Rome et Marseille entre - 77 et - 75 av. n. è.... Les Cavares auraient fui vers le Nord à cause de la répression romaine... Auraient-ils emporté leur matériel de frappe dans leur migration?

K.G. et R.C.

\section{L'occupation du plateau à l'âge du Fer}

Les documents métalliques de l'âge du Fer découverts sur le plateau sont tous datables de La Tène $\mathrm{D}$, plus précisément pour la plupart, de La Tène D1: il s'agit surtout de parures et de monnaies. Tous proviennent de la partie basse du site, c'est-à-dire la bordure ouest du Camp de Larina. La majeure partie d'entre eux ont été découverts dans des contextes sans rapport avec leur chronologie: des remblais de l'habitat du 
Bas-Empire et du début de l'époque mérovingienne. Les céramiques contemporaines sont difficiles à isoler, à l'exception de quelques importations italiques au demeurant peu abondantes.

Quelques structures ont pu être observées sur une surface fouillée qui dépasse à ce jour 4 hectares : toutes se rapportent au Bronze final III b. Les sauvetages effectués à partir des années 1950, à l'occasion des destructions dues aux carrières, attestent aussi l'existence de structures du Bronze final III $b$ (et du Néolithique), l'âge du Fer étant pratiquement absent des découvertes. La fonction des fosses du Bronze final n'est pas encore clairement établie. Il s'agit généralement de fosses dont les parois sont rubéfiées et qui livrent des céramiques conservées dont les remontages sont possibles (fours rudimentaires?).

127 A partir de ce bilan, qui ne sera définitif qu'après l'étude de tous les documents céramiques, il semble que la majeure partie des données protohistoriques du plateau appartient plutôt à la fin de l'âge du Bronze qu'à l'âge du Fer. Pour ce qui concerne cette période, on peut cependant établir que diverses structures ont nécessairement dû exister à l'emplacement de l'habitat galloromain tardif, mais qu'elles ont été totalement détruites. Sur une surface fouillée qui représente $1 / 5$ de la surface enclose, à laquelle s'ajoutent toutes les surfaces non chiffrables observées lorsque les carrières étaient en activité (plusieurs hectares), une cinquantaine de monnaies, une dizaine de parures et une trentaine d'amphores ne forment pas un lot très important si on le compare aux masses de documents livrés par les oppida qui ont fait l'objet de fouilles extensives (Manching, par exemple). En fait, seule l'unique parcelle cultivable du site, d'une surface d'environ 3 hectares, pourrait encore receler les vestiges d'une occupation dense de l'âge du Fer: les prospections effectuées montrent la présence de tessons d'amphores du type Dressel 1, de quelques objets métalliques et de céramiques campaniennes ${ }^{12}$. Cependant, s'agissant du seul terrain doté d'un potentiel agricole sur le Camp de Larina, on peut estimer que les chances d'observer un jour les témoins d'une occupation dense de l'âge du Fer sont minimes.

L'absence de structures de l'âge du Fer et la présence d'un mobilier épars (parures, monnaies, vaisselle) de La Tène $\mathrm{D}$ n'auraient rien d'étonnant si plusieurs sondages réalisés dans une faille de la falaise bordant le côté ouest du site n'avaient livré un important mobilier protohistorique : la faille de La Chuire.

\section{NOTES}

1. Carte topographique 1/25000 I.G.N. 3131 Est-Crémieu; carte géologique BRGM. XXX, 3, Confluent Ain-Rhône.

2. Dépôt de fouilles Nord-Dauphiné/Maison du Patrimoine de Hières-sur-Amby.

3. Ce mobilier pourrait provenir du tumulus extérieur au camp mentionné par E. Chantre. Sur ce type d'anneau-amulette : cf. Aime 1979 ; Oggiano-Bitar 1985 : p. 69. 
4. Aux découvertes citées par J. Werner, on peut notamment ajouter celles de Crodo, Val Antigorio; Vallegio (Verona); Introbio; Musée de Trévise; Borgo delle Orsoline (Parma); Nocera ; Pompei (au moins 2 ex.) ; Ispignoli (Sardaigne) ; épave de Spargi.

5. A la liste de J. Werner s'ajoutent les exemplaires de Velem- Szenvit, Komorn (Hongrie), Stradonice (Bohême), Karlstein (Haute-Bavière).

6. Cf. par exemple Arcelin 1979 : p. 80.

7. Datation sur laquelle s'arrête en dernier ressort A. Tchernia dans sa communication à la TableRonde CNRS de Valbonne (nov. 1986) : Gaule interne et Gaule méditerranéenne aux IIe -Ier siècles av. J. -C. Confrontations chronologiques.

8. Mobilier présenté par J.-P. Guillaumet au colloque de Yenne- Chambéry (mai 1986) : Les Celtes et les Alpes.

9. Mémoire de maîtrise de Ch. Cécillon et D. Frascone "Les céramiques et les monnaies de Larina (comm. de Hières-sur-Amby) : contribution à la datation d'un site de l'Antiquité tardive et du Haut-MoyenAge" sous les directions de P.-A. Février et G. Démians d'Archimbault. Université d'Aix-Marseille 1, Aix-en- Provence, 1989.

10. Une fosse a livré plusieurs vases de type laténien; ces derniers rappellent cependant les productions augustéeennes de tradition locale, technologiquement plus évoluées.

11. Trente-quatre nouvelles pièces sont venues s'ajouter aux numéraires déjà étudiés : B. Fischer, Les monnaies marseillaises et celtiques de Larina (Hières-sur-Amby, Isère), Les âges du Fer dans les Alpes, Actes du X colloque de l'AFEAF, à paraître.

12. Depuis la rédaction de ce texte, de nouveaux documents de l'âge du Fer ont été découverts lors des fouilles de l'habitat de l'Antiquité tardive. Il s'agit de fibules (type de Lauterach et variantes de Nauheim miniatures), d'un bracelet en tôle de bronze et surtout de rouelles en bronze, inédites sur le site jusqu'à présent ; certaines parures présentent des torsions peut-être volontaires. D'autre part, la présence, dans des fosses, d'amphores italiques (Dressel 1A) complètes, constitue, vraisemblablement, la première observation de structures en place du second âge du Fer sur le site. 


\title{
Chapitre 2. Le site de La Chuire
}

\author{
Jean-Paul Morel, Brigitte Fischer, Patrice Méniel et Henri Duday
}

1 En plus des quelques éléments laténiens provenant du plateau, une faille située au sommet des falaises qui bordent le site sur sa façade ouest et une petite cavité située dans cette faille, ont toutes deux livré du mobilier des âges du Bronze et du Fer.

2 La faille de La Chuire ${ }^{1}$ est une des fractures d'origine tectonique et érosive qui ont profondément entaillé la bordure ouest du plateau de Crémieu, et plus particulièrement la falaise qui longe le Camp de Larina. Etroite de quelques mètres à son point de départ, elle s'élargit progressivement pour finir par se confondre avec les immenses éboulis qui bordent l'Isle Crémieu. Le pendage moyen de son remplissage est de quarante-cinq degrés. La faille constitue un accès direct au Camp au mépris des fortifications, par un sentier qui part de la plaine au niveau de la tourbière d'Hièressur-Amby. Une petite cavité s'ouvre dans la paroi sud: la grotte de La Chuire. C'est cette petite anfractuosité qui a attiré l'attention des premiers chercheurs dont l'intérêt s'est ensuite porté sur toute la faille.

Comme sur le plateau, c'est $\mathrm{E}$. Chantre qui le premier a effectué un sondage dans la grotte de La Chuire, sans laisser de compte rendu de ses travaux. A partir des années 1950, les recherches reprennent par un sondage effectué au sommet de la faille. Le mobilier exhumé comprend tout à la fois des objets métalliques de la fin du Hallstatt D, de la Tène $\mathrm{C}$ et $\mathrm{D}$, mais aussi de la céramique, de la faune, des bracelets en lignite et en verre, une obole de Marseille (Chauffin 1960 : p. 27-50). En 1970-1971, un nouveau sondage est implanté dans la faille de La Chuire (Pélatan 1986), le long de sa paroi sud et quelques recherches sont effectuées dans la grotte. Mais les plus importants travaux débutent en 1975 et se poursuivront jusqu'en 1977 (Chausse 1977: p. 115-120). Ces recherches vont conduire à l'implantation de huit sondages, le long de la paroi sud, sur une dizaine de mètres de longueur. Dernièrement, un sondage a été effectué le long de la paroi nord en 1983-84 (Perrin 1983-1984) (fig. 13) ; ses objectifs étaient la vérification de l'extension du gisement et de l'éventuelle conservation d'une succession stratigraphique cohérente. 


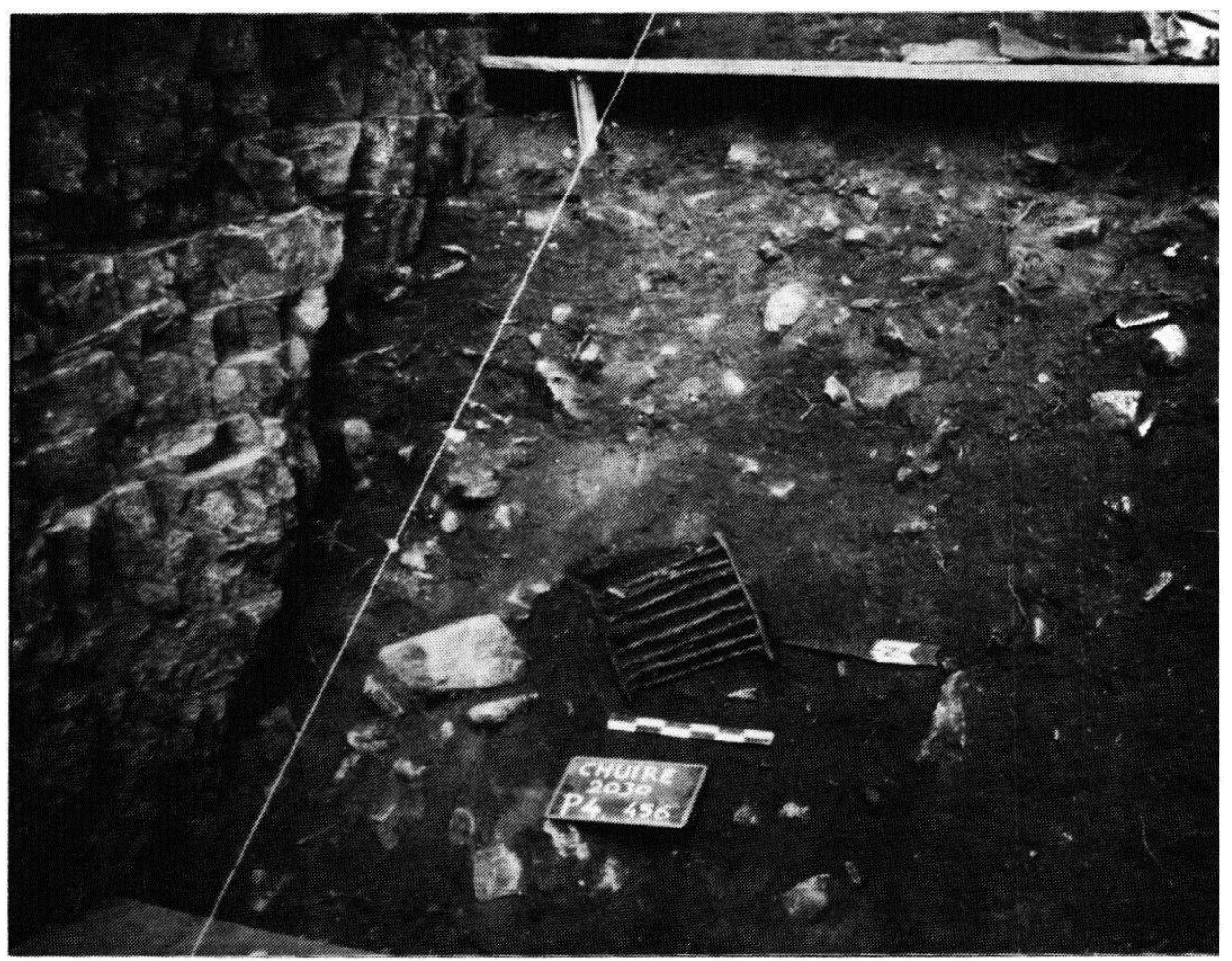

\section{Les données de terrain}

4 Les données stratigraphiques concernant les divers sondages effectués dans la grotte et dans la faille de La Chuire sont extrêmement lacunaires. Pour les travaux des années 1950 et 1975-1977, elles se limitent à des descriptions sommaires de couches sans relevés stratigraphiques ou avec quelques croquis imprécis. Les fouilleurs ont cependant observé deux grands ensembles se distinguant par des variations de teintes: l'un appartiendrait à l'âge du Fer, l'autre à l'âge du Bronze. Malheureusement, le mobilier n'a pas été individualisé et il est donc impossible de rattacher ce dernier aux données imprécises de terrain. L'ensemble du mobilier doit donc être considéré comme hors contexte et étudié comme tel.

5 Le sondage effectué en 1983-1984 (rapports F. Perrin DRAH. Rhône-Alpes) a permis de vérifier le remplissage de la faille : ce dernier est constitué par une succession d'éboulis constitués d'éclats de calcaire provenant du délitage de la falaise. Sous deux mètres de colluvions récentes apparaît une succession d'éboulis qui livrent un très abondant mobilier archéologique (céramique, faune, objets métalliques, monnaies) hétérogène et tout à fait identique aux documents provenant des précédents sondages. Ce mobilier réunit des céramiques de l'âge du Bronze final, du premier et surtout de la fin du second âge du Fer. Les proportions de documents antérieurs à La Tène sont telles qu'il est impossible de les interpréter comme du mobilier résiduel; d'ailleurs pour ce qui concerne les vestiges de la fin de La Tène, on observe dans les mêmes couches d'éboulis l'association de documents de La Tène $C$ et $D$. L'importance du pendage $\left(45^{\circ}\right)$ explique à elle seule les remaniements multiples qui ont bouleversé le gisement et le perturbent encore actuellement. En région Rhône-Alpes, l'habitat du Bronze final III b des Gandus, 
à Saint-Ferréol-Trente-Pas (Drôme) est établi sur « une pente d'environ $30 \%$ et les fouilleurs ont constaté un glissement général du mobilier suivant la dénivellation (Daumas 1985). A fortiori, dans des pendages supérieurs, toute conservation des situations d'origine s'avère très hasardeuse. Toutefois, en l'absence d'information sur le profil du terrain naturel, il reste possible que ponctuellement existe une succession stratigraphique cohérente, stabilisée par des remontées ou des renfoncements du substrat.

6 Outre ces observations, le sondage de 1983-1984 a permis de confirmer la bonne représentation du mobilier métallique notée précédemment: a priori, on pouvait se demander si ce type de mobilier n'avait pas fait l'objet d'une recherche privilégiée. D'autre part, le tamisage systématique des sédiments a permis de récolter quatre oboles de Marseille; seules trois monnaies ayant été signalées lors des sondages précédents, on doit supposer qu'un nombre élevé d'exemplaire est passé inaperçu. De plus, les emplacements de plusieurs travaux clandestins ont permis d'estimer la surface du gisement qui s'étend sur un triangle d'environ deux cents mètres carrés; en fait, il est fort probable que les vestiges occupent une surface beaucoup plus importante puisque l'on a affaire à un cône d'éboulis.

\section{Les découvertes de la grotte}

7 Cette cavité, profonde de quelques mètres à peine, a livré du mobilier du Bronze final au Moyen-Age ; aucune série n'ayant été isolée selon la stratigraphie, le matériel (fig. 14) est donc hors contexte. Quelques objets métalliques pourraient appartenir à l'âge du Fer. Bien que le contexte de la découverte ne permette pas de confirmer leur association, on remarque que tous ces objets se retrouvent dans la faille de La Chuire voisine où les documents gallo-romains et médiévaux sont très rares. De plus, dans les compte rendus des recherches plusieurs descriptions semblent concerner des céramiques campaniennes et des amphores italiques. 

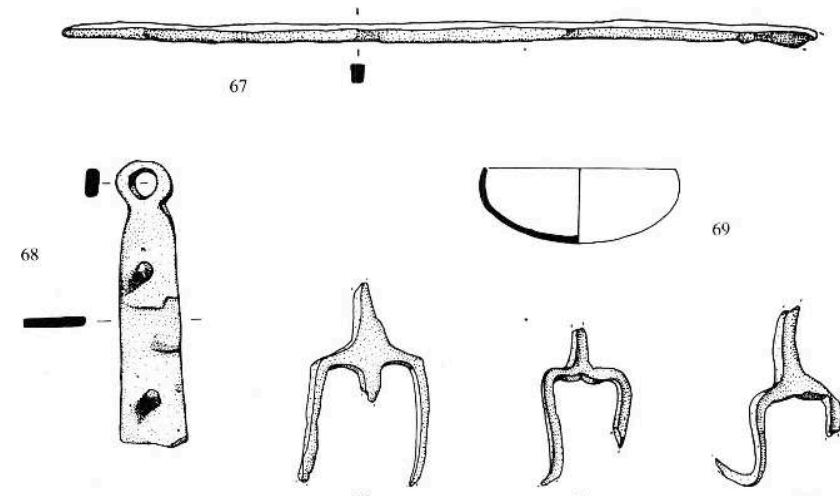

$\sqrt{1}$
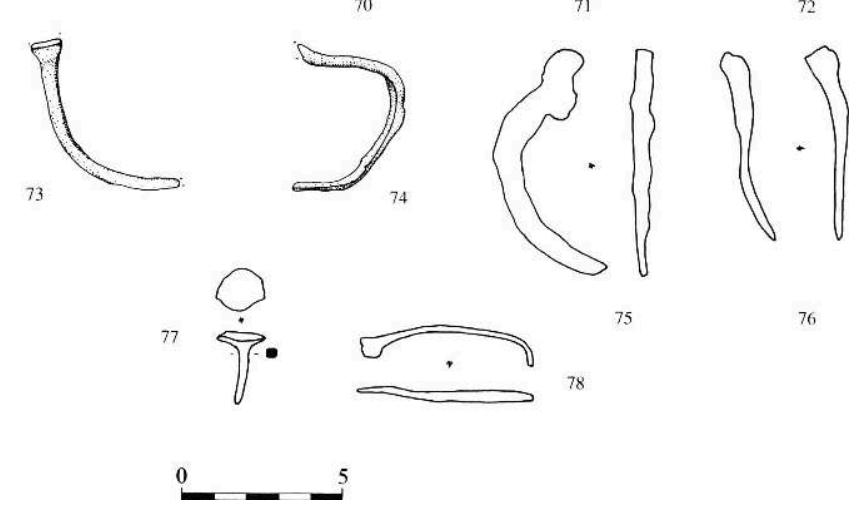

$8 \quad$ Le gril

$\mathrm{n}^{\circ}$ 67. Fragment de gril en fer.

Tige de section rectangulaire qui s'amincit légèrement à une extrémité.

Il s'agit certainement d'une barre transversale de gril ; plusieurs de ces objets, liés à des activités culinaires, sont d'ailleurs attestés dans La Chuire. (cf. p. 60).

\section{Les récipients}

$\mathrm{n}^{\circ}$ 68. Pièce en fer de seau.

Tige de section rectangulaire terminée à une extrémité par un anneau et comportant deux rivets en place (largeur : $15 \mathrm{~mm}$ ).

Il s'agit d'une attache d'anse de récipient en bois, vraisemblablement un seau; la disposition des rivets indique que la pièce était fixée à l'origine dans une rainure d'une des douves du récipient. (cf. p. 70).

$\mathrm{n}^{\circ}$ 69. Fragment de tôle de fer appartenant à un petit récipient (?) hémisphérique (bol ?).

13 Des bols en fer sont connus au second âge du Fer, dans le mobilier de la tombe à char d'Hannogne (Ardennes), datée de La Tène D (Flouest 1977 : p. 67), mais il s'agit dans ce cas d'une forme très différente de cet exemplaire; le diamètre de ce dernier est peu important et pourrait correspondre à une vasque de louche, proche de celle de Montbellet (Saône-et-Loire) (Guillaumet 1983).

\section{Les fourchettes à chaudron}

Plusieurs fragments en fer permettent d'identifier des fourchettes à chaudron. (cf. p. 63).

$\mathrm{n}^{\circ}$ 70. Partie métallique d'une fourchette à chaudron à trois dents recourbées, comprenant une soie, emmanchée à l'origine sur une tige en bois. 

en laboratoire au Centre d'Etude et de Recherche Archéologique de Vienne (Travaux M.-C. Depassiot et V. Langlet). Au préalable, il a été nécessaire de débarrasser les pièces en métal d'un enduit appliqué par les fouilleurs et destiné à stopper la corrosion. Par la suite, la restauration a eu pour objectif de stabiliser la dégradation due à l'oxydation du mobilier et de rechercher la forme initiale de chaque pièce ainsi que d'éventuels décors.

\section{La parure et le costume}

\section{Les fibules en bronze (fig. 15, 17-18)}

$n^{\circ} 79$. Exemplaire en bronze et en fer du type Golfe du Lion. Le ressort compte sept spires enserrant un axe en fer. La corde du ressort est externe à son départ, mais s'inverse ensuite. La section de l'arc est sub-hémi-circulaire. Quant au pied, il est relevé et surmonté d'un bouton conique massif. La fibule est intacte, l'ardillon en position fermée. 

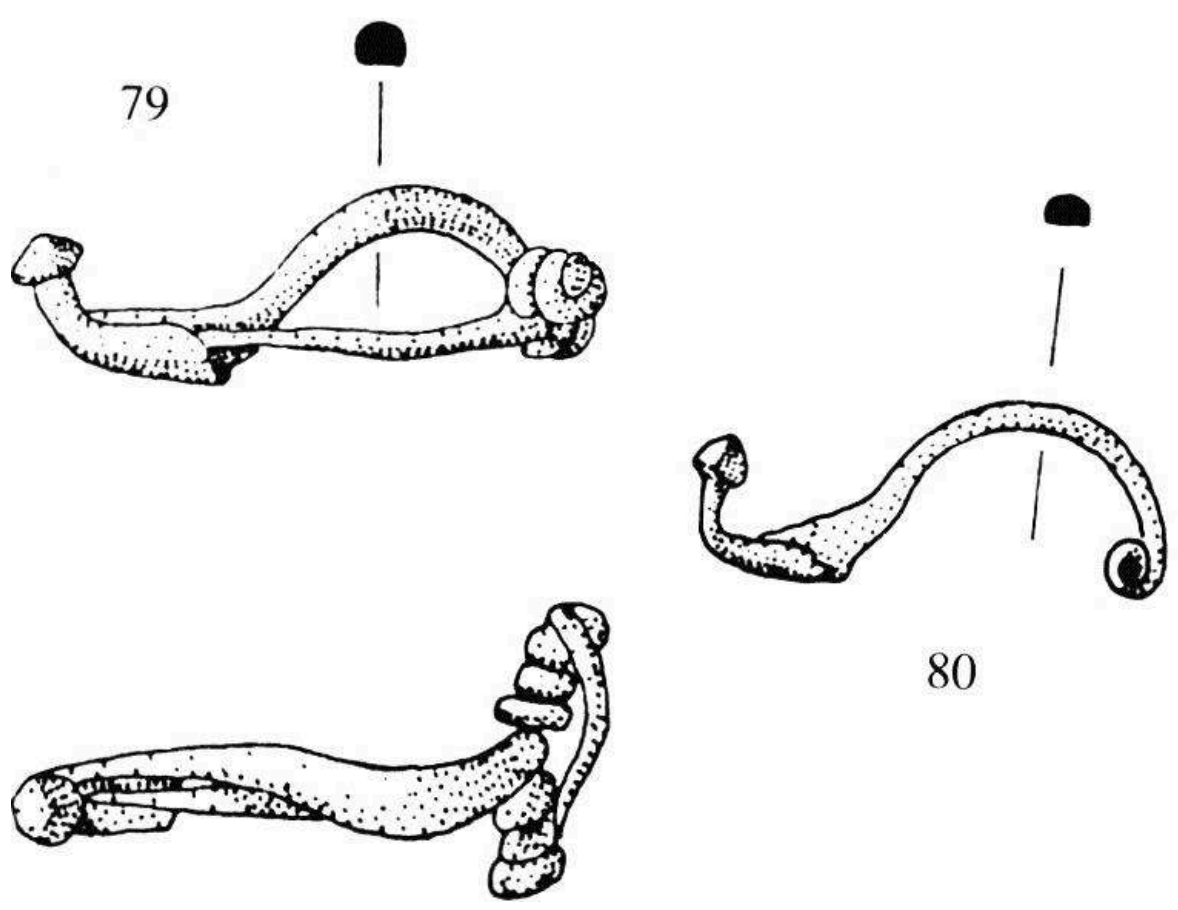

$\mathrm{n}^{\circ}$ 80. Exemplaire incomplet du même type.

L'arc a une section demi-circulaire, le pied est relevé verticalement et il est orné d'un bouton conique. Les deux spires conservées montrent la présence d'un axe en fer.

Ces deux fibules (fig. 15) à pied relevé et à angle droit terminé par un bouton conique appartiennent au type Golfe du Lion dont les différentes variantes attestées en Languedoc ont récemment été étudiées (Tendille 1978: p.77-112). Ce type a vraisemblablement pour origine les fibules à arc serpentiforme et bouton ornemental conique, connues en Languedoc au VIIe siècle av. n. è. Il s'agit donc d'un objet de typologie méditerranéenne. Ce type est bien représenté de la Provence à la Catalogne, dans des contextes du VIe siècle av. n. è.; quelques rares exemplaires persistent cependant au Ve siècle av. n. è. (Tendille 1983 : p. 58 ; Charmasson 1981 : p. 77).

La répartition de ces fibules ne concerne pas uniquement le Sud de la France et le Nord de l'Espagne. Quelques exemplaires sont connus sur des sites septentrionaux (fig. 16), le plus souvent sur des habitats de hauteur qui témoignent de la circulation des produits massaliotes (Perrin, à paraître). Il s'agit donc vraisemblablement d'objets diffusés en compagnie des amphores et des céramiques provençales. Sur les sites majeurs du Hallstatt final du Centre-Est de la Gaule, ces fibules ne sont représentées que par un ou deux exemplaires au plus. Cette faible représentation est peut-être à mettre en rapport avec la rareté générale du mobilier métallique sur les sites méridionaux des VIe-Ve siècles av. $n$. è. Le type Golfe du Lion a d'autre part suscité des imitations en Bourgogne, comme l'indique l'exemplaire de Charmes (Saône-et-Loire) dont l'arc est orné d'incisions formant une torsade. Cette décoration est inconnue sur les exemplaires méridionaux, mais existe par contre sur des fibules laténiennes de la seconde moitié du Ve siècle av. n. è. (Moosleitner 1974 : Taf. 138 ; Hodson 1968 : p. 79). Il reste à définir le ou les lieux de fabrication des fibules du type Golfe du Lion attestées 
au nord du Pègue (Saint-Marcel, Drôme), qui paraissent former une série homogène (toutes sont de petites dimensions) : a priori, on peut penser à des sites localisés en Provence.

\section{6- Répartition des fibules du type « Golfe du Lion » au nord de Bollène}

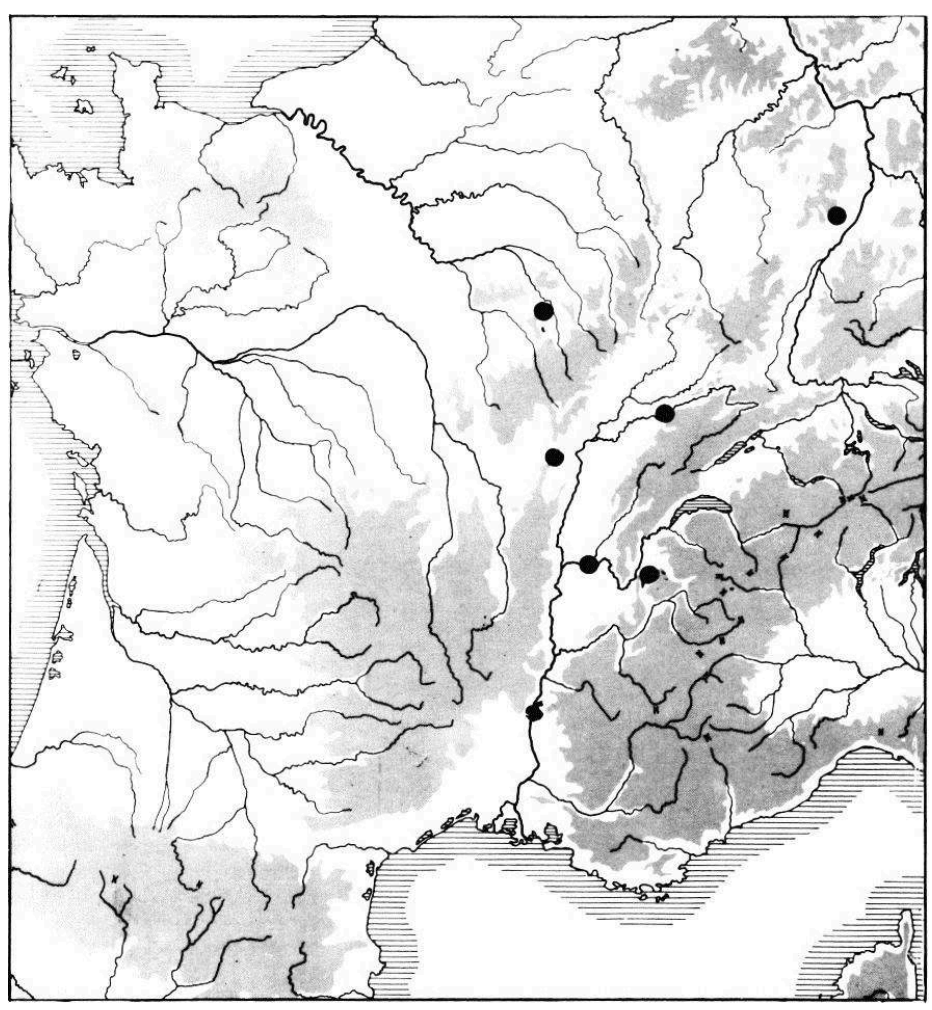




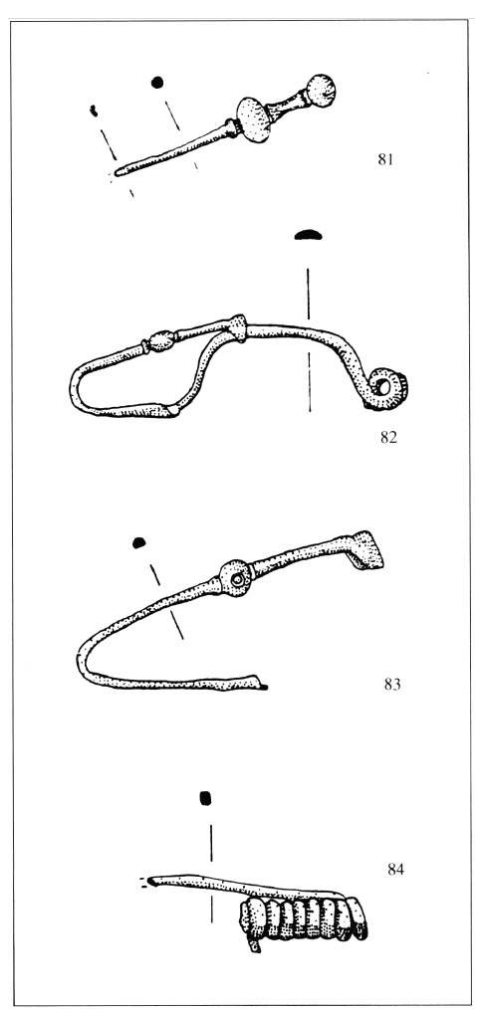

$28 \mathrm{n}^{\circ}$ 81. Pied de fibule (fig. 17).

Celui-ci est orné d'un sphéroïde légèrement aplati, bien dégagé du pied par deux moulures, précédé d'une petite nodosité et tenniné par un nouveau sphéroïde, plus réduit que le précédent.

29 Ce fragment appartient à une fibule de schéma La Tène I à pied libre. Il s'agit d'une fibule du type Hodson 62, défini par l'exemplaire $n^{\circ} 149$ de la sépulture $n^{\circ} 171$ de la nécropole de Munsingen (BE. Suisse) et connu par plusieurs exemplaires dans cette même nécropole. C'est un type tardif de schéma La Tène I, qui est parfois associé à des fibules de schéma La Tène II (Hodson 1968 : p. 153). $\mathrm{n}^{\circ}$ 82. Exemplaire incomplet de schéma La Tène II.

L'arc s'inscrit dans un trapèze et possède une section lenticulaire. Le pied s'attache à l'arc par une bague et est orné d'une demi-sphère creuse, légèrement aplatie et encadrée par deux moulures.

31 L'objet se rapproche de l'exemplaire $n^{\circ} 125$ de la sépulture $n^{\circ} 161$ de Munsingen, qui associe des fibules de schéma La Tène II à des exemplaires à pied libre. Le pied de la fibule provenant de Münsingen présente une série de moulures encadrant la demisphère qui sont absentes sur l'exemplaire de La Chuire. Une autre fibule $\left(n^{\circ} 116\right)$ de cette même tombe, connue seulement par une photographie, paraît encore plus proche (Hodson 1968 : p. 146 et pl. 112). La présence d'une demisphère sur le pied se retrouve sur des fibules à pied libre du type de Duchcov, et indique qu'il s'agit d'un modèle précoce de construction La Tène II. L'exemplaire de La Chuire est par ailleurs très proche de celui de la sépulture $n^{\circ} 47$, terrain De Lucca de Bologne (Prov. de Bologne, Italie), et qui est attaché par une chaîne à une fibule de schéma La Tène I, confirmant ainsi l'ancienneté de cette forme (Kruta 1980: p.17). On peut également citer 
l'exemplaire du sanctuaire de Mirebeau (Côte-d'Or), unique fibule de schéma La Tène II associée à plusieurs fibules à pied libre (Brunaux $1985 \mathrm{a}: \mathrm{p}$. 84).

$n^{\circ}$ 83. Pied de fibule de schéma La Tène II.

Ce dernier comporte une bague de fixation indiquant un schéma La Tène II. Il est de plus orné d'une sphère décorée de deux estampages circulaires.

Ce fragment correspond à une fibule du type Hodson 65 défini par l'exemplaire $\mathrm{n}^{\circ} 212$ de la sépulture 181 de Miinsingen (Hodson 1968 : p. $146 ; 164 ; 158$ ). Cette forme est bien représentée à Münsingen par de nombreux exemplaires qui ne diffèrent entre eux que par la décoration de leur perle. L'origine de ce modèle semble être des fibules de schéma La Tène I, dont la perle porte également des estampages circulaires. Le nombre élevé de sépultures contenant ce type d'objet indique son emploi durant toute la phase La Tène $\mathrm{Cl}$, soit deux à trois générations d'individus.

Ces fibules sont généralement portées par paire d'exemplaires présentant une décoration similaire dans des sépultures de femmes richement parées, comme par exemple la tombe $n^{\circ} 184$ de Miinsingen. En plus des découvertes de cette nécropole, on peut signaler la présence d'exemplaires dans des sépultures de la région de Berne (Kaenel 1983: p. 200) et sur le versant français des Alpes: dans les inhumations savoyardes de Saint-Laurent-la-Côte et de Saint-Jean-d'Arves (Boucher 1980: p. 531; Hudry 1955 : p. 89-91) ainsi que dans la sépulture 1 de Peyre-Haute à Guillestre (HautesAlpes) (Déchelette 1914 : p. 1 057). $\mathrm{n}^{\circ}$ 84. Ressort.

Il s'agit d'un demi-ressort à huit spires conservées et qui possède un axe en fer massif de section rectangulaire; la corde est externe.

Les dimensions de l'objet écartent une éventuelle attribution aux fibules hallstattiennes, généralement de petite taille. Par contre, certaines fibules provenant de contextes tardifs de La Tène $B$ possèdent des ressorts très longs avec un axe en fer : par exemple, une fibule de la sépulture 6 de Pecky (Dist. de Nymburk, Tchécoslovaquie) ou certaines fibules à pied libre de la nécropole de Miinsingen (Hodson 1968: p. 143; Kruta 1975 : p. 170). Les formes à ressort long réapparaissent durant La Tène C2, mais il s'agit souvent d'exemplaires plus graciles que la fibule $n^{\circ} 84:$ ce fragment appartient donc vraisemblablement à une forme ancienne de parure, probablement à une fibule de schéma La Tène I. L'axe en fer, en place dans le ressort, était destiné à assurer un triple rôle : mettre en forme les spires, consolider le ressort et éventuellement fixer des cabochons en corail.

$\mathrm{n}^{\circ}$ 85. Fibule intacte du type de Nauheim (fig. 18-19).

L'arc trapézoïdal porte un décor constitué d'un triple trémolo. 
18 - Fibules en bronze de la Tène D

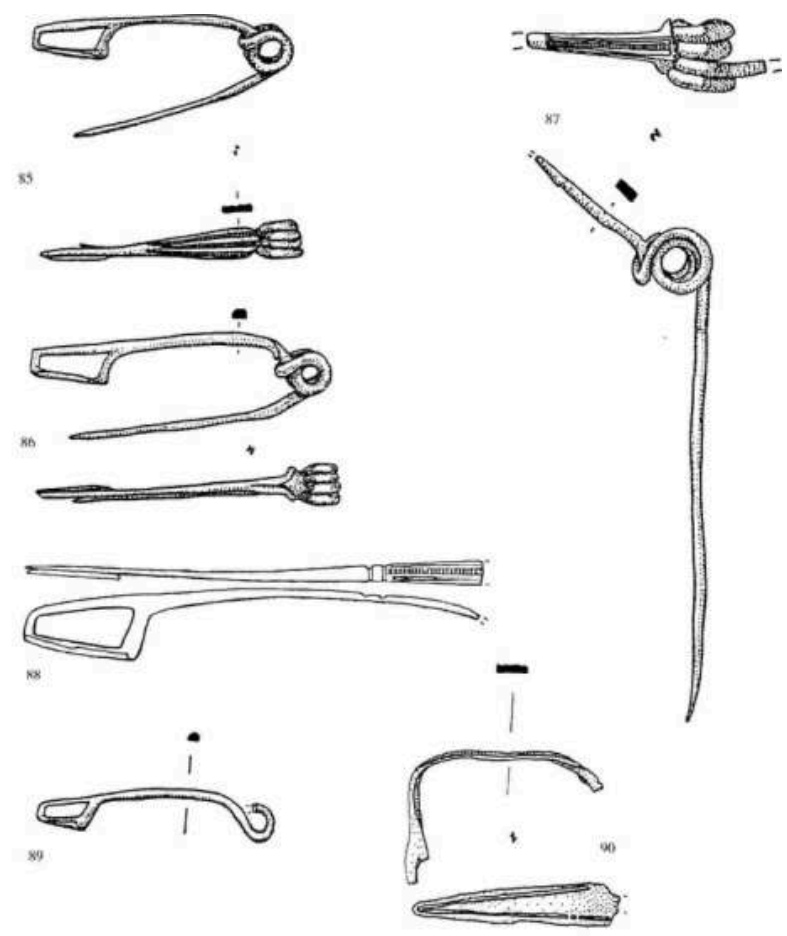

19- Fibule en bronze du type de Nauheim

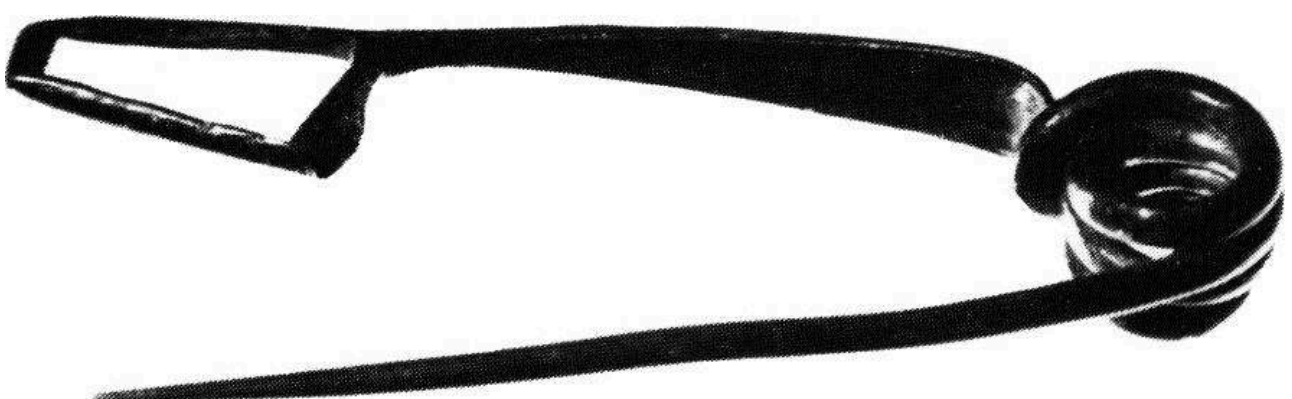

Il s'agit du type 5a 29 défini par M. Feugère et connu par deux exemplaires en Isère, sur le site de Revel-Tourdan, et par plusieurs exemplaires dans la nécropole à inhumation de Lanslevillard (Savoie) (Feugère $1985 \mathrm{a}:$ p. 208) ; Anonyme $1986 \mathrm{a}$ : p. 31). Ce type est par contre absent de l'importante série de Sainte-Blandine. Ces fibules sont bien représentées en Gaule méridionale, sur les deux rives du Rhône : par exemple, sur le site de hauteur fortifié de La Cloche. Dans le domaine celtique, ce type de fibule est connu sur le site de Bâle-Gasfabrik (T. 19), dans un contexte de La Tène D1 (FurgerGunti 1980 : p. 52).

$\mathrm{n}^{\circ}$ 86. Exemplaire intact du type de Lauterach. L'arc est orné de deux incisions, il s'évase près de la tête pour former deux ailettes.

Ce type ( = Feugère $5 \mathrm{c} 5$ ), du nom d'un dépôt comprenant, entre autres, une paire de fibules en argent attachées par une chaîne (Krämer 1971; Feugère 1985 a : p. 222), est représenté par deux exemplaires découverts sur le plateau de Larina (cf. p. 19). Les fibules du type de Lauterach sont attestées de la Bourgogne à la Suisse, essentiellement 
sur les oppida (fig. 20). On peut signaler la présence d'exemplaires à Bibracte, à Montbellet (Saône-et-Loire), dans le lit de la Saône, à Alésia (Côte d'Or), à Besançon (Doubs), à Berne-Enge, à Altenburg-Rheinau (DL. RFA/ZH. Suisse), dans la nécropole de Bâle-Gasfabrik (T. 16 A), à BâleMunsterberg, à Breisach-Hochstetten (Forêt-Noire, RFA) et à Manching (Bavière, RFA). Dans la Provincia, en plus des trois exemplaires de Larina, le type de Lauterach n'est attesté qu'à Sainte-Blandine, par un unique exemplaire. Chronologiquement, ce modèle appartient à La Tène $\mathrm{Dl}$, voire au tout début de La Tène D2: il est associé dans le site éponyme à des deniers de la République dont les plus récents sont datés des années 117-116 av. n. è. mais figure encore dans la couche 2 du Münsterberg à Bâle (un seul exemplaire cependant). On peut remarquer que les deux points de découvertes les plus méridionaux sont situés en limite des territoires qui sous Auguste constituent la Narbonnaise.

\section{0- Répartition des fibules du type de Lauterach en Gaule}

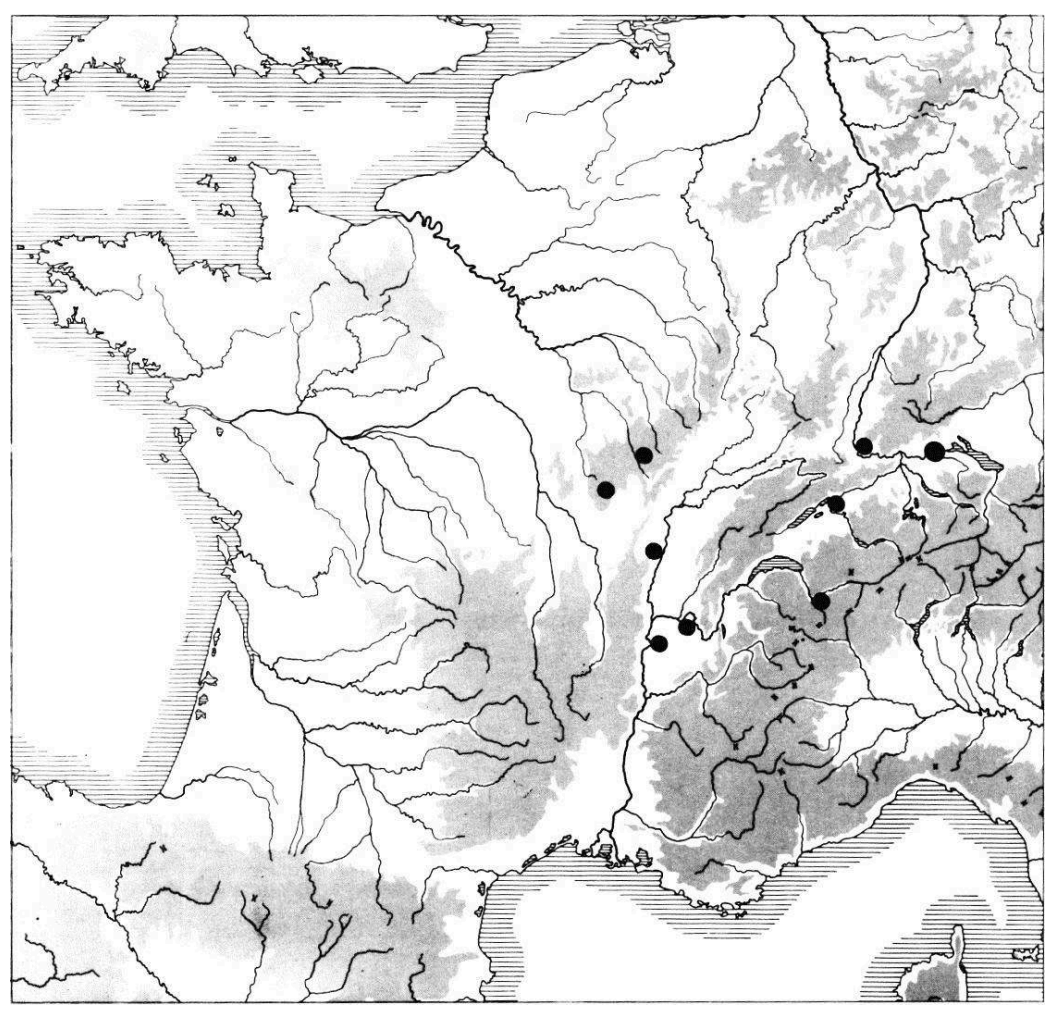

$\mathrm{n}^{\circ} 87$. Fibule du type de Nauheim incomplète.

Il s'agit d'une variante de grande taille; l'arc est orné d'un trémolo encadré par deux incisions. La tête de l'arc montre la présence de deux ailettes latérales rappelant le type de Lauterach. Cette fibule a été volontairement déformée en l'ouvrant au maximum.

On peut rapprocher cette fibule de certains exemplaires du type Feugère $5 \mathrm{a} 20$, en particulier d'une fibule de Glanum (Saint-Rémy-de-Provence, Bouches-du-Rhône), d'une fibule de Bâle-Gasfabrik et d'un exemplaire découvert dans le Rhin à Mayence (RFA) (Feugère 1985 a : p. 222 ; Werner 1979 : Abb. 5, B 5). $n^{\circ} 88$. Variante du type de Nauheim incomplète.

L'arc est orné d'un trémolo encadré par deux incisions et délimité par deux incisions transversales. 
Cette fibule constitue l'unique représentant du type Feugère $5 c 1$ par ailleurs assez proche des modèles du type $5 \mathrm{a}$ (Feugère $1985 \mathrm{a}: \mathrm{p}$ 222).

$\mathrm{n}^{\circ}$ 89. Fragment de fibule filiforme.

Cet exemplaire de construction extrêmement simple (Feugère $5 b$; Guillaumet 2) est très bien représenté régionalement par 12 exemplaires à Sainte-Blandine et 3 exemplaires à Lyon, dans le fossé aval du Verbe-Incarné (Chapotat 1970 ; Sandoz 1989 : p. 72). Ce modèle connaît une très large aire de répartition dans toute la Gaule et dans le monde celtique (Feugère $1985 \mathrm{a}:$ p. 222) et les ateliers ayant fabriqué ce type sont certainement nombreux. Le nombre élevé d'exemplaires régionaux plaide en faveur de l'existence, en pays allobroge, d'un ou de plusieurs ateliers ayant produit cette forme gracile et totalement utilitaire. Pour ce qui est de la chronologie de ce modèle, les données fournies par l'étude des sites ségusiaves (Guichard 1988) et par la fouille du Verbe-Incarné montrent son existence durant La Tène D1.

$\mathrm{n}^{\circ}$ 90. Type de Nauheim incomplet.

L'arc porte un décor simple, constitué de deux incisions. La fibule a été volontairement repliée à angle droit, au niveau du porte-ardillon.

Ce fragment correspond au type Feugère $5 \mathrm{a} 12$ attesté dans le Dauphiné sur les sites de Revel-Tourdan (1 ex.) et de Sainte-Blandine (2 ex.) (Feugère 1985 a : p. 216).

Plusieurs fibules sont trop incomplètes pour être attribuées avec certitude à un type répertorié (fig. 21).

\section{1- Fragments de Fibules en bronze}

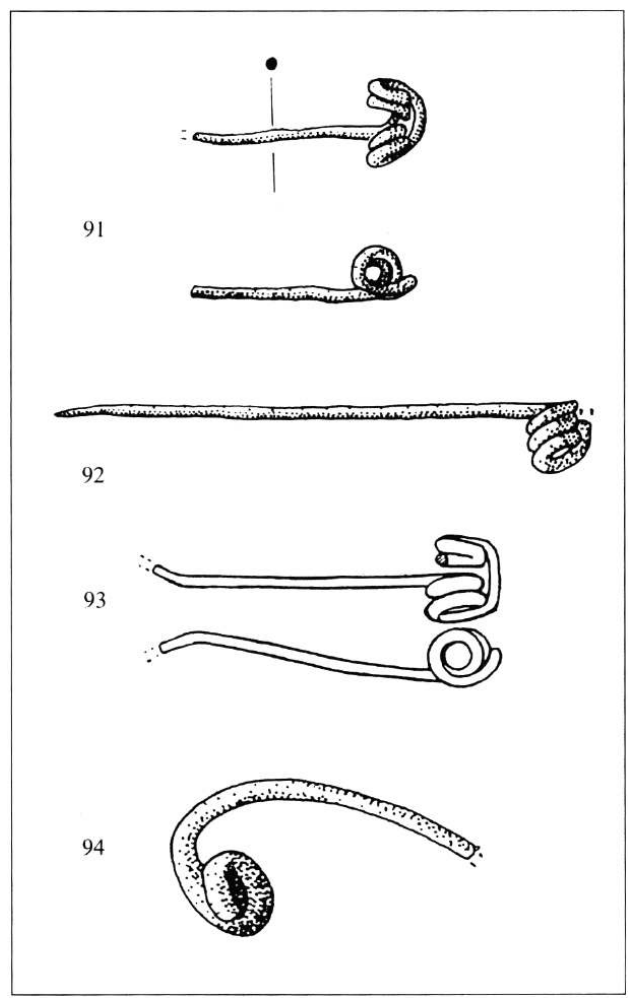

$\mathrm{n}^{\circ}$ 91. Ressort.

Exemplaire à 2 x 2 spires, corde externe et départ d'ardillon. 
Des fibules de schéma La Tène II de Münsingen présentent des ressorts assez proches dans des contextes de La Tène $C$, mais ce type de ressort reste encore en usage au Ier siècle av. n.è. (Feugère $1985 \mathrm{a}: \mathrm{pl} .3$, nº 62-63).

$\mathrm{n}^{\circ}$ 92. Ardillon et fragment de ressort.

Trois spires à droite sont conservées. Il s'agissait certainement d'une fibule dont le ressort comportait à l'origine 2 x 3 spires et une corde externe.

$\mathrm{n}^{\circ}$ 93. Ressort à $2 \times 2$ spires et corde externe.

$\mathrm{n}^{\circ}$ 94. Fragment de fibule massive.

L'objet a vraisemblablement été déformé volontairement.

Cette série comprend 16 fibules en bronze et la plupart d'entre elles sont datables de La Tène Dl. Seules trois sont intactes. En outre, trois fibules semblent présenter des traces de déformations volontaires.

\section{Les fibules en fer (fig. 22-31)}

$\mathrm{n}^{\circ}$ 95. Fragment d'appendice caudal.

Il s'agit certainement d'un exemplaire de schéma La Tène I ; il faut, en effet, plutôt voir dans l'extrémité de l'objet une "patte » reposant à l'origine sur l'arc, qu'une bague d'attache incomplète. Il s'agit donc d'un modèle à pied libre tardif, de dimensions réduites comme le sont les dernières fibules de ce schéma. Le pied comporte une perle encadrée par deux moulures et ornée d'une esse en léger relief, obtenue peut-être par matriçage. Les deux extrémités de l'esse sont repliées sur elles-mêmes et remplies d'une matière jaune, vraisemblablement de l'émail à l'origine rouge, aujourd'hui altéré. Un examen à la binoculaire a montré que l'émail recouvrait un "rivet » en bronze d'environ 1/10 de $\mathrm{mm}$ de diamètre, destiné à assurer sa fixation sur le fer. Cette technique artisanale est connue à l'âge du Fer, sur des rivets d'umbo de bouclier de Gournay-sur-Aronde (Oise).

$\mathrm{n}^{\circ}$ 96. Pied de grande fibule de schéma La Tène II.

Comme le fragment précédent, la perle qui orne l'arc est décorée d'une esse en léger relief, incrustée cette fois d'émail rouge-sang. A la surface de celui-ci, on observe une série d'incisions entrecroisées formant un damier irrégulier: plutôt qu'un décor, d'ailleurs pratiquement invisible, il faut voir dans ces traces le résultat de la mise en place de l'émail. Par endroits, on observe une oxydation verdâtre qui indique la présence d'un rivet en bronze. La perle présente un aplatissement opposé au décor qui est probablement la conséquence de sa réalisation. Elle est en outre encadrée par deux moulures (la moulure antérieure étant surmontée d'un «ergot » triangulaire) qui masquent partiellement l'esse : leur mise en forme est donc postérieure à la réalisation du décor.

En ce qui concerne ces deux fibules à décor incrusté d'émail (fig. 22), les comparaisons demeurent rares. Une fibule en fer provenant de la nécropole de Rives (Isère) appartient sans doute à la même série (fig. 23). Il s'agit d'un modèle de schéma La Tène II, très proche par sa forme équilibrée des fibules en bronze du type Hodson 65 , luimême daté de La Tène $\mathrm{Cl}$. La perle de l'exemplaire de Rives est ornée en plus fort relief que sur les fibules de La Chuire. L'émail a disparu, mais à l'emplacement présumé de celui-ci on peut noter deux dépressions en amande qui le contenaient à l'origine (Charvet 1882 : p. 295315 ; Perrin à paraître). Le décor d'esses sur des fibules en fer est connu dès le début du IIIe siècle, par exemple sur une des parures de la tombe 163 d'Ensérune (Hérault) (Rapin 1987 : p. 178). 


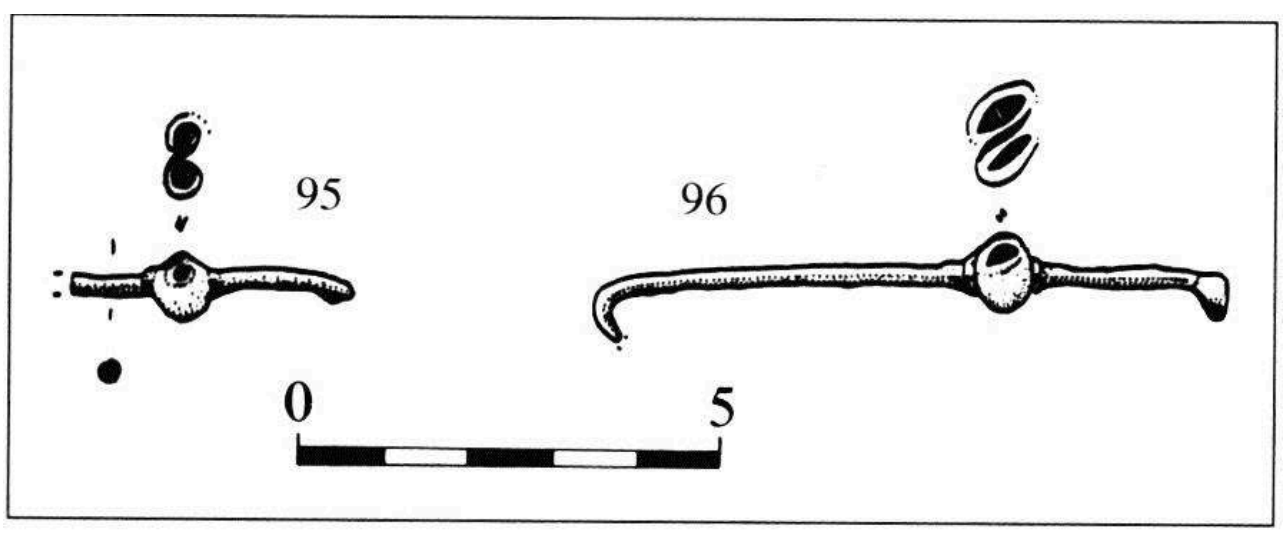

23- Fibule en fer de la nécropole de Rives (Isère)

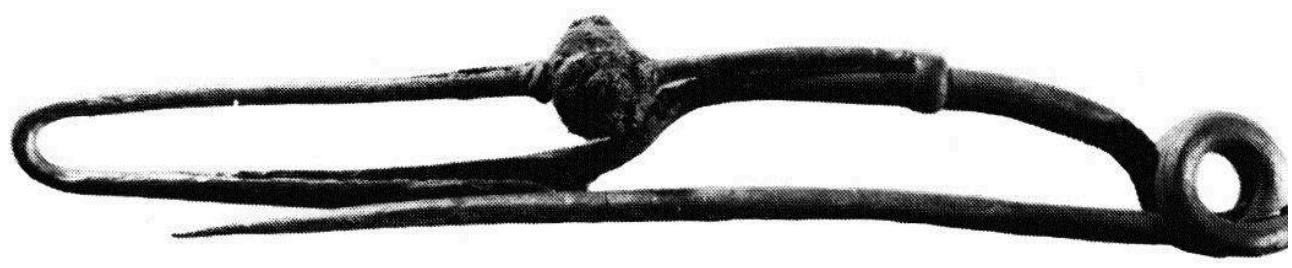

L'emploi de l'émail est reconnu dès le IVe siècle av. n. è. où il constitue l'un des principaux substituts du corail d'origine méditerranéenne dont il imite la couleur. Dès cette époque son usage est attesté en association avec le bronze sur les oenochoés de Basse-Yutz (Moselle) (Kruta 1986 a : p. 25, fig. 12), mais aussi associé au fer sur le casque d'Amfreville-sous-les-Monts (Eure) (Duval 1986 : p. 83-84).

L'étude de D. Viollier sur les sépultures du second âge du Fer du Plateau Suisse signale un certain nombre de torques à motifs ternaires ainsi que des fibules à pied libre, en fer ou en bronze, incrustés d'émail (Viollier 1916: p. 33 et 41). Après l'abandon du corail au cours du IIIe siècle av. n. è., l'émail est employé sur des chaînes de ceintures féminines datées de La Tène $C$ (Kruta 1975 : p. 186), puis au cours de La Tène $D$ sur des éléments de harnachement et des pièces d'armement. Un atelier produisant des objets émaillés est d'ailleurs reconnu à Bibracte (Beck 1985 : p. 237245. fig. 3-4).

Le principal intérêt des fibules de La Chuire est de montrer qu'après l'abandon du corail, dont l'emploi est lié au vin et à l'iconographie de l'une des principales divinités celtiques (Lug ?), l'usage d'orner d'une manière proche certaines de ces parures s'est maintenu (Kruta 1986 a). Le fait que le support de cette décoration soit le fer explique que peu d'exemplaires aient été signalés : une fibule en fer provenant d'une sépulture féminine (T. 14) de Gempenach (FR. Suisse) possédait une perle décorée d'une esse qui pourrait également être incrustée d'émail (Kaenel 1983: p. 200, pl. 3, $\mathrm{n}^{\circ} \mathrm{l}$ ). Actuellement, rien ne permet d'estimer la part qu'occupent ces fibules dans l'ensemble des modèles en fer. Toutefois, on peut supposer une relative rareté pour ces parures, qui sont des pièces complexes et sans doute difficiles à réaliser. A ce propos, l'émaillage du fer semble être une technique propre au second âge du Fer ; apparemment inconnu à l'époque gallo-romaine, cet artisanat est toutefois mentionné à l'époque médiévale (Feugère $1985 \mathrm{a}$ : p. 363 ; Gauthier 1972 : p. 24). 
$\mathrm{n}^{\circ}$ 97. Fragment de fibule de schéma La Tène II (fig. 24).

Le ressort comporte quatre spires $(2 \times 2)$ et la corde est externe ; l'arc s'inscrit dans un demi-cercle, sa section est circulaire. Le pied est orné d'un sphéroïde incomplet et s'attache à l'arc par une bague.

\section{4- Fibules en fer de schéma La Tène II}
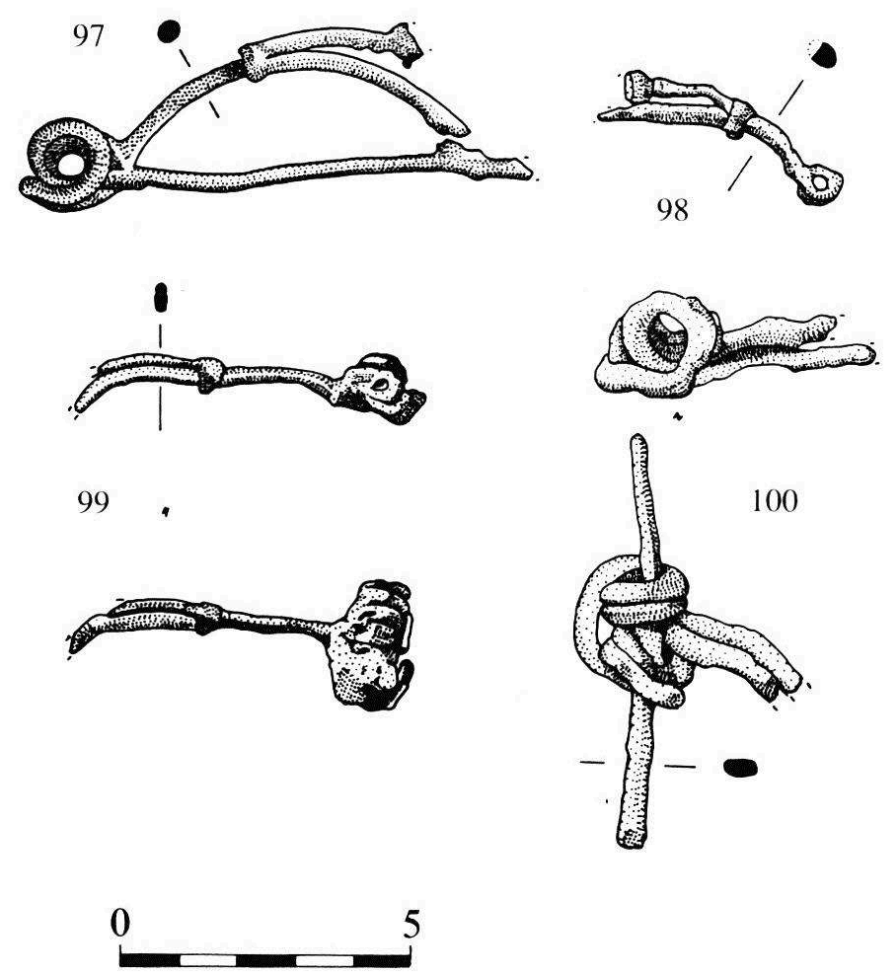

La présence d'une perle, d'un diamètre supérieur à la section du pied, permet de dater ce fragment de La Tène $\mathrm{Cl}$.

$\mathrm{n}^{\circ}$ 98. Fragment de fibule de schéma La Tène II.

Le ressort comporte quatre spires (type à $2 \times 2$ ?). L'arc est de section ovalaire : le pied s'attache à l'arc par une bague massive et il est orné d'un sphéroïde incomplet (la cassure est franche). Il s'agit également d'un modèle de La Tène $\mathrm{Cl}$. $\mathrm{n}^{\circ}$ 99. Exemplaire incomplet de schéma La Tène II.

Pied d'une parure de schéma La Tène II, orné d'une sphère de petite taille. L'objet est très déformé : le ressort comptait vraisemblablement à l'origine quatre spires $(2 \times 2)$. Celles de gauche sont complètement écrasées au point qu'on ne les distingue plus. Le métal paraît fondu, comme après une violente crémation, et l'objet a peut-être subi un martelage réalisé à chaud : la corde est sectionnée en son milieu et l'arc est totalement aplati.

$\mathrm{n}^{\circ}$ 100. Grande fibule incomplète.

Exemplaire très déformé de grandes dimensions. Le ressort compte quatre spires $(2 \mathrm{X}$ 2), la corde est externe. L'arc a une section circulaire ; comme l'ardillon, il est tordu, probablement volontairement. Une tige en fer de section rectangulaire traverse le ressort : il s'agit sans doute d'un fragment d'outil, utilisé comme levier pour déformer le corps de la fibule. Les deux spires à gauche, ainsi que l'outil, sont partiellement écrasés de la même manière que l'exemplaire précédent. 


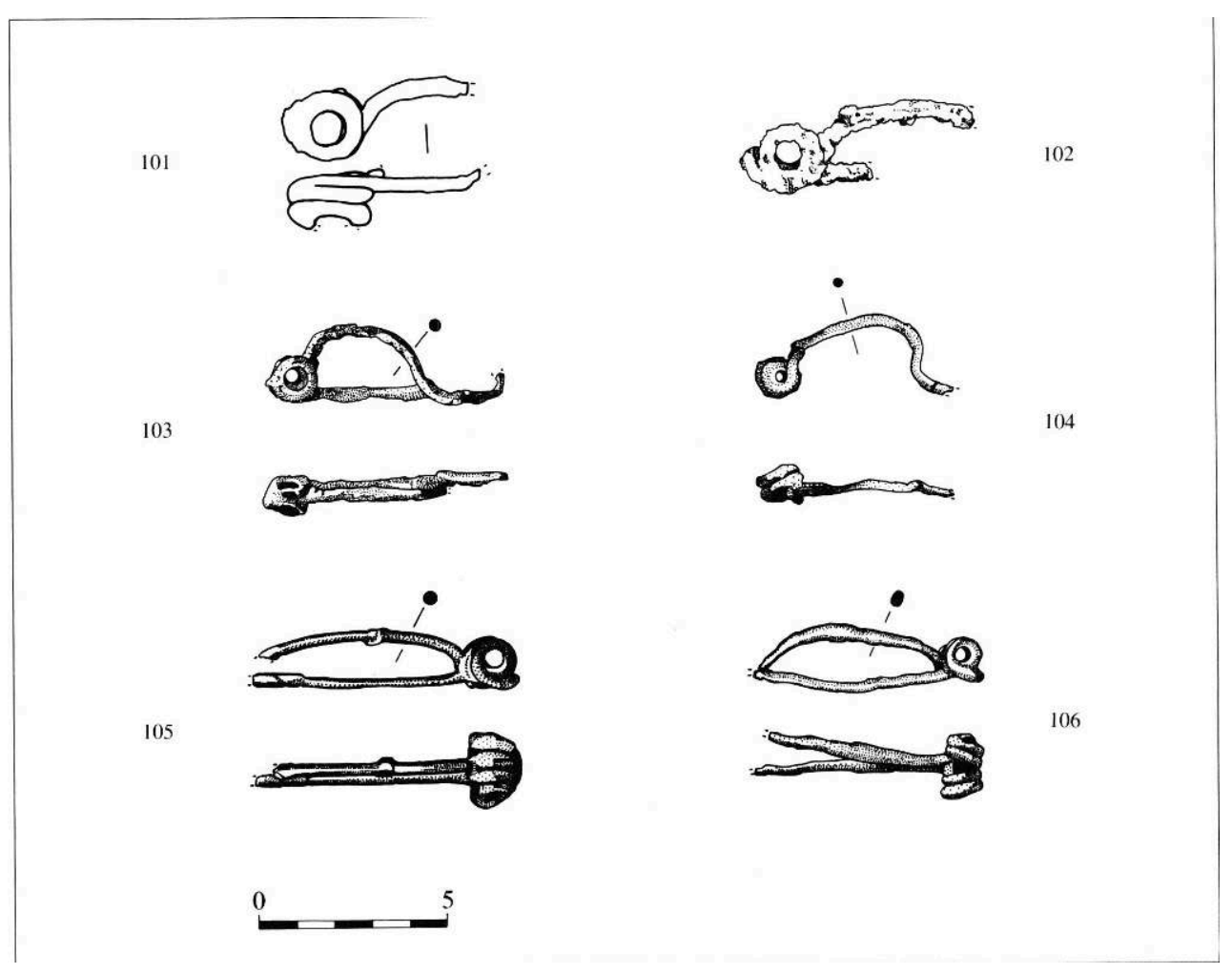

$\mathrm{n}^{\circ}$ 102. Exemplaire de schéma La Tène II.

L'extrémité conservée montre l'existence d'une bague d'attache du pied. Le ressort à corde externe comprend quatre spires $(2 \times 2)$. Contrairement à l'ensemble du mobilier en fer du site, cette fibule était très corrodée.

$\mathrm{n}^{\circ}$ 103. Fibule incomplète.

L'absence du pied ne permet pas d'identifier le schéma de construction de l'objet et il n'y a pas non plus de trace de bague sur l'arc. Le ressort ne conserve que deux spires, la corde est externe. Cette partie de l'objet montre les mêmes déformations que les exemplaires précédents.

Cette fibule, comme un certain nombre d'autres, est trop incomplète pour être datée. Cependant, la rareté des fibules de schéma La Tène I dans la série permet de supposer que tous les fragments indiquant un schéma autre que celui de La Tène III, sont probablement des modèles de schéma La Tène II.

$\mathrm{n}^{\circ}$ 104. Fibule incomplète.

Cette parure présente une légère déformation au niveau de l'arc; l'objet a conservé deux spires du ressort à droite de l'arc qui est de section circulaire. $\mathrm{n}^{\circ}$ 105. Exemplaire de schéma La Tène II.

Son ressort compte quatre spires $(2 \times 2)$ et possède une corde externe. L'arc est de section circulaire et a, semble-t-il, conservé une partie d'une bague d'attache. La restauration a mis en évidence la présence, à l'intérieur du ressort, d'un cylindre en fer d'un diamètre égal au diamètre intérieur des spires. L'objet dépasse d'environ $1 \mathrm{~mm}$ de 
chaque côté du ressort. Cet objet devait permettre à l'artisan de mettre en forme des spires de dimensions constantes.

$72 \mathrm{n}^{\circ}$ 106. Fibule incomplète.

Celle-ci est légèrement déformée au niveau de l'arc dont la section est ovalaire. Le ressort compte quatre spires $(2 \times 2)$ et la corde est externe.

$73 \mathrm{n}^{\circ}$ 107. Pied d'un type de schéma La Tène II (fig. 26).

La taille réduite de la perle est peut-être l'indice d'une datation basse dans La Tène $C$. L'objet rappelle une fibule provenant du comblement de l'enclos A de la nécropole du Gringalet à Serguines (Yonne) (Parruzot 1977 : p. 65, fig. 27, c).

26- Fibules en fer de schéma La Tène II

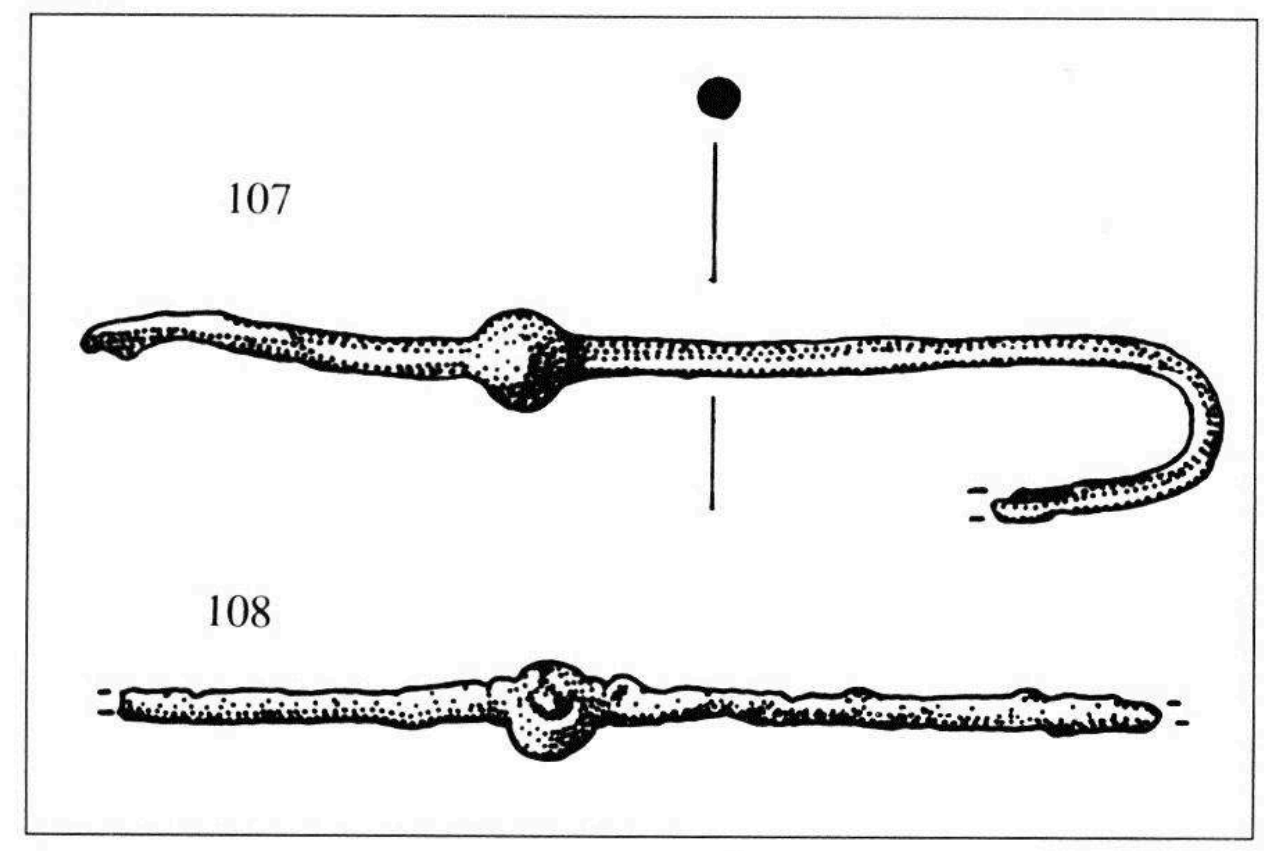

$74 \mathrm{n}^{\circ}$ 108. Pied de fibule de schéma La Tène II.

Celui-ci est orné d'une petite perle, encadrée par deux moulures, qui semblent être décorées d'un cercle estampé. Il pourrait s'agir d'une variante en fer tardive du type Hodson 65.

$\mathrm{n}^{\circ}$ 109. Fragment indiquant une parure de schéma La Tène II (fig. 27) 


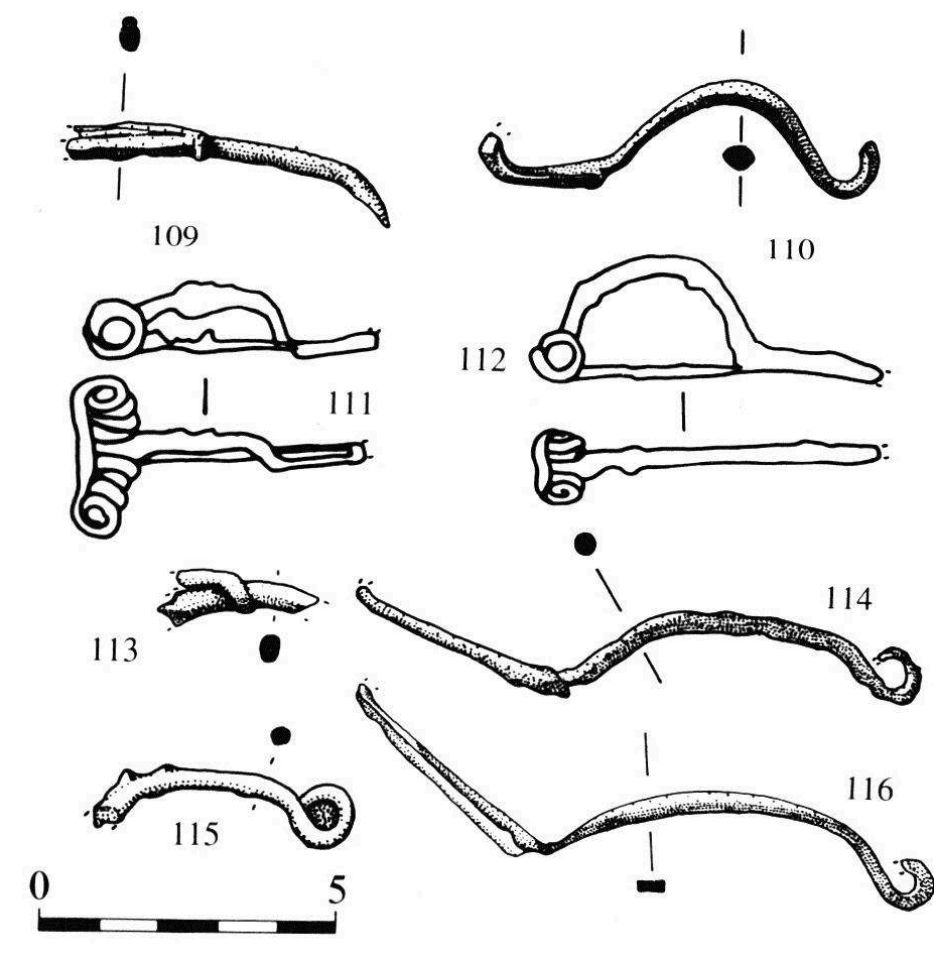

$76 \mathrm{n}^{\circ}$ 110. Fragment de fibule massive.

La forme de son arc évoque plus les exemplaires hallstattiens et de schéma La Tène I que les modèles suivants. Aucune tra ce de bague d'attache n'est visible sur l'arc dont la section est ovalaire.

$77 n^{\circ} 111$. Exemplaire de schéma La Tène II.

L'objet n'est connu que par un dessin. Le ressort, à corde externe, compte 8 ( ?) spires. L'arc surbaissé se situe sur le même plan que le sommet des spires et semble comporter une bague d'attache. L'ardillon est en position fermée.

La fibule évoque les exemplaires du type Feurs 1c, qui appartient à La Tène Dl, mais l'absence du pied ne permet pas de confirmer cette attribution. Cependant l'existence d'un ressort long est un critère d'ancienneté qui rapproche cette fibule du type lb de Feurs (Loire) qui date de La Tène C2 (Guichard 1988 : p. 152). $\mathrm{n}^{\circ}$ 112. Fibule incomplète.

Elle est caractérisée par un ressort de faible diamètre qui compte quatre spires $(2 \times 2)$, et un arc très haut en forme de demi-cercle. Cette parure est comparable aux fibules du type Feurs lb. $\mathrm{n}^{\circ}$ 113. Exemplaire de schéma La Tène II.

Fragment d'arc de section ovalaire ayant conservé une partie du pied et sa bague d'attache.

$81 \mathrm{n}^{\circ}$ 114. Grande fibule incomplète.

Modèle filiforme dont l'arc, très tendu, a une section circulaire. Bien que ce dernier ne porte pas de trace de bague d'attache, il s'agit certainement d'un modèle de construction La Tène II. 

type la de $M$. Feugère qui a perduré en Gaule méridionale jusqu'au début du Ier siècle av. n. è. Un exemplaire très proche provient du site de La Lagaste (Pomas, Aude) qui n'a pas livré de documents antérieurs à 100 av. n. è. $\mathrm{n}^{\circ}$ 115. Fragment.

Exemplaire de schéma La Tène II comme l'indiquent quelques traces de la bague d'attache sur l'arc. $\mathrm{n}^{\circ}$ 116. Grande fibule incomplète.

Exemplaire de schéma La Tène II,à arc tendy et porteardillon très long.

Cette parure est très proche de l'exemplaire $n^{\circ} 114$ : elle n'en diffère que par la section quadrangulaire de son arc qui traduit une influence nette du type de Nauheim (arc aplati). La coexistence de fibules de schéma La Tène II et La Tène III étant démontrée (Guichard 1988 : p. 152-155), il est possible de dater cette parure de La Tène Dl. On ne peut toutefois exclure que l'on ait affaire à un prototype de la fibule de Nauheim. $\mathrm{n}^{\circ}$ 117. Fibule incomplète (fig. 28).

Elle est très déformée ; le ressort compte apparemment quatre spires $(2 \times 2)$, la corde est indiscernable et l'arc possède une section circulaire.

28- Fragments de fibules en fer

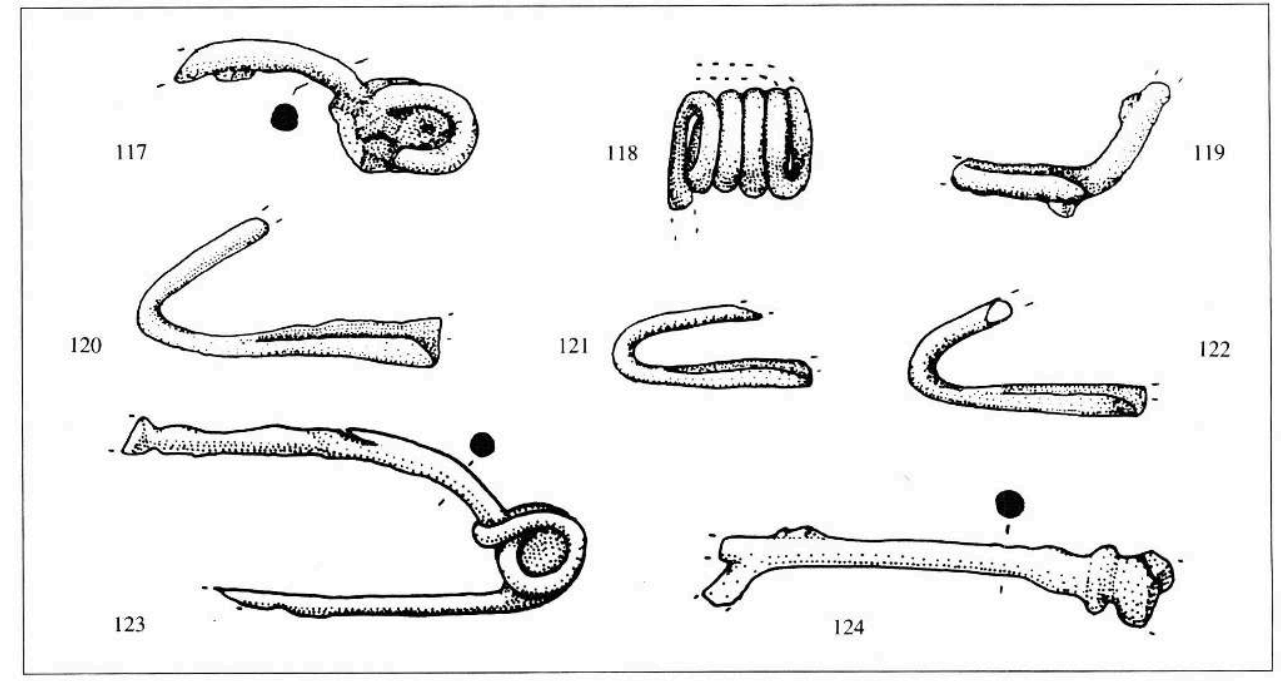

Ce fragment conserve quatre spires à droite et le départ de la corde externe. Il s'agit sans doute d'un type à deux fois quatre spires. Le nombre élevé de celles-ci indique soit une fibule tardive de schéma La Tène I, soit les derniers modèles de schéma La Tène II. $\mathrm{n}^{\circ}$ 119. Fragment.

Porte-ardillon et arc appartenant à une fibule de schéma antérieur à La Tène III.

$\mathrm{n}^{\circ}$ 120. Fragment.

Porte-ardillon et partie de pied. L'inflexion de ce dernier pourrait indiquer une fibule de schéma La Tène I.

$\mathrm{n}^{\circ}$ 121. Porte-ardillon et fragment de pied. 
Fibule dont le ressort compte quatre spires $(2 \times 2)$ et une corde interne; la section de l'arc est circulaire. Bien que le porte-ardillon soit absent, il s'agit sans doute d'une fibule de schéma La Tène II.

$\mathrm{n}^{\circ} 124$. Fibule incomplète de schéma La Tène III.

L'arc est orné d'une nodosité située à l'approche du ressort.

$\mathrm{n}^{\circ}$ 125. Fibule incomplète de schéma La Tène III (fig. 29). L'arc de section circulaire s'infléchit brusquement, puis s'épaissit avant de former le ressort. Ce dernier est bilatéral à quatre spires $(2 \times 2)$ et possède une corde externe remontant parallèlement à l'arc orné d'autre part d'une petite nodosité.

29- Fibules en fer de schéma La Tène III

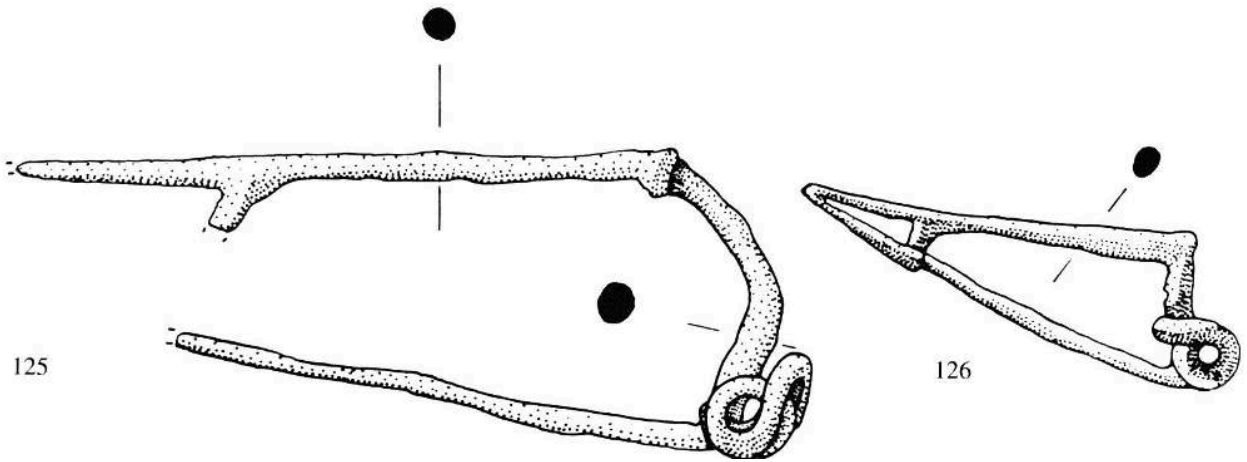

La forme générale des fibules $n^{\circ} 124-125$, et surtout le léger changement de section de l'arc à l'approche du ressort, évoquent certains exemplaires en bronze appartenant au type Feugère 8 (Knotenfibeln ou à ailettes naissantes), plus spécialement le type $8 \mathrm{~b}$ ( = Almgren 65). Pour ce qui concerne ces modèles, ils se rapprochent de fibules découvertes à Berne-Engehalbinsel, Heidetränk et La Heuneburg (RFA) (Ettlinger 1973 : Taf. 20, $\mathrm{n}^{\circ} 4$ et Taf. 21, nº 6; MüllerKarpe 1979: Abb. 1, nº 9 ; Sievers 1984: Taf. 52, $\mathrm{n}^{\circ}$ 646).

$\mathrm{n}^{\circ} 126$. Type intact de schéma La Tène III.

L'arc de section ovale forme un coude à angle droit à l'approche du ressort. Ce dernier comprend quatre spires $(2 \times 2)$ et une corde interne. La fibule est fermée, l'ardillon en place dans sa loge.

Il s'agit d'un exemplaire du type Feugère 4c 2 bien connu en Gaule du Centre-Est sur les oppida du Crêt-Châtelard (Saint-Marcel-Les-Félines, Loire), de Bibracte, d'Alésia, de Besançon et d'Altenburg-Rheinau (Feugère 1985 a: p. 200; Guillaumet 1984: p. 24; Lerat 1979: p. 23). Ce type de parure figure également sur des sites apparemment ouverts comme Roanne-Saint-Joseph (Loire), Tournus, Marloux (Saône-et-Loire), Malain (Côte-d'Or). Outre le Centre-Est de la Gaule, ces fibules sont attestées dans le Nord de la Gaule dans les sanctuaires de Vendeuil-Caply (Oise) et de Bennecourt (Yvelines) et aussi à Chérain-Brisy (Belgique) (Piton 1985 : p. 39; Anonyme 1985 : p. 47 ; Cahen-Delahay 1981 : p. 64). En Gaule méridionale, les seules découvertes proviennent des grottes-sanctuaires de l'Aven du Rajal à Millau (Aveyron) et de Montpeyroux (Hérault), localisées sur le territoire des Rutènes (Feugère 1985 a : p. 200). D'autre part, ces parures sont également connues en Europe centrale et constituent le type Beltz $\mathrm{K}$ (Beltz 1911 ; Waldhauser 1974 : p. 244 ; Hachman 1960 : Taf. 2, nº 31). 

troisième quart du Ier siècle av. n. è. Quant aux fibules de l'Aven du Rajal, elles ne seraient pas antérieures aux années 40-30 av. n. è.; celles de Bennecourt sont situées dans la fourchette 70-20 av. n. è. Il s'agirait donc d'un modèle de La Tène D2 qui constitue l'objet le plus récent du mobilier noncéramique de La Chuire. La répartition de ces fibules, qui concerne surtout le Centre-Est de la Gaule, n'est pas sans rappeler celle du type Feugère $5 c 5$, si l'on excepte les découvertes rutènes qui proviennent de contextes très particuliers. Régionalement on peut d'ailleurs remarquer l'absence $\mathrm{du}$ type 4c 2 dans l'importante série de Sainte-Blandine. $\mathrm{n}^{\circ}$ 127. Fibule incomplète (fig. 30).

Exemplaire à ressort bilatéral probablement à quatre spires $(2 \times 2)$ et corde externe. Le ressort est partiellement très déformé et il est impossible de distinguer les spires. Cet aspect pourrait être la conséquence d'une très violente crémation.

30- Fragments de fibules en fer

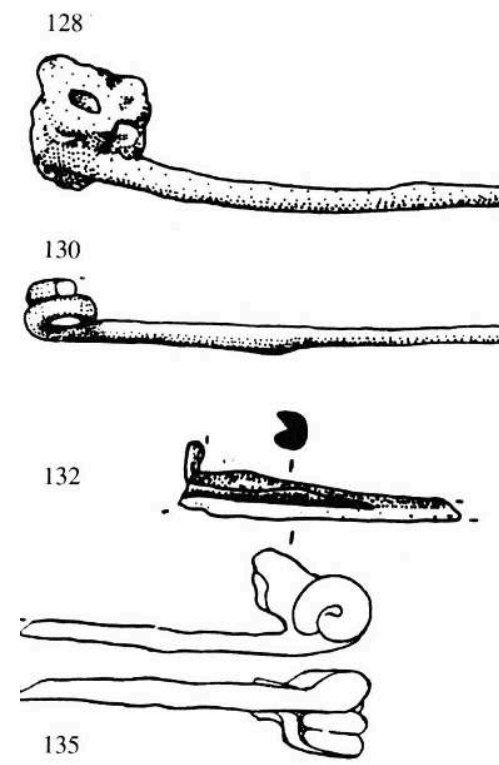

$\mathrm{n}^{\circ}$ 128. Fragment de fibule.

Ardillon et ressort à $2 \times 2$ spires et corde interne appartenant probablement à une fibule de schéma La Tène III.

$\mathrm{n}^{\circ} 129$. Ardillon et fragment de ressort ayant conservé trois spires à droite.

$\mathrm{n}^{\circ}$ 130. Ardillon et fragment de ressort ayant conservé deux spires à droite.

$n^{\circ} 131$. Ardillon et fragment de ressort comprenant une spire.

$\mathrm{n}^{\circ}$ 132. Fragment de porte-ardillon.

$\mathrm{n}^{\circ}$ 133. Fragment de porte-ardillon.

$n^{\circ} 134$. Fragment de porte-ardillon indiquant un exemplaire de schéma antérieur à La Tène III.

$\mathrm{n}^{\circ} 135$. Fibule à ressort 2 x 2 ( ?) spires et une corde interne.

$\mathrm{n}^{\circ} 136$. Ardillon et ressort. 
$\mathrm{n}^{\circ}$ 137. Fibule inachevée (fig. 31).

Tige de section circulaire recourbée en formant un angle supérieur à $90^{\circ}$ et comportant une nodosité située avant le repliement ; il pourrait s'agir d'une fibule abandonnée en cours de fabrication et proche des $n^{\circ} 124-125$. L'objet rappelle d'ailleurs une fibule de Nages (Feugère $1985 \mathrm{a}: \mathrm{p} .437$ et pl. 63, $\mathrm{n}^{\circ}$ 886).

31- Fibule en fer abandonnée en cours de fabrication

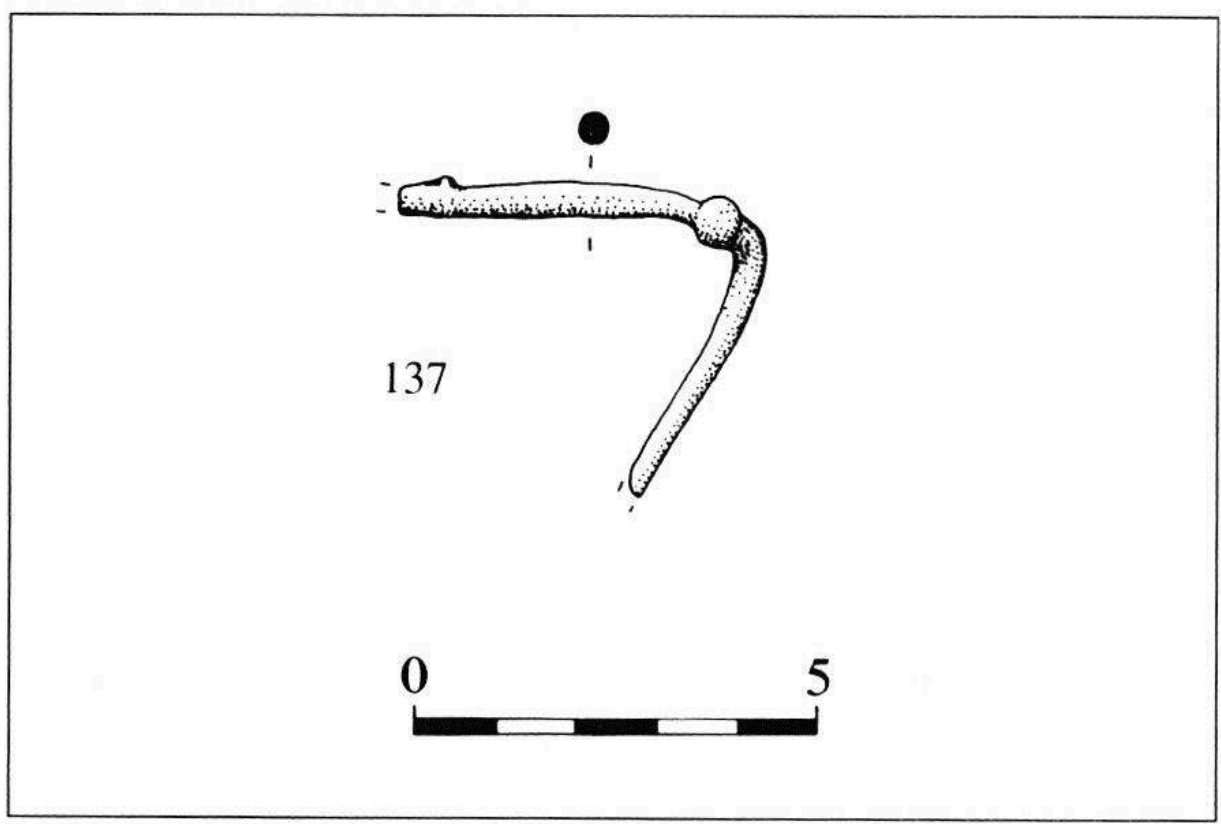

110 Les bracelets et armilles en bronze et en fer (fig. 32-37)

$111 \mathrm{n}^{\circ}$ 138. Armille en bronze.

Fragment de section aplatie, orné de deux séries d'incisions $(4+3)$.

$112 \mathrm{n}^{\circ}$ 139. Armille en bronze.

Fragment non décoré de section circulaire.

$\mathrm{n}^{\circ} 140$. Armille en bronze.

Deux fragments de la même parure annulaire, non décoré et de section aplatie.

114 Ces bracelets (fig. 32) très fins et fermés, portés généralement en série, sont connus dès le VIe siècle av. n. è. dans le Sud de la France. Ils apparaissent dans le Centre-Est au début du Ve siècle av. n. è. A partir de l'importante série de Charmes, M. Feugère a proposé d'expliquer ce décalage chronologique par l'importation préalable d'armilles méridionales, imitées par la suite par les artisans locaux : somme toute, un phénomène comparable à la diffusion des fibules du type Golfe du Lion (Rajot 1985 : p. 164-167). 


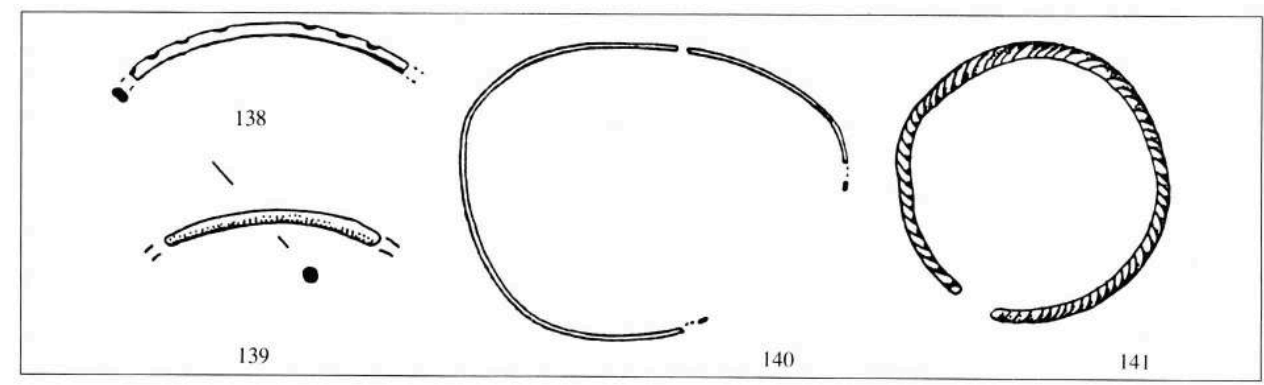

115 Régionalement, ces armilles sont attestées sur les sites du Hallstatt final du val de Saône qui constituent des relais dans l'acheminement des produits et des denrées méridionales : Gorge-deLoup à Lyon-Vaise (Rhône) et Bragny (Saône-et-Loire) (Bellon 1986 : p. 249 ; Feugère 1986 : p. 164-167). On les retrouve en petit nombre sur les sites princiers hallstattiens de Châtillon-sur-Glâne (Fr. Suisse) et du Mont-Lassois (Côte d'Or). Le port de ce type de parure, associé à de véritables bracelets, est également attesté au Ve siècle av. n. è. dans le domaine alpin (Courtois 1976 : p. 717). $\mathrm{n}^{\circ} 141$. Bracelet intact en bronze.

Petit exemplaire à jonc plein, ouvert et décoré de fausses torsades.

Un bracelet ouvert en bronze faussement torsadé, comparable à cet exemplaire, fait partie du mobilier funéraire de l'incinération $n^{\circ} 2$ de Chamboux (Isère) (Vital 1986: p. 6-7). Il s'agit là aussi d'un bracelet de faible diamètre, analogue à l'exemplaire de la tombe 71/2 du Dürnberg (Autriche), datée du dernier tiers du Ve siècle av. n. è. (Moosleitner 1974: Taf. 138, h). Les dimensions réduites de ces parures annulaires indiquent qu'elles appartiennent de toute évidence à de jeunes enfants. Cette parure paraît isolée chronologiquement puisque aucun autre objet du Ve siècle n'a été identifié dans le mobilier.

$118 \mathrm{n}^{\circ}$ 142. Fragment de parure en bronze.

Ce bracelet (fig. 33) a une section plus qu'hémisphérique. Le jonc est orné d'une triple série de trois nodosités, elles-mêmes décorées de "pastilles » entourant un petit cône. Chaque série de nodosités est décorée de la façon suivante : trois pastilles disposées perpendiculairement à l'axe du bracelet sur la première nodosité, quatre pastilles disposées en losange sur la seconde, puis répétition du premier motif sur la troisième et dernière nodosité. Les séries de nodosités sont séparées par une petite protubérance ornée d'une incision transversale ayant l'aspect d'un grain de café. Cette protubérance est légèrement décalée par rapport à l'axe du jonc. Le bracelet est légèrement tordu à l'approche d'une cassure, ce qui explique son faible diamètre actuel. 


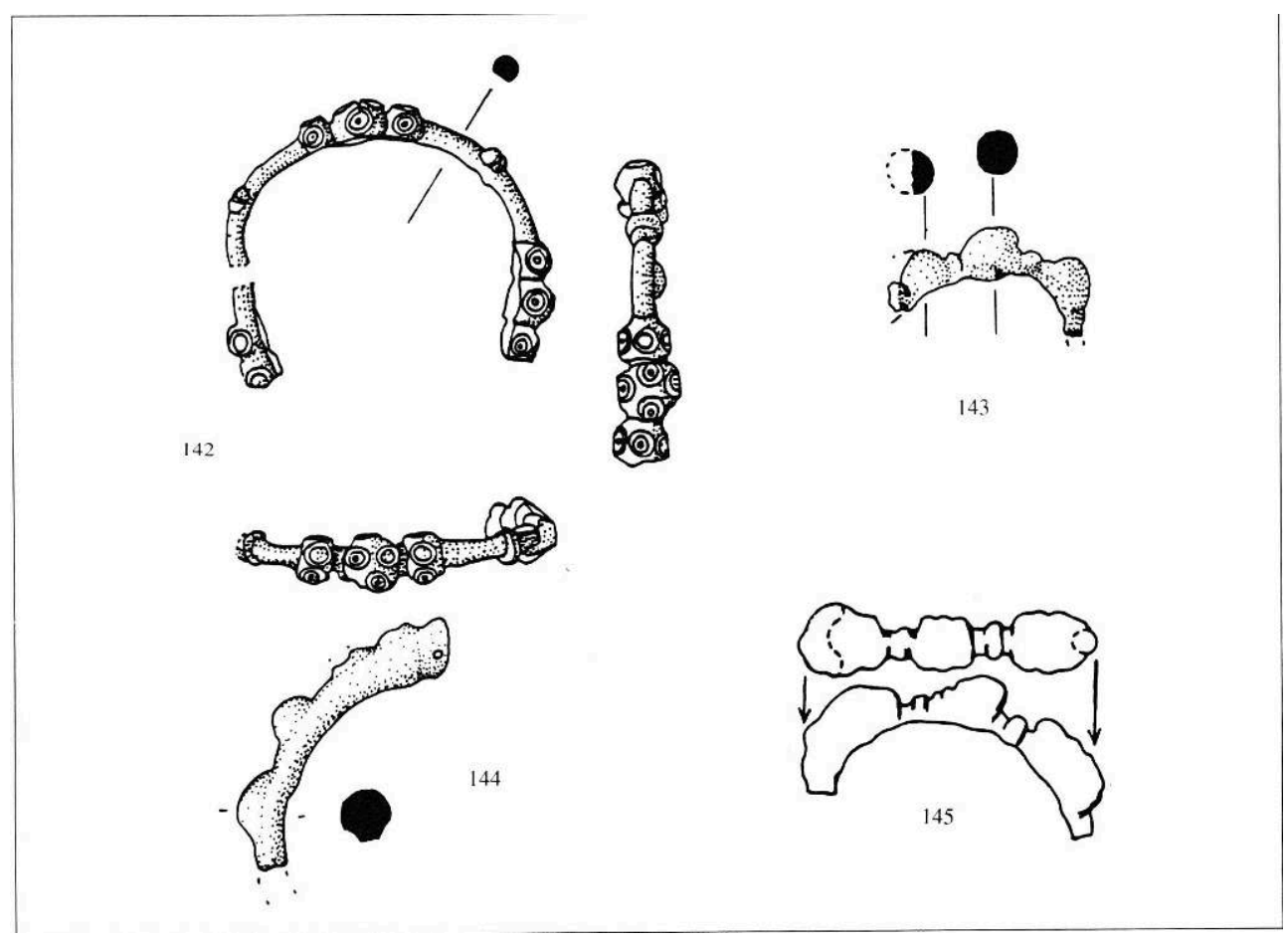

Cette parure annulaire est ornée selon la technique dite du "pastillage » (fig. 34), bien attestée en Bohême et plus généralement sur le Moyen-Danube, où elle semble avoir été élaborée au début du IIIe siècle av. n. è. (Kruta 1975 : p. 7074). Les bracelets découverts dans les sépultures de Nový Bydžov, de Podlešin (Bohême) et d'Eggelfing (Bavière) constituent les parallèles les plus proches à cet exemplaire (Krämer 1985 : taf. 69, A, 3-4). En Gaule, les objets décorés par " pastillage " sont peu nombreux. Dans la région champenoise, l'existence de ce type d'ornementation, adaptée sur des parures typiquement marniennes, est l'une des conséquences d'un apport de populations originaires du Moyen-Danube, perceptible également par certaines innovations dans les usages vestimentaires et les pratiques funéraires (Kruta 1985: p. 27-51). Une situation sensiblement comparable peut être observée en Cisalpine, là où les sources antiques situent le peuplement boïen, comme l'atteste l'existence de parures ornées selon la technique du "pastillage » associées à un certain nombre d'objets présentant des affinités marquées avec les mobiliers centre-européens. (Kruta 1983 a : p. 1-15). 


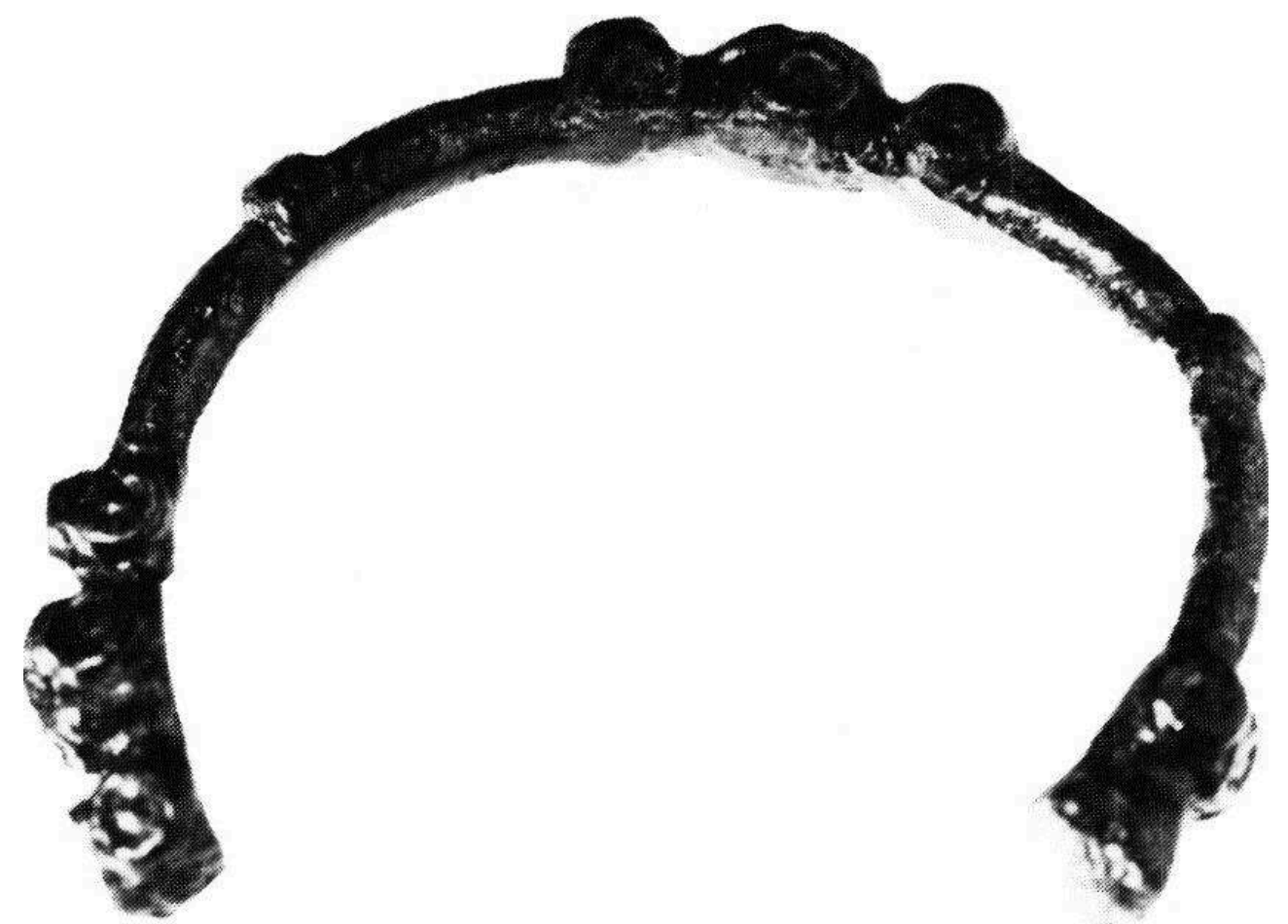

En Gaule (fig. 35), seuls les bracelets découverts dans le complexe cultuel de Buzeins (Aveyron) et à Saint-Sulpice (T. 77 ; Suisse) peuvent être comparés à la parure de La Chuire (Mohen 1979 : p. 35, fig. 4 ; Anonyme 1986 b : p. 162). Par contre, plusieurs autres objets découverts dans le Sud de la Gaule trouvent des parallèles convaincants dans le domaine celtique centre-européen. C'est le cas pour les célèbres torques en or du Fenouillet (Haute-Garonne) (Anonyme 1983 : p. 119-121; Kruta 1982 : p. 7677) proches de l'exemplaire de Gajíc (Yougoslavie), mais aussi pour un bracelet de Roanne (Guichard 1989) et une agrafe de ceinture de Jarrier (Savoie) (Anonyme 1986 a) qui portent une ornementation très similaire à celle d'une fibule «à rosettes " provenant de Vukovar (Yougoslavie) (Duval 1977 : p. 261) : d'une certaine manière, la décoration de ces objets se rapproche du pastillage, mais elle évoque également l'ornementation végétale de certains torques en or. D'autres parures féminines, fibules et bracelets ou anneaux de chevilles à oves creux, méritent d'être signalées et proviennent de Mùnsingen (Hodson 1968 : p. 139), du Pègue (Lagrand 1973 : p. 156) et du lit du Tarn. En Provence, une dizaine de bracelets à fort décor plastique ont été découverts sur les oppida celto-ligures (Brun 1984) : ces parures, datables du IIe siècle av. n. è., sont de plus représentées sur la statuaire d'Entremont (Aix-en-Provence, Bouches-du-Rhône) (2 exemples sur des mains féminines) et paraissent dériver de modèles centre-européens, datés du IIIe siècle av. n. è. 


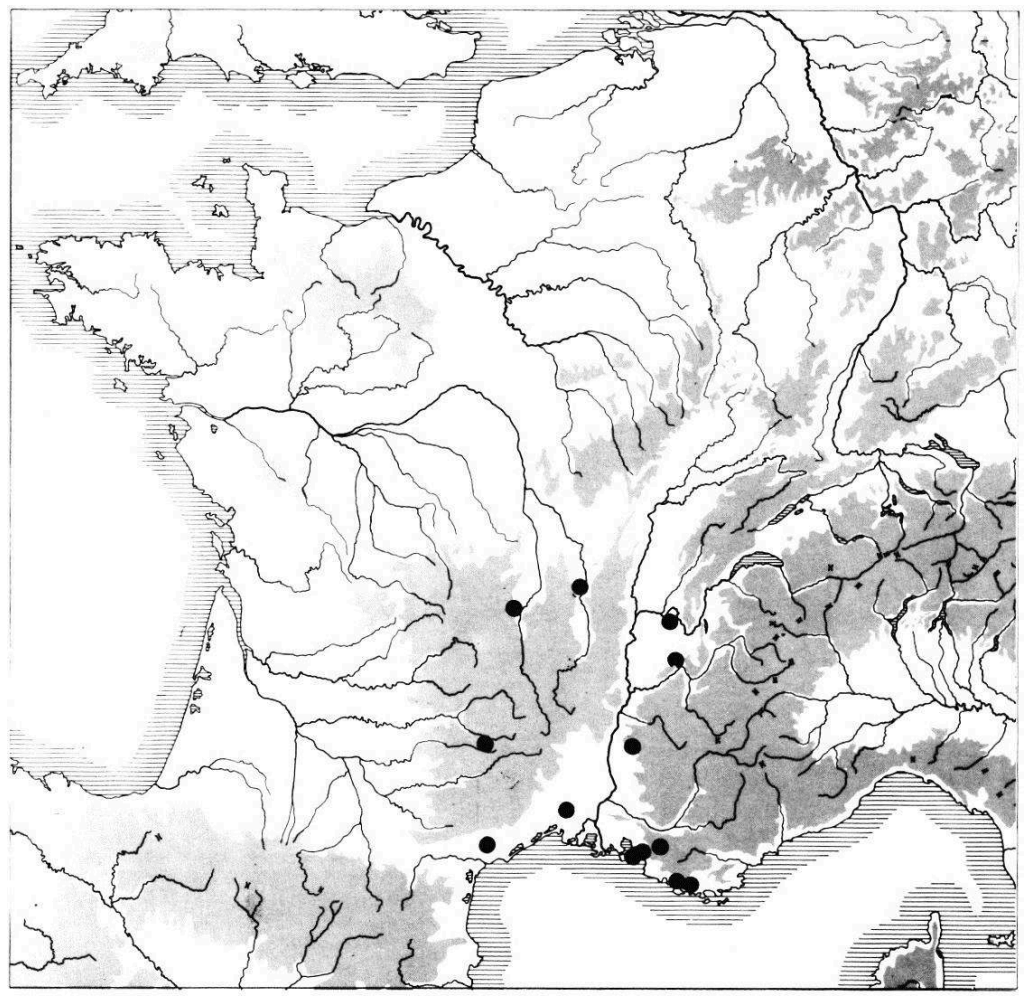

121 A eux seuls, ces objets, qui ne proviennent pas d'ensembles clos comme des sépultures, ne permettent pas de définir un phénomène analogue à celui perceptible en Champagne. Il s'agit le plus souvent de parures féminines découvertes dans un vaste ensemble géographique (région de Berne, Dauphiné, moyenne et basse vallée du Rhône, Languedoc et bordures sud et est du Massif Central), où les données archéologiques disponibles sont très différentes de celles utilisables en région champenoise. Quoiqu'il en soit, le bracelet de La Chuire et les objets découverts en Gaule méridionale montrent une nouvelle aire de diffusion des objets d'origine danubienne.

$n^{\circ} 143$. Fragment d'un exemplaire en fer.

L'objet est constitué d'une succession de trois éléments sphériques séparés par de légères nodosités.

Il s'agit soit d'un petit bracelet à nodosités, comme on en connaît à La Tène $C$ (Martin Kilscher 1981 : p. 115 ; Krämer 1985 : Taf. 122), soit de l'arc d'une fibule de schéma La Tène I tardive (Bocquet 1970). Quelle que soit la nature réelle de ce fragment, il est de toutes façons datable de La Tène B2/C.

$\mathrm{n}^{\circ}$ 144. Parure incomplète en fer.

Il s'agit là certainement d'un fragment de bracelet orné de trois nodosités hémisphériques nettement séparées les unes des autres. A l'origine, celui-ci appartenait à une parure comportant un fermoir amovible, comme en témoigne l'existence d'une perforation située à l'extrémité du jonc et destinée au passage d'une goupille.

Cette parure à fermoir amovible est proche par sa forme d'un bracelet de la sépulture à inhumation féminine 8 de Vevey (VD, Suisse), datable du début de La Tène $\mathrm{Cl}$ (MartinKilscher 1981). 
$\mathrm{n}^{\circ}$ 145. Fragment de bracelet en fer.

Ce dernier est orné de trois nodosités marquées. L'objet n'est connu que par un dessin, mais il pourrait s'agir de la partie amovible d'une parure annulaire.

Ce fragment déformé, très proche de la parure de Vevey T. 8, n'est pas sans rappeler des bracelets de typologie centre-européenne (Martin-Kilscher 1981 : p. 115 et p. 137).

$n^{\circ} 146$. Exemplaire intact en bronze.

Parure tubulaire (fig. 36-37) montée vraisemblablement à l'origine sur une âme en bois et tissu (pour permettre la mise en forme de l'objet). Le système de fermeture consiste en une tôle de bronze insérée de force dans le bracelet renforçant sans doute un tenon disparu. Cette parure est ornée d'une succession de lignes de pointillés obtenus au poinçon (2 lignes, un espace, 3 lignes, un espace, à nouveau 2 lignes).

36- Bracelet en tôle de bronze de La Tène $D$

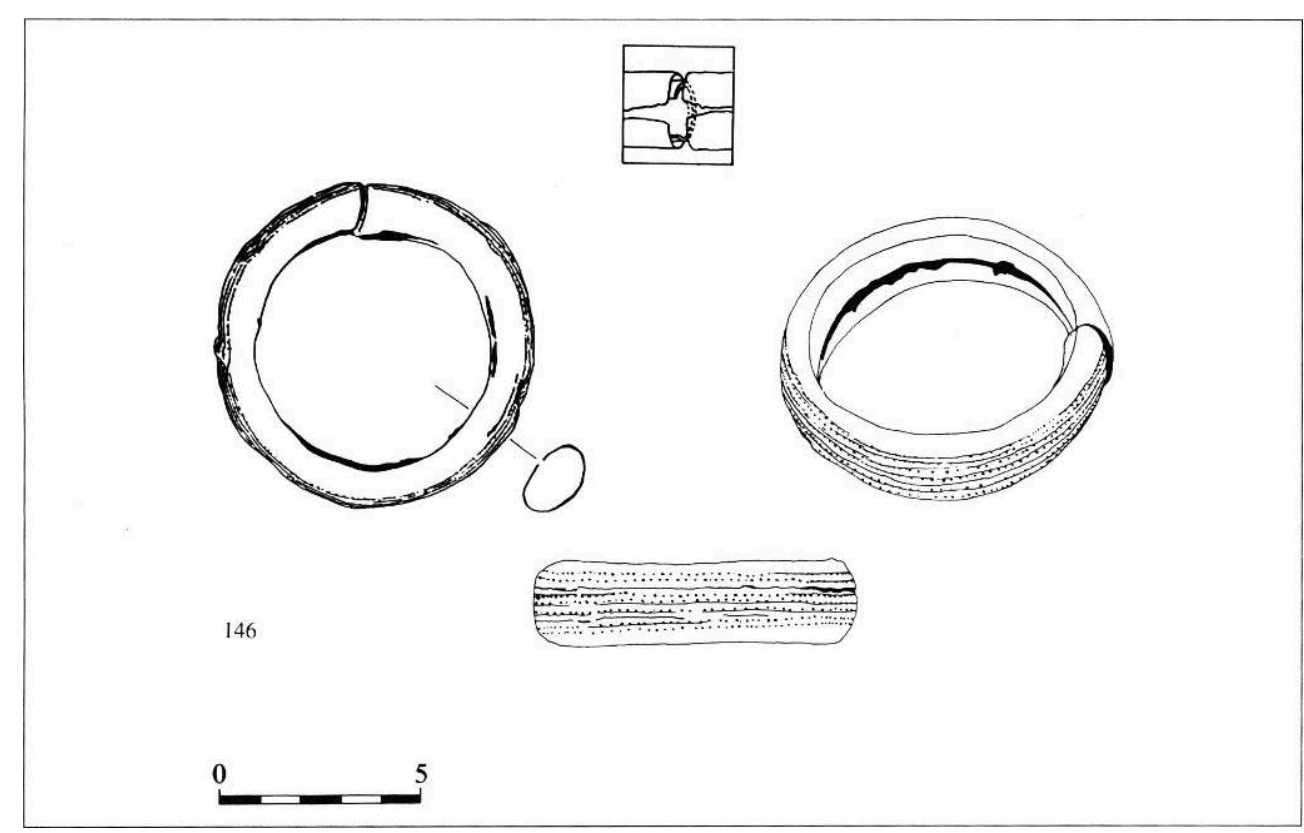




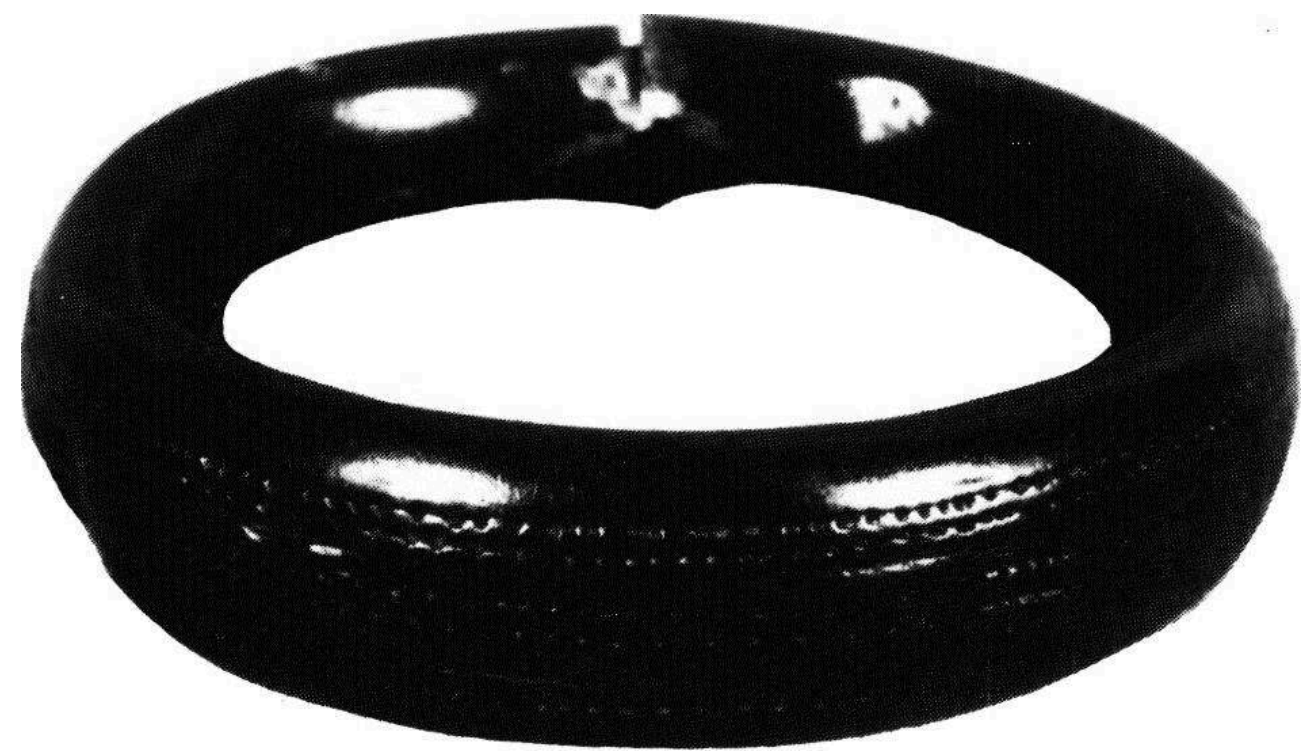

Si les bracelets tubulaires sont connus dès le Hallstatt D (Ramseyer 1983), cet exemplaire peut être daté de La Tène D1 par comparaison avec une parure identique provenant d'Essenheim (T. 1, RFA), qui était accompagnée de fibules de Nauheim (Werner 1955 : p. 192, Abb. 6, D). L'association du bracelet tubulaire et de la fibule de Nauheim est attestée par de multiples exemples dans les nécropoles rhénanes de la Tène D1 (Bantelmann 1972 : p. 104-105). Dans ces contextes, l'absence d'armement et d'instruments de toilette, tels que les forces et les rasoirs, indique que Ton a sans doute affaire à une parure féminine.

En Gaule, quelques exemplaires datés de la Tène D sont connus, dans la tombe $3 \mathrm{~A}$ de la nécropole de Bâle-Gasfabrik (Furger-Gunti 1980: taf. 10; n²03-206) et dans le sanctuaire de Vendeuil-Caply (Piton 1985 : fig. 19, n 8); d'autres, sans contexte précis sont mentionnés dans le lit de la Saône (Bonnamour 1985 a : p. 241) et le département de l'Allier ${ }^{2}$. Ces parures constituent la variante d'une forme beaucoup plus fréquente ornée d'incisions géométriques (Tendille 1980). Leur répartition semble se limiter à la Gaule interne, alors que le type à décor géométrique est connu jusqu'en Languedoc. Cette situation n'est pas sans rappeler la circulation d'autres types laténiens, comme celui de Lauterach, qui ne sont pas diffusés dans la Provincia. Techniquement, ces bracelets sont le fruit d'un travail de chaudronnerie et on pourrait évoquer, sans argument cependant, une production éduenne (Beck 1985).

Les bracelets et perles en verre (fig. 38-39)

Les objets en verre de La Chuire sont essentiellement des bracelets, généralement considérés comme des parures féminines. La production locale de certains de ces objets pourrait être indiquée par l'existence dans le mobilier d'un fragment de terre cuite recouvert sur sa face interne d'une coulée vitreuse (creuset?); cependant, d'autres activités artisanales peuvent produire des traces analogues (par exemple, la métallurgie du bronze) et en l'absence de bloc de verre brut, la fabrication sur place ne peut être envisagée qu'à titre d'hypothèse. 


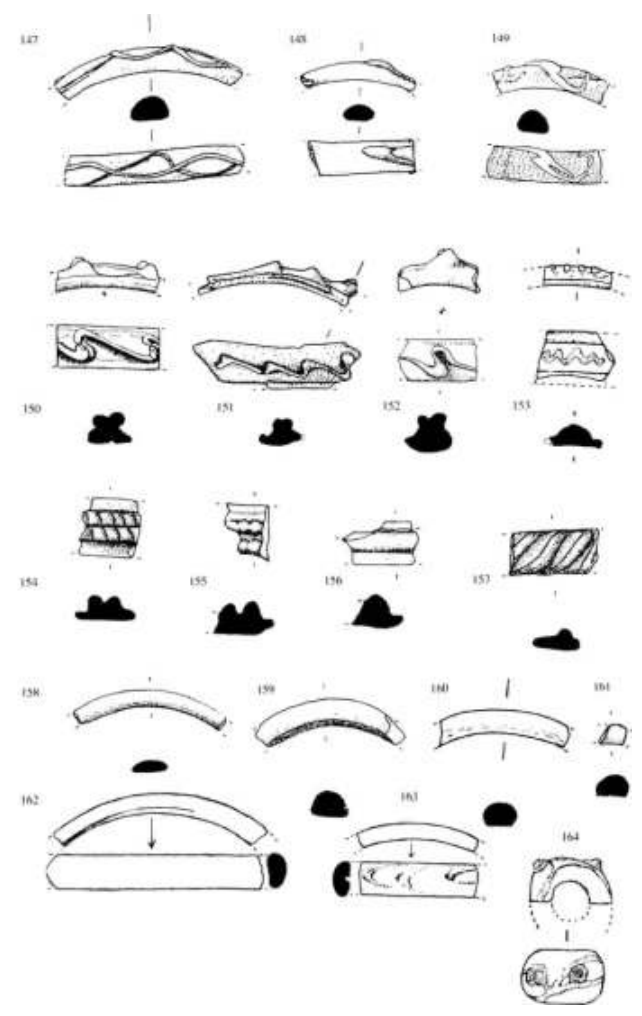

$\mathrm{n}^{\circ}$ 147. Fragment de bracelet.

Exemplaire de couleur naturelle (en fait légèrement verdâtre), transparent et décoré de filets ondulés s'entrecroisant. L'objet a une section hémisphérique.

Ce bracelet appartient au groupe Haevernick 5, variante a ( = Gebhard 1989, forme 10). A la différence des exemplaires classiques, cette parure est ornée d'incisions remplies de paillettes dorées (poudre de verre ou or ?) et non de filets lisses bleus ou jaunes. Ces paillettes sont prises dans la masse du verre dégagée par l'incision, qui a été refermée pour former le filet. Il semble que ce bracelet soit le seul du groupe Haevernick 5a à présenter cette sorte de décoration : cette particularité paraît être le résultat d'un choix délibéré, plutôt que la conséquence d'une imperfection survenue lors de la fabrication (Haevernick 1960 : p. 121-123).

$n^{\circ}$ 148. Fragment de bracelet.

Parure de couleur naturelle dont la section est presque hémisphérique. Celle-ci est ornée d'un filet de verre de couleur jaune. Comme l'exemplaire précédent, il s'agit d'un bracelet du groupe 5 a.

$n^{\circ} 149$. Fragment de bracelet.

Exemplaire de couleur bleue, orné de filets opaques de couleur jaunâtre dont la structure est très différente de celle $\mathrm{du}$ jonc. L'objet possède une section hémisphérique. Il s'agit là aussi d'un exemplaire appartenant au groupe $5 \mathrm{a}$, bien que ses couleurs le distinguent des exemplaires classiques.

Ces bracelets de type Haevernick 5a sont bien représentés sur la partie occidentale du Plateau Suisse (Kaenel 1989 : p. 122), en Bavière, Bohême et Slovaquie (Venclová 1989 : p. 88) ; en France, ils demeurent rares, mais sont toutefois signalés jusqu'en Languedoc (Feugère 1989: p. 164-165). Selon R. Gebahrd, qui a récemment étudié l'importante série de parures en verre découvertes à Manching, ces bracelets se situent 
chronologiquement vers $260-215$ av. n. è. (Gebahrd 1989 : p. 100-102); de fait, tous les contextes dans lesquels figurent ces parures appartiennent à la phases $\mathrm{Cl}$ de La Tène. Les découvertes funéraires suisses indiquent que le port de ces bracelets caractérise des femmes de haut rang social, souvent inhumées avec des chaînes de ceinture métalliques, de nombreuses fibules et des parures annulaires en or ou en argent. Si les lieux de productions probables sont les régions de Berne et de Manching, l'aspect original des exemplaires de La Chuire peut suggérer une fabrication régionale.

$\mathrm{n}^{\circ}$ 150. Fragment de bracelet.

Parure de couleur bleue ornée d'une bande en relief formant des $\mathrm{Z}$.

Cette parure évoque les bracelets du type Haevernick 14, qui datent de La Tène C.

$n^{\circ}$ 151. Fragment de bracelet.

Exemplaire transparent, peut-être décoloré, possédant à l'intérieur du jonc une pellicule de verre jaune, et orné d'une bande de verre non rapportée serpentant à sa surface.

141 A la différence des bracelets appartenant au groupe Haevernick 5, la bande de verre n'est pas rapportée, mais obtenue par un travail de la surface du verre, sans doute à l'aide d'un outil.

$\mathrm{n}^{\circ}$ 152. Fragment de bracelet.

De couleur bleue, cet exemplaire est orné d'une bande de verre non rapportée serpentant à sa surface.

143 Les bracelets $n^{\circ} 151-152$ se rapprochent des exemplaires du groupe Haevernick 16 (bien que leur section possède des reliefs plus marqués) (Haevernick 1960 : p. 205-208). Ces parures sont datables de La Tène; elles sont attestées dans la culture des oppida à Stradonice et Staré Hradisko (Tchécoslovaquie) ainsi qu'en Gaule méridionale, à Nages où elles sont présentes dès le troisième quart du IIe siècle av. n. è. (Feugère 1989 : p. 160).

$144 \mathrm{n}^{\circ}$ 153. Fragment de bracelet. Parure de couleur bleue, ornée d'un filet de verre rapporté de couleur jaune.

Ce bracelet appartient au groupe Haevernick $6 \mathrm{~b}$ attesté à Manching (Bavière) (Gebahrd 1989 : p. 74) et à Berne dans une sépulture datable de LT Cl (Suter 1984 : p. 77).

$146 \mathrm{n}^{\circ}$ 154. Fragment de bracelet.

Exemplaire de couleur bleue, orné de deux bandes de verre en relief non rapportées et décorées d'incisions transversales.

147 Cette parure appartient au groupe Haevernick 13. Des bracelets analogues sont connus dès La Tène $C$, par exemple dans la sépulture 17 de Vevey (Martin-Kilscher 1981: 141, Abb. 30,5$)$ ainsi qu'à Nages, où ils sont représentés du milieu du IIIe siècle av. n. è. jusqu'au Ier siècle av. n. è. (Feugère 1989 : p. 154).

$148 \mathrm{n}^{\circ}$ 155. Fragment de bracelet.

De couleur bleue, l'objet est orné de deux bandes en relief non rapportées, formées chacune d'une succession de nodosités.

Il s'agit probablement d'une variante d'un type Haevernick 13.

$150 n^{\circ}$ 156. Fragment de bracelet.

Exemplaire de couleur bleue, appartenant au groupe Haevernick 6a (Haevernick 1960 : p. 124-133, Taf. 4, 6a). 

Cette décoration particulière constitue sans doute une tentative pour adapter sur le verre les décors plastiques réalisés sur bronze (cf. le bracelet de Nové Zámki dans : Szabó 1983 : p. 18). Ce type de perle est connu tant dans le monde celtique qu'en Gaule méridionale. Les exemplaires du IIIe siècle comme ceux de Saliceta San Giuliano (prov. de Modène, Italie) et de Vevey (Kruta Poppi 1978 : p. 431, fig. 5, $\mathrm{n}^{\circ} 11$; Martin-Kilscher 1981: p. 141, Abb. 30, n³) sont caractérisés par un nombre élevé de protubérances ornées de spirales ne débordant pas sur le corps de l'objet. Un exemplaire de Nages, daté de la fin du IIIe siècle av. n. è. ou du début du IIe siècle av. n. è. illustre l'évolution de cette forme : la perle présente des protubérances plus marquées, ornées de spirales envahissant la totalité de l'objet (Py 1978 : p. 293). Des perles analogues sont toujours attestées aux IIe et Ier siècles av. n. è., en Gaule méridionale (Lagrand 1979: p. 196), dans des sépultures laténiennes (Mahr 1981 : p. 260 ; Viollier 1916 : p. 121) et dans les 
oppida (Pic 1906 : pl. VI, nº 9 et 45 ; Schwab 1983 : p. 252). Les exemplaires les plus proches de la perle $n^{\circ} 164$ sont datés de La Tène $\mathrm{D}$ et sont connus dans l'habitat de Bâle et dans la nécropole tessinoise de Solduno (FurgerGunti 1980 : pl. 9, n 136-137; Stockli 1975 : pl. 46, H 2, n 6).

$n^{\circ}$ 165. Perle intacte (fig. 39).

Cet exemplaire massif possède un décor de damier alternativement noir, gris, marron et jaune ; comme sur le bracelet $n^{\circ} 147$, on observe à la surface de l'objet des particules dorées prises dans la masse du verre.

39- Perle polychrome de La Tène D

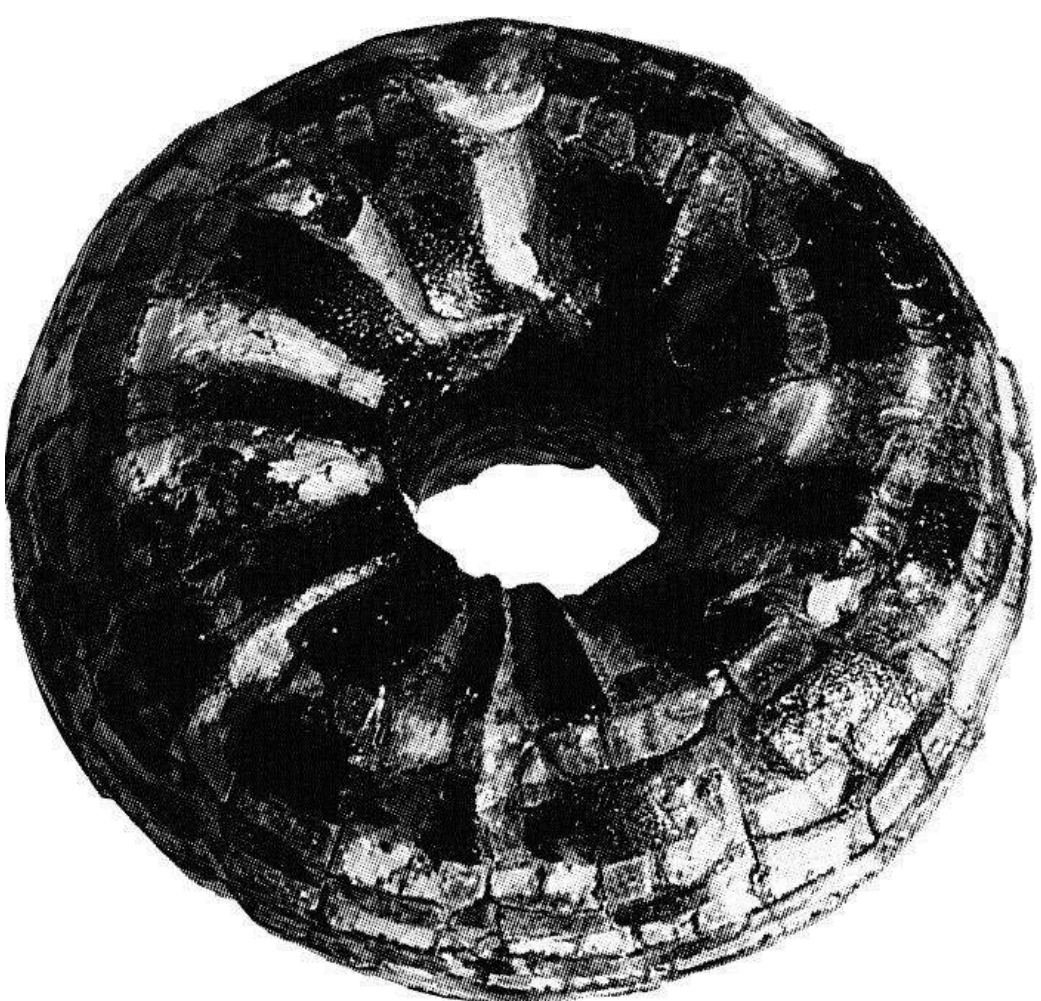

Ce type de perle est connu dans le mobilier des oppida, par exemple à Stradonice ; il s'agit de productions exceptionnelles, techniquement très complexes à réaliser.

Plusieurs bracelets sont fabriqués à partir de matières indéterminées, et qui sont désignées dans la littérature archéologique sous différents noms : lignite (bois fossile), sapropélite (boue fossile), jais... 


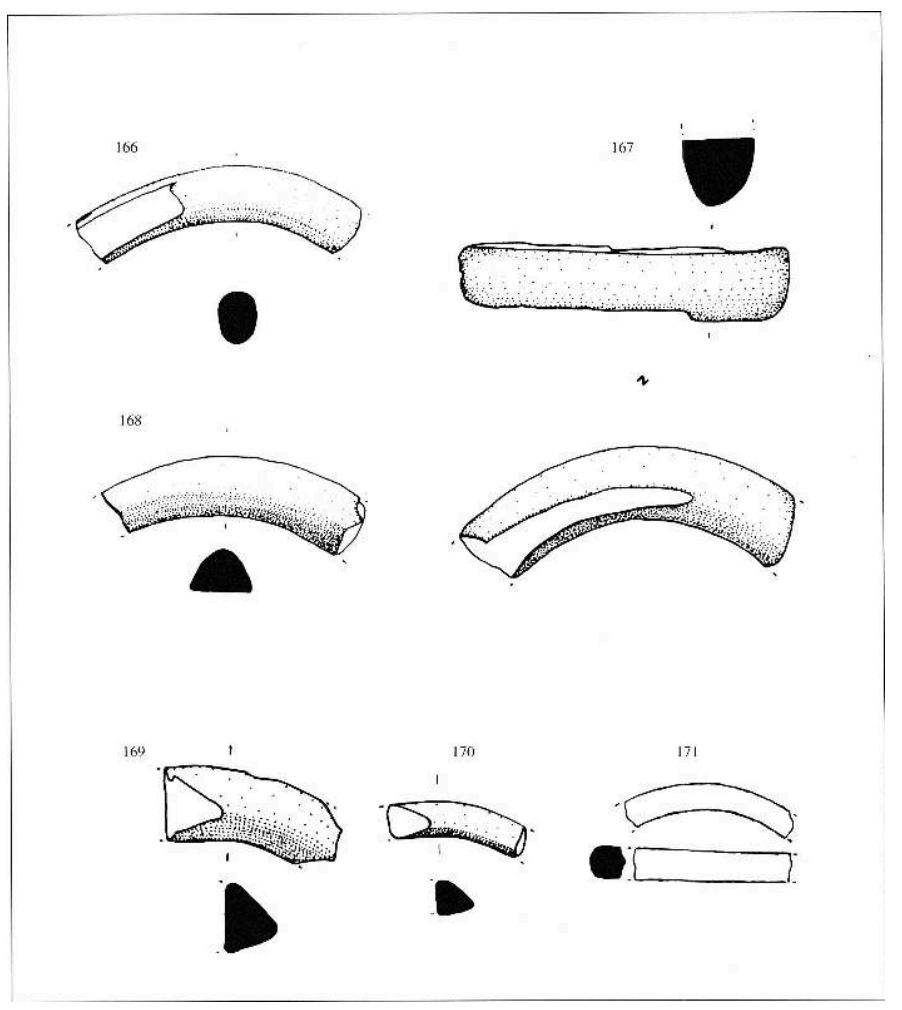
des perles. Le port de ces parures ne semble pas caractériser de classe sociale particulière; ils figurent à la fois dans certaines sépultures princières masculines et féminines (Chaume 1987: p. 226; Kimmig 1987: p. 263) et dans des sépultures plus modestes (Dattingen, T. 20, Kr. Breisgau-Hochswartzwald R.F.A.). Pourtant, l'existence d'imitation soigneuse en céramique (Feugère 1986; Bellon 1989: p. 20) et en schiste (Penninger $1987:$ p. 239) semble indiquer une valeur marchande importante pour ces parures. Les parures en lignite se raréfient en direction de la Méditerranée (Lagrand 1973 : p. 156; Py 1984) et il n'est pas improbable que les découvertes méridionales soient des importations en provenance du domaine hallstattien : en effet, dès la fin du 
VIe puis surtout au début du Ve siècle av. n. è., divers documents propres à la culture hallstattienne sont attestés dans le Sud de la France (céramique peinte, fibules). En retour, la zone princière voit l'arrivée de plusieurs types de parures (agrafe ibérique du Magdalenenberg en Forêt-Noire, fibule du type Golfe du Lion et armilles de Vix) et de céramiques provenant des régions provençales et languedociennes.

L'usage de tels matériaux (sapropélite) est cependant également attesté au cours de La Tène $\mathrm{Cl}$ en particulier en Bavière (Manching) et en Bohême. En Gaule, ces parures sont connues dans des contextes de La Tène $\mathrm{Cl}$ (Kruta 1985) et il n'est pas improbable qu'elles soient originaires du domaine celtique centre-européen. Elles perdurent cependant jusqu'à La Tène Dl, comme l'attestent les découvertes de Feurs (Guichard 1988: p. 152-155), de Levroux (Indre) (Bouyer 1982) et du Camp de la Curade en Dordogne (Couloumieix-Chamières) (Chevillot 1982: p. 122). Il pourrait cependant s'agir d'un phénomène ponctuel, lié à l'existence de plusieurs gisements dans le Nord et le Nord-Ouest du Massif Central. Durant l'époque impériale romaine, le lignite continue d'être utilisé pour la confection de parures annulaires (Anonyme 1982 : p. 121, n 90-90 bis ; Perrichet-Thomas 1975 : p. 242). Le bracelet gallo-romain à médaillons de Presles (Heinault, Belgique) montre la maîtrise atteinte au IIIe siècle ap. n. è. dans l'utilisation de ce matériau (Brulet 1982 : p. 41).

En conclusion, les parures en lignite paraissent difficilement datables avec précision (hormis certaines formes particulières « en tonnelet » qui sont absentes de cette série); pourtant, une évolution dans les dimensions de ces objets est sensible au cours de l'âge du Fer et il apparait que les exemplaires hallstattiens sont généralement plus massifs que les bracelets datés de La Tène. La série livrée par la faille de La Chuire pourrait donc appartenir plutôt au Hallstatt D, exception faite du $n^{\circ} 171$ qui est tout à la fois, très gracile et unique par sa section.

Les objets divers liés au costume (fig. 41)

$\mathrm{n}^{\circ}$ 172. Anneau en bronze de section losangique, présentant deux traces d'usure opposées.

$\mathrm{n}^{\circ}$ 173. Anneau en bronze de section ovale ; le jonc présente une trace d'usure.

$n^{\circ} 174$. Anneau en bronze de section ovale.

$n^{\circ} 175$. Anneau en argent de section ovale, présentant une trace d'usure.

$n^{\circ} 176$. Anneau en bronze, de section losangique, qui montre une trace d'usure.

$\mathrm{n}^{\circ} 177$. Anneau en bronze, de section ovale aplatie, présentant trois traces d'usures.

$\mathrm{n}^{\circ} 178$. Anneau en bronze de section ovale sans trace d'usure apparente.

$n^{\circ} 179$. Fragment d'anneau en bronze de section plan convexe. 


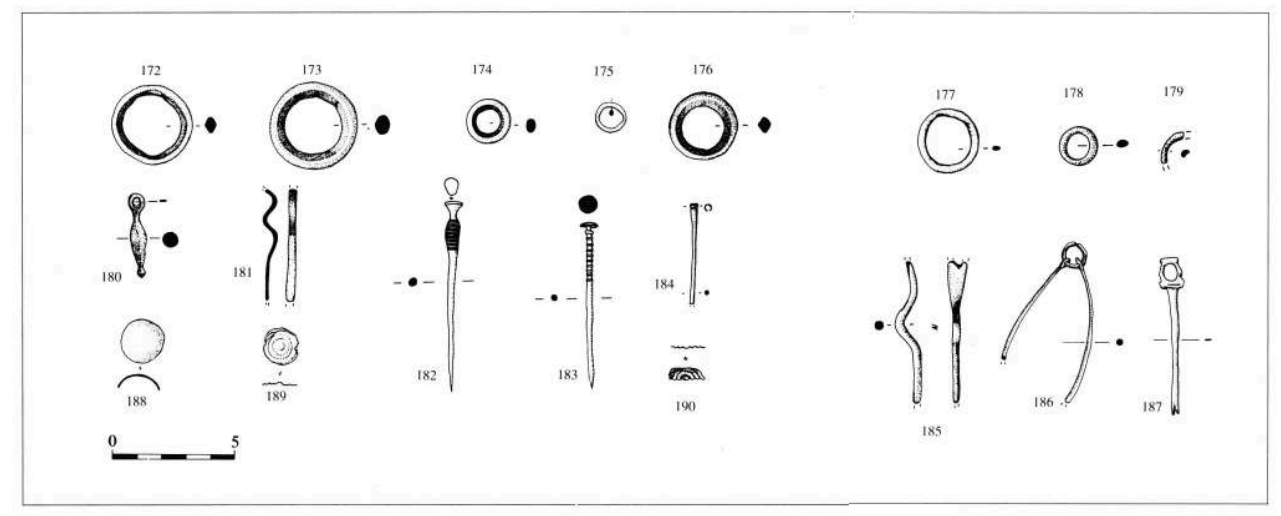

185 thésaurisation et on peut observer une certaine cohérence dans différents dépôts qui associent à des monnaies, soit des bracelets et des paires de fibules pour le domaine celtique, soit des fibules allogènes et des monnaies pour la Provence. Au cours de la Tène, l'argent pourrait avoir un rôle particulier, peut-être lié aux circulations pour relier entre elles des courroies de cuir que ce soit pour des ceintures ou pour du harnachement.

L'exemplaire en argent est le seul objet de cette nature découvert dans La Chuire (exception faite des monnaies). L'argent est un métal peu employé en Gaule et plus généralement au nord des Alpes pour la fabrication de parures; par contre son usage est fréquent en Italie, dès le VIIe siècle av. n. è. En Gaule, dans des contextes de la fin de premier âge du Fer, on ne peut mentionner que la phiale du tumulus de Vix ainsi qu'une fibule du type de la Certosa découverte à Antibes (AlpesMaritimes) (Eluère 1989: p. 25-27; Goudineau 1973 : p. 564). A partir du IVe siècle av. n. è. les parures en argent se multiplient dans les régions nord-alpines, en particulier sur le Plateau Suisse.

Il s'agit pour l'essentiel de fibules (exemplaire de Berne-Shosshalde BE. Suisse) et de diverses parures annulaires (Kruta 1982 : p. 211). Dans le Sud-Est de la Gaule les parures en argent apparaissent au cours du IIIe siècle av. n. è. : l'exceptionnel torque de Pallon (Freissinières, Hautes-Alpes) découvert à proximité du Mont-Genèvre est sans doute une offrande comparable à celle d'Erstfeld (Anonyme 1983: p. 114, n 125). Quelques sépultures alpines et provençales ont livré des bracelets, des bagues-spirales et des fibules en argent dans des contextes du IIIe-IIe siècle av. n. è. (Hudry $1955:$ p. 89-91; Anonyme 1983 : p. 95 ; Arcelin 1976: p. 664 et p. 667). Dans des contextes différents datés de La Tène $\mathrm{D}$, plusieurs fibules en argent, proches du type d'Ornavasso sont connues en Provence, associées à de petits dépôts monétaires (Feugère $1985 \mathrm{a}:$ p. 438 ; Chabot $1986:$ p. 123). Ces découvertes ne sont pas sans rappeler un certain nombre de dépôts, probablement cultuels, rassemblant des objets en argent et connus de l'Italie au Danemark (Manerbio, Lauterach, Le Câtillon, Gundestrup). Dans le domaine celtique et hormis les dépôts, les objets en argent datés de La Tène $\mathrm{D}$ ne semblent guère nombreux. Quelques fibules seulement sont recensées surtout dans les oppida (Guillaumet 1984 : p. 26-28; Kaenel 1984 : p. 103 ; Chossenot $1989:$ p. 109), mais il faut tenir compte des probables refontes.

Le regroupement d'objets en argent semble avoir une fonction autre que celle de la Tène, largent pourrait avoir un rôle particulier, peut-être hié aux circulations 
monétaires et au commerce. L'existence sur le site du Pègue d'une fibule de La Tène $\mathrm{D}$ présentant une déformation très proche des torsions à caractère sacrificiel observables sur les fibules en or de Hochdorf (Kr. Ludwigsburg, Baden-Württemberg, RFA) datées du Hallstatt final va dans le sens d'une fonction votive pour les objets de la fin de l'âge du Fer (Lagrand 1976 : fig. 10, n 27 ; Hartmann 1987 : p. 170).

L'anneau $\mathrm{n}^{\circ} 175$ est typologiquement difficile à dater, mais au vu des contextes dans lesquels figurent des objets en argent, il pourrait s'agir d'une pièce de La Tène C/D. $\mathrm{n}^{\circ} 180$. Pendeloque en fer.

Exemplaire au corps fuselé et aplati. L'objet est perforé à une extrémité pour sa suspension et terminé du côté opposé par une nodosité globulaire. Les pendeloques, en bronze ou plus rarement en fer, sont des éléments de chaînes de ceintures féminines (Gürtelkette), qui se multiplient à partir de La Tène $\mathrm{Cl}$.

Les formes de ces objets évoluent entre des exemplaires carénés dotés d'un "pied » aplati et des exemplaires fuselés. Les premiers modèles reproduisent parfois fidèlement des formes de céramiques, toujours des vases balustres et leurs coupes-couvercles (Suter 1984 : p. 77). Quelques chaînes complètes de la région bernoise possèdent ainsi trois reproductions miniatures de récipients, qui sont très certainement des formes destinées aux liquides et qui servent parfois d'urnes funéraires (Brunella 1987 : p. 62). Sans que l'on puisse établir de liaison claire, il faut noter que certaines chaînes de ceintures, auxquelles sont suspendues ces pendeloques vasiformes, sont parfois incrustées d'émail, et que leurs agrafes sont ornées de têtes zoomorphes analogues à celles qui décoreront les seaux en bois destinés au service du vin au cours de la phase suivante.

Les pendeloques les plus proches de l'exemplaire de La Chuire sont connues dans des contextes de La Tène B2/C de Münsingen (T. 149 ; T. 178) : il s'agit donc d'un objet du IIIe siècle av. n. è. $\mathrm{n}^{\circ} 181$. Tige ondulée de section rectangulaire.

Bien que sans comparaison, ce fragment pourrait être identifié comme un élément de coiffure (épingle à cheveux ?).

$\mathrm{n}^{\circ}$ 182. Epingle en bronze intacte.

Cet accessoire vestimentaire possède une tête aplatie et un corps fuselé, orné d'une dizaine de fines cannelures. L'objet évoque des formes du Bronze moyen, mais s'en distingue par ses dimensions, et il s'agit sans doute d'une variante appartenant à une phase ancienne du Bronze final (Audouze $1981:$ p. 63-64, $\mathrm{n}^{\circ}$ 6).

$196 \mathrm{n}^{\circ}$ 183. Epingle en bronze intacte.

Exemplaire à tête discoïdale ornée de cercles concentriques incisés ; la tige est décorée de 10 légères nodosités; il s'agit d'un type du Bronze final III $b$, très fréquent dans les stations du Lac du Bourget (Savoie) (Audouze 1981 : p. 111-114).

$197 \mathrm{n}^{\circ}$ 184. Epingle en bronze incomplète.

Tige de section circulaire dont l'extrémité, évidée, est soulignée d'une légère cannelure. La tête de l'objet présente donc une cavité conique partiellement remplie d'une matière dure et blanchâtre. Il s'agit vraisemblablement d'un fragment de corail altéré, reste d'un cabochon disparu. L'objet est incomplet, mais peut être identifié sans trop grand risque d'erreur comme une épingle de vêtement.

C'est vers la fin du VIe et au début du Ve siècle av. n. è. qu'apparaissent en Gaule et au nord des Alpes, les premiers objets incrustés de corail. La présence de branches de 
corail brut sur les sites princiers (Mohen 1988) et dans certaines sépultures hallstattiennes (Millotte 1963: p.303) indique la transformation sur place de ce matériau importé surtout de la côte napolitaine. La présence de corail brut sur le site italique de Forcello $^{3}$, qui a aussi livré de nombreuses fibules hallstattiennes, montre le cheminement effectué par cette matière (De Marinis 1987 : p. 89-99). Son emploi est lié à la représentation d'une des principales divinités celtiques (Kruta 1986 a).

L'utilisation du corail au premier âge du Fer concerne la fabrication de perles de collier et d'appliques rivetées sur certains types de fibules (Vogelkopffibeln). L'usage de ce matériau va se développer au cours du second âge du Fer, toujours comme incrustation sur des fibules (type de Miinsingen), mais aussi sur des torques (type à pastille). Le seul atelier laténien nord-alpin travaillant sur place le corail est localisé en pays arverne, sur le site d'Aulnat (Puy-de-Dôme) (Collis 1980 : p. 41) ; le contexte chronologique est le début du IIIe siècle av. n. è., soit peu avant le moment où le corail cesse d'être utilisé dans le domaine celtique. Il n'est pas assuré que la provenance de corail découvert en pays arverne soit la Campanie ou plus généralement les côtes italiennes; en effet, le corail se trouve aussi sur les côtes provençales (Var) et des fragments bruts sont signalés sur plusieurs oppida méditerranéens (Arcelin 1976: p. 669; Benoit 1965 : p. 195). D'autres ateliers ont donc pu exister dans le Sud de la Gaule et mettre en forme le corail qui orne certaines parures laténiennes, particulièrement surchargées, découvertes dans le Midi.

Bien que l'on connaisse quelques épingles au début de La Tène, cet exemplaire appartient plutôt à la fin du Hallstatt : quelques exemplaires, sensiblement différents, mais ornés de cabochons en corail, sont connus à Chassey (Saône-et-Loire) (Thévenot 1983: p. 29, n 7), à Soyons (Ardèche) (Beeching 1985: p. 4-12) et à la Heuneburg (Sievers 1984 : Taf. 54, $n^{\circ}$ 675).

$201 n^{\circ} 185$. Fragment d'épingle en fer.

Tige de section circulaire arquée vers son milieu et terminée par une partie plate perforée.

202 Il s'agit d'une épingle de vêtement, identique aux exemplaires découverts dans le tumulus du Magdalenenberg (Kr. Schwarzwald-Baar, RFA) et au Châtelet d'Etaulles (Côte-d'Or), datés du début du Hallstatt D (Spindler 1976: Taf. 131 a-d; Nicolardot 1988 : p. 124). Massive, cette épingle devait plus aisément fermer des vêtements en peau ou en fourrure, que des textiles fins et fragiles.

$\mathrm{n}^{\circ} 186$. Trousse de toilette en fer incomplète.

Anneau ouvert auquel sont suspendues deux tiges courbes aux extrémités disparues. Il s'agit très certainement d'une trousse de toilette comprenant à l'origine un scalptorium et une sonde.

Scalptorium, pincette et sonde apparaissent, isolés ou réunis en trousse, dès le premier âge du Fer en Italie où ils sont d'usage courant (Ridgway 1979 : p. 463, fig. 32, nº 7). En Gaule, en Languedoc occidental, ces éléments de trousses de toilette figurent dans nombre de tombes à incinérations dès le VIIe siècle av. $n$. è. (Mailhac Grand-Bassin $1, T$. 8 et 17). Si la plupart des trousses du premier âge du Fer sont en bronze, des exemplaires en fer proches de celui de La Chuire sont connus dans les phases Golasecca I C-II A d'Italie du Nord ou dans les contextes du Hallstatt final occidental, à Bragny (Saône-et-Loire) (Feugère 1986 : p. 184) et dans le tumulus IV de Glandon (Haute-Vienne) (Daugas 1976 : p. 738, fig. 2, n 9). 
$\mathrm{n}^{\circ}$ 187. Elément de trousse de toilette en bronze.

L'objet est formé à partir d'une tôle de bronze découpée. Constitué d'une tige aplatie terminée à une extrémité par deux dents, par une sorte d'anneau plat de l'autre, il s'agit d'un scalptorium appartenant à une trousse de toilette.

L'objet, bien qu'isolé, est assurément datable de La Tène D. En effet, les trousses de la fin du second âge du Fer sont en général montées sur un axe en bronze sur lequel pivotent les différents outils: l'examen de la tête de cet exemplaire montre deux incisions qui peuvent résulter d'une telle disposition (Furger-Gunti 1980 : p. 78, Taf. 12, $\left.\mathrm{n}^{\circ} 264\right)$.

$\mathrm{n}^{\circ} 188$. Bouton de forme hémisphérique.

L'objet ne montre aucune trace indiquant son mode de fixation; peut-être s'agit-il d'une garniture de rivet.

$n^{\circ} 189$. Bouton formé d'une tôle de bronze ornée au repoussé de cercles concentriques.

$n^{\circ} 190$. Ce bouton, identique au précédent, a volontairement été replié sur lui-même.

L'emploi de ces éléments décoratifs est reconnu dès le Hallstatt $\mathrm{D}$, comme ornements de ceintures en cuir, comme l'atteste la découverte régionale de la tombe féminine de Lanslevillard en Savoie (Prieur 1977 : p. 48). Il pourrait cependant s'agir d'une garniture de rivet à tête plate, puisque aucune patte de fixation n'est visible.

211 Si le pliage indéniablement volontaire du bouton $\mathrm{n}^{\circ} 190$ peut évoquer des pratiques de bronzier (préparation de pièces pour la refonte)-bien que dans le cas présent la masse de métal soit dérisoire-, il semble que cette opération puisse être aussi liée à des pratiques magiques : c'est du moins l'hypothèse proposée pour diverses tôles de bronze repliées provenant de la Heuneburg (Drescher 1984 : p. 126-136, Abb 18, nº 2).

\section{Ustensiles et outillage}

Cela forme un groupe important dans la série métallique de La Chuire, comprenant 156 objets se rapportant à trois catégories principales : les activités culinaires, les activités agricoles et les activités artisanales.

213 A la différence des parures, les outils ne permettent que peu de remarques d'ordre chronologique : une part importante des formes présentées ici apparaît au cours du premier âge du Fer, comme en témoigne le mobilier de La Heuneburg, seul site princier qui ait fait l'objet de fouilles étendues. Au cours de La Tène, la culture des oppida est, pour l'outillage, une période tout à la fois de multiplication, de diversification et de spécialisation. L'essentiel des formes d'outils va se stabiliser au cours de La Tène pour rester en usage jusqu'à nos jours, sans changement notable. Les outils, du moins certaines formes, ont vraisemblablement une durée de vie élevée et peuvent être conservés durant plus d'une génération. L'étude de ce type de mobilier a avant tout pour objet la détermination de la fonction de chaque outil et tend à définir la composition des panoplies spécifiques à chaque artisanat ou activité. Cependant, à une forme d'outil peuvent correspondre de multiples usages, et, en ce qui concerne les artisanats, on ne peut que constater la rareté des panoplies de l'âge du Fer formellement identifiées. Il est d'ailleurs probable que des trousses à usages multiples ont existé à une date haute de l'âge du Fer, avant que la diversification et la spécialisation des outils conduisent à l'existence de panoplies spécifiques à un corps de métier. 


\section{Les ustensiles de cuisine}

Couteaux (fig. 42-46)

214 Tous ces couteaux en fer ne se rapportent pas nécessairement à des activités culinaires et la fonction de l'objet (couper) le destine à des usages variés. Seuls les exemplaires de grande taille peuvent être identifiés, sans trop grand risque d'erreur, comme des formes spécialisées dans les travaux de boucherie. Par commodité, tous les couteaux sont néanmoins regroupés dans la même catégorie, comprenant trois types classés selon les caractéristiques des manches.

Le premier type rassemble des couteaux dont le manche, doté ou non de rivet, comporte un anneau destiné à la suspension de l'outil (fig. 43).

$216 \mathrm{n}^{\circ}$ 191. Outil complet.

Exemplaire à manche quadrangulaire terminé par un anneau, et comportant, sur une seule face, une gorge marquée. Dans cette dépression sont fixés trois rivets; le dernier est positionné sur le début de la lame, indiquant ainsi les limites du manche en bois ou en os. Le dos est convexe vers le raccord entre le manche et la lame, puis légèrement concave à l'approche de la pointe (celle-ci est absente). Comme sur l'exemplaire suivant, on observe des traces d'usures $d u$ tranchant, indiquant les parties fonctionnelles de la lame.

$217 \mathrm{n}^{\circ}$ 192. Exemplaire incomplet.

Ce dernier possède un manche massif, de section rectangulaire, et comportant une rainure marquée sur un côté. A chaque extrémité de cette gorge sont fixés deux rivets nécessaires à la fixation d'un manche en matière périssable (sans doute en bois). Le dos est légèrement convexe au niveau du raccord entre le manche et la lame, qui forme un angle droit. La lame montre deux traces d'usures dues aux affûtages successifs des parties les plus utilisées du tranchant. L'usure la plus marquée est située au plus large de la lame, juste après le manche : là où l'utilisateur dispose de la plus grande force possible pour couper. Le couteau possédait très probablement un anneau permettant sa suspension ; la restauration a montré que l'excroissance située à l'extrémité du manche n'était pas due à une oxydation, mais qu'il s'agissait bien de la trace d'une pièce disparue (fig. 42). 
42- Reconstitution d'un couteau en fer

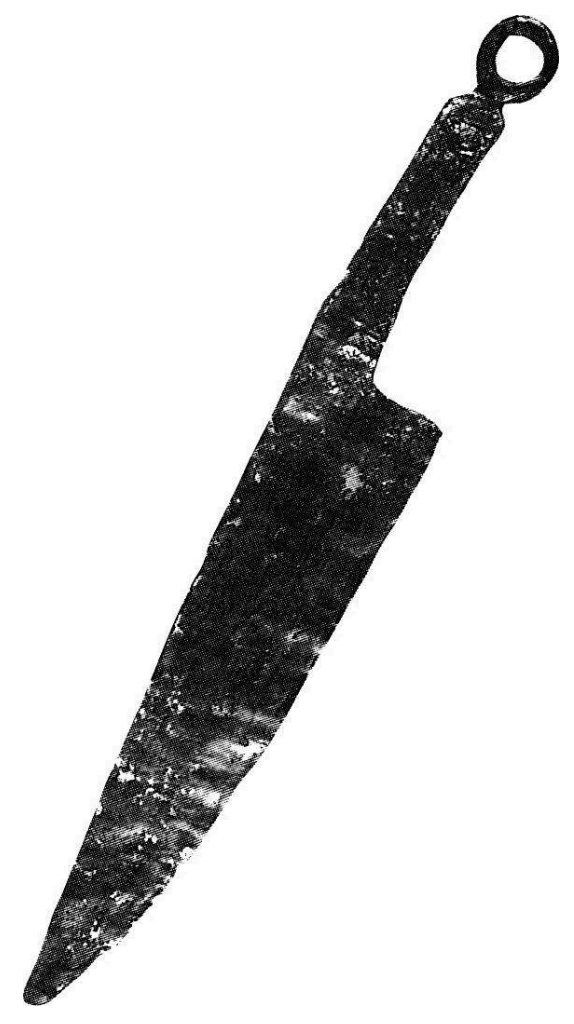

43- Couteaux en fer

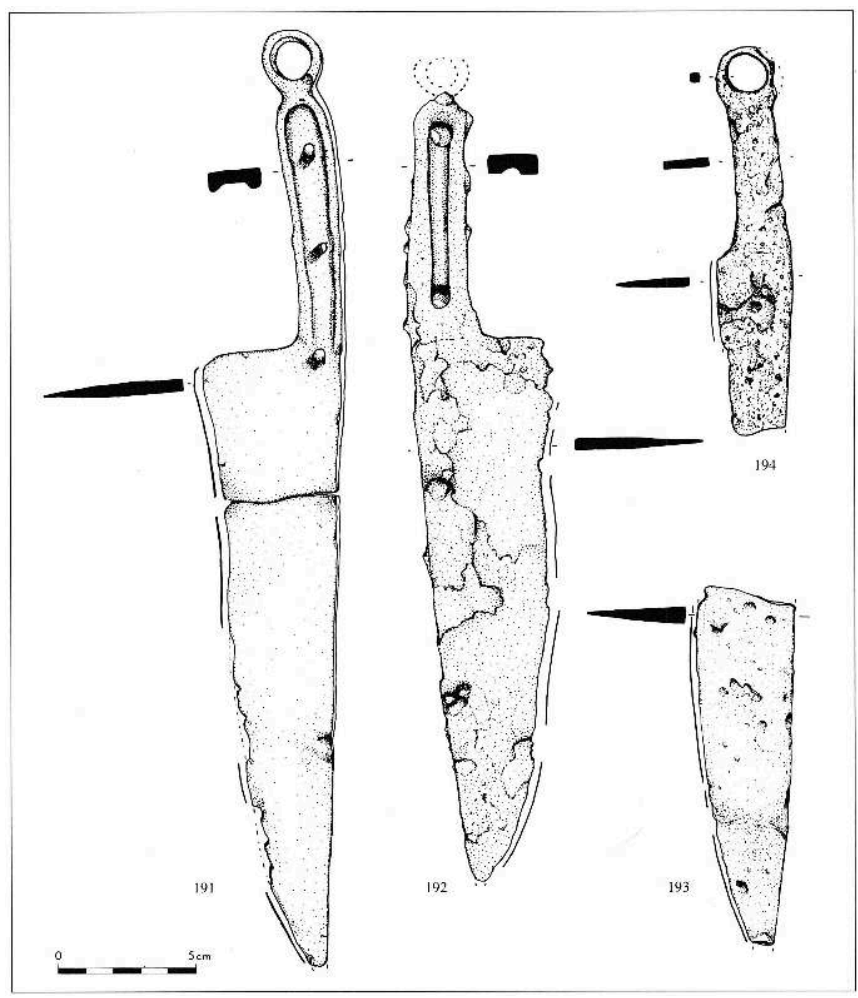

$218 n^{\circ}$ 193. Extrémité de la lame d'un couteau de grande taille, possédant un dos large. Il s'agit probablement d'un exemplaire analogue aux deux précédents. 
219 Ces trois couteaux sont sans doute des outils liés aux travaux de boucherie. En effet, les traces de réaffûtages successifs écartent l'utilisation de tels objets comme armes (utilisés dans ce cas d'estoc), et il faut plutôt les considérer comme des outils utilisés pour des découpes alimentaires.

220 Des objets comparables par leur forme (anneau et cannelure du manche) et leur dimension existent dans la culture des oppida, mais aucune illustration n'indique la présence de rivets, peut-être masqués par l'oxydation. Des couteaux de ce type sont attestés à Manching (Jacobi 1974 : Taf. 17, n 293-295, 297), ainsi qu'à Port (Tschumi 1940 : p. 22), Corneaux (NE. Suisse) (Schwab $1973:$ p. 68) et au Mont-Vully (FR. Suisse) (Kaenel 1983 b : p. 108). D’autres exemplaires sont attestés dans des dépôts métalliques, à Kolín (Tchécoslovaquie) (Rybová 1983). Les sites du Sud de la Gaule ont livré plusieurs fragments d'outils comparables : par exemple, dans la sépulture de Calvisson (Gard) ou sur le site fortifié de hauteur de Mauressip (Gard) (Tendille 1982: p. 46-47 et fig. 8, $\mathrm{n}^{\circ}$ 50-51).

Régionalement, ce type de couteau figure dans le matériel de Sainte-Blandine (Chapotat 1970 : pl. XIX, n²).

$n^{\circ}$ 194. Couteau incomplet.

Cet exemplaire de petite taille possède un dos convexe assez marqué. Le raccord du manche et de la lame forme un angle ouvert ; le tranchant est peu dégagé du manche.

Cette forme gracile de couteau se rencontre déjà dans la sépulture 6 de la nécropole du Dürrnberg (Penninger 1972 : Taf. 5, A, 1), puis dans le mobilier des oppida, à Heidetränk, Pohanská (Tchécoslovaquie) ou au Camp de La Curade (Müller-Karpe 1977 : Abb. 10, n 1 et 6 ; Paulik 1976 : p. 252, Tab. L, n 4 ; Simonnet 1982 : p. 102, fig. 6, n 9).

Le deuxième type comprend plusieurs couteaux à manche massif sans rivet indiquant l'existence de renforts en os ou en bois (fig. 44). 


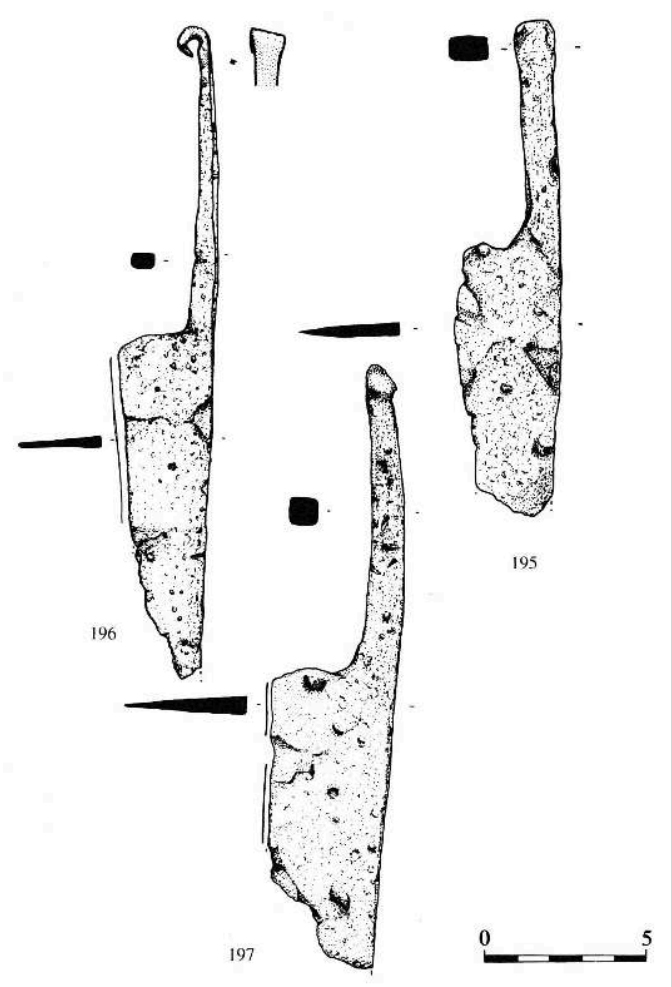

$\mathrm{n}^{\circ}$ 195. Exemplaire incomplet.

Le manche de ce dernier est massif, de section rectangulaire, s'épaississant graduellement vers son extrémité. La lame est bien dégagée, formant un angle droit au niveau de son raccord avec le manche.

$n^{\circ}$ 196. Outil incomplet.

Comme l'exemplaire précédent, le manche de ce couteau est massif, s'épaississant vers son extrémité ; sa section est carrée. Le dos, assez large, est nettement convexe au niveau du manche, puis probablement concave au niveau de la lame. Celle-ci est bien dégagée du manche, formant un raccord à angle droit.

La forme est connue dès le Hallstatt C (Ruoff 1974: Taf. 41, n 7). Plus tardivement, d'autres exemplaires, découverts en milieux funéraires dans le Sud de la Gaule (Tendille 1982 : p. 47-48, fig. 8, n 54-58), sont datés du Ier siècle av. n. è. (Les Colombes, T. 5, Beaucaire, Gard). Cette forme est représentée par un fragment dans le matériel de Sainte-Blandine (Chapotat 1970: pl. XIX, n ${ }^{\circ}$ ). Elle ne semble pas avoir possédé de manche en matière périssable et a dû être utilisée avec un manchon de cuir.

$\mathrm{n}^{\circ} 197$. Couteau ( ?) incomplet.

L'objet est constitué d'un manche quadrangulaire, aplati, élargi et recourbé à son extrémité.

Plutôt qu'une forme spécifique, il s'agit certainement d'une lame de petites forces réutilisée comme couteau.

Le troisième type, qui comprend le plus grand nombre d'objets, regroupe des pièces à manche rectangulaire, très plat et doté de rivets (fig. 45). 
45-Couteaux en fer

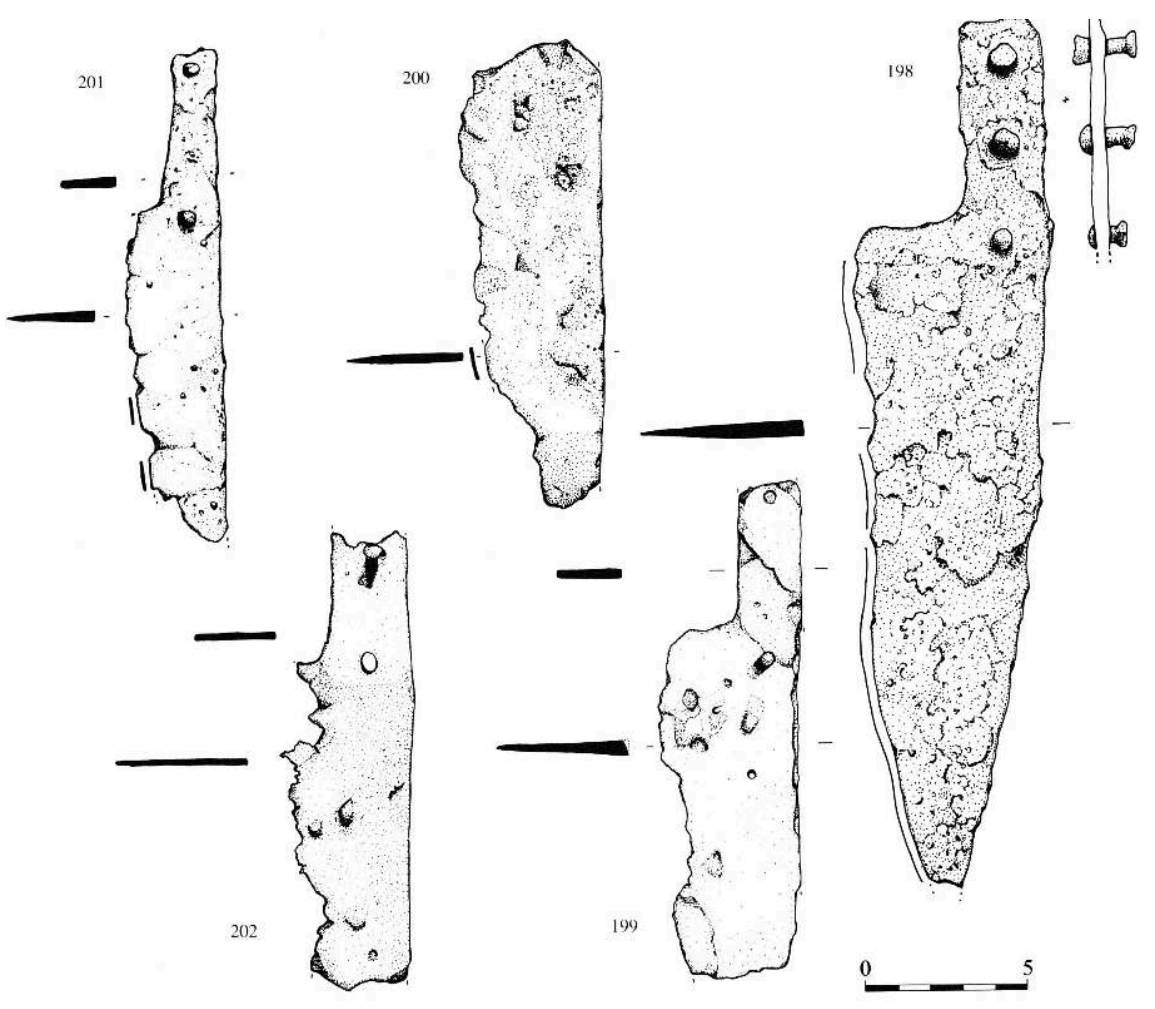

$\mathrm{n}^{\circ}$ 198. Couteau incomplet.

Exemplaire de grande taille, possédant un dos légèrement arqué (fig. 46). La lame est bien dégagée du manche, formant avec celui-ci un angle droit. Ce dernier, de forme rectangulaire, a encore conservé trois rivets destinés à maintenir les renforts de préhension en os ou en bois. Le dernier rivet est fixé sur la lame, indiquant ainsi la limite de celui-ci. Le tranchant présente deux traces de réaffûtages identiques à celles observées sur les exemplaires à anneau de suspension. 


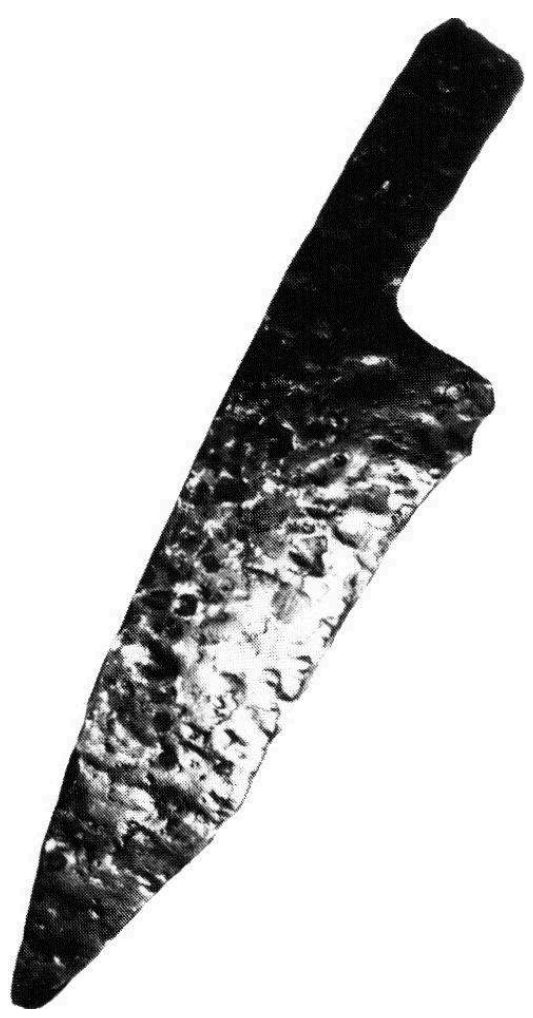

$n^{\circ}$ 199. Couteau incomplet.

Très proche du précédent, bien que de dimensions plus réduites, ce couteau possède un dos rectiligne. Le manche est rectangulaire avec deux emplacements de rivets. La lame est bien dégagée du manche, formant ainsi un angle droit avec celui-ci. La position du dernier rivet - sur la lame - indique que la partie périssable de l'outil débordait nettement sur cette dernière.

$n^{\circ}$ 200. Fragment de lame appartenant à un couteau de grande taille, peut-être un modèle proche du $n^{\circ} 198$.

$\mathrm{n}^{\circ} 201$. Couteau incomplet.

Exemplaire à dos rectiligne ; le manche montre deux emplacements de rivets, le dernier étant fixé sur la lame. Celle-ci est légèrement pliée, peut-être volontairement. La restauration a mis en évidence un fragment d'os sur un rivet, indiquant ainsi la nature du manche disparu.

$\mathrm{n}^{\circ}$ 202. Exemplaire incomplet.

Celui-ci a un dos rectiligne et un manche rectangulaire à deux emplacements de rivets ; le dernier est fixé sur la lame.

Des formes de couteaux à manche plat et rivets se rencontrent dans nombre de contextes funéraires du Sud de la Gaule, datés du Ier siècle av. n. è. mais aussi plus rarement semble-t-il, en Gaule interne (Guichard 1988 : p. 158). Il est probable que les exemplaires de grande taille étaient des outils de boucherie, comme les modèles à anneau de suspension (Tendille 1982: p. 47-51; Arcelin 1973: fig. 44, $\mathrm{n}^{\circ}$ 131-132; Arcelin 1979 b : p. 144, fig. 13, n 9). 
Grils (fig. 47-19)

La série métallique de la Chuire comprend les fragments d'au moins six grils en fer.

$47-48$ Gril en fer

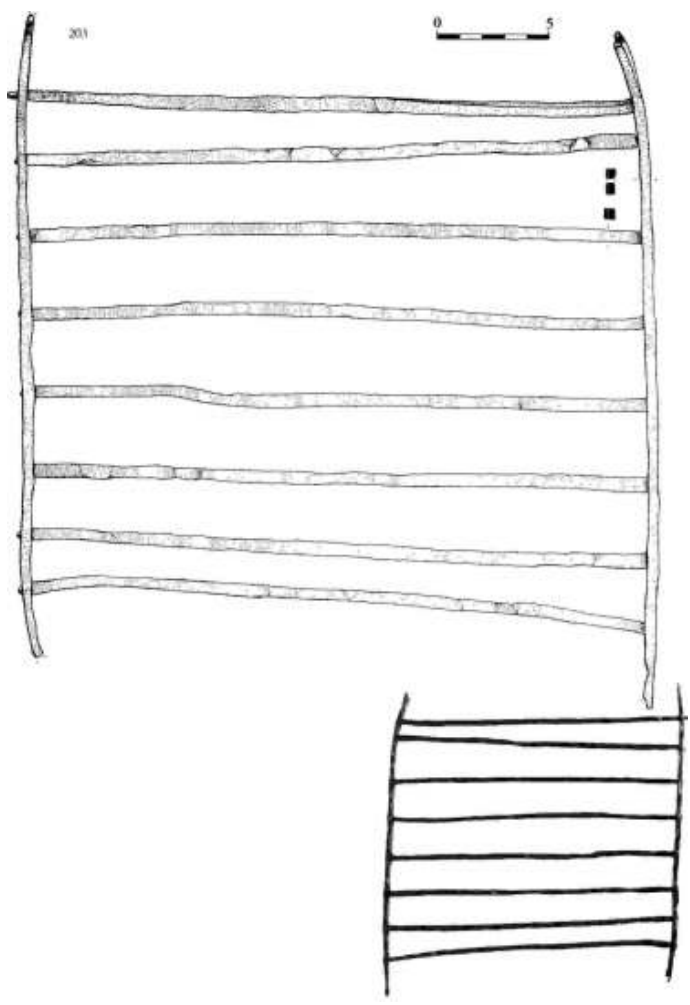

$n^{\circ}$ 203. Exemplaire incomplet (fig. 47-48).

Celui-ci est constitué par deux tiges transversales de maintien, ayant conservé huit barres transversales de support et la trace d'une neuvième. Les barres, de section carrée, sont disposées régulièrement et parallèlement, à part les huitièmes et neuvièmes, peut-être rapprochées à la suite d'une réparation.

$n^{\circ}$ 204. Fragment de tige latérale de maintien (fig. 49).

Cette dernière, de section rectangulaire, comprenait à l'origine au moins cinq barres transversales. Elle est recourbée à angle droit pour former un pied légèrement épaissi à son extrémité. 


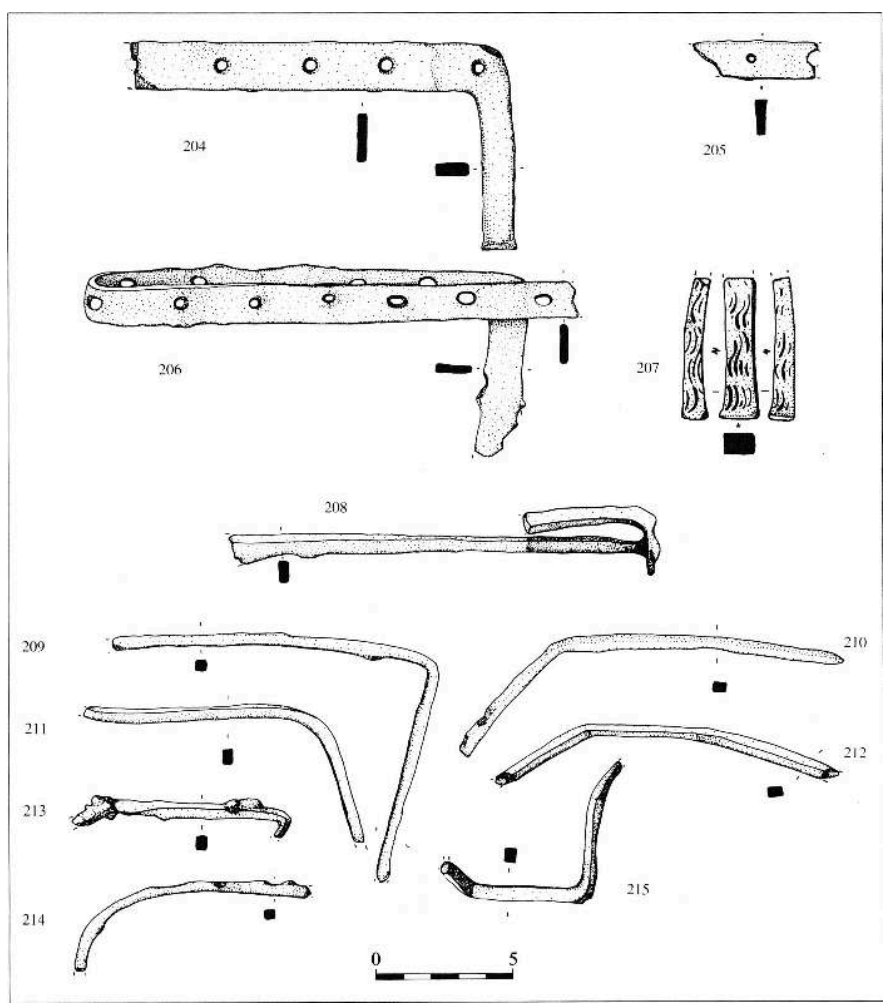

$\mathrm{n}^{\circ} 205$. Fragment de tige latérale de maintien comportant deux perforations de fixation des barres transversales.

$\mathrm{n}^{\circ}$ 206. Tige latérale de maintien.

Celle-ci comportait au moins onze barres transversales. La tige est recourbée à angle droit pour former un pied dont l'extrémité a disparu. Ce gril de grande taille a été démonté ; les barres ont été retirées, puis la barre de maintien a été repliée sur ellemême, subissant une rotation de $180^{\circ}$.

$\mathrm{n}^{\circ}$ 207. Pied de gril ( ?).

Tige de section rectangulaire, s'épaississant à son extrémité, et possédant une inflexion peu marquée sur deux faces. Trois des quatre côtés de l'objet sont ornés d'ondulations peu profondes, peu soignées, qui évoquent certains décors sur céramiques de La Tène D. Il pourrait s'agir d'un pied de gril orné sur ses trois faces visibles.

$\mathrm{n}^{\circ}$ 208. Fragment de tige latérale déformée et barre transversale de gril.

$n^{\circ}$ 209. Barre transversale de section carrée, volontairement repliée à angle droit.

$n^{\circ} 210$. Barre transversale de section carrée, presque coudée à angle droit.

$n^{\circ} 211$. Barre transversale de section carrée, dont l'extrémité est coudée.

$n^{\circ} 212$. Barre transversale de section carrée : la tige est courbée.

$\mathrm{n}^{\circ}$ 213. Barre transversale de section carrée, légèrement coudée.

$n^{\circ} 214$. Barre transversale de section carrée, légèrement courbée.

$\mathrm{n}^{\circ}$ 215. Barre transversale de section carrée. Elle est coudée deux fois, formant à un endroit un angle droit, à l'autre un angle ouvert. 
(Jacobi 1974: p.110111; Müller-Karpe 1977: Abb. 5, nº 13; Gruet 1986: p. 21). Régionalement, le gril est aussi présent dans le mobilier de Sainte-Blandine (Chapotat 1970 : pl. XXII, n² 2). Cet ustensile de cuisine a pu être utilisé à la fois pour la cuisson des poissons et des viandes. Pour le premier type de consommation, si les sources antiques (Poseidonios d'ap. Athénée 151 e-152 d) mentionnent le goût des Celtes pour le poisson grillé, elles n'indiquent cependant pas comment la cuisson était réalisée : néanmoins l'utilisation du gril semble probable. D'une manière plus générale, certaines viandes devaient aussi être cuites sur les grils puisque Poseidonios, relatant les usages à table des Celtes, distingue « les viandes.... grillées sur la braise ou à l'aide de broches ». Les traces de calcination observées sur certaines pièces anatomiques animales (Krausz 1989 : p. 49) indiquent qu'elles ont été grillées et les dimensions importantes mesurées sur les grils les plus complets sont certainement en rapport avec ce type de consommation. La fonction culinaire du gril (rôtir les viandes et les poissons) l'oppose à celle du chaudron (bouillir les viandes) qui, s'il n'est pas attesté dans la série métallique de La Chuire, est du moins représenté par certains de ses accessoires. Il convient cependant de signaler un autre usage pour le gril, utilisé dans l'artisanat du tablettier cornetier pour la chauffe des cornes avant leur découpe (Diderot 1771: pl. VII, $\mathrm{n}^{\circ}$ 14-18).

La plupart de ces grils semble avoir fait l'objet d'un démontage, suivi d'une torsion des différentes pièces les composant : les barres transversales sont tordues ou absentes des tiges latérales de maintien. Même l'exemplaire $n^{\circ} 203$, le plus complet, montre une légère torsion de l'extrémité de ses deux tiges latérales de maintien, à l'emplacement d'une barre disparue.

Trépieds (fig. 50)

Plusieurs fragments en fer se rapportent à des ustensiles à pieds multiples, destinés à supporter des récipients à fond rond du type chaudron. 


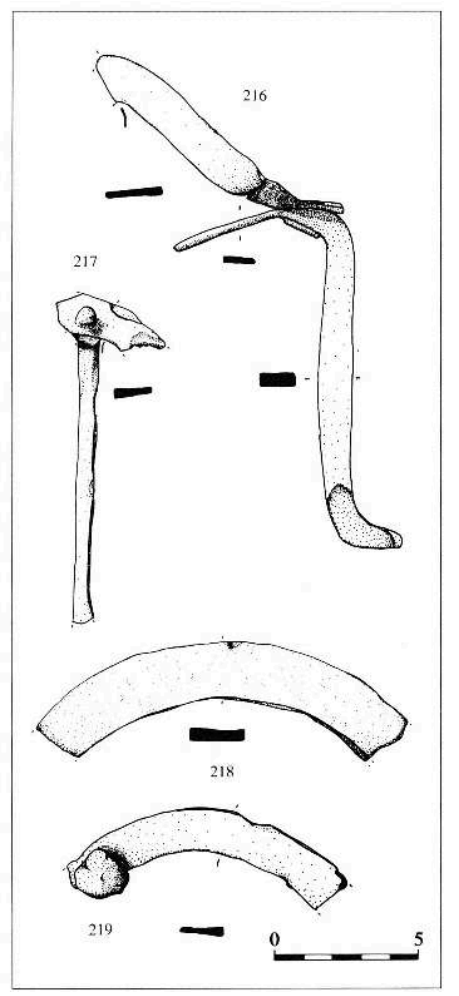

$254 n^{\circ} 216$. Trépied incomplet.

L'objet est formé de deux parties distinctes : d'une part, un bandage circulaire, disposé à plat, sur lequel est fixée par rivetage une tige de section rectangulaire. Une des extrémités de cette dernière est recourbée pour former un pied ; l'autre se prolonge audelà du cerclage, par une bande étroite et plate, qui plonge vers le centre supposé du cerclage. Ce dernier est tordu, presque sectionné à un endroit. Il semble difficile d'attribuer ces déformations à des contraintes mécaniques et l'état de cet ustensile est peut-être plutôt la conséquence d'une destruction volontaire.

$255 \mathrm{n}^{\circ}$ 217. Trépied incomplet.

Ce dernier a conservé une partie d'un de ses pieds et un fragment de son cerclage riveté. Le pied est tordu, replié contre le cerclage.

$\mathrm{n}^{\circ}$ 218. Fragment de trépied (?).

Bande circulaire de section rectangulaire. Il s'agit sans doute d'un fragment de cerclage d'un troisième trépied, mais l'absence de rivet ou de départ de pied ne permet pas d'être affirmatif.

$n^{\circ} 219$. Fragment de trépied.

Ce cerclage a conservé un rivet de fixation du pied disparu.

Ces fragments se rapportent sans doute à quatre trépieds de construction identique. Un cinquième exemplaire, disparu, a été signalé lors des premiers sondages réalisés sur le site (Chauffin 1960 : p. 43).

Les trépieds sont attestés dès le premier âge du Fer au nord des Alpes. Il s'agit cependant d'objets de luxe importés d'Etrurie où ils sont connus dans nombre de sépultures aristocratiques: en Italie, ces supports, connus dès la fin du VIIIe siècle, peuvent être en bronze mais aussi en fer (Bouloumié 1988 : p. 360-372). Au second âge 
du Fer, quelques rares trépieds sont attestés dans le monde celtique et leur usage est intimement lié aux chaudrons, plus fréquemment signalés (Feugère 1982: p. 168-169; Marcadal 1985: p.79; Willaume 1987). En effet, le trépied est indispensable à la stabilité du chaudron qui ne possède pas de fond plat. Il est difficile de préciser l'utilisation exacte du trépied: ce dernier peut être employé directement pendant la cuisson comme support du chaudron (qui peut aussi être suspendu à une crémaillère) ou après celle-ci, lors du service des viandes.

260 Les quelques trépieds connus, dans le mobilier des oppida (Stradonice, Entremont) et dans certaines tombes aristocratiques datées de La Tène $\mathrm{D}$, sont très différents de ceux provenant de La Chuire. Ceux de Château-Porcien et d'Hannogne (Ardennes) sont constitués d'un bandage en fer disposé verticalement; ils possèdent en outre des extrémités des pieds zoomorphes et leurs diamètres sont nettement supérieurs à ceux des trépieds de La Chuire. En plus de leur utilisation culinaire, il semble que certains exemplaires aient été utilisés dans des activités artisanales puisqu'à Bibracte un trépied figure dans une panoplie de fondeur (Beck 1985 : p. 238, fig. 1, nº 4). Si aucun chaudron n'a été identifié dans le mobilier métallique de La Chuire, la présence de nombreuses fourchettes à chaudron incite à considérer les trépieds de La Chuire comme des ustensiles de cuisine ou de table.

\section{Fourchettes à chaudron (fig. 51-57)}

261 La faille de La Chuire a livré un nombre considérable d'objets en fer qui ont en commun une extrémité formée de fines tiges courbes. Il s'agit de fourchettes ou de crocs utilisés pour la préhension des viandes bouillies à l'intérieur des chaudrons. Leur extrémité multiple et courbe était forgée de manière à éviter de percer la fine tôle de bronze des récipients lors de l'utilisation. L'identification comme ustensile culinaire est la plus fréquemment avancée, bien qu'aucun contexte associant sûrement fourchette et chaudron ne soit connu. 


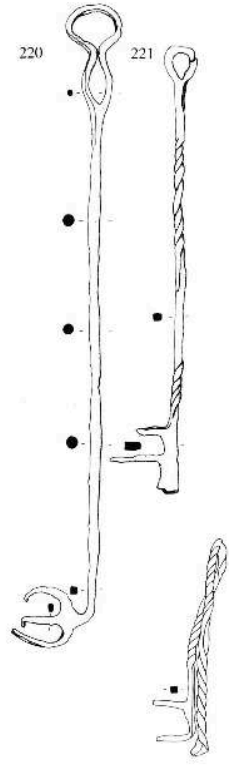

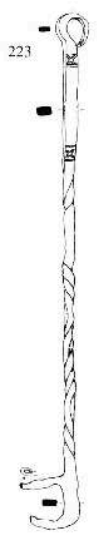

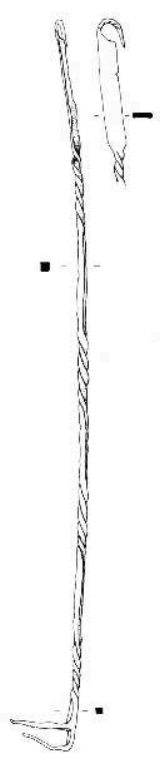

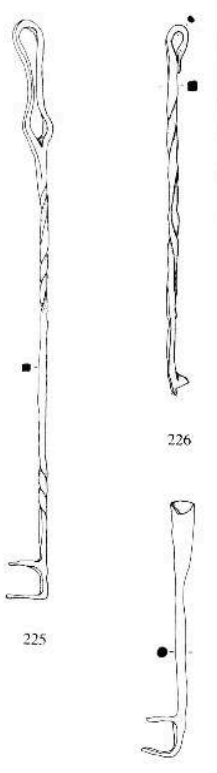

227

Le nombre et la variété de ces ustensiles ont permis leur classement en utilisant diverses caractéristiques ordonnées comme suit :

- L'extrémité active (la fourchette proprement dite) qui permet d'identifier l'objet est en fer (type 1); tous les fragments de La Chuire appartiennent à ce type. Un exemplaire en bronze serait rangé dans le type 2 .

- La partie proximale et médiane (manche ou tige) peut être entièrement en métal (sous-type 1), mixte en associant une partie en bois à une partie métallique (sous-type 2), entièrement en bois (sous-type 3).

- Les dents peuvent être précédées d'une partie perpendiculaire à la tige (1), ou directement forgées à partir de la tige (2).

- Leur nombre est variable (de 1 à n), généralement 2 ou 3.

Chaque fourchette peut être désignée par un nombre à quatre chiffres. En envisageant une prochaine étude d'ensemble de ces ustensiles, la description pourra être précisée par l'ajout d'autres critères, codifiés de la même façon : la forme des dents (en esse ou en arc de cercle), le mode de suspension (crochet, anneau, faux anneau, en matière périssable, sans), le décor (absent, torsadé, mixte, autre).

Les fourchettes entièrement métalliques de type 11 sont au nombre de sept (fig. 51-53).

$\mathrm{n}^{\circ}$ 220. Fourchette incomplète (type 1113).

L'objet est formé d'une tige de section circulaire plus ou moins large, formant trois renflements successifs (la section devient carrée vers les dents). La suspension s'effectue grâce à un anneau allongé et cintré. L'extrémité est coudée à angle droit pour former trois dents dont les pointes ont disparu. Cette disposition des dents est unique dans la série des fourchettes métalliques; c'est également la seule dont la tige ne soit pas torsadée. 
Ce type de fourchette à extrémité coudée est connu dans la culture des oppicla, à Manching, Stradonice et Sainte-Blandine, mais cette dispositon des dents semble cependant plus fréquente sur le type 121, à manche mixte (Jacobi 1974: Taf. 32, $n^{\circ}$ 569-571; Pic 1906 : pl. XXXV, n 5, 10, 23 ; Chapotat 1970 : pl. XX, nº 1). La suspension rappelle celle d'une fourchette de Sanzeno nelle Anaunia (Vénétie, Italie) (Fogolani 1960 : p. 315).

$\mathrm{n}^{\circ} 221$. Fourchette incomplète (type 1 123).

L'objet consiste en une tige de section carrée, terminée à une extrémité par un anneau fermé. L'autre extrémité voit la section de la tige devenir rectangulaire, pour former deux dents. Une excroissance du métal indique qu'une troisième dent a disparu. Le manche est orné de deux séries de torsades (sept, puis quatre), toutes dans le même sens de rotation. Un exemplaire du même type que le $\mathrm{n}^{\circ} 221$ figure dans le dépôt de Sainte-Blandine; il en diffère par l'agencement de ses dents (Chapotat 1970 : pl. XX. $\left.\mathrm{n}^{\circ} 6\right)$.

$\mathrm{n}^{\circ}$ 222. Fourchette incomplète (type 1 122) (fig. 52).

La fourchette comprend une tige de section carrée, ornée de trois séries de torsades ( $5+$ $9+7)$; la dernière série est obtenue en inversant le sens de rotation de la tige. L'anneau de suspension manque : à son emplacement logique, le métal montre un aplatissement marqué, peut-être dû à un choc. Les deux dents sont forgées directement sur le manche sans que celui-ci soit coudé. L'objet a été volontairement replié sur lui-même par une rotation de plus de $180^{\circ}$ : les deux extrémités de l'objet se croisent. Il s'agit de la seule fourchette de la série qui présente une telle déformation.

\section{2- Fourchette déformée}

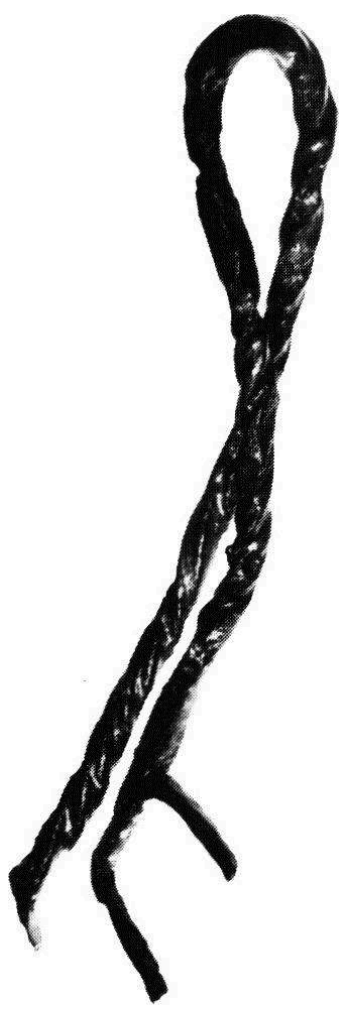

$\mathrm{n}^{\circ}$ 223. Fourchette complète (type 1 122) (fig. 53).

Le manche de section rectangulaire est orné de quatre séries de torsades, alternées 
selon leur sens de rotation. La partie supérieure de l'objet, destinée à la préhension, n'est pas torsadée, mais est par contre décorée sur ses deux faces de deux croisillons limités par des incisions. La suspension s'effectue grâce à un crochet. La fourchette possède deux dents dont une a manifestement été volontairement repliée sur ellemême, rendant l'objet, par ailleurs quasi-complet, inutilisable.

\section{3- Fourchette décorée}

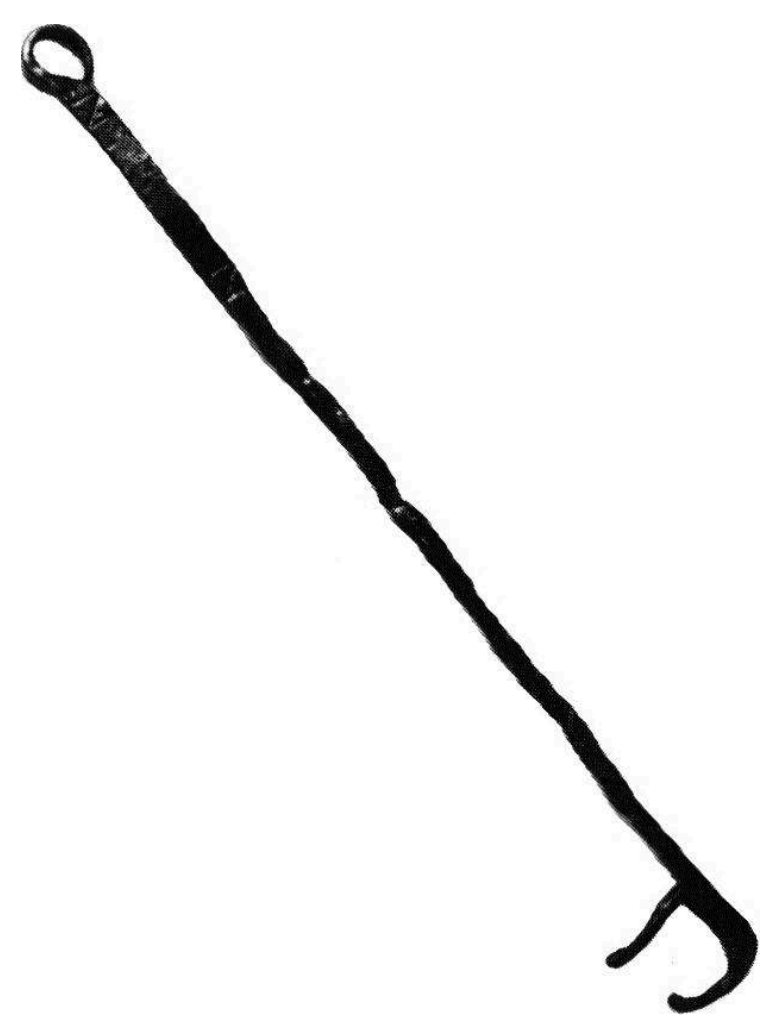

270 Les outils et ustensiles en fer semblent peu décorés à l'âge du Fer, mais ce constat tient peut être avant tout à l'absence de restauration systématique de ces catégories d'objets. Seul le site latènien du Dunsberg (Hesse, RFA) a livré une importante série d'objets en fer décorés, certains d'une manière proche de la fourchette $n^{\circ} 223$ de La Chuire (Jacobi 1977 : Taf. $28, \mathrm{n}^{\circ}$ 4-6).

$271 \mathrm{n}^{\circ} 224$. Fourchette complète (type 1122 ).

C'est la plus grande et la plus complète des fourchettes. La suspension s'effectue grâce à un crochet fin orné de plusieurs torsades. La partie destinée à la préhension est plate, sans décor et de section rectangulaire. La tige, de section carrée, est ornée de quatre séries de quatre torsades toutes dans le même sens de rotation. L'extrémité du manche comprend deux dents fines, forgées directement à partir de celui-ci. D'autre part, le manche présente une courbure marquée et régulière, trace probable d'une utilisation répétée.

$\mathrm{n}^{\circ} 225$. Fourchette complète (type 1122 ).

Le système de suspension est, comme pour l'exemplaire $n^{\circ} 220$, un anneau allongé et cintré. Le manche quadrangulaire est orné de deux séries de trois torsades alternant de sens de rotation. L'extrémité possède deux dents forgées directement à partir du manche. 
$\mathrm{n}^{\circ}$ 226. Fourchette incomplète (type 112).

La suspension se fait grâce à un crochet grossièrement ornithomorphe, replié contre le manche. Ce dernier est orné de deux séries de torsades alternant leurs sens de rotation. Seul le départ d'une dent est conservé, mais indique qu'il s'agit bien d'une fourchette à manche droit, non coudée.

274 Le type 1122 figure dans les mobiliers de la culture des oppida, par exemple à Manching. On le rencontre, représenté par quatre exemplaires, dans le mobilier de Sainte-Blandine, ainsi que dans le sanctuaire d'Holzhausen (Bavière, RFA) (Jacobi 1974 : Taf. 32, n 565, 567, 568 ; Chapotat 1970 : pl. XX. n² 2, 12-14 ; Schwartz 1975 : p. 340, Abb. $\left.14, n^{\circ} 5\right)$. L'exemplaire $n^{\circ} 224$ et une fourchette de Sainte-Blandine sont presque identiques, et il est possible que ces deux objets proviennent du même atelier.

275 Le type 12, à manche mixte, n'est représenté que par un exemplaire dans le mobilier de La Chuire.

$276 \mathrm{n}^{\circ}$ 227. Fourchette incomplète (type 1222 ).

L'objet est constitué d'une douille représentant un tiers de lu longueur totale, se prolongeant par une tige de section circulaire non recourbée, terminée par deux dents. Le manche était fixé à la douille par une virole encore conservée.

277 Ce type est représenté dans le mobilier de Sainte-Blandine par deux exemplaires de dimensions supérieures, et aux tiges torsadées (Chapotat 1970: pl. XX, $\mathrm{n}^{\circ} 7$ et 9). D'autre part, on remarque l'absence du type 121, très proche, pourtant attesté à SainteBlandine (au moins 5 ex.) (Chapotat $1970: \mathrm{pl} . \mathrm{XX}, \mathrm{n}^{\circ} 8,10,11$ ) et connu dans certains contextes funéraires du Sud de la Gaule, datés du Ier siècle av. n. è. (Tendille 1982 : p. 46).

278 Le type 13 (fig. 54-56) regroupe des fourchettes à manche entièrement en bois, également désignées par le terme de croc. Ces objets ne présentent pas de traces permettant de reconstituer le mode de fixation du manche. Celui-ci devait posséder une gorge destinée à loger le sommet de la fourchette, maintenue par une charnière et/ ou une ligature. 
54- Crocs à chaudron en fer

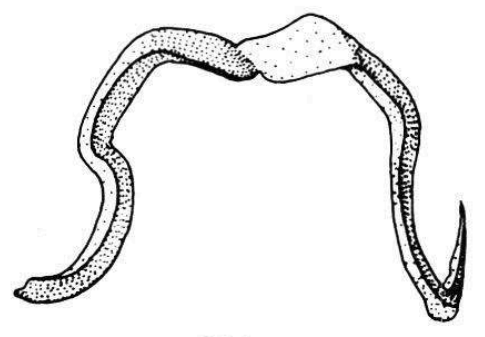

228

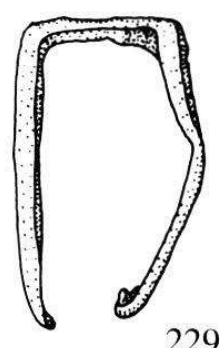

229

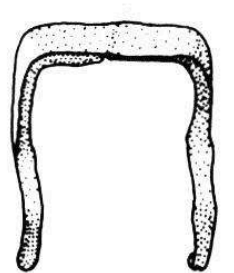

230

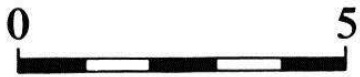

5

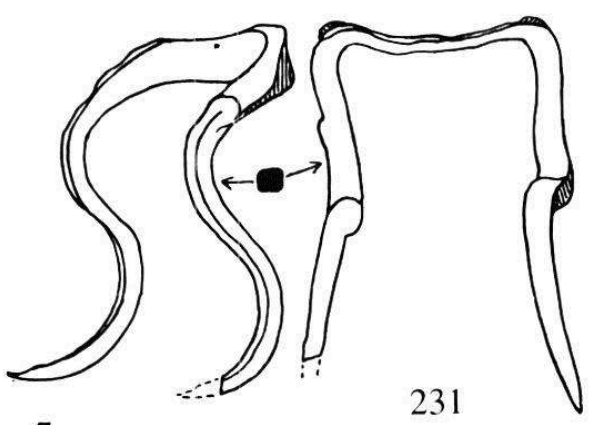
54).

$\mathrm{n}^{\circ}$ 228. Ustensile complet (type 1322), déformé au niveau de la tige transversale (fig.

$\mathrm{n}^{\circ}$ 229. Exemplaire complet (type 1322 ).

$\mathrm{n}^{\circ}$ 230. Fourchette complète (type 1312 ).

$n^{\circ} 231$. Exemplaire complet du type 1312 .

$\mathrm{n}^{\circ}$ 232. Exemplaire incomplet particulier du type 1313 (fig. 55). 
55- Crocs en fer

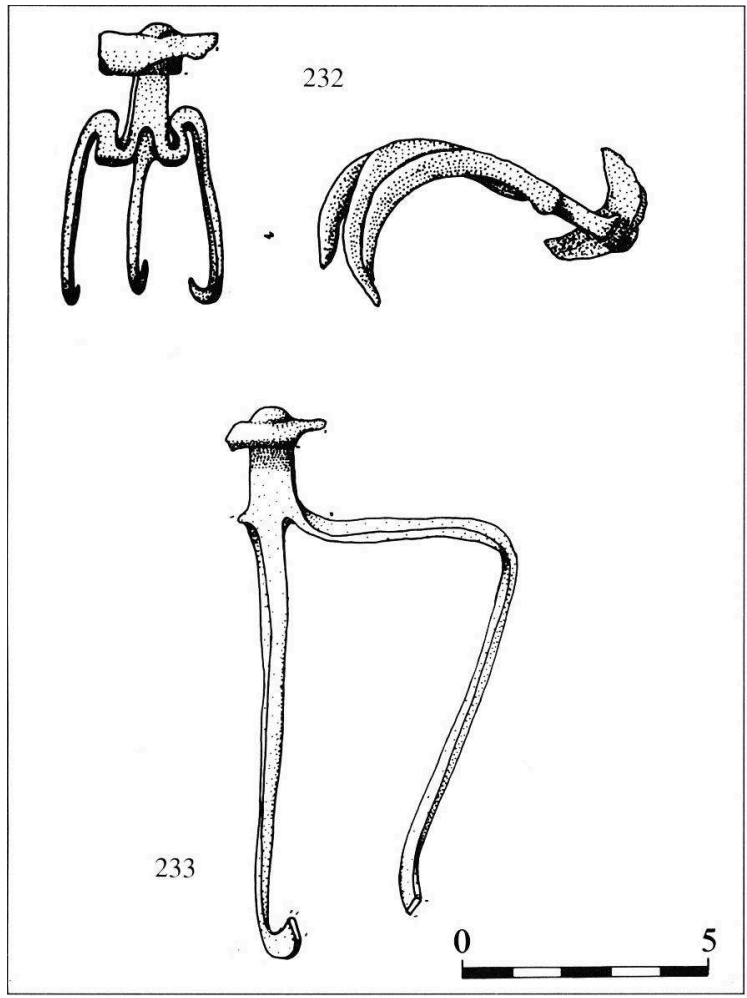

284 L'objet est formé à partir d'une tige de section carrée, fendue sur la moitié de sa longueur, la partie réservée servant de soie. Les deux tiges obtenues ont été recourbées en forme de esse le long de la soie, puis ont été tordues en arc de cercle. Une troisième dent, forgée à part, a été insérée de force dans la soie (sur plusieurs millimètres, d'après une radiographie du Centre de Restauration de Vienne). Une tôle de fer hémicylindrique renforçait la fixation du manche en bois. $\mathrm{n}^{\circ}$ 233. Modèle de très grande dimension du type 1323.

$\mathrm{n}^{\circ} 234$. Fourchette complète type 1322 (fig. 56). 
56- Croc en fer

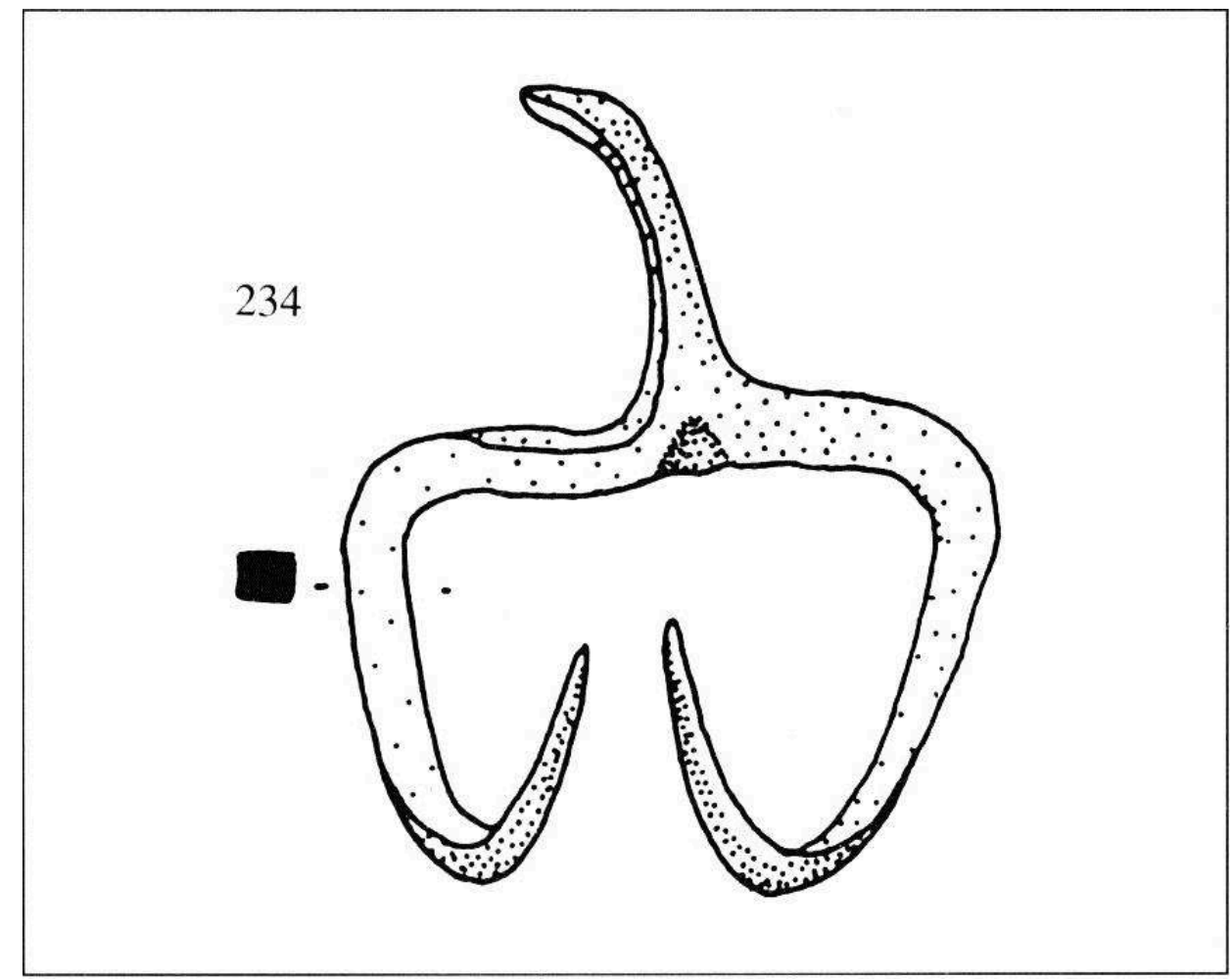

Ustensile comprenant deux dents fixées directement à la tige les reliant. Cette dernière se prolonge par une soie fine et recourbée, qui devait pénétrer dans le manche.

Plusieurs fourchettes sont trop fragmentées pour être classées (fig. 57). 


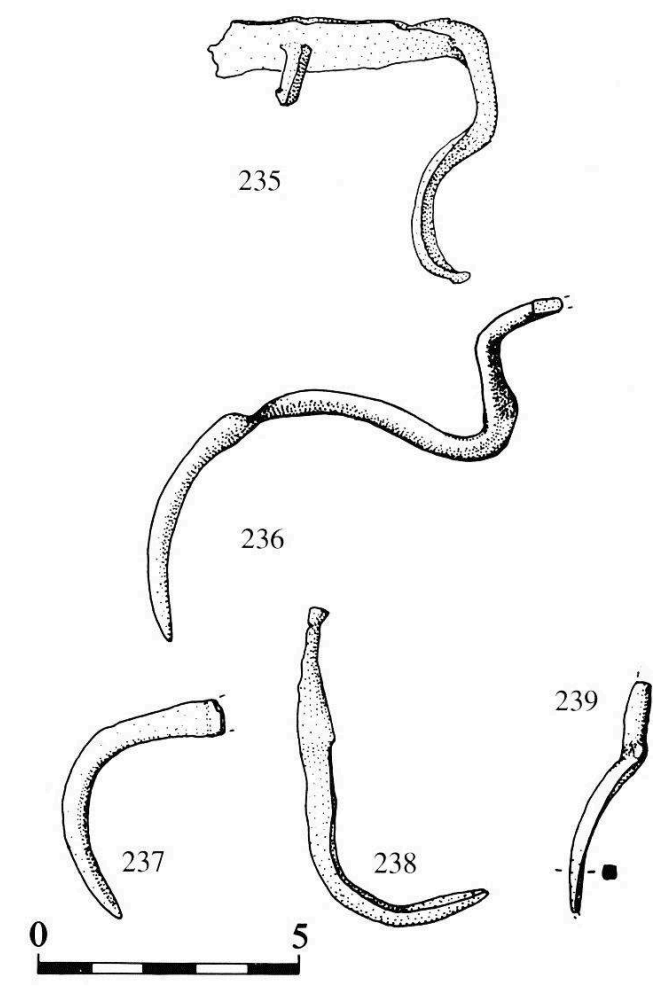

$\mathrm{n}^{\circ} 235$. Fourchette comportant sans doute à l'origine trois dents fixées indirectement sur la tige de liaison.

$n^{\circ} 236$. Grande fourchette ayant conservé une dent à fixation indirecte.

$\mathrm{n}^{\circ}$ 237. Fragment de dent isolée.

$n^{\circ} 238$. Dent isolée ; la tige la reliant à l'autre dent a été tordue.

$\mathrm{n}^{\circ} 239$. Dent isolée indiquant un modèle à fixation indirecte.

Dans la série de fourchettes livrées par La Chuire, on note la présence d'exemplaires intacts alors que d'autres ont été volontairement détruits : la fourchette $\mathrm{n}^{\circ} 222$ montre une torsion volontaire marquée, alors que l'exemplaire $n^{\circ} 223$ comporte une dent volontairement tordue. Un certain nombre de cassures et d'enfoncements observables sur les tiges pourraient éventuellement résulter de chocs volontaires.

Ces objets, bien que sensiblement différents, sont tous des ustensiles de cuisine, liés au service des viandes préalablement bouillies dans des chaudrons ou éventuellement dans certaines céramiques qui en imitent la forme (c'est probablement le cas de la jatte d'Aulnat connue en pays arverne). L'existence à l'époque de La Tène d'ustensiles mixtes, en forme de fourchette à une extrémité et de louche à l'autre, confirme la fonction de ces objets, qui servent à extraire, après la cuisson, la viande bouillie des récipients (Bonnamour 1985 a). D'autres documents, très différents par leur origine et leur chronologie, attestent également cet usage : d'abord, une hydrie ionienne à figures noires, découverte à Caere, montre en détail le déroulement d'un sacrifice animal, des premières manipulations de boucherie à la consommation des viandes. Sur cette frise exceptionnelle, entre le rôtissage des viscères et la mise en place des viandes sur des broches, une scène montre un des officiants sortant à l'aide d'une fourchette (kréagra) des morceaux de viandes d'un lébès où ils ont été cuits, pour les déposer dans un plat 
(Durant 1979: p. 153). Dans un contexte tout autre, un passage de l'épopée irlandaise, datée du XIIe siècle, décrit l'hôtel du roi du Leinster, Mac Dâtho : celui-ci « avait sept portes et sept chemins y passaient; il contenait sept foyers et sept chaudrons. Quiconque passait sur le chemin mettait la fourchette dans le chaudron, et quoi qu'il attrapât du premier coup, il ne recommençait » (Dottin 1980 : p. 52).

Si les auteurs antiques n'ont pas expressément mentionné l'usage de la fourchette lors des banquets celtiques, ils signalent néanmoins la consommation des viandes bouillies dans des chaudrons: tout porte à croire que cet oubli est dû au fait qu'ils en connaissaient l'usage, comme l'indique l'inventaire au IVe siècle av. $n$. è. d'une cuisine grecque où figure une fourchette (Athénée ap. Anaxippus, IV, 169 b). La fonction de la fourchette semble établie, ainsi que son usage à la fois dans le monde celtique et grec. Quant au domaine italique, il connaît un ustensile proche, quoique assez différent dans sa construction : l'harpago, qui serait un crochet à viande en fer ou en bronze. Connu dès le VIIe siècle av. $n$. è. chez les Etrusques, l'harpago apparaît exceptionnellement dans la sépulture hallstattienne sud-alpine de Radkensburg (Slovénie) (Daremberg 1969: p.1112; Egg 1986: Abb. 11-12). L'identification de cet ustensile demeure incertaine, et divers usages non-culinaires sont possibles (porte-bougies ?)

L'histoire de ces ustensiles est très ancienne : des fourchettes sont connues dès le IIe millénaire dans les Kourganes 1 et 2 de Novosvobadnaja (URSS) appartenant à la culture de Koban (Müller-Karpe 1974: Taf. n 686, B, 2). En Europe occidentale, des crocs en bronze (type 23) figurent dans des contextes du Hallstatt A (Mariën 1958: p. 302), puis restent en usage jusqu'au Hallstatt D (Kromer 1959: Taf. 38 et 40 ; Sievers 1984 : Taf. 114, $\mathrm{n}^{\circ}$ 1491). Une fourchette entièrement en bronze (type 21), découverte à Antrim (Irlande), est même datée du Bronze final (Briard 1976 : p. 358, n² 220).

Les fourchettes en fer apparaissent dès le Hallstatt $C$ dans le dépôt de Schorlenberg (Alsenborn, Palatinat, RFA) associées à de l'armement, de l'outillage et des tôles de bronze, vestiges vraisemblables de récipients (chaudron). Un autre exemplaire, daté du VIe siècle av. n. è., provient d'une sépulture aristocratique de cavalier (T. 3) découverte à Court-Saint-Etienne (Belgique) ; il s'agit d'une fourchette du type 1212 (Mariën 1958 : p. 302). Ce contexte atteste l'ancienneté de cette forme bien connue par la suite. Le simple croc en fer (type 13) est connu dès le Hallstatt $\mathrm{D}$, sur le site princier de La Heuneburg (Sievers 1984 : Taf. 193, n²023). Quant à la forme entièrement en fer (type 11), elle semble a priori typique de la culture des oppida (Jacobi 1974) : cependant c'est ce modèle qui paraît figurer sur l'hydrie de Caere datée du VIe siècle av. n. è. Vu les multiples relations entre l'Italie et l'Europe intérieure à la fin du premier âge du Fer, en particulier l'introduction des broches à rôtir et des chenets, on ne peut exclure une date ancienne pour l'apparition du type 11 bien qu'aucun contexte ne l'atteste.

Il apparaît clairement que toute datation précise des fourchettes de La Chuire s'avère impossible : ces ustensiles sont datables de l'âge du Fer et se situent chronologiquement entre le VIe et le Ier siècle av. n. è. Néanmoins, l'étude du mobilier vestimentaire montre la prédominance des objets des IIIe-Ier siècles av. n. è. et on peut raisonnablement envisager une datation analogue pour les fourchettes.

Ces ustensiles sont d'ailleurs plus fréquents durant le second âge du Fer et les contextes de découvertes plus variés. Outre les exemplaires découverts sur les oppida, ces objets sont connus dans des sanctuaires (Schwartz 1975; Déchelette 1914), des dépôts métalliques (Rybová 1983 : p. 150) et plus rarement dans des sépultures (Tendille 1982; Gustin 1984). Quelques pratiques régionales sont même perceptibles: ainsi en 
Provence, le type 121 est majoritaire et figure dans des tombes à incinération du Ier siècle av. n. è., qui livrent aussi des éléments de service à boire ; en Slovénie, le type 13 apparaît dans des tombes de guerriers de La Tène D. Mais la plupart des exemplaires connus proviennent du territoire allobroge. Ainsi, le site de Sainte-Blandine a livré 133 exemplaires et 84 dents isolées du type 13. L'usage de tels ustensiles se perpétue à la période gallo-romaine (Anonyme 1987: p. 100) et jusqu'au Moyen Âge comme le montre la célèbre «tapisserie » de Bayeux dite «de la Reine Mathilde»; sur cette oeuvre de la fin du XIe siècle, on distingue un cuisinier extrayant, à l'aide d'une fourchette, des viandes d'un ustensile de cuisson, avant le festin qui marque l'arrivée de Guillaume Le Conquérant en Angleterre (Wilson 1985 : fig. 47).

On peut se demander dans quelles conditions les fourchettes (et les autres composants du service de table) étaient employés durant la Protohistoire. S'agissait-il d'un usage régulier dans le cadre domestique ou bien ces ustensiles étaient-ils utilisés de façon exceptionnelle, dans des situations particulières? Dans le monde grec, la consommation des viandes est généralement liée au sacrifice des animaux domestiques; une part de la victime (os, graisse) est réservée aux dieux, tandis que le reste est partiellement consommé sur place par les officiants (rôtissage des viscères), puis partagé, bouilli et réservé pour des consommations ultérieures élargies à l'aristocratie guerrière. De telles pratiques alimentaires sont aussi mentionnées dans un cadre politique, lors de la fondation de colonies. En Grèce, la cuisson par ébullition des viandes et la consommation de celles-ci sont donc des pratiques consécutives aux sacrifices, dont elles perpétuent le sens (Détienne 1977; Détienne 1979: p. 20; Bouloumié $1988:$ p. 346).

Cette situation perçue dans le monde grec est-elle valable pour le domaine celtique ? En premier lieu, les pratiques alimentaires entre les deux cultures sont certainement très différentes et l'importance du poisson dans l'alimentation est bien connue en Grèce (Bats 1988: p. 38), alors qu'elle est certainement plus marginale en Europe continentale : a priori, les deux situations sont donc difficilement comparables.

Pourtant, dans les sources antiques concernant les Celtes, la cuisson par ébullition est toujours mentionnée lors de consommations "conviviales", réunissant l'aristocratie guerrière autour d'un hôte souvent royal, qui se terminent par des querelles, puis des luttes pour des raisons de préséances, liées au non-respect du partage hiérarchisé des viandes (cf. les sources réunies dans Bats 1988: p. 211-213). La même structure se retrouve dans les sources plus tardives de l'épopée irlandaise (cf. la suite du récit sur Mac Dâtho dans Dottin 1980), bien que dans ce cas, il semble que la coutume imposée lors de l'arrivée des convives ait eu pour but de répartir d'une façon aléatoire les meilleurs morceaux cuits dans le chaudron. D'autres mentions dans la littérature médiévale irlandaise signalent aussi l'importance de ce type de cuisson lors de rites qui se déroulent avant une élection royale (Le Roux 1986: p. 76-77); ces mêmes sources indiquent par ailleurs la consommation du bouillon de cuisson qui est attestée à l'âge du Fer par les ustensiles mixtes (fourchette-louche) d'Alésia et de Montbellet.

Les contextes archéologiques n'apportent pas d'information sur le mode d'utilisation des fourchettes; tout au plus peut-on signaler leur relative rareté sur les oppida, pour le moins curieuse s'il s'agissait d'un objet fréquemment employé dans un cadre domestique. Cependant, il est possible que cet ustensile ait pu être remplacé par de modestes louches en bois, comme le propose M. Bats (Bats 1988 : p. 216). L'existence, au demeurant rare, de fourchettes dans des contextes « cultuels » mérite cependant d'être 
signalée. Le seul objet découvert dans l'un des puits du Viereckschanze d'Holzhausen est justement une fourchette à chaudron; ces enceintes quadrangulaires ont été rapprochées des structures décrites par Poseidonios dans un passage relatant un banquet offert par un roi arverne (Berger 1963 : p. 2628).

$\mathrm{Au}$ vu de ces différentes sources, il est difficile d'assigner à la fourchette à chaudron témoin matériel de la consommation des viandes cuites par ébullition-une fonction quotidienne dans un cadre domestique. Les analogies entre les domaines grec et celtique sont assurément multiples et permettent d'envisager pour cet ustensile des usages particuliers. D'ailleurs, la cuisson par ébullition implique une consommation des viandes fraîches, avec comme préalable l'abattage peu de temps auparavant des animaux d'élevage. Alors que d'autres façons de consommer les viandes sont connues dans l'Antiquité (salaisons, fumage) et signalées chez les Celtes, ce type d'alimentation peut être envisagé dans un cadre collectif du type banquet qui peut prolonger des pratiques religieuses : un passage de Phylarque concernant un banquet chez les Galates mentionne d'ailleurs les sacrifices préalables au repas.

\section{Accessoires de foyer, (fig. 58-59)}

$\mathrm{n}^{\circ}$ 240. Tisonnier en fer incomplet (fig. 58).

Tige de section carrée sur la moitié de sa longueur conservée. L'extrémité de la tige s'épaissit puis la section devient circulaire. L'objet est orné de torsades comme le sont les fourchettes à chaudron.

58- Tissonnier en fer

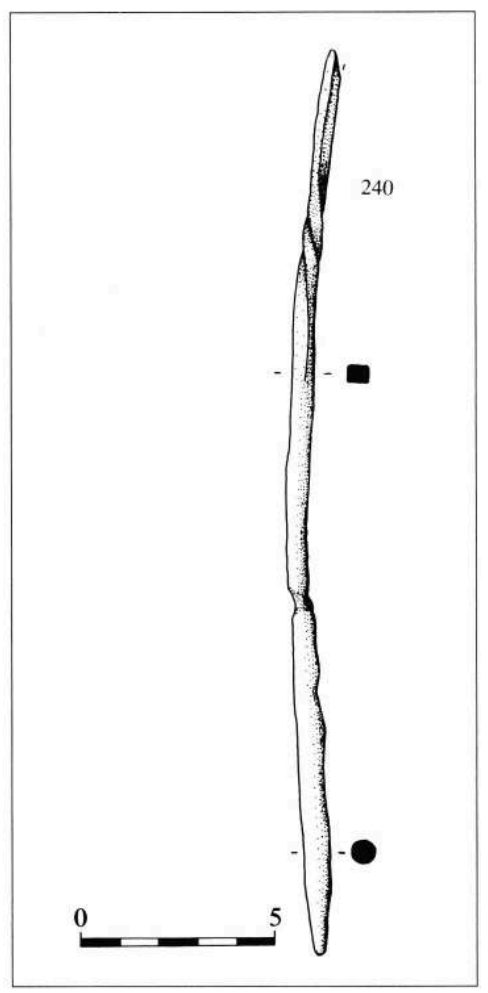

On peut identifier ce fragment comme l'extrémité distale d'un tisonnier. Ce type d'ustensile est connu dès le premier âge du Fer et plusieurs exemplaires proviennent du site de La Heuneburg (Sievers 1984 : Taf. 186). D’autres formes différentes, datées de 
La Tène, sont attestées dans les oppida, à Manching (Jacobi 1974), et sur des habitats ouverts à Feurs (Guichard 1988 : p. 156, fig. 126, nº 13).

$n^{\circ} 241$. Coupe-bûches en fer complet (fig. 59).

L'outil massif possède une lame tendue, s'élargissant progressivement, recourbée et tronquée à son extrémité. La soie courte présente un épaississement marqué avant le début de la lame.

59- Coupe-bûches en fer

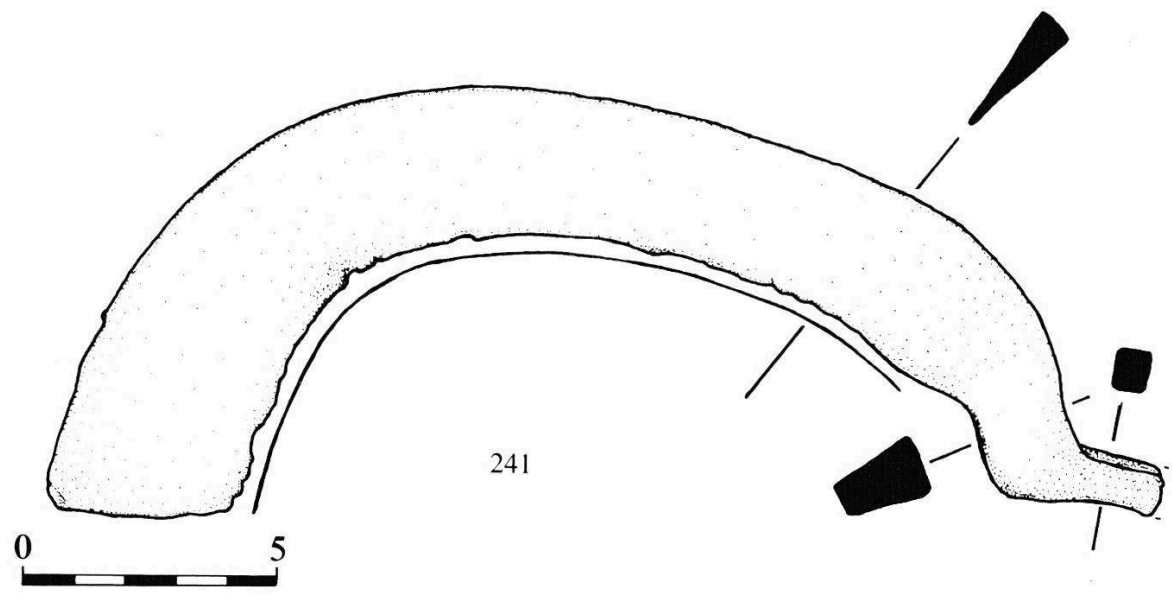

L'outil évoque un coupe-bûches, utilisé avec un percuteur métallique frappant le dos de l'outil ; si l'indentification est correcte, on aurait alors affaire à un accessoire de foyer.

Situles, seaux et passoires (fig. 60-66)

310 Plusieurs fragments se rapportent à des récipients en bois (seaux); quelques objets appartiennent cependant à la vaisselle métallique (situles, passoires). Tous ces récipients sont utilisés pour contenir des liquides et certains sont liés à la consommation du vin.

311 Un premier groupe réunit des fragments appartenant probablement à des situles (fig. 60). 
60 - Anses en fer de situles

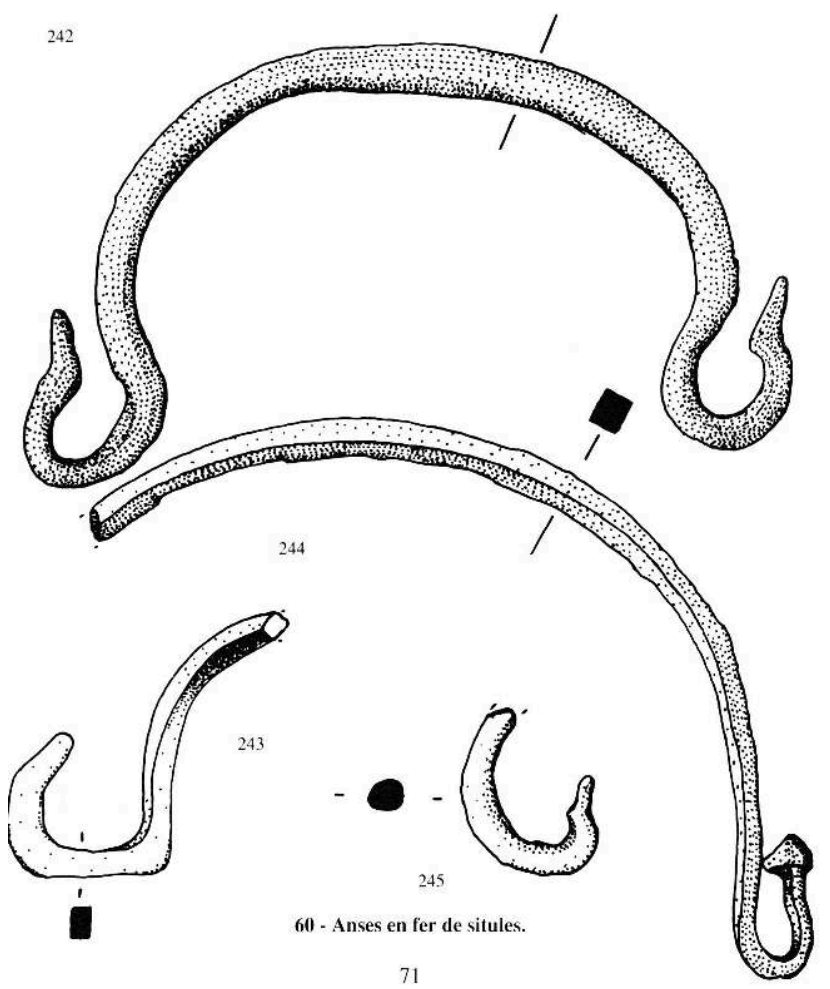

$312 n^{\circ} 242$. Anse en fer complète.

Anse en forme d'oméga, de section circulaire ; les deux extrémités sont grossièrement ornithomorphes. Le diamètre du récipient, déduit de la largeur de l'anse, indique que cette suspension se rapporte plutôt à une situle qu'à un chaudron.

$313 n^{\circ} 243$. Fragment d'anse en fer.

L'objet a une section quadrangulaire et présente une torsion marquée.

$314 n^{\circ} 244$. Anse en fer incomplète.

Celle-ci est en forme d'arc de cercle de section quadrangulaire. L'extrémité conservée est terminée par un bouton conique, replié régulièrement contre la partie de préhension. Vu ses dimensions conservées $(115 \mathrm{~mm})$, l'anse se rapporte sans doute plus à une situle qu'à un chaudron.

$315 n^{\circ} 245$. Fragment d'anse en fer.

Cette dernière, légèrement déformée, possède une extrémité grossièrement ornithomorphe.

316 Ces quatre anses en fer semblent se rapporter toutes à des situles plutôt qu'à des cistes, des chaudrons ou des seaux. Les situles en tôle de bronze à anse mobile sont attestées dès le VIIIe siècle av. n. è. en Etrurie (Tarquinia) ; ces récipients sont ensuite présents jusqu'à l'époque romaine. Bien que dès le début du second âge du Fer des anses mobiles en fer soient exceptionnellement signalées (Bouloumié 1977 : p. 8 et 10), il est probable que les fragments de La Chuire appartiennent à des situles plus tardives (Déchelette 1914 : p. 1443-1444).

317 Plusieurs fragments sont des pièces métalliques appartenant à des seaux en bois : soit des attaches d'anses, soit des cerceaux en tôle de bronze. 
$\mathrm{n}^{\circ} 246$. Fragment d'attache en fer de seau (fig. 61).

Il s'agit d'une plaque rectangulaire, comportant un emplacement de rivet. L'aspect de l'extrémité de l'objet montre que l'attache devait comporter un anneau disparu.

61- Attaches en fer de seaux en bois

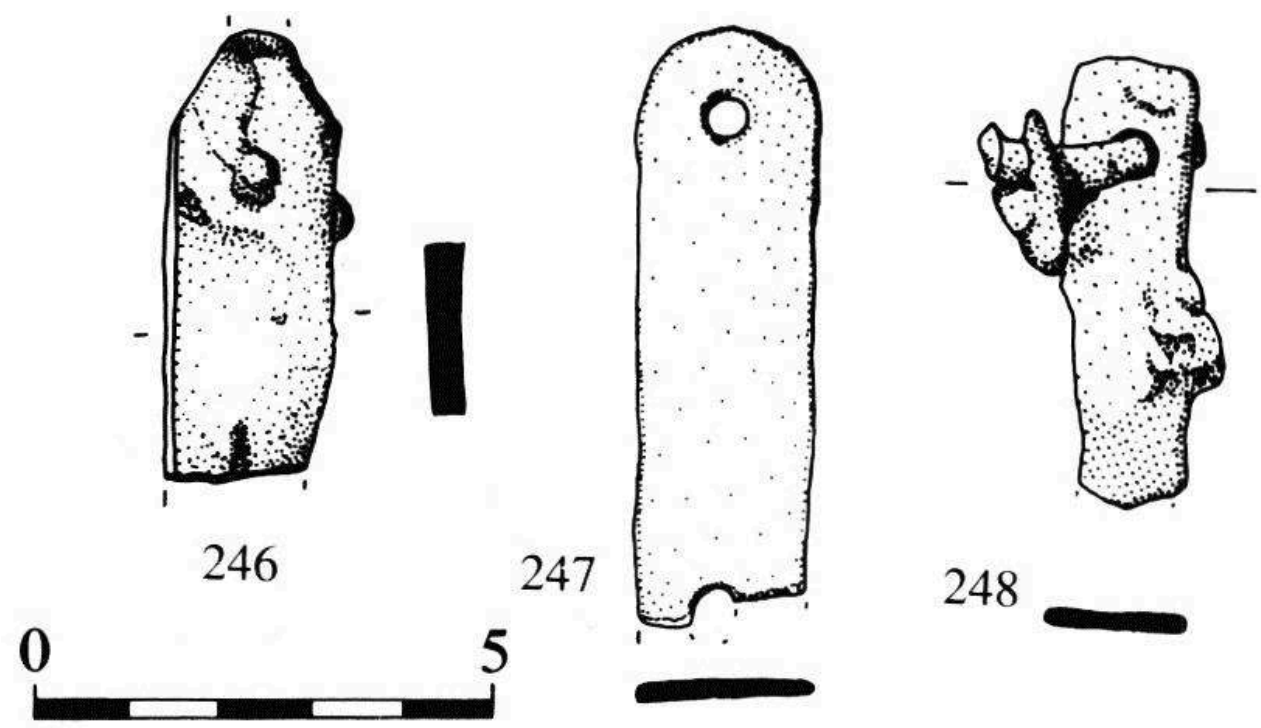

$\mathrm{n}^{\circ}$ 247. Fragment d'attache en fer de seau.

Plaque rectangulaire arrondie à une extrémité et comportant deux perforations destinées à la mise en place des rivets. Les seaux de l'âge du Fer les mieux conservés montrent que ce type d'attache était fixé par paire de chaque côté d'une douve.

$\mathrm{n}^{\circ}$ 248. Paire d'attaches maintenues par un rivet, appartenant au même type que le $\mathrm{n}^{\circ} 247$.

$n^{\circ} 249$. Attache en fer complète (fig. 62).

Elle est formée à partir d'une tige de section rectangulaire et terminée par un anneau. La pièce a encore conservé deux rivets en place. Elle est repliée volontairement vers son milieu. L'attache pouvait être insérée dans une ouverture façonnée dans une des douves du récipient, puis martelée, pour être repliée contre cette dernière. Le fait que l'extrémité de l'attache ne dépasse pas la base de l'anneau et laisse libre le passage de l'anse confirme cette reconstitution. 
62- Attache en fer de seau en bois
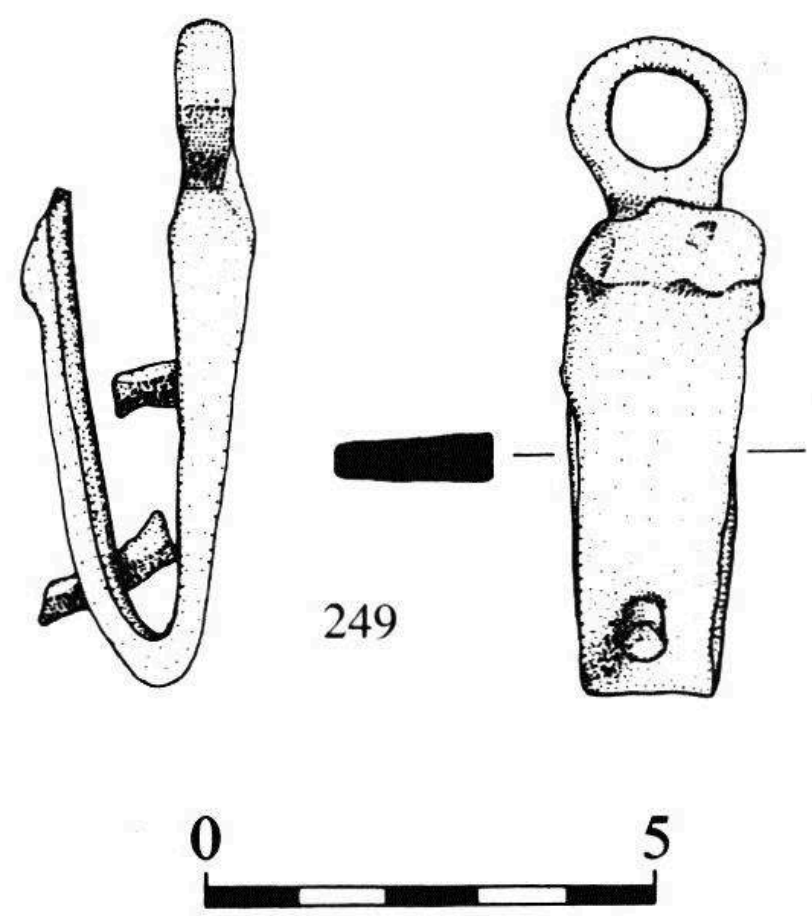

$\mathrm{n}^{\circ}$ 250. Attache en fer de seau (fig. 63).

Celle-ci est constituée d'une tige fine de section rectangulaire, terminée par un anneau. Elle devait être insérée de force dans une des douves du récipient.

63- Attaches en fer de seaux en bois

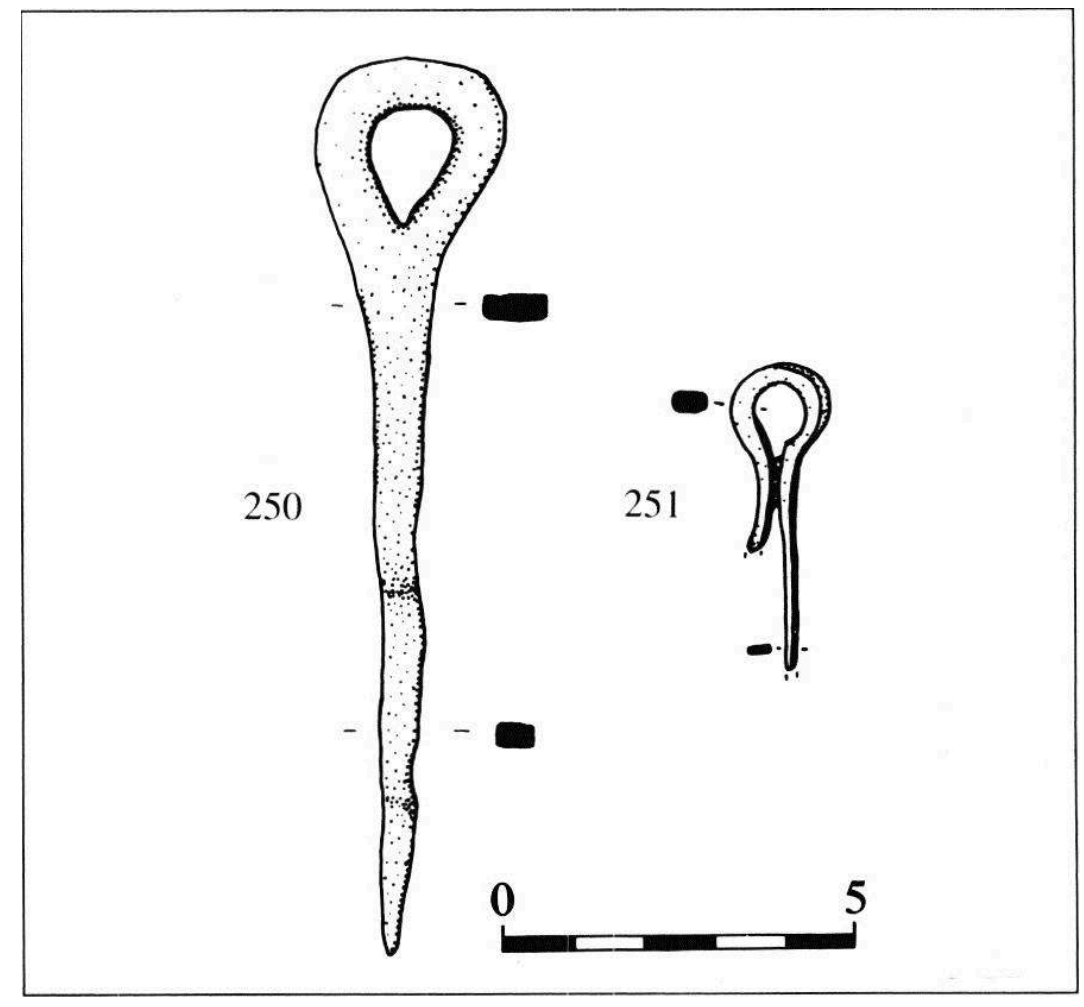


$\mathrm{n}^{\circ}$ 251. Attache en fer incomplète.

Cette dernière est formée d'une tige repliée sur elle-même et cintrée pour obtenir un anneau.

Ces fragments permettent d'identifier un minimum de cinq seaux. Si certaines de ces attaches appartiennent à des récipients destinés au service du vin $\left(\mathrm{n}^{\circ} 248\right)$, d'autres $\left(n^{\circ} 250\right)$ pourraient plutôt être des pièces de seaux ou baquets utilitaires, analogues à certains exemplaires découverts dans des puits. Ceux de Vieille-Toulouse (Baulaguet) et de Toulouse (Saint-Roch) (Haute-Garonne) sont datés du Ier siècle av. n. è. (Anonyme 1982 : p. 18 ; Anonyme 1988 : p. 42-43).

$\mathrm{n}^{\circ} 252$. Fragment de cerceau en bronze (fig. 64).

Il s'agit d'une tôle décorée de deux côtes rectilignes obtenues au repoussé. Le fragment, bien que sans courbure, est certainement un cerceau de seau en bois.

64- Cerceaux en tôle de bronze de seaux en bois
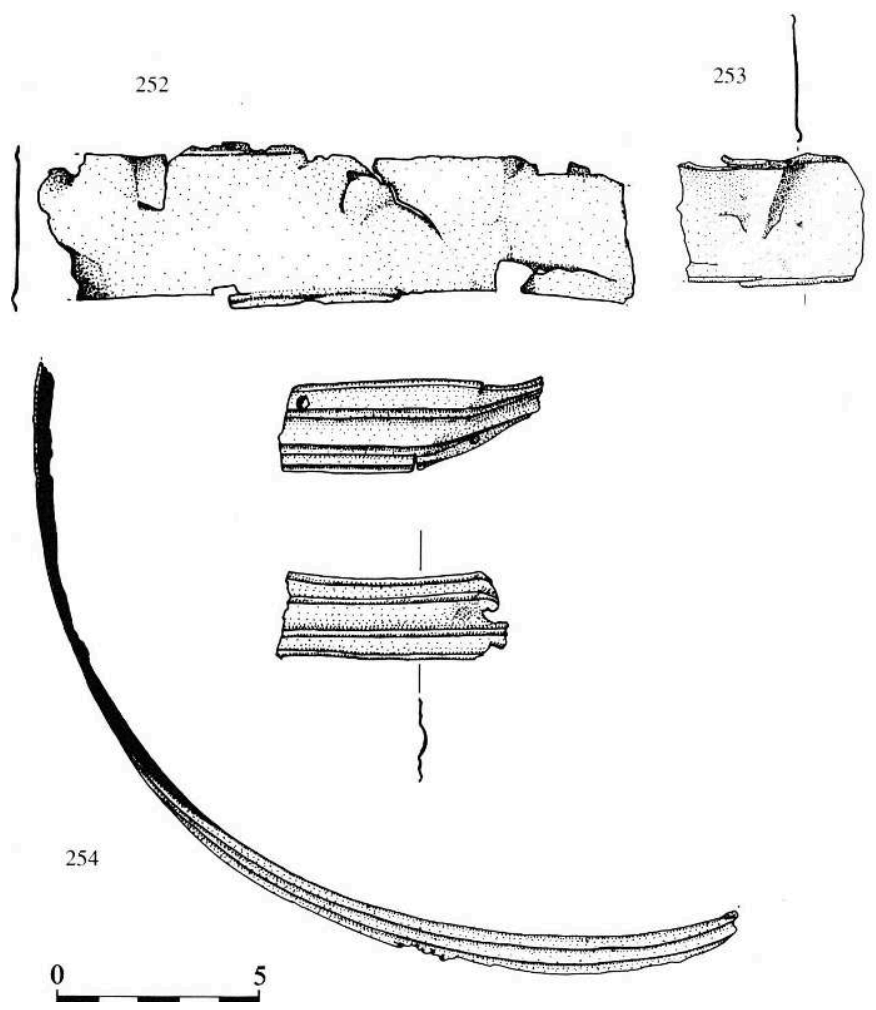

$n^{\circ}$ 253. Cerceau de seau identique au précédent.

$n^{\circ} 254$. Cerceau de seau, en bronze et en fer.

Cet exemplaire est formé d'une tôle de bronze, ornée d'une moulure médiane encadrée par deux moulures plus étroites. Il était fixé sur les douves par de petits clous en fer disposés alternativement sur les deux bords de la tôle.

Les seaux en bois à cerceaux métalliques en bronze sont connus en Etrurie dès le VIT siècle av. n. è. En Gaule, si le seau de la sépulture 3 de Tartigny (Oise) est attribuable au début de La Tène C, la plupart des découvertes datent de La Tène D (Rapin 1986 : p. 59-78 ; Vidal 1976 : p. 167-200 ; Feugère 1985 b : p. 71-78). L'usage de tels récipients perdure jusqu'à l'époque mérovingienne, où les seaux sont bien attestés, toujours dans des sépultures aristocratiques (Perrin 1981). 
Pour ce qui concerne le second âge du Fer, les seaux sont représentés dans le mobilier des oppida, mais aussi dans certaines tombes aristocratiques de la fin de La Tène, où ils sont accompagnés par d'autres récipients liés à la consommation du vin. Aucun cerceau de La Chuire ne permet d'identifier des seaux luxueux ornés au repoussé, cependant l'alternance de tôles non décorées et de tôles décorées est reconnue sur certains récipients. Le seau est l'un des composants des services à boire diversement constitués dans la culture des oppida. Comme les situles, il s'agit de vases pour lesquels on peut envisager un usage cérémoniel, lié à la consommation du vin. Les seaux de La Chuire ne sont pas isolés et régionalement plusieurs fragments de cerceaux ainsi qu'une anse figurent dans le mobilier de Sainte-Blandine.

Les passoires, destinées à filtrer le vin, ne sont représentées que par trois fragments (fig. 65).

65- Fragments de doigtier et de pouciers de passoires en bronze

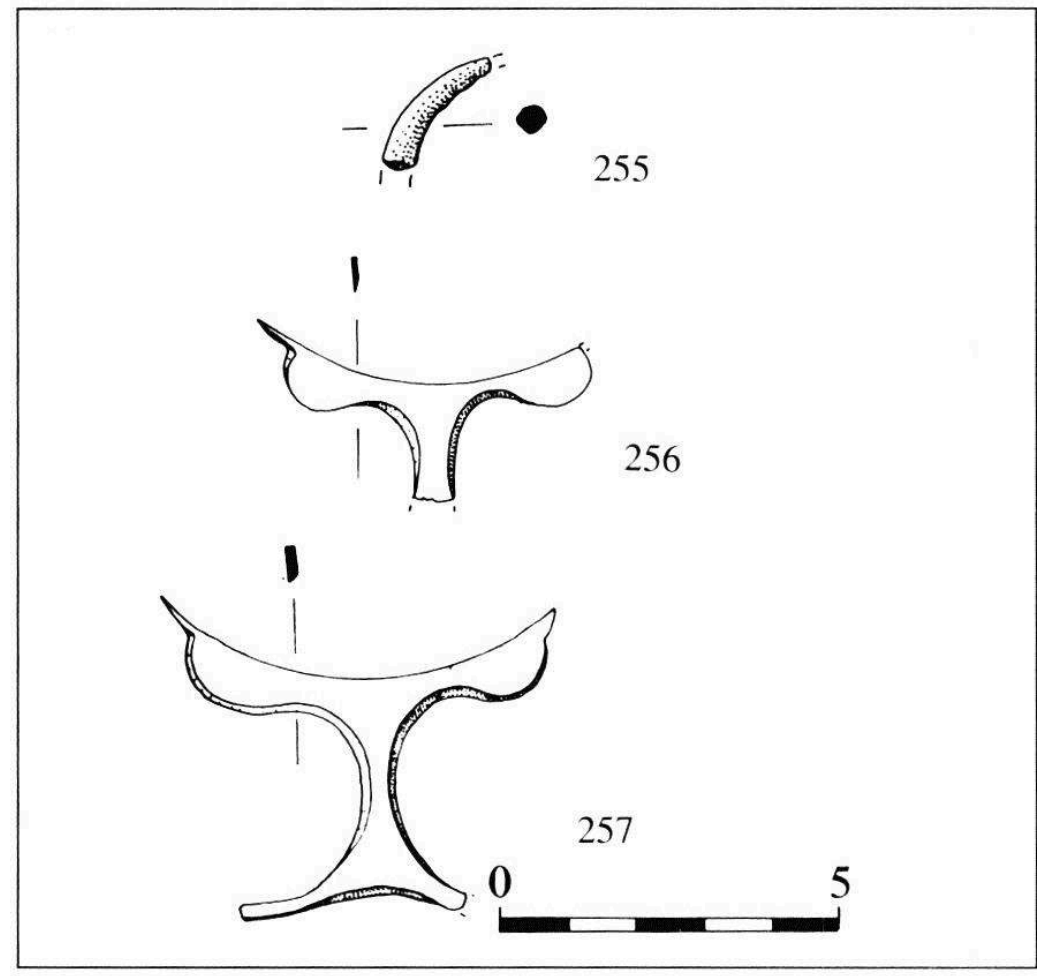

$\mathrm{n}^{\circ} 255$. Fragment de doigtier en bronze?

Il s'agit d'une petite tige courbe, de section losangique, s'amincissant à une extrémité.

$\mathrm{n}^{\circ}$ 256. Poucier en bronze incomplet (fig. 66).

$n^{\circ} 257$. Poucier en bronze complet. 


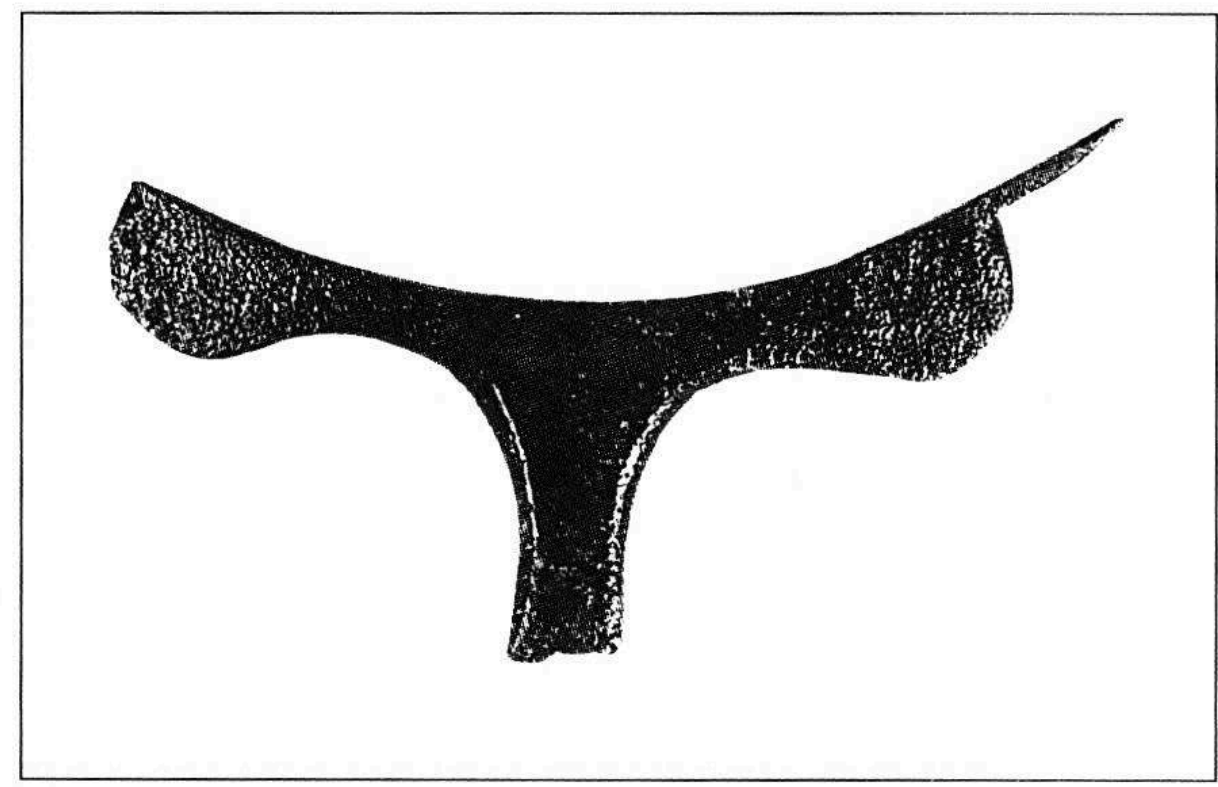

Comme sur l'exemplaire précédent, les deux extrémités des branches sont schématiquement en forme de tête d'oiseau. La face interne du poucier montre deux traces de brasure, qui assuraient la fixation du poucier sur le bord de la vasque.

Les passoires, comme les autres formes de récipients métalliques, sont attestées en Italie dès le VIIIe siècle av. n. è. (Ridgway 1979 : p. 428, fig. 3, n 1), mais ces vases en bronze munis de poucier apparaissent surtout au nord des Alpes dans des contextes du second âge du Fer (Guillaumet 1977 : p. 240-249). Ces récipients sont essentiellement représentés dans le mobilier des oppida et figurent plus rarement dans des sépultures (Christlein 1964: p. 16). Régionalement, plusieurs exemplaires ont été découverts à Sainte-Blandine.

\section{L'outillage agricole}

Quelques outils se rapportent aux travaux agricoles et aux activités traditionnelles dans un mode de vie rural; celles-ci sont d'ailleurs représentées par des faisselles et un fragment de catillus de meule. On peut classer les outils agricoles en deux groupes, selon la forme de leur extrémité, qui peut être soit en pointe, soit tronquée.

\section{Serpes et faucilles (fig. 67-68)}

$\mathrm{n}^{\circ} 258$. Serpette en fer complète.

L'outil (fig. 67) comprend une soie longue de section rectangulaire, recourbée à son extrémité pour assurer la fixation d'un manche en bois. Ce dernier était maintenu par une virole, encore en place sur la soie. La lame, peu épaisse, est en forme d'arc de cercle se terminant en pointe. Le tranchant montre une usure marquée due au réaffûtage : il ne s'agit donc pas d'un outil neuf. 
67 - Serpette

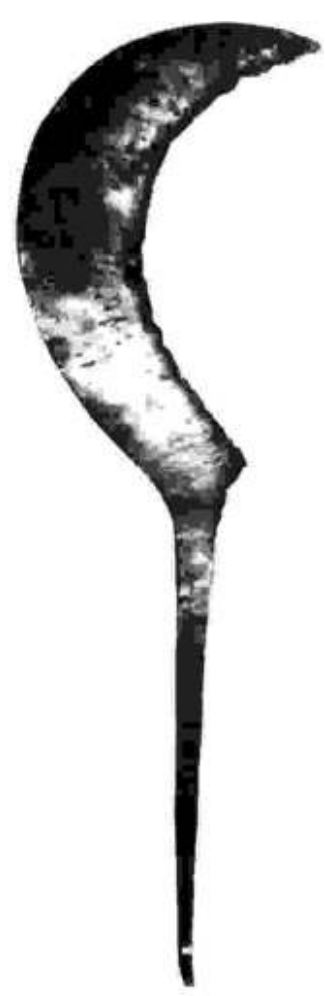

339 Les dimensions de l'outil évoquent plutôt une serpette qu'une faucille dont la lame est en général plus étroite et longue.

$340 n^{\circ}$ 259. (fig. 68) Faucille en fer complète.

La lame fine est en forme d'arc de cercle, s'amincissant vers son extrémité pour se terminer en pointe. La fixation du manche est assurée par deux rivets, renforcés par deux contre-rivets quadrangulaires. Le tranchant montre des traces d'usure dues à l'utilisation. 
68- Serpes et faucille en fer

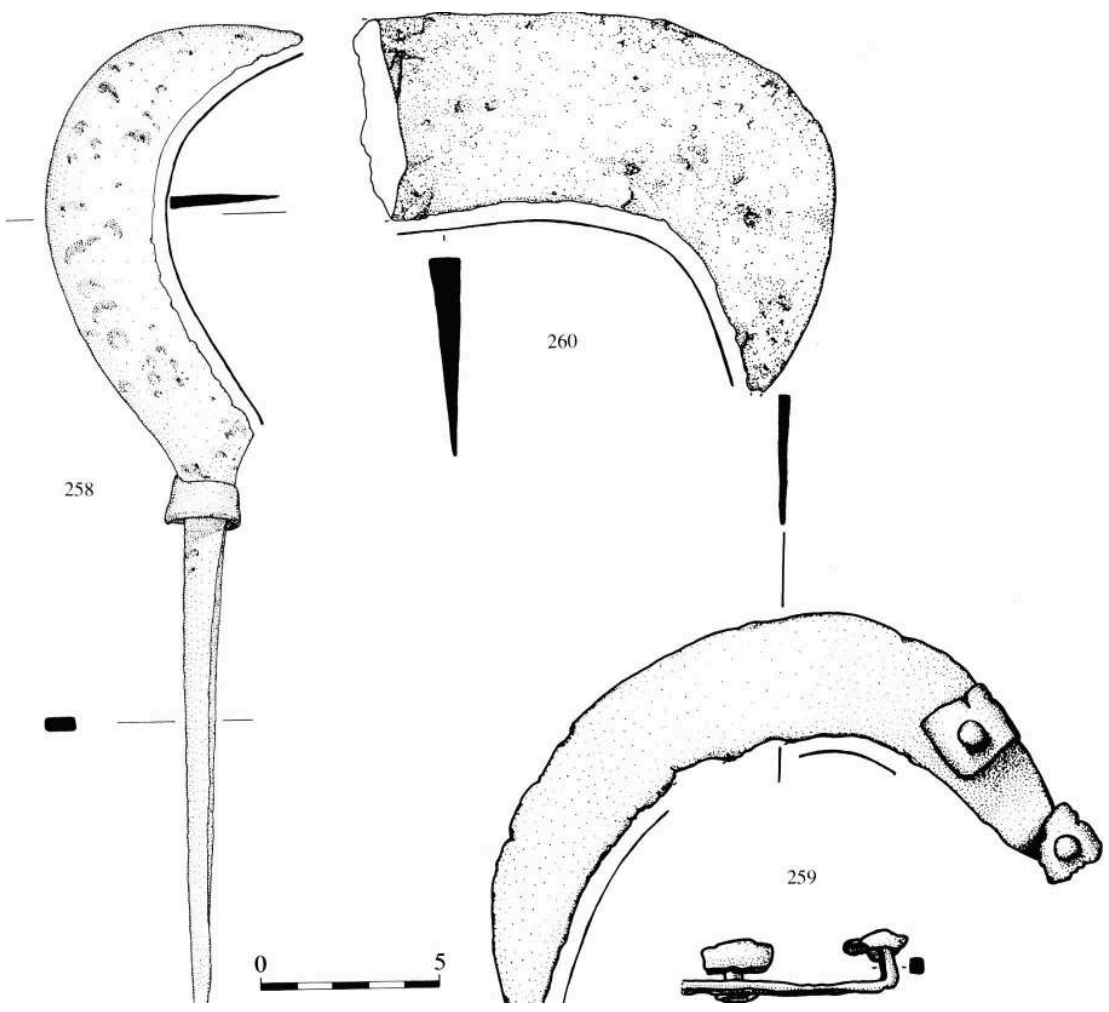

Cette forme d'outil agricole n'est pas représentée dans la culture des oppida ; par contre un exemplaire très proche est connu dans le dépôt d'époque gallo-romaine de Mengen (Baden-Württemberg, RFA) (Spitzing 1984). Au vu de la rareté des documents postérieurs à La Tène dans la faille de La Chuire, on pourrait envisager l'hypothèse d'une forme d'origine italique, comme cela semble le cas pour d'autres types d'outils. $\mathrm{n}^{\circ} 260$. Fragment de serpe en fer.

La lame est massive, recourbée et terminée en pointe.

343 Ce type d'outil est connu dans le mobilier de Sainte-Blandine (Chapotat 1970 : pl. XV, $\mathrm{n}^{\circ}$ 11) ainsi que dans le probable lieu de culte de Corneaux-les-Sauges (Schwab 1973: p. 68).

Ebranchoirs (fig. 69) et faux (fig. 70-71)

$344 \mathrm{n}^{\circ} 261$. Outil en fer complet.

Celui-ci comprend une longue soie à section rectangulaire s'amincissant à son extrémité. La lame est large, en forme d'arc de cercle, tronquée à son extrémité ; le dos possède un ergot tranchant situé au début de celle-ci.

$345 \mathrm{n}^{\circ} 262$. Outil en fer complet.

Si la forme générale de cet exemplaire évoque l'objet précédent, il en diffère par une extrémité située dans le même plan que la soie. Celle-ci est massive, de section quadrangulaire, possédant encore un anneau destiné à renforcer la fixation du manche. La lame est large, en forme d'arc de cercle. Sa section diminue progressivement et son extrémité est tronquée. 


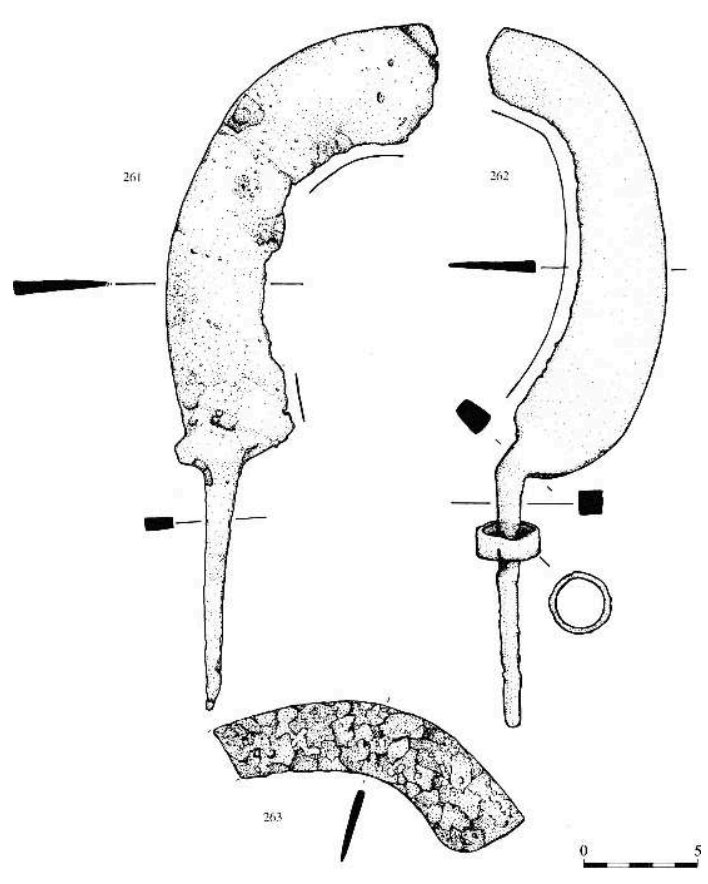

Ces outils massifs (fig 69) possèdent une longue soie droite qui devait s'insérer dans un manche long. Il s'agit probablement d'ébranchoirs destinés à l'élagage des arbres. Des outils proches sont attestés dans l'habitat celto-italique de Monte Bibele (prov. de Bologne, Italie) occupé du IVe siècle av. n. è., jusqu'au tout début du IIe siècle av. n. è. ; d'autres exemplaires figurent dans la série métallique de Sainte-Blandine (Dall'Aglio 1981 : p. 163 ; Chapotat 1970 : pl. XV, n 12-13). $n^{\circ} 263$. Fragment de lame en fer.

En forme d'arc de cercle et à l'extrémité tronquée, cet outil est beaucoup plus gracile que les précédents : de fait, son identification n'est guère assurée. $\mathrm{n}^{\circ}$ 264. Lame de faux en fer (fig. 70-71).

Cette dernière est complète. Faiblement incurvée et large, elle est tronquée à son extrémité. La fixation du manche était assurée par un clou massif. La lame est repliée sur elle-même à un peu plus de son milieu ; la torsion réalisée est d'environ $180^{\circ}$; elle a probablement été obtenue à chaud, vu la largeur du dos de l'outil. Le tranchant est extrêmement usé, alors que ce type d'outil ne fait pas l'objet d'une utilisation quotidienne ; son emploi nécessite cependant des rectifications fréquentes de la partie coupante (martelage et réaffûtage). L'outil, peu corrodé, témoigne donc d'une longue durée d'utilisation. 
70- Lame de faux déformée
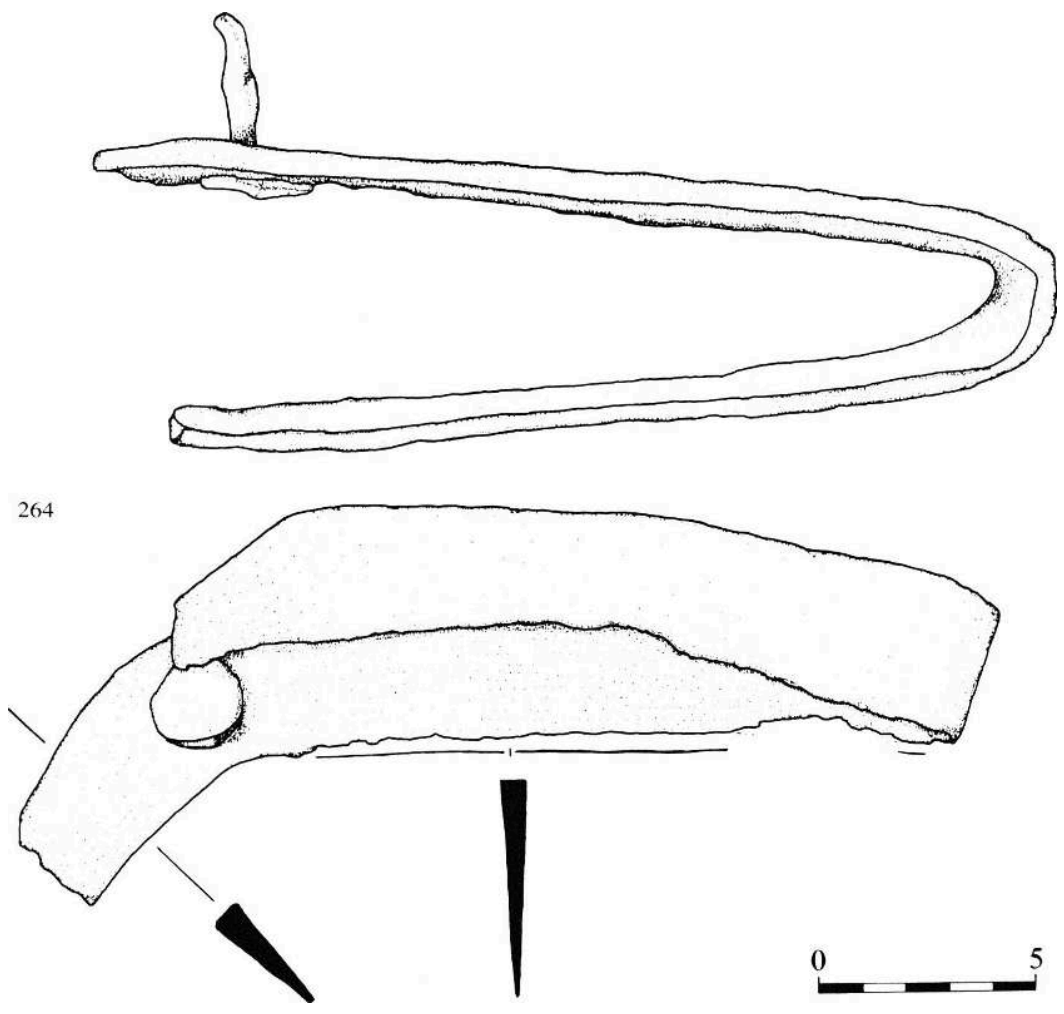

71- Lame de faux

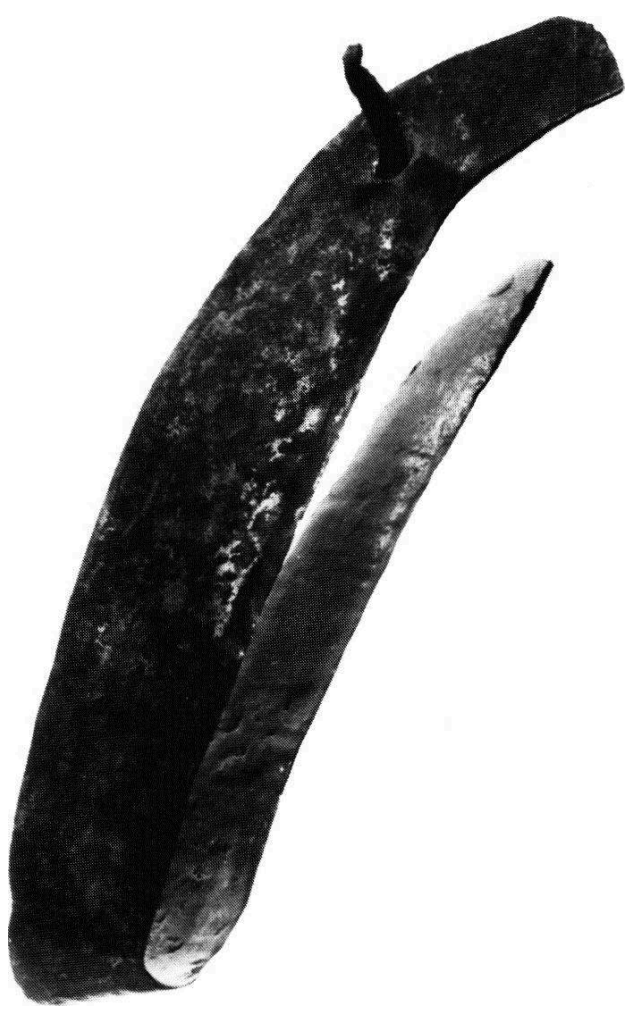

349 Il s'agit d'une lame d'outil lancé, tranchant par percussion, certainement d'une faux courte. L'emploi de celle-ci lors de la récolte des céréales n'est attesté que tardivement, 
à l'époque médiévale (Sigaut 1988 : p. 27) ; concernant l'âge du Fer, il faut donc lier cet outil à la coupe des fourrages (foin) et à la présence de prairies. Toutefois, il est possible que la faux ait été employée pour la coupe du chaume destiné à la couverture des toitures et à la confection des litières. En plus de son utilisation dans des activités agricoles, la faux a également été utilisée comme arme, montée sur des chars de combat: cet emploi très particulier est mentionné dans les sources antiques et la littérature médiévale irlandaise (Markale 1971: p. 101). Ce type d'outil apparait au second âge du Fer dans le mobilier des oppida (Stradonice) mais aussi dans certains contextes funéraires (Déchelette 1914 : p. 1380-1382), des sanctuaires (Brunaux $1985 \mathrm{~b}$ : p. 122) et des dépôts métalliques (Paulik 1976: Tab. XLII, nº 1; Rybová 1983. Abb. 12, $\mathrm{n}^{\circ}$ 1). Le site éponyme de La Tène a livré à lui seul 22 lames de ces outils (Egloff 1980 : p. 144). L'exemplaire de La Chuire n'est pas isolé puisque deux autres faux ont été découvertes en territoire allobroge, à Sainte-Blandine et dans la sépulture de Vernas à Saint-Romain de Jalionas (Chapotat 1970 : pl. XV, n 2 ; Guillaumet 1986).

L'outillage agricole n'est donc que très peu présent dans le mobilier de la faille de La Chuire. Quelques types d'outils sont absents, par exemple les socs métalliques d'araires. Tous les outils montrent des traces nettes d'usure; quelques uns sont complets et seule la faux témoigne d'une torsion volontaire.

\section{L'outillage artisanal et domestique}

351 Ce type d'outillage forme une série quantitativement importante. Ces outils se rapportent soit à des activités artisanales et domestiques (travaux du métal, du bois, de l'os, du textile...), soit à des activités de la vie quotidienne rurale (élevage, pêche). A quelques exceptions près, presque tous ces objets sont en fer.

\section{Travail du bois et de l'os (fig. 72-83)}

$\mathrm{n}^{\circ}$ 265. Hache complète (fig. 72-73).

Celle-ci possède une douille carrée nécessaire à la fixation du manche ; une perforation, destinée au passage d'un clou de renfort, est d'ailleurs visible sur la partie supérieure de l'objet. Le corps de ce dernier adopte une forme triangulaire et son tranchant est rectiligne. 
72- Hache à douille en fer

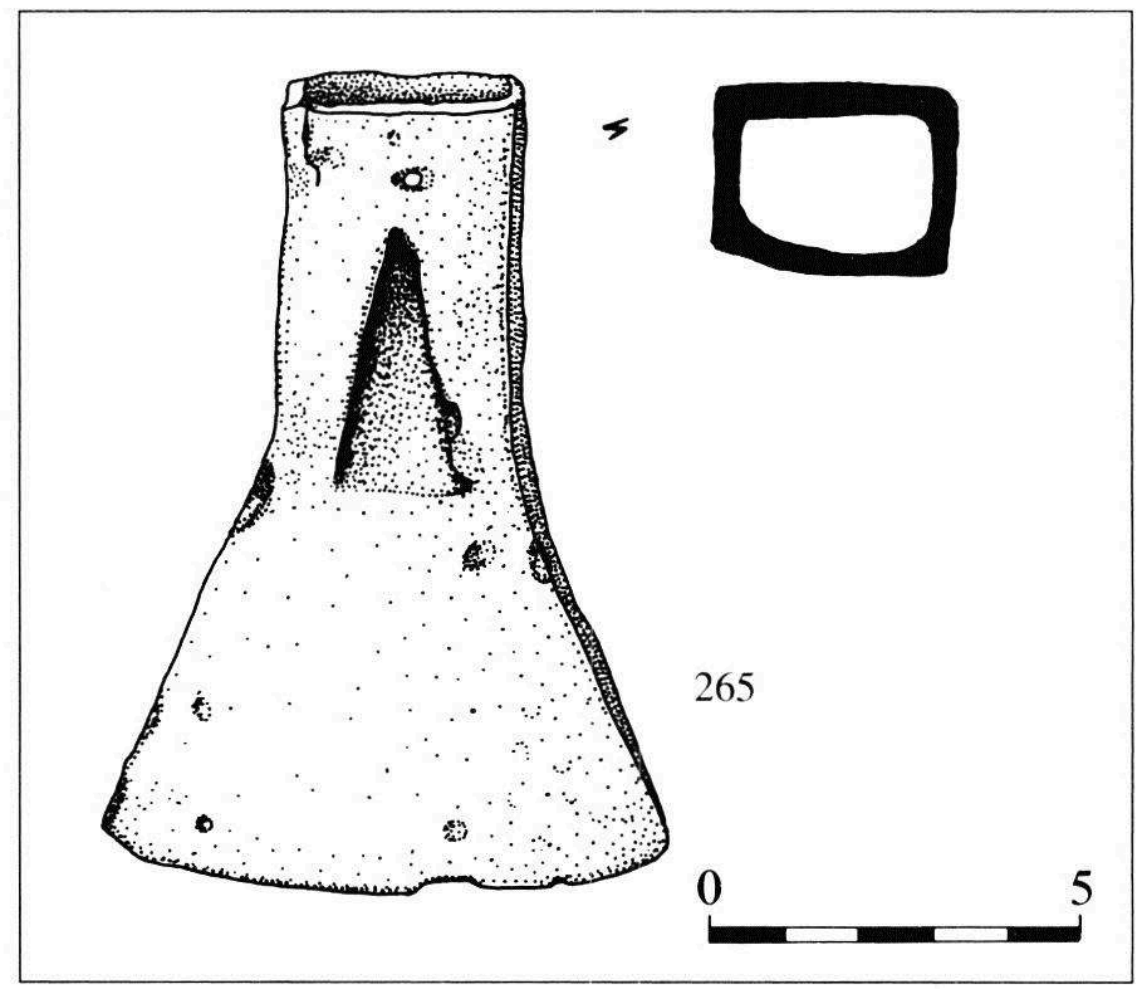

73- Hache

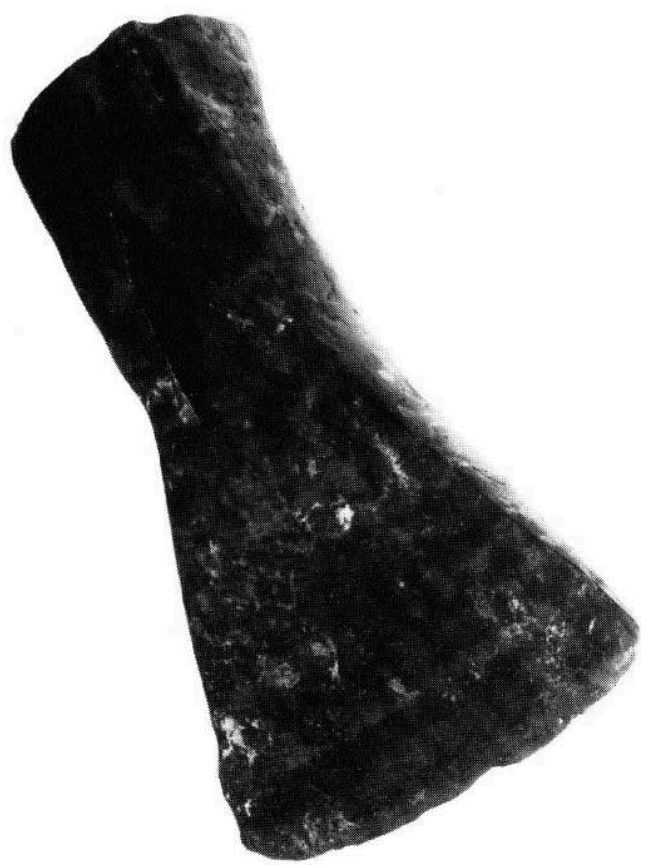

La hache est un outil destiné à la coupe et aux travaux du bois, qui est attesté dès le premier âge du Fer. au Mont-Lassois et à La Heuneburg. Cependant, cet objet est 
également présent dans certaines sépultures aristocratiques et princières, datées du Hallstatt C et D (Oss en Hollande, Hochdorf, Pontecagnano T. 4461 en Italie) où figurent des coutelas; il semble que dans ces contextes particuliers, on ait affaire à des instruments utilisés pour l'abattage sacrificiel du bétail, tel qu'il était pratiqué dans l'Antiquité, plutôt qu'à de l'outillage (Bouloumié 1988; Cerchiaï 1988: p. 104). Si la hache, du moins certaines formes, a été aussi utilisée comme arme, comme le montre la frise qui orne un ceinturon de Vace (Brunaux 1986 c : p. 57), la majeure partie des objets découverts sur les oppida du second âge du Fer (Manching, Heidetrânk, Stradonice, Entremont) est assurément de l'outillage ; une fonction identique est retenue pour les exemplaires provenant de dépôts métalliques (Rybová 1983).

$\mathrm{n}^{\circ}$ 266. Scie complète (fig. 74-75).

Elle est constituée d'une soie plate traversée par deux rivets, dont un a encore conservé son contre-rivet. La lame est légèrement courbe ; l'extrémité montre un dos abattu. Les dents sont triangulaires, fines et serrées. Leur disparition partielle indique l'usure de l'outil. La scie est brisée en trois endroits, sans qu'il soit possible de préciser s'il s'agit d'un bris volontaire ou accidentel (cf. un bris identique dans Guillaumet 1982 : p. 195).

74- Scie en fer

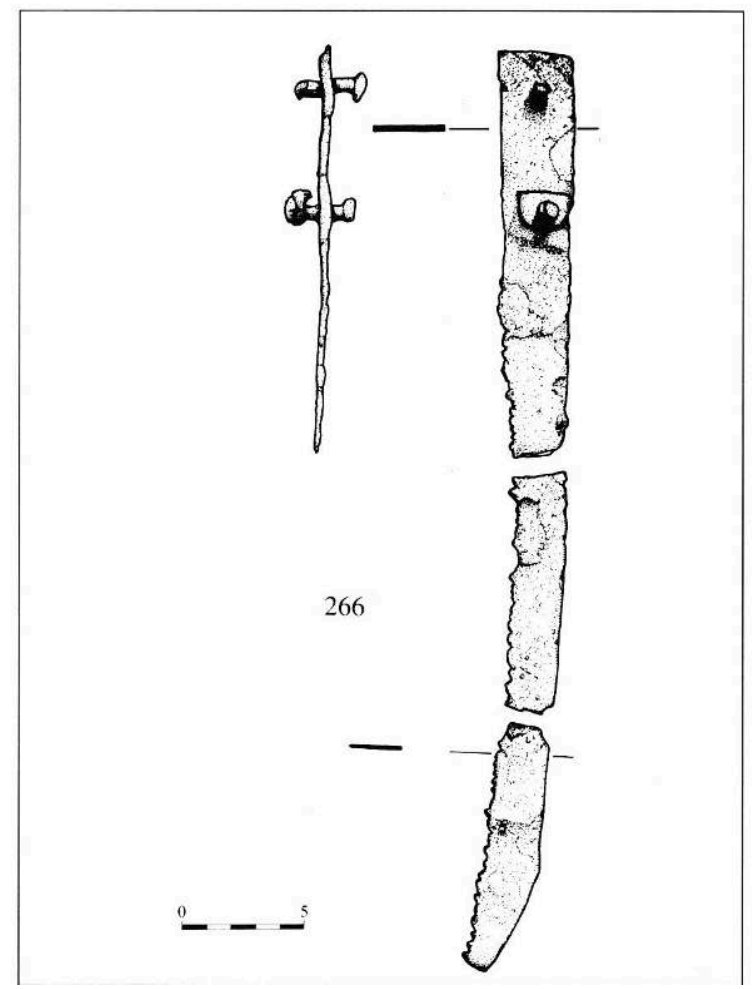




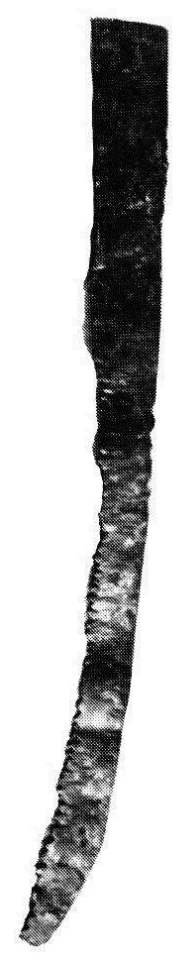

La fonction de l'objet est incertaine; il peut s'agir soit d'un outil lié à un artisanat (menuiserie), soit d'un objet en relation avec certains travaux agricoles, comme la taille des arbres. Ce type de scie égoïne est attesté dès le Hallstatt D, à La Heuneburg (Sievers 1984). Dans le Sud de la Gaule, il figure dans des contextes datés de la fin du IIe siècle av. n. è. à la période augustéenne (Tendille 1982: p. 38). Une autre forme de scie, possédant une lame très courbe, existe également dans le mobilier de la culture des oppida, à La Tène, Manching, Villeneuve-Saint-Germain (Aisne) et Sainte-Blandine (Vouga 1923 : p. 117 ; Jacobi 1974: Taf. 24; Debord 1982: p. 247; Chapotat 1970 : pl. XIV). Ce type d'outil est surtout présent dans les habitats, mais il faut rappeler sa présence dans le tumulus de Celles (Cantal), pour lequel on ne peut exclure une interprétation funéraire: ce site, probablement du IIIe siècle av. $n$. è. a livré de l'outillage, ainsi que de l'armement et des attaches en fer fréquentes dans le mobilier des tombes à char (Guillaumet 1982). $\mathrm{n}^{\circ}$ 267. Plane en fer (fig. 76).

L'outil est constitué d'une lame à dos arqué. Son manche est étroit, possédant deux emplacements de rivets, dont un situé sur la lame; celle-ci forme un angle droit avec l'axe du manche. 
76- Plane en fer

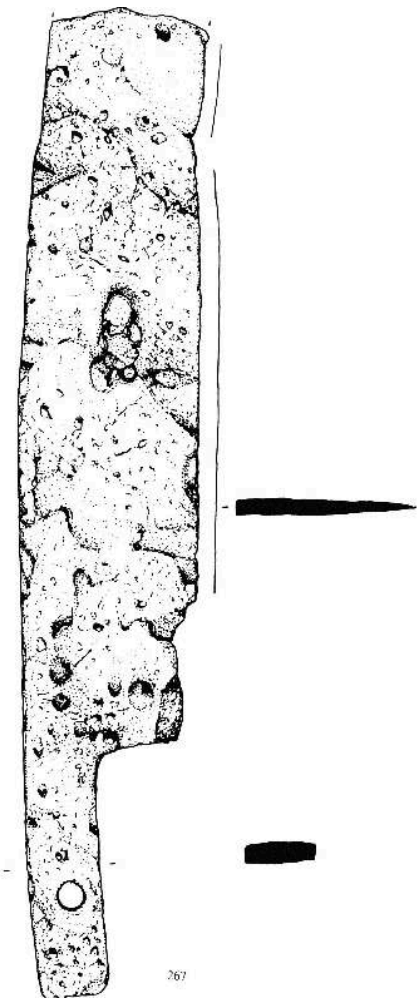

357 L'objet est incomplet et l'extrémité manque ; sa forme rappelle certains outils : soit une plane de douvier utilisée par les tonneliers, soit un outil à écharner les peaux employé par les tanneurs (Veter 1976 : p. 398-399).

$358 \mathrm{n}^{\circ} 268$. Outil complet.

Outil très proche du suivant comprenant un manche terminé par une partie repliée à angle droit. L'extrémité de la lame consiste en une tige de section circulaire.

$359 \mathrm{n}^{\circ} 269$. Outil complet (fig. 77).

L'outil comporte une partie de section quadrangulaire terminée par un crochet. La partie active de l'objet comprend une lame recourbée à angle droit, s'enroulant sur elle-même à son extrémité. L'outil, comme le précédent devait être utilisé en tension sur anneau fixé sur une planche ; la partie recourbée servant de préhension. 


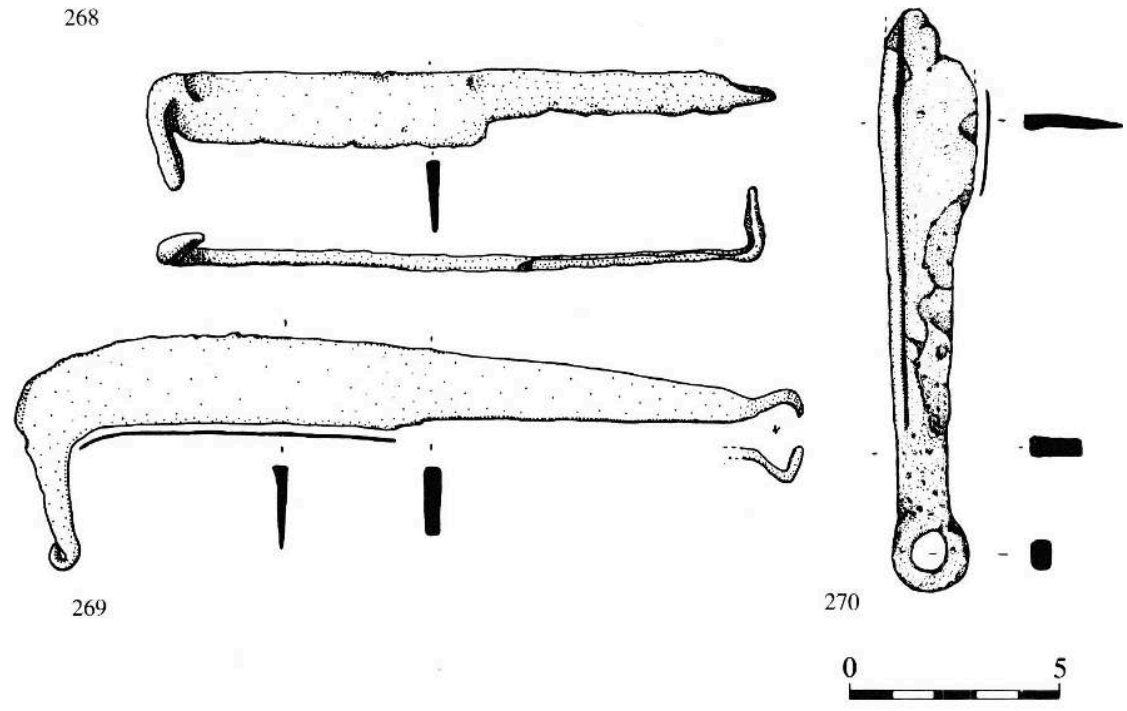

$\mathrm{n}^{\circ} 270$. Outil incomplet.

L'objet comporte un manche de section rectangulaire terminé par un anneau. La lame possède un dos épaissi, légèrement convexe. Il s'agit peut-être d'un outil du même type que les précédents, mais la forme de l'objet rappelle aussi celle d'un rasoir.

Ces outils évoquent par leur mode d'utilisation supposé les paroirs de sabotiers qui sont cependant nettement plus grands ; la fabrication des sabots n'est d'ailleurs connue qu'à partir de l'époque gallo-romaine (Ciceron: De Inventione, 2, 149; Goudineau 1980 : p. 311, n²37). Il s'agit certainement d'outils liés aux travaux du bois, sans qu'il soit possible de préciser leur fonction.

$\mathrm{n}^{\circ}$ 271. Gouge complète (fig. 78-79).

L'outil est constitué d'une tige de section quadrangulaire terminée à une extrémité par une soie recourbée. La partie active de l'objet est formée d'un tranchant à bord relevé. 
78- Gouge en fer

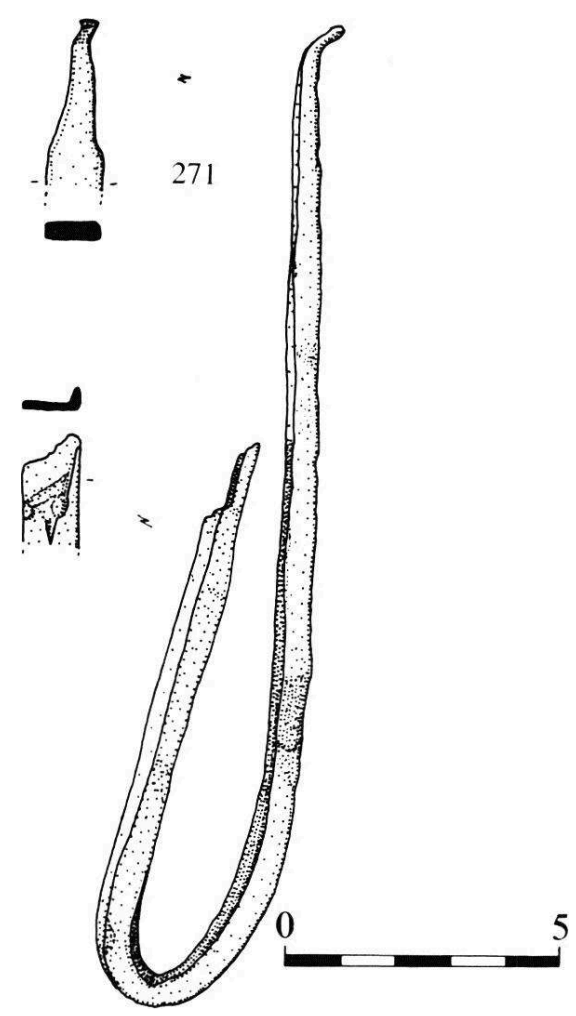

79- Gouge déformée

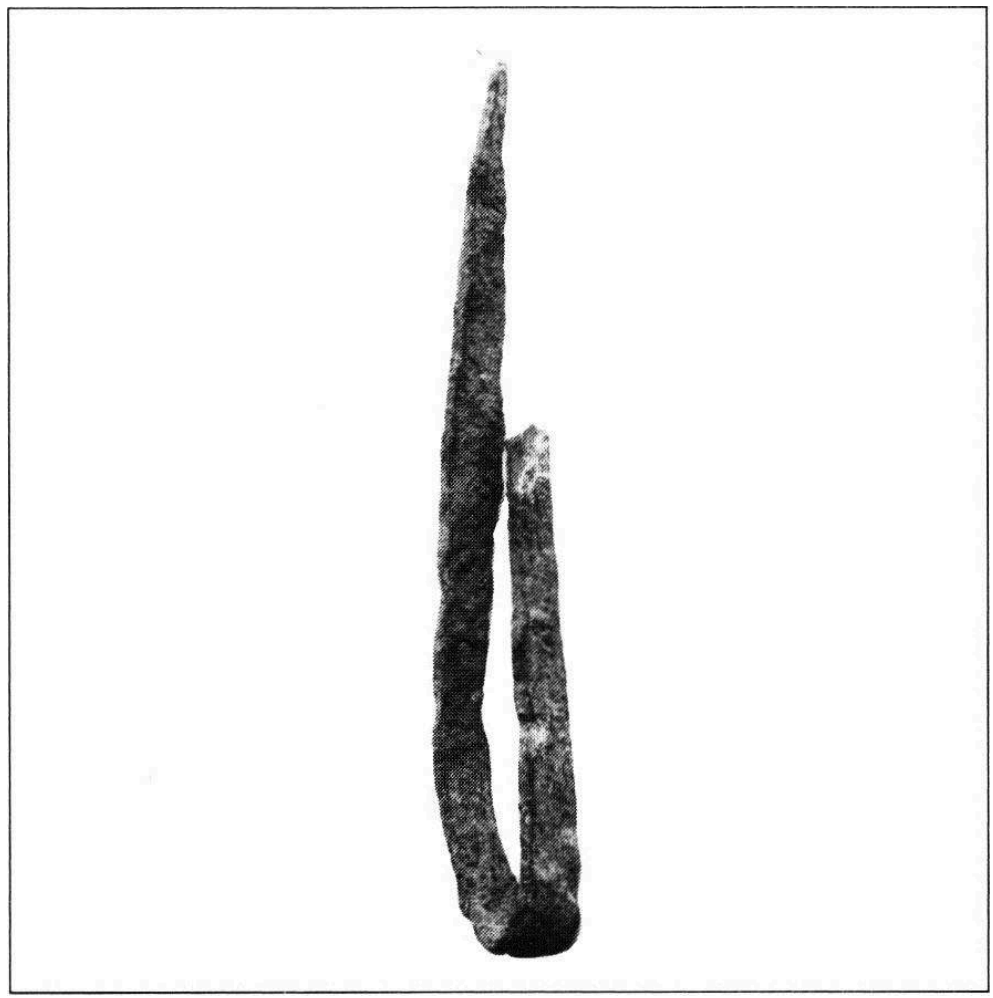

On peut identifier l'outil comme étant une gouge destinée à travailler le bois, le long manche permettant d'accéder à des endroits étroits. L'outil a été volontairement replié 
sur lui-même, après une rotation de la tige d'environ $180^{\circ}$. Des objets comparables figurent dans la trousse d'artisan découverte sur le site de La Tène (Vouga 1923).

$n^{\circ}$ 272. Râpe complète (fig. 80).

L'outil comprend une soie de section quadrangulaire, coudée successivement deux fois, pour se terminer par une partie de section plan-convexe. Sur la partie bombée sont visibles plusieurs entailles parallèles formant des dents.

80- Râpe en fer

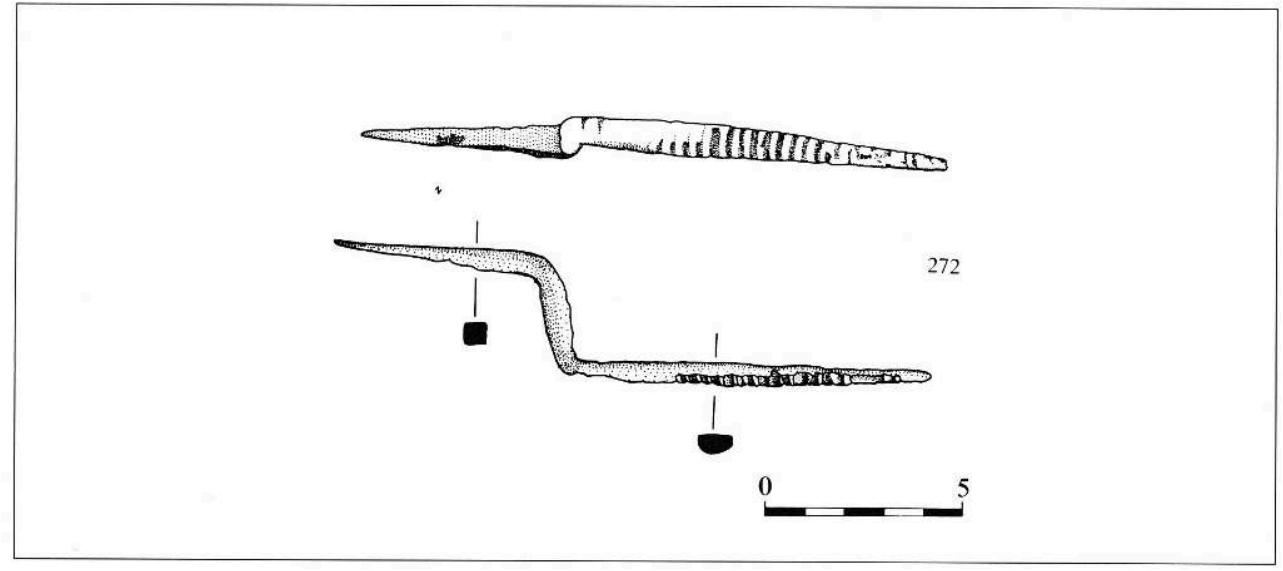

De telles râpes, déjà connues au Hallstatt D (La Heuneburg), se rapportent peut-être au travail du tablettier-cornetier ; un exemplaire sensiblement différent découvert sur le site du premier âge du Fer de Lyon-Vaise (Gorge-de-Loup) était associé à des déchets d'un atelier travaillant la corne ${ }^{4}$. Ces formes figurent par la suite dans le mobilier des oppida, par exemple à Heidetränk (Müller-Karpe 1977).

$366 \mathrm{n}^{\circ}$ 273. Ciseau complet (fig. 81).

Le corps de l'objet est de section rectangulaire; il se prolonge par une partie évasée et un tranchant oblique. Il s'agit d'un ciseau sans doute destiné aux travaux du bois. 


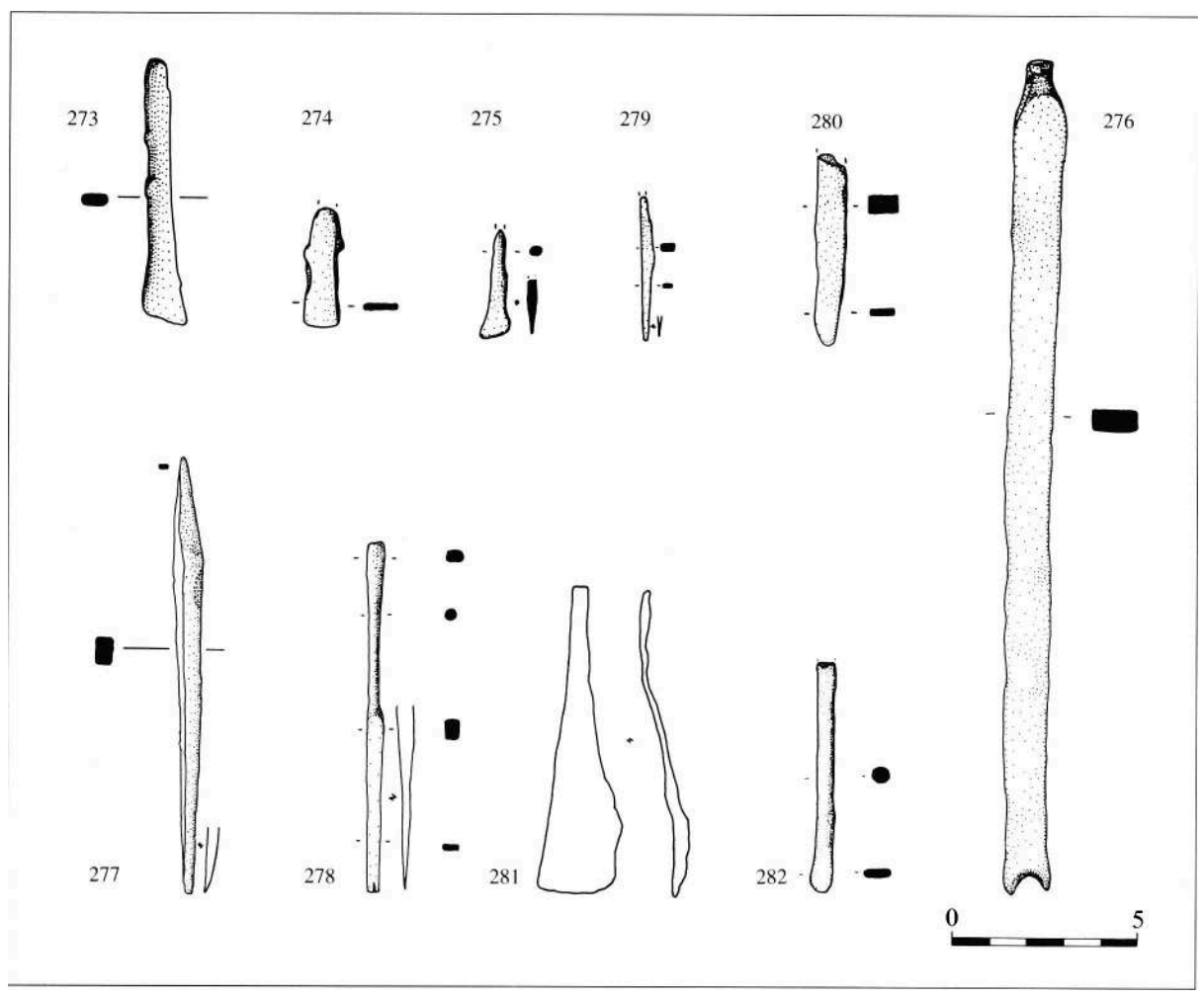

$\mathrm{n}^{\circ}$ 274. Ciseau ( ?) incomplet de section très aplatie.

$\mathrm{n}^{\circ} 275$. Ciseau incomplet.

Ce dernier est constitué d'une tige de section approximativement ovale, prolongée par une partie évasée terminée par un tranchant oblique.

$\mathrm{n}^{\circ}$ 276. Outil complet.

Il est formé d'une tige de section rectangulaire, terminée à une extrémité par une soie massive. La partie fonctionnelle de l'objet prend la forme de deux ergots, dégageant un tranchant en arc de cercle.

$\mathrm{n}^{\circ} 277$. Ciseau complet.

Celui-ci est formé d'une tige de section quadrangulaire. L'outil possède une soie représentant environ un tiers de sa longueur totale. Après un épaississement de la section destiné à bloquer le manche, la tige se prolonge pour former un tranchant étroit légèrement courbe. Il s'agit probablement d'un ciseau à bois.

$n^{\circ} 278$. Outil complet.

L'outil possède un manche de section quadrangulaire à son début, devenant circulaire ensuite. Après un épaississement marqué de la section, qui devient de nouveau rectangulaire, la partie active de l'outil adopte un profil biseauté pour former un tranchant étroit et rectiligne.

$\mathrm{n}^{\circ} 279$. Minuscule ciseau incomplet.

Formé d'une tige de section rectangulaire dont l'extrémité tranchante adopte une profil biseauté; on note un épaississement de blocage qui caractérise les outils à manche en matière périssable rapporté.

$\mathrm{n}^{\circ} 280$. Fragment de ciseau.

Sa section est rectangulaire ; quant au tranchant, il adopte une forme convexe. 
$\mathrm{n}^{\circ} 281$. Outil complet.

Il comprend une soie courte, prolongée par une lame ondulée à l'extrémité tranchante rectiligne.

Il s'agit d'un outil à bois, adapté à la sculpture de ce matériau. Cette forme est attestée dès le VIe av. n. è. à La Liquière (Calvisson, Gard) (Deyts 1983 : pl. CXXI, a-b ; Py 1984 : p. 64 , fig. $43, \mathrm{n}^{\circ} 10$ ).

$\mathrm{n}^{\circ} 282$. Ciseau incomplet.

Ciseau formé d'une tige de section circulaire, se prolongeant par une partie évasée et un tranchant courbe.

L'outil est constitué d'une tige de section circulaire, appointée de façon dissymétrique à son extrémité.

82- Poinçons à bois en fer

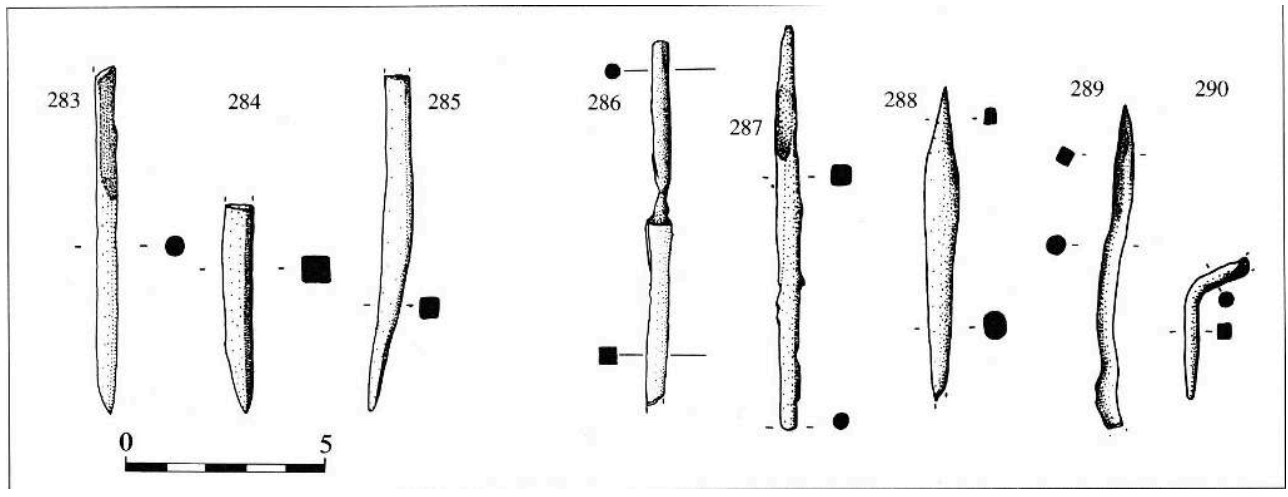

$\mathrm{n}^{\circ}$ 284. Fragment de poinçon.

Sa section est carrée et son extrémité appointée de façon dissymétrique.

$\mathrm{n}^{\circ} 285$. Fragment de poinçon.

Outil de section carrée dont l'extrémité est dissymétrique.

$380 \mathrm{n}^{\circ} 286$. Outil incomplet.

Celui-ci possède une soie de section circulaire prolongée par une tige de section carrée.

287. Outil incomplet.

La soie de ce dernier est courte, de section carrée; elle se prolonge par un corps de section circulaire.

$n^{\circ} 288$. Outil massif incomplet.

Sa soie courte et pointue précède un corps de section ovale, s'amincissant progressivement.

$383 \mathrm{n}^{\circ} 289$. Outil incomplet.

Celui-ci, au corps de section circulaire, comprend une soie de section losangique.

$384 n^{\circ}$ 290. Fragment d'outil.

Tige de section variable, carrée puis circulaire. L'outil, sans doute un poinçon, a été plié selon un angle d'environ $40^{\circ}$.

$\mathrm{n}^{\circ}$ 291. Outil incomplet (fig. 83).

Il se compose d'une tige de section circulaire, terminée à une extrémité par une douille, 
également circulaire. L'autre extrémité montre une courbure régulière de la tige. La partie active manque et il est donc difficile de préciser la fonction de l'objet.

83- Outil à douille en fer

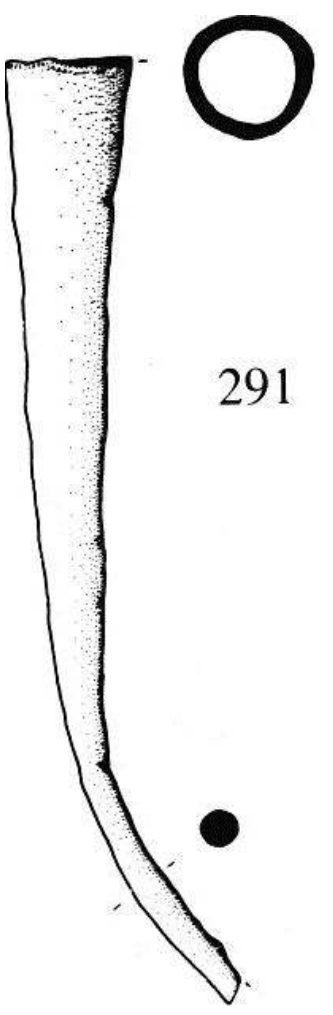

La forme rappelle les boutoirs de sabotiers, utilisés pour finir l'intérieur de l'objet. On peut seulement supposer que cet outil est utilisé dans le travail du bois, pour évider des pièces massives. Ces formes apparaissent au premier âge du Fer, puis se multiplient dans la culture des oppida ; le site d'Heidetränk a livré un outil à extrémité coudée très proche de l'exemplaire de La Chuire. Quant aux ciseaux droits à douille, ils sont également représentés dans le mobilier des oppida ainsi que régionalement dans le matériel de Sainte-Blandine (Müller-Karpe 1977 ; Chapotat 1970).

\section{Travaux du cuir et des textiles (fig. 84-90)}

Les forces, premier type d'outil en rapport avec ces activités, sont représentées par quatre exemplaires. Elles correspondent aux ciseaux actuels, mais la forme archaïque est restée en usage jusqu'à nos jours dans les activités liées à l'élevage : par exemple, dans le Massif Central où cet outil, conservé emballé dans du tissu, est utilisé pour les tontes annuelles de la fin du printemps. 
84- Forces de drapier en fer

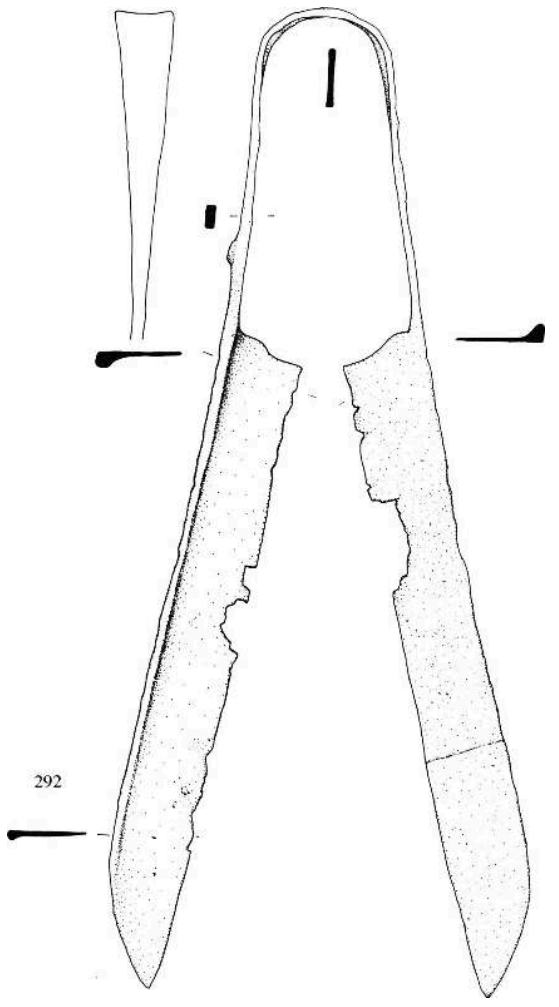

$n^{\circ} 292$. Forces complètes (fig. 84-85).

Constituées d'une tige aplatie en U servant de ressort, prolongée par deux lames, ces dernières possèdent un rebord marqué empêchant leur croisement lors de l'utilisation de l'outil.

$389 n^{\circ} 293$. Extrémité de lame de forces (fig. 86).

$390 n^{\circ} 294$. Fragment de ressort et lame de forces de petites dimensions.

$391 \mathrm{n}^{\circ} 295$. Autre fragment de lame de forces ( ?) 
85- Forces

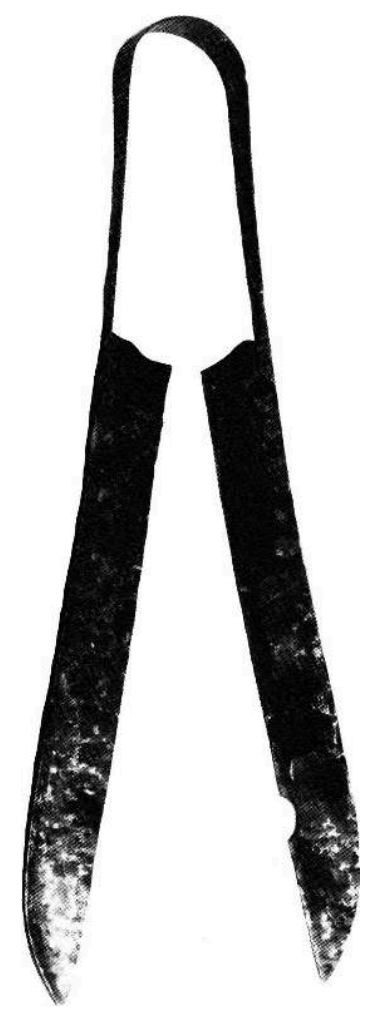

86- Fragments de forces

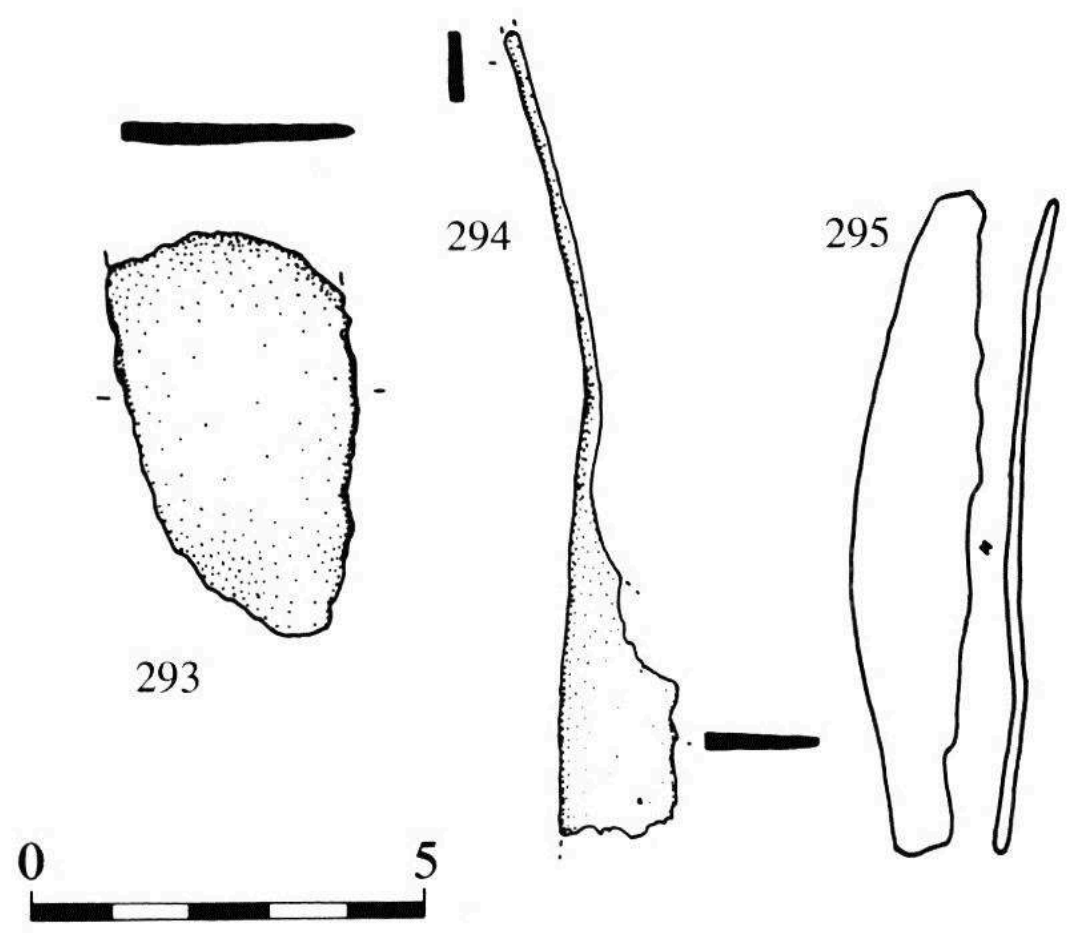

Les forces, inconnues durant l'âge du Bronze, apparaissent au cours de l'âge du Fer, sans doute pendant La Tène. Ce type d'outil est utilisé dans plusieurs activités très 
différentes. Les forces dont les dimensions varient entre 25 et $35 \mathrm{~cm}$, sont généralement considérées comme des outils destinés à la coupe de la laine et sont des objets liés à l'élevage. D'autres usages dans l'agriculture sont mentionnés dans les sources antiques : la coupe des petites branches d'arbres (fruitiers ?) et celle des grains de raisin avariés (Columelle XII, 4344). Les exemplaires de très grande taille comme le $\mathrm{n}^{\circ} 292(470 \mathrm{~mm})$ sont vraisemblablement des outils spécialisés dans une activité artisanale; une stèle d'époque gallo-romaine montre un artisan, tenant de grandes forces auprès d'un long tissu ou d'une fourrure (Goudineau 1980 : p. 378, n 313). D'autre part, des exemplaires assez grands, associés à des rasoirs, sont attestés dans des sépultures datées de La Tène $\mathrm{C}$ et D. Dans ces contextes, les forces sont considérées comme des objets de toilettedestinés à la coupe des cheveux, des moustaches et de la barbe-dont l'usage permet d'affirmer certaines distinctions sociales décrites dans les sources antiques. En contexte funéraire, les forces sont uniquement attestées dans des tombes masculines d'individus armés ou non et ce, dans diverses régions du monde celtique (Kruta 1980: p. 19-23; Kruta 1985 : p. 30 ; Gustin $1984:$ p. 331 et 335 ; Penninger 1972 : Taf. 7 et 24, B). Un dernier type d'utilisation mérite d'être mentionné : une scène de sacrifice, peinte sur céramique grecque, montre un personnage tenant, entre autres, des forces (Déchelette 1914: fig. 635). Celles-ci devaient servir à la découpe des viscères qui sont ensuite grillés sur des broches. Les utilisations des forces sont donc très diverses tout comme les contextes dans lesquel elles figurent: sépultures, oppida et dépôts métalliques (Jacobi 1974 ; Rybová 1983). $\mathrm{n}^{\circ}$ 296. Rasoir complet ( ?) (fig. 87)

L'objet n'est connu que par un dessin et il pourrait s'agir d'un rasoir : dans ce cas, on aurait affaire à un instrument de toilette, bien que l'on ne puisse exclure d'autres usages, peut-être artisanaux, pour ce type d'objet.

87- Rasoir en fer

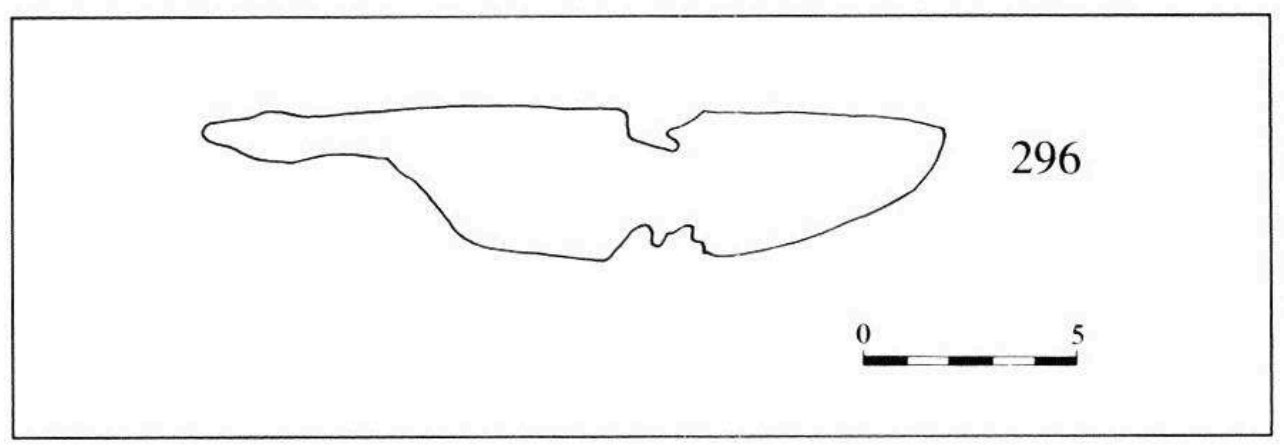

394 Témoins des activités de la vie quotidienne, les aiguilles sont attestées par des exemplaires en bronze et en fer (fig. 88). 
88- Aiguilles en bronze et en fer

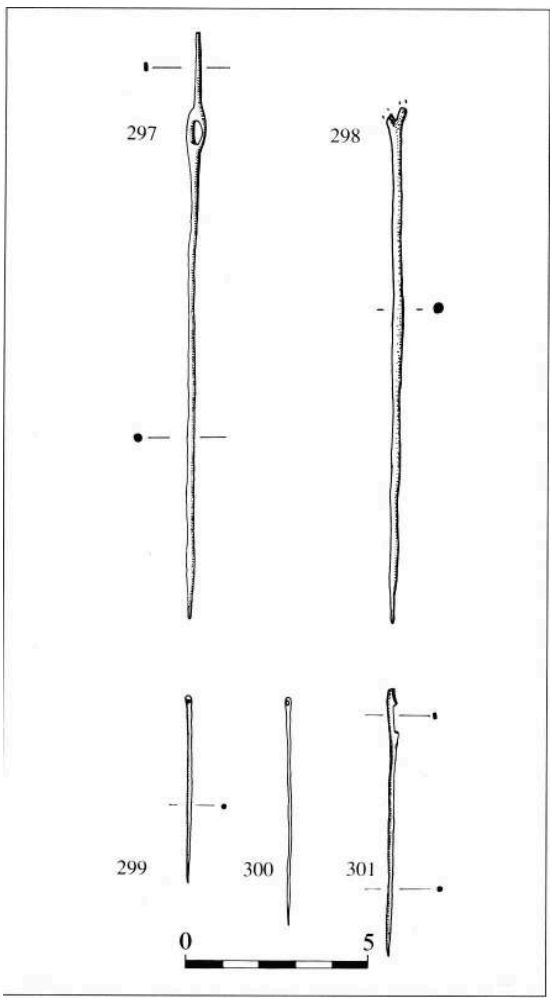

$n^{\circ}$ 297. Aiguille en bronze.

Exemplaire intact formé à partir d'une tige de bronze, élargie à un endroit pour former un chas ovale. La section est quadrangulaire avant le chas; elle évolue pour devenir circulaire ensuite.

$\mathrm{n}^{\circ} 298$. Fragment du même type, en fer.

$n^{\circ}$ 299. Aiguille en bronze intacte, à chas circulaire situé à la tête de l'objet.

$n^{\circ}$ 300. Même type que l'exemplaire précédent.

$\mathrm{n}^{\circ}$ 301. Aiguille incomplète en bronze.

Le chas adopte une forme quadrangulaire ; l'objet diffère ainsi des nº 299-300.

Les plus petites aiguilles à chas circulaire ( $\left.n^{\circ} 299-301\right)$ sont en rapport avec la couture, les vêtements et des activités sans doute domestiques. Ces instruments sont très bien représentés dès les VIe-Ve siècles av. n. è. sur les sites princiers hallstattiens (Ramseyer 1983) et connus dans des contextes chronologiques proches en Gaule méridionale (Tendille 1982: p. 41-42). Naturellement, ces aiguilles se rencontrent aussi dans le mobilier plus tardif des oppida. Le type à chas quadrangulaire est plutôt caractéristique du début du second âge du Fer (Feugère 1986: p.186). Quant aux exemplaires $\mathrm{n}^{\circ}$ 297-298, ils sont particuliers à la culture des oppida et sont attestés à Stradonice, Manching et Sainte-Blandine (Pic 1906 : pl. XIV, n 1-6; 17-22 ; Jacobi 1974: Taf. 26, $\mathrm{n}^{\circ} 422448$; Chapotat 1970 : pl. IX, $\mathrm{n}^{\circ} 10-11$ ). Ces longues aiguilles sont sans doute en rapport avec une activité artisanale bien précise (confection de filets de pêche ou de chasse ?).

401 Les métiers du cuir fournissent un nombre élevé d'outils en fer.

$\mathrm{n}^{\circ}$ 302. Emporte-pièce complet (fig. 89).

L'outil comprend une soie carrée, s'épaississant nettement vers le milieu de l'objet, 
pour se prolonger par une partie de section circulaire. L'extrémité de cette dernière est constituée par deux pattes rectangulaires, recourbées sur elles-mêmes pour former un tube.

89- Emporte-pièces en fer

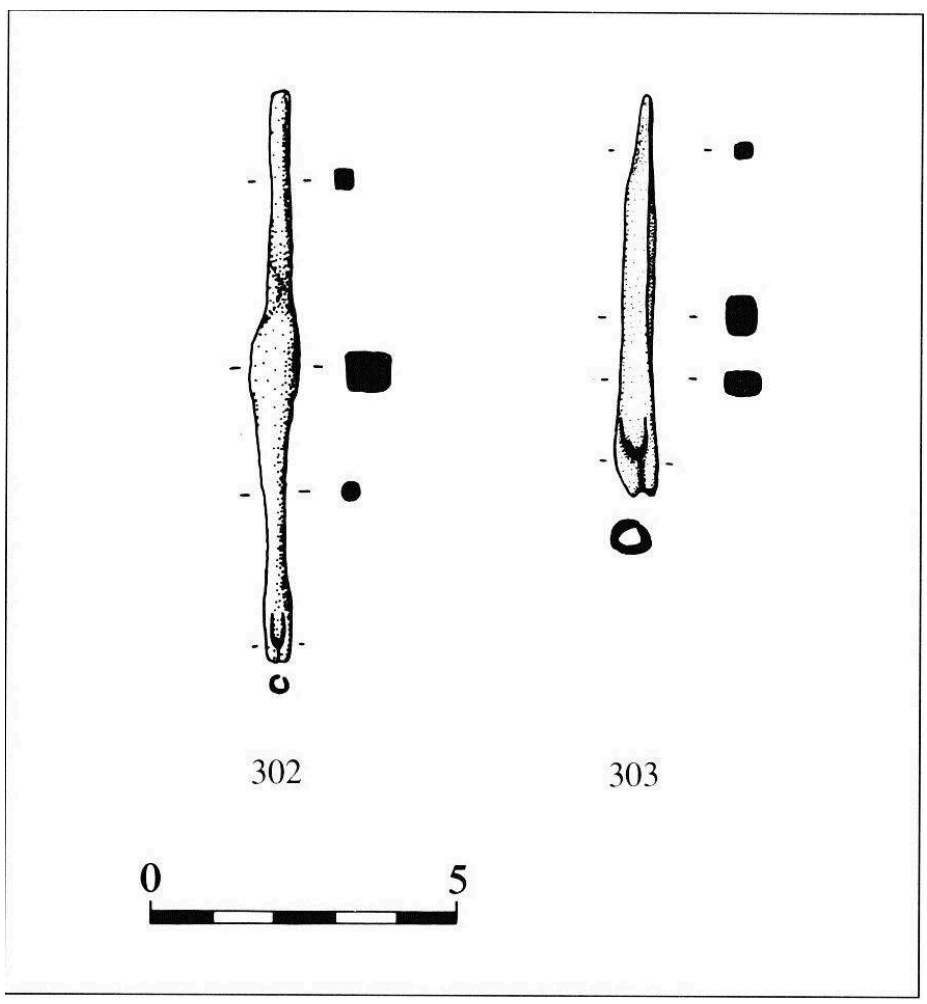

$403 n^{\circ}$ 303. Emporte-pièce complet.

Très proche du précédent, cet outil comprend une soie courte de section quadrangulaire, prolongée d'une tige plus épaisse terminée par deux pattes façonnées pour obtenir un tube.

404 Ces deux objets sont destinés à découper un matériau, selon une forme définie à l'avance par l'outil.

Indispensables aux travaux du cuir et des peaux, les alènes sont très bien représentées dans la série métallique de La Chuire (fig. 90). 
90- Alènes en fer

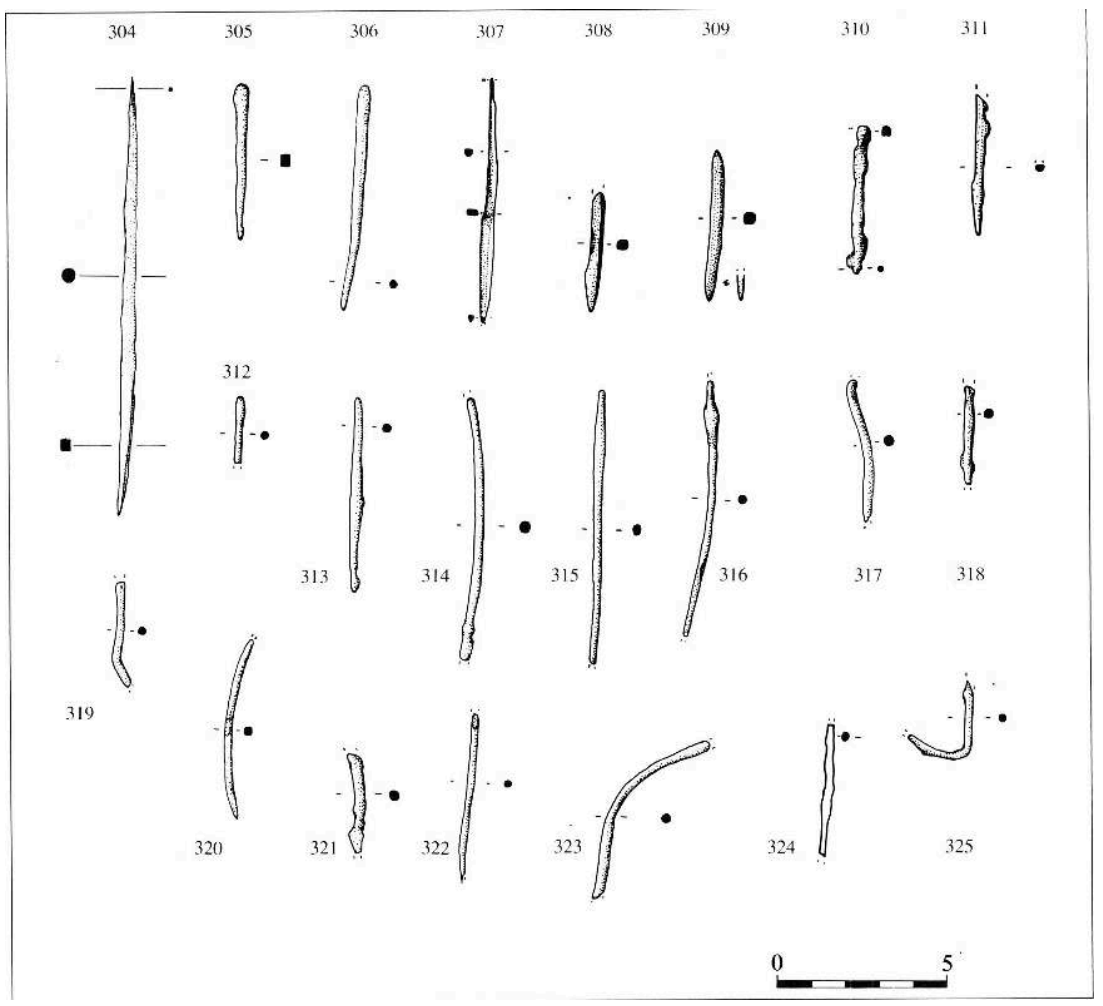

$\mathrm{n}^{\circ}$ 304. Alène complète double ( ?).

Il s'agit peut-être d'une alène double, de section circulaire sur les deux tiers de sa longueur, puis de section carrée sur le tiers restant. Cette dernière partie de l'outil est légèrement courbe.

$\mathrm{n}^{\circ} 305$. Alène complète à tête épaissie et corps de section carrée.

$\mathrm{n}^{\circ}$ 306. Alène complète à tête épaissie et corps de section circulaire.

$\mathrm{n}^{\circ} 307$. Alène complète à soie de section hémicirculaire et corps de section rectangulaire.

$\mathrm{n}^{\circ}$ 308. Alène incomplète à soie de section carrée.

$411 n^{\circ} 309$. Alène complète massive de section carrée.

412

$\mathrm{n}^{\circ} 310$. Possible fragment d'alêne à section variable : d'abord carrée, puis circulaire.

$n^{\circ} 311$. Alène incomplète de section circulaire, $n^{\circ} 312$. Fragment d'alêne à tête épaissie.

$n^{\circ}$ 313. Fragment d'alêne (?) de section circulaire.

$\mathrm{n}^{\circ}$ 314. Fragment d'alène (?) de section circulaire.

$\mathrm{n}^{\circ} 315$. Alène ( ?) incomplète de section circulaire, légèrement renflée à son sommet.

$n^{\circ} 316$. Alène (?) incomplète de section circulaire, possédant un renflement marqué à son sommet.

$\mathrm{n}^{\circ}$ 317. Fragment d'alène ( ?) de section circulaire.

$\mathrm{n}^{\circ}$ 318. Fragment d'alène (?) de section circulaire.

$\mathrm{n}^{\circ}$ 319. Fragment d'alène (?) de section circulaire. La tige est repliée et forme un angle d'environ $45^{\circ}$.

$421 n^{\circ} 320$. Alène incomplète courbe de section carrée. 
est constitué d'une tige de section plan-convexe, précédée d'une soie de section quadrangulaire. Cette dernière possède à sa base deux encoches permettant la fixation d'un manche disparu. Le côté bombé de l'objet a conservé quelques dents permettant d'identifier l'objet comme une lime demi-ronde. Celle-ci a été ployée et montre ainsi un angle d'environ $40^{\circ}$.

\section{1- Limes en fer}

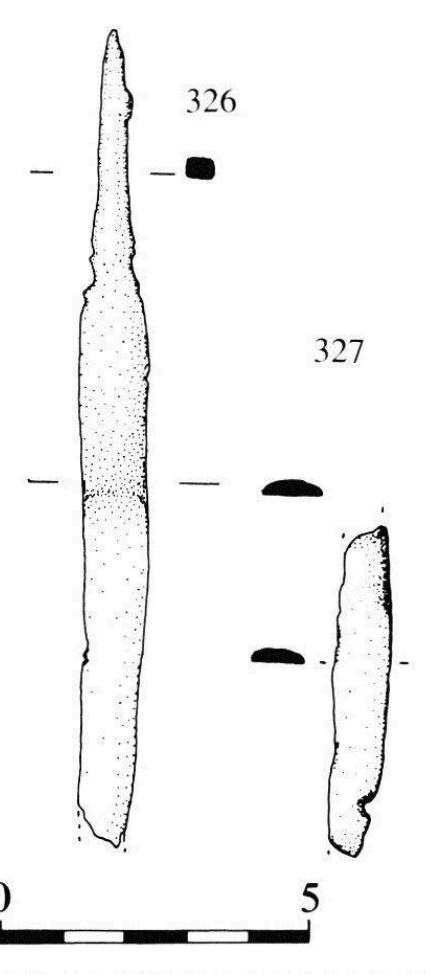

328

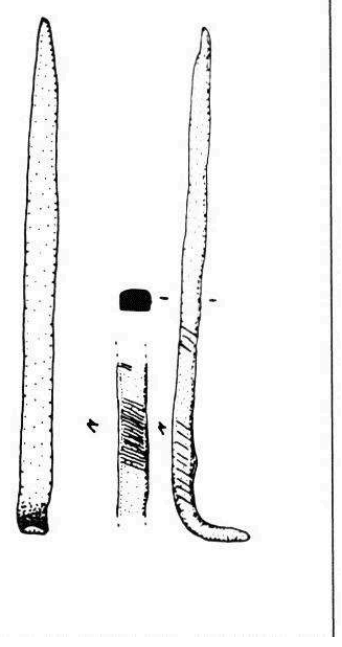


Des formes comparables existent durant le second âge du Fer, sur les oppida de Manching, de Velemszent-vid et de Straré Hradisko (Jacobi 1974 : Taf. 55, n 37-38 et p. 18).

$\mathrm{n}^{\circ}$ 327. Fragment de lime demi-ronde, analogue à l'exemplaire précédent.

$\mathrm{n}^{\circ}$ 328. Lime complète.

L'outil consiste en une tige de section quadrangulaire, appointée à une extrémité et recourbée à angle droit de l'autre. Des dents obliques, serrées et parallèles, sont encore visibles sur deux côtés de l'objet.

Des limes similaires sont attestées dès le Hallstatt D (La Heuneburg) et se multiplient dans la culture des oppida (Manching) (Sievers 1984 ; Jacobi 1974); leur forme semble adaptée au travail du bronze, plus particulièrement aux finitions. On peut, en effet, observer des traces nettes de l'action de la lime sur la face antérieure de certaines fibules de Nauheim découvertes sur le plateau de Larina.

$434 \mathrm{n}^{\circ}$ 329. Outil complet (fig. 92).

Celui-ci est court et massif. La tête de l'objet est épaisse, de section approximativement ovale, indiquant probablement une percussion directe, sans la présence d'un manche. Le corps de l'outil est quadrangulaire; le tranchant est étroit, légèrement relevé. Il pourrait s'agir d'un outil destiné au travail du métal.

92 - Outils en fer destinés aux travaux des métaux

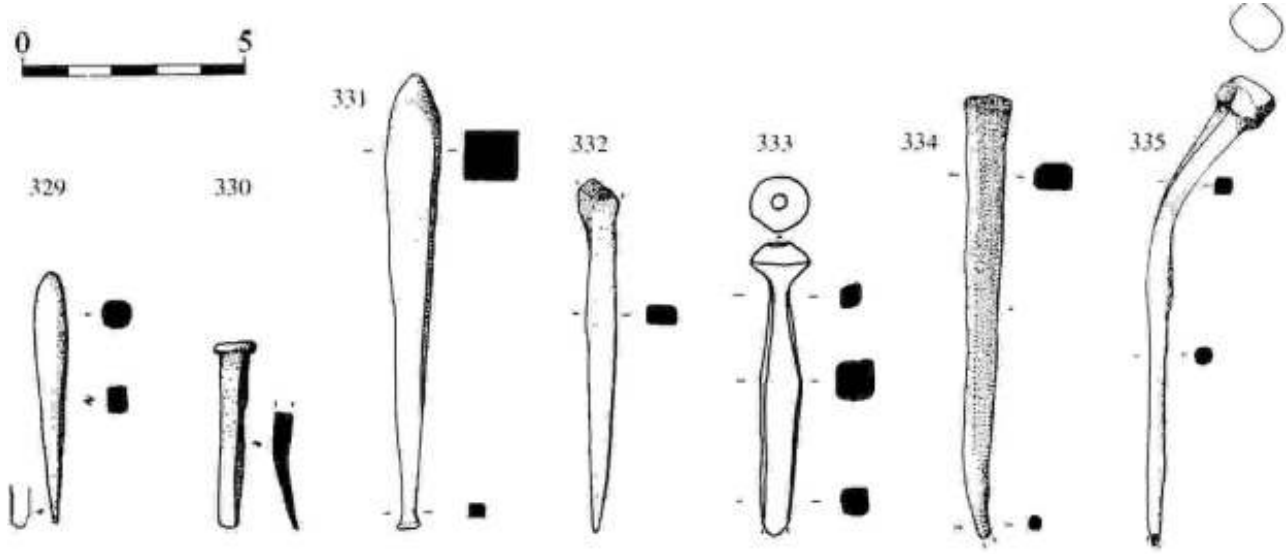

$\mathrm{n}^{\circ}$ 330. Ciseau complet.

La tête est plate et le corps présente une inflexion marquée.

Le tranchant est étroit et rectiligne. L'écrasement de la tête du ciseau indique que l'on a affaire à un outil utilisé en percussion directe, destiné au travail des métaux.

$437 \mathrm{n}^{\circ} 331$. Outil complet.

Il est formé d'une tige de section carrée s'amincissant progressivement. L'extrémité active de l'outil est marquée par un léger aplatissement du métal qui conserve une forme carrée. La tête de l'outil adopte une forme conique sans trace apparente de percussion. L'objet paraît neuf, mais a très bien pu être utilisé avec un percuteur en bois. 
Il pourrait s'agir d'un outil destiné à estamper des objets métalliques, comme certaines fibules de Nauheim à décor d'échelle.

$n^{\circ} 332$. Fragment de poinçon.

De section rectangulaire, il est appointé de façon dissymétrique à son extrémité. L'outil montre une trace nette de torsion ayant conduit à sa cassure.

$\mathrm{n}^{\circ}$ 333. Outil incomplet.

Le corps, de section carrée, est précédé d'une tête biconique; il s'agit probablement d'un outil destiné au travail des métaux.

Il comprend une tige de section rectangulaire, devenant circulaire vers sa partie active. La tête montre des traces nettes d'écrasements dues à l'emploi d'un percuteur métallique (marteau) : il s'agit sans doute d'un poinçon utilisé dans le travail du métal. $\mathrm{n}^{\circ} 335$. Outil incomplet.

La tête massive, de forme losangique, se prolonge par une tige de section carrée, évoluant pour devenir circulaire.

\section{Travail de la pierre}

$\mathrm{n}^{\circ}$ 336. Herminette complète en fer (fig. 93-94).

Massive, elle comporte une perforation destinée à la fixation d'un manche en bois ou en bois de cerf. Le corps de l'outil est courbe, s'élargissant pour former le tranchant. Les traces d'usure indiquent la double utilisation de cette herminette: fendre d'un côté, percuter de l'autre.

\section{Herminette en fer}

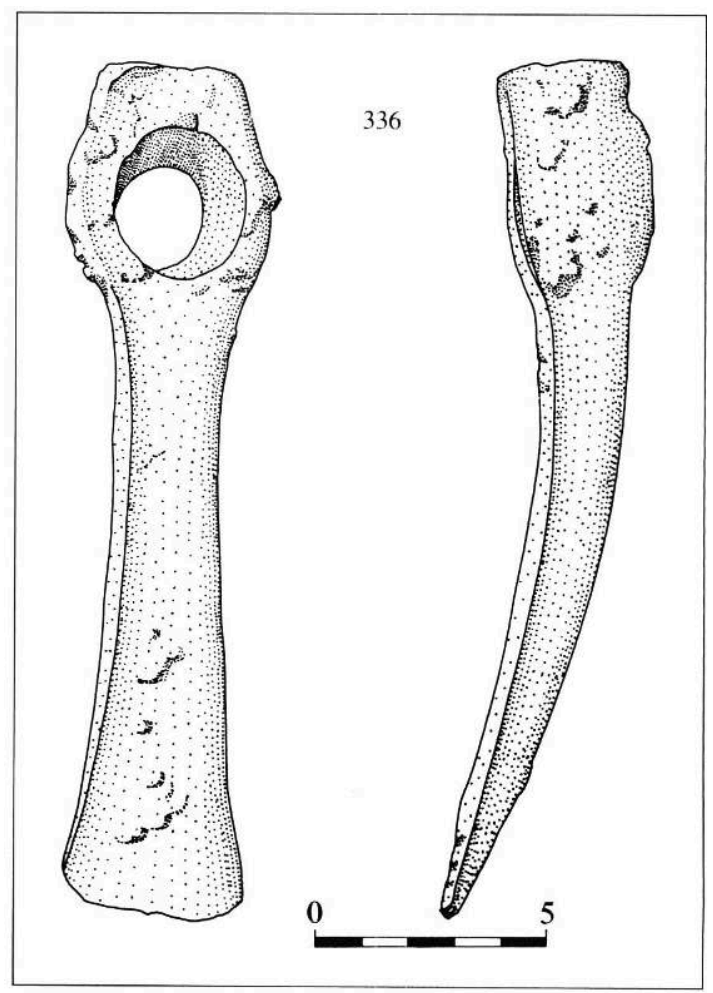




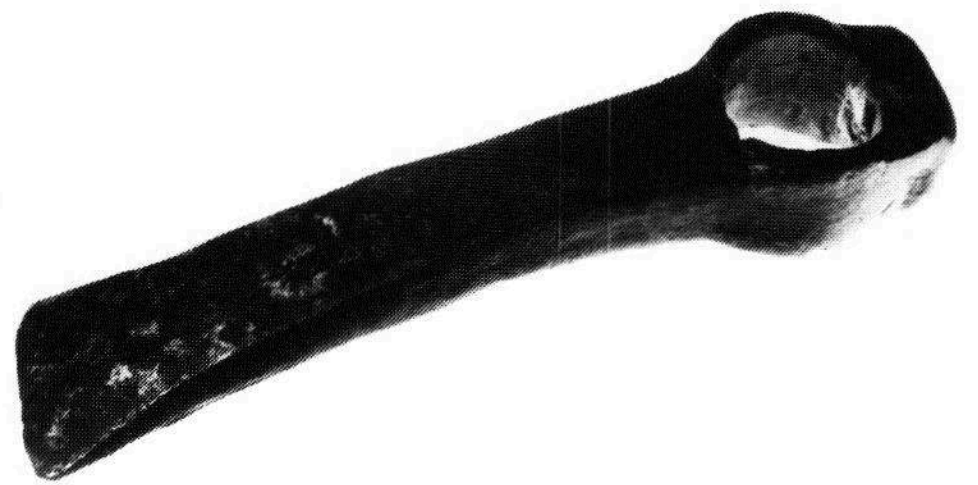

Peut-être s'agit-il là d'un outil destiné au travail de la pierre, en particulier à l'extraction des lauzes en calcaire (Bedon 1984: pl. 28, n' 16200). Cette forme est surtout connue dans le Sud de la Gaule, dans des contextes du Ier siècle av. n. è. (Taffanel 1967: p.1-10; Py 1979: p. 87, n²1; Willaume 1987; Brun 1984: p. 14) et semble étrangère au répertoire laténien.

Instruments de pêche (fig. 95)

95- Instruments de pêche en bronze $\left(n^{\circ} 338\right)$ et en fer

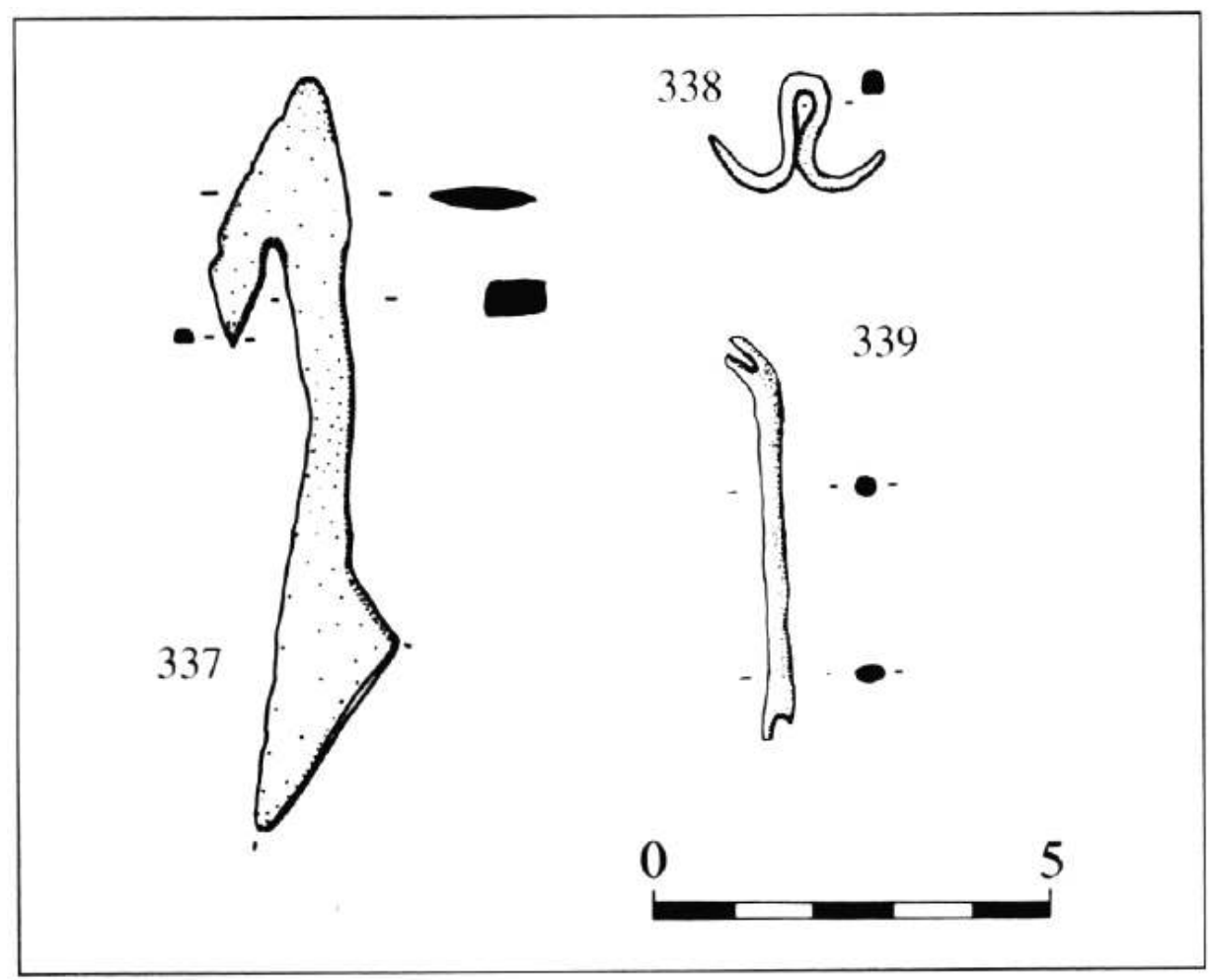

$\mathrm{n}^{\circ}$ 337. Fragment de trident en fer.

Ces instruments sont connus sur des habitats proches de la Méditerranée mais aussi sur des sites continentaux (Déchelette 1914: p. 13841386 ; Py 1979: p. 92). Il s'agit 
assurément d'un instrument de pêche en eaux calmes (lacs, lagunes, étangs) comme l'indiquent les contextes de découvertes. Alors que les hameçons métalliques sont bien attestés dès l'âge du Bronze, il semble que le trident soit un apport méditerranéen, apparu tardivement au cours de La Tène.

$\mathrm{n}^{\circ}$ 338. Hameçon complet en bronze.

Il est formé d'une simple tige de bronze repliée pour former une boucle, puis recourbée aux extrémités.

Ces instruments de pêche sont connus dès l'âge du Bronze puis au premier âge du Fer dans les habitats mais aussi dans des sépultures (Feugère 1986). Des exemplaires identiques à celui de La Chuire sont attestés dans la culture des oppida à Manching (Jacobi 1974 : Taf. 26, nº 459 en fer). $n^{\circ} 339$. Outil incomplet en fer.

Il s'agit d'une tige de section variable : ovale à la suite de ce qui pourrait être un chas, elle devient circulaire ensuite. La tige se prolonge pour finir par se recourber pour former deux branches.

La forme évoque des outils utilisés pour repriser les filets, mais les dimensions paraissent trop réduites pour assurer une identification. Un objet proche provient de l'oppidum de Stradonice (Pic 1906 : pl. XXII, nº 6).

Outils indéterminés (fig. 96)

Plusieurs outils, en fer, sont trop fragmentaires pour qu'il soit possible d'assurer une identification.

96 - Outils non déterminés en fer

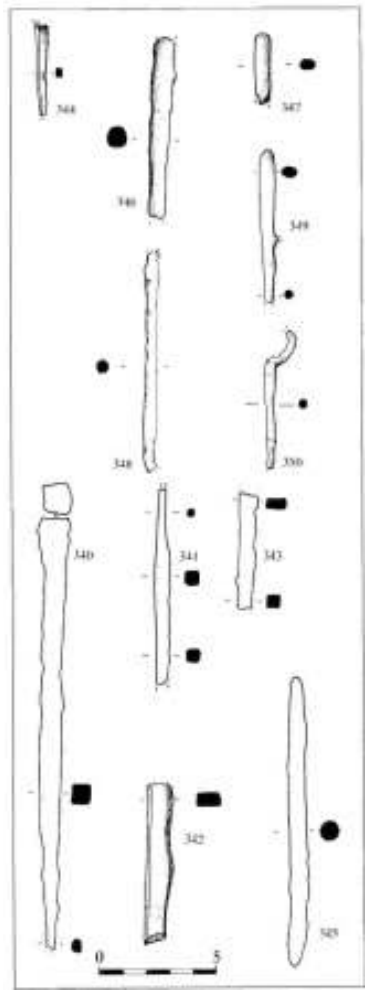


Les 24 fragments se rapportant à l'équipement militaire se répartissent en deux groupes : l'armement offensif : épées, fourreaux et chaînes de ceinturon, pointe et talon de lance; l'armement défensif: umbo, manipule et bordures de boucliers. Aucun fragment de casque ou de paragnathides n'a été identifié.

\section{Les épées, fourreaux et éléments de suspension}

$n^{\circ} 340$. Tige de section carrée, s'épaississant à une extrémité. L'objet n'est connu que par un dessin; il pourrait s'agir d'un outil ou de l'extrémité d'un lingot du type Spitzbarren.

n 341. Tige de section carrée, précédée par une partie plus fine de section circulaire : il s'agit sans doute d'un outil.

$n^{\circ} 342$. Tige de section trapézoïdale, évoquant un objet en cours de fabrication, tel qu'il en existe à Manching.

$\mathrm{n}^{\circ} 343$. Tige de section rectangulaire, évoluant pour devenir carrée.

$\mathrm{n}^{\circ}$ 344. Fragment de tige de section rectangulaire, correspondant peut-être à l'extrémité active d'un outil.

$\mathrm{n}^{\circ}$ 345. L'objet, complet (?), n'est connu que par un dessin: il s'agit d'une tige de section circulaire.

$\mathrm{n}^{\circ} 346$. Tige de section circulaire : peut-être un fragment d'outil.

$n^{\circ} 347$. Tige de section ovale qui pourrait être une tête d'outil.

$n^{\circ} 348$. Tige de section circulaire, légèrement courbée à son extrémité conservée.

$\mathrm{n}^{\circ} 349$. Tige de section ovale, puis circulaire, montrant la trace d'un arrachement latéral.

$\mathrm{n}^{\circ} 350$. Tige de section circulaire recourbée à son extrémité, pour former probablement un anneau.

Dans cette série, pratiquement la moitié des outils sont complets tout en présentant des traces nettes d'usure. Quelques outils montrent des torsions volontaires : l'exemple le plus net est la gouge $n^{\circ} 271$, mais il en va sans doute de même pour les outils $n^{\circ} 325$, 326,332 . La torsion volontaire est plus difficile à retenir pour l'outil $n^{\circ} 335$. La majeure partie de ces outils se rapporte aux travaux du bois (ou de l'os) et du cuir. Quelques outils à tête écrasée semblent cependant plutôt adaptés aux travaux du métal. Cette activité n'est que faiblement représentée et il manque les outils habituels de la forge (enclume, pince, marteau) dont la production s'exprime pourtant dans la diversité des formes d'outils.

\section{L'armement offensif et défensif}

L'armement ne constitue qu'une faible catégorie dans la série métallique de la Chuire.

$n^{\circ} 351$. Fragment de bouterolle en bronze (fig. 97). 


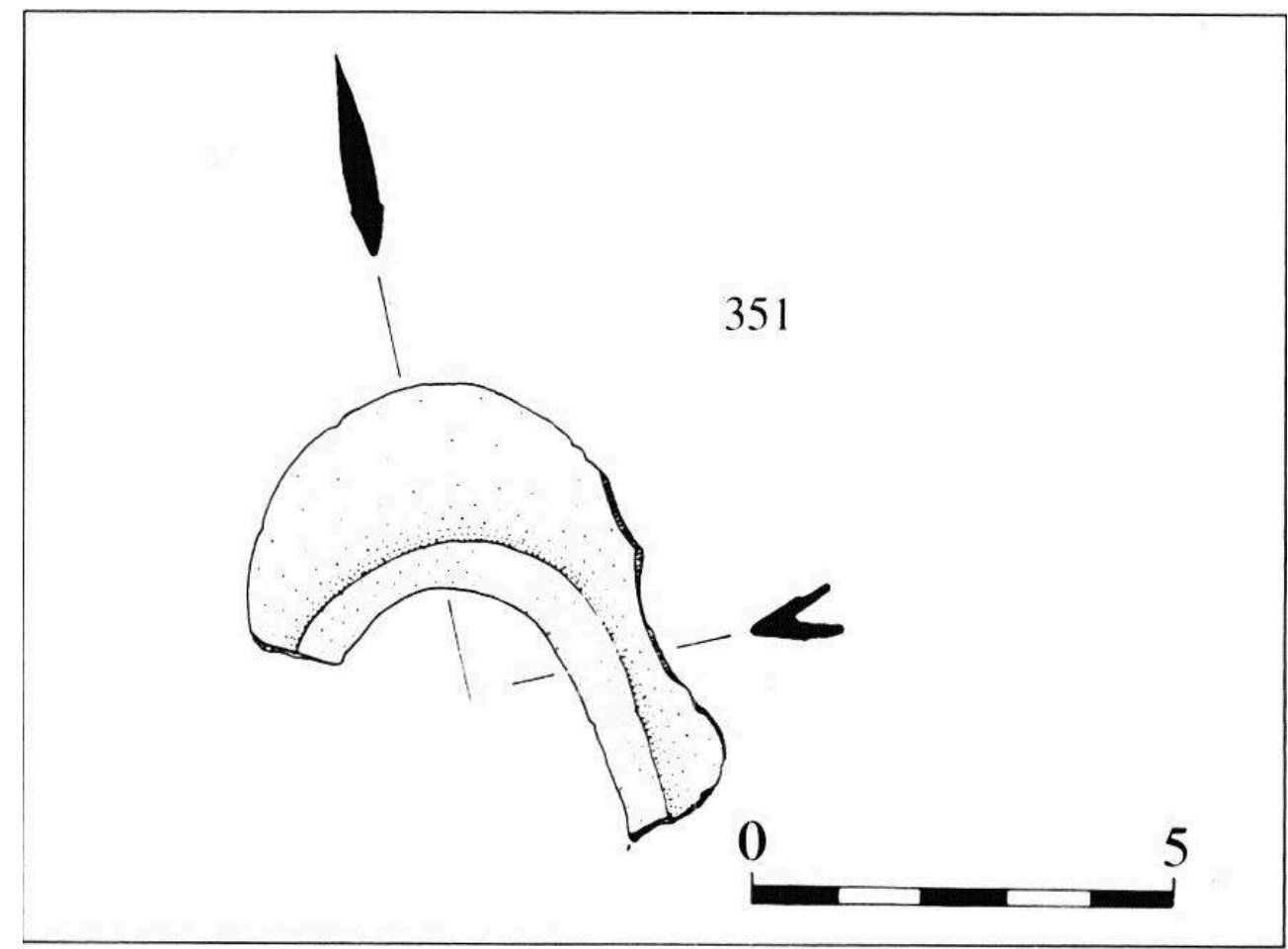

Ce type (Vuaillat 1981: p. 199-215) est attesté dans le Jura, dans la sépulture ${ }^{\circ} 1$ de Chavéria (Jura) et dans les Alpes, dans la sépulture tumulaire de Chavignières (HautesAlpes). Quant aux épées en bronze auxquelles est associée cette forme de bouterolle, elles sont très bien représentées le long de l'Ain, en particulier sur son cours supé rieur, ainsi que sur la rive gauche du Rhône (Gerdsen 1985: p.65-69; Millotte 1976: p. 724-725; Courtois $1976:$ p. 709). Ces pièces d'armement sont généralement datées du Hallstatt $\mathrm{C} 1 / \mathrm{C} 2$, soit des Ville-Vile siècles av. $n$. è. Si elles figurent plus généralement dans des sépultures de cavaliers, quelques exemplaires proviennent néanmoins de fosses dépotoirs (Vital 1988).

$\mathrm{n}^{\circ}$ 352. Bouterolle incomplète en fer (fig. 98).

Il s'agit d'un élément de fourreau métallique, constitué d'une tige de fer martelée et repliée sur elle-même pour former une gouttière. Les deux branches permettant la fixation de la bouterolle sur le fourreau ont disparu, probablement sectionnées volontairement, vu la régularité des cassures. 
98 - Epée, fourreaux, bouterolle et éléments de ceinturons en fer de La Tène

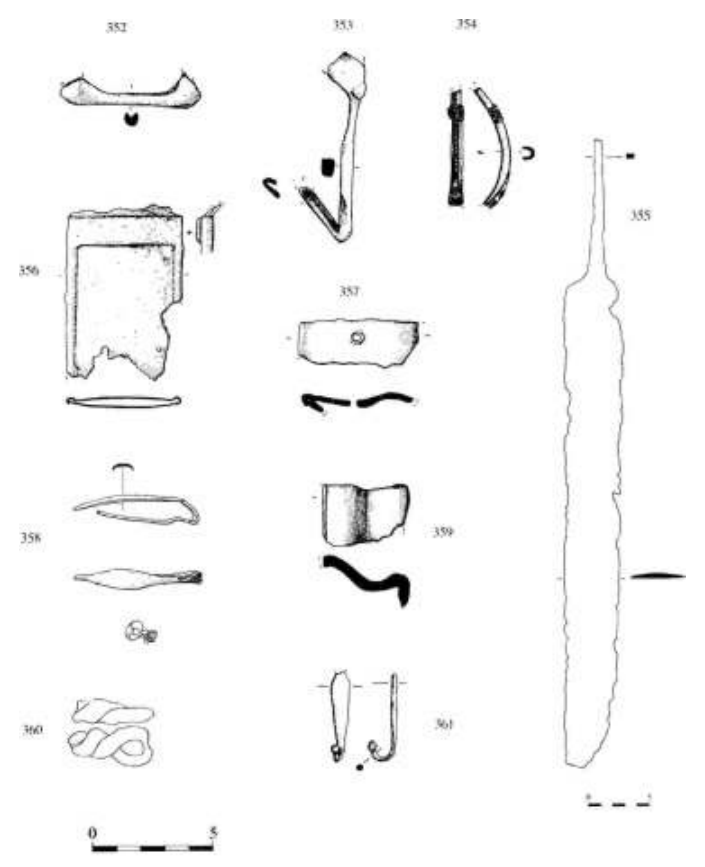

467 Ce type de bouterolle rectiligne est généralement de grande taille, avec de multiples renforts latéraux : il caractérise les fourreaux dits «à échelles» (Rapin 1983 : p. 79, pl. $\left.\mathrm{V}, \mathrm{n}^{\circ} \mathrm{D}\right)$. Ces accessoires militaires sont connus à Feurs, dans un contexte de La Tène D1 (Guichard 1988 : p. 158). Cette forme de fourreau est bien attestée dans le territoire allobroge : plusieurs exemplaires sont connus dans la nécropole de Mépieu (Anonyme $1986 \mathrm{a}: \mathrm{p}$. 24) et à Sainte-Blandine (Chapotat $1970:$ pl. I, n 5) ; plusieurs fourreaux du même type, mais en tôle de bronze, sont recensés sur le territoire éduen et ont été découverts dans le lit de la Saône (Bonnamour 1983 : p. 75-76).

$\mathrm{n}^{\circ}$ 353. Fragment de bouterolle ( ?) en fer.

Il s'agit d'une tige de section tout d'abord carrée, puis en gouttière, précédée d'une plaque incomplète. L'objet semble tordu intentionnellement et pourrait être un fragment de renfort latéral de bouterolle.

$\mathrm{n}^{\circ}$ 354. Pièce d'armement ( ?) en bronze.

Il s'agit d'une tige de bronze courbe, à section en U, obtenue à la coulée. La pièce est ornée de trois cercles concentriques pointés, réalisés par estampage. L'axe de la pièce est orné par deux cannelures encadrant de fines incisions rapprochées. Ce décor est interrompu par deux nodosités encadrant trois « pastilles » transversales rapportées, et se prolonge par la suite. L'intérieur de l'objet montre des traces de métal gris-blanc (plomb ou étain). Pourrait-il s'agir d'un fragment de bouterolle? L'ornementation n'est pas sans rappeler celle du bracelet $n^{\circ} 142$, décoré selon la technique du pastillage.

$470 \mathrm{n}^{\circ}$ 355. Epée incomplète en fer.

Arme à bords parallèles, de section lenticulaire. La soie, de section rectangulaire, se raccorde avec la lame en formant des angles ouverts. Cette dernière ne présente pas de nervure médiane. Sans caractéristique particulière, ce fragment appartient probablement à une épée du second âge du Fer. 
$n^{\circ}$ 356. Fragment de fourreau en fer.

Celui-ci est constitué par deux tôles de fer. L'une d'entre elles possède deux gouttières latérales permettant la fixation de l'autre. L'une des faces de l'objet montre l'existence d'un renfort transversal. Le fourreau a été plié au-dessus de la barrette de renfort : le pli parait trop régulier pour être accidentel et rappelle les conséquences de certaines torsions sacrificielles observées à Gournay-Sur-Aronde (Brunaux 1985 b : p. 119).

\section{$\mathrm{n}^{\circ}$ 357. Fragment de fourreau en fer.}

Il est constitué d'une plaque aux bords recourbés en gouttière, enserrant un fragment d'une seconde tôle. Le fourreau montre un renflement central peu marqué, ainsi qu'une perforation. Celle-ci devait permettre le passage d'un rivet maintenant une barrette décorative transversale.

$\mathrm{n}^{\circ}$ 358. Barrette transversale de fourreau, en bronze.

L'objet est formé d'une tige de bronze au profil lenticulaire, celle-ci étant repliée pour épouser, à l'origine, la bordure du fourreau. Cette partie de la pièce est ornée d'un motif rappelant des lèvres.

Des barrettes identiques, mais en fer, sont connues dès le IIIe siècle av. $n$. è. (De Navarro 1972 : pl. XXXI, a-b, nº 66; Tizzoni 1987 : p. 7073). D'autres exemplaires en bronze, ornant des fourreaux en tôle de bronze et datables de La Tène $\mathrm{D}$, sont recensés en territoire éduen où cet armement était sans doute produit (Bonnamour 1983 : p. 76, C; Guillaumet 1985 : p. 243).

$\mathrm{n}^{\circ}$ 359. Fragment de fourreau ( ?) en fer.

La forme de l'objet évoque un fourreau à forte nervure centrale, mais le fragment semble à la fois trop large et trop massif pour être identifié avec certitude.

$n^{\circ} 360$. Fragment de chaîne de ceinturon en fer.

L'objet est constitué d'une tige de section circulaire, torsadée sur elle-même.

Il s'agit d'un exemplaire du type de Ceretolo (prov. de Bologne, Italie). Le port de ces chaînes de ceinturon entièrement métalliques se développe dès le deuxième quart du IIIe siècle av.n.è., parallèlement à l'usage du ceinturon mixte associant à une partie en cuir, des anneaux métalliques.

Ce type de chaînes de ceinturons, destinées à la suspension de l'épée, est bien attesté dans des contextes laténiens centre-orientaux, mais il figure aussi dans nombre de nécropoles celtiques d'Italie (Kruta 1983 a) et du Nord de la Gaule. Par contre, dans le Sud de la France, ces objets sont plus rares et ne sont signalés qu'en Languedoc occidental, à Ensérune (Jannoray 1955 : p. 242) ainsi qu'en Dauphiné, dans le mobilier de la sépulture A de Voreppe (Isère) datable du deuxième quart du IIIe siècle av. n. è. (Müller 1913: p. 1, n 4 et 5). Des variantes du type de Ceretolo sont connues en Suisse, dans les sépultures de Gumefens (T. 1 et T. 2) et Bevaix (Schwab 1981: p. 15-20 ; Egloff 1980 : p. 148) ; ces chaînes sont caractérisées par des maillons partiellement torsadés. Outre les contextes funéraires, ces ceinturons sont également présents dans certains sanctuaires, comme Gournay-sur-Aronde et Faye-Labesse (Deux-Sèvres) (Brunaux 1985 b: p. 124 ; Gendron 1986 : p. 91). Chronologiquement, l'usage de ces ceinturons se situe au cours des phases $\mathrm{B} 2$ et $\mathrm{Cl}$ de La Tène.

$\mathrm{n}^{\circ}$ 361. Agrafe de ceinturon (?) en fer.

L'objet est formé d'une tige aplatie de section rectangulaire, se rétrécissant pour se recourber et former un crochet terminé par un sphéroïde. La partie opposée montre le départ d'un anneau, aujourd'hui disparu. 
Cette agrafe était destinée à assurer la fermeture d'une ceinture en matière organique (cuir). Des formes proches, parfois en bronze, sont connues dès la fin de La Tène B2, dans des sépultures féminines. Cependant, cette agrafe trouve de proches parallèles dans des contextes datés de La Tène D1 (Brunaux 1986 a) et il pourrait s'agir d'un élément de ceinturon appartenant à une panoplie de guerrier. Ce type de crochet de ceinture figure également dans le mobilier de Sainte-Blandine.

\section{Les boucliers (fig. 99-102)}

$\mathrm{n}^{\circ}$ 362. Umbo à ailettes trapézoïdales incomplet (fig. 99-100).

Exemplaire à coque bombée et légère nervure médiane. La fixation de l'umbo sur le bois était assurée par un rivet situé dans le prolongement de la nervure médiane et complétée par un second rivet, de dimensions inférieures, situé vers un des angles de l'ailette. L'absence de ces rivets, dont l'empreinte est visible, est peut-être due à un démontage volontaire de l'umbo.

482 Cet umbo appartient au type $G$ de Gournay-surAronde. Ses caractéristiques (ailettes légèrement trapézoïdales, nervure de la coque) permettent de dater cette forme de La Tène C2 (Rapin 1988 : p. 245).

99- Umbo en fer à ailettes de La Tène

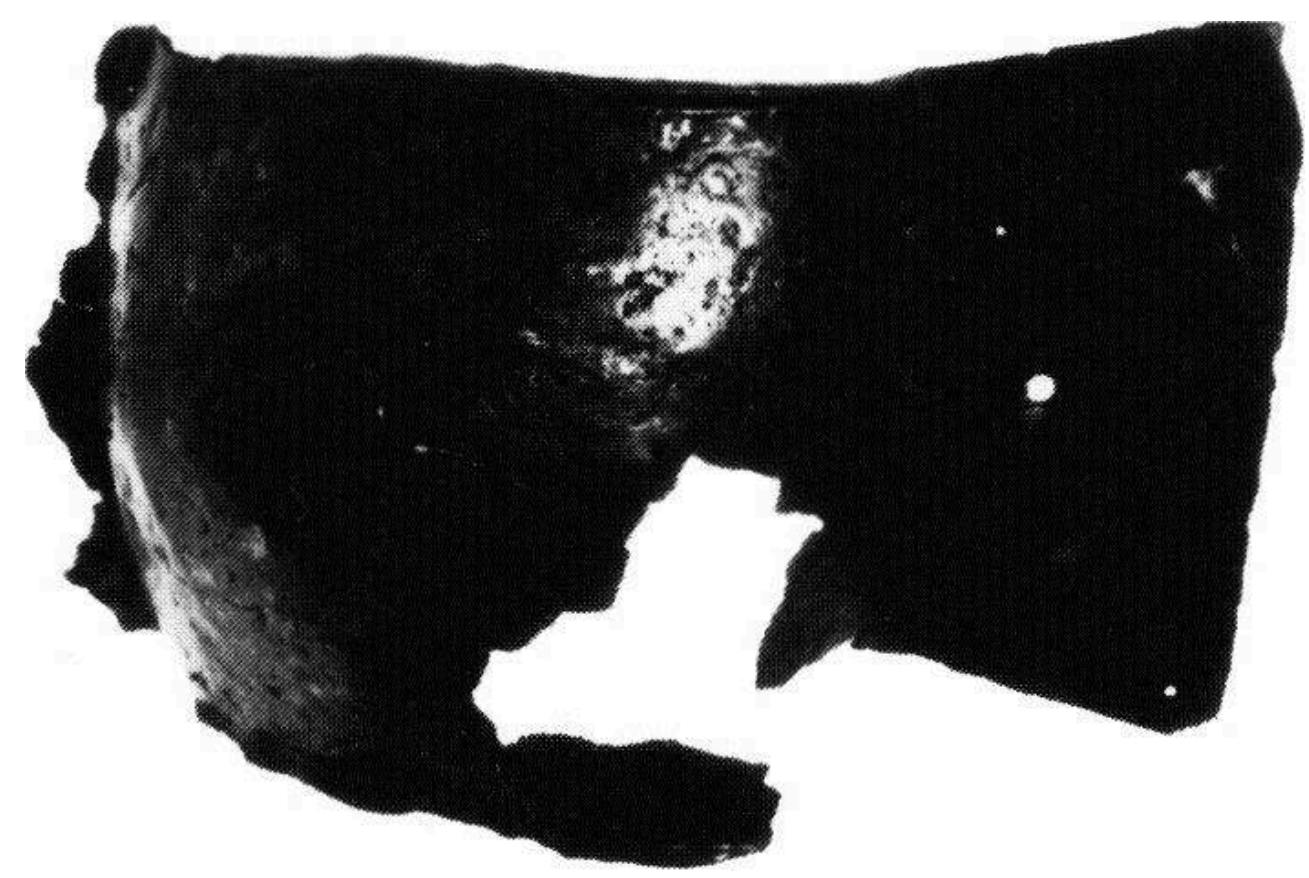


100- Umbo de bouclier

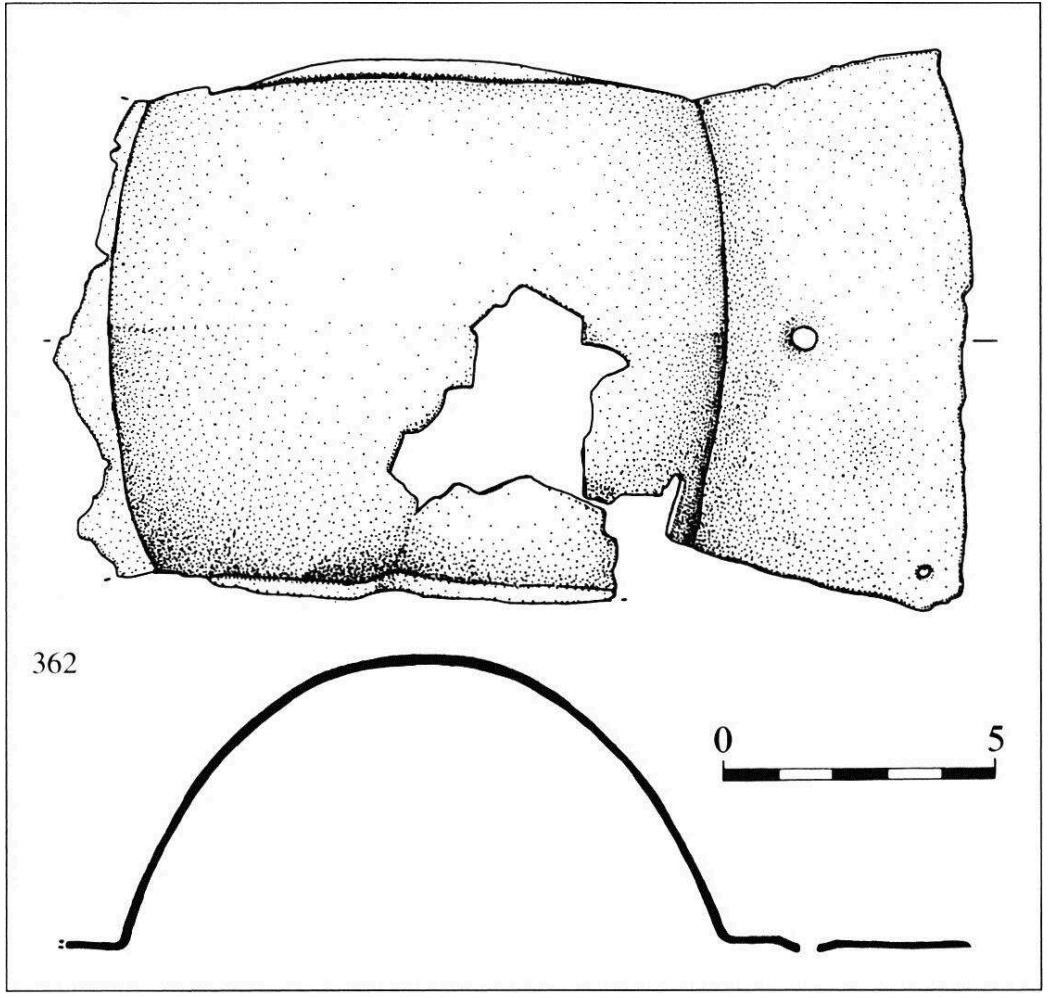

$\mathrm{n}^{\circ}$ 363. Fragment d'umbo à ailettes (fig. 101).

Comme l'exemplaire précédent, les bords de la coque sont épaissis. Il n'est guère possible de préciser la datation de ce fragment assez massif, qui appartient de toutes façons aux phases $C$ ou D de La Tène. 


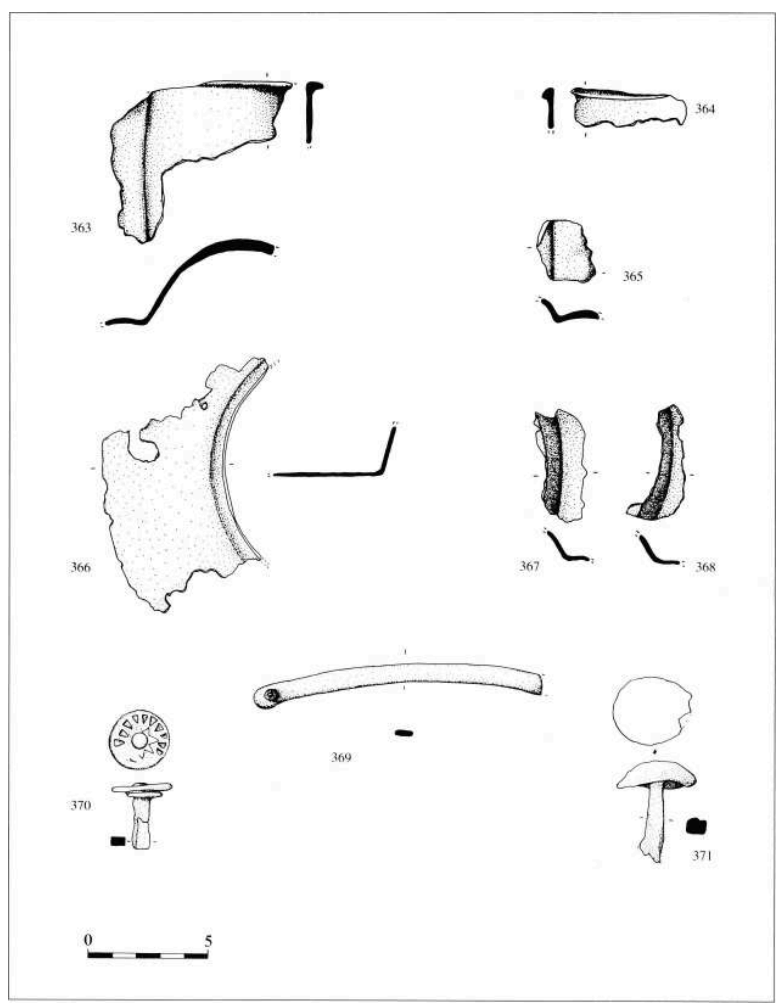

$n^{\circ}$ 364. Fragment de bord de coque appartenant à un umbo sans doute à ailettes.

$\mathrm{n}^{\circ} 365$. Possible fragment d'umbo à ailettes.

Beaucoup plus rares que les boucliers à umbo à ailettes, les armes défensives à umbo circulaire sont représentées par quelques exemplaires très fragmentés.

$\mathrm{n}^{\circ} 366$. Fragment d'umbo de type circulaire ou pré-circulaire.

$n^{\circ} 367$. Fragment d'umbo circulaire.

$n^{\circ} 368$. Fragment d'umbo circulaire.

Les boucliers à umbo circulaire appartiennent uniquement à La Tène $\mathrm{D}$ et ils constituent l'évolution des formes à ailettes. Ils paraissent plus fréquents en Yougoslavie que dans d'autres régions du monde celtique (Gustin 1984: p.334-335; Déchelette 1914: p.1172-1173). Ce type d'armement défensif est cependant signalé en Allemagne (Bantelmann $1972:$ p. 105, Tab. 1: Déchelette $1914:$ p. 922 et 1076) et jusqu'en Italie du Nord (Rapin 1988 : p. 66). En Gaule, les boucliers à umbo de type circulaire sont assez rares. Ils existent néanmoins à Alésia, sur le site de La Tène, avec un exemplaire à rivets émaillés (Verchère de Reffye $1864: 348$; Déchelette 1914 : p. 1550), et dans le Sud de la Gaule, avec les récentes découvertes de Sigoyer (Hautes-Alpes) (Gauthier 1985: p. 523-524). Ce type d'umbo figure sur un autel découvert à Nîmes (Gard) et daté du IIe siècle av. n. è : chronologiquement, les boucliers dotés d'umbo circulaire semblent apparaître à La Tène D1 et restent en usage jusqu'au milieu du Ier siècle av. n. è. En Dauphiné, à part le ou les exemplaires de La Chuire, aucun autre umbo circulaire n'est connu, ni dans les nombreuses sépultures de guerriers de La Tène $\mathrm{D}$, ni dans le mobilier de Sainte-Blandine. 
$\mathrm{n}^{\circ}$ 369. Manipule de bouclier incomplet (fig. 101).

Il s'agit d'une tige en fer courbe, de section aplatie, et dont l'extrémité est perforée pour laisser le passage à un rivet.

Ce fragment est un renfort métallique de manipule en bois. Ce type est connu dans la Marne, à Ecury-sur-Coole, et figure aussi sur le site de La Tène (Haffner 1979: p. 406, Abb. 1, $\left.n^{\circ} 13\right)$.

$\mathrm{n}^{\circ}$ 370. Rivet d'umbo ( ?) en fer, bronze et émail ( ?).

Il s'agit d'un rivet à tête circulaire, orné d'une série de triangles en creux orientés vers le centre du rivet, puis d'une seconde série de triangles affrontés aux précédents. L'objet est en fer, avec des placages de bronze; quant aux triangles, ils sont peut-être remplis d'une matière moins dure que le métal, sans doute de l'émail.

Quelques rares exemples de rivets émaillés sont connus à Gournay-sur-Aronde, La Tène, Battersea (Angleterre) et Nebringen (RLA) (Rapin 1988: p. 34-35). Dans tous les cas, il s'agit de rivets servant à la fixation d'umbo de bouclier, sauf pour ce qui concerne la tombe 5 de Nebringen où des rivets émaillés étaient logés sur une poignée d'épée (Krämer 1964: Taf. 9, n 25-26). L'ornementation à base d'estampages triangulaires apparaît ponctuellement dès La Tène A sur des objets métalliques. Au cours des phases suivantes, ce type de décoration est plus fréquemment signalé, en particulier sur des fibules et de l'armement découverts en Yougoslavie (Duval 1977: p. 164; Todorovic 1974 : p. 87, pl. 66).

$\mathrm{n}^{\circ}$ 371. Rivet d'umbo.

Exemplaire en fer, à tête hémisphérique. Bien que possédant une tige plutôt massive, ce fragment peut être identifié comme un rivet d'umbo de bouclier à ailettes; sa forme est analogue à celle des exemplaires découverts dans la tombe de Ceretolo, datée du IIIe siècle av. n. è. (Kruta Poppi 1979 : p. 13-25).

$6 n^{\circ} 372$. Bordure en fer incomplète de bouclier (fig. 102).

L'objet consiste en une tige de section rectangulaire, forgée pour obtenir une patte rectangulaire sur un de ses bords, et une languette arrondie de l'autre. L'ensemble est traversé par un rivet massif dont l'extrémité est repliée pour assurer sa fixation. Il s'agit d'une orle de bouclier, fixée à l'origine sur le pourtour de celui-ci, et destinée à le renforcer contre les chocs, inhérents à ce type d'objet.

$\mathrm{n}^{\circ}$ 373. Orle en fer.

Elle diffère de la précédente par la forme de la patte de renfort qui est dans ce cas triangulaire.

$\mathrm{n}^{\circ}$ 374. Fragment d'orle à patte triangulaire.

$n^{\circ} 375$. Fragment analogue au précédent. 
102 - Orles en fer de La Tène

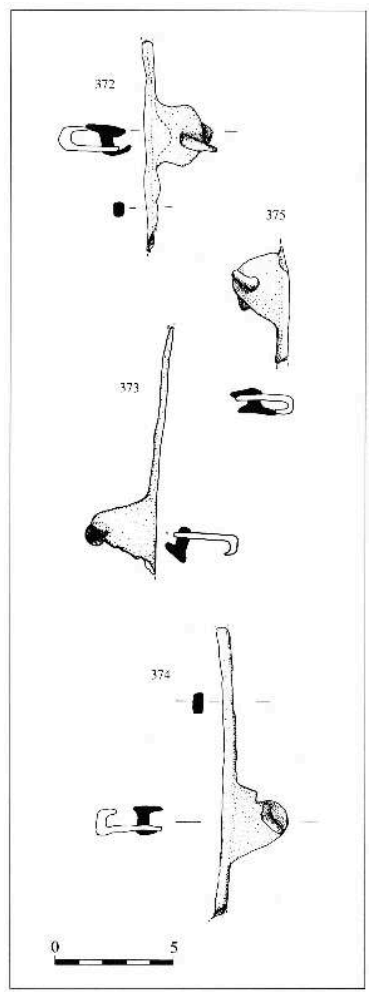

500 Les bordures de bouclier, destinées à renforcer le pourtour de ce dernier, sont attestées régionalement par plusieurs fragments découverts à Sainte - Blandine (Chapotat 1970 : pl. $\left.1, n^{\circ} 12\right)$ et par un unique fragment dans le mobilier funéraire de Rives (Etude en cours L. Perrin).

501 Les lance et javelot (fig. 103)

Ce type d'armement est très mal représenté dans le mobilier livré par La Chuire puisque deux fragments seulement permettent de l'identifier. 
103 - Lance et talon de javelot en fer de La Tène

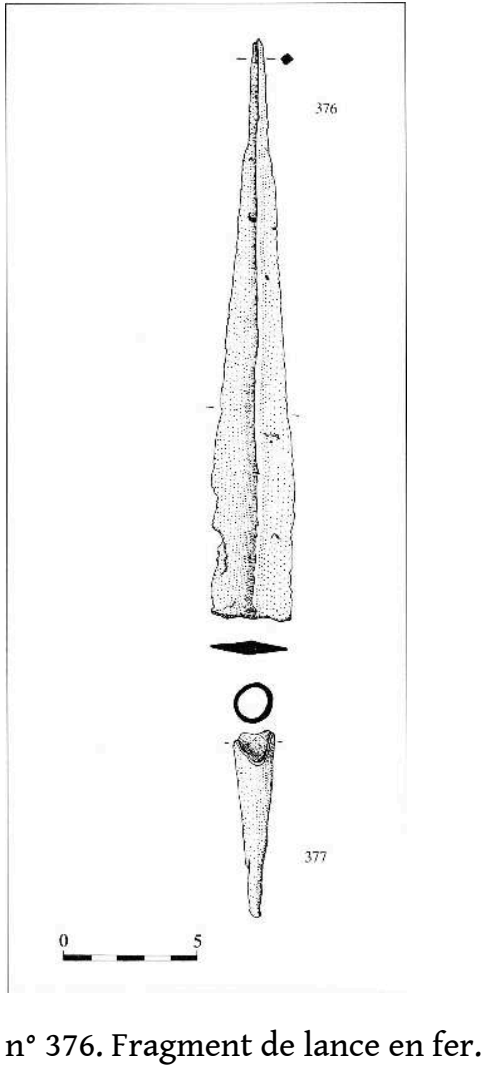

La lame, de section losangique, possède une nervure peu marquée ; la pointe est acérée, de section quadrangulaire. L'un des bords de l'amie montre la trace d'un choc violent ayant écrasé le métal. Il est difficile d'affirmer que ce choc est le résultat d'un geste volontaire, mais de tels traitements sont attestés durant l'âge du Fer, par exemple ; sur une lance du sanctuaire de Mirebeau (Brunaux 1985 a : p. 91).

504 Cette lance "à baïonnette » appartient au type IV de Gournay-sur-Aronde ; l'arme est datable de l'extrême fin du IIIe au milieu du IIe siècle av. n. è., soit de la fin de La Tène $\mathrm{Cl}$ et de La Tène $\mathrm{C} 2$. Plusieurs exemplaires analogues sont connus dans les sépultures de Mazerolles (HauteVienne), de Barbey T. 2 (Yonne) et de Dobova T. 6 (Yougoslavie) (Rapin 1988 : p. 133-134).

$505 \mathrm{n}^{\circ}$ 377. Talon en fer incomplet à douille circulaire.

Les dimensions réduites de l'objet permettent d'identifier plutôt un javelot qu'une lance.

506 Les talons d'armes sont connus dès le premier âge du Fer et sont de plus en plus fréquents jusqu'à la fin du second âge du Fer. Les contextes dans lesquels apparaissent ces armes sont, d'une part, les sépultures militaires et d'autre part, certains lieux de cultes. Le lit de la Thielle a livré respectivement 269 de ces objets à La Tène et 14 à Corneaux-les-Sauges. En Picardie, plus d'une cinquantaine de ces armes ont été découvertes à Gournay-Sur-Aronde et les éléments de lances sont très nombreux à Ribemont-sur-Ancre (Somme). Sur les habitats, par contre, ces armes ne sont que faiblement représentées. 


\section{Les pièces de char et l'harnachement (fig. 104)}

$\mathrm{n}^{\circ}$ 378. Pièce de char ( ?) incomplète, en bronze.

Tige de section ovale terminée à une extrémité par un anneau ; à l'opposé de celui-ci. la tige présente un aplatissement au profil hémi circulaire ; il pourrait s'agir d'une attache mobile pour courroie, fixée à l'origine sur une partie en bois. L'objet demeure sans comparaison mais pourrait s'apparenter aux attaches découvertes dans les sépultures à char de l'âge du Fer.

$\mathrm{n}^{\circ}$ 379. Pièce en fer de char.

Il s'agit d'une plaque ayant conservé un angle droit. Un petit emplacement de clou est visible près d'un bord, et la plaque montre une perforation quadrangulaire due au passage d'un clou massif.

104 - Pièces de char et mors en bronze $\left(n^{\circ} 378\right)$ et en fer
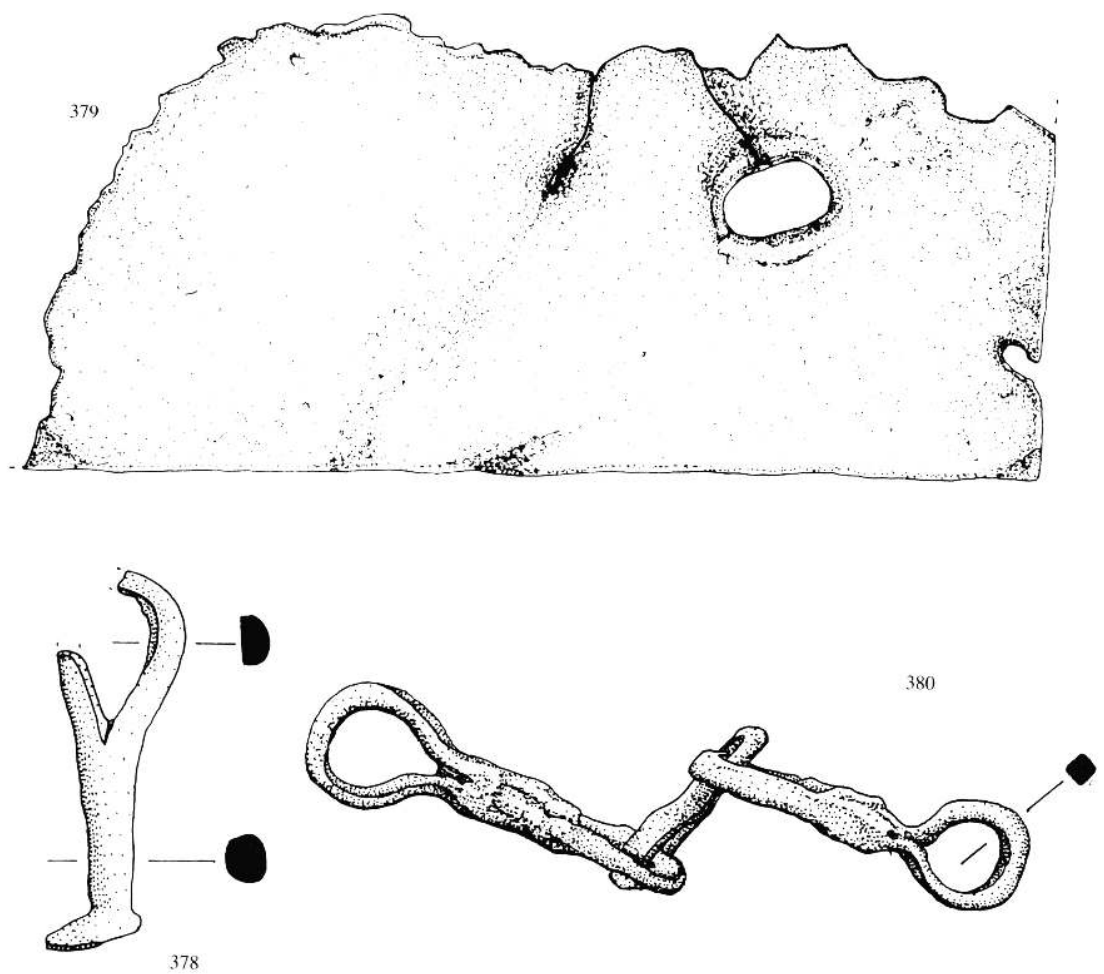

Le char d'Apremont (Haute-Saône), daté du VIe siècle av. n. è., comportait une litière amovible dont les angles étaient renforcés par des plaques analogues à celle-ci (Bouard 1987 : p. 89-90).

$\mathrm{n}^{\circ} 380$. Mors en fer incomplet.

L'objet est constitué de trois maillons aplatis auxquels sont attachés deux faux anneaux. Ces derniers, repliés en boucle et cintrés, sont formés d'une tige de fer de section carrée.

Bien que les grands anneaux nécessaires à la fixation des brides soient absents, ce fragment appartient assurément à un mors de bridon. On peut supposer que les anneaux, indispensables à son fonctionnement, ont disparu après une double cassure (volontaire ?). Ce type de mors est attesté dans le mobilier des oppida, à Manching (Jacobi 1974: Taf. 50, $\mathrm{n}^{\circ}$ 776), dans la sépulture 45 de Wederath (RFA) (Haffner 1979: 
Taf. 68, $\left.\mathrm{n}^{\circ} 1\right)$ et figure, plus près de Larina, sur le site bourguignon du Petit Chauvort (Verdun-sur-le-Doubs, Saône-et-Loire) (Guillot 1983 : p. 23).

\section{Serrurerie et pièces d'assemblages de bois}

512 Cette catégorie regroupe le plus grand nombre d'objets, en majorité des clous. Les dimensions variées de ces objets indiquent des usages multiples. Ces derniers sont utilisés pour l'assemblage de pièces en bois pour tout ce qui concerne le bâti : celui-ci pourrait être attesté par les clés et des plaques de serrures (fig. 105), mais ces objets peuvent tout aussi bien indiquer des coffres ou des coffrets. Les clous, en particulier ceux de petites dimensions, ont également dû être utilisés pour la fabrication de mobilier destiné à l'intérieur de l'habitat. De petits meubles peuvent être identifiés par des anses et des placage décoratifs.

$n^{\circ}$ 381. Fragment de clé en fer.

Elle est formée à partir d'une tige de section circulaire coudée.

105- Clé et plaque de serrure en fer de La Tène

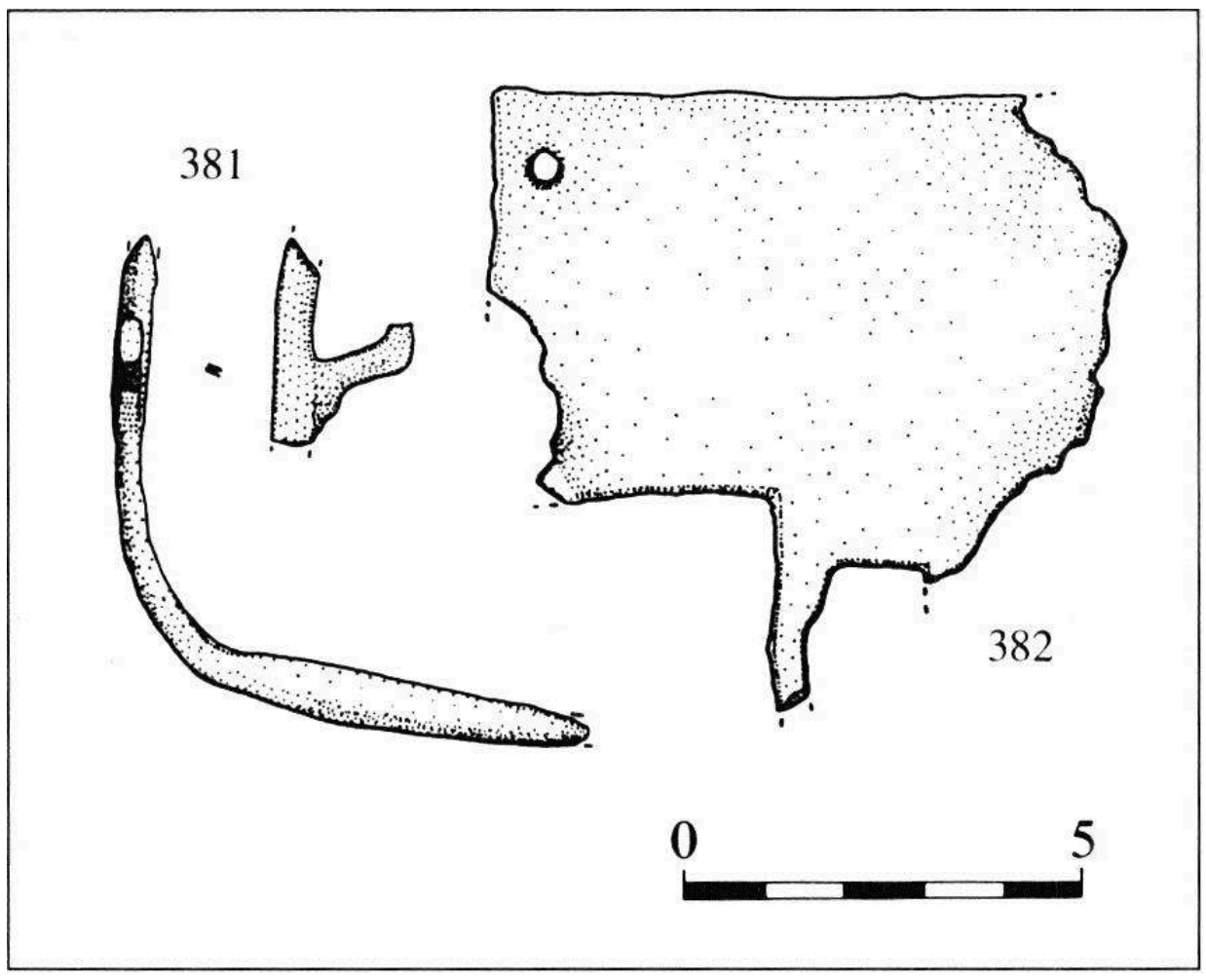

514 Les clés figurent dans le mobilier des oppida, à Manching ou Stradonice (Jacobi 1974: Taf. 48; Pic 1908 : pl. XXXII). Elles apparaissent aussi en contexte funéraire, dans la tombe $\mathrm{n}^{\circ} 7$ de Ménil-Annelles (Ardennes), datée de La Tène D (Anonyme 1984: p. 160, E) : dans ces situations, elles se rapportent sans doute plus à des meubles fermés qu'à des vestiges de portes démontées et incinérées. Régionalement, plusieurs exemplaires existent à Sainte-Blandine.

$\mathrm{n}^{\circ}$ 382. Plaque de serrure en fer, incomplète.

L'objet est constitué d'une plaque de fer comportant deux loges ajourées. Il s'agit d'une 
plaque de serrure dont la fixation était assurée par des clous : un emplacement est d'ailleurs visible à l'angle conservé.

516 Les plaques de serrures sont bien représentées dans le mobilier des oppida (Jacobi 1974 : Taf. 48 et p. 161 ; Pic 1908 : pl. XXXII) et des habitats ouverts (Guichard $1988:$ p. 158). Comme les clés, elles figurent aussi dans des contextes funéraires : c'est le cas dans la sépulture $\mathrm{n}^{\circ} 59$ bis, enclos VII, de la nécropole de Fère-Champenoise (Marne) (Guillaumet 1984: pl. 66, n c-d). Régionalement, plusieurs plaques sont attestées à Sainte-Blandine. L'utilisation de ces plaques se rapporte aux portes, mais sans doute aussi, pour les petits exemplaires, aux coffres et coffrets.

Les clous sont représentés par 81 exemplaires (fig. 106-107) ; c'est donc le document métallique le plus abondant du site.

106- Clous en fer

383

384

385

386

387

388
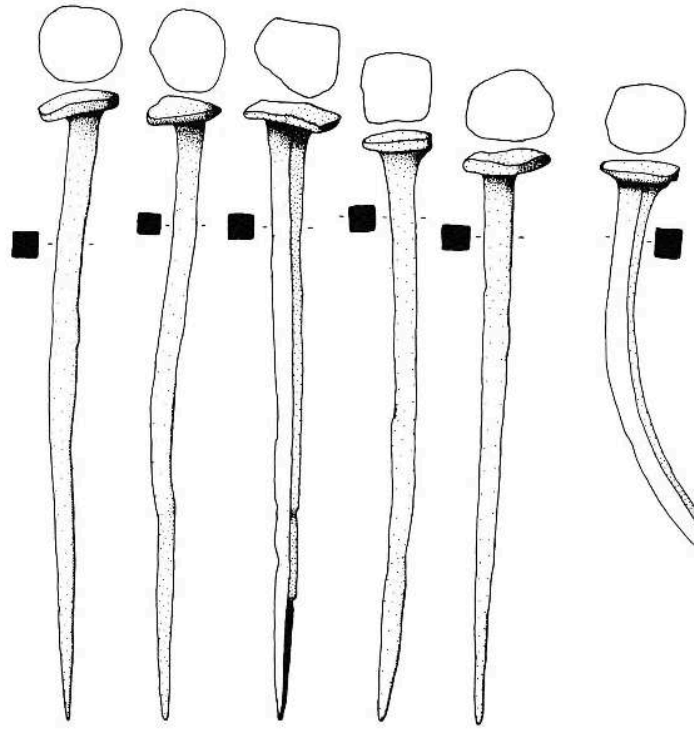
107 - Clous divers en fer

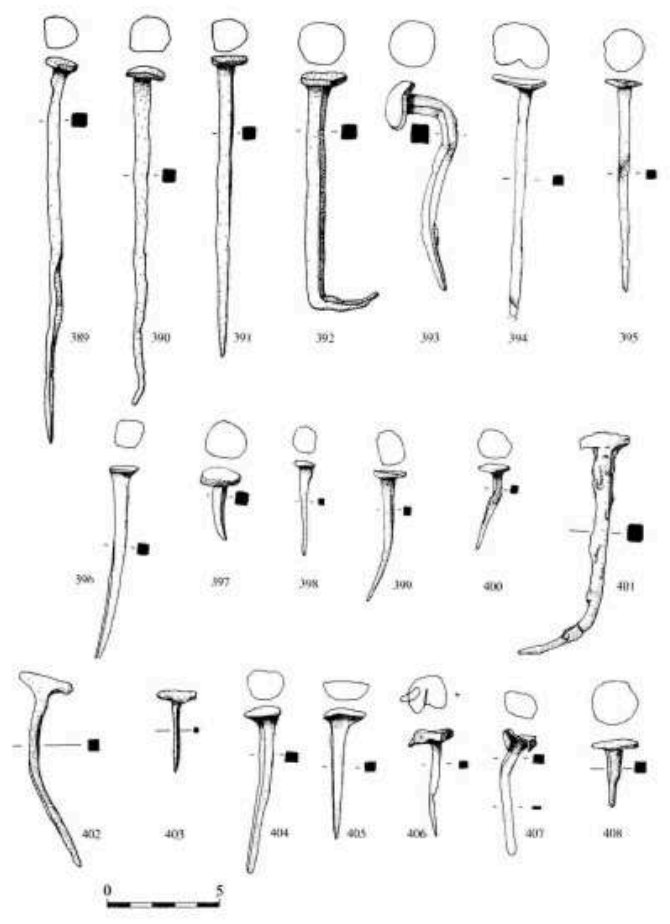

$518 n^{\circ}$ 383-408. Clous en fer intacts ou fragmentés.

Ces derniers montrent une très grande variété dans leurs dimensions, en relation avec leur usage. Les plus grands exemplaires sont des clous de charpente et on ne peut exclure leur emploi dans des assemblages du type murus gallicus. Certains petits exemplaires complets se rapportent peut-être à des meubles. Les clous montrent aussi des variantes de formes, et bien que la majorité d'entre eux possède une tête circulaire ou quadrangulaire, un certain nombre d'exemplaires adopte des profils différents. Certains clous paraissent ne jamais avoir été utilisés, d'autres au contraire montrent des torsions très nettes d'utilisation ou ne sont représentés que par des fragments. Curieusement, tous les plus grands exemplaires, dont les longueurs sont comprises entre 14 et $20 \mathrm{~cm}$, sont intacts (fig. 108). La présence sur plusieurs clous de traces d'oxydation orangées indique que ces objets ne sont en fait que les restes matériels d'assemblages en bois aujourd'hui disparus. 
108- Dispersion des clous selon leur longueur

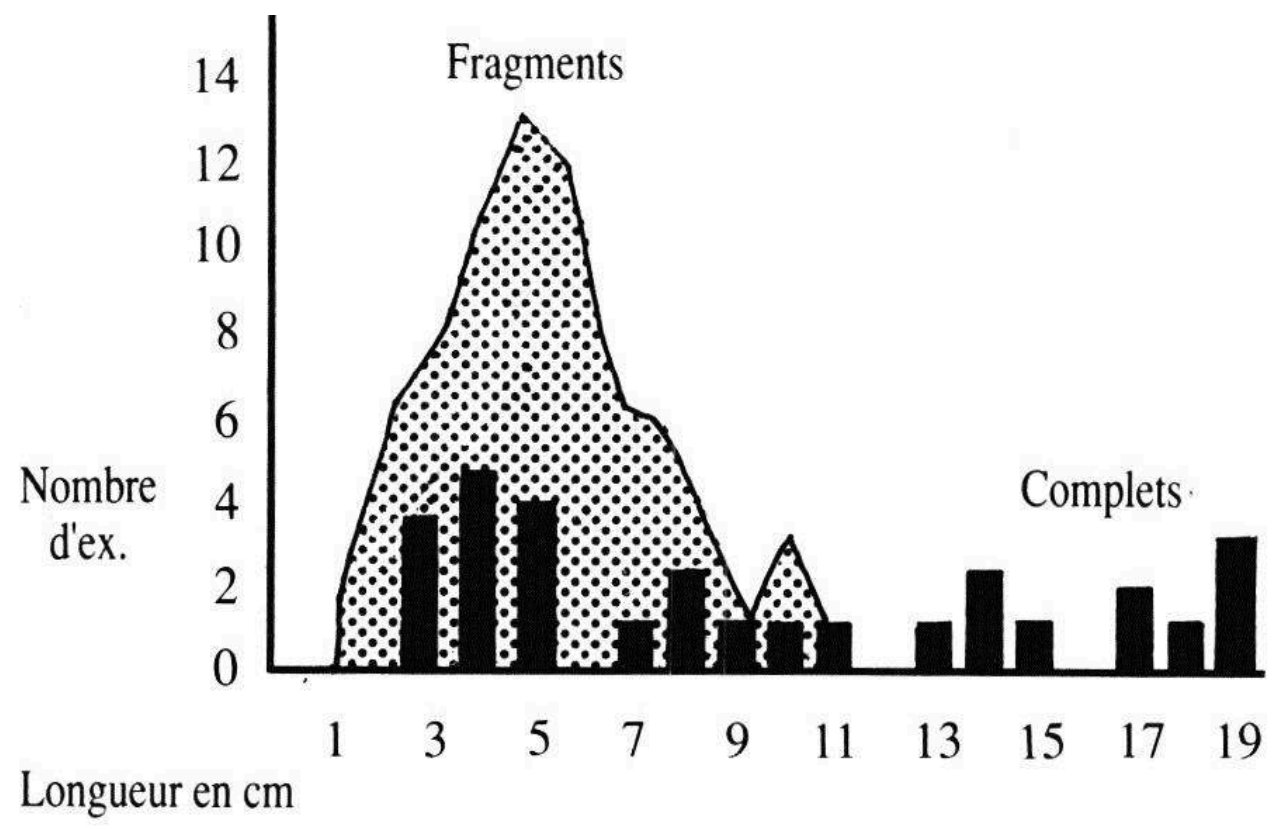

519 La clouterie est bien attestée dès la fin du premier âge du Fer, comme l'attestent les découvertes de Bragny-Sur-Saône, mais c'est surtout dans le mobilier des oppida laténiens, comme Manching, que ces objets apparaissent en grand nombre. La multiplication des fortifications à poutrage interne à la fin de La Tène explique l'accroissement du nombre de ces objets dont l'utilisation n'exclut pas des modes de constructions traditionnels à base de mortaises et de tenons. Si les clous sont naturellement fréquents dans le mobilier des oppicla, ils figurent également dans certaines sépultures du second âge du Fer, en particulier dans le Midi de la Gaule; s'agissant de tombes à incinération, on peut supposer que la présence de ces objets s'explique en partie par l'existence de bûchers construits. Régionalement, ce type de document est très bien attesté à Sainte-Blandine, puisque au moins 165 exemplaires ont pu être dénombrés.

D'autres fragments sont des renforts d'assemblages de bois non identifiés (fig. 109). 
109 - Eléments en fer d'assemblages de bois

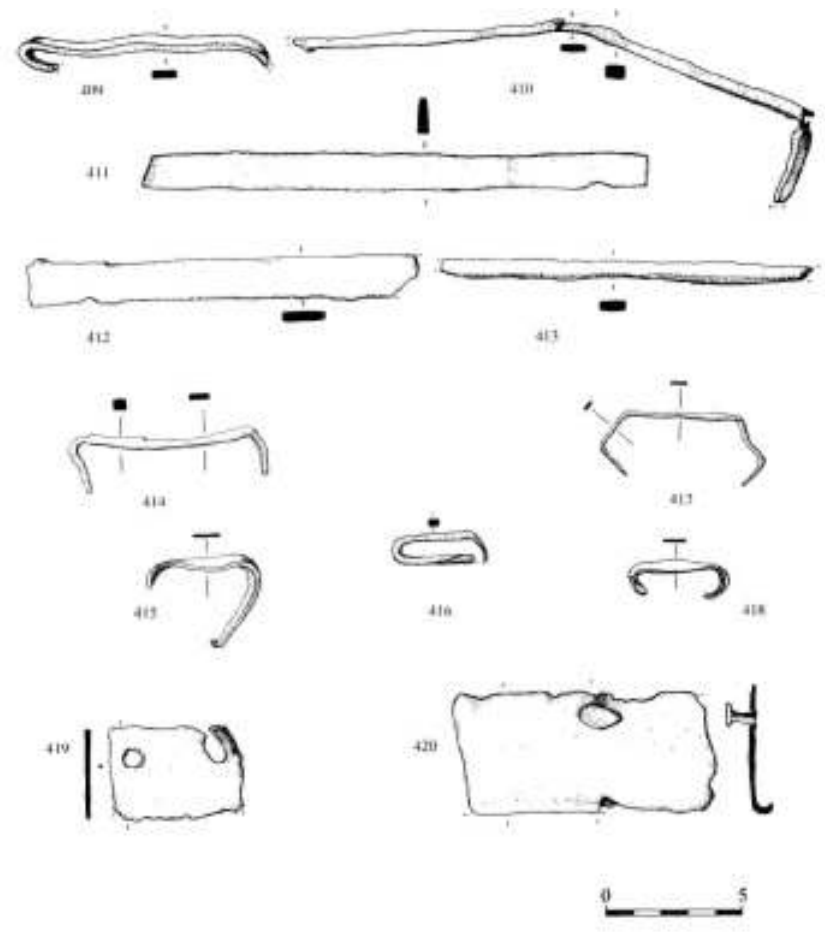

$\mathrm{n}^{\circ}$ 409. Fragment en fer.

Tige de section rectangulaire aplatie, repliée sur elle-même à une extrémité, comme c'était vraisemblablement aussi le cas de la partie opposée.

$\mathrm{n}^{\circ} 410$. Longue tige en fer incomplète, de section quadrangulaire puis plate.

$n^{\circ} 411$. Fragment de tige en fer pliée, de section rectangulaire aplatie.

$n^{\circ}$ 412. Fragment de tige en fer, droite et de section rectangulaire aplatie.

$n^{\circ} 413$. Fragment analogue au précédent.

$\mathrm{n}^{\circ}$ 414. Agrafe en fer incomplète.

Tige de section quadrangulaire, puis carrée, dont les extrémités sont repliées à angle droit. L'objet rappelle la tige $\mathrm{n}^{\circ} 409$; il s'agit d'une agrafe destinée à relier entre elles des pièces en bois.

$\mathrm{n}^{\circ}$ 415. Fragment d'agrafe en fer de section quadrangulaire.

$n^{\circ}$ 416. Agrafe en fer (?).

$\mathrm{n}^{\circ}$ 417. Agrafe en fer intacte.

Gracile, celle-ci est formée d'une tige de section rectangulaire aux extrémités repliées.

$n^{\circ} 418$. Petite agrafe en fer intacte (Jacobi 1974 : Taf. 66-70 ; Furger-Gunti 1980 : Taf. 17, $\left.\mathrm{n}^{\circ} 388-396\right)$

419. Plaque en fer.

Elle est de forme quadrangulaire et comporte deux larges emplacements de rivets à ses angles.

$n^{\circ} 420$. Fragment de plaque en fer.

Elle adopte une forme rectangulaire et son bord est replié pour former une gouttière ; quant à sa base, elle a conservé un rivet à tête losangique. Des plaques similaires 
figurent dans le mobilier de Sainte-Blandine et il pourrait s'agir de plaques de serrure (Chapotat 1970 : pl. XVIII, n 16, 18).

Quelques menus objets permettent d'identifier le petit mobilier, sans doute domestique

(fig. 110).

110- Anse en fer et placage décoratifs en bronze de petits meubles

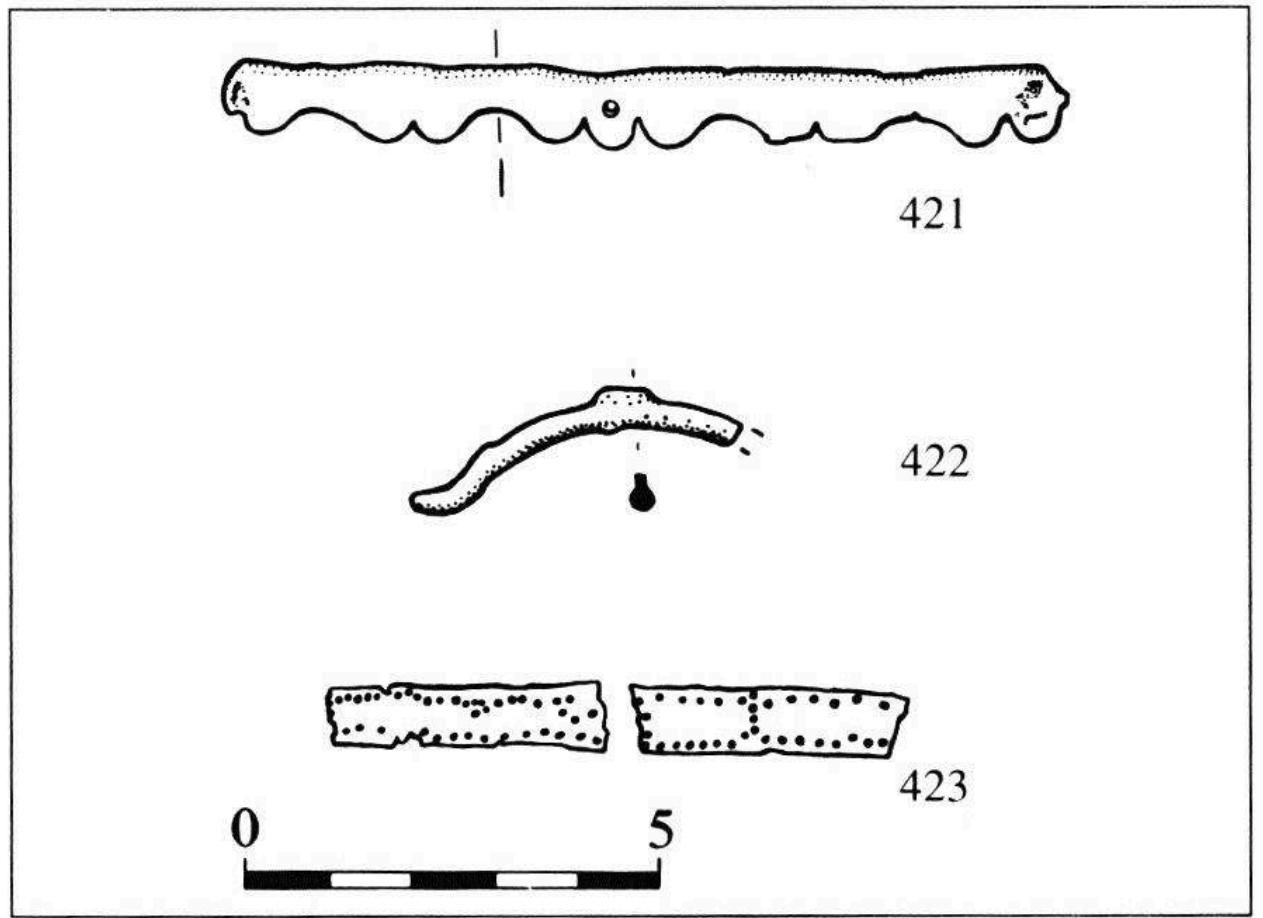

$\mathrm{n}^{\circ}$ 421. Ornement de coffret ( ?) en bronze, complet.

Il s'agit d'une tôle de bronze rectiligne sur un bord, et découpée en forme d'accolade sur l'autre. Le bandage a conservé trois petits clous en fer nécessaires à sa fixation. L'objet ne présente pas de courbure et était donc fixé sur une surface plate, sans doute du bois : il pourrait s'agir d'un ornement de coffret. L'aspect de l'objet n'est pas sans rappeler les cerceaux de seaux, (cf. P. 70.) et ces différents types de tôles sont sans doute le produit du même artisanat. $\mathrm{n}^{\circ} 422$. Fragment d'anse en fer de coffret.

L'objet est formé à partir d'une tige de fer de section circulaire, forgée en arc de cercle. Il s'agit probablement d'une petite anse de coffret. $\mathrm{n}^{\circ} 423$. Fragment d'ornement en bronze de coffret ( ?).

Tôle de bronze ornée au répoussé d'une suite de dépressions parallèles aux bords, formant ainsi deux lignes très irrégulières. Quelques dépressions sont disposées perpendiculairement aux précédentes. Aucun emplacement de rivet n'est visible, mais ce placage est sans doute un ornement d'objet en bois.

537 Anse et placage de coffret sont attestés à Sainte-Blandine, ainsi qu'à Bâle, sur le site de l'usine à Gaz (Chapotat 1970 : pl. XXIV, n 1-3 ; Furger-Gunti 1980 : Taf. 11, n²11-213). 


\section{Les objets divers}

Plusieurs objets sont trop fragmentés pour être identifiés avec certitude, ou bien restent sans comparaison.

\section{1- Objets divers en fer}

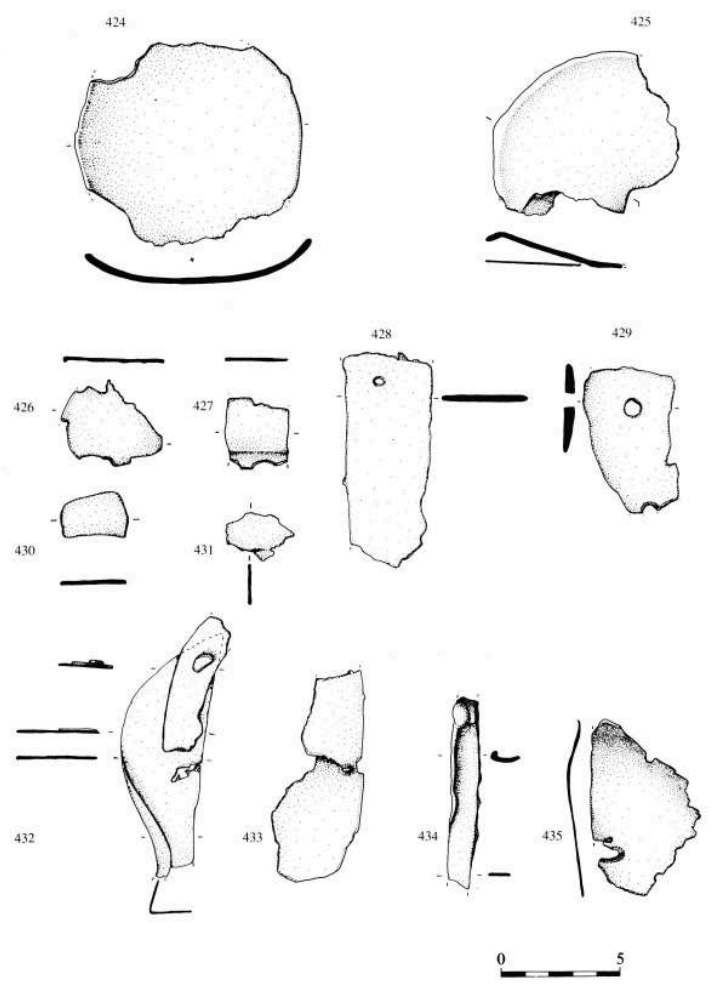
précieuses et vérifier le poids des monnaies (Kruta 1978 : ill. $n^{\circ} 74$ ). repliée. A une des extrémités est fixée, par un rivet, une tige courbe et plate. 
De forme convexe, ses deux bords se rejoignent pour former un angle aigu : fragment d'umbo en fer (?).

112 - Objets divers en fer et en bronze $\left(n^{\circ} 451\right)$

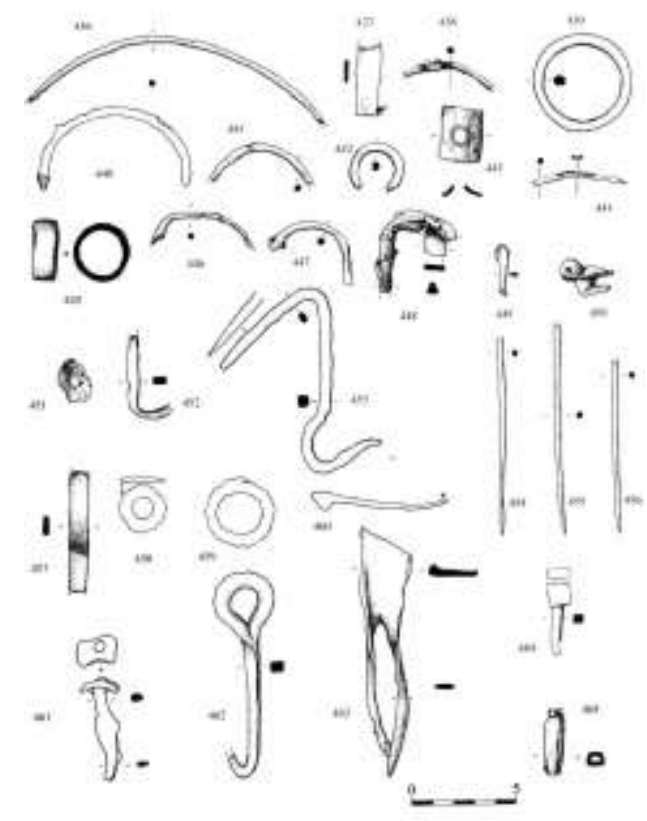

$\mathrm{n}^{\circ}$ 436. Fragment de torque en fer ( ?) (fig. 112).

Tige de section circulaire en forme d'arc de cercle. L'objet rappelle certains torques filiformes, attestés dès la fin du premier âge du Fer, par exemple dans le tumulus II de Chaumouzey (Vosges) (Anonyme 1987 a : p. 79).

$\mathrm{n}^{\circ}$ 437. Fragment de barrette de fourreau (?), en fer.

Tige rectangulaire de section aplatie. Elle est repliée, formant ainsi un angle aigu.

$554 \mathrm{n}^{\circ}$ 438. Objet en fer incomplet.

Il s'agit d'une tige de section circulaire, courbée en arc de cercle. Deux nodosités séparent un emplacement rectangulaire, peut-être destiné à loger une incrustation. De plus, la tige est ornée de fines moulures très rapprochées. S'agit-il d'un fragment de bracelet ou d'une pièce de fourreau déformée?

$555 \mathrm{n}^{\circ}$ 439. Anneau en fer intact.

Anneau de section ovalaire. Trop petit pour être un anneau de mors de bridon, il pourrait s'agir d'un élément de crémaillère.

$556 \mathrm{n}^{\circ} 440$. Fragment de bracelet en fer (?).

L'objet n'est connu que par dessin ; il s'agit d'une tige forgée en arc de cercle, terminée par une partie pointue. Il pourrait s'agir d'un fragment de bracelet. 
Il est formé d'une partie plate torsadées se rejoignant. 
$\mathrm{n}^{\circ} 464$. Objet incomplet en fer.

Tige de section carrée, surmontée d'une partie massive rectangulaire. Un objet proche figure dans le mobilier du site de Charmes (Mancey, Saône-et-Loire) occupé au Hallstatt final (Rajot 1985 : p. 169, fig. 21, $\mathrm{n}^{\circ}$ 54).

$n^{\circ} 465$. Fragment d'objet en fer, creux, massif et de section quadrangulaire.

L'étude du mobilier métallique et non céramique de La Chuire autorise plusieurs remarques. Tout d'abord, il faut noter la chronologie extrêmement longue, qui va du Bronze final à La Tène $\mathrm{D}$, avec quelques absences et des différences notables de représentations : cette situation évoque a priori plus les sites de hauteur de Gaule méridionale que les gisements de même type de Gaule interne. En fait, sur les oppida celtiques, des fréquentations, voire des occupations antérieures à La Tène $\mathrm{D}$, semblent pouvoir être discernées dans la masse des documents livrée par ces sites (GranAymerich 1989 : p. 352-353).

L'examen partiel du mobilier de La Chuire montre l'écrasante prépondérance des documents de l'âge du Fer sur ceux de l'âge du Bronze puisque ceux-ci se réduisent à quelques unités : en fait, l'examen des mobiliers céramiques (cf p. 108.) va montrer que cette appréciation ne peut être généralisée à l'ensemble du site. L'âge du Fer est remarquablement représenté: bien que le site ne soit connu que par quelques sondages, le nombre, la variété des objets (fig. 113) et la qualité de leur conservation font de cet ensemble l'un des plus riches de la Gaule. Si l'on excepte quelques documents du premier âge du Fer, la majeure partie de ce mobilier appartient aux phases B2/C et $\mathrm{D}$ de La Tène. L'apparition des premiers objets laténiens est sensiblement contemporaine de l'émergence de nombreux habitats ouverts (Manching, Aulnat, Levroux) qui évoluent de façon distincte au cours des IIe-Ier siècles av. n. è.; l'oppidum majeur des Vindéliciens se dotera d'une enceinte monumentale, alors que sur d'autres gisements, on observe soit un abandon des habitats ouverts au profit, semble$\mathrm{t}$-il, de sites fortifiés de hauteur, soit le développement parallèle et partiellement contemporain des deux modes d'habitats (Vaginay 1989 : p. 66). 


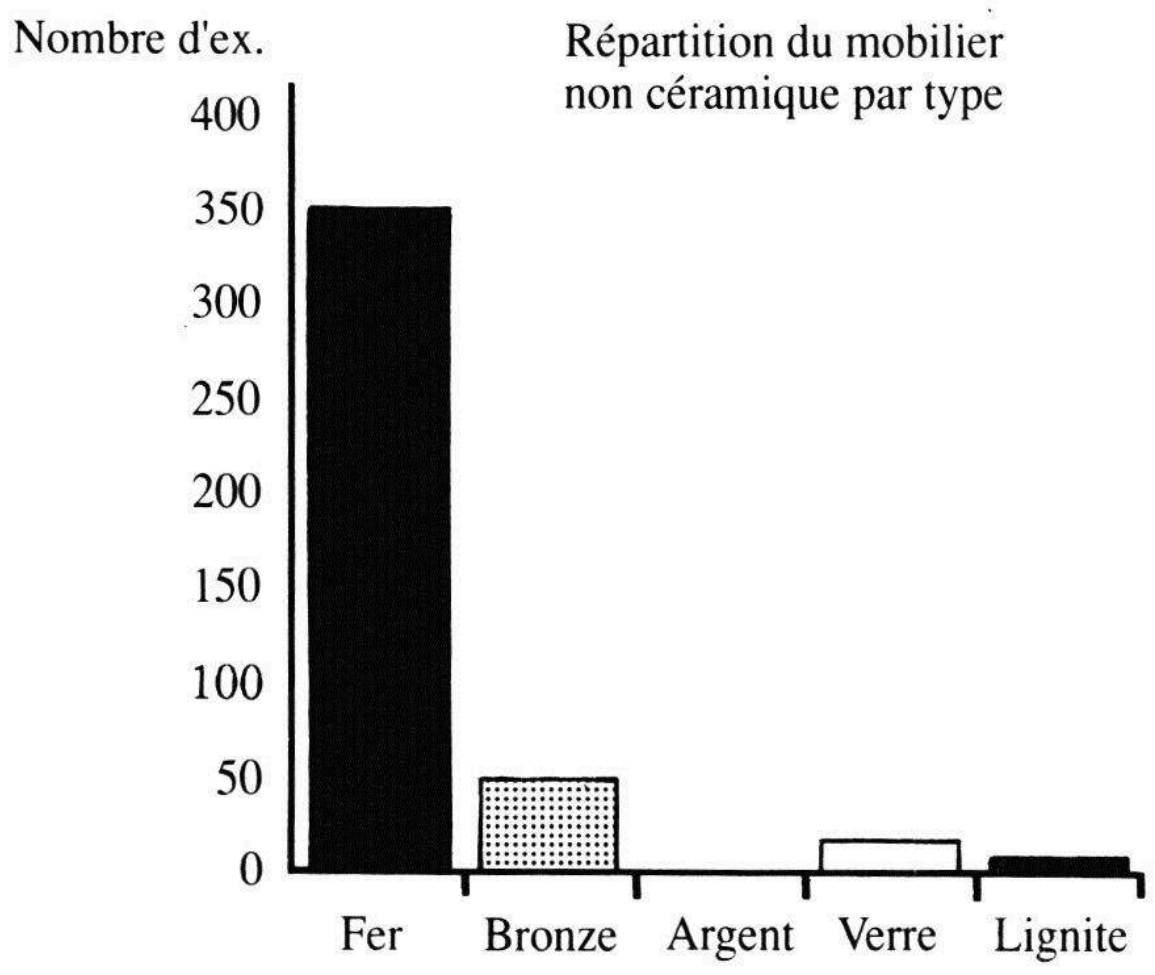

584 Le site de Larina participe avec d'autres gisements, aux profondes mutations qui affectent le monde celtique au cours du IIIe siècle av. n. è. Le fait qu'il s'agisse d'un site de hauteur n'est pas tout à fait original puisque récemment des indices de fréquentations à La Tène $\mathrm{Cl}$ ont été reconnus sur le site-capitale des Eduens (fibule inachevée, vraisemblablement de schéma LT I tardif) et une occupation véritable a pu être datée dans la Loire (Gran-Aymerich 1989; Guichard 1989). La distinction la plus nette avec les sites de la culture des oppida tient à l'absence de mobilier de La Tène D2 et de l'époque augustéenne : en fait, seuls quelques très rares objets peuvent être situés en chronologie vers le milieu du Ier siècle av. n. è., alors que sur les oppida, les occupations les mieux documentées datent du dernier quart du Ier siècle av.n.è.

\section{La céramique}

Les céramiques constituent, par leur nombre, le document le mieux représenté dans la faille de La Chuire ; un comptage ${ }^{5}$ permet d'évaluer le nombre de fragments à 30000 . La diversité des périodes chronologiques, appréhendée à partir du mobilier non céramique se retrouve bien évidemment dans la vaisselle et rend l'étude de celle-ci difficile, puisqu'aucune association stratigraphique n'est possible. De plus, on ne peut écarter a priori l'hypothèse que les périodes chronologiques non individualisées par l'étude des objets non céramiques existent et soient attestées par de la vaisselle.

Actuellement, en Dauphiné et dans les régions limitrophes, force est de constater la rareté des ensembles céramiques clos utilisables et publiés pour les époques du Bronze final et de l'âge du Fer. Sur le site même de Larina, les données concernant la céramique protohistorique n'ont fait l'objet que de publications très partielles (Pélatan 1986) qui ne concernent que la fin de l'âge du Bronze. Cependant, plusieurs sites des 
âges du Bronze et du Fer, récemment observés lors de sauvetages effectués en amont et en aval du Camp de Larina, sont en cours d'étude et seule la publication des études céramologiques de ces gisements permettra d'effectuer le reclassement de l'ensemble de la vaisselle découverte dans la faille de La Chuire.

Dans l'état actuel des recherches sur le site et en tenant compte du bilan exposé plus haut, seule une sélection des principaux types de récipients a été faite. Ce travail ne peut prétendre donner une image parfaite du répertoire céramique du gisement, puisque aucune donnée quantitative, par type ou par classe d'objet, n'est disponible. Cette restriction limite donc la définition du faciès céramique de Larina; néanmoins devant la rareté des études céramologiques fondées sur des critères typométriques, seules habilitées à définir un répertoire de vaisselle, cette sélection peut être considérée comme relativement représentative et utilisable à court terme. Une étude globale de cet ensemble sera indispensable dans l'avenir car, bien que sans contexte, le mobilier céramique de La Chuire constitue le principal moyen de connaissance du site de Larina.

Le lot a été divisé en d'une part, les céramiques d'importation, réunissant les productions grecques d'Occident et les productions italiques, et d'autre part, la céramique indigène. Cette catégorie est formée par deux types de productions, séparées selon leurs modes de fabrication: la céramique indigène non tournée des âges du Bronze et du Fer et la céramique tournée, qui dans le contexte régional, appartient dans son ensemble aux phases récentes $C$ et $\mathrm{D}$ de La Tène. Dans la mesure du possible, un regroupement par phase chronologique a été effectué mais ce classement doit être considéré comme provisoire et sujet à modification. Les profils complets étant rares dans un ensemble assez original, les indications de formes hautes et basses sont purement indicatives.

\section{La céramique d'importation}

\section{Les importations de la fin du premier âge du Fer (fig. 114-116) et du second âge du Fer}

(fig. 117-119)

Quelques récipients appartiennent à des productions bien connues en Gaule méridionale : il s'agit soit d'amphores massaliotes à pâte micacée, soit de céramiques dites "grise monochrome» et "pseudo-ionienne » d'origine provençale. Ce type de production est très minoritaire dans l'ensemble du mobilier, mais est assez caractéristique pour que peu de vases aient pu échapper au tri.

\section{Amphores massaliotes}

590 Trois tessons-un fragment informe, une anse et un bord-présentent les caractéristiques des productions amphoriques massaliotes, aisément identifiables grâce à la présence d'un dégraissant constitué de longues feuilles de mica; seul le fragment de col peut apporter des précisions chronologiques.

$n^{\circ}$ 466. Fragment de col (fig. 114).

Le bord est replié sur lui-même pour former le col, ce dernier étant souligné par une très légère cannelure. La pâte est rose à l'intérieur, beige en surface, et contient en abondance des paillettes de mica blanches et dorées, et des nodules rouges. L'aspect de la pâte du récipient n'est pas sans évoquer une surface métallique. Le col présente une 
légère dépression qui rappelle certaines marques connues sur les amphores de Marseille, en particulier le digamma, mais une cassure empêche d'assurer cette identification (Arcelin 1982: p. 85 ; Bats $1986:$ p. 24); d'autre part, quelques traces brunes à la surface extérieure et intérieure du col semblent indiquer que le conteneur était partiellement peint ${ }^{6}$ comme le sont de rares amphores (Lagrand 1963).

114 - Céramiques d'importation du premier âge de Fer

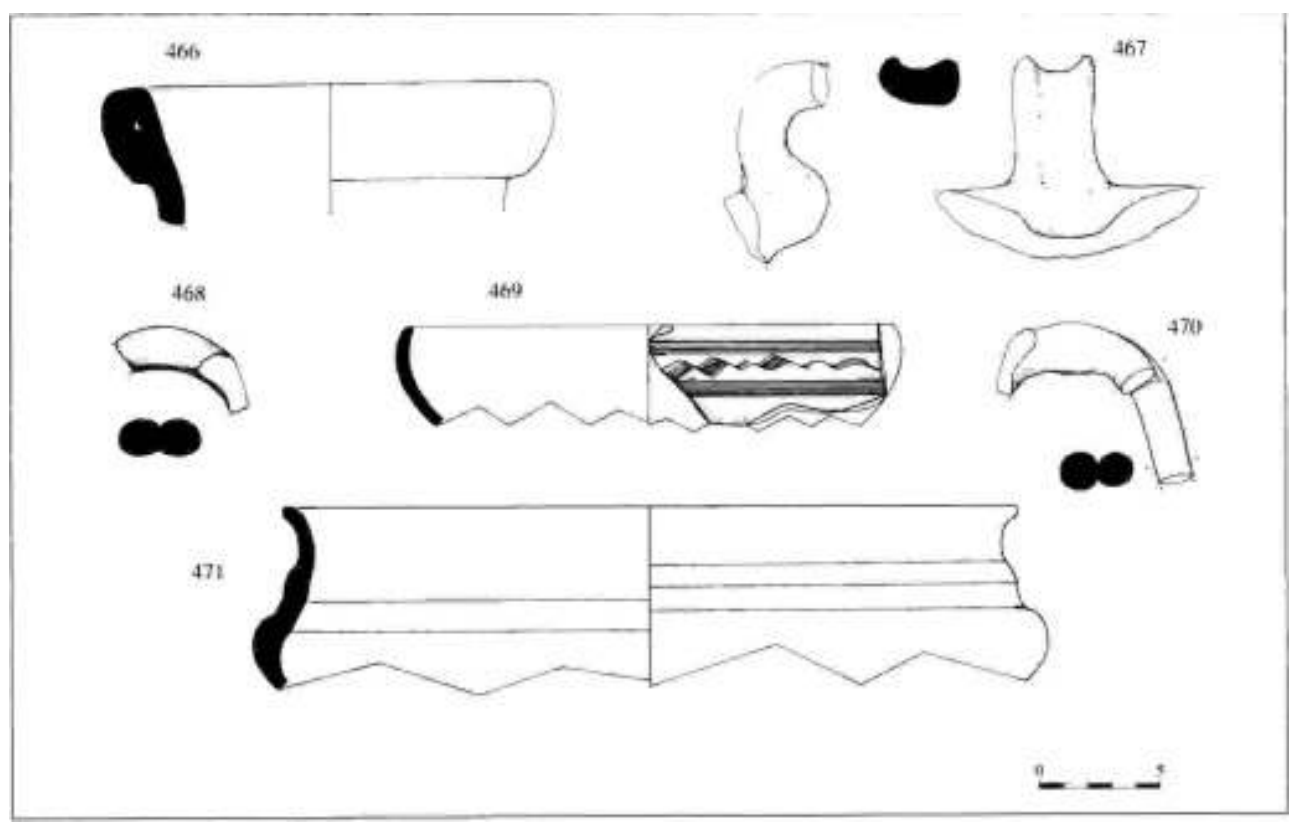

Le mode de confection du bord permet d'attribuer ce fragment de col au type 1 de la typologie de M. Py, appartenant à une amphore massaliote de forme 1 de la même classification (Py 1978 : p. 6-7). Chronologiquement, ce type, en pâte micacée, apparaît dans le Midi de la France dès le dernier quart du VIe siècle et semble disparaître vers 500 av. n. è. ou peu après : il s'agit du plus ancien type d'amphore massaliote, si l'on met de côté les productions «ionio-massaliotes » ou "massaliotes archaïques » qui possèdent un dégraissant très différent et dont la production dans le comptoir phocéen même a été récemment confirmée ${ }^{7}$.

Dans le Centre-Est de la France, les bords de type 1 sont très rares : un seul col de ce type sur les sites de Bragny-sur-Saône et Vix, deux cols au Camp-du-Château à Salins (Jura) (Feugère 1986 ; Benoit 1965 : pl. 45. n 17-18 ; Villard 1988). Par contre, la plupart des sites du Val de Saône ont livré des bords de type 2, 3 et 4, plus récents que les bords de type 1, mais appartenant tous au Ve siècle av. $n$. è. Dans la moyenne vallée du Rhône (Bellon à paraître), ces mêmes types sont représentés avec parfois des types tardifs (Py $5,6)$; le site du Pègue est par exemple approvisionné en amphores massaliotes du Ve jusqu'au début du IIe siècle av. n. è. ${ }^{8}$.

594 En Gaule interne, ces fragments attestent la diffusion, dès le dernier quart du VIe siècle av. n. è., du vin produit par le vignoble marseillais ; bien que les amphores aient pu être utilisées pour le transport d'autres denrées, leur fréquente association avec des oenochoés en céramique " grise monochrome » et " pseudo-ionienne » indique bien la nature du contenu des emballages massaliotes. Quant à la fin de cette circulation de denrée, elle semble se situer vers le milieu du Ve siècle av. n. è. Il s'agit d'un phénomène bref, limité à quelques générations d'individus et sans continuité jusqu'à 
l'arrivée des amphores italiques aux IIe-Ier siècles av. n. è. En fait, d'autres solutions de transport du vin sont envisageables et rien ne permet d'écarter l'hypothèse d'une circulation de conteneurs en matière périssable durant les premiers siècles de La Tène. Ainsi, la consommation du vin étrusque n'est perceptible que par l'existence de services à boire métalliques déposés dans les sépultures princières de la fin du premier âge du Fer alors que l'on ne connaît aucune amphore étrusque au nord des Alpes (excepté l'unique exemplaire de Gorge-de-Loup à Lyon-Vaise) (Bellon à paraitre).

Les conteneurs massaliotes attestés généralement par un peu plus d'une dizaine d'exemplaires sur chaque site, circulent rapidement sur de très longues distances peu après le début de leur production (fig. 115). Leur répartition, limitée à l'axe RhôneSaône jusqu'à Bragny, s'étend au nord de ce site. Ainsi, les amphores massaliotes sont reconnues en direction de l'Est, jusque sur le Haut-Danube (La Heuneburg), vers le Nord, au Mont-Lassois et vers l'ouest comme l'attestent les découvertes récentes de Bourges (Cher). Après une circulation dans la moyenne vallée du Rhône qui délaisse les reliefs (Alpes et bordure est du Massif Central), la répartition des conteneurs massaliotes montre une diffusion en éventail beaucoup plus large. En Gaule interne, ces amphores sont attestées principalement sur les sites fortifiés princiers du Hallstatt Final; sur les limites méridionales de la zone princière, dans le Val de Saône, ces conteneurs figurent sur des sites de plaine mais aussi dans des sépultures aristocratiques (Feugère 1986; Bellon 1989; Millotte 1983). Comme l'avait proposé M. Feugère, c'est bien dans ce secteur, compris entre les régions lyonnaise et chalonnaise, que s'est effectué le regroupement des produits et denrées provençales.

115- Répartition des amphores de Marseille au nord de Bollène

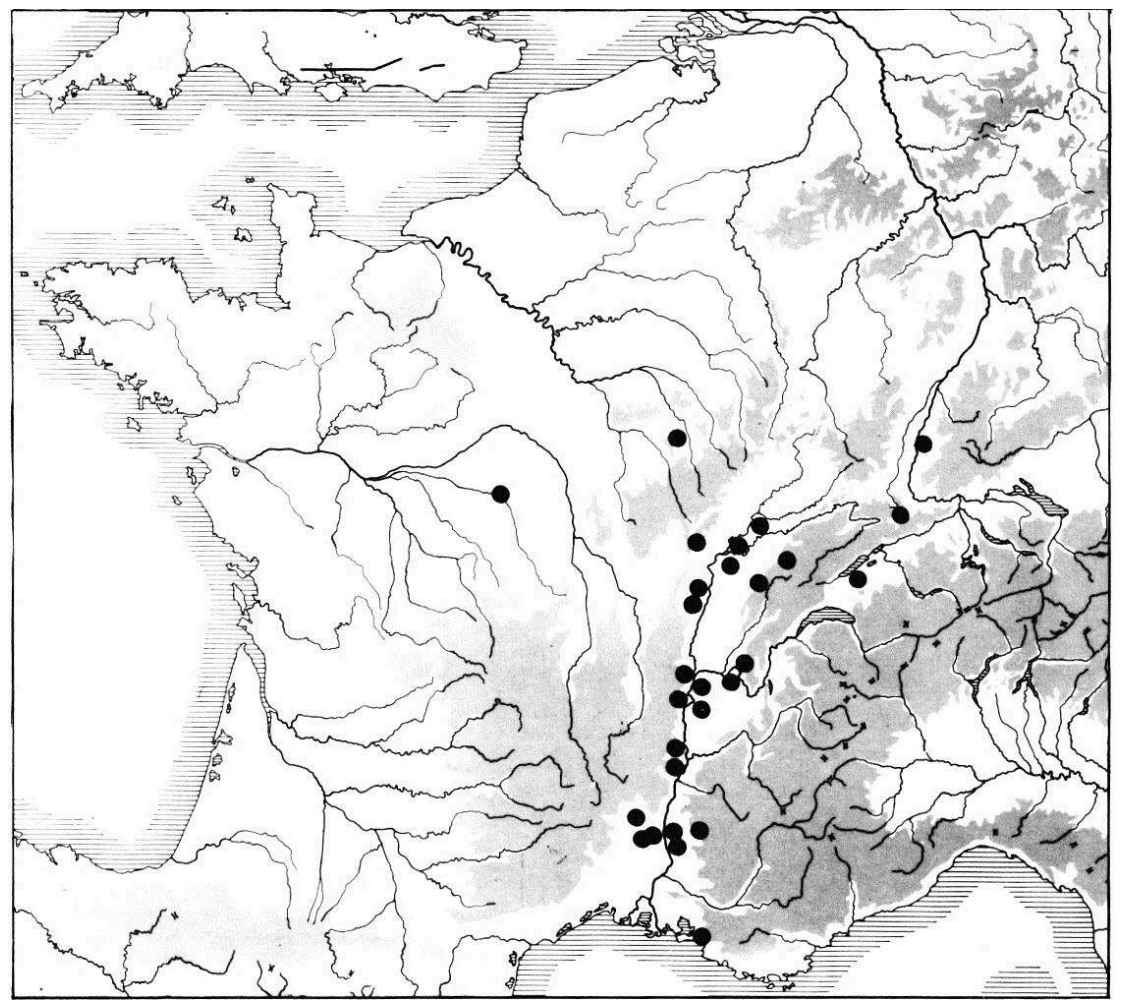




\section{Céramique grise monochrome}

Dans l'ensemble des céramiques tournées, il a été possible d'isoler quelques vases dont les caractéristiques morphologiques et techniques ne correspondaient pas avec celles des productions tournées du second âge du Fer; les comparaisons se sont orientées vers les productions de céramique grecque d'Occident, plus particulièrement vers le groupe des vases "gris monochrome " produits entre le VIe et la fin du Ve siècle av. n. è. en Provence et en Languedoc.

$n^{\circ} 467$. Anse d'oenochoé.

Fragment d'anse surélevée d'une oenochoé. La pâte est très dure, non feuilletée, de couleur grise (légèrement plus sombre à l'intérieur), des vacuoles rondes et étirées sont visibles sur les cassures et à la surface. Le dégraissant est constitué de calcaire, de mica blanc et de petits coquillages fossiles. Par endroits subsistent les traces d'un enduit gris, plus foncé que la pâte.

L'aspect de ce tesson le rapproche nettement des vases du groupe 3, produits dans le Vaucluse (Mourre-de-Sève, Sorgues) entre le deuxième quart du VIe siècle et la fin du Ve siècle av. n. è. (Arcelin-Pradelle 1984 : p. 25-26; 86-88; 146). En Gaule interne, la présence de céramiques du groupe 3 est reconnue sur les sites bourguignons de Bragny et de Chassey, ainsi qu'à Montmorot (Scotto 1985: p. 50 ; Gaiffe 1985: p. 221-224 ; Feugère 1986 : p. 169).

$\mathrm{n}^{\circ} 468$. Anse d'oenochoé.

Fragment d'anse bifide d'une oenochoé de forme Arcelin-Pradelle VIII. La pâte est grise au centre, puis passant graduellement du beige au brun, elle vire au brun foncé sous la surface. Elle contient de petits grains de quartz et du mica. De nombreuses vacuoles sont visibles sur les cassures. L'anse est couverte d'un enduit noir, épais, partiellement disparu. L'attribution à un groupe n'est guère aisée, tout juste pourrait-on évoquer le groupe 7 de Saint-Blaise (Arcelin-Pradelle 1984 : p. 118-122).

$\mathrm{n}^{\circ}$ 469. Bord de coupe.

Il s'agit de la forme II de la typologie de Ch. Arcelin-Pradelle. La pâte est d'une texture légèrement feuilletée; de couleur rose-orangé au centre, elle vire brutalement au gris sous la surface. La pâte contient des inclusions d'argile pulvérulente, du mica en fine division et quelques rares grains de quartz. La surface du vase montre l'existence d'un enduit, partiellement conservé, ainsi qu'un décor incisé obtenu au peigne: il s'agit d'une onde dissymétrique à gauche, encadrée par des bandes rectilignes incisées (Arcelin-Pradelle 1984 : p. 12-15 et p. 52-67).

01 L'aspect de cette céramique pourrait la rapprocher des productions du groupe 2, aspect 1, défini en Provence, et dont les ateliers sont sans doute localisés à Marseille et dans ses environs. Cependant, en l'absence d'une détermination précise effectuée à la binoculaire, toute identification reste incertaine.

Chronologiquement, la production du groupe 2 semble commencer dès le deuxième quart du VIe siècle av. n. è. pour se terminer dans le courant du Ve siècle av. n. è. En Provence, ce groupe est particulièrement bien attesté vers le milieu et le troisième quart du VIe siècle av. n. è. (ArcelinPradelle 1984 : p. 63 ; Arcelin-Pradelle 1982 : p. 36). Dans le Centre-Est de la France, le site de Montmorot (Jura) a livré des tessons attribuables au groupe 2, mais il s'agit de productions attribuées à l'aspect 3 de ce groupe (Scotto 1985 : p. 49). 
Dans le domaine hallstattien, la céramique grise monochrome apparaît généralement sur des sites qui livrent des amphores vinaires massaliotes. Dans le répertoire des céramiques grises monochromes importées, on note la présence de formes hautes du type oenochoé qui sont des vases à verser du service de table. Ainsi, amphores et oenochoés en céramique grise monochrome sont associées sur les sites de Bragny et de Châtillon-sur-Glâne. Très vraisemblablement, les céramiques " grise monochrome " qui ont été diffusées au nord de la moyenne vallée du Rhône, ont constitué des services à boisson, comprenant des vases à verser et des formes à boire, équivalents «massaliotes » des services à vin étrusques. Il semble que ce soit principalement le ou les ateliers du groupe 3 centré sur le Vaucluse, qui ait diffusé vers la Gaule interne ; cela ne peut surprendre dans la mesure où la céramique " grise monochrome » bien qu'issue des productions de Grèce de l'Est, caractérise plutôt les sites indigènes de Gaule méridionale, que des sites strictement grecs. C'est donc vers les régions nordprovençales qu'il convient de rechercher les sites qui auraient pu assurer la diffusion des amphores de Marseille vers le monde celtique en accompagnant le vin produit dans la chora massaliote, de céramiques locales. L'attribution incertaine de certains vases à des ateliers localisés près de Marseille et la présence d'assiettes typiquement marseillaises à Vix indiquent cependant une diffusion plus marginale de mobilier d'accompagnement du vin depuis le comptoir phocéen.

\section{Céramique pseudo-ionienne}

Ce terme regroupe des productions de Gaule méridionale dérivées des céramiques à décor géométrique de Grèce de l'Est parfois qualifiées de «sub-géométrique rhodanien » ou de " céramique à pâte claire ». Si ce type de céramique est fréquent en Provence, en Languedoc et jusque dans un secteur compris entre Bollène et Valence, il est par contre beaucoup plus rare dans des régions plus septentrionales.

$\mathrm{n}^{\circ}$ 470. Anse d'oenochoé.

Plusieurs fragments d'anses bifides permettent d'identifier au moins 2 oenochoés, attribuables aux productions dites "pseudo-ionienne » ou "claire peinte ». En Gaule interne, ces céramiques figurent dans les mêmes contextes que les amphores massaliotes et les céramiques "grise monochrome" mais sont cependant moins fréquentes que ces dernières. Cette céramique peinte est attestée au nord de la moyenne vallée du Rhône, sur les sites de Gorge-de-Loup à Lyon-Vaise (Bellon 1989 : p. 20), ainsi qu'à Bragny, Châtillon-sur-Glâne (Feugère 1986: p. 169). Quelques gisements ont livré des fragments appartenant à des oenochoés : Breisach-Miinsterberg (RFA) sur le Rhin et Ambérieu-en-Bugey à proximité du Camp de Larina (Kimmig 1983 : p. 24, pl. VI, no 2 ; Bomatico 1957 : p. 33, fig. 11)

Ces vases peints ont sans doute eu la même fonction que leurs équivalents en céramique "grise monochrome » et participé à de modestes services de table, destinés à la consommation du vin. Curieusement, alors que les céramiques peintes "pseudoionienne » sont bien représentées dans la moyenne vallée du Rhône, en particulier au Pègue, ce sont les céramiques "grise monochrome" produites plus au sud qui sont majoritairement attestées dans le répertoire des importations provençales présent sur les sites hallstattiens nordrhodaniens. Quant au lieu de fabrication des oenochoés de La Chuire, il est impossible à définir précisément, en l'absence d'étude synthétique sur ce type de productions : l'aspect des ces tessons évoque plus les céramiques du Pègue que celles de Marseille. 


\section{Céramique " cannelée "}

607 Cette production, de filiation nord-italique, ne constitue pas à proprement parler une céramique d'importation dans le monde hallstattien occidental; toutefois sa rareté dans l'ensemble céramique de La Chuire pourrait indiquer une provenance extrarégionale.

$608 \mathrm{n}^{\circ}$ 471. Céramique cannelée.

Il s'agit d'une céramique tournée. La pâte est dure, bien cuite, de couleur brun clair. Du mica finement broyé et des nodules rouges constituent le dégraissant. La surface extérieure a été soigneusement lissée et présente un aspect brillant. Le vase est orné de quatre cannelures horizontales entre le haut de la panse et la base du bord. L'intérieur du récipient montre la présence d'un dépôt blanchâtre non calcaire : il pourrait s'agir éventuellement des traces d'un contenu, des laitages ou de la saumure.

Ce récipient, par ses caractéristiques, appartient aux productions dites "cannelées" systématiquement représentées sur les sites majeurs du Hallstatt final, principalement sur les sites princiers, mais aussi sur des habitats à vocation commerciale. Leur production locale est assurée sur les habitats de La Heuneburg et de Châtillon-surGlâne ; elle est probable au Pègue, puisque le décor cannelé se retrouve sur des vases typiquement locaux par leur forme et leur décor (Lagrand 1973). Dans la partie méridionale de la zone princière et dans la moyenne vallée du Rhône ces productions ne sont représentées que par quelques exemplaires, toujours de la même forme (Feugère 1986; Courbin 1976) (fig. 116). Si l'hypothèse d'une diffusion technologique par un ou des potiers s'impose en raison des découvertes du Pègue, on ne peut écarter la possibilité d'un circulation commerciale à partir de centres producteurs, Pour ce qui concerne l'unique vase de La Chuire, seule une analyse pourrait permettre d'identifier l'éventuel contenu qui a généré un dépôt blanchâtre, et d'associer à ces vases particuliers une quelconque matière périssable. 
116 - Répartition des céramiques cannelées dans l'Est de la France

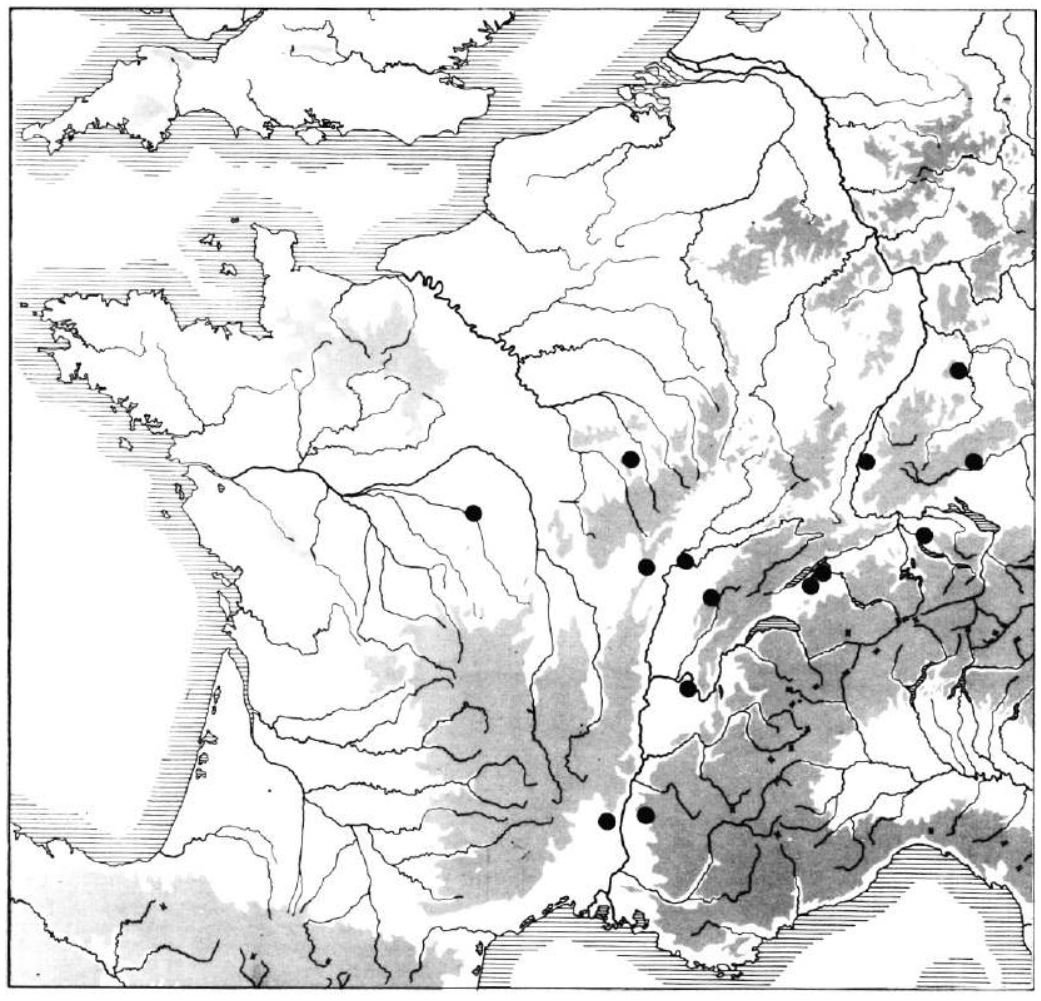

\section{La céramique à vernis noir}

610 Les céramiques à vernis noir découvertes à Larina proviennent de la faille de La Chuire, à l'exception de 2 fragments $\left(n^{\circ} 483,491\right)$ mis au jour lors des fouilles de l'habitat du Bas-Empire (fig. 117). 


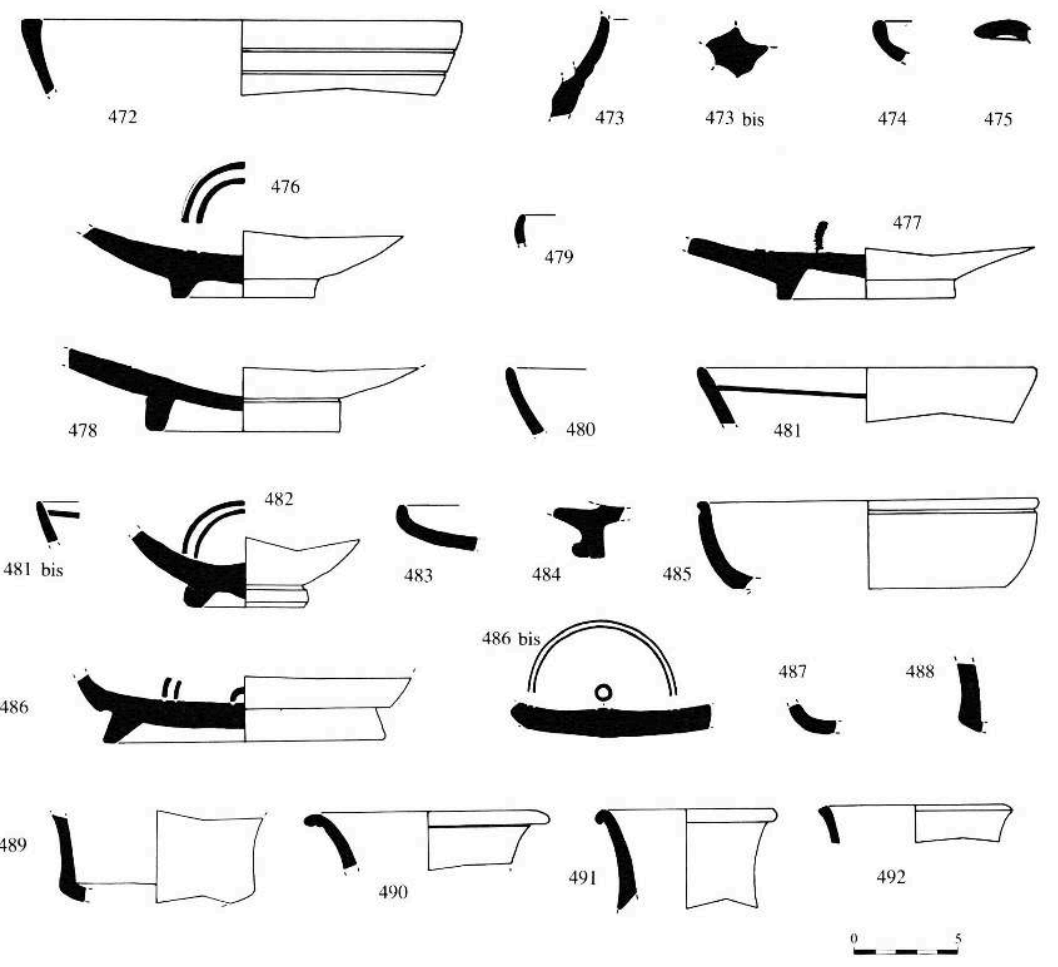

611 Cette classe de céramique comporte 68 fragments (en comptant pour un seul fragment les pièces recollées à partir de plusieurs tessons), qui représentent approximativement une vingtaine de vases.

612 Ils se répartissent ainsi :

- campanienne A : 29 fragments ;

- cercle de la campanienne B : 37 fragments ;

- autres : 2 fragments.

En outre, un autre fragment pourrait éventuellement être classé parmi les céramiques à vernis noir (voir infra, $\mathrm{n}^{\circ} 473$ bis).

614 « $\mathrm{F}$ » (pour les formes) et « $\mathrm{P}$ » (pour les pieds) suivis d'un nombre renvoient à la typologie de Morel 1981 ; « Lamb. » renvoie à la typologie de Lamboglia 1952.

\section{Fragments anciens}

Les deux tessons sûrement à vernis noir qu'il est impossible de classer dans la campanienne A ou B se distinguent nettement du reste du lot par leur datation relativement haute. Il en est peut-être de même pour un fragment insolite.

$616 \mathrm{n}^{\circ} 472$. Fragment du bord d'un bol. Pâte épurée, ocre ; vernis lisse, luisant, franchement noir, avec toutefois quelques reflets métalliques. A l'extérieur, sous le bord, deux fins sillons horizontaux. Diamètre du bord de l'ordre de $19 \mathrm{~cm}$.

617 L'aspect du vernis, l'épaississement de la lèvre, les sillons à l'extérieur, rappellent des vases de la Campanie septentrionale et en particulier de la fabrique de Teano (aucun parallèle exact dans Morel 1981, qui comporte peu de ces vases de Teano; mais voir F 
2411, de dimensions plus petites). La date la plus vraisemblable est les environs de 300 ou le premier tiers du IIIe siècle av.n.è.

$618 \mathrm{n}^{\circ}$ 473. Fragment de paroi d'une petite cruche, avec l'attache inférieure d'une anse verticale en boudin aplati. Pâte épurée, chamois ; vernis noir un peu pâle, mat, solide, à l'extérieur comme à l'intérieur du vase. La paroi interne est mal lissée.

619 La forme est difficile à reconstituer. On peut penser à titre d'hypothèse à un profil proche de F 5222. La datation de ce fragment est probablement voisine de celle du $n^{\circ} 472$ ci-dessus ; elle a toutes chances en tout cas d'être antérieure au IIe siècle.

$\mathrm{n}^{\circ} 473$ bis. Fragment énigmatique dont l'appartenance à la céramique campanienne n'est pas certaine. Paroi épaisse : pâte variant du marron clair à l'ocre, incluant un assez gros gravier blanc; surface ocre-jaune; seule une petite partie de la superficie (près de l'arrachement du pied ?) porte un vernis, ou plutôt une couverte noir pâle, micacée, lisse au toucher. A noter une sorte de cupule (?) centrale non vernissée.

\section{Campanienne A}

621 Nous ne décrirons pas individuellement les caractéristiques visuelles de ces fragments de la grande production napolitaine. Ils appartiennent généralement à une $\mathrm{A}$ très médiocre et manifestement tardive: pâte semée de vacuoles; vernis mat ou franchement terne, à tendance cuivrée, avec des taches rougeâtres autour du pied, couvrant toujours la totalité du vase, souvent très usé ; tournage et lissage très négligés engendrant fréquemment de nettes traces de doigts horizontales en forme de côtelures irrégulières, et/ou des irrégularités de forme; pieds bas ou très bas, peu obliques. Quant à la texture de la pâte, sableuse au toucher, elle peut être due à la nature du sol où ces fragments ont été enfouis.

Les formes représentées sont uniquement des patères et des bols.

$\mathrm{n}^{\circ} 474$. Fragment de bord de patère à lèvre redressée obliquement et légèrement épaissie. Qualité nettement mauvaise. Rappelle (mais avec une lèvre plus épaisse) $\mathrm{F}$ 2 252b, ou F 2 822. Date : vers $100+/-50$.

$\mathrm{n}^{\circ}$ 475. Deux fragments de bord d'une patère Lamb. 36 à paroi épaisse et à lèvre presque horizontale, proche de F 1315. Date : première moitié du Ier s. ?

$\mathrm{n}^{\circ}$ 476. Fond d'une patère presque plate. Qualité exécrable : pâte à vacuoles, vernis très terne, surface particulièrement mal lissée. Pied très bas, trapézoïdal (rappelant P 221c 4). Au centre, deux sillons concentriques irrégulièrement tracés. Date : première moitié ou milieu du Ier siècle.

$\mathrm{n}^{\circ}$ 477. Fragment de fond d'une patère plate, comprenant quatre tessons recollés. Qualité exécrable. Au centre, une zone de guillochures sans timbres (ce qui est tout à fait exceptionnel). Date : fin du IIe s. ou (plutôt ?) première moitié du Ier $\mathrm{s}$. $\mathrm{n}^{\circ}$ 478. Fragment de fond d'une patère presque plate. Qualité exécrable (une énorme vacuole superficielle, une crevasse). Au raccord du pied et de la paroi externe, une petite gorge due au tournassage. Aucun décor. Date : probablement première moitié du Ier $\mathrm{s}$. A noter 8 autres fragments de paroi de patères.

$\mathrm{n}^{\circ}$ 479. Petit fragment du bord d'un bol à lèvre bombée légèrement rentrante. Assez belle qualité. Voir F 2784d. Date : deuxième moitié du Ile s. ou autour de 100 ? 
$\mathrm{n}$

$\mathrm{n}^{\circ}$ 480. Fragment du bord d'un bol évasé. Mauvaise qualité. Pour la forme, cf. F 2941 ou peut-être 2942. Date : première moitié ou milieu du Ier s. A noter 2 autres fragments de forme analogue.

$\mathrm{n}^{\circ}$ 481. Fragment du bord d'un bol. Qualité mauvaise. La forme peut être F 2954 ou F 2 977a. Sous le bord, à l'intérieur. un filet surpeint en blanc. Date : deuxième moitié du IIe s. ou commencement du Ier s. ?

$n^{\circ} 481$ bis. Un autre fragment analogue, dont le filet blanc est tracé irrégulièrement.

$\mathrm{n}^{\circ}$ 482. Fragment $\mathrm{du}$ pied et $\mathrm{du}$ fond d'un bol. Qualité très mauvaise, pied irrégulièrement tourné. Forme : F 2 974a, ou (à la rigueur) F 2 952a ou 2 954. Deux filets concentriques surpeints en blanc sur le fond interne. Date : deuxième moitié du IIe s. ou plutôt (d'après le profil du pied) autour de 100, voire un peu plus tard. A noter encore deux fragments de bord et un fragment de paroi de bol.

\section{Cercle de la campanienne B}

3 On sait les problèmes d'identification que pose la nébuleuse de productions qui s'est progressivement constituée autour des premières campaniennes $B$ d'Etrurie. Dans les exportations vers la Gaule, les pseudo-B, et notamment la B-oïde de Calès, jouent un rôle de premier plan (Morel 1978: p.162), et on ne peut du reste exclure que des pseudo-B aient été produites en Gaule même.

4 La plupart des fragments de Larina (que sauf exception nous ne décrirons pas individuellement) sont caractérisés par une pâte variant du chamois assez foncé au chamois-ocre, parfois nettement micacée ; et par un vernis qui atteint rarement un noir intense, presque toujours mat, souvent un peu rugueux. Il est impossible de déterminer leur origine en l'absence d'analyses physico-chimiques ou de caractéristiques visuelles qui nous orienteraient vers Calès, comme un vernis violacé ou des timbres en losange.

5 Ces céramiques sont très difficiles à dater avec une certaine précision, surtout à l'état de fragments, et nous préférons n'avancer de datation que dans de rares cas.

$\mathrm{n}^{\circ}$ 483. Fragment de bord d'une patère très peu profonde à bord relevé, forme Lamb. 5 : voir F 2 255d ou plutôt F 2 257. Date : fin du IIe s. ou début du Ier s. ? 4 fragments de bord se rattachent à une forme analogue. Il en est sans doute de même de 7 fragments de paroi, dont un a été découvert sur le plateau de Larina.

$7 \mathrm{n}^{\circ} 484$. Fragment du fond et du pied d'une grande patère. Qualité médiocre. Pied à bourrelet épais, à sillon sous le plan de pose (type absent de la typologie de Morel 1981).

$8 n^{\circ} 485$. Fragment de paroi et de bord d'un bol Lamb. 1. Assez belle qualité; au bas de la paroi, méplat à carène arrondie. Un sillon sous le bord, à l'extérieur. Variante à un seul sillon de F 2322 ou F 2324.

$\mathrm{n}^{\circ}$ 486. Deux fragments jointifs du fond d'un bol Lamb. 1. Pâte fortement micacée. Pas de gorge autour du fond externe; méplat très accentué au bas de la paroi, autour du pied; décor incisé composé d'un petit cercle central et de deux autres cercles concentriques. Le fond du vase s'est scindé horizontalement en deux parties, indice probable de la façon dont cette pièce a été montée sur le tour. F 2324.

comme le précédent. 
$641 \mathrm{n}^{\circ}$ 487. Deux fragments du bas de la paroi d'un bol Lamb. 1, probablement avec un méplat autour du pied.

$\mathrm{n}^{\circ}$ 488. Fragment du bas de la paroi carénée d'une pyxide Lamb. 2, de la série F 1222 (la carène forme un angle obtus, cf. par exemple $\mathrm{F} 1222 \mathrm{~d}, \mathrm{e}, \mathrm{f}, \mathrm{g}$ ). Deux autres fragments se rattachent sûrement ou peut-être au même vase. $\mathrm{n}^{\circ}$ 489. Fragment de paroi d'une pyxide Lamb. 2 à carène émoussée, probablement de la série F 1225 . Date probable : première moitié du Ier $\mathrm{s}$.

$644 \mathrm{n}^{\circ}$ 490. Trois fragments de bord appartenant très probablement à une pyxide Lamb. 2, à lèvre fortement évasée: cf. F $1222 \mathrm{a}, \mathrm{b}$ ou $\mathrm{f}$. Un détail insolite: deux sillons très nettement tracés à l'extérieur, sous la lèvre.

$\mathrm{n}^{\circ}$ 491. Fragment (deux morceaux recollés) de la paroi et du bord d'une pyxide Lamb. 3. Bord à petit bourrelet arrondi nettement marqué : voir par exemple $\mathrm{F} 7544 \mathrm{e}$.

$\mathrm{n}^{\circ} 492$. Petit fragment de bord d'interprétation difficile. Paroi verticale, lèvre formant un petit bourrelet anguleux à l'extérieur. Il pourrait s'agir du bord d'une pyxide Lamb. 3, à comparer par exemple avec $\mathrm{F} 7$ 544c 1.

$\mathrm{n}^{\circ}$ 493. Fragment de paroi assez atypique et nettement différent des autres tessons de Larina appartenant au cercle de la B. Paroi fine (épaisseur 3,5 mm). Pâte chamois, épurée, plutôt tendre: vernis d'un noir assez franc, luisant et solide à l'intérieur, extrêmement usé à l'extérieur. La forme parait être un bol évasé $\mathrm{F} 2960$ (surtout $\mathrm{F}$ 2961 ou 2964$)$ non illustré.

648 Signalons également un minuscule éclat de céramique conservant son vernis d'un côté seulement. Ce vernis d'un noir profond, un peu luisant, très lisse, est d'une très belle qualité qui tranche sur la masse des tessons de Larina. Ce fragment pourrait être attribué toutefois au cercle de la $\mathrm{B}$, sans que son appartenance à une $\mathrm{B}$ étrusque soit probable.

\section{Le faciès campanien de La Chuire}

Il faut noter avant tout la présence de deux fragments sûrement antérieurs au IIe siècle, et remontant peut-être aux environs de 300 (No 472 et 473). Une telle présence en Gaule interne est à ce jour exceptionnelle, puisqu'on ne peut citer vers $300 \mathrm{ou}$ peu après que deux fragments de l'atelier des petites estampilles au Pègue - un site plus méridional et précocement irrigué par le commerce méditerranéen - et, dans la deuxième moitié du IIIe siècle, un fragment à timbre L. Saura de Vieille-Toulouse (Morel 1985 : p. 183); vers le tournant du IIIe siècle au IIe siècle, mais peut-être encore dans le IIIe siècle, on connaît des fragments de A précoce à Lacoste en Gironde (ibid.), à Aulnat et Gerzat dans le Puy-de-Dôme (inédits). On voit que Larina se singularise avec Vieille-Toulouse, dans ce tableau, par la présence loin de la Méditerranée de deux fragments nettement antérieurs à 200 et qui n'appartiennent ni à l'atelier des petites estampilles, ni à la campanienne A.

Le reste de la campanienne de La Chuire dessine en revanche un faciès tardif. Insistonsy encore : il est souvent difficile de dater les campaniennes du cercle de la B. Mais les Boïdes de La Chuire ne peuvent guère avoir été importées avant le dernier tiers du IIe siècle (Morel, 1978: p. 162); et, surtout, la campanienne A qui les accompagne est tardive. Certes, toutes les formes attestées pour cette dernière pourraient remonter au IIe siècle: mais les caractéristiques du façonnage, les formes des pieds, l'aspect du 
vernis, les maigres décors, tout semble conduire vers une période comprise entre la fin du IIe siècle et le début de la seconde moitié du Ier siècle, avec sans doute une nette prédominance des importations du Ier siècle. Par ailleurs, la forte proportion de campanienne A, et cela en Gaule interne, déconseille de faire trop systématiquement descendre la totalité de ce lot vers le milieu du Ier siècle.

Quant au cercle de la $\mathrm{B}$, il pose le problème habituel de sa provenance. On peut penser à Calès, bien sûr, quoique nous ayons indiqué supra les raisons qui empêchent d'adopter sans réserve cette hypothèse. On peut penser aussi à des fabriques de la Narbonnaise voire, pour une époque tardive, de la région de Lyon-, ou encore d'Italie du Nord (ainsi, le $\mathrm{n}^{\circ} 491$ provenant du plateau peut être comparé à $\mathrm{F} 7544 \mathrm{e} 1$, de Bergame; cf. par ailleurs l'étude par $M$. Feugère du simpulum $n^{\circ} 1$ ). Mais d'une façon générale le faciès campanien de Larina se différencie très nettement de celui de l'Italie du Nord, qui se prolonge jusqu'à Genève (Morel 1987 : p. 129-130) : aussi est-il peu vraisemblable que beaucoup de ces céramiques, d'aspect très "méditerranéen" (par opposition à des faciès plus terrestres riches en céramiques à vernis noir d'Arezzo ou de Modène, par exemple) soient parvenues à La Chuire par les Alpes, et la voie du Rhône semble dans la grande majorité des cas le cheminement le plus probable.

652 Le répertoire des formes, pour les IIe-Ier siècles, se caractérise d'une part par une grande monotonie et une grande simplicité (aucune forme à anses, par exemple); et d'autre part, en ce qui concerne le cercle de la B, par la relative abondance des pyxides (utilisées comme vases à onguents? comme salières ?).

653 Enfin, le faciès de la campanienne de Larina diffère de celui de sites relativement voisins comme Tournus (Morel-Perrin 1976), ou Roanne (Morel 1985 : p. 183, 185), ou Feurs (Morel 1988 : p. 96), confirmant ainsi la grande diversité des situations en Gaule interne, qui doit inciter à de nombreuses études de détail avant qu'une vision d'ensemble ne puisse se dégager.

654 J.-P. M.

Céramique à pâte claire du Ile-Ier siècle av. n. è. (fig. 118)

$655 \mathrm{n}^{\circ}$ 494. Fragment de cruche tournée.

La pâte est fine, de couleur beige-clair. Le col est droit, doté d'un bord légèrement éversé adoptant un profil triangulaire. La surface du récipient porte encore les traces d'un engobe rosé et la base de la lèvre est soulignée par une double incision, tracée dans la pâte encore fraîche. 


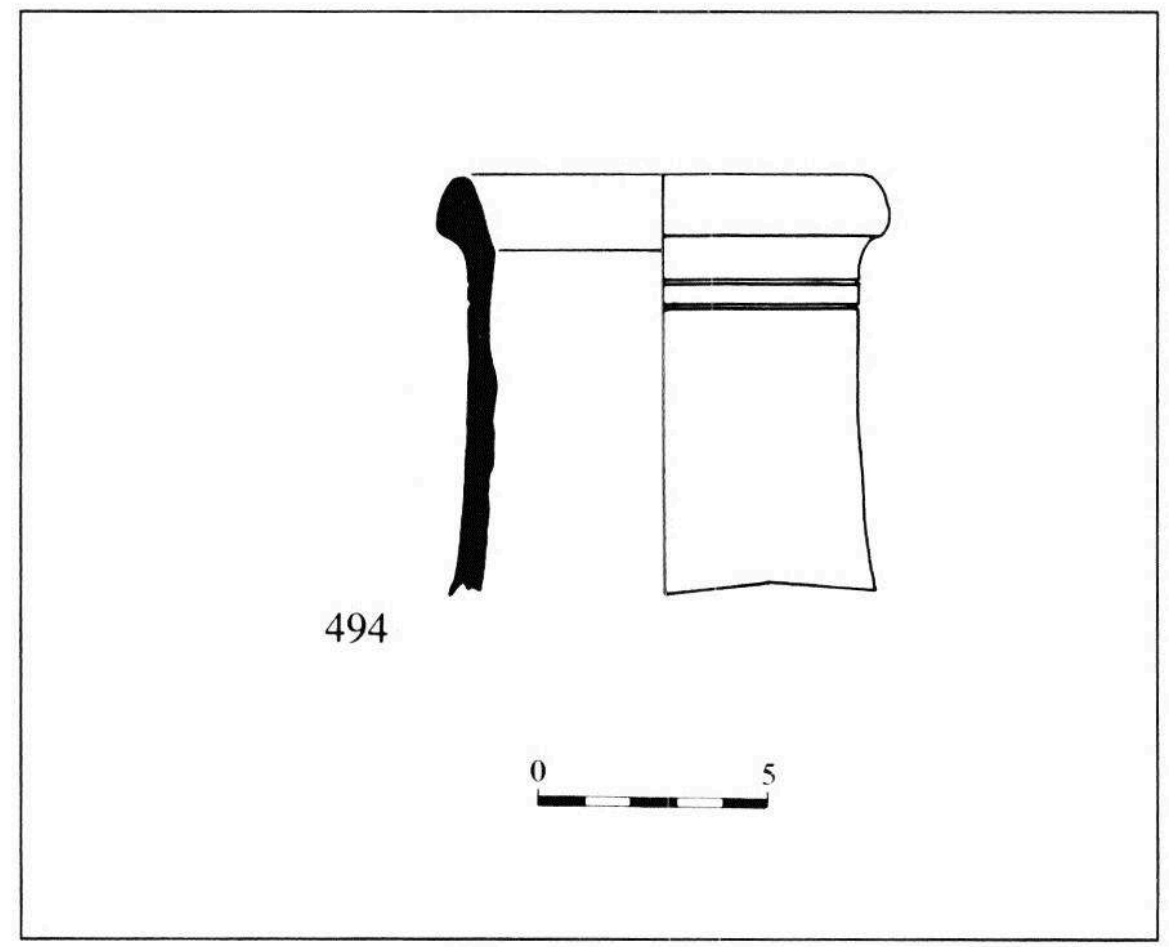

Cette céramique est représentée par une dizaine de vases attestés par des fragments de col large et de panse. Une seule forme a été identifiée : la cruche à liquide, qui est un des récipients du service de table. Ces récipients d'origine italique ou provençale sont diffusés en Gaule interne dès la fin du IIe siècle av. n. è. En Forez, ces productions sont attestées sur les sites de Goincet (Loire) et de Feurs dans des contextes de La Tène C2 et D (Morel 1988 : p. 9798); elles sont plus rares en Roannais. Régionalement, plusieurs cruches figurent dans les mobiliers de Lyon (Verbe-Incarné : 3 ex. ; rue Châtelier : 1 ex.) dans des contextes de La Tène D2, ainsi qu'à Vienne (Sainte-Blandine: 4 ex.). Aux confins du territoire allobroge, deux exemplaires figurent dans l'horizon II de Genève (Suisse), daté des années 123-95 av. n. è. (Bonnet 1989; p. 15). Très certainement, ces cruches parviennent sensiblement au même moment en territoires allobroge et ségusiave. La présence de tels vases dans des sépultures du Ier siècle av. n. è. du sud de la Gaule où figurent des composants du service à boire (simpulum, situles, amphores) et le fait que leurs surfaces soient engobées indiquent le lien probable avec la consommation du vin (Dedet 1978: p. 127-134). En Gaule interne, cette fonction n'est pas démontrée puisqu'en Forez ces récipients sont connus dans des niveaux anciens qui ne livrent pas d'amphores (Vaginay 1984). L'absence de conteneurs à vin n'impliquant pas nécessairement l'absence de vin qui peut être redistribué dans des emballages variés (outre, tonneau), on ne peut pas écarter pour ces cruches l'hypothèse d'un usage analogue en Gaule méridionale et en Gaule interne.

Amphores républicaines (fig. 119)

$n^{\circ}$ 495-508. Fragments de cols. 

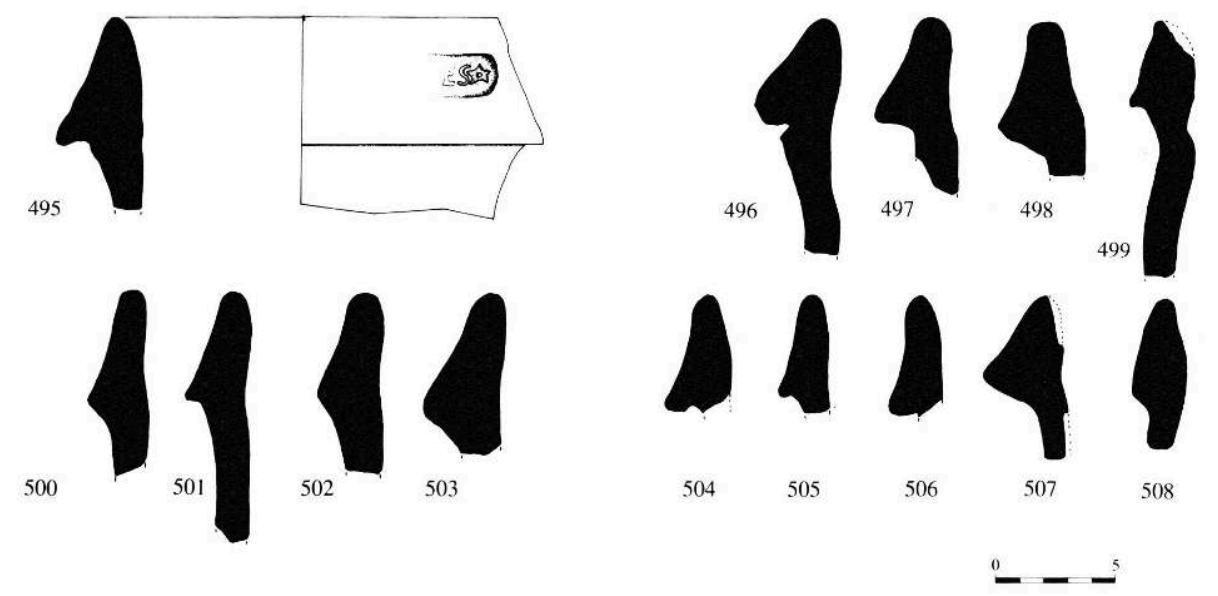

Les amphores italiques sont attestées par 14 récipients, identifiés par des fragment de cols, appartenant en majorité au type Dressel 1 A (Républicaine III de F. Benoit). Seul un col porte une estampille de fabricant : il s'agit du type "Sestius à l'étoile ", originaire d'Etrurie et connu par 10 exemplaires dans le fossé aval du VerbeIncarné à Lyon (Genin 1989 : p. 62). Le nombre d'individus est nettement inférieur aux décomptes calculés sur les sites ségusiaves de la fin du second âge du Fer (Aulas 1988: p. 91) et sur les sites suisses de Bâle (Furger-Gunti 1979 et 1980) ; la même constatation peut être faite sur les sites gallo-romains de Lyon et de Saint-Romain-en-Gal (Desbat 1989: p. 106). Cette distorsion est probablement due à une différence chronologique qui s'exprime dans le mobilier de La Chuire par la rareté des documents datables de La Tène D2. A SainteBlandine, les amphores italiques sont de même très peu nombreuses ( 8 ex.) dans un ensemble céramique certainement incomplet et qui ne compte que 1054 tessons de l'âge du Fer (Chapotat 1970 : p. 96). Comme l'a noté V. Guichard (Guichard $1988:$ p. 154), cet ensemble comprend surtout des documents métalliques de La Tène D1 et très peu d'objets peuvent être rapportés à la phase suivante (en excluant plusieurs parures qui n'apparaissent que sous le règne d'Auguste). La découverte récente à Genève d'amphores apuliennes antérieures aux années 123 av. n. è. (Bonnet 1989 p. 12-13) confirme d'ailleurs l'arrivée précoce des vins italiques en territoire allobroge.

Le site de La Chuire montre une situation rarement observée dans le Centre-Est de la Gaule, puisqu'il témoigne à la fois de la circulation des produits massaliotes à la fin du VIe siècle av. $n$. è. et de la diffusion des produits italiques au cours des IIIe-Ier siècles av. n. è. Si des situations identiques sont fréquentes dans la moyenne vallée du Rhône, au Pègue (Saint-Marcel, Drôme), à Soyons (le Malpas, Ardèche) et à Saint-Etienne-deDions (Ardèche), et même à Vienne, les sites plus septentrionaux qui témoignent de la circulation des produits massaliotes ne livrent généralement pas d'objets liés à la diffusion des vins italiques: c'est le cas de Bragny (Saône-et-Loire), de Montmorot (Jura), de Châtillon-sur-Glâne (FR. Suisse)... Cela tient au fait que les sites princiers hallstattiens ne sont pratiquement pas réoccupés après leur abandon à la fin du premier âge du Fer. Pour ce qui concerne les importations au cours du second âge du Fer, la présence de vases du IIIe siècle av. n. è. est tout à fait remarquable, puisque jusqu'à présent, en Gaule interne, les documents italiques de cette époque sont exceptionnels, et appartiennent à d'autres catégories de Campanienne. (Morel 1978 : p. 165-166; Morel 1985: p.181-187; Morel 1988: p. 96). C'est peut-être le cas d'une 
lampe « italique " à vernis noir provenant d'une tombe de la nécropole des Poplainnaux à Gourgançon (Marne) datée du IIIe siècle av. n. è. (Kruta 1985 : p. 40).

En fait, le site de La Chuire ne serait pas un cas unique et d'autres points de découvertes ont été signalés dans le Centre-Est de la Gaule : par exemple à Lijay (Guichard 1989), à Saint-Romain-en $\mathrm{Gal}^{9}$ et Vienne (Pelletier 1966 : p. 152). Tout le problème se pose de connaître le cheminement effectué par ces vases. A priori on peut penser à une diffusion par la moyenne vallée du Rhône où plusieurs sites de hauteur ont livré des vases, vraisemblablement du IIIe siècle av. n. è., par exemple le Pègue (Lagrand 1973 : p. 98-103) et Soyons. On pourrait alors lier ces premières importations italiques aux circulations précoces d'espèces massaliotes qui sont attestées jusqu'en Suisse (Allen 1973). La présence d'une obole massaliote dans la tombe 22 de Vevey est particulièrement significative à cet égard puisque le mobilier de cette nécropole présente de multiples analogies avec les documents de La Tène $\mathrm{C}$ de La Chuire (Von Kaenel 1981 : p. 119-120, Abb. 13); en ce qui concerne Larina, le poids élevé de certaines oboles ( $\left.\mathrm{n}^{\circ} 764-765\right)$ plaide en faveur de frappes anciennes, mais pas nécessairement de circulations précoces. Toutefois, il ne faut pas exclure d'autres voies de circulation, en particulier celles des cols alpins. Il faut, en effet, noter que jusqu'au niveau des sites du Pègue et de Soyons, ces productions anciennes coexistent avec des amphores massaliotes tardives, alors que plus au nord aucun de ces conteneurs n'a été signalé.

Un autre aspect intéressant la chronologie de La Tène est perceptible à partir du mobilier à vernis noir. En effet, la datation très ancienne de certains fragments constitue un élément de confirmation de la datation haute du début de La Tène $C$, proposée par V. Kruta (Kruta 1983 a: p.9). Malgré l'absence d'associations stratigraphiques, il n'y a aucune raison de dissocier ces vases importés des premières formes de fibules adoptant le schéma La Tène II présentes à La Chuire. C'est donc dans la première moitié du IIIe siècle qu'il convient de situer chronologiquement l'apparition de ces dernières. La remarque n'est pas sans conséquence pour la datation des nécropoles laténiennes du Plateau Suisse qui livrent un mobilier analogue à celui de La Chuire. Sur le site éponyme de La Tène qui paraît débuter à la phase $\mathrm{C}$, la seule datation dendro-chronologique significative est celle d'un bouclier à umbo bipartite (229 av. n. è.) par contre un pieu et une planche ont fourni des dates antérieures, dans le deuxième quart du IIIe siècle av. n. è. $(251+/-8 ; 254+/-8)$ (Suter 1984 : p. 88).

\section{La céramique indigène}

662 Bien qu'aucun calcul statistique n'existe, la céramique modelée ou finie au tour lent semble majoritaire sur le site.

\section{La céramique de l'âge du Bronze}

663 Dans l'ensemble du mobilier céramique livré par la faille de La Chuire se distinguent de nombreux vases dont la morphologie et l'ornementation sont caractéristiques de la fin du Bronze final, mais il n'est guère évident d'apporter des précisions chronologiques pour certaines formes. Cette céramique, cuite en modes B et B', est généralement d'excellente qualité, bien que modelée à partir de pâtes grossières ou mi-grossières et les surfaces de certains vases sont parfois soigneusement lissées. 


\section{Céramique peinte (fig. 120)}

Plusieurs coupes à profil rectiligne et à lèvre en marli, lisse ou cannelée, ont conservé un décor peint bicolore. Les pâtes sont évidemment grossières, mais les surfaces, dans la plupart des cas, ont été soigneusement égalisées.

120- Céramiques peintes du Bronze final

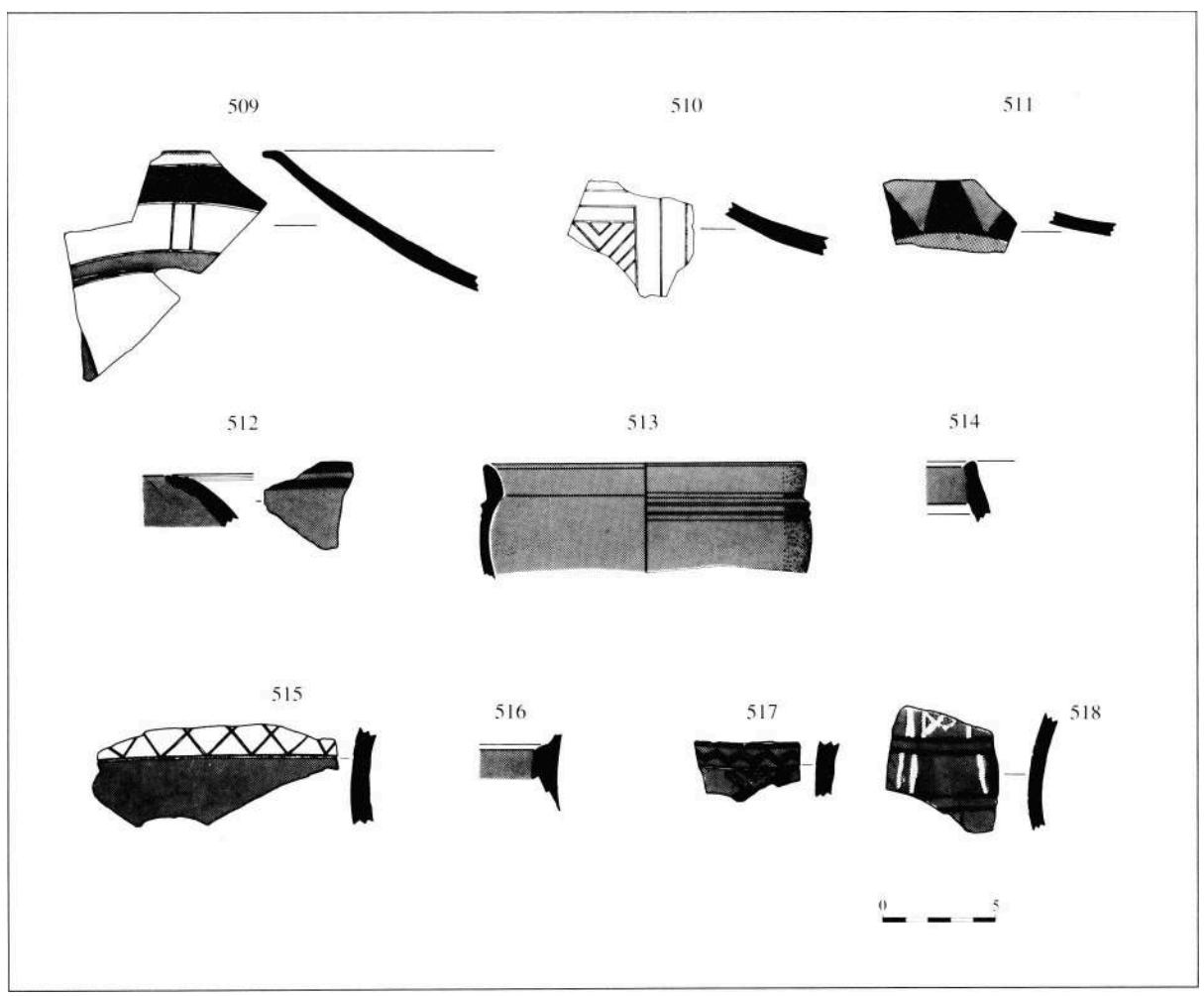

$665 n^{\circ}$ 509. Tesson de coupe.

Avant cuisson, le récipient est orné de cercles concentriques incisés de largeur variable; les zones obtenues sont cloisonnées par de nouvelles bandes transversales. Le vase est ensuite peint en rouge lie-de-vin, soit entièrement, soit uniquement sur la face interne de la coupe; cette peinture est appliquée de manière à réserver certaines bandes qui par la suite sont peintes en noir mat ou brillant, mais il arrive que le noir soit appliqué sur une bande préalablement rouge.

$\mathrm{n}^{\circ}$ 510. Un tesson porte un décor incisé sans trace de peinture; le décor obtenu est pourtant analogue aux incisions délimitant des surfaces peintes. $\mathrm{n}^{\circ}$ 511. Partie centrale de coupe.

Ce tesson porte un décor de triangles incisés peints en noir, vraisemblablement avec du graphite, vu l'aspect métallique brillant de la peinture ; le reste du vase est de couleur rouge lie-de-vin.

$n^{\circ}$ 512. Fragment de coupe à lèvre cannelée peinte en rouge et noir.

Les formes fermées et peintes sont moins nombreuses; comme les coupes, elles peuvent être bicolores, mais le plus souvent il s'agit de vases uniquement rouge lie-devin.

$n^{\circ}$ 513. Petit vase à épaulement marqué par une double cannelure, entièrement peint en rouge lie-de vin. 

présence de matières minérales colorantes (graphite, hématite) qu'il faut rechercher et transporter; dans l'état actuel des recherches, on ne sait si elles figurent à proximité du site de Larina. De même, on peut se demander s'il s'agit de fabrication strictement locale et marginale ou de productions qui auraient pu faire l'objet d'une diffusion restreinte à partir de sites particuliers.

Céramique commune fine ( $n^{\circ}$ 519-553) (fig. 121-122) et grossière ( $n^{\circ}$ 554-592) (fig. 123-124)

Le site de La Chuire a livré une part notable de tessons attribuables à la phase récente de l'âge du Bronze. Si les vases fins ne posent pas de problèmes de comparaisons, il n'en va pas de même pour les formes modelées dans des pâtes grossières pour lesquelles il est difficile d'assurer une attribution chronologique tant les confusions avec des périodes plus récentes sont possibles. 
Sous l'appellation "céramique fine", on peut rassembler des vases à parois fines et bien cuits, quoique des changements de teintes, fréquemment observés sur les surfaces, indiquent que les cuissons ont parfois été mal contrôlées. Les surfaces sont généralement soigneusement lissées, à un point tel pour certains récipients que l'on peut parler de polissage. Le répertoire comprend surtout des coupes à profil rectiligne divergent à marli ou à lèvre facettée, mais aussi des vases globulaires à col divergent et en «bulbe d'oignon ». L'ornementation consiste en des cannelures fines ou larges, des incisions simples ou doubles qui se répètent à la surface du vase ou des impressions fines sur les angles dégagés par les cannelures. Quelques décors sont un peu plus élaborés, en particulier les méandres symétriques formés de doubles incisions qui ornent des urnes à col droit et lèvre oblique ainsi que des vases globulaires. Toutes ces formes existent dans le répertoire régional du Bronze final III b (Daumas 1985 ; Vital 1984 ; Bocquet 1969 a) et certains vases se retrouvent dans quelques fosses observées sur le plateau de Larina (Pélatan 1986). Il convient cependant d'exclure quelques formes qui appartiennent sans doute à une phase antérieure de l'âge du Bronze final, en particulier un vase à décor de cannelures obliques et un récipient ansé à fond ombiliqué (Prades 1985 : p. 35 ; Dedet 1985 : p. 13). Diverses céramiques semblent donc devoir être rapportées au Bronze final II, peut-être même pour certaines à la phase précédente comme le laissait supposer l'analyse du mobilier métallique (cf. p. 31).

Le groupe des céramiques grossières rassemble à la fois des formes hautes à col droit ou divergent et des coupes à lèvres biseautées ou obliques. Modelés à partir d'argile contenant un dégraissant hétérogène, les vases possèdent des surfaces parfois brutes, le plus souvent égalisées par raclage ou lissage. Le répertoire ornemental se réduit à de larges cannelures et à des impressions oblongues ou triangulaires réalisées respectivement au doigt ou avec une baguette. Un certain nombre de vases destinés sans doute au stockage des denrées est orné par des cordons, rapportés ou non, décorés d'impressions variées que l'on retrouve parfois sur la lèvre. Si certaines peuvent être attribuées sans réserve au Bronze final III b, d'autres ne sont pas assez caractéristiques pour assurer leur chronologie. 
121 - Céramiques fines du Bronze final

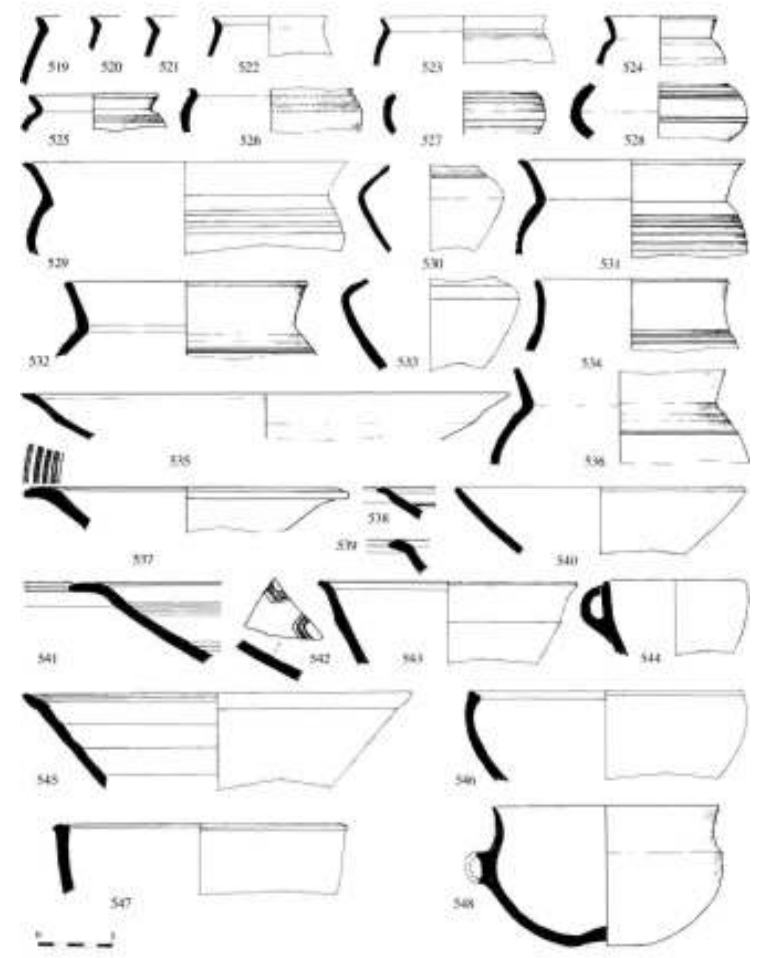

122- Céramiques fines du Bronze final

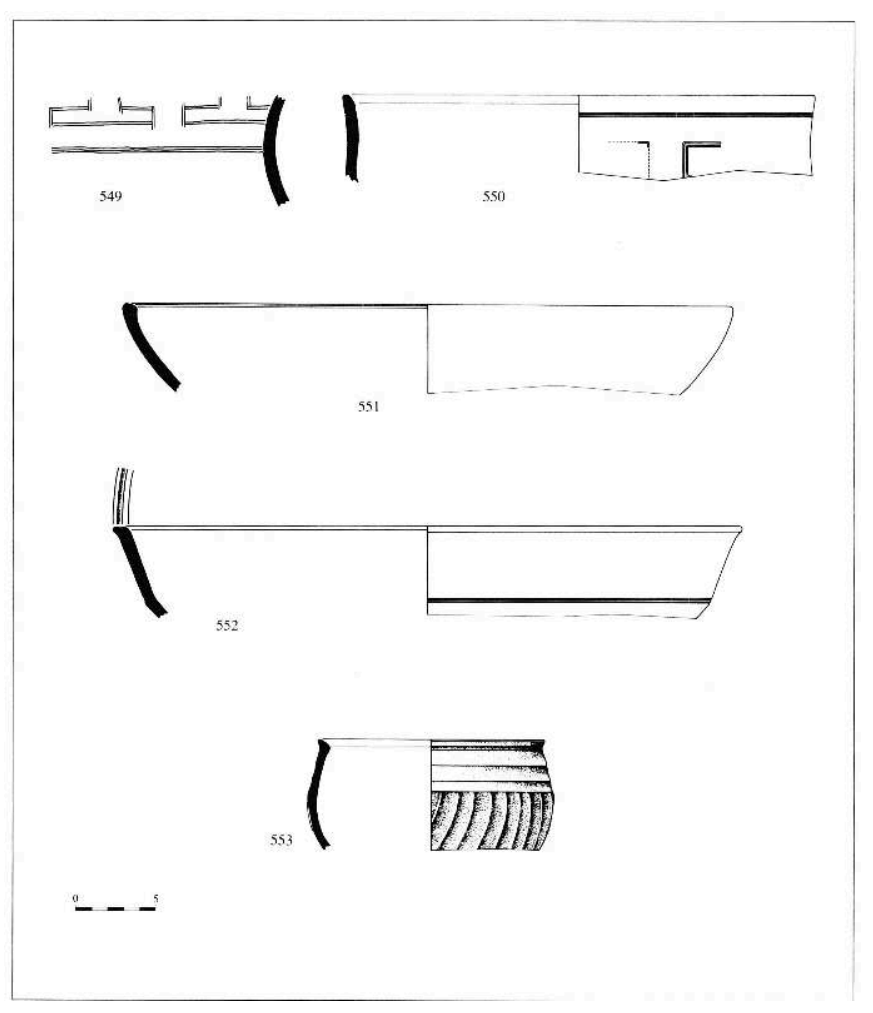


123- Céramiques grossières du Bronze final

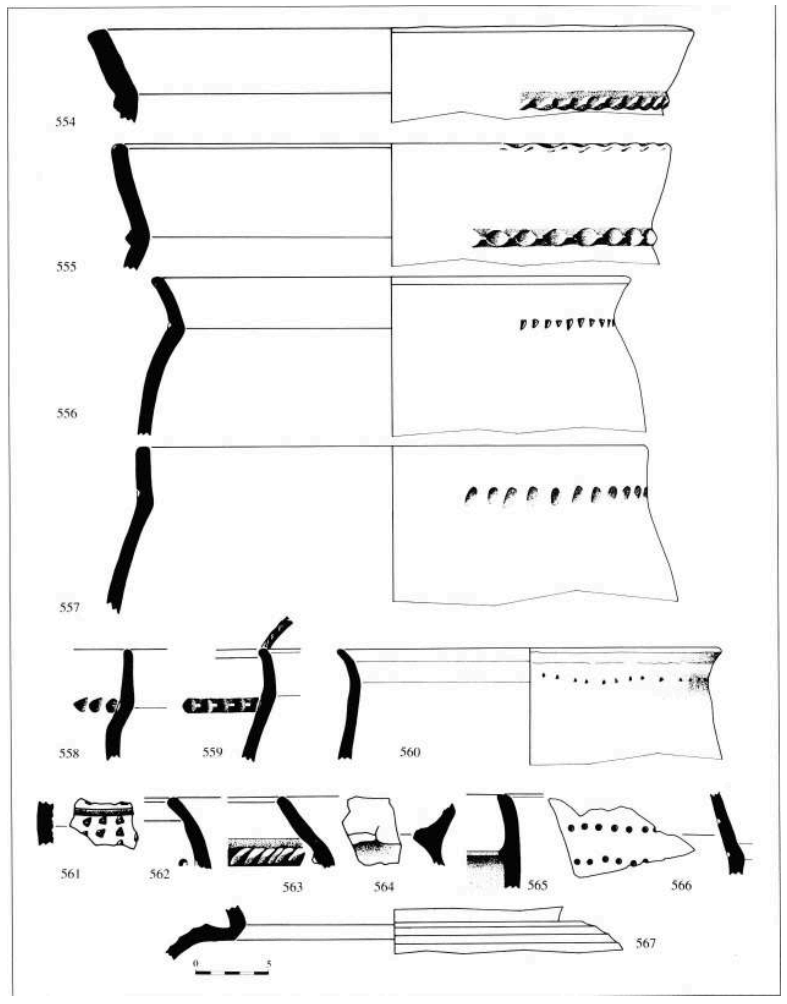

124 - Céramiques grossières du Bronze final
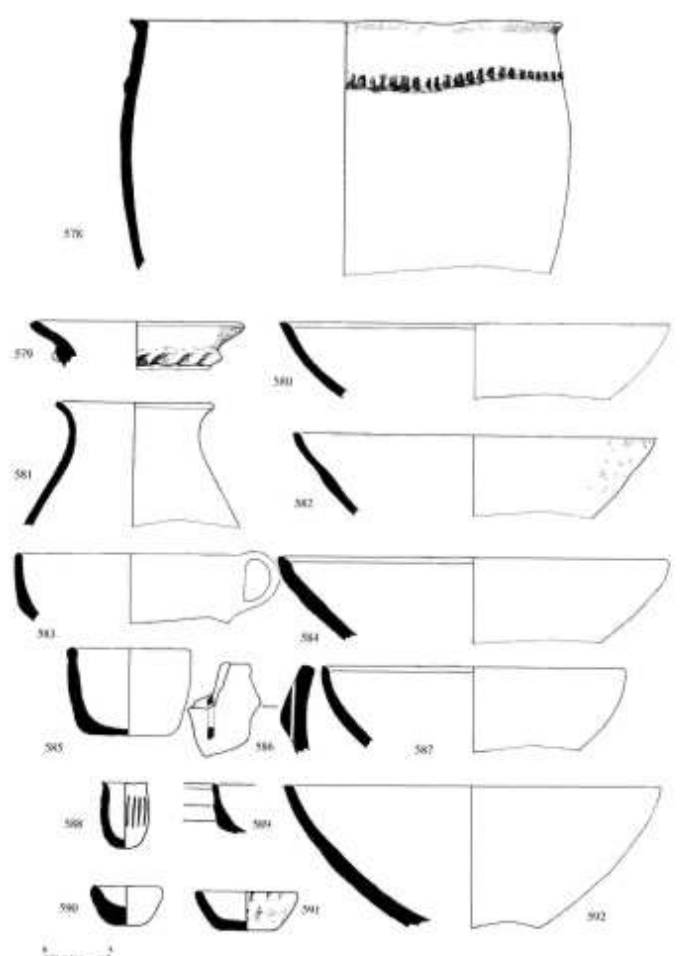


\section{La céramique indigène de l'âge du Fer}

Si la céramique tournée ne pose que peu de problème de datation et peut être rapportée dans son ensemble au second âge du Fer, il est plus difficile de situer chronologiquement les vases non tournés.

\section{Céramique non tournée (fig. 125-133)}

681 La plus grande difficulté de classement concerne les vases hauts fermés, modelés dans des pâtes le plus souvent grossières. Ces vases ( $n^{\circ}$ 593-618) (fig. 125) forment un répertoire extrêmement diversifié, tant par les profils que par les décors. Si ces derniers demeurent impossibles à traiter dans l'état présent des recherches, les études en cours portant sur plusieurs sites proches de Larina permettront dans l'avenir leur reclassement ; à cet égard, les sites du Pré-de-la-Cour (phase ancienne du premier âge du Fer) et de Gorge-de-Loup (phase récente de la même période) constitueront de précieuses séries de références.

125- Céramiques grossières non tournées de l'âge du Fer

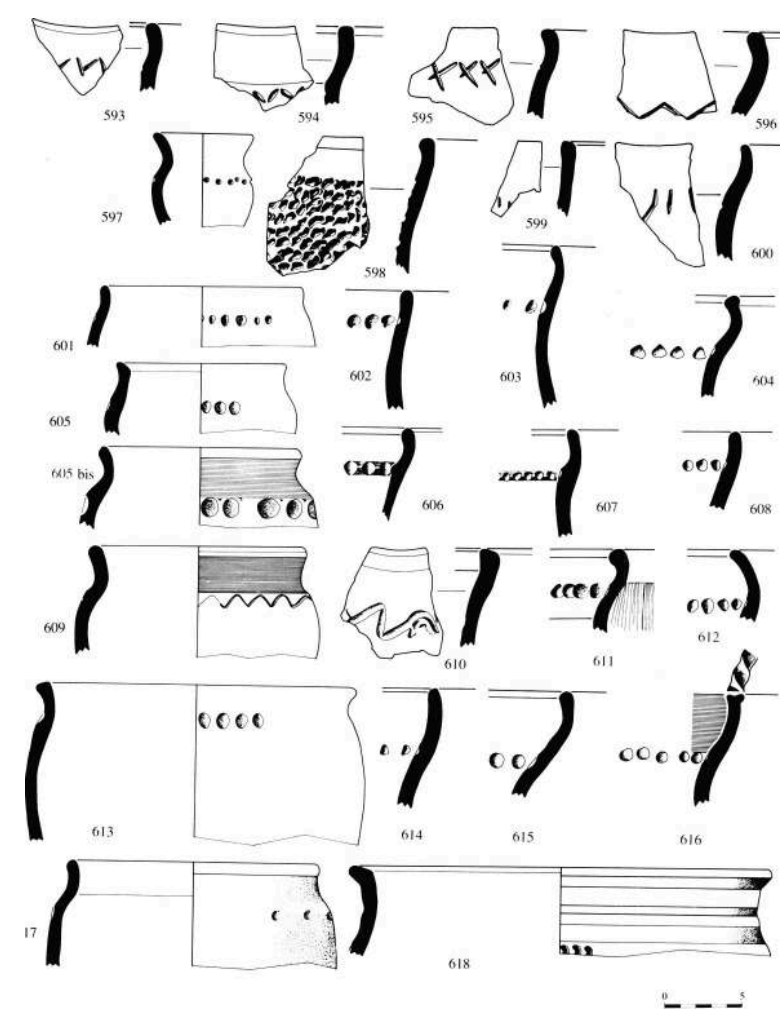

Dans le vaste ensemble des récipients non tournés, il est cependant possible d'isoler d'ores et déjà quelques vases qui paraissent dater du premier âge du Fer ; ces derniers peuvent être associés aux importations provençales, voire aux rares objets métalliques antérieurs à la fin du VIe siècle av. n. è. (nº 619-622) (fig. 126). 
126 - Céramiques grossières du premier âge du Fer

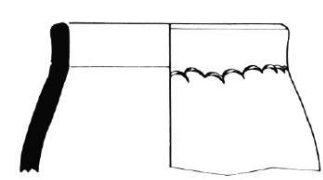

619

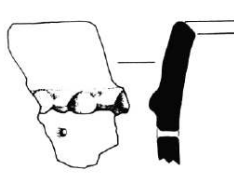

620

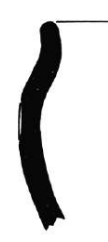

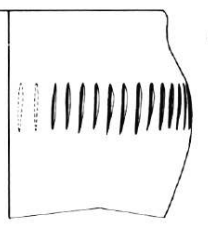

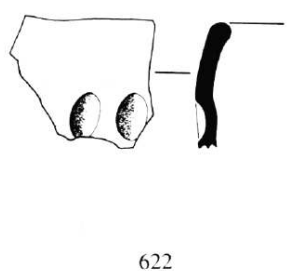

622

D'autre part, l'existence dans l'ensemble de vestiges non céramiques de parures datables de La Tène $C$ laissait entrevoir la présence de céramiques contemporaines. Ces productions restent très méconnues dans le Centre-Est de la Gaule, exception faite de la bordure orientale du Massif Central (Guichard 1989; Vaginay 1984). Par contre, le mobilier des oppida laténiens, plus particulièrement celui de Manching, apporte une masse de documents de comparaisons (Pingel 1971). Quant aux formes du répertoire de La Tène $\mathrm{D}$, de récentes études font que la vaisselle de cette période est bien connue dans des régions proches du territoire allobroge (Vaginay 1988; FurgerGunti 1980). Malgré l'absence d'associations stratigraphiques, il a été possible, par comparaisons, de sélectionner un nombre important de récipient ! « regroupés selon des critères simples (morphologie, aspect des pâtes).

Un groupe de récipients se caractérise par une coloration noire des surfaces et de la pâte due à des cuissons en mode $B$; des teintes plus variées indiquent des cuissons mal contrôlées du type $B^{\prime}$. Ces formes (fig. 127-129), généralement ouvertes ( $n^{\circ}$ 623-649), ont fait l'objet d'un lissage général de l'extérieur des parois, rarement décorées de motifs lissés. Ces récipients sont modelés, mais finis au tour lent, dans des pâtes migrossières possédant parfois un dégraissant calcaire. Certains de ces vases se caractérisent par les profils très sinueux de leurs cols. Ce mode de fabrication très particulier se retrouve surtout dans la vaisselle de la phase ancienne de Manching. Les parallèles avec le mobilier de l'oppidum des Vindéliciens ne se limitent pas à cette particularité technologique et, sans entrer dans le détail des formes, il faut constater une analogie marquée entre les formes à profils sinueux de La Chuire et le répertoire de Manching. La plupart de ces vases appartiennent vraisemblablement à la phase $\mathrm{C}$ de La Tène, très bien attestée dans le mobilier métallique de La Chuire. En effet à la phase suivante, ce mode de fabrication devient plus rare (cf. néanmoins Vaginay 1988 : fig. 78, $\mathrm{n}^{\circ} 16$ et fig. $93, \mathrm{n}^{\circ} 2$ ) et dans l'ensemble les profils tendent à plus de régularité. En Gaule, outre La Chuire, quelques vases aux formes évoquant le répertoire de Manching sont connus à Ensérune et Mailhac (Pingel 1969). 
127-Céramiques non tournées de La Tène

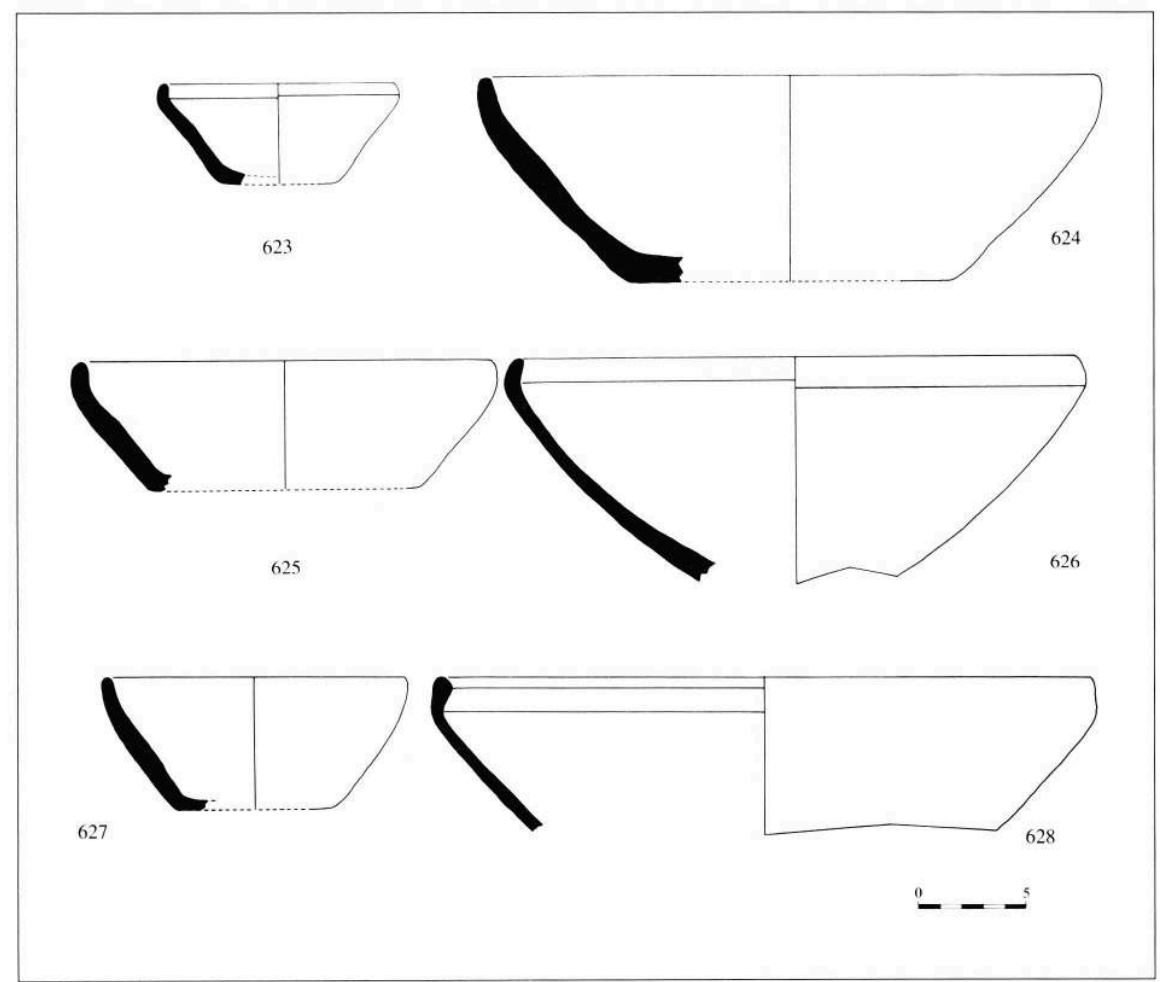

128 - Céramiques non tournées de La Tène
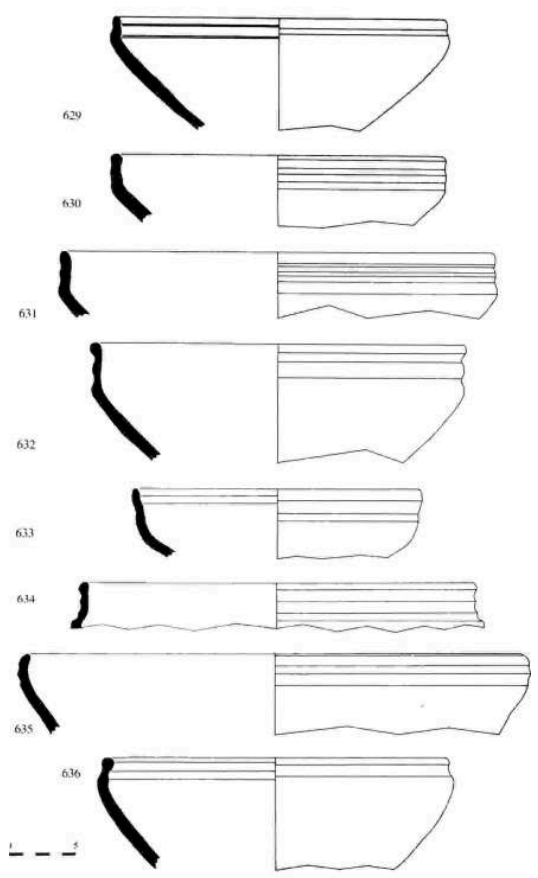
129 - Céramiques non tournées de La Tène

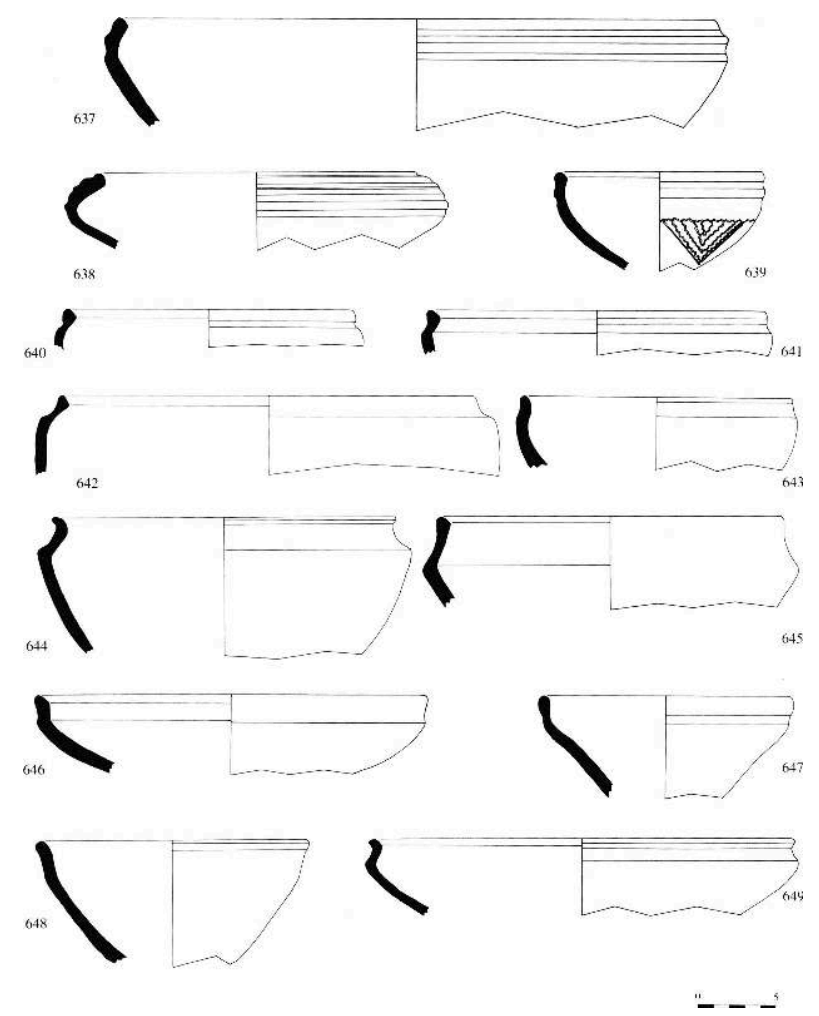

Plusieurs formes de récipients ( $\mathrm{n}^{\circ}$ 650-655) (fig. 130) ont en commun une pâte cuite en mode B qui comporte un abondant dégraissant constitué de grosses feuilles de mica, évoquant les pâtes d'amphores et de mortiers massaliotes produits de la fin du VIe au IIe siècle av. $n$. è. Certains de ces vases trouvent des comparaisons dans le mobilier de Sainte-Blandine, en particulier les formes d'écuelle à lèvre digitée et les couvercles (Chapotat 1970 : pl. XLVIII, n 6-9 et pl. XLV, n 11-12); il s'agit également de vases en pâte très micacée. 
130 - Céramiques non tournées micacées de la Tène

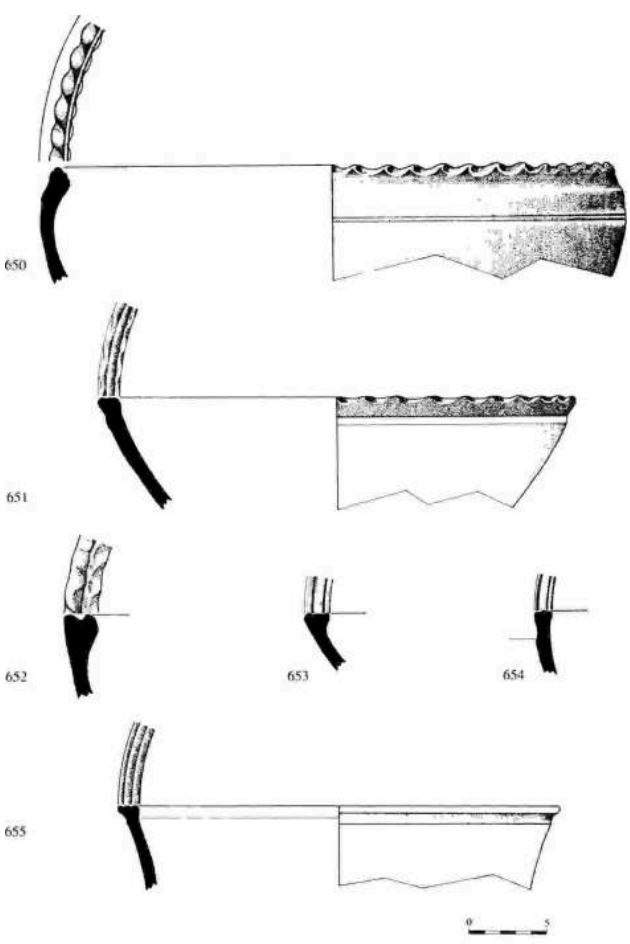

Quelques vases ( $n^{\circ}$ 656-658), totalement indatables, possèdent des fonds et des parois perforés avant cuisson et sont des faisselles destinées à la confection de différentes sortes de fromages (fig. 131).

\section{1 - Faisselles}

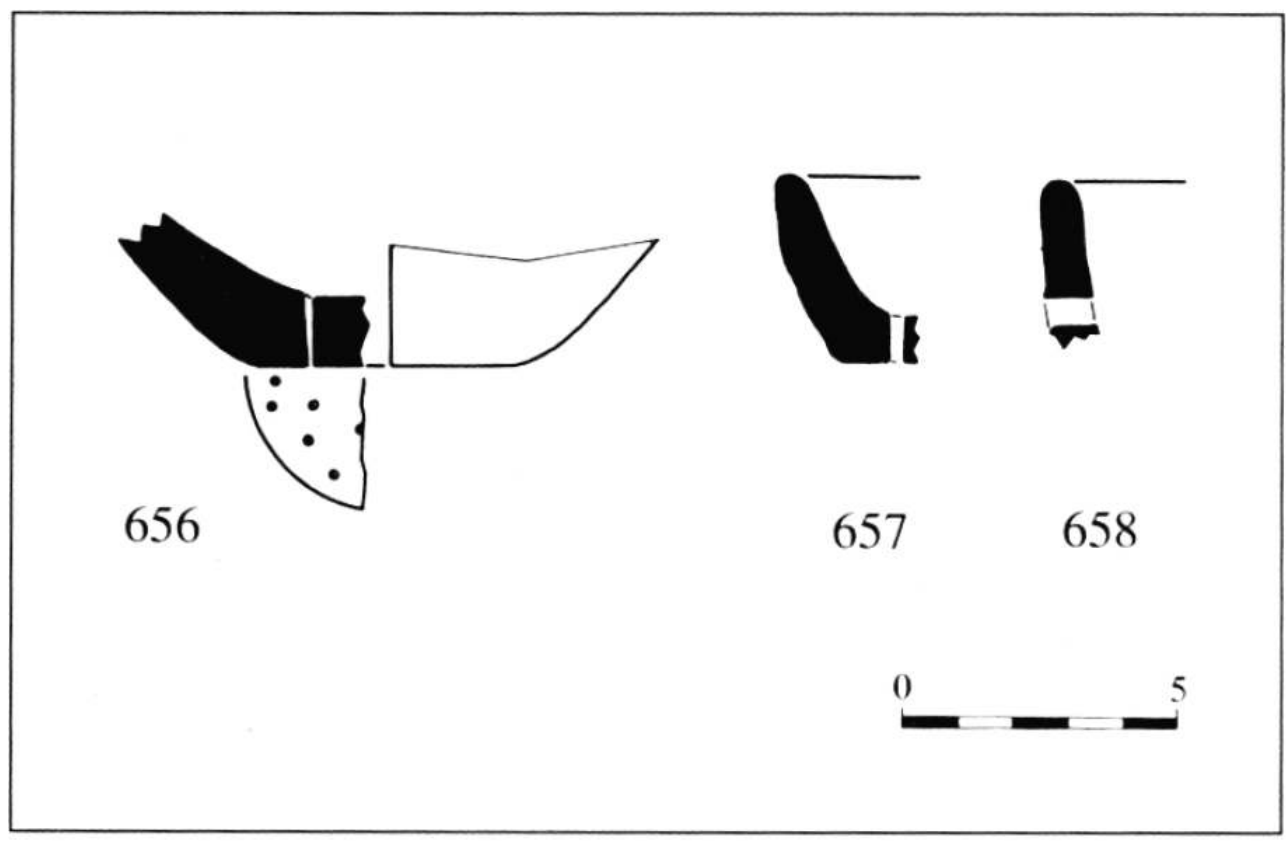

Il faut isoler deux récipients ( $n^{\circ}$ 659-660) de filiation méditerranéenne, destinés au stockage des denrées. Ces dolia (fig. 132) semblent très rares dans le mobilier 
céramique de La Chuire, tout comme à Feurs (Vaginay 1988: p. 51), mais sont par contre mieux représentés à Sainte-Blandine (Chapotat 1970 : p. 117 et pl. XLIX).

132 - Dolia du second âge de Fer

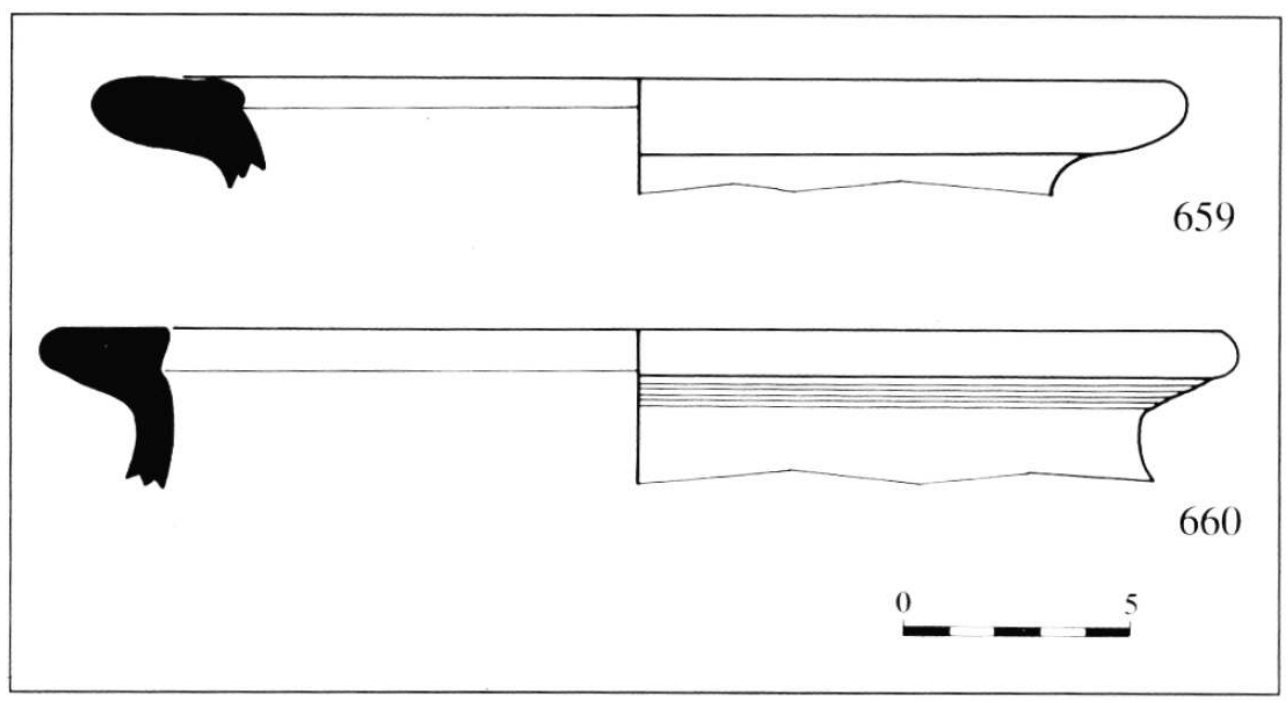

Quelques tessons isolés sont le support de décors particuliers (fig. 133).

133- Décors isolés sur céramique non tournée
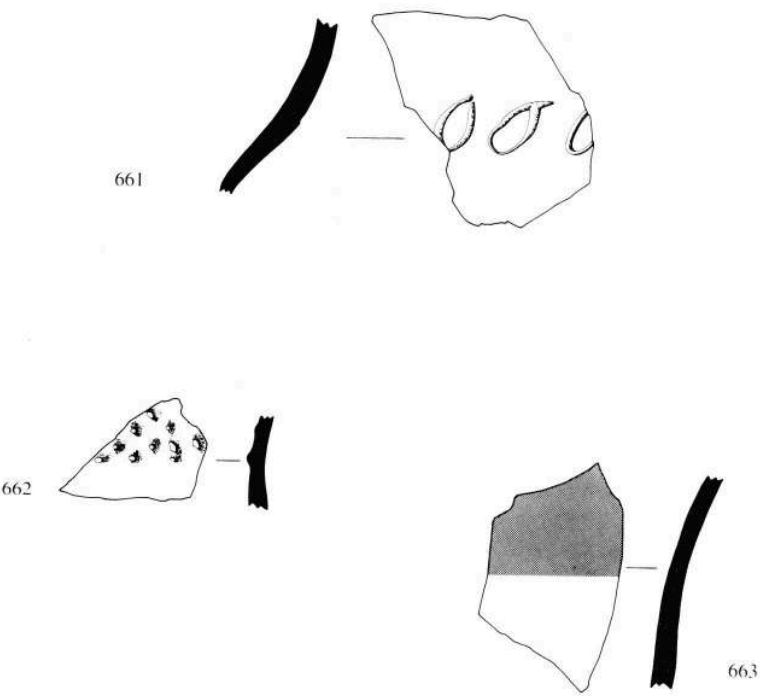

$n^{\circ}$ 661. Décor lissé, grossièrement ovale sur panse de forme haute.

$n^{\circ}$ 662. Décor plastique sur panse de forme haute.

691 Le décor plastique en céramique est connu dès le premier âge du Fer et persiste au cours de La Tène jusqu'à la phase Dl, de l'Italie du Nord (Giubiasco T. 78 ; Ornavasso T. 
61) au Bassin Parisien (Trümpler 1957 : p. 72-73). Dans les régions proches du Dauphiné, il est présent à Feurs dans des contextes de La Tène C2 et Dl (Vaginay $1988:$ p. 52); en Suisse, des vases à décors plastiques sont attestés dans les sépultures de La Tène $\mathrm{C} 2$ de Levron (VD).

$\mathrm{n}^{\circ}$ 663. Décor peint.

La surface de cette forme haute de grande dimension porte une large bande rouge. Il s'agit vraisemblablement d'une production des phases anciennes de La Tène, analogue aux vases fabriqués aux IVe-IIIe siècles av. n. è. en Champagne (Anonyme 1987 d).

\section{Céramique commune tournée (fig. 134-141)}

Les vases tournés posent moins de problème d'identification que ceux qui sont modelés puisque Ton peut tous les rapporter au second âge du Fer, plus précisément aux phases $\mathrm{C}$ et $\mathrm{D}$ de La Tène. En effet, dans le contexte régional de l'âge du Fer, l'usage du tour rapide est inconnu au Hallstatt D3, si l'on excepte le cas particulier des céramiques " cannelées ». Récemment, un ensemble clos inédit observé à Vénissieux (Rhône) a fourni un repère sûr pour les céramiques de la phase $\mathrm{Cl}$ de La Tène et une première étude montre que, dès cette période, l'usage du tour est parfaitement maîtrisé (Sandoz 1988). Dans le contexte régional du second âge du Fer, les données permettant d'effectuer un classement de la vaisselle tournée de La Chuire sont cependant peu nombreuses. Pour ce qui concerne les phases les plus récentes de La Tène, seul le site de Sainte-Blandine a livré un répertoire de formes de céramique: il s'agit malheureusement de vestiges hors contexte, qui semblent avoir fait l'objet d'une sélection au moment de la découverte, pour lesquels une datation précise s'avère difficile. Bien que le mobilier métallique associé montre la bonne représentation de la phase D1 de La Tène, on note l'existence de documents de La Tène D2 et vraisemblablement aussi de La Tène $\mathrm{C}$. Faute de données régionales, il était nécessaire de s'appuyer sur les séries bien étudiées du Massif Central, de la Provence et de la Suisse en tenant compte de certaines lacunes : par exemple, la céramique de La Tène $\mathrm{C} 1$ demeure pratiquement inconnue sur le Plateau Suisse. Dans cette situation, l'ensemble des vases tournés sélectionné ici ne peut être considéré que globalement et constituer une approche du répertoire des céramiques en usage régionalement entre le IIIe et le milieu du Ier siècle av. n. è., soit durant environ deux cents ans; seule la publication des séries récemment découvertes à Vienne (rue de Bourgogne) et à Vénissieux permettra dans l'avenir une bonne définition du faciès céramique allobroge au second âge du Fer. Dans l'état présent des recherches, le principal intérêt de la vaisselle tournée de La Chuire est qu'elle tend à relier entre - elles deux régions particulièrement bien étudiées sous l'aspect céramologique : le Massif Central et les peuples ségusiave et arverne (recherches en cours V. Guichard) d'une part, le Plateau Suisse, les peuples helvètes et leurs voisins rauraques d'autre part. A cet égard, les Allobroges, dernier peuple de la Provincia avant la Gaule chevelue, constituent un terrain de recherche prometteur. 


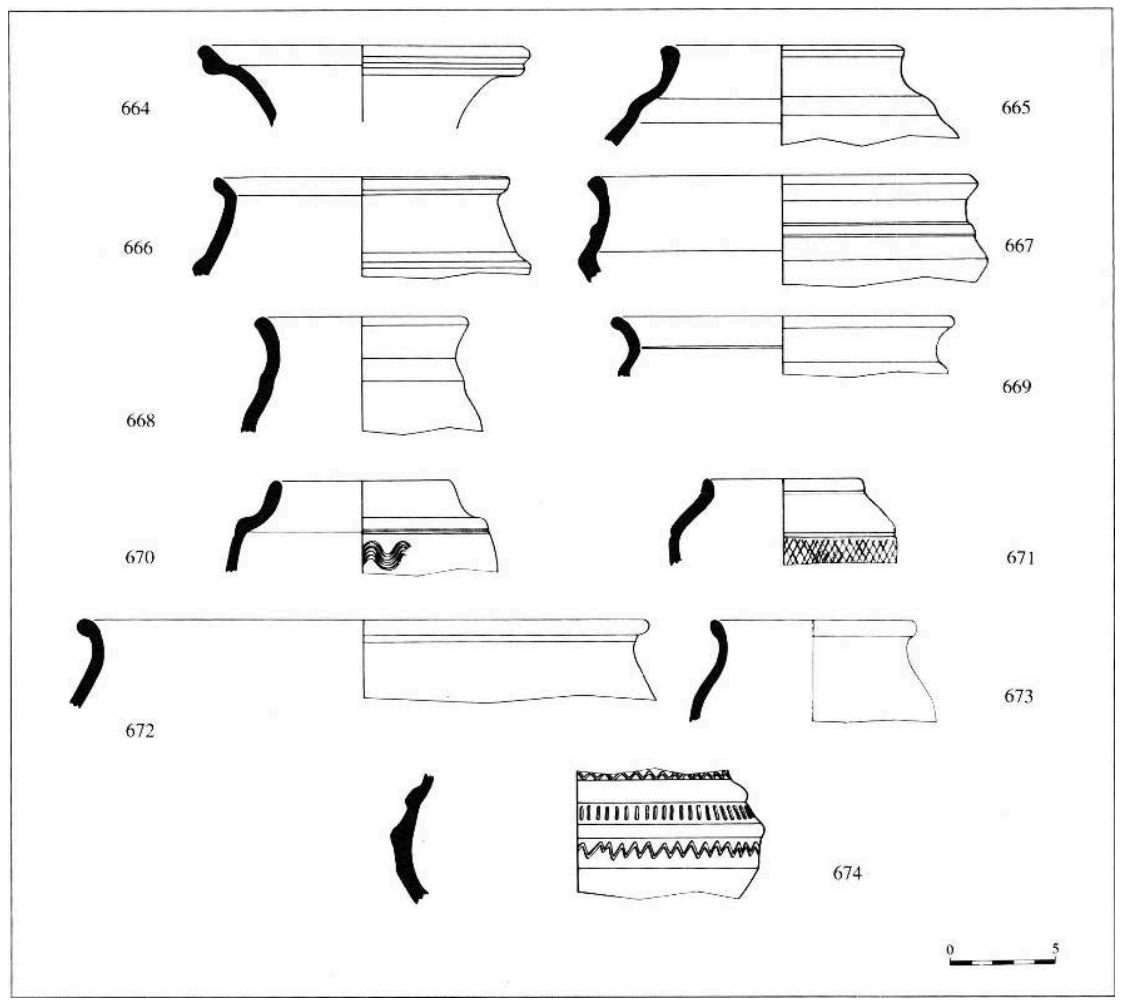

Les vases de formes hautes $\left(n^{\circ} 664-674\right)$ sont pratiquement tous montés au tour rapide à partir d'une argile fine et épurée puis cuits en mode B ; les surfaces sont le plus souvent grises et soigneusement lissées (fig. 134).

$n^{\circ}$ 664. Fragment de col divergent à lèvre éversée moulurée.

Il s'agit d'une forme attestée en territoire ségusiave dans le répertoire des formes peintes et grises lissées. Quelques vases provenant de Feurs, de Goincet et de Roanne sont datés de La Tène C2 (Vaginay 1988 : p. $68-69$ et p. 82 ; Bessou 1976: pl. 45, n²). Ce fragment n'est pas sans rappeler un vase de Sainte-Blandine (Chapotat 1970 : pl. XLII, $\mathrm{n}^{\circ}$ 8), ainsi qu'un récipient peint du Pègue (Lagrand 1973 : pl. XXXVI, n 35).

$\mathrm{n}^{\circ}$ 665. Vase à col rentrant à lèvre arrondie; la liaison panse/col est marquée par un épaulement.

$\mathrm{n}^{\circ}$ 666. Vase à col rentrant à lèvre verticale oblique et peu éversée : la liaison panse/col est marquée par un épaulement.

$\mathrm{n}^{\circ}$ 667. Vase à col rentrant à lèvre verticale oblique et peu éversée ; la liaison panse/col est marquée par une baguette.

$\mathrm{n}^{\circ} 668$. Vase à col éversé et lèvre légèrement aplatie ; la liaison avec le col est marquée par un léger épaulement.

$\mathrm{n}^{\circ}$ 670. Vase à carène haute, col rentrant et lèvre arrondie : un décor ondé réalisé au peigne se situe sous la carène.

$n^{\circ} 671$. Vase à col rentrant et décor de croisillons incisés avant cuisson.

$n^{\circ}$ 672. Grand vase ovoïde à col peu éversé et lèvre éversée arrondie.

$n^{\circ}$ 673. Vase à col droit et lèvre éversée. 

(fig. 135). Ce mode de support semble apparaître au IVe siècle et il s'agit certainement d'un emprunt technologique au répertoire céramique méditerranéen. Chez les Ségusiaves, les vases à piédestal sont attestés dans des contextes du IIIe siècle av. n. è. et sont rares au siècle suivant (Guichard 1989 ; Vaginay 1984 ; Vaginay 1988 : p. 59). En Dauphiné, ce type de base est connu par un exemplaire dans le mobilier de SainteBlandine (Chapotat 1970 : pl. XLI, n 9).

135-Vases à piédestal de La Tène

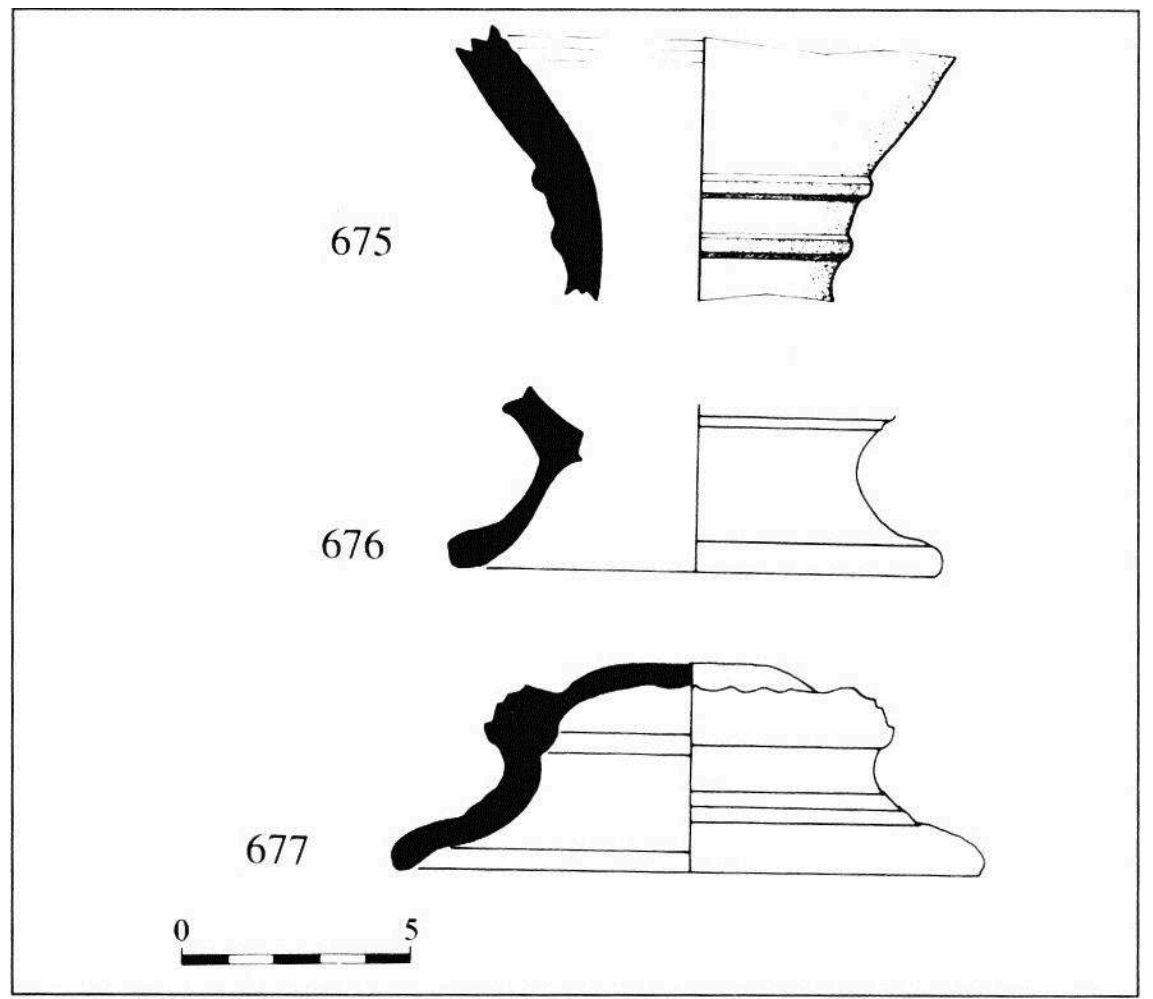

La faille de La Chuire a livré un nombre important de récipients montés au tour rapide dans une pâte fine. Les surfaces, uniformément grises dans la plupart des cas, ont fait l'objet d'un lissage soigné : la majeure partie des vases sont sans décor ( $\mathrm{n}^{\circ}$ 678-713) (fig. 136-138), certains toutefois ont été décorés au lissoir ( $n^{\circ}$ 714-727) (fig. 139-140). 
136- Céramiques tournées de La Tène : formes ouvertes

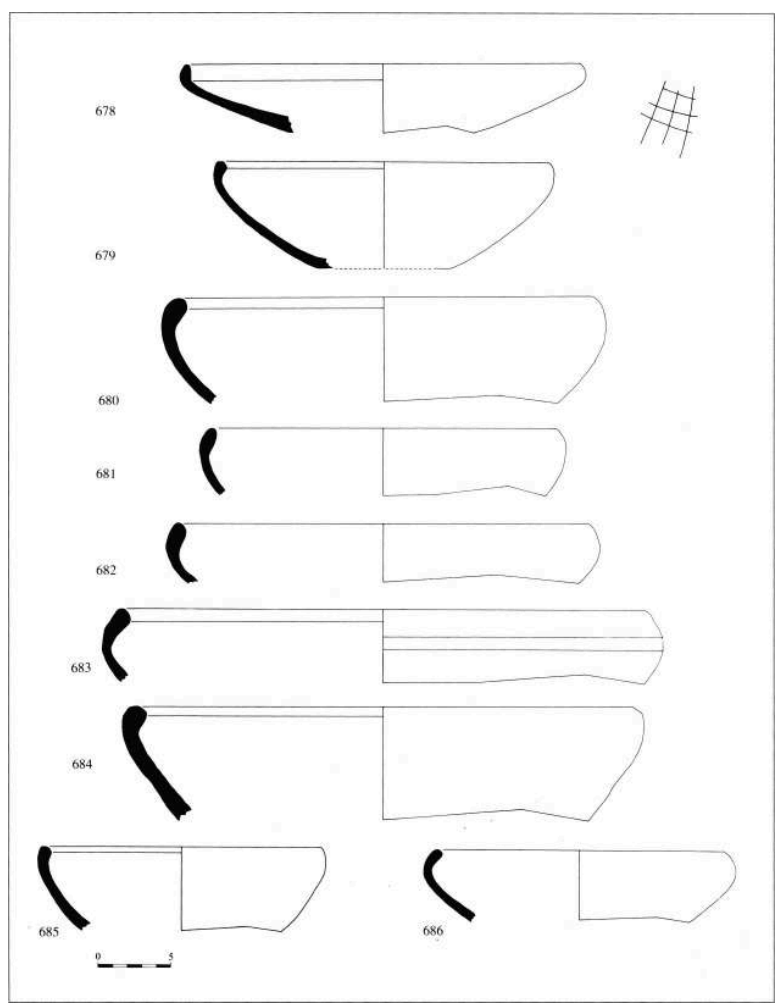

137- Céramiques tournées de La Tène : formes ouvertes

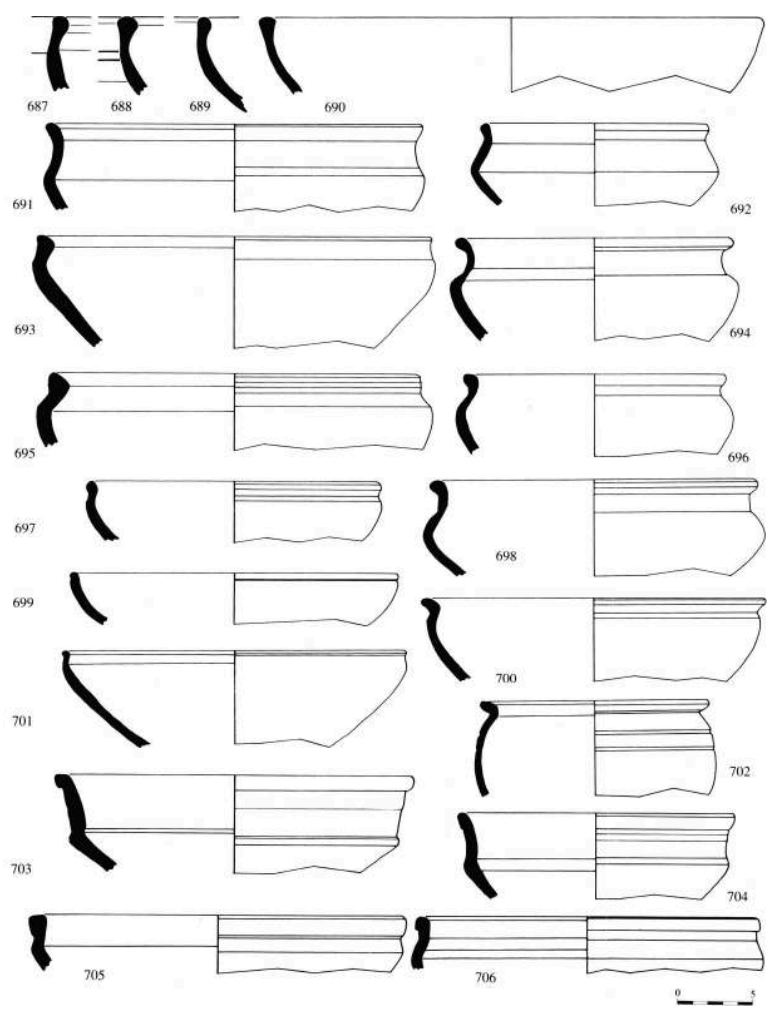


138- Céramiques tournées de La Tène : formes ouvertes et fermées

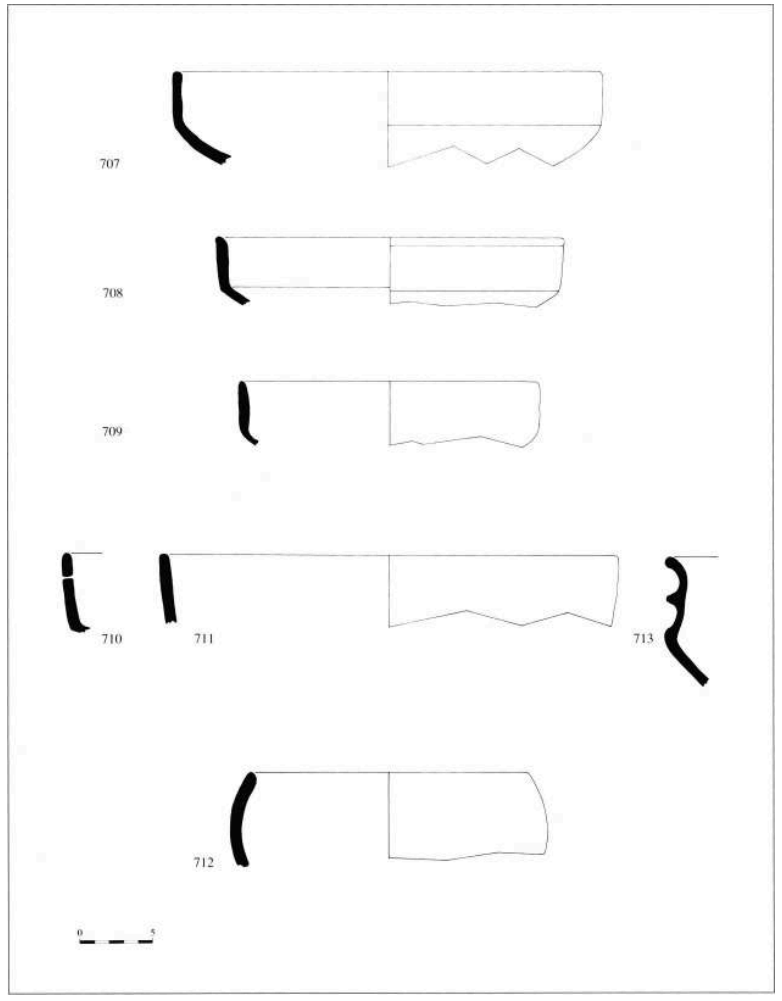

139- Céramiques tournées et décorées de La Tène
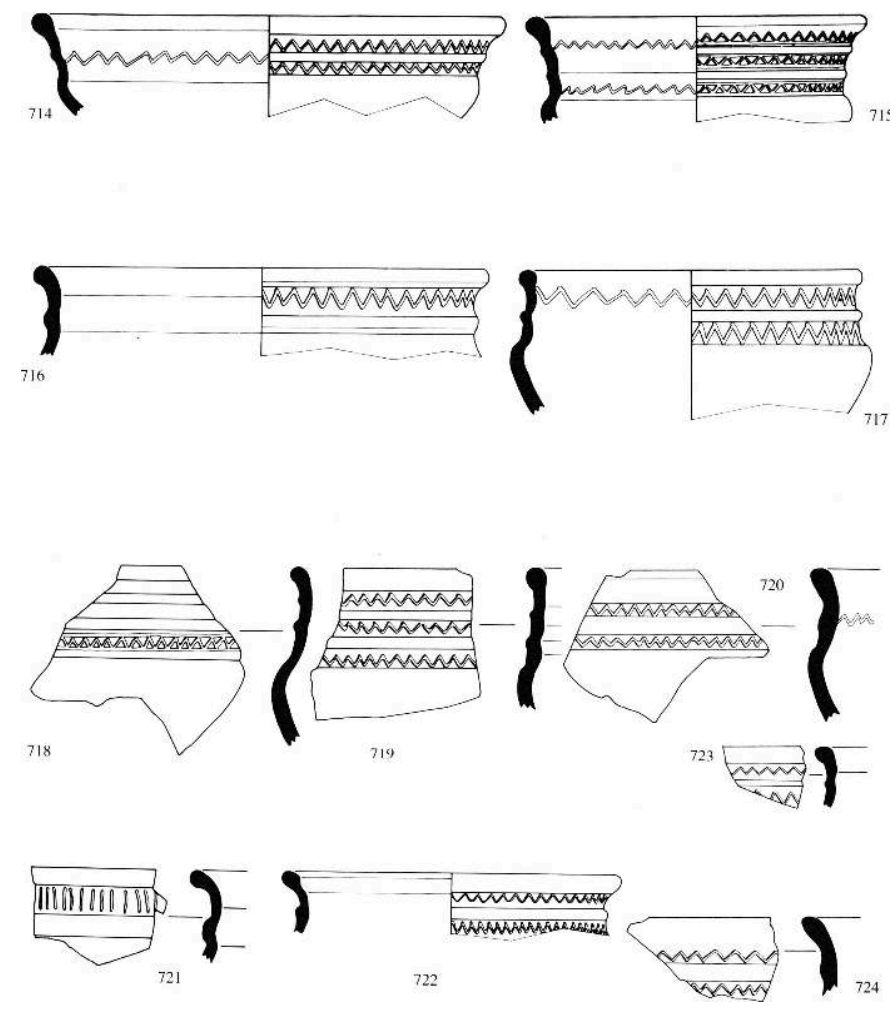


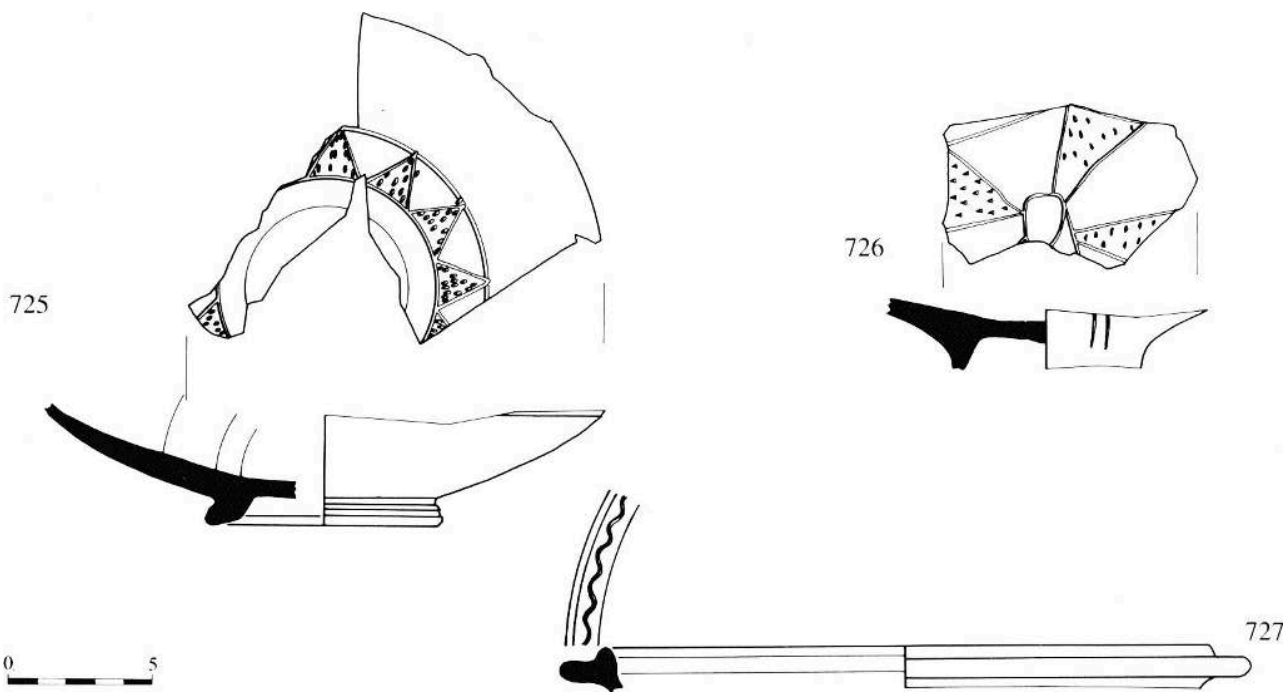

$n^{\circ}$ 714. Jatte à col éversé et baguette ; la lèvre est arrondie et épaissie. Double décor linéaire en zigzag de part et d'autre de la baguette ; simple décor en zigzag interne.

$\mathrm{n}^{\circ}$ 715. Jatte à col éversé et double baguette; triple décor linéaire en zigzag entre des doubles traits horizontaux et double décor linéaire ondé à l'intérieur.

$\mathrm{n}^{\circ}$ 716. Jatte à col droit légèrement épaissi et lèvre éversée aplatie. Décor en zigzag encadré par deux lignes horizontales lissées.

n17. Jatte à col rentrant et baguette externe ; la lèvre est verticale et épaissie. Double décor linéaire en zigzag sur la surface externe et ligne identique à l'intérieur du vase. $\mathrm{n}^{\circ}$ 718. Jatte à col rentrant et double baguette; la lèvre éversée est arrondie. Décor linéaire lissé en zigzag encadré de lignes horizontales. $\mathrm{n}^{\circ}$ 719. Jatte à col presque vertical et double baguettes et lèvre épaissie arrondie ; triple ligne ondée sur la surface externe. $\mathrm{n}^{\circ}$ 720. Jatte à col rentrant légèrement épaissi et lèvre éversée aplatie. Double décor ondé externe et simple onde interne.

$715 \mathrm{n}^{\circ}$ 721. Jatte à col rentrant, épaulement marqué et lèvre très éversée arrondie. Décor lissé de traits verticaux situés entre la lèvre et l'épaulement.

$716 \mathrm{n}^{\circ}$ 722. Jatte à col rentrant, baguette externe et lèvre éversée arrondie à dépression interne. La surface externe est ornée de part et d'autre de la baguette d'un décor linéaire zigzagant et ondé.

$717 \mathrm{n}^{\circ}$ 723. Jatte à col droit, baguette et lèvre épaissie éversée. Double décor en zigzag de chaque côté de la baguette, et simple décor ondé interne.

$718 \mathrm{n}^{\circ}$ 724. Jatte à col droit et moulure; la lèvre est éversée et arrondie. Le vase est orné d'un double décor linéaire en zigzag situé de part et d'autre de la moulure.

$719 \mathrm{n}^{\circ} 725$. Fond de forme basse à pied annulaire orné de deux incisions concentriques lissées encadrant des triangles également lissés et remplis d'incisions peu profondes (fig. 140). $\mathrm{n}^{\circ} 726$. Fond de vase de forme basse à pied en couronne orné d'un décor malhabile constitué d'un ovale central et d'un motif rayonnant constitué de triangles obtenus par lissage et remplis d'incisions. 
montrent des surfaces extérieures ornées avant cuisson (fig. 141).

141 - Décors isolés sur céramiques tournées

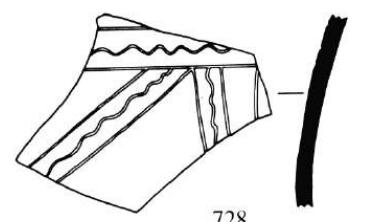

728

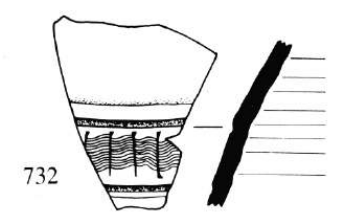

736

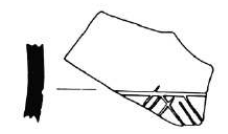

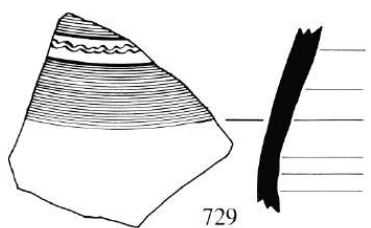

729

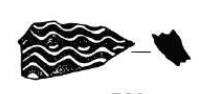

733

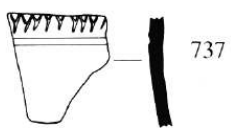

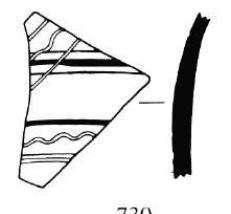

730
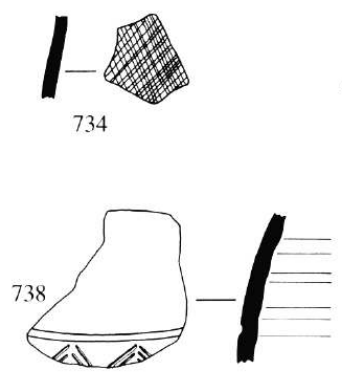

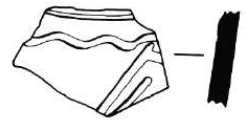

731
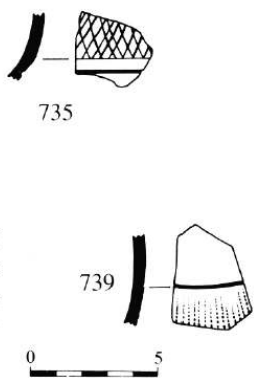

Le décor lissé $\left(\mathrm{n}^{\circ} 728-731\right)$ : il s'agit de décors linéaires rectilignes et ondés tracés sur des vases dont les surfaces extérieures ont fait l'objet d'une finition partielle par lissage. Des bandes circonscrites par des incisions horizontales ont été réservées, c'està-dire non lissées. Le résultat obtenu est une alternance de bandes plus ou moins larges mates et brillantes. Les bandes réservées portent différents types de décors tracés à la pointe mousse mais peuvent aussi être vierges de toute ornementation. On observe soit une bande ondée entre deux lignes horizontales, soit un motif reprenant le même principe mais disposé verticalement et en oblique sous une bande horizontale. Le décor lissé sur des surfaces rendues régulières par lissage est également connu. Les décors 
lissés apparaissent dès le premier âge du Fer, dans la culture de Golasecca; en Gaule, c'est à partir du IVe siècle av. n. è. que certains vases portent des décors curvilignes lissés (Lagrand 1973) qui se multiplient à partir du siècle suivant (Brunella 1987) pour rester en usage jusqu'à la fin de La Tène (Vaginay 1988 : p. 148). Bien qu'incomplets, les décors lissés de La Chuire sont à rapprocher de ceux de Bâle, de Feurs et de Roanne (Furger-Gunti 1980: Taf. 143; Vaginay 1988 : p. 5960). A propos des décors lissés, on constate une analogie marquée entre ces derniers et les décors plus ou moins plastiques de certains bracelets laténiens en verre (Pingel 1971: Abb. 7-8 ; Gebhard 1989).

Le décor incisé $\left(n^{\circ} 732-738\right)$ : un premier type de décor $\left(n^{\circ} 732\right)$ est obtenu à l'aide d'un peigne qui trace sur la pâte fraîche une onde peu incisée. C'est un décor attesté dans la Loire dans des contextes de La Tène $\mathrm{D}$, sur un des récipients caractérisés par la présence de baguettes dégagées à la pointe mousse qui encadrent l'onde (Vaginay 1988 : p.60) : ce type de vase est représenté dans La Chuire par un récipient aux surfaces légèrement micacées et de couleur brune, très différent des autres céramiques. Le décor ondé au peigne est aussi connu en Suisse, bien que peu représenté (Furger-Gunti 1980 : Taf. 143; Furger-Gunti 1980 : Taf. 33 ; Curdy 1984 : p. 123-136). Un autre type de décor $\left(n^{\circ} 733\right)$ est ondé, mais à la pointe mousse cette fois, en incisant profondement la pâte ; ce décor est connu à Bâle-Gasfabrik où il est cependant assez rare (Furger-Gunti 1980 : Taf. 57, n 1265). D'autres décors à base d'incisions sont représentés; il s'agit de croisillons plus ou moins fins et de chevrons plus profondément tracés.

Le décor impressionné ( $\left.n^{\circ} 739\right)$ : il est obtenu à l'aide d'un peigne appliqué perpendiculairement à la surface du récipient. Des vases ornés de cette manière datés de La Tène D1 sont connus à Bâle (Furger-Gunti 1980 : Taf. 143, n² 2217-2218).

\section{Céramique peinte de «la Moyenne vallée du Rhône » (fig. 142-143)}

La faille de La Chuire a livré plusieurs centaines de tessons de vases tournés, portant des traces de peintures. Deux types apparaissent diversement représentés : le premier qui rassemble la majeure partie de ces fragments peints appartient à un modèle de céramique rarement signalé à l'âge du Fer et rappelant les productions dites pseudoioniennes de Gaule méridionale; d'autre part, quelques rares fragments sont attribuables aux productions peintes dites celtiques, datées de la fin de l'âge du Fer.

Il s'agit d'une céramique tournée, à pâte fine, épurée, cuite en mode $\mathrm{A}$, dont la couleur des surfaces varie de beige à orange vif. Dans l'ensemble, ces tessons sont assez mal conservés, les surfaces sont altérées et les décors peints ont partiellement disparu. Un nombre élevé de tessons n'a d'ailleurs sans doute jamais été peint, mais les caractéristiques de la pâte permettent de les attribuer assurément à ce type de production. L'essentiel du matériel céramique semble se rapporter à une seule forme dont le profil complet demeure inconnu. 
142- Céramiques peintes de la Moyenne vallée du Rhône

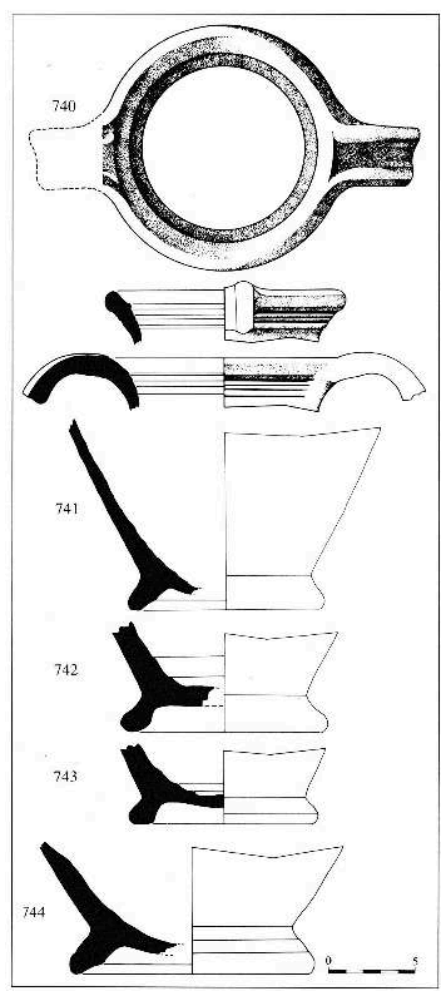

Il s'agirait d'un vase (fig. 142) haut, fermé, à col droit, lèvre éversée, panse ovoïde sur un pied creux ( $\left.\mathrm{n}^{\circ} 740-744\right)$. Le récipient est doté, semblet-il, de deux anses symétriques faussement bifides : cependant, vu la fragmentation des céramiques, on ne peut exclure l'existence de variantes monoansées. Seul le sommet de la panse et le départ du col de ces récipients possèdent un décor peint (fig. 143), la base étant réservée. Dans l'ensemble, la production est peu soignée et il s'agit sans doute de vases utilitaires, destinés à transporter, à stocker et verser des liquides. Ces récipients appartiennent à la vaisselle de table et le terme le plus adapté à les désigner semble être celui d'amphorette (Bats 1988 : p. 71). 

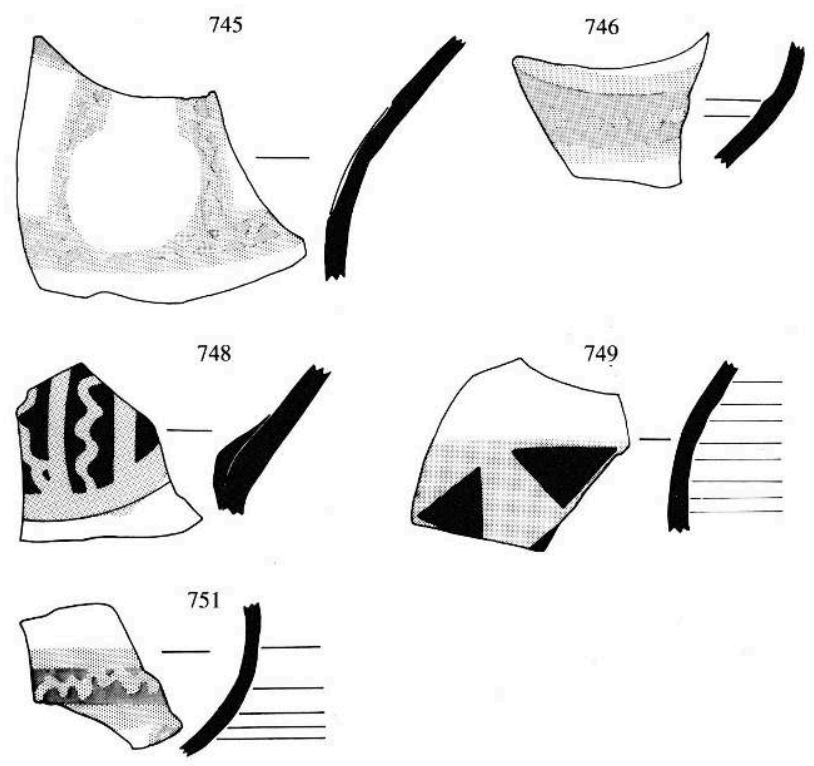
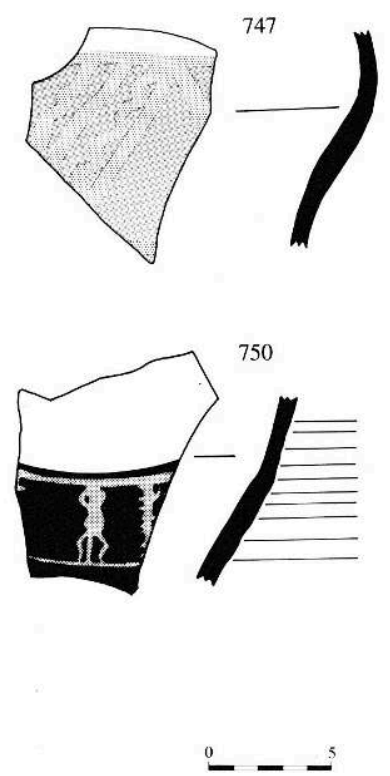

$n^{\circ} 745$. Type 1 - Le décor peint le mieux représenté consiste en une bande rouge à brunrouge, large de 1 à $2 \mathrm{~cm}$, disposée horizontalement à la base de l'attache inférieure de l'anse. Cette bande est encadrée par deux bandes blanches, plus étroites, qui la recouvrent partiellement; la partie centrale ainsi définie est de plus surchargée d'une bande ondulée blanche ou d'un zigzag de même couleur. La base de l'élément de préhension est encadrée par deux bandes disposées verticalement qui bifurquent rapidement à angle droit pour former une nouvelle bande horizontale disposée au sommet de l'attache : l'impossibilité de peindre la partie du vase située derrière l'anse explique cette disposition orthogonale. Il semble que les deux bandes horizontales principales soient parfois cloisonnées par l'ajout d'autres bandes verticales, formant ainsi une succession de casiers rectangulaires.

D'autres décors sont connus mais sont, semble-t-il, bien moins fréquents.

$\mathrm{n}^{\circ}$ 746. Type 2 - il s'agit d'une variante du décor principal, caractérisée par une succession de cercles blancs, disposés sur une bande rouge et remplaçant ainsi le décor ondé ou en zigzag habituel.

$n^{\circ} 747$. Type 3 - il consiste en une large bande rouge à brun-rouge, encadrée de bandes blanches et surchargée de bandes blanches, en alternance rectiligne et ondée, disposées en oblique pour former des chevrons.

$\mathrm{n}^{\circ} 748$. Type 4 - sur une large bande rouge, l'artisan a disposé en surcharge, des bandes verticales blanches, reliées par une bande oblique, blanche, légèrement ondée.

$\mathrm{n}^{\circ} 749$ Type 5 - décor composé d'une large bande brune, surchargée de peinture blanche appliquée de manière à délimiter des triangles: il s'agit du seul exemple de décor réservé sur ce type de céramique. Une variante est cependant connue par plusieurs tessons découverts lors du sondage réalisé en 1950 ; elle est constituée par des triangles réservés remplis de points blancs (Chauffin 1960: pl. IV, nº 4-5). Le décor réservé sur céramique apparaît dans les productions attiques à figures rouges, puis est adapté par les potiers celtiques, dès le IVe siècle av. n. è. en Champagne (Anonyme 1987 d: p. 76-80). 
$\mathrm{n}^{\circ} 750$. Type 6 - il se compose d'une large bande horizontale peinte brune, surchargée par deux étroites bandes blanches; l'espace délimité est cloisonné par deux bandes verticales blanches sur lesquelles sont disposés des traits, horizontaux, fins et blancs. Entre ces deux motifs vaguement arborescents, l'artisan a peint une fine bande verticale encadrée par deux bandes ondulées affrontées. Le résultat de cette disposition a un aspect anthropomorphe, mais il est difficile d'affirmer que l'artisan ait voulu figurer un personnage debout, les genoux pliés et les bras levés au-dessus de la tête.

Type 7 - décor formé d'arc de cercle disposé en "guirlande »; ce type de décoration n'est actuellement pas individualisé dans le mobilier de la Chuire, mais est par contre présent à Vénissieux (« Fosse Gambetta ». Rhône).

$\mathrm{n}^{\circ} 751$. Type 8 - En dernier lieu, il faut isoler un tesson qui porte l'habituelle bande rouge surchargée de bandes blanches, mais sous laquelle a été peint un cercle rouge pointé et entouré de blanc; un certain nombre de motifs annexes ont dû exister et enrichir le répertoire linéaire, mais la conservation des peintures ne permet pas de les identifier.

739 Cette céramique peinte est tout à fait originale, puisque outre le site de La Chuire, elle n'avait été signalée que sur le site du Pègue (Lagrand 1973). Sur ce gisement, ces céramiques, représentées entre autres par des vases de forme haute à deux anses, apparaissent dès le deuxième quart du IVe siècle av. n. è. ${ }^{10}$. Ces productions, quantitativement faibles, sont ensuite présentes dans les niveaux du site du IIIe siècle av. n. è. (couche C2A). On les retrouve dans des niveaux plus récents du IIe siècle av. $n$. è., mais il s'agit de couches de remblais. On peut donc estimer que ces céramiques sont datables du IVe-IIIe siècle av. n. è. ; pour les IIe-Ier siècles, rien ne permet de confirmer ou d'infirmer leur existence. Outre le Pègue, un certain nombre de gisements de la moyenne vallée du Rhône ont livré des tessons appartenant à des formes hautes à deux anses, identiques aux céramiques de La Chuire: ces vases existent à Soyons - La Brégoule dans un contexte stratigraphique imprécis (de ce site provient une fibule de schéma La Tène I tardive) ; à Vénissieux près de Lyon, la même forme de céramique peinte est associée à des vases laténiens et à un bracelet celtique en verre datable de La Tène $\mathrm{Cl}$; cet ensemble précieux permet de confirmer l'existence de ces productions au cours du IIIe siècle en pays allobroge. D'autres découvertes proviennent de la vallée de l'Isère (grotte de Choranches) et même du val de Saône, sur le site du Petit-Chauvord ${ }^{11}$. En Provence, seul un tesson de forme haute peinte de ce type peut être mentionné, il provient du Mont-Garou (Sanary, Var) et sa datation serait curieusement le VIe siècle av. n. è. (Benoit 1965).

L'origine de ces productions peintes est à rechercher dans le répertoire pseudo-ionien et à pâte claire provençal, bien qu'il n'existe apparemment pas de continuité chronologique entre ces deux types de céramiques : en effet, l'abandon du site du Pègue entre le milieu du Ve siècle et le début du IVe siècle av. n. è. ne permet pas d'établir de liens sûrs entre les deux types peints. Un certain nombre de points communs permet néanmoins de proposer une filiation. D'abord, la forme haute et ansée est totalement étrangère au répertoire laténien où les seules exceptions sont des imitations et des dérivés de la vaisselle métallique étrusque (Vaginay 1984). Par contre, dans la vaisselle " pseudo-ionienne » et à pâte claire peinte, les vases ansés sont très bien attestés, par des oenochoés à bec trilobé aux VIe-Ve siècles av. n. è. et par des vases à embouchure ronde, à une et parfois deux anses, qui restent en usage jusqu'au IIe siècle av. n. è. (Lagrand 1973: p. 63-68; Dedet 1987: p. 59; Arcelin 1982: p. 89-94). Pour ce qui 
concerne le décor peint, l'absence d'étude synthétique complique l'analyse comparative; de plus, la mauvaise conservation générale des surfaces implique une inégalité des données selon les sites. Cela dit, les décors de la céramique de La Chuire se retrouvent dans le répertoire pseudoionien, en particulier au Pègue: bandes horizontales de largeurs variées, ligne ondée, points, cercle oculé, guirlandes, chevrons et triangles ornent de façon complexe des formes hautes dont la partie inférieure de la panse reste réservée. La différence principale entre les deux types provient de l'emploi de la peinture blanche exceptionnelle sur les productions des VIe-Ve siècles av. $n$. è. De plus, le répertoire de motifs peints est réduit pour les séries récentes d'ailleurs techniquement médiocres.

Dans l'état actuel des recherches, la céramique peinte du type de La Chuire paraît constituer le terme de l'évolution des productions grecques d'Occident, dérivées de Grèce de l'Est, et particulièrement bien attestées jusqu'au Pègue et même Soyons ${ }^{12}$. Sur les sites de la fin du premier âge du Fer de Gaule interne, on constate la faible représentation des vases tournés peints, considérés comme des importations liées à la diffusion du vin massaliote. Sur le site de Lyon-Vaise (Gorge-deLoup), seul gisement de référence pour cette période dans la région, ces céramiques ne sont que faiblement attestées jusqu'à la fin du Ve siècle av. n. è. (elles le sont cependant un peu mieux que sur des sites plus septentrionaux). Dans le mobilier de La Chuire même, les vases de ce type ne sont attestés que par deux exemplaires identifiés par leurs anses bifides peintes (cf. p. 112).

742 En tout état de cause, c'est au cours du IVe ou au début du IIIe siècle av. n. è., que cette production s'est développée sans doute à partir de la Provence (peut-être du Pègue même) pour constituer rapidement une vaisselle certainement commune dans la moyenne vallée du Rhône. La masse de céramique de ce type livrée par La Chuire est l'indice d'une production locale qui, si elle n'est pas localisée sur le Camp de Larina, est sûrement à situer en territoire allobroge. L'examen des vases peints analogues de Soyons et du Pègue montre des différences notables dans la qualité des pâtes et des peintures et indique l'existence d'ateliers locaux multiples. Par contre, l'aspect des vases de La Chuire et de Vénissieux semble indiquer un lieu commun de production.

743 Le principal intérêt de cette céramique est de montrer la coexistence dans le couloir rhodanien, de formes issues du répertoire méditerranéen et de formes typiquement celtiques. Seules des nouvelles données sur les habitats occupés aux IVe-IIIe siècles dans la région Rhône-Alpes et une étude fine de l'ensemble des tessons découverts dans La Chuire pourront expliquer ce phénomène.

\section{Céramique peinte de type celtique (fig. 144)}

744 Quelques rares vases, montés à partir d'argile soigneusement épurée et cuite en mode A, portent des traces de peinture blanche surchargée de décor rouge ou brun. Ces récipients s'apparentent aux productions dites celtiques bien attestées sur les sites de Feurs, Bâle et Manching (Vaginay 1988 ; Furger-Gunti 1980 ; Maier 1970). Treize tessons possèdent ces caractéristiques et se rapportent à plusieurs formes sans doute hautes et fermées et à une forme basse ouverte. Aucun profil n'est complet et les décors peints ne sont donc connus que d'une manière partielle. 
144 - Céramiques peintes de type celtique

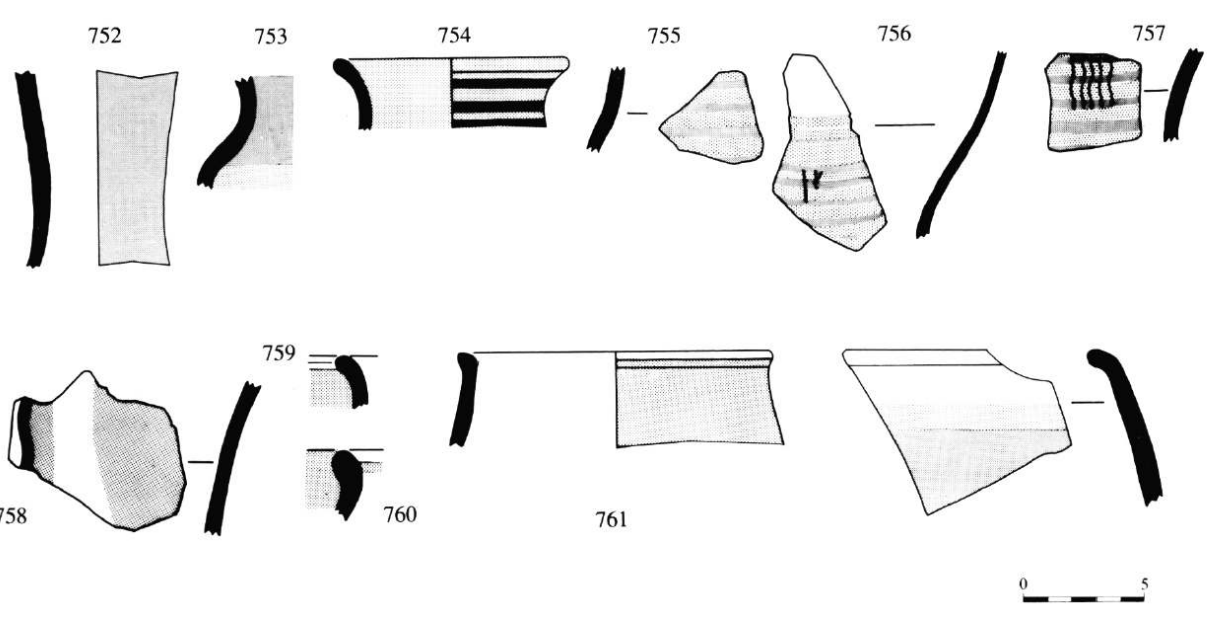
phase D1 de La Tène, on aurait pu s'attendre à retrouver en territoire allobroge des proportions proches de celles relevées en Suisse ou dans le Massif Central (Vaginay 1988); de toute évidence il n'en est rien et cette rareté n'est pas sans rappeler la situation observée en Gaule méridionale où les céramiques peintes celtiques semblent être du mobilier d'importation. Il faut tenir compte de l'existence dans La Chuire des 
productions peintes issues du répertoire pseudo-ionien et on peut se demander si elles ne perdurent pas tard dans le second âge du Fer, excluant ainsi toute autre production peinte. Dans l'état actuel des recherches sur La Tène en Dauphiné, il est impossible de répondre à cette question qui trouvera peut-être une réponse dans les résultats des découvertes récentes de Viennerue de Bourgogne.

\section{Les monnaies}

\section{Les monnaies massaliotes}

\section{Les oboles de Marseille}

$\mathrm{n}^{\circ}$ 763. Au droit, tête d'Apollon à gauche. Le revers est divisé en 4 cantons. Dans 2 d'entre eux on voit les lettres $\mathrm{M}$ et $\mathrm{A} . \mathrm{P}=0,55 \mathrm{~g}^{13}$.

$\mathrm{n}^{\circ}$ 764. Exemplaire de même type. $\mathrm{P}=0,62 \mathrm{~g}$.

$\mathrm{n}^{\circ}$ 765. Pièce de même type que la précédente. $\mathrm{P}=0.62 \mathrm{~g}$. (fig. 145).

145- Obole de Marseille en argent
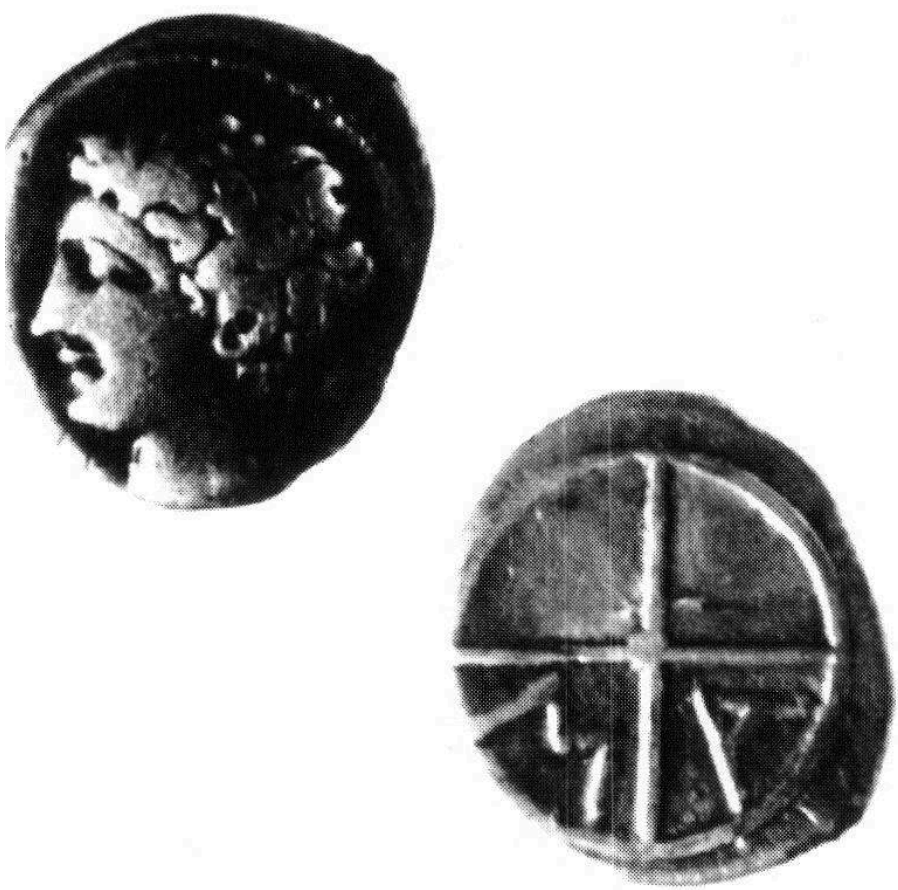

$\mathrm{n}^{\circ}$ 766. Exemplaire identique aux deux précédents, mais on remarque au revers une étrange graphie du A. $\mathrm{P}=0,36 \mathrm{~g}$.

$\mathrm{n}^{\circ}$ 767. Par son style, la tête $\mathrm{du} d$. rappelle certaines espèces arvernes. L'oreille est recouverte de favoris et le bas du visage est carré. $\mathrm{P}=0,49 \mathrm{~g}$ (fig. 146). 
146- Imitation d'obole de Marseille en argent

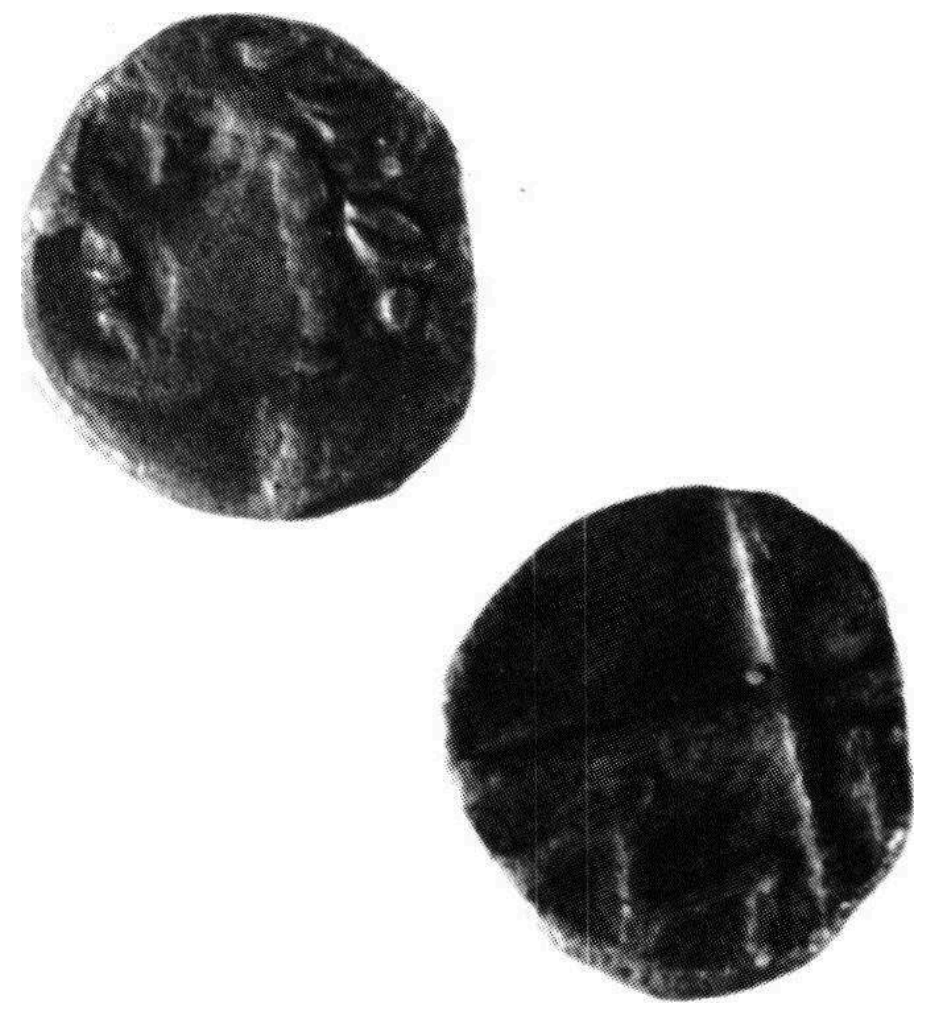

\section{Les monnaies allobroges}

$\mathrm{n}^{\circ}$ 768. La frappe de cet exemplaire en argent est légèrement décentrée. Au droit, tête casquée à g., grènetis. Le revers est orné d'un hippocampe à crinière bouletée à g. On ne voit que l'avant de l'animal. Grènetis au pourtour. Type LT VII. 2924. P =1,9 $\mathrm{g}^{14}$.

Une monnaie, enfin, est de provenance inconnue :

$\mathrm{n}^{\circ}$ 769. Potin au long cou. Ce bronze coulé présente sur une face une tête stylisée à g., sur l'autre, un quadrupède schématisé. $\mathrm{P}=2,75 \mathrm{~g}$. Selon $\mathrm{G}$. Gentric «....la zone d'émission de ces pièces est certainement la basse vallée du Rhône... » (Gentric 1981 : p. 44).

761 F. Perrin et P. Porte, qui ont fouillé respectivement dans La Chuire et sur le plateau de Larina, ont tous deux noté d'importants bouleversements stratigraphiques, qui rendent le contexte de découverte des monnaies inutilisable au point de vue de la chronologie. Cette carence est regrettable, mais l'étude du numéraire peut nous fournir d'autres observations non dépourvues d'intérêt.

Sur 50 pièces identifiées, 16 sont massaliotes, soit près du tiers du lot. Le fait dominant est la remarquable représentation des numéraires de Narbonnaise : 45 exemplaires au total. Deux monnaies sont inédites, il n'est pas possible, en l'état actuel de nos connaissances, de savoir si leur émission a eu lieu en Provincia ou en Comata, seules 3 espèces proviennent donc à coup sûr de Gaule Chevelue. Il s'agit des 2 pièces d'argent des Lingons et du potin sénon. Après la conquête de la Gaule, le numéraire à légende KALETEDOY s'est répandu sur une grande partie du territoire gaulois et c'est probablement après 52 que le bronze coulé des Senons est parvenu sur ce site. La présence tout à fait écrasante des monnayages de Narbonnaise prouve le rôle de 
frontière joué par le Rhône, que les numéraires étrangers ne franchissent qu'à titre exceptionnel.

De nombreuses espèces présentent des particularités qui méritent d'être soulignées. Nous avons constaté l'existence d'oboles copiées sur les monnaies massaliotes; il n'est pas possible actuellement de savoir s'il s'agit d'imitations locales ou de pièces provenant d'autres sites, qui restent à déterminer. Le succès du numéraire de la cité phocéenne explique la fabrication de ces contrefaçons.

Par ailleurs, la présence des oboles d'argent et des bronzes de Marseille n'est pas seulement importante numériquement, elle constitue aussi une nouveauté par rapport aux découvertes étudiées dans cette vaste zone. A. Deroc a effectué le recensement des espèces isolées et des trésors (Deroc 1983). Ce travail permet de constater que les monnaies massaliotes sont absentes des sites qui ont livré des pièces d'argent des Allobroges, des Cavares, des exemplaires au cavalier. L'observation est valable pour l'Isère et les départements limitrophes: seuls les trésors offrent un tel mélange. L'originalité de Larina apparaît donc bien ; en ce lieu le numéraire de Marseille et ses copies sont intégrées à la circulation monétaire normale.

Ces petites espèces d'argent ont connu un grand succès dans une partie importante de la Provincia. Elles jalonnent la vallée du Rhône et sont parvenues jusque dans l'Est de la Gaule sur des sites tels que Mâlain (Côte-d'Or) et Mandeure (Doubs). Il était tentant de copier ce monnayage si utilisé dans les échanges, tout comme on avait imité, à l'origine, les statères de Philippe II de Macédoine en Gaule centrale et les statères de Tarente en Gaule Belgique. A Larina, 5 exemplaires au moins sont, selon toute vraisemblance, des imitations du numéraire massaliote. Il s'agit des pièces qui portent les numéros 14, 15, 18, 766-767.

Pour les monnaies attribuées aux Cavares, deux faits importants doivent être signalés : la présence d'un exemplaire en bronze, alors que toutes les monnaies de ce type, connues à ce jour, sont en argent, et la découverte d'un coin de revers en bronze destiné à frapper des pièces au cheval galopant ${ }^{15}$. Au-dessus de l'animal, on voit un rameau ou une épée. La monnaie de bronze étant très oxydée, il n'est pas possible de savoir exactement quel est son type de revers. Dans sa belle étude : "Les monnaies gauloises d'argent de la vallée du Rhône", A. Deroc ne mentionne que des espèces d'argent de poids largement supérieur à 2 g. (Deroc 1983 : p. 6-7), or, à Larina, en plus de cet exemplaire entièrement fait de bronze, trois pièces fourrées ont été recueillies.

Ces constatations obligent à se demander si un atelier monétaire a fonctionné en ce lieu. A. Deroc a considéré ces pièces comme étant des émissions cavares, en se fondant principalement sur la carte de répartition. Il a, en effet, recensé 51 exemplaires isolés sur le territoire de ce peuple et 10 (maintenant 18, grâce à Larina) chez les Allobroges. Par ailleurs, c'est dans cette dernière région que la concentration de trésors est nettement la plus importante. L'auteur attribue ce fait aux : « ....graves événements de 77-75 av. J.-C., qui poussèrent un certain nombre de Cavares a fuir chez leurs voisins allobroges avec leur fortune.... » (Deroc 1983 : p. 46). Cette explication est parfaitement vraisemblable. Il n'en reste pas moins qu'il faut tenter de comprendre pourquoi ce coin a été trouvé à Larina.

Deux hypothèses peuvent être avancées: ces espèces auraient été émises par les Allobroges et non par les Cavares. Cependant, pour passer sur ce point au stade de la certitude, il faudrait que des découvertes bien plus nombreuses de monnaies de ce type soient effectuées dans la région. Seules des fouilles à venir pourront nous apporter une 
réponse. La seconde hypothèse est qu'il s'agit bien d'un monnayage cavare, à l'origine, mais qu'à la suite des troubles dramatiques qui se produisirent aux environs de 77, une partie de la population des Cavares s'était réfugiée chez les Allobroges de Larina, en apportant ce coin, qui aurait permis des émissions monétaires sur place. Les difficultés du temps expliqueraient la mauvaise qualité de trois sur quatre de ces pièces. Dans l'état actuel des connaissances, il n'est pas possible de trancher, seules des trouvailles abondantes et bien datées permettront de résoudre le problème.

Les monnaies à l'hippocampe des Allobroges sont remarquables par leur nombre : 16 exemplaires, soit près du tiers des espèces identifiées. Il y a ici coexistence d'espèces rares (une pièce de la classe I et une pièce de la classe IV) avec de nombreuses monnaies fourrées (approximativement la moitié du lot) et même un exemplaire intégralement fait de bronze. Ce recensement met en évidence une donnée fondamentale: le numéraire des Cavares recueilli à Larina représente la phase absolument finale de ces émissions, alors que pratiquement toute la gamme des monnaies allobroges à l'hippocampe existe en ce lieu. Cette constatation accrédite l'hypothèse de Cavares qui seraient venus se réfugier dans cette cité fortifiée emportant avec eux un coin monétaire. Peut-être trouvera-t-on plus tard le coin de droit correspondant?

Sans qu'il puisse clairement être expliqué actuellement, un autre fait doit être signalé : les monnaies au cavalier de la vallée du Rhône qui ont été fabriquées en très grandes quantités et ont abondamment circulé dans cette région, ne sont représentées ici que par deux exemplaires appartenant aux émissions de tête. La partie du site, dont les numéraires proviennent, semble avoir été à peu près abandonnée peu de temps après la révolte contre Rome et la terrible répression qui lui succéda. Une occupation normale, continue, après 70 aurait apporté de nombreuses monnaies au cavalier. Cet indice négatif ne doit pas être négligé pour la chronologie du lieu.

147- Répartition du monnayage par type

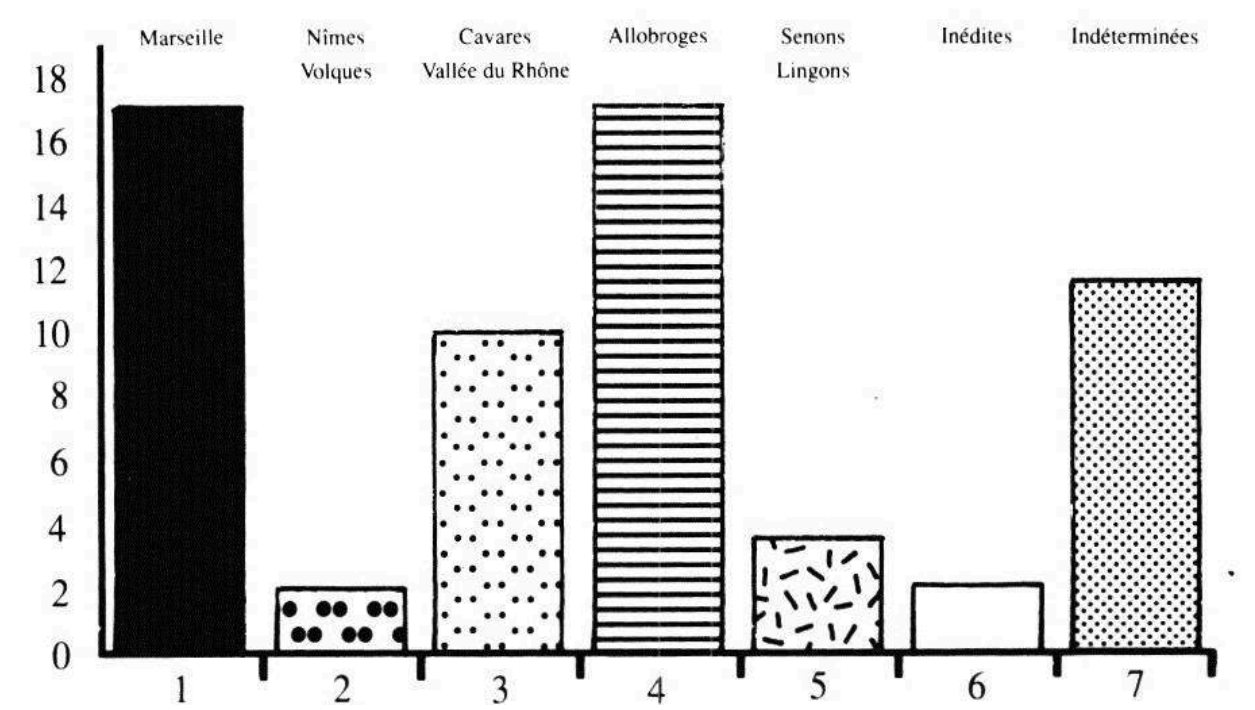

La récolte monétaire effectuée à Larina (fig. 147), qui ne comporte aucune espèce prestigieuse, statère d'or, par exemple, nous a apporté deux petites monnaies d'argent inédites. Elle présente, par ailleurs, un intérêt exceptionnel, puisqu'elle confirme des faits attestés par l'histoire de cette région. Elle constitue un témoignage vivant, 
irremplaçable sur la vie économique et politique de cette cité à la situation privilégiée, puisqu'elle se trouvait à la limite de la Narbonnaise et de la Gaule Chevelue. En dépit de cette proximité de la Comata, Larina appartient complètement au domaine de la Provincia, comme le révèlent les numéraires recueillis à ce jour.

B.F.

\section{La faune}

Dans le site de La Chuire les restes animaux sont très abondants et relativement bien conservés. L'étude du mobilier archéologique, et notamment des objets métalliques qui présentent des traces de destructions volontaires, laisse entrevoir la possibilité de dépôts particuliers, autres que de simples dépotoirs ; c'est pour cette raison qu'il a été décidé de pratiquer un examen des restes animaux, dont l'un des inconvénients majeurs était de ne pas être daté, faute d'un contexte précis (éboulis calcaire), autrement que dans une fourchette chronologique allant du Bronze final à la fin de l'âge du Fer. Dans ces conditions, seules des anomalies remarquables, dans le spectre des espèces (seulement des restes de chevaux, par exemple), ou dans celui des pièces anatomiques (que des crânes ou des tali), auraient pu apporter quelques indices supplémentaires pour une interprétation des dépôts.

L'examen des restes osseux a porté sur un bon millier de pièces, qui proviennent essentiellement des mammifères domestiques classiques, auxquels s'ajoutent le cerf, le lièvre et le sanglier représentés par une ou deux pièces chacun, et le coq (deux os).

Les proportions calculées sur les nombres de restes (N. R.) sont remarquablement proches de celles obtenues à partir des données publiées par Th. Poulain, sur un autre échantillon du même site recueilli en 1950 (Poulain-Josien 1960 : p. 51-63).

Bœuf Porc Mouton-Ch Chien Cheval N.R.

$\begin{array}{lllllll}\mathbf{1 9 7 5 - 7 7} & 34 & 42 & 17 & 4 & 3 & \mathbf{1 1 2 7} \\ \mathbf{1 9 5 0} & 34 & 43 & 17 & 5 & 1 & \mathbf{6 9 2}\end{array}$

Fréquence des espèces domestiques exprimée en \%

La différence essentielle tient ici à la présence de nombreux restes de sangliers dans l'échantillon étudié par Th. Poulain (102 restes, soit $13 \%$ ). Ici seule une scapula de cet animal a été trouvée (soit $0,1 \%$ ).

Quelques observations méritent d'être signalées : la présence de cinq os humains, ainsi que des traces de découpes sur les os de chiens et sur un métatarse de cheval. Les autres espèces représentées par des os fragmentés et découpés témoignent de leur consommation par l'homme.

777 Mais il faut également signaler que les décomptes ont été établis en laissant de côté une bonne partie du matériel qui se présentait sous la forme de dents isolées, de très loin bien plus nombreuses que celles manquant sur les mâchoires présentes. Seuls les os ont été examinés et des distorsions sont également apparues, la principale étant la forte représentation des mâchoires. Ces anomalies, très intéressantes si elles étaient le fait 
des Gaulois, rappelaient beaucoup la sélection qu'effectuaient les archéologues désireux de ne pas s'encombrer, tout en collectant la faune. Depuis, il a été montré que c'était aussi le plus sûr moyen de se priver de tout l'intérêt d'un échantillon d'ossements. Une rapide enquête menée par F. Perrin a effectivement permis de mettre en évidence une collecte différentielle, privilégiant les dents (toutes conservées) au détriment d'une partie du matériel jugé sans intérêt et réenfoui sur place et recréant du même coup un nouveau dépôt archéologique.

Dans ces conditions-absence d'attributions chronologiques entre le Bronze final et La Tène finale, absence d'anomalies dans le spectre des espèces, ce sont des animaux habituellement présents dans des dépotoirs des âges des Métaux, dans des proportions qui ne choquent pas et impossibilité définitive de juger d'une éventuelle sélection des parties-cet ensemble ne mérite pas d'étude plus poussée.

P.M.

\section{Les restes humains}

Quelques vestiges humains se rapportant à au moins deux individus ont été isolés lors du tri des restes osseux effectué préalablement à l'examen de la faune ; ces restes ne provenant pas de contexte stratigraphique déterminé, rien ne permet de préciser leur datation qui doit se situer entre le Bronze final et La Tène D. Leur examen était motivé par la présence dans le mobilier métallique d'objets présentant des destructions volontaires et il convenait de vérifier si ces ossements ne portaient pas de traces de décarnisation analogues à celles observées dans certains contextes cultuels à caractère sacrificiel.

- Fragment de crâne de taille adulte

L'os est clivé au niveau du diploé, et seule la partie endocrânienne est préservée. L'existence d'une crête tranchante permet de situer ce vestige sur le frontal, dans la région médiane et inférieure de l'écaillé. On constate en outre sur la face endocrânienne quelques appositions osseuses irrégulières, qui correspondent très vraisemblablement à un processus débutant d'hyperostose frontale; on doit donc attribuer ce fragment à un sujet adulte, d'âge relativement avancé. On notera enfin que cette pièce a subi une exposition au feu, de sorte qu'elle a pris sur la majeure partie de sa surface une coloration noire: il ne s'agit manifestement pas là d'une véritable incinération, car la température à laquelle l'os a été porté est relativement faible.

- Diaphyse presque complète d'un humérus droit d'enfant

L'extrémité proximale est légèrement érodée. La longueur diaphysaire peut être estimée à $125 \mathrm{~mm}$ (longueur conservée $=121 \mathrm{~mm}$ ), ce qui correspond à un âge compris entre deux et trois ans.

- Moitié proximale d'une ulna d'adulte

L'os est robuste et mouluré, avec une diaphyse fortement incurvée. Sur le processus coronoïde, le bord antérieur de l'incisure humérale est bordé d'un bourrelet osseux néoformé qui signe une lésion dégénérative (arthrose du coude).

- Phalange proximale de la main d'un adulte

Il s'agit très vraisemblablement de la phalange proximale du troisième doigt de la main droite. Elle est remarquablement longue (longueur max. : 46, $4 \mathrm{~mm}$ ) et gracile (périmètre au milieu : $25 \mathrm{~mm}$ ).

- Diaphyse tibiale gauche de taille adulte ;

L'insertion du muscle soléaire se présente sous la forme d'une crête discontinue 
extrêmement puissante constituée d'une succession de tubercules irréguliers ; un tel aspect est inhabituel, et bien qu'il ne soit pas franchement pathologique, il évoque l'aspect d'un hématome calcifié ; la crête tibiale est tranchante, sinueuse; au sommet de sa convexité latérale, sensiblement au milieu de la diaphyse, on note sur la face médiale une petite irrégularité de l'os cortical, qui correspond sans doute à un petit hématome sous-périosté. C'est probablement le même diagnostic qu'il convient d'avancer pour un soulèvement de l'os cortical, un peu plus étendu (env. $20 \mathrm{~mm}$ de haut sur $15 \mathrm{~mm}$ de large), qui affecte la face postérieure de la diaphyse à l'union de ses tiers moyen et distal. Sur la face antéro-latérale, on note la présence de trois sillons vasculaires arciformes, concaves vers le haut; il s'agit là d'une variation anatomique banale, sans signification pathologique.

Malgré le soin que nous avons apporté à l'observation de ces quelques os, nous n'avons repéré aucune trace qui puisse être interprétée comme le résultat d'un travail de décarnisation.

H.D.

\section{NOTES}

1. Autres noms locaux : La Chuira. Le Trou de La Chuire, Le Trou de La Chuira.

2. Information P. Pion.

3. Ce site est particulièrement intéressant dans le cadre des relations entre l'Italie septentrionale et la Gaule interne, puisque, outre du corail brut, il a livré de nombreux vases en verre polychrome qui sont attestés dans le domaine hallstattien occidental ; il y a donc eu probablement deux axes de circulation pour ces objets.

4. Information C. Bellon.

5. Comptage effectué par MM. Chausse et Nicollet.

6. Information B. Bouloumié.

7. Lors de la Table-Ronde CNRS de Lattes (mars 1989) : Diffusion et chronologie des amphores massaliètes.

8. Information Ch. Lagrand.

9. Trois fragments à vernis noir dans un contexte du début du IIIe siècle av. n. è. à Lijay ; un tesson apparemment ancien isolé à Saint-Romain-en-Gal (inf. A. Desbat).

10. Information Ch. Lagrand.

11. Information A. Guillot.

12. Tous mes remerciements à G. Dal Pra, conservateur du Musée de Soyons, pour m'avoir permis d'examiner les collections du Musée.

13. Il s'agit là d'une découverte plus ancienne et l'identification de cette pièce a été réalisée par J.-P. Colbert de Beaulieu.

14. La note précédente s'applique également à cette pièce.

15. Le moulage de cet objet est visible à la Maison du Patrimoine de Hières-sur-Amby. 


\section{Chapitre 3. Synthèse}

1 A partir de l'étude exhaustive des objets non céramiques, d'une sélection des vestiges céramiques, de l'analyse des monnaies, des restes osseux animaux et humains et malgré les incertitudes dues aux conditions de découvertes, il semble possible d'appréhender la nature et la fonction du gisement.

\section{Chronologie du site}

2 La faille de La Chuire a livré du mobilier très différent selon les époques. Pour ce qui concerne l'âge du Bronze final, les documents sont en quasi-totalité des vestiges céramiques et le métal n'est représenté que par deux parures intactes. Si la majeure partie du mobilier appartient au Bronze final III $b$, il est possible d'isoler quelques récipients plus anciens datables vraisemblablement de la phase II.

3 Le premier âge du Fer est apparemment très peu représenté; le Hallstatt $C$ est individualisé par un unique objet fragmentaire appartenant à l'armement et le Hallstatt D n'est perceptible qu'à partir de quelques objets vestimentaires. Une incertitude demeure et demeurera sans doute longtemps sur l'éventuelle attribution à cette époque de divers ustensiles et outils: ces derniers, très stables dans leur morphologie, ne constituent pas de bons indices chronologiques et rien ne permet de les attribuer assurément à telle ou telle phase de l'âge du Fer. D'autre part, demeure le problème de la définition d'un faciès céramique régional pour le premier âge du Fer; dans l'état actuel des recherches, il est impossible de préciser s'il y a eu une continuité chronologique à partir du Bronze final III $b$ jusqu'à la fin du premier âge du Fer, qui se traduirait par la présence de vaisselle indigène. Par contre, l'arrivée des premières importations méditerranéennes est sensible dès la fin du VIe siècle av. n. è. et il s'agit tout à la fois de céramiques et d'objets métalliques peu nombreux.

Les phases La Tène $A$ et $B$ du second âge du Fer sont très mal attestées; deux parures seulement sont rapportées sans certitude aux périodes anciennes de La Tène. Par contre, les phases $\mathrm{C}$ et $\mathrm{D} 1$ sont très bien reconnues, tant dans le mobilier noncéramique que dans la vaisselle, par une grande diversité de formes et d'activités : objets vestimentaires, domestiques, culinaires, artisanaux, agricoles et militaires. La phase finale D2 de La Tène est plus difficile à saisir et semble même absente. Un second 
courant d'importation originaire du domaine italique peut être situé au cours de la phase D1 à partir d'objets céramiques. Chronologiquement, tous les documents laténiens se situent entre le deuxième quart et le milieu du IIIe siècle av. n. è. et le deuxième quart du Ier siècle av. n. è., soit une durée d'un peu plus de deux cents ans correspondant à une dizaine de générations d'individus.

5 Dans l'état actuel des recherches ce sont donc surtout deux époques distinctes qui semblent massivement attestées ; l'une appartient à la phase finale de l'âge du Bronze et l'autre à la culture des oppida qui caractérise les phases finales de La Tène.

\section{Nature du gisement}

\section{Un dépotoir d'habitat?}

6 La coexistence de restes de consommations alimentaires d'espèces d'élevage, de vaisselle céramique et de mobilier métallique, le plus souvent usagé, s'accorde avec la définition la plus courante des dépotoirs d'habitats. Il s'agit de regroupements comprenant des déchets alimentaires et des objets inutilisables, usagés ou périmés, localisés dans les angles de pièces, stockés dans des fosses d'extraction de matériaux ou repoussés le long de fortifications. Ces structures, extrêmement fréquentes dans les habitats, sont généralement considérées comme le résultat de balayages réguliers des sols des demeures. Le plus souvent, les dépotoirs sont constitués rapidement et ont ainsi une chronologie brève, mais il existe aussi des dépotoirs constitués durant un long laps de temps : plus de deux siècles pour le dépotoir J de Nages (Py 1978).

7 La présence de restes humains d'adultes et d'adolescents dans ce type de contexte ne peut surprendre et ce genre d'observation est fréquente lors de la fouille de fosses dépotoirs de La Tène. Le site de Bâle-Gasfabrik est exemplaire quant à la localisation des restes humains : ceux-ci apparaissent dans de multiples fosses liées à l'habitat, mais aussi dans et aux abords d'une enceinte quadrangulaire vraisemblablement cultuelle et dans une nécropole à inhumation pauvre en mobilier (Wyss 1975). Dans ce cas, la présence de restes humains dans des fosses à déchets peut s'expliquer par l'exclusion de certains individus du groupe social et leur rejet hors de la nécropole classique. D'autres explications peuvent être évoqués pour expliquer cette présence : l'existence de sépultures à inhumations méconnues, oubliées et un jour fortuitement bouleversées, générant ainsi des restes erratiques déplacés dans des fosses à déchets. Quelques anomalies laissent entrevoir d'autres interprétations: la présence de restes non incinérés dans des régions où seule cette pratique est attestée et la fréquente surreprésentation des os du crâne (qui se conservent mieux) sur les autres parties du corps sont autant d'observations qui peuvent être liées à la conservation de reliques dans les habitats, par ailleurs décrite dans les sources antiques. Comme on le voit, l'existence de restes humains dans le mobilier osseux de La Chuire n'est pas contradictoire avec la fonction de dépotoir suggérée a priori pour le site.

Dans l'hypothèse d'un dépotoir d'habitat, l'ensemble de La Chuire parait cependant assez singulier par plusieurs aspects. D'abord sa chronologie, bien que discontinue, est extrêmement longue puisqu'elle débute au Bronze final pour finir à La Tène D, avec des époques mieux et diversement représentées que d'autres. Cette première observation distingue le site des autres dépotoirs protohistoriques et seules les découvertes effectuées en grotte semblent comparables, du moins pour ce qui concerne leur 
chronologie. Ensuite, la concentration de mobilier dans la faille de La Chuire implique un regroupement préalable des restes et surtout leur transport, à partir des habitats en direction de la falaise où ils sont ensuite jetés. Il $\mathrm{y}$ a là une pratique dans le traitement des déchets qui paraît très naturelle et qui trouve des analogies sur quelques sites du Midi de la Gaule : à La Liquière, un dépotoir du VIe siècle av. n. è. était localisé sur la bordure même du plateau (Py 1984 : p. 312). Cependant, des dépotoirs situés au pied des falaises ne semblent pas connus, mais il y a peut-être là un défaut de la recherche. Il paraît peu probable que le cas de La Chuire soit unique et des dépotoirs analogues doivent exister sur de nombreux gisements de hauteur installés le long d'un à-pic. Leur découverte pourrait sensiblement modifier la connaissance de ce type d'habitat en apportant un complément de données, s'ajoutant aux informations provenant des niveaux de sols et des dépotoirs situés dans l'habitat même.

Une autre remarque concerne les rapports entre les découvertes de La Chuire et celles effectuées sur le plateau du Camp de Larina.

Chronologiquement, on n'observe que deux coïncidences, l'une au Bronze final III $b$ et l'autre à La Tène D. La fin de l'âge du Bronze est attestée sur le Camp par de multiples fosses, partiellement étudiées, qui pourraient être des structures comblées par des déchets; quant à l'âge du Fer, seule sa phase la plus récente est connue et le peu de mobilier recueilli hors contexte peut provenir de niveaux de sols ou de structures érodées. La rareté des vestiges laténiens sur le site peut très bien s'expliquer par leur rejet en masse dans la faille de La Chuire. Il semblerait que divers traitements des déchets aient coexisté et que l'on ait soit enterré, soit jeté ces derniers à la fin de l'âge du Bronze, et plutôt massivement jeté ces restes à La Tène.

\section{Un dépôt de sanctuaire?}

11 L'hypothèse, pratique et immédiate d'un dépotoir, doit être nuancée par diverses observations ponctuelles d'ordre quantitatif et qualitatif, limitées à la série métallique de l'âge du Fer. Celle-ci est quantitativement importante, et le demi-millier d'objets exhumés lors d'une dizaine de sondages rapproche le Camp de Larina des grands oppida laténiens où le nombre de ces vestiges atteint plusieurs milliers (plus de 2000 à Manching). Il s'agit cependant de sites sans commune mesure avec le Camp de Larina, dotés d'enceintes considérables enserrant des surfaces dépassant parfois plusieurs centaines d'hectares.

12 Si la série métallique appartient à la culture des oppida, elle comporte quelques absences notables qui la distinguent des corpus établis sur les sites majeurs laténiens : pas de mobilier lié aux activités de forge (pinces de forgeron, marteau, enclume) et même peu de mobilier en rapport avec les travaux du métal, pas de socs de charrues mais pourtant des outils agricoles, pas de chaudrons mais nombre de ses accessoires, une seule hache alors que les oppida en livrent par dizaines. Manifestement, le corpus habituel des oppida ne figure que partiellement dans La Chuire et l'on peut douter de la représentativité du mobilier ou invoquer des sélections volontaires qui réserveraient certains objets à d'autres finalités : sans qu'il y ait de caractère systématique, il faut constater, par exemple, que les chaudrons figurent parfois dans des contextes fluviaux (la Saône, la Thielle) et les socs d'araires sont parfois déposés hors des habitats pour servir de bornages agraires (Brunaux 1986 c: p. 92-93). La rareté des outils de 
métallurgiste est plus surprenante dans la mesure où le minerai de fer est présent au pied même du site.

Outre ces absences, la série métallique offre quelques autres particularités définies par le degré de conservation du mobilier métallique. Si une bonne part des objets montre des traces nettes d'utilisation ayant conduit à la cassure, un nombre relativement élevé d'entre eux est simplement usagé ou même intact et rien ne permet d'expliquer le rejet en dépotoir, alors que d'autres contextes auraient pu les accueillir ou qu'ils auraient pu être encore longtemps utilisés, tels quels ou après une légère transformation (reforgeage, réaffûtage). C'est le cas pour des parures, des accessoires du service des viandes, de l'outillage de boucherie, des outils agricoles et artisanaux. Certains objets paraissent ne pas avoir servi, par exemple, certains clous intacts. La présence d'objets complets dans les habitats n'est pas très fréquente, elle caractérise plutôt les contextes funéraires ou certains sites cultuels. Néanmoins, l'hypothèse de rejet dans la faille implique l'état de dépôt définitif, alors que sur un habitat, les pièces périmées peuvent faire l'objet de multiples manipulations ayant pour conséquence une fragmentation extrême.

14 Si des objets sont complets ou intacts, d'autres, très peu nombreux, montrent des déformations manifestement volontaires (fig. 148). Un ou deux cas de déformations au plus sont attestés dans les différentes catégories regroupant les objets de même fonction : la parure, les ustensiles liés à la cuisson et au service des viandes, l'outillage agricole et des travaux du bois, peut-être même l'armement. Les cas les plus nets montrent des torsions ayant pour résultat la superposition presque exacte d'une des extrémités de l'objet sur l'autre, suite à une rotation d'environ $180^{\circ}$. Il ne s'agit donc pas de torsions anarchiques et le résultat très simple obtenu est la conséquence d'un choix. Ces déformations peuvent affecter la totalité de l'objet ou la partie la plus fonctionnelle de celui-ci : ainsi, une dent d'une fourchette à chaudron a été martelée jusqu'à être recourbée sur elle-même. Quelques objets montrent des torsions médianes moins marquées, variant de $40^{\circ}$ à $90^{\circ}$. La plupart ont pour conséquence la réduction de la longueur initiale de l'objet; seule une torsion a conduit à l'effet inverse, certainement en raison de la morphologie particulière de l'objet. Un autre traitement peut être appréhendé à partir de divers fragments et consiste au démontage de certains objets composites, suivi de torsions. Cela pourrait être le cas pour un gril, dont les barres transversales ont dû être retirées avant la torsion d'une des deux barressupports. Plusieurs barres transversales isolées montrent d'ailleurs des torsions allant jusqu'à $90^{\circ}$. Le démontage pourrait aussi concerner quelques armes, en particulier les boucliers, puisqu'au moins un umbo ne possède plus ses rivets de fixation, alors que sont visibles les traces de leur mise en place. Ces démontages pourraient aussi concerner les trépieds et les seaux. Un certain nombre d'objets présentent des écrasements, des traces de chocs et des cassures qui pourraient résulter d'une action délibérée, mais les stigmates de ces éventuels traitements ne sont pas assez cohérents et ne permettent pas d'être affirmatif. En fait, vu les conditions de découvertes (dans un éboulis rocheux), seuls les cas de torsions et les démontages peuvent être retenus avec certitude comme étant la conséquence d'un traitement qui a pour but la mise hors d'usage définitive de l'objet. Ces destructions volontaires ont pu être obtenues de différentes manières : à froid, manuellement ou à l'aide d'un support rigide; avec un marteau ou tout autre percuteur ; vraisemblablement après un passage au feu pour les objets les plus massifs. 


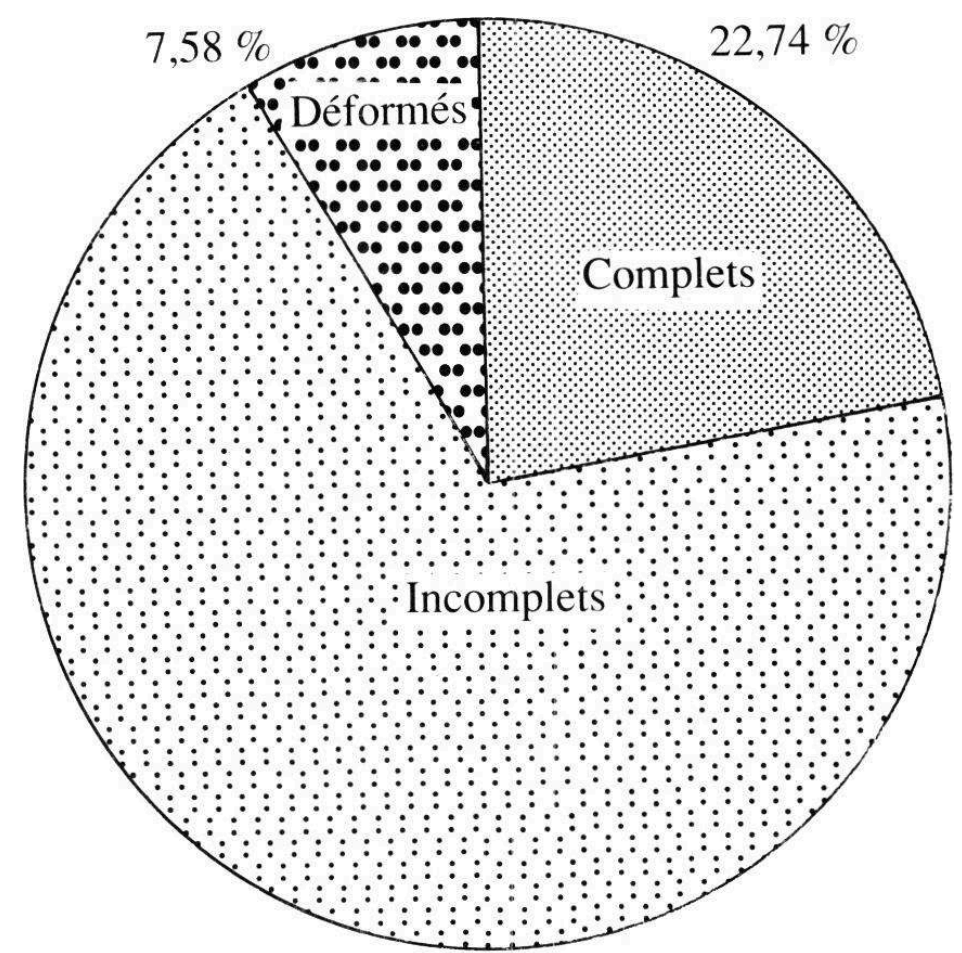

$69,68 \%$

15 L'existence de destructions volontaires, ponctuelles et rudimentaires, dans la série métallique de l'âge du Fer de La Chuire, pose un certain nombre de problèmes quant à leur présence dans ce qui apparaît au premier abord comme une masse de déchets, issue des activités normales d'un habitat. En effet, on ne peut s'empêcher de rapprocher ces traitements de ceux reconnus depuis longtemps en milieux funéraires et attestés depuis peu dans certains sites cultuels où ils constituent le pendant dans le domaine matériel du sacrifice des êtres vivants.

Dans les sépultures, les pratiques ayant pour but de rendre un objet inutilisable sont connues dès le début de l'âge du Fer et se multiplient jusqu'à la fin de cette époque. Elles concernent principalement l'armement, mais on peut les observer plus rarement sur des parures (Biel 1987: p. 167-170; Vitali $1985:$ p. 268) et sur des pièces de char (Gustin 1985: p. 71-73; Marcadal 1986: p. 76). Si elles sont très fréquentes dans les contextes funéraires à incinération, on connaît néanmoins de rares exemples de destructions volontaires dans des tombes à inhumations. Manifestement, les destructions volontaires observées dans le mobilier de La Chuire n'ont que peu de rapports avec les pratiques liées aux rites funéraires qui ne s'appliquent pas aux mêmes objets. Bien que l'on puisse envisager la présence d'inhumations bouleversées dans La Chuire, puisque l'étude des restes osseux a montré l'existence de vestiges humains, il semble difficile d'associer à ces fragments erratiques tous les cas de torsions et de démontages recensés.

Les destructions volontaires d'objets sont aussi reconnues dans des contextes cultuels, en particulier dans les sanctuaires dits de type belge, définis à partir de l'étude du site de Gournay-sur-Aronde (Brunaux 1985 b: Brunaux 1986 b). Ces rassemblements, constitués sur plusieurs siècles, comptent plusieurs centaines ou milliers de fragments 
d'objets détruits. Ces destructions volontaires concernent principalement des panoplies militaires, mais parfois aussi des objets vestimentaires.

$\mathrm{Si}$, à l'âge du Fer. les destructions volontaires concernent donc surtout l'équipement militaire dans le cadre de rituels religieux, le mobilier de La Chuire montre que des traitements similaires concernent d'autres catégories d'objets. Pourtant, il paraît difficile de les considérer comme le résultat de gestes dénués de sens et effectués sans raison, et il faut envisager qu'elles sont la conséquence de motivations indéterminées, dont le but reste le même que dans les sanctuaires : rendre un objet inutilisable.

Ces déformations associées aux anomalies telles que la présence d'objets rejetés intacts ou réutilisables, ainsi que certaines absences permettent-elles de reconsidérer l'hypothèse initiale d'un dépotoir d'habitat? Bien que limitées aux objets métalliques de l'âge du Fer, elles sont assez nombreuses pour permettre d'envisager d'autres interprétations, du moins en ce qui concerne cette époque. Outre les activités de la vie quotidienne dans un habitat, d'autres sources pourraient générer des déchets comparables à ceux de La Chuire. Leur approche est la conséquence directe de la disparité observée entre le mobilier de l'âge du Fer découvert sur le Camp de Larina et celui provenant de La Chuire. Il faut au préalable dissocier la documentation de l'âge du Bronze final du reste du mobilier : a priori aucune anomalie n'a été constatée dans l'ensemble céramique se rapportant à cette époque et, sans trop préjuger de l'étude des structures de la fin de l'âge du Bronze découvertes sur le plateau, on peut considérer que l'on a affaire à des structures comblées par des déchets attestant une intense occupation du site à cette époque ; au cours de laquelle la faille de La Chuire aurait déjà constitué un dépotoir.

La situation concernant l'âge du Fer est toute différente. Actuellement, le plateau n'a livré que des documents épars attribuables à La Tène et aucune structure ou niveau de sol n'a été mis en évidence. Le mobilier retrouvé hors contexte apparaît comme intimement lié à la notion d'échange : il s'agit d'une part de monnaies dont une part importante est d'origine extra-régionale auxquelles il faut ajouter un coin monétaire qui indique éventuellement la frappe d'espèces monétaires sur le site, et d'autre part de témoins liés à la diffusion de produits italiques (amphores, campaniennes, simpulum) et la consommation du vin. De même, dans les quelques parures existantes figurent aussi des types extérieurs à la Provincia, à laquelle le site est rattaché. En outre, si on ne peut nier l'existence de céramiques indigènes de l'âge du Fer dans les 30000 tessons présents dans les remblais gallo-romains, il faut constater une fragmention poussée impliquant un nombre réduit de récipients dans un lot qui livre surtout des tessons du Bronze final. Dans l'état actuel des recherches sur le site, l'absence de structure, la rareté et la nature des documents laténiens sur le plateau semblent difficilement attester une occupation dense et durable du Camp de Larina au cours de l'âge du Fer. Que la faille de La Chuire ait constitué le principal lieu de rejet du site est une chose, que l'on ne trouve pas de traces nettes d'occupation en est une autre. Comment alors expliquer la présence en masse de documents de l'âge du Fer dans La Chuire et les anomalies constatées dans la série métallique? Au terme de l'étude, on peut proposer l'hypothèse suivante : ces derniers ne seraient pas le produit d'une occupation dense et durable du site mais plutôt le résultat de fréquentations ponctuelles du Camp de Larina. Il pourrait s'agir de rassemblements périodiques au cours desquels se dérouleraient des consommations alimentaires collectives, ainsi que des activités artisanales et des échanges économiques. D'autres pratiques, aboutissant à des destructions volontaires 
d'objets et évoquant le domaine cultuel seraient aussi effectuées lors de ces rassemblements. Dans ce cas, le Camp de Larina serait avant tout un habitat fortifié de hauteur du Bronze final fréquenté épisodiquement au cours de l'âge du Fer en raison de sa position privilégiée.

21 L'hypothèse de la fréquentation d'un sanctuaire peut être envisagée mais demeure fragile. En effet, bien que l'on connaisse surtout les lieux de cultes consacrés à des divinités guerrières, les quelques sanctuaires préromains se rapportant à d'autres dieux livrent des offrandes bien particulières (séries de monnaies, fibules, céramiques importées, vases miniatures) très différentes du mobilier livré par La Chuire. Un autre type de rassemblement peut être proposé: les foires ou marchés qui réunissent périodiquement un grand nombre d'individus, nécessitent la présence pendant une durée limitée de constructions et doivent naturellement générer une masse importante de déchets.

L'existence de foires ou de marchés en dehors des habitats n'est pas connue à l'âge du Fer et ces activités sont localisées à l'intérieur des grands oppida laténiens. Par contre, diverses sources postérieures à l'âge du Fer attestent la réalité de rassemblements en dehors des habitats : la plus connue est celle se déroulant au Mont-Beuvray (Chédeville 1980 : p. 114), mais d'autres exemples pourraient être cités, notamment dans le Massif Central. D'autre part, la littérature médiévale irlandaise, formée à partir d'un fond oral celtique, relate plusieurs types de réunions qui méritent d'être mentionnés. La fête de Lugnasad donne lieu tous les trois ans à des rassemblements, réunissant toutes les classes sociales lors d'une trêve générale. A l'occasion de cette fête se déroulent des banquets, des échanges économiques, des jeux et des cérémonies religieuses et politiques. Dans un cas, l'emplacement de la fête est lié à la présence de sépultures princières ou de tertres supposés tels (Leroux 1986). Il est bien sûr difficile dans l'état actuel des recherches d'affirmer que ces mentions tardives soient l'écho de réalités anciennes, voire protohistoriques; cependant, l'exemple concret de la foire de Bibracte incite à envisager ce type d'hypothèse pour le camp de Larina. Dans ce cas, on aurait dans la faille de La Chuire le produit d'une récolte de déchets.

Ces fréquentations semblent cesser à la fin de La Tène D1 ou au début de La Tène D2, soit à l'approche du soulèvement allobroge de 62 av. n. è. Par la suite, sur le site de Larina existe probablement un bâtiment public. Ce dernier est révélé par la présence de blocs monumentaux épars et par l'existence d'une inscription (Corpus Inscriptionum Latinarum XII 2373) dont la provenance locale n'est pas totalement assurée, qui mentionne la réfection à l'époque augustéenne d'un bâtiment dédié à Mercure (la nature de celui-ci n'est pas précisée : temple, autel ?). Cette dédicace est très complexe puisqu'elle associe au nom de Mercure le qualificatif de vainqueur (Victor) et ce qui pourrait être un nom de peuple : les Magniaci. Si l'existence à l'intérieur du Camp d'un bâtiment dédié à Mercure devait se confirmer, on aurait sans doute là un lien éloquent avec la situation suggérée pour l'âge du Fer. En effet, Mercure, ou plutôt l'interprétation romaine de la première divinité gauloise, est qualifié « ... d'inventeur de tous les arts... guide des voyageurs... protecteur actif et influent du gain et du commerce... » (Rémy 1971 : p. 179-181; Buisson 1987). D'autre part, on peut noter que le site de Larina ne génère pas d'occupation importante à l'époque gallo-romaine dans sa périphérie; sur le site même, il faut attendre l'Antiquité tardive pour voir se développer un habitat durable et dans les alentours, seules quelques villas sont signalées, en particulier un très grand domaine à Saint-Romain-de-Jalionas. 
24 L'hypothèse proposée pour expliquer les caractéristiques de La Chuire et du Camp de Larina ne peut évidemment servir de modèle et devra être vérifiée au cours de l'extension des fouilles qui concernent actuellement l'habitat de l'Antiquité tardive. On peut se demander si d'autres sites fortifiés de hauteur ou oppida du domaine celtique n'auraient pas eu la même fonction à une époque précise de leur histoire ; il semble, en effet, que si une occupation véritable est fréquemment reconnue à La Tène D2 sur certains gisements, les éléments de confirmation indiquant l'existence des phases antérieures sont loin d'être nombreux.

Existe-il d'autres sites de "dépotoirs" qui pourraient ne pas être en rapport avec des habitats permanents? L'ensemble du mobilier découvert à Vienne sur la colline de Sainte-Blandine présente de nombreuses analogies avec le mobilier métallique laténien de La Chuire. Il s'agit d'une découverte fortuite, se présentant sous la forme d'une masse compacte d'objets métalliques et céramiques, localisée à proximité de l'enceinte gallo-romaine de la ville. Au vu des conditions de découvertes, on peut douter du prélèvement systématique des documents archéologiques ${ }^{1}$, expliquant la rareté de la vaisselle et l'absence de faune. Une différence notable entre les deux gisements concerne la chronologie, puisqu'à Sainte-Blandine les phases C2 et D1 sont principalement représentées et que le gisement a livré un nombre conséquent d'objets gallo-romains. La colline de Sainte-Blandine recèle les vestiges d'un important bâtiment gallo-romain certainement public. Peu de données existent concernant l'occupation à l'âge du Fer du site de Vienne, mais des découvertes récentes et encore inédites (information; Service Municipal d'Archéologie de Vienne) attestent une occupation laténienne dans la partie basse de la ville. Il semble donc peu probable que la découverte de Sainte-Blandine soit un dépotoir lié à un habitat de hauteur dont la surface d'occupation potentielle est d'ailleurs réduite et il faut envisager une interprétation analogue à celle de La Chuire. Dans ce cas, le territoire allobroge apparaîtrait comme délimité au nord par des sites à vocations commerciales localisés sur le cours du Rhône ; les récentes fouilles de Genève ont justement mis en évidence l'existence d'un port établi entre 123 et 105 av. n. è. et précédé d'une fréquentation de nature cultuelle (Bonnet 1989). Si on confronte la création de cette structure portuaire à la situation perceptible par l'étude monétaire de Larina, où font défaut les espèces de Gallia Comata, les limites de la Provincia semblent se dessiner: celles-ci ne sont pas seulement naturelles (le Rhône) et il faut envisager le contrôle politique d'anciens sitesmarchés et la réorganisation des circuits économiques impliquant la création de nouveaux sites d'échanges immédiatement après la conquête de 121 av. n. è. Cette hypothèse est d'ailleurs renforcée par l'examen des répartitions d'objets de type italique (simpulum du type de Pescate) et celtiques (fibules du type de Lauterach et Feugère type $4 \mathrm{c} 2$ ) : il reste à expliquer les étapes du processus qui a conduit à "figer" la limite nord de la Provincia et à ce propos, on ne peut que rappeler la présence à Lyon de fossés romains de type militaire dont la datation très discutée pourrait se situer au plus tôt dans le second quart du Ier siècle av. $n$. è. (cf. la conclusion générale de $\mathrm{Ch}$. Goudineau dans l'ouvrage "Aux origines de Lyon" DARA n ${ }^{\circ} 2$ ).

D'autres sites évoquant La Chuire, et par là l'interprétation du Camp de Larina, méritent d'être mentionnés en particulier le "Massenfunde" découvert sur l'oppidum de la Engehalbinsel de Berne. Des analogies existent aussi avec plusieurs dépôts hétéroclites, parfois isolés et exclusivement métalliques disséminés dans tout le monde celtique : par exemple celui de Kolín en Tchécoslovaquie ${ }^{2}$. Toutefois, le peu de qualité 
des données de terrain disponibles pour toutes ces découvertes incite à se demander si leur compréhension n'est pas avant tout liée à la reprise de nouvelles fouilles, par exemple, sur la colline de Sainte-Blandine....

\section{Le site et son contexte culturel}

Le Camp de Larina et le site de La Chuire apportent une masse de données considérable pour ce qui concerne la connaissance de la protohistoire tardive en Dauphiné. Toutefois, les conditions de découvertes permettent d'appréhender de manières très différentes le problème de la définition du faciès régional et son rapport avec les cultures protohistoriques limitrophes. Dans l'état actuel des recherches, il est sans doute prématuré de vouloir préciser l'appartenance culturelle des documents du Bronze final alors que plusieurs sites régionaux de cette période sont en cours d'étude. Vraisemblablement plusieurs phases existent, et seule la plus récente est bien documentée. Le mobilier du Bronze final III b évoque, par son répertoire de formes, les sites septentrionaux du domaine rhodano-alpin; la présence de céramiques peintes le distingue des sites plus méridionaux (Sud Drôme, Sud Ardèche) où ces productions ne figurent que d'une manière ponctuelle. L'occupation de l'Isle Crémieu semble très dense à cette époque et le Camp de Larina occupe très certainement une place privilégiée dans un contexte où les sites de plaines et les occupations en grottes sont bien attestés. La découverte récente d'une sépulture aristocratique, datée du Ville siècle av. n. è. et située à moins de deux heures de marche du Camp de Larina, pourrait être mise en relation avec ce dernier. Une datation des fortifications de celui-ci s'avèrerait sans doute pleine d'intérêt s'il devait se confirmer qu'il s'agit d'une structure de la fin de l'âge du Bronze, ce que la présence de mobilier de cette époque dans la masse de matériau rapportée semble indiquer. L'existence d'une organisation sociale de type aristocratique à l'extrême fin de l'âge du Bronze et au début de l'âge du Fer semble envisageable en Dauphiné. Outre le secteur de l'Isle Crémieu, un autre terroir a livré des éléments en rapport avec ce type de structure sociale : il s'agit de la plaine de Bièvre-Valloire, qui relie la vallée du Rhône à celle de l'Isère, d'où provient la célèbre découverte du char de la Côte-Saint-André, située non loin du site fortifié de hauteur de Plan (Chapotat 1962 : p. 33-78; Lasfargues 1984 : p. 21).

D'autres incertitudes concernent une éventuelle continuité entre la fin de l'âge du Bronze et le début de l'âge du Fer, et seuls quelques objets permettent d'entrevoir l'existence des périodes intermédiaires entre la fin de l'âge du Bronze et l'arrivée des premières importations méridionales. A la fin du premier âge du Fer, le site de Larina n'atteste que partiellement la circulation des produits et denrées méditerranéens. Ceux-ci ne sont que faiblement représentés et on note l'absence des céramiques attiques et des flacons en verre polychrome, pourtant connus à Lyon-Vaise et à SaintRomain-en-Gal. Il ne semble donc pas que le site de Larina ait été l'un des aboutissements de la circulation du vin massaliote et de ses produits d'accompagnement et on peut l'écarter de la liste des sites princiers hallstattiens. Il est vrai que l'hypothèse proposée pour le gisement explique le peu de mobilier importé, mais bien qu'il ne soit guère aisé d'isoler la céramique indigène contemporaine, celle-ci semble minoritaire et le site de Larina paraît être entré dans une période de déclin dès la fin du VIe siècle av. $n$. è. L'essentiel de la circulation des produits méditerranéens en direction des sites princiers devait transiter par la moyenne vallée du Rhône, puis au 
niveau de Lyon, suivre la vallée de la Saône, pour aboutir à la « ... tête de pont... » que constituait le site de Bragny (Feugère 1986).

Quant au second âge du Fer, il se caractérise par la coexistence de mobiliers témoignant de filiations diverses. Le mobilier non céramique et céramique appartient sans conteste à la culture laténienne et montre des affinités marquées avec les sites du Plateau Suisse, voire de Bavière. Toutefois, on constate la présence de productions dérivées des céramiques grecques d'Occident qui semblent être apparues aux portes de la Provence. Cette situation qui se retrouve sur d'autres sites de la moyenne vallée du Rhône permet d'établir un lien entre les populations de Gaule méridionale et nord-alpines. C'est certainement dans le secteur compris entre les sites du Pègue et de Larina que s'expriment le mieux les modalités de la celtisation du Midi de la Gaule. Dans la moyenne vallée du Rhône ce phénomène ne peut se réduire à des raisons d'ordre économique, mais semble mieux s'expliquer par l'arrivée aux IVe-IIIe siècles av. n. è. de populations celtiques qui ont su intégrer certains aspects de la culture matérielle locale.

30 Ainsi, l'ethnonyme "Allobroges", signifierait, selon l'étymologie la plus communément admise : « les gens venus d'un autre pays ».

\section{NOTES}

1. La relation de la découverte signale "une infinité de tessons" et seuls 1054 tessons sont étudiés.

2. Cf. Rybovâ 1983. Les découvertes regroupées dans le type de Kolín sont variées et ces découvertes ne semblent d'ailleurs pas typiques de l'âge du Fer, puisque des dépôts analogues sont datés du IXe siècle ap. n. è. Cf. A. Pleterski, Sebenjki zaklag. Arheoloski vestik, Acta Archaeologica, 38. 1987, p. 237-330. 


\section{Index des lieux de conservation et des données typométriques}

\section{Abreviations :}

DFND = Dépôt de Fouille du Nord Dauphiné, Hières-sur-Amby (Isère).

MCGR = Dépôt Musée de la Civilisation gallo-romaine, Lyon (Rhône).

Ch. $=$ La Chuire

La. $=$ Larina

$\mathrm{L}=$ longueur ;

LC = longueur conservée.

$\mathrm{I}$ = largeur.

lc = largeur conservée.

$\mathrm{h}=$ hauteur.

$\max .=$ maximal

inv. = inventaire.

D. = diametre

$\mathbf{n}^{\circ}$ 1. LC : $216 \mathrm{~mm} ; \mathrm{n}^{\circ}$ inv. La. DFND.

$n^{\circ}$ 2. $\mathrm{LC}: 48 \mathrm{~mm} ; \mathrm{n}^{\circ}$ inv. La. DFND.

$n^{\circ}$ 3. LC : $48 \mathrm{~mm} ; \mathrm{n}^{\circ}$ inv. La. DFND.

$n^{\circ}$ 4. $\mathrm{LC}: 27 \mathrm{~mm} ; \mathrm{n}^{\circ}$ inv. La. DFND.

$n^{\circ}$ 5. LC : $27 \mathrm{~mm} ; \mathrm{n}^{\circ}$ inv. La. DFND.

$n^{\circ}$ 6. LC : $54 \mathrm{~mm} ; \mathrm{n}^{\circ}$ inv. La. DFND.

$\mathbf{n}^{\circ}$ 7. LC : $33 \mathrm{~mm}: \mathrm{n}^{\circ}$ inv. La. 2052. DFND.

$n^{\circ}$ 8. LC : $12 \mathrm{~mm}$; $\mathrm{n}^{\circ}$ inv. La. 1977. DFND.

$n^{\circ}$ 9. $\mathrm{LC}: 70 \mathrm{~mm} ; \mathrm{n}^{\circ}$ inv. La. DFND.

$n^{\circ}$ 10. LC : mm ; Pélatan 1986, PL. XLVIII, n 5. Dépôt (?).

$n^{\circ}$ 11-65. DFND. 
$\mathbf{n}^{\circ}$ 66. DFND.

$\mathrm{n}^{\circ}$ 67. LC ; $232 \mathrm{~mm} ; \mathrm{n}^{\circ}$ inv. Ch. G. 75. 259. MCGR.

$n^{\circ}$ 68. $\mathrm{L}: 89 \mathrm{~mm} ; \mathrm{n}^{\circ}$ inv. Ch. G. 75. 082. MCGR.

$n^{\circ}$ 69. $D: 60 \mathrm{~mm} ; \mathrm{h}: 13 \mathrm{~mm} ; \mathrm{n}^{\circ}$ inv. Ch. G. 75. sans $\mathrm{n}^{\circ} \mathrm{MCGR}$.

$n^{\circ}$ 70. LC : $60 \mathrm{~mm}: \mathrm{n}^{\circ}$ inv. Ch. G. 75. 164. MCGR.

$n^{\circ}$ 71. $L C: 48 \mathrm{~mm} ; \mathrm{n}^{\circ}$ inv. Ch. G. 75. 168. MCGR.

$n^{\circ}$ 72. LC: $56 \mathrm{~mm}$; $\mathrm{n}^{\circ}$ inv. Ch. G. 75. 165. MCGR.

$n^{\circ}$ 73. LC : $64 \mathrm{~mm}: \mathrm{n}^{\circ}$ inv. Ch. G. 75. 018. MCGR.

$n^{\circ}$ 74. $\mathrm{LC}: 46 \mathrm{~mm}$; $\mathrm{n}^{\circ}$ inv. Ch. G. 75. 033. MCGR.

n 75. LC : 70 mm ; Pélatan 1986 : p. 71, pl. L.. nº 6. Dépôt (?).

n 76. LC : $60 \mathrm{~mm}$; Pélatan 1986 : p. 71, pl. L., $\mathrm{n}^{\circ}$ 7. Dépôt (?).

n 77. LC : $22 \mathrm{~mm}$; Pélatan 1986 : p. 71. pl. L. nº 10. Dépôt (?).

n 78. LC : $55 \mathrm{~mm}$; Pélatan 1986 : p. 71, pl. L. n 4. Dépôt (?).

$n^{\circ}$ 79. $\mathrm{L}: 33 \mathrm{~mm}$; $\mathrm{n}^{\circ}$ inv. Ch. 75. 77. 001. MCGR.

$n^{\circ}$ 80. LC : $27 \mathrm{~mm} ; \mathrm{n}^{\circ}$ inv. Ch. 75. 77. 002. MCGR.

$n^{\circ}$ 81. LC : $39 \mathrm{~mm}$; $\mathrm{n}^{\circ}$ inv. Ch. 75. 77. 038. MCGR.

$n^{\circ}$ 82. $\mathrm{L}$ : $55 \mathrm{~mm}$; $\mathrm{n}^{\circ}$ i nv. Ch. 75. 77. 014. MCGR.

$n^{\circ}$ 83. LC: $52 \mathrm{~mm}$; $\mathrm{n}^{\circ}$ inv. Ch. 75. 77. 011. MCGR.

$n^{\circ}$ 84. $\mathrm{LC}: 36 \mathrm{~mm}$; $\mathrm{n}^{\circ}$ inv. Ch. 75. 77. 016. MCGR.

$n^{\circ}$ 85. LC : $49 \mathrm{~mm}$; $\mathrm{n}^{\circ}$ inv. Ch. 84. 861. MCGR.

$n^{\circ}$ 86. $\mathrm{L}$ : $58 \mathrm{~mm}$; $\mathrm{n}^{\circ}$ inv. Ch. 84. 681. MCGR.

$\mathrm{n}^{\circ}$ 87. LC : $110 \mathrm{~mm}$; $\mathrm{n}^{\circ}$ inv. Ch. 83. 004. MCGR.

$n^{\circ}$ 88. LC : $88 \mathrm{~mm} ; \mathrm{n}^{\circ}$ inv. Ch. 50. 014. Dépôt (?).

$n^{\circ}$ 89. $\mathrm{LC}: 46 \mathrm{~mm} ; \mathrm{n}^{\circ}$ inv. Ch. 75. 77. 039. MCGR.

$n^{\circ}$ 90. LC: $37 \mathrm{~mm} ; \mathrm{n}^{\circ}$ inv. Ch. 75. 77. 039. MCGR.

$n^{\circ}$ 91. $\mathrm{LC}: 29 \mathrm{~mm} ; \mathrm{n}^{\circ}$ inv. Ch. 75. 77. 017. MCGR.

$n^{\circ}$ 92. LC : $41 \mathrm{~mm} ; \mathrm{n}^{\circ}$ inv. Ch. 50. 013. MCGR.

$n^{\circ}$ 93. $\mathrm{LC}: 66 \mathrm{~mm}$; $\mathrm{n}^{\circ}$ inv. Ch. 75. 77. 037. MCGR.

$n^{\circ}$ 94. $\mathrm{LC}: 37 \mathrm{~mm}$; $\mathrm{n}^{\circ}$ inv. Ch. 83. 004 bis. MCGR.

$\mathrm{n}^{\circ}$ 95. LC : $33 \mathrm{~mm}$; D de la perle : 7, $4 \mathrm{~mm} \times 7 \mathrm{~mm} ; \mathrm{n}^{\circ}$ inv.

Ch. 75. 77. 027. MCGR.

$n^{\circ}$ 96. LC : $74 \mathrm{~mm}$; D de la perle : $9.1 \mathrm{~mm} \times 9,8 \mathrm{~mm} ; \mathrm{n}^{\circ}$ inv.

Ch. 75. 77. 009. MCGR.

$n^{\circ}$ 97. LC : $88 \mathrm{~mm}$; $\mathrm{n}^{\circ}$ inv. Ch. 75. 77. 015. MCGR.

$n^{\circ}$ 98. $\mathrm{LC}: 44 \mathrm{~mm} ; \mathrm{n}^{\circ}$ inv. Ch. 75. 77. 013. MCGR.

$n^{\circ}$ 99. $\mathrm{LC}: 70 \mathrm{~mm} ; \mathrm{n}^{\circ}$ inv. Ch. 75. 77. 023. MCGR.

$n^{\circ}$ 100. $\mathrm{LC}: 40 \mathrm{~mm}$; $\mathrm{n}^{\circ}$ inv. Ch. 75. 77. 007. MCGR.

n 101. LC : $51 \mathrm{~mm}$; Pélatan 1986 : pl. L, n 1, p. 71. Dépôt (?).

$\mathrm{n}^{\circ}$ 102. LC ; $59 \mathrm{~mm}$; $\mathrm{n}^{\circ}$ inv. Ch. 75. 77. 021. MCGR.

$n^{\circ}$ 103. LC : $64 \mathrm{~mm}$; $\mathrm{n}^{\circ}$ inv. Ch. 75. 77. 005. MCGR. 
$n^{\circ}$ 104. $L C: 49 \mathrm{~mm} ; \mathrm{n}^{\circ}$ inv. Ch. 75. 77. 018. MCGR.

$\mathrm{n}^{\circ}$ 105. LC ; $70 \mathrm{~mm}: \mathrm{n}^{\circ}$ inv. Ch. 75. 77. 185. MCGR.

$n^{\circ}$ 106. LC : $61 \mathrm{~mm}$; $n^{\circ}$ inv. Ch. 75. 77. 006. MCGR.

$n^{\circ}$ 107. LC : $70 \mathrm{~mm}$; $\mathrm{n}^{\circ}$ inv. Ch. 75. 77. 023. MCGR.

$n^{\circ}$ 108. $\mathrm{LC}: 63 \mathrm{~mm} ; \mathrm{n}^{\circ}$ inv. Ch. 75. 77. 006 bis. MCGR.

$n^{\circ}$ 109. LC : $59 \mathrm{~mm}$; $\mathrm{n}^{\circ}$ inv. Ch. 75. 77. 025. MCGR.

$n^{\circ}$ 110. LC : $67 \mathrm{~mm}$; $\mathrm{n}^{\circ}$ inv. Ch. 75. 77. 003. MCGR.

$n^{\circ}$ 111. LC : 50 mm ; Pélatan 1986 ; pl. L. n 3, p. 71. Dépôt (?).

n 112. LC : 58 mm ; Pélatan 1986 : pl. L, n 2, p. 71. Dépôt (?).

$n^{\circ}$ 113. LC : $27 \mathrm{~mm}$; $\mathrm{n}^{\circ}$ inv. Ch. 75. 77. 028. MCGR.

$n^{\circ}$ 114. LC ; $93 \mathrm{~mm}$; $\mathrm{n}^{\circ}$ inv. Ch. 75. 77. 019. MCGR.

$n^{\circ}$ 115. LC : $43 \mathrm{~mm} ; \mathrm{n}^{\circ}$ inv. Ch. 84. 860. MCGR.

$n^{\circ}$ 116. LC : $103 \mathrm{~mm}$; $\mathrm{n}^{\circ}$ inv. Ch. 75. 77. 020. MCGR.

$n^{\circ}$ 117. LC : $40 \mathrm{~mm}$; $\mathrm{n}^{\circ}$ inv. Ch. 75. 77. 030. MCGR.

$n^{\circ}$ 118. LC : $18 \mathrm{~mm}$; $\mathrm{n}^{\circ}$ inv. Ch. 75. 77. 029. MCGR.

$n^{\circ}$ 119. LC : $27 \mathrm{~mm}$; $\mathrm{n}^{\circ}$ inv. Ch. 75. 77. 036. MCGR.

$n^{\circ}$ 120. LC : $49 \mathrm{~mm}$; $\mathrm{n}^{\circ}$ inv. Ch. 75. 77. 032. MCGR.

$n^{\circ}$ 121. LC : $26 \mathrm{~mm}$; $\mathrm{n}^{\circ}$ inv. Ch. 75. 77. 033. MCGR.

$n^{\circ}$ 122. $\mathrm{LC}: 31 \mathrm{~mm} ; \mathrm{n}^{\circ}$ inv. Ch. 75. 77. Sans $\mathrm{n}^{\circ}$ MCGR.

$n^{\circ}$ 123. LC : $60 \mathrm{~mm}$; $\mathrm{n}^{\circ}$ inv. Ch. 84. S2. 370. MCGR.

$n^{\circ}$ 124. $\mathrm{LC}: 60 \mathrm{~mm} ; \mathrm{n}^{\circ}$ inv. Ch. 84 . S2. 370 bis. MCGR.

$n^{\circ}$ 125. LC : $92 \mathrm{~mm}$; $\mathrm{n}^{\circ}$ inv. Ch. 75. 77. 008. MCGR.

$n^{\circ}$ 126. $\mathrm{L}$ : $54 \mathrm{~mm}$; $\mathrm{n}^{\circ}$ inv. Ch. 75. 77. 010. MCGR.

$n^{\circ}$ 127. LC : $41 \mathrm{~mm}$; $\mathrm{n}^{\circ}$ inv. Ch. 75. 77. 024. MCGR.

$n^{\circ}$ 128. $L C: 75 \mathrm{~mm}$; $\mathrm{n}^{\circ}$ inv. Ch. 83. 010. MCGR.

$n^{\circ}$ 129. LC : $49 \mathrm{~mm}$; $\mathrm{n}^{\circ}$ inv. Ch. 75. 77. 032. MCGR.

$n^{\circ}$ 130. LC : $65 \mathrm{~mm}$; $\mathrm{n}^{\circ}$ inv. Ch. 75. 77. 022. MCGR.

$n^{\circ}$ 131. LC : $43 \mathrm{~mm}$; $\mathrm{n}^{\circ}$ inv. Ch. 75. 77. 031. MCGR.

$n^{\circ}$ 132. LC : $32 \mathrm{~mm}$; $\mathrm{n}^{\circ}$ inv. Ch. 75. 77. Sans $\mathrm{n}^{\circ}$ MCGR.

$n^{\circ}$ 133. LC : $21 \mathrm{~mm}$; $\mathrm{n}^{\circ}$ inv. Ch. 75. 77. 035. MCGR.

$n^{\circ}$ 134. LC : $22 \mathrm{~mm}$; $\mathrm{n}^{\circ}$ inv. Ch. 50. 017. Dépôt (?).

$n^{\circ}$ 135. LC : $40 \mathrm{~mm}$; $\mathrm{n}^{\circ}$ inv. Ch. 50. 018. Dépôt (?).

$n^{\circ}$ 136. LC : $53 \mathrm{~mm}$; $\mathrm{n}^{\circ}$ inv. Ch. 50. 019. Dépôt (?).

$n^{\circ}$ 137. LC : $46 \mathrm{~mm}$; $\mathrm{n}^{\circ}$ inv. Ch. 75. 77. 275. MCGR.

$n^{\circ}$ 138. $\mathrm{D}: 60 \mathrm{~mm}$; $\mathrm{n}^{\circ}$ inv. Ch. 50. 012. DFND.

$n^{\circ}$ 139. $D$ : env. $80 \mathrm{~mm} ; \mathrm{n}^{\circ}$ inv. Ch. 83. 011. MCGR.

$n^{\circ}$ 140. $\mathrm{D} ; 36 \mathrm{X} 48 \mathrm{~mm} ; \mathrm{n}^{\circ}$ inv. Ch. 50. 010. DFND.

$n^{\circ}$ 141. $D$ : 31 X $32 \mathrm{~mm} ; \mathrm{n}^{\circ}$ inv. Ch. 75. 77. 055. MCGR.

$n^{\circ}$ 142. $\mathrm{D}: 33 \mathrm{~mm}$; $\mathrm{n}^{\circ}$ inv. Ch. 75. 77. 054. MCGR.

$n^{\circ}$ 143. $D:$ ? ; LC : $26 \mathrm{~mm} ; \mathrm{n}^{\circ}$ inv. Ch. 75. 77. 079. MCGR. 
$n^{\circ}$ 144. $D$ : ? ; LC : $38 \mathrm{~mm} ; \mathrm{n}^{\circ}$ inv. Ch. 84. S2. 010. MCGR.

$n^{\circ}$ 145. D : ? ; LC : $39 \mathrm{~mm} ; \mathrm{n}^{\circ}$ inv. Ch. 50. 016. (?).

$n^{\circ}$ 146. $D$ : $58 \mathrm{~mm} ; \mathrm{n}^{\circ}$ inv. Ch. 75. 77. 130. MCGR.

$\mathrm{n}^{\circ}$ 147. $\mathrm{D}: 50 \mathrm{~mm}$; $\mathrm{n}^{\circ}$ inv. Ch. 75. 77. V. 010. MCGR.

$n^{\circ}$ 148. $\mathrm{D}: 88 \mathrm{~mm}$ : $\mathrm{n}^{\circ}$ inv. Ch. 75. 77. V. 001. MCGR.

$n^{\circ}$ 149. D : env. $80 \mathrm{~mm}$; $\mathrm{n}^{\circ}$ inv. Ch. 75. 77. V. 002. MCGR.

$n^{\circ}$ 150. D : env. $78 \mathrm{~mm}$; $\mathrm{n}^{\circ}$ inv. Ch. 75. 77. V. 003. MCGR.

$\mathrm{n}^{\circ}$ 151. $\mathrm{D}$ : env. $80 \mathrm{~mm}$; $\mathrm{n}^{\circ}$ inv. Ch. 75. 77. V. 003 bis. MCGR.

$n^{\circ}$ 152. $\mathrm{D}$ : env. $80 \mathrm{~mm}$; $\mathrm{n}^{\circ}$ inv. Ch. 50. 005. DFND.

$n^{\circ}$ 153. $D$ : ?; LC : $18 \mathrm{~mm}$ : $\mathrm{n}^{\circ}$ inv. Ch. 75. 77. V. 004. MCGR.

n 154. D : ? ; LC : $18 \mathrm{~mm}$; Pélatan 1986, pl. XLIX, n 4, p.70. Dépôt (?).

$n^{\circ}$ 155. D : ? ; LC : $14 \mathrm{~mm}$; $\mathrm{n}^{\circ}$ inv. Ch. 75. 77. V. 006. MCGR.

$n^{\circ}$ 156. LC : $10 \mathrm{~mm}$; $\mathrm{n}^{\circ}$ inv. Ch. 75. 77. V. 005. MCGR.

$n^{\circ}$ 157. LC : $17 \mathrm{~mm}$; $\mathrm{n}^{\circ}$ inv. Ch. 75. 77. V. 007. MCGR.

$n^{\circ}$ 158. LC : $20 \mathrm{~mm} ; \mathrm{n}^{\circ}$ inv. Ch. 75. 77. V. 008. MCGR.

$n^{\circ}$ 159. $\mathrm{D}: 70 \mathrm{~mm}$; $\mathrm{n}^{\circ}$ inv. Ch. 75. 77. V. 009. MCGR.

n 160. D : env. $70 \mathrm{~mm}$ : Pélatan 1986 : pl. XLIII, n 3, p. 70. Dépôt (?).

$n^{\circ}$ 161. $\mathrm{D}:$ ? ; LC : $7 \mathrm{~mm} ; \mathrm{n}^{\circ}$ inv. Ch. 83. S1. 012. MCGR.

$n^{\circ}$ 162. D : env. $70 \mathrm{~mm} ; \mathrm{n}^{\circ}$ inv. Ch. 50. 007. DFND.

$n^{\circ}$ 163. $\mathrm{D}$ : env. $70 \mathrm{~mm}: \mathrm{n}^{\circ}$ inv. Ch. 50. 006. DFND.

$n^{\circ}$ 164. D : $18 \mathrm{~mm}$; Pélatan 1986 : pl. XLVIII n 2, p. 70. Dépôt ?

$n^{\circ}$ 165. $\mathrm{D}: 28 \mathrm{~mm} ; \mathrm{n}^{\circ}$ inv. Ch. 75. 77. V. 030. MCGR.

$n^{\circ}$ 166. D : env. $80 \mathrm{~mm}$; $\mathrm{n}^{\circ}$ inv. Ch. 75. 77. L. 001. MCGR.

$n^{\circ}$ 167. D : env. $70 \mathrm{~mm}: \mathrm{n}^{\circ}$ inv. Ch. 75. 77. L. 002. MCGR.

$n^{\circ}$ 168. D : env. $70 \mathrm{~mm}$; $\mathrm{n}^{\circ}$ inv. Ch. 75. 77. L. 003. MCGR.

$n^{\circ}$ 169. D : env. $80 \mathrm{~mm}$; $\mathrm{n}^{\circ}$ inv. Ch. 75. 77. L. 004. MCGR.

$n^{\circ}$ 170. D : env. $70 \mathrm{~mm}$; $\mathrm{n}^{\circ}$ inv. Ch. 75. 77. L. 005. MCGR.

$n^{\circ}$ 171. D : env. $70 \mathrm{~mm} ; \mathrm{n}^{\circ}$ inv. Ch. 50. 008. Dépôt (?).

$n^{\circ}$ 172. $D$ : 33 X 52 mm; $n^{\circ}$ inv. Ch. 75. 77. 047. MCGR.

$n^{\circ}$ 173. $D$ : $35 \mathrm{~mm}$; $\mathrm{n}^{\circ}$ inv. Ch. 75. 77. 046. MCGR.

$n^{\circ}$ 174. $\mathrm{D}: 18 \mathrm{~mm} ; \mathrm{n}^{\circ}$ inv. Ch. 75. 77. 049. MCGR.

$n^{\circ}$ 175. D : 8 mm ; nº inv. Ch. 75. 77. 077. MCGR.

$n^{\circ}$ 176. $D$ : $28 \mathrm{~mm} ; \mathrm{n}^{\circ}$ inv. Ch. 75. 77. 048. MCGR.

$n^{\circ}$ 177. D : 24 X 25 mm; n' inv. Ch. 75. 77. 050. MCGR.

$n^{\circ}$ 178. $\mathrm{D}: 9 \mathrm{~mm} ; \mathrm{n}^{\circ}$ inv. Ch. 83. S1. 013. MCGR.

$n^{\circ}$ 179. $D$ : ?; $n^{\circ}$ inv. Ch. 84. S2. 004. MCGR.

$\mathrm{n}^{\circ}$ 180. $\mathrm{L}: 34 \mathrm{~mm}$; $\mathrm{n}^{\circ}$ inv. Ch. 75. 77. 173. MCGR.

$n^{\circ}$ 181. LC : $46 \mathrm{~mm}$; $\mathrm{n}^{\circ}$ inv. Ch. 75. 77. 075. MCGR.

$n^{\circ}$ 182. $\mathrm{L}$ : $77 \mathrm{~mm}$; $\mathrm{n}^{\circ}$ inv. Ch. 75. 77. 041. MCGR.

$n^{\circ}$ 183. $\mathrm{L}: 67 \mathrm{~mm}$; $\mathrm{n}^{\circ}$ inv. Ch. 75. 77. 040. MCGR. 
$n^{\circ}$ 184. LC : $41 \mathrm{~mm}$; $\mathrm{n}^{\circ}$ inv. Ch. 75. 77. 076. MCGR.

$\mathrm{n}^{\circ}$ 185. $\mathrm{L}: \mathrm{mm} ; \mathrm{n}^{\circ}$ inv. Ch. 75. 77. 249. MCGR.

$n^{\circ}$ 186. LC : $64 \mathrm{~mm}$; $\mathrm{n}^{\circ}$ inv. Ch. 75. 77. 156. MCGR.

$n^{\circ}$ 187. LC : $62 \mathrm{~mm}$; $\mathrm{n}^{\circ}$ inv. Ch. 75. 77. 063. MCGR.

$n^{\circ}$ 188. $D$ : $18 \mathrm{~mm}$; $\mathrm{n}^{\circ}$ inv. Ch. 75. 77. 069. MCGR.

$n^{\circ}$ 189. $D$ : $15 \mathrm{~mm}$; $\mathrm{n}^{\circ}$ inv. Ch. 75. 77. 068. MCGR.

$n^{\circ}$ 190. $D$ : $15 \mathrm{~mm}$; $\mathrm{n}^{\circ}$ inv. Ch. 83. S1. 014. MCGR.

$n^{\circ}$ 191. LC : $298 \mathrm{~mm} ; \mathrm{n}^{\circ}$ inv. Ch. 84. S2. 007. MCGR.

$n^{\circ}$ 192. LC : $354 \mathrm{mmn}^{\circ}$ inv. Ch. 75. 77. 086/087. MCGR.

$n^{\circ}$ 193. LC : $131 \mathrm{~mm} ; \mathrm{n}^{\circ}$ inv. Ch. 75. 77. 085. MCGR.

$\mathrm{n}^{\circ}$ 194. $\mathrm{LC}: 146 \mathrm{~mm} ; \mathrm{n}^{\circ}$ inv. Ch. 75. 77. 090. MCGR.

$n^{\circ}$ 195. LC : $153 \mathrm{~mm}$; $\mathrm{n}^{\circ}$ inv. Ch. 75. 77. 201. MCGR.

$n^{\circ}$ 196. LC : $188 \mathrm{~mm} ; \mathrm{n}^{\circ}$ inv. Ch. 75. 77. 093. MCG̣R.

$n^{\circ}$ 197. LC : $201 \mathrm{~mm} ; \mathrm{n}^{\circ}$ inv. Ch. 75.77. 091. MCGR.

$n^{\circ}$ 198. LC : $268 \mathrm{~mm} ; \mathrm{n}^{\circ}$ inv. Ch. 84. S1. 011. MCGR.

$\mathrm{n}^{\circ}$ 199. $\mathrm{LC}: 151 \mathrm{~mm} ; \mathrm{n}^{\circ}$ inv. Ch. 75. 77. 093. MCGR.

$\mathrm{n}^{\circ}$ 200. LC : $144 \mathrm{~mm}$; $\mathrm{n}^{\circ}$ inv. Ch. 75. 77. 089. MCGR.

$\mathrm{n}^{\circ}$ 201. LC : $240 \mathrm{~mm}$; $\mathrm{n}^{\circ}$ inv. Ch. 75. 77. 083. MCGR.

$n^{\circ}$ 202. $\mathrm{LC}: 150 \mathrm{~mm} ; \mathrm{n}^{\circ}$ inv. Ch. 75. 77. 094. MCGR.

$n^{\circ}$ 203. $\mathrm{L} x \mathrm{l}=288 \times 284 \mathrm{~mm} ; \mathrm{n}^{\circ}$ inv. Ch. 84. S1. 456. MCGR.

$n^{\circ}$ 204. LC : $140 \mathrm{~mm} ; 140 \mathrm{~mm}$ : hauteur du pied ; $75 \mathrm{~mm} ; \mathrm{n}^{\circ}$ inv. Ch. 75 .

77. 153. MCGR.

$n^{\circ}$ 205. LC : $45 \mathrm{~mm}$; $\mathrm{n}^{\circ}$ inv. Ch. 75. 77. 160. MCGR.

$n^{\circ}$ 206. LC : env. $190 \mathrm{~mm}$; $\mathrm{n}^{\circ}$ inv. Ch. 83. S1. 009. MCGR.

$n^{\circ}$ 207. LC : $52 \mathrm{~mm}: \mathrm{n}^{\circ}$ inv. Ch. 75. 77. 254. MCGR.

$n^{\circ}$ 208. LC : $158 \mathrm{~mm} ; \mathrm{n}^{\circ}$ inv. Ch. 75. 77. 132. MCGR.

$n^{\circ}$ 209. LC : env. $100 \mathrm{~mm}$; $\mathrm{n}^{\circ}$ inv. Ch. 75. 77. 257. MCGR.

$\mathrm{n}^{\circ}$ 210. $\mathrm{LC}: 127 \mathrm{~mm} ; \mathrm{n}^{\circ}$ inv. Ch. 75. 77. 239. MCGR.

$n^{\circ}$ 211. LC : $80 \mathrm{~mm}$; $\mathrm{n}^{\circ}$ inv. Ch. 75. 77. 281. MCGR.

$n^{\circ}$ 212. LC : $87 \mathrm{~mm}$; $\mathrm{n}^{\circ}$ inv. Ch. 75. 77. 228. MCGR.

$n^{\circ}$ 213. $L C: 136 \mathrm{~mm}: \mathrm{n}^{\circ}$ inv. Ch. 75. 77. 258. MCGR.

$n^{\circ}$ 214. $\mathrm{LC}: 113 \mathrm{~mm} ; \mathrm{n}^{\circ}$ inv. Ch. 75. 77. 240. MCGR.

$n^{\circ}$ 215. LC : $67 \mathrm{~mm}$; $\mathrm{n}^{\circ}$ inv. Ch. 75. 77. 277. MCGR.

n $^{\circ}$ 216. $\mathrm{h}: 116 \mathrm{~mm}$; $\mathrm{D}: 190 \mathrm{~mm}$; $\mathrm{n}^{\circ}$ inv. Ch. 75. 77. 175. MCGR.

$n^{\circ}$ 217. LC: $114 ; n^{\circ}$ inv. Ch. 75. 77. 211. MCGR.

$n^{\circ}$ 218. LC: $170 ; n^{\circ}$ inv. Ch. 75. 77. 209. MCGR.

$n^{\circ}$ 219. $\mathrm{D}: 130 \mathrm{~mm}$; $\mathrm{n}^{\circ}$ inv. Ch. 75. 77. 210. MCGR.

$n^{\circ}$ 220. LC : $449 \mathrm{~mm}$ : $\mathrm{n}^{\circ}$ inv. Ch. 75. 77. 098. MCGR.

$n^{\circ}$ 221. LC : $313 \mathrm{~mm}$; $\mathrm{n}^{\circ}$ inv. Ch. 75. 77.101. MCGR.

$n^{\circ}$ 222. LC : env. $281 \mathrm{~mm}$; $\mathrm{n}^{\circ}$ inv. Ch. 75. 77. 096. MCGR. 
$n^{\circ}$ 223. LC : $360 \mathrm{~mm}: \mathrm{n}^{\circ}$ inv. Ch. 75. 77. 100. MCGR. $n^{\circ}$ 224. $\mathrm{LC}: 514 \mathrm{~mm} ; \mathrm{n}^{\circ}$ inv. Ch. 75. 77. 097. MCGR. $n^{\circ}$ 225. LC : $408 \mathrm{~mm}$; $\mathrm{n}^{\circ}$ inv. Ch. 75. 77. 099. MCGR. $\mathrm{n}^{\circ}$ 226. $\mathrm{LC} ; 258 \mathrm{~mm}$; $\mathrm{n}^{\circ}$ inv. Ch. 75. 77. 179. MCGR. $n^{\circ}$ 227. LC : $181 \mathrm{~mm}$; $\mathrm{n}^{\circ}$ inv. Ch. 75. 77. 103. MCGR. $n^{\circ}$ 228. $L C: 70 \mathrm{~mm}: \mathrm{n}^{\circ}$ inv. Ch. 75. 77. 163. MCGR. $n^{\circ}$ 229. LC ; $47 \mathrm{~mm}$; $\mathrm{n}^{\circ}$ inv. Ch. 75. 77. 162. MCGR. $n^{\circ}$ 230. $\mathrm{LC}: 50 \mathrm{~mm}: \mathrm{n}^{\circ}$ inv. Ch. 75. 77. 166. MCGR. $n^{\circ}$ 231. LC : $58 \mathrm{~mm}: \mathrm{n}^{\circ}$ inv. Ch. 50. 021. Dépôt (?). $n^{\circ}$ 232. LC : $112 \mathrm{~mm} ; \mathrm{n}^{\circ}$ inv. Ch. 75. 77. 102. MCGR. $n^{\circ}$ 233. LC: $66 \mathrm{~mm}: \mathrm{n}^{\circ}$ inv. Ch. 75. 77. 095. MCGR. $n^{\circ}$ 234. LC : $50 \mathrm{~mm}$; $\mathrm{n}^{\circ}$ inv. Ch. 84. S2. 016. MCGR. $n^{\circ}$ 235. LC: $50 \mathrm{~mm}: \mathrm{n}^{\circ}$ inv. Ch. 75. 77. 167. MCGR. $n^{\circ}$ 236. LC: $74 \mathrm{~mm}$; $\mathrm{n}^{\circ}$ inv. Ch. 75.77. 202. MCGR. $n^{\circ}$ 236. LC : $44 \mathrm{~mm}$; $\mathrm{n}^{\circ}$ inv. Ch. 75. 77. 206. MCGR. $n^{\circ}$ 238. LC : $62 \mathrm{~mm}$; $\mathrm{n}^{\circ}$ inv. Ch. 75. 77. 203. MCGR n' 239. LC : $44 \mathrm{~mm} ; \mathrm{n}^{\circ}$ inv. Ch. 75. 77. 288. MCGR.

$n^{\circ}$ 240. $L C: 181 \mathrm{~mm} ; \mathrm{n}^{\circ}$ inv. Ch. 75. 77. 230. MCGR. $n^{\circ}$ 241. $\mathrm{L} ; 215 \mathrm{~mm}$; $\mathrm{n}^{\circ}$ inv. Ch. 75. 77. 108. MCGR. $\mathrm{n}^{\circ}$ 242. $\mathrm{L}: 121 \mathrm{~mm}: \mathrm{n}^{\circ}$ inv. Ch. 75. 77. 124. MCGR. $n^{\circ}$ 243. LC: $56 \mathrm{~mm}$; $\mathrm{n}^{\circ}$ inv. Ch. 75. 77. 208. MCGR. $n^{\circ}$ 244. $L C: 134 \mathrm{~mm} ; \mathrm{n}^{\circ}$ inv. Ch. 75. 77. 198. MCGR. $n^{\circ}$ 245. LC: $26 \mathrm{~mm} ; \mathrm{n}^{\circ}$ inv. Ch. 75. 77. 207. MCGR. $n^{\circ}$ 246. LC : $59 \mathrm{~mm}: \mathrm{n}^{\circ}$ inv. Ch. 75. 77. 266. MCGR. $n^{\circ}$ 247. LC : $65 \mathrm{~mm}$; $n^{\circ}$ inv. Ch. 75. 77. 236. MCGR. $n^{\circ}$ 248. LC : $50 \mathrm{~mm}$; $\mathrm{n}^{\circ}$ inv. Ch. 83. S1. 014. MCGR. $n^{\circ}$ 249. $\mathrm{L}: 75 \mathrm{~mm}$; $\mathrm{n}^{\circ}$ inv. Ch. 75. 77. 088. MCGR. $n^{\circ}$ 250. $\mathrm{L}: 128 \mathrm{~mm}: \mathrm{n}^{\circ}$ inv. Ch. 75. 77. 340. MCGR. $\mathrm{n}^{\circ}$ 251. LC: $44 \mathrm{~mm}$; $\mathrm{n}^{\circ}$ inv. Ch. 75. 77. 010 bis. MCGR. $n^{\circ}$ 252. LC: $148 \mathrm{~mm} ; 1: 42 \mathrm{~mm} ; \mathrm{n}^{\circ}$ inv. Ch. 75. 77. 177. MCGR. $n^{\circ}$ 253. LC : $46 \mathrm{~mm}: 1: 32 \mathrm{~mm} ; \mathrm{n}^{\circ}$ inv. Ch. 83. S1. 015. MCGR. $n^{\circ}$ 254. $\mathrm{D}$ : > $240 \mathrm{~mm} ; 1: 22 \mathrm{~mm} ; \mathrm{n}^{\circ}$ inv. Ch. 83. S1.016. MCGR. $n^{\circ}$ 255. LC : $22 \mathrm{~mm}$; $\mathrm{n}^{\circ}$ inv. Ch. 83. S1. 015. MCGR. $n^{\circ}$ 256. LC : $26 \mathrm{~mm}$; $\mathrm{n}^{\circ}$ inv. Ch. 75. 77. 058. MCGR. $n^{\circ}$ 257. LC : $47 \mathrm{~mm}: \mathrm{n}^{\circ}$ inv. Ch. 75. 77. 057. MCGR. $n^{\circ}$ 258. $\mathrm{L}: 273 \mathrm{~mm}$; $\mathrm{n}^{\circ}$ inv. Ch. 75. 77. 105. MCGR. $n^{\circ}$ 259. $\mathrm{L}: 171 \mathrm{~mm} ; \mathrm{n}^{\circ}$ inv. Ch. 75. 77. 107. MCGR. $n^{\circ}$ 260. LC : $134 \mathrm{~mm}$; $\mathrm{n}^{\circ}$ inv. Ch. 75. 77. 110. MCGR. $n^{\circ}$ 261. LC : $313 \mathrm{~mm}$; $\mathrm{n}^{\circ}$ inv. Ch. 75. 77. 106. MCGR. $n^{\circ}$ 262. $\mathrm{L}$ : $303 \mathrm{~mm}$; $\mathrm{n}^{\circ}$ inv. Ch. 75. 77. 109. MCGR. 
$n^{\circ}$ 263. LC: $142 \mathrm{~mm} ; \mathrm{n}^{\circ}$ inv. Ch. 84. S2. 279. MCGR. $n^{\circ}$ 264. L : $404 \mathrm{~mm}$; $n^{\circ}$ inv. Ch. 75. 77. 104. MCGR. $n^{\circ}$ 265. L : $106 \mathrm{~mm}$; $\mathrm{n}^{\circ}$ inv. Ch. 75. 77. 112. MCGR. $n^{\circ}$ 266. $\mathrm{L}$ : $370 \mathrm{~mm}$; $\mathrm{n}^{\circ}$ inv. Ch. 75. 77. 111. MCGR. $n^{\circ}$ 267. LC : $212 \mathrm{~mm}$; $\mathrm{n}^{\circ}$ inv. Ch. 75. 77. 081. MCGR. $n^{\circ}$ 268. $\mathrm{L}: 188 \mathrm{~mm}$; $\mathrm{n}^{\circ}$ inv. Ch. 84. S2. 001. MCGR. $n^{\circ}$ 269. $\mathrm{L}: 150 \mathrm{~mm} ; \mathrm{n}^{\circ}$ inv. Ch. 75. 77. 122. MCGR. $n^{\circ}$ 270. LC: $138 \mathrm{~mm}: \mathrm{n}^{\circ}$ inv. Ch. 75. 77. 084. MCGR. $n^{\circ}$ 271. $\mathrm{L}$ : $301 \mathrm{~mm}$; $\mathrm{n}^{\circ}$ inv. Ch. 75. 77. 183. MCGR. $n^{\circ}$ 272. $\mathrm{L}: 151 \mathrm{~mm}$; $\mathrm{n}^{\circ}$ inv. Ch. 75.77. 113. MCGR. $n^{\circ}$ 273. $\mathrm{L}: 71 \mathrm{~mm}$; $\mathrm{n}^{\circ}$ inv. Ch. 83. S1. 008. MCGR. $n^{\circ}$ 274. LC: $32 \mathrm{~mm}$; $\mathrm{n}^{\circ}$ inv. Ch. 75. 77. 261. MCGR. $n^{\circ}$ 275. LC : $29 \mathrm{~mm}$; $\mathrm{n}^{\circ}$ inv. Ch. 75. 77. 262. MCGR. $n^{\circ}$ 276. $\mathrm{L}: 222 \mathrm{~mm}$; $\mathrm{n}^{\circ}$ inv. Ch. 75. 77. 182. MCGR. $n^{\circ}$ 277. L : $116 \mathrm{~mm}$; ${ }^{\circ}$ inv. Ch. 75. 77. 128. MCGR. $n^{\circ}$ 278. $\mathrm{L}$ : $93 \mathrm{~mm}$; $\mathrm{n}^{\circ}$ inv. Ch. 75. 77. 132. MCGR. $n^{\circ}$ 279. LC: $33 \mathrm{~mm}$; $\mathrm{n}^{\circ}$ inv. Ch. 75. 77. 245. MCGR. $n^{\circ}$ 280. LC: $50 \mathrm{~mm}: \mathrm{n}^{\circ}$ inv. Ch. 75. 77. 247. MCGR. $n^{\circ}$ 281. L : $82 \mathrm{~mm}$; $n^{\circ}$ inv. Ch. 50. 003. DFND. $n^{\circ}$ 282. LC : $61 \mathrm{~mm}$ : $\mathrm{n}^{\circ}$ inv. Ch. 75. 77. 144. MCGR. $n^{\circ}$ 283. LC : $85 \mathrm{~mm}$; $\mathrm{n}^{\circ}$ inv. Ch. 75. 77. 255. MCGR. $n^{\circ}$ 284. LC: $51 \mathrm{~mm}$; $\mathrm{n}^{\circ}$ inv. Ch. 75. 77. 217. MCGR. $n^{\circ}$ 285. LC : $83 \mathrm{~mm}$; $\mathrm{n}^{\circ}$ inv. Ch. 75. 77. 242. MCGR. $n^{\circ}$ 286. LC: $90 \mathrm{~mm}$; $\mathrm{n}^{\circ}$ inv. Ch. 75. 77. 133. MCGR. $n^{\circ}$ 287. LC : $98 \mathrm{~mm}$; $\mathrm{n}^{\circ}$ inv. Ch. 75. 77. 243. MCGR. $n^{\circ}$ 288. LC : $72 \mathrm{~mm}$; $\mathrm{n}^{\circ}$ inv. Ch. 75. 77. 135. MCGR. $n^{\circ}$ 289. LC : $79 \mathrm{~mm}: \mathrm{n}^{\circ}$ inv. Ch. 75. 77. 145. MCGR. $n^{\circ}$ 290. LC : $37 \mathrm{~mm}$; $\mathrm{n}^{\circ}$ inv. Ch. 75. 77. 159. MCGR. $n^{\circ}$ 291. LC : $200 \mathrm{~mm} ; \mathrm{n}^{\circ}$ inv. Ch. 75. 77. 176. MCGR. $n^{\circ}$ 292. L : $470 \mathrm{~mm}$; $\mathrm{n}^{\circ}$ inv. Ch. 84. S1. 027/279. DFND. $n^{\circ}$ 293. LC : $51 \mathrm{~mm}$; $\mathrm{n}^{\circ}$ inv. Ch. 75. 77. 252. MCGR. $\mathrm{n}^{\circ}$ 294. $\mathrm{LC}: 102 \mathrm{~mm}: \mathrm{n}^{\circ}$ inv. Ch. 75. 77. 125. MCGR. $n^{\circ}$ 295. LC : $83 \mathrm{~mm}$; $\mathrm{n}^{\circ}$ inv. Ch. 50. 004. MCGR. $n^{\circ}$ 296. $\mathrm{L}: 195 \mathrm{~mm} ; \mathrm{n}^{\circ}$ inv. Ch. 50. 002. DFND. $n^{\circ}$ 297. $\mathrm{L}: 159 \mathrm{~mm}$; $\mathrm{n}^{\circ}$ inv. Ch. 75. 77. 062. MCGR. $n^{\circ}$ 298. LC : $140 \mathrm{~mm}$; $\mathrm{n}^{\circ}$ inv. Ch. 75. 77. 060. MCGR. $n^{\circ}$ 299. $\mathrm{L}: 51 \mathrm{~mm}: \mathrm{n}^{\circ}$ inv. Ch. 75. 77. 061. MCGR. $n^{\circ}$ 300. $\mathrm{L}: 64 \mathrm{~mm} ; \mathrm{n}^{\circ}$ inv. Ch. 50. 011. MCGR. $n^{\circ}$ 301. LC : $73 \mathrm{~mm}$; $\mathrm{n}^{\circ}$ inv. Ch. 75. 77. 059. MCGR. $n^{\circ}$ 302. $\mathrm{L}$ : $93 \mathrm{~mm}$; $\mathrm{n}^{\circ}$ inv. Ch. 75. 77. 227. MCGR. 
$n^{\circ}$ 303. $\mathrm{L}: 65 \mathrm{~mm}$; $\mathrm{n}^{\circ}$ inv. Ch. 75. 77. 192. MCGR.

$n^{\circ}$ 304. $L: 128 \mathrm{~mm}$; $\mathrm{n}^{\circ}$ inv. Ch. 75. 77. 134. MCGR.

$n^{\circ}$ 305. $\mathrm{L}: 46 \mathrm{~mm} ; \mathrm{n}^{\circ}$ inv. Ch. 75. 77. 220. MCGR.

$n^{\circ}$ 306. $L$ : $66 \mathrm{~mm}$; $n^{\circ}$ inv. Ch. 75. 77. 246. MCGR.

$n^{\circ}$ 307. $\mathrm{L}: 71 \mathrm{~mm} ; \mathrm{n}^{\circ}$ inv. Ch. 75. 77. 244. MCGR.

$n^{\circ}$ 308. LC : $35 \mathrm{~mm} ; \mathrm{n}^{\circ}$ inv. Ch. 75. 77. 306. MCGR.

$n^{\circ}$ 309. $\mathrm{L}$ : $44 \mathrm{~mm}$; $\mathrm{n}^{\circ}$ inv. Ch. 75. 77. 269. MCGR.

$n^{\circ}$ 310. LC : $43 \mathrm{~mm}: \mathrm{n}^{\circ}$ inv. Ch. 75. 77. 149. MCGR.

$n^{\circ}$ 311. LC : $41 \mathrm{~mm}$; $n^{\circ}$ inv. Ch. 75. 77. 264. MCGR.

$n^{\circ}$ 312. LC : $19 \mathrm{~mm}: \mathrm{n}^{\circ}$ inv. Ch. 75. 77. 271. MCGR.

$n^{\circ}$ 313. LC : $56 \mathrm{~mm}$; $\mathrm{n}^{\circ}$ inv. Ch. 75. 77. 126. MCGR.

$n^{\circ}$ 314. LC: $77 \mathrm{~mm}$; $\mathrm{n}^{\circ}$ inv. Ch. 75. 77. 276 MCGR.

$n^{\circ}$ 315. LC : $80 \mathrm{~mm}: \mathrm{n}^{\circ}$ inv. Ch. 75. 77. 147. MCGR.

$\mathbf{n}^{\circ}$ 316. LC : $76 \mathrm{~mm}$; $\mathrm{n}^{\circ}$ inv. Ch. 75. 77. 150. MCGR.

$\mathbf{n}^{\circ}$ 317. LC : $41 \mathrm{~mm}: \mathrm{n}^{\circ}$ inv. Ch. 75.77. 224. MCGR.

$n^{\circ}$ 318. LC : $29 \mathrm{~mm} ; \mathrm{n}^{\circ}$ inv. Ch. 75. 77. 265. MCGR.

$n^{\circ}$ 319. LC : $31 \mathrm{~mm}: \mathrm{n}^{\circ}$ inv. Ch. 75. 77. 263. MCGR.

$n^{\circ}$ 320. LC : $53 \mathrm{~mm}: \mathrm{n}^{\circ}$ inv. Ch. 75. 77. 214. MCGR.

$n^{\circ}$ 321. LC : $29 \mathrm{~mm}$; $\mathrm{n}^{\circ}$ inv. Ch. 75. 77. 272. MCGR.

$n^{\circ}$ 322. LC : $50 \mathrm{~mm} ; \mathrm{n}^{\circ}$ inv. Ch. 75. 77. 270. MCGR.

$\mathbf{n}^{\circ}$ 323. $\mathrm{LC}: 57 \mathrm{~mm} ; \mathrm{n}^{\circ}$ inv. Ch. 75. 77. 172. MCGR.

$n^{\circ}$ 324. LC : $78 \mathrm{~mm}: \mathrm{n}^{\circ}$ inv. Ch. 50. 009. Dépôt (?).

$n^{\circ}$ 325. LC : $23 \mathrm{~mm} ; \mathrm{n}^{\circ}$ inv. Ch. 75. 77. 274. MCGR.

$\mathbf{n}^{\circ}$ 326. LC : $131 \mathrm{~mm}$; $\mathrm{n}^{\circ}$ inv. Ch. 75. 77. 127. MCGR.

$n^{\circ}$ 327. LC : $52 \mathrm{~mm} ; \mathrm{n}^{\circ}$ inv. Ch. 75. 77. 305. MCGR.

$n^{\circ}$ 328. $\mathrm{L}: 82 \mathrm{~mm}: \mathrm{n}^{\circ}$ inv. Ch. 75. 77. 221. MCGR.

$n^{\circ}$ 329. $\mathrm{L}: 56 \mathrm{~mm}$; $\mathrm{n}^{\circ}$ inv. Ch. 75. 77. 020 bis. MCGR.

$n^{\circ}$ 330. $\mathrm{L}: 42 \mathrm{~mm} ; \mathrm{n}^{\circ}$ inv. Ch. 75. 77. 030 bis. MCGR.

$n^{\circ}$ 331. $\mathrm{L}: 102 \mathrm{~mm}: \mathrm{n}^{\circ}$ inv. Ch. 84. S2. 565. MCGR.

$n^{\circ}$ 332. LC : $78 \mathrm{~mm}$; $\mathrm{n}^{\circ}$ inv. Ch. 75. 77. 040 bis. MCGR.

n 333. LC : $65 \mathrm{~mm}$; Pélatan 1986 : pl. L, n 16. p. 71. Dépôt (?).

$n^{\circ}$ 334. LC: $94 \mathrm{~mm} ; \mathrm{n}^{\circ}$ inv. Ch. 75. 77.174. MCGR.

$n^{\circ}$ 335. LC : $107 \mathrm{~mm}$; $\mathrm{n}^{\circ}$ inv. Ch. 75. 77. 359. MCGR.

$n^{\circ}$ 336. $\mathrm{L}: 184 \mathrm{~mm}$; $\mathrm{n}^{\circ}$ inv. Ch. 83. S1. 002. MCGR.

$n^{\circ}$ 337. LC : $94 \mathrm{~mm}$; $\mathrm{n}^{\circ}$ inv. Ch. 75. 77. 155. MCGR.

$n^{\circ}$ 338. $\mathrm{L}: 22 \mathrm{~mm} ; \mathrm{n}^{\circ}$ inv. Ch. 75. 77. 072. MCGR.

$n^{\circ}$ 339. LC : $51 \mathrm{~mm} ; \mathrm{n}^{\circ}$ inv. Ch. 75. 77. 248. MCGR.

$n^{\circ}$ 340. LC : $182 \mathrm{~mm}$; $n^{\circ}$ inv. Ch. 50. 010. Dépôt (?).

$n^{\circ}$ 341. LC : $82 \mathrm{~mm}$; Pélatan 1986 : pl. L, n 5. p. 71. Dépôt (?).

$n^{\circ}$ 342. LC : $68 \mathrm{~mm}$; $\mathrm{n}^{\circ}$ inv. Ch. 75. 77. 229. MCGR. 
$n^{\circ}$ 343. LC : $49 \mathrm{~mm}: \mathrm{n}^{\circ}$ inv. Ch. 50. 005. Dépôt (?).

$n^{\circ}$ 344. $\mathrm{LC}: 40 \mathrm{~mm}$; $\mathrm{n}^{\circ}$ inv. Ch. 75. 77. sans $\mathrm{n}^{\circ} \mathrm{MCGR}$.

$n^{\circ}$ 345. $\mathrm{L}: 122 \mathrm{~mm} ; \mathrm{n}^{\circ}$ inv. Ch. 50. 013. Dépôt (?).

n $^{\circ}$ 346. LC : $77 \mathrm{~mm}$; $\mathrm{n}^{\circ}$ inv. Ch. 75. 77. 215. MCGR.

$n^{\circ}$ 347. LC : $30 \mathrm{~mm} ; \mathrm{n}^{\circ}$ inv. Ch. 75. 77. 060 bis. MCGR.

$n^{\circ}$ 348. LC : $93 \mathrm{~mm}$; $\mathrm{n}^{\circ}$ inv. Ch. 75. 77. 218. MCGR.

$n^{\circ}$ 349. LC : $65 \mathrm{~mm}$; $\mathrm{n}^{\circ}$ inv. Ch. 75. 77. 216. MCGR.

$n^{\circ}$ 350. LC : $59 \mathrm{~mm}$; $\mathrm{n}^{\circ}$ inv. Ch. 83. S1. 015. MCGR.

$n^{\circ}$ 351. LC : $43 \mathrm{~mm}$; $\mathrm{n}^{\circ}$ inv. Ch. 75. 77. 066. MCGR.

$n^{\circ}$ 352. $1: 59 \mathrm{~mm}$; $\mathrm{n}^{\circ}$ inv. Ch. 75. 77. 197. MCGR.

$n^{\circ}$ 353. LC : $79 \mathrm{~mm}$; $\mathrm{n}^{\circ}$ inv. Ch. 75. 77. 196. MCGR.

$n^{\circ}$ 354. $\mathrm{LC}: 50 \mathrm{~mm} ; \mathrm{n}^{\circ}$ inv. Ch. 84 . $\mathrm{S} 2.070$ bis. MCGR.

$n^{\circ}$ 355. LC : $513 \mathrm{~mm}$; $\mathrm{n}^{\circ}$ inv. Ch. 75. 77. 121. MCGR.

$n^{\circ}$ 356. LC : $72 \mathrm{~mm}: 1: 48 \mathrm{~mm}: \mathrm{n}^{\circ}$ inv. Ch. 75. 77. 300. MCGR.

$\mathrm{n}^{\circ}$ 357. LC : $50 \mathrm{~mm} ; \mathrm{n}^{\circ}$ inv. Ch. 75. 77. 212. MCGR.

$n^{\circ}$ 358. $\mathrm{LC}: 50 \mathrm{~mm}: \mathrm{n}^{\circ}$ inv. Ch. 75. 77. 301. MCGR.

$n^{\circ}$ 359. LC : $52 \mathrm{~mm}: \mathrm{n}^{\circ}$ inv. Ch. 75. 77. 065. MCGR.

$n^{\circ}$ 360. LC : $39 \mathrm{~mm} ; \mathrm{n}^{\circ}$ inv. Ch. 50. 020. MCGR.

$n^{\circ}$ 361. LC : $36 \mathrm{~mm}: \mathrm{n}^{\circ}$ inv. Ch. 75. 77. 078. MCGR.

$n^{\circ}$ 362. LC : $166 \mathrm{~mm} ; 1: 99 \mathrm{~mm} ; \mathrm{n}^{\circ}$ inv. Ch. 84. S2.035/262. MCGR.

$n^{\circ}$ 363. LC : $76 \mathrm{~mm}$ : lc : $62 \mathrm{~mm}: \mathrm{n}^{\circ}$ inv. Ch. 75.77. 120. MCGR.

$n^{\circ}$ 364. $\mathrm{LC}: 48 \mathrm{~mm} ; \mathrm{n}^{\circ}$ inv. Ch. 75. 77. 312. MCGR.

$n^{\circ}$ 365. LC : $24 \mathrm{~mm}$; $\mathrm{n}^{\circ}$ inv. Ch. 75. 77. 141. MCGR.

$n^{\circ}$ 366. LC : $51 \mathrm{~mm}$; $\mathrm{n}^{\circ}$ inv. Ch. 75. 77. 119. MCGR.

$n^{\circ}$ 367. LC: $17 \mathrm{~mm} ; \mathrm{n}^{\circ}$ inv. Ch. 75. 77. 310. MCGR.

$n^{\circ}$ 368. LC : $17 \mathrm{~mm}: \mathrm{n}^{\circ}$ inv. Ch. 75. 77. 311. MCGR.

$n^{\circ}$ 360. $\mathrm{LC}: 119 \mathrm{~mm}$; $\mathrm{n}^{\circ}$ inv. Ch. 75. 77. 256. MCGR.

$n^{\circ}$ 370. $\mathrm{D}: 26 \mathrm{~mm}$ : $\mathrm{h}: 28 \mathrm{~mm}$; $\mathrm{n}^{\circ}$ inv. Ch. 75. 77.080 bis. MCGR.

$n^{\circ}$ 371. LC : $42 \mathrm{~mm}$; $\mathrm{n}^{\circ}$ inv. Ch. 75. 77. 350. MCGR.

$n^{\circ}$ 372. LC : $89 \mathrm{~mm}$; $\mathrm{n}^{\circ}$ inv. Ch. 75. 77. 118. MCGR.

$n^{\circ}$ 373. LC : $105 \mathrm{~mm} ; \mathrm{n}^{\circ}$ inv. Ch. 75. 77. 350. MCGR.

$n^{\circ}$ 374. $\mathrm{LC}: 122 \mathrm{~mm} ; \mathrm{n}^{\circ}$ inv. Ch. 75. 77. 116. MCGR.

$n^{\circ}$ 375. LC : $49 \mathrm{~mm}$; $\mathrm{n}^{\circ}$ inv. Ch. 75. 77. 117. MCGR.

$n^{\circ}$ 376. LC : $216 \mathrm{~mm}$; $\mathrm{n}^{\circ}$ inv. Ch. 75. 77. 114. MCGR.

$n^{\circ}$ 377. $\mathrm{L}: 69 \mathrm{~mm}$; $\mathrm{n}^{\circ}$ inv. Ch. 75. 77. 178. MCGR.

$n^{\circ}$ 378. $\mathrm{L}: 105 \mathrm{~mm}$; $\mathrm{n}^{\circ}$ inv. Ch. 75. 77. 143. MCGR.

$n^{\circ}$ 379. LC : $105 \times 50 \mathrm{~mm} ; \mathrm{n}^{\circ}$ inv. Ch. 75. 77. 161. MCGR.

$n^{\circ}$ 380. LC : $54 \mathrm{~mm}: \mathrm{n}^{\circ}$ inv. Ch. 75. 77. 064. MCGR.

$n^{\circ}$ 381. LC : $61 \mathrm{~mm}$; $\mathrm{n}^{\circ}$ inv. Ch. 75. 77. 123. MCGR.

$n^{\circ}$ 382. LC : $88 \mathrm{~mm}$; lc : $77 \mathrm{~mm}$; $\mathrm{n}^{\circ}$ inv. Ch. 75.77. 180 bis. MCGR. 
$n^{\circ}$ 383. $\mathrm{L}: 195 \mathrm{~mm}$; $\mathrm{n}^{\circ}$ inv. Ch. 75. 77. 302. MCGR. $n^{\circ}$ 384. $\mathrm{L}$ : $193 \mathrm{~mm}$; $\mathrm{n}^{\circ}$ inv. Ch. 75. 77. 303. MCGR. $n^{\circ}$ 385. $\mathrm{L}$ : $191 \mathrm{~mm}$; $\mathrm{n}^{\circ}$ inv. Ch. 75. 77. 304. MCGR. $n^{\circ}$ 386. $\mathrm{L}$ : $183 \mathrm{~mm}$; $\mathrm{n}^{\circ}$ inv. Ch. 75. 77. 307. MCGR. $n^{\circ}$ 387. $\mathrm{L}: 179 \mathrm{~mm}$; $\mathrm{n}^{\circ}$ inv. Ch. 75. 77. 308. MCGR. $n^{\circ}$ 388. $\mathrm{L}: 142 \mathrm{~mm}$; $\mathrm{n}^{\circ}$ inv. Ch. 75. 77. 309. MCGR. $n^{\circ}$ 389. $\mathrm{L}$ : $171 \mathrm{~mm} ; \mathrm{n}^{\circ}$ inv. Ch. 75. 77. 314. MCGR. $n^{\circ}$ 390. $\mathrm{L}: 150 \mathrm{~mm}: \mathrm{n}^{\circ}$ inv. Ch. 75. 77. 315. MCGR. $n^{\circ}$ 391. $\mathrm{L}: 133 \mathrm{~mm}$; $\mathrm{n}^{\circ}$ inv. Ch. 75. 77. 316. MCGR. $n^{\circ}$ 392. $L$ : $110 \mathrm{~mm} ; \mathrm{n}^{\circ}$ i nv. Ch. 75. 77. 313. MCGR. $n^{\circ}$ 393. $\mathrm{L}: 93 \mathrm{~mm}$; $\mathrm{n}^{\circ}$ i nv. Ch. 75. 77. 324. MCGR. $n^{\circ}$ 394. $\mathrm{L}$ : $94 \mathrm{~mm}$; $\mathrm{n}^{\circ}$ inv. Ch. 75. 77. 322. MCGR. $n^{\circ}$ 395. $\mathrm{L}: 88 \mathrm{~mm}$ : $\mathrm{n}^{\circ}$ inv. Ch. 75. 77. 352. MCGR. $n^{\circ}$ 396. $\mathrm{L}: 32 \mathrm{~mm}$; $\mathrm{n}^{\circ}$ inv. Ch. 75. 77. 171. MCGR. $n^{\circ}$ 397. $\mathrm{L}: 42 \mathrm{~mm}$; $\mathrm{n}^{\circ}$ inv. Ch. 75.77. 342. MCGR. $n^{\circ}$ 398. $\mathrm{L}: 36 \mathrm{~mm} ; \mathrm{n}^{\circ}$ inv. Ch. 75. 77. 345. MCGR. $n^{\circ}$ 399. $\mathrm{L}: 59 \mathrm{~mm} ; \mathrm{n}^{\circ}$ inv. Ch. 75. 77. 334. MCGR. $\mathrm{n}^{\circ}$ 400. $\mathrm{L}: 39 \mathrm{~mm}$; $\mathrm{n}^{\circ}$ inv. Ch. 75. 77. 341. MCGR. $\mathrm{n}^{\circ}$ 401. $\mathrm{L}: 102 \mathrm{~mm}$; $\mathrm{n}^{\circ}$ inv. Ch. 83. S1. 016. MCGR. $n^{\circ}$ 402. $\mathrm{L}: 86 \mathrm{~mm} ; \mathrm{n}^{\circ}$ inv. Ch. 83. S1. 017. MCGR. $n^{\circ}$ 403. $\mathrm{L}: 38 \mathrm{~mm} ; \mathrm{n}^{\circ}$ inv. Ch. 83. S1. 018. MCGR. $n^{\circ}$ 404. $\mathrm{L}: 75 \mathrm{~mm}$; $\mathrm{n}^{\circ}$ inv. Ch. 75. 77. 353. MCGR. $\mathrm{n}^{\circ}$ 405. $\mathrm{L}: 54 \mathrm{~mm}$ : $\mathrm{n}^{\circ}$ inv. Ch. 75. 77. 352. MCGR. $n^{\circ}$ 406. $\mathrm{L}: 47 \mathrm{~mm}$; $\mathrm{n}^{\circ}$ inv. Ch. 75. 77. 349. MCGR. $\mathrm{n}^{\circ}$ 407. $\mathrm{L}: 55 \mathrm{~mm}$ : $\mathrm{n}^{\circ}$ inv. Ch. 75. 77. 354. MCGR. $\mathrm{n}^{\circ}$ 408. $\mathrm{L}: 30 \mathrm{~mm}$ : $\mathrm{n}^{\circ}$ inv. Ch. 83. S1. 019. MCGR. $n^{\circ}$ 409. LC : $92 \mathrm{~mm}$; $\mathrm{n}^{\circ}$ inv. Ch. 75. 77. 291. MCGR. $n^{\circ}$ 410. LC : $192 \mathrm{~mm}$; $\mathrm{n}^{\circ}$ inv. Ch. 75. 77. 232. MCGR. $n^{\circ}$ 411. LC : $188 \mathrm{~mm}$ : $\mathrm{n}^{\circ}$ inv. Ch. 75. 77. 231. MCGR. $n^{\circ}$ 412. LC : $145 \mathrm{~mm}$; $\mathrm{n}^{\circ}$ inv. Ch. 75. 77. 260. MCGR. $n^{\circ}$ 413. $L C$ : $145 \mathrm{~mm}$ : $\mathrm{n}^{\circ}$ inv. Ch. 75. 77. 260. MCGR. $n^{\circ}$ 414. $\mathrm{LC}: 138 \mathrm{~mm} ; \mathrm{n}^{\circ}$ inv. Ch. 75. 77. 233. MCGR. $n^{\circ}$ 415. LC : $73 \mathrm{~mm}$; $\mathrm{n}^{\circ}$ inv. Ch. 75. 77. 319. MCGR. $n^{\circ}$ 416. LC: $35 \mathrm{~mm}$; $\mathrm{n}^{\circ}$ inv. Ch. 75. 77. 323. MCGR. $n^{\circ}$ 417. $\mathrm{L}: 60 \mathrm{~mm}$ : $\mathrm{n}^{\circ}$ inv. Ch. 75. 77. 318. MCGR. $n^{\circ}$ 418. LC : $42 \mathrm{~mm}$; $\mathrm{n}^{\circ}$ inv. Ch. 75. 77. 190. MCGR. $n^{\circ}$ 419. LC: 52 X $35 \mathrm{~mm}$; $\mathrm{n}^{\circ}$ inv. Ch. 75. 77. 152. MCGR. $n^{\circ}$ 420. $\mathrm{L}$ : $98 \mathrm{~mm}$; $\mathrm{n}^{\circ}$ inv. Ch. 75. 77. 138. MCGR. $n^{\circ}$ 421. $\mathrm{L}$ : $101 \mathrm{~mm}$; $\mathrm{n}^{\circ}$ inv. Ch. 75. 77. 070. MCGR. $n^{\circ}$ 422. LC : $39 \mathrm{~mm}$; $\mathrm{n}^{\circ}$ inv. Ch. 75. 77. 273. MCGR. 
$n^{\circ}$ 423. LC : $70 \mathrm{~mm}$; $\mathrm{n}^{\circ}$ inv. Ch. 75. 77. 071. MCGR.

$\mathrm{n}^{\circ}$ 424. $\mathrm{D}$ : $94 \mathrm{~mm}$; $\mathrm{n}^{\circ}$ inv. Ch. 84. S2. 110 bis. MCGR.

$n^{\circ}$ 425. D : (?) ; $n^{\circ}$ inv. Ch. 75. 77. 234. MCGR.

$n^{\circ}$ 426. LC : $44 \mathrm{~mm}$; $\mathrm{n}^{\circ}$ inv. Ch. 75. 77. 295. MCGR.

$n^{\circ}$ 427. LC : $30 \mathrm{~mm}$; $\mathrm{n}^{\circ}$ inv. Ch. 75. 77. 251. MCGR.

$n^{\circ}$ 428. LC : $90 \mathrm{~mm}$; $\mathrm{n}^{\circ}$ inv. Ch. 75. 77. 156. MCGR.

$n^{\circ}$ 429. LC : $62 \mathrm{~mm}$; $\mathrm{n}^{\circ}$ inv. Ch. 75. 77. 235. MCGR.

$n^{\circ}$ 430. LC : $29 \mathrm{~mm}$; $\mathrm{n}^{\circ}$ inv. Ch. 75. 77. 294. MCGR.

$n^{\circ}$ 431. LC : $29 \mathrm{~mm}$; $\mathrm{n}^{\circ}$ inv. Ch. 75. 77. 140. MCGR.

$n^{\circ}$ 432. LC : $112 \mathrm{~mm}$; $\mathrm{n}^{\circ}$ inv. Ch. 75. 77. 120 bis. MCGR.

$n^{\circ}$ 433. LC : $92 \mathrm{~mm}$; $\mathrm{n}^{\circ}$ inv. Ch. 75. 77. 154. MCGR.

$n^{\circ}$ 434. LC : $80 \mathrm{~mm}$; $\mathrm{n}^{\circ}$ inv. Ch. 75. 77. 250. MCGR.

$n^{\circ}$ 435. LC : $74 \mathrm{~mm}$; $\mathrm{n}^{\circ}$ inv. Ch. 75. 77. 267. MCGR.

$n^{\circ}$ 436. $\mathrm{D}:$ ? $\mathrm{mm}$; $\mathrm{n}^{\circ}$ inv. Ch. 75. 77. 026. MCGR.

$n^{\circ}$ 437. LC : $34 \mathrm{~mm}$; $\mathrm{n}^{\circ}$ inv. Ch. 75. 77. 225. MCGR.

$n^{\circ}$ 438. $\mathrm{D}:$ ? $\mathrm{mm}$; $\mathrm{n}^{\circ}$ inv. Ch. 75. 77. 219. MCGR.

$n^{\circ}$ 439. $\mathrm{D}: 38 \mathrm{~mm}$; $\mathrm{n}^{\circ}$ inv. Ch. 75. 77. 143. MCGR.

$n^{\circ}$ 440. LC : $64 \mathrm{~mm}$; n inv. Ch. 50. 024. Dépôt (?).

$\mathrm{n}^{\circ}$ 441. $\mathrm{LC}: 50 \mathrm{~mm} ; \mathrm{n}^{\circ}$ inv. Ch. 75. 77. 140 bis. MCGR.

$n^{\circ}$ 442. D : $18 \mathrm{~mm}$; $\mathrm{n}^{\circ}$ inv. Ch. 75. 77. 241. MCGR.

$n^{\circ}$ 443. Lxl : 25 X 20 mm ; $n^{\circ}$ inv. Ch. 75. 77. 230. MCGR.

$n^{\circ}$ 444. $\mathrm{LC}: 46 \mathrm{~mm}$; $\mathrm{n}^{\circ}$ inv. Ch. 75. 77. 238. MCGR.

$\mathrm{n}^{\circ}$ 445. $\mathrm{D}: 22 \mathrm{~mm}$; $\mathrm{n}^{\circ}$ inv. Ch. 75. 77. 190 bis. MCGR.

$n^{\circ}$ 446. LC : $48 \mathrm{~mm}$; $\mathrm{n}^{\circ}$ inv. Ch. 75. 77. 293. MCGR.

$n^{\circ}$ 447. LC : $46 \mathrm{~mm}$; $\mathrm{n}^{\circ}$ inv. Ch. 75. 77. 282. MCGR.

$n^{\circ}$ 448. LC : $40 \mathrm{~mm}$; $\mathrm{n}^{\circ}$ inv. Ch. 75. 77. 195. MCGR.

$n^{\circ}$ 449. LC : $24 \mathrm{~mm}$; $\mathrm{n}^{\circ}$ inv. Ch. 75. 77. 195. MCGR.

$n^{\circ}$ 450. $\mathrm{L}: 26 \mathrm{~mm}$; $\mathrm{n}^{\circ}$ inv. Ch. 75. 77. 194. MCGR.

$\mathrm{n}^{\circ}$ 451. $\mathrm{L}$ : $22 \mathrm{~mm}$; $\mathrm{n}^{\circ}$ inv. Ch. 83. S1. 150 bis. MCGR.

$n^{\circ}$ 452. LC : $40 \mathrm{~mm}$; $\mathrm{n}^{\circ}$ inv. Ch. 75. 77. 298. MCGR.

$n^{\circ}$ 453. LC : $90 \mathrm{~mm}$; $\mathrm{n}^{\circ}$ inv. Ch. 75. 77. 210 bis. MCGR.

$n^{\circ}$ 454. LC : $94 \mathrm{~mm}$ : $\mathrm{n}^{\circ}$ inv. Ch. 75. 77. 043. MCGR.

$n^{\circ}$ 455. LC : $101 \mathrm{~mm}$; $\mathrm{n}^{\circ}$ inv. Ch. 75. 77. 042. MCGR.

$n^{\circ}$ 456. LC : $83 \mathrm{~mm}$ : $\mathrm{n}^{\circ}$ inv. Ch. 75. 77. 044. MCGR.

$n^{\circ}$ 457. LC : $59 \mathrm{~mm}$; $\mathrm{n}^{\circ}$ inv. Ch. 75. 77. 237. MCGR.

$n^{\circ}$ 458. D : $22 \mathrm{~mm}$; $\mathrm{n}^{\circ}$ inv. Ch. 50. 022. Dépôt (?).

$n^{\circ}$ 459. D : $10 \mathrm{~mm}$; $\mathrm{n}^{\circ}$ inv. Ch. 50. 023. Dépôt (?).

$n^{\circ}$ 460. LC : $66 \mathrm{~mm}: \mathrm{n}^{\circ}$ inv. Ch. 50. 012. Dépôt (?).

n 461. LC : $50 \mathrm{~mm}$; Pélatan 1986. p. 71. pl. L. n 9. Dépôt (?). n 462. LC : 98 mm : $\mathrm{n}^{\circ}$ inv. Ch. 75. 77. 188. MCGR. 
$n^{\circ}$ 463. LC : $120 \mathrm{~mm}$; $\mathrm{n}^{\circ}$ inv. Ch. 75. 77. 115. MCGR.

$\mathrm{n}^{\circ}$ 464. LC : $34 \mathrm{~mm}$; $\mathrm{n}^{\circ}$ inv. Ch. 75. 77. 160 bis. MCGR.

$\mathrm{n}^{\circ}$ 465. LC : $32 \mathrm{~mm}$ : $\mathrm{n}^{\circ}$ inv. Ch. 75. 77. 170 bis. MCGR.

$n^{\circ}$ 466. $n^{\circ}$ inv. Ch. 75. 77. 448. MCGR.

$n^{\circ}$ 467. $n^{\circ}$ inv. Ch. 75. 77. 450. MCGR.

$n^{\circ}$ 468. $n^{\circ}$ inv. Ch. 75. 77. 452. MCGR.

$n^{\circ}$ 469. $n^{\circ}$ inv. Ch. 75. 77. 452. MCGR.

$n^{\circ}$ 470. $n^{\circ}$ inv. Ch. 75. 77. 453. MCGR.

$n^{\circ}$ 471. $n^{\circ}$ inv. Ch. 75. 77. 455. MCGR.

$n^{\circ}$ 472. $n^{\circ}$ inv. Ch. 75. 77. 604. MCGR.

$n^{\circ}$ 473. $n^{\circ}$ inv. Ch. 75. 77. 617. MCGR.

$\mathrm{n}^{\circ} 473$ bis. $\mathrm{n}^{\circ}$ inv. Ch. 75. 77. 626. MCGR.

$n^{\circ}$ 474. $n^{\circ}$ inv. Ch. 75. 77. 624. MCGR.

$n^{\circ}$ 475. $n^{\circ}$ inv. Ch. 75. 77. 640 et 641. MCGR.

$n^{\circ} 476 . n^{\circ}$ inv. Ch. 83.600 .

$\mathrm{n}^{\circ}$ 477. $\mathrm{n}^{\circ}$ inv. Ch. 75. 77. 611. MCGR.

$n^{\circ}$ 478. $n^{\circ}$ inv. Ch. 75. 77. 601. MCGR.

$n^{\circ}$ 479. $n^{\circ}$ inv. Ch. 75. 77. 634. MCGR.

$n^{\circ}$ 480. $n^{\circ}$ inv. Ch. 75. 77. 622. MCGR.

$n^{\circ}$ 481. $n^{\circ}$ inv. Ch. 75. 77. 639. MCGR.

$\mathrm{n}^{\circ} 481$ bis. $\mathrm{n}^{\circ}$ inv. Ch. 75. 77. 633. MCGR.

$n^{\circ}$ 482. $n^{\circ}$ inv. Ch. 75. 77. 610. MCGR.

$n^{\circ}$ 483. $n^{\circ}$ inv. Ch. 75. 77. 616. MCGR.

$n^{\circ}$ 484. $n^{\circ}$ inv. Ch. 75. 77. 614. MCGR.

$n^{\circ}$ 485. $n^{\circ}$ inv. Ch. 75. 77. 606. MCGR.

$n^{\circ}$ 486. $n^{\circ} \mathrm{s}$ inv. Ch. 75. 77. 602 et 608. MCGR.

$\mathrm{n}^{\circ} 486$ bis. $\mathrm{n}^{\circ}$ inv. Ch. 75. 77. 621. MCGR.

$n^{\circ}$ 487. $n^{\circ}$ s d'inv. Ch. 75. 77. 632 et 643. MCGR.

$n^{\circ}$ 488. $n^{\circ}$ inv. Ch. 75. 77. 652. MCGR.

$\mathrm{n}^{\circ}$ 489. $\mathrm{n}^{\circ}$ inv. Ch. 75. 77. 628. MCGR.

$\mathrm{n}^{\circ}$ 490. $\mathrm{n}^{\circ} \mathrm{s}$ inv. Ch. 75. 77. 605, 649, sans $n^{\circ}$ MCGR.

$\mathrm{n}^{\circ}$ 491. $\mathrm{n}^{\circ}$ inv. La. 7763. MCGR.

$n^{\circ}$ 492. $n^{\circ}$ inv. Ch. 75. 77. 646. MCGR.

$n^{\circ}$ 493. $n^{\circ}$ inv. Ch. 75. 77. 622. MCGR.

$n^{\circ}$ 494. $n^{\circ}$ inv. Ch. 75. 77. Sans $n^{\circ}$ MCGR.

$n^{\circ}$ 495-518. $n^{\circ}$ inv. Ch. 75. 77. 478-492. MCGR.

$n^{\circ}$ 519-553. MCGR.

n' 534-592. MCGR.

$n^{\circ}$ 593-618. MCGR.

$\mathrm{n}^{\circ}$ 619-621. MCGR. 
n 622-649. MCGR.

$\mathrm{n}^{\circ}$ 650-655. MCGR.

$n^{\circ}$ 656-658. MCGR.

$n^{\circ}$ 659-674. MCGR.

$n^{\circ}$ 675-677. MCGR.

no 678-713. MCGR.

$n^{\circ}$ 714-724. MCGR.

$n^{\circ}$ 725-727. MCGR.

$n^{\circ}$ 728-739. MCGR.

$n^{\circ}$ 740-744. MCGR.

$\mathrm{n}^{\circ}$ 745-751. MCGR.

$n^{\circ}$ 752-762. MCGR.

$n^{\circ}$ 763-769. DFND. 


\section{Bibliographie}

Aime 1979 : AIME (G.). - Les âges du Bronze et du Fer dans la Baume de Sancey-le-Long (Doubs). Bulletin de la Société Préhistorique Française, t. 76, fasc. 10-12, 1979, p. 421-433.

Allen 1973 : ALLEN (D.-F.). - The coins found at La Tène. Etudes celtiques, XIII, 2, 1973, p. 478-479.

Anonyme 1982 : Ain-Autoroute-Archéologie. Musée de Brou, Bourg-en-Bresse, 24 avril-20 juin 1982, 176 p., 49 pl.

Anonyme 1983 : L'art celtique en Gaule. Collection des Musées de Province, 1983/1984, 219 p.

Anonyme 1985 : La civilisation gauloise en pays carnute. Châteaudun, 1985,112 p.

Anonyme 1986 a : Les Celtes et les Alpes. Catalogue d'exposition, Musée savoisien, Chambéry 9 mai-11 oct. $1986,52 \mathrm{p}$.

Anonyme 1986 b: Chronologie, datation archéologique en Suisse. Antiqua 15, Société Suisse de Préhistoire et d'Archéologie, 1986, 241 p.

Anonyme 1986 c : Les Ségusiaves à l'Age du Fer. Exposition Musée d'Assiers, Feurs, 1985-1986, 75 p., 54 fig.

Anonyme 1987 a : L'âge du Fer en Lorraine. Musée de Sarreguemines, mai 1987, Sarreguemines, $101 \mathrm{p}$.

Anonyme $1987 \mathrm{~b}$ : Corpus des objets domestiques et des armes en fer de Normandie, du Ier au XVIe siècle. Cahier des Annales de Normandie, $\mathrm{n}^{\circ}$ 20, Caen, 1987.

Anonyme 1987 c : Trésors des princes celtes. Ed. réunion des Musées nationaux, 1987,266 p.

Anonyme $1987 \mathrm{~d}$ : La céramique peinte gauloise en Champagne du VIe au Ier siècle av. J.-C. Musée d'Epernay, 10 juin-30 oct. $1987.102 \mathrm{p}$.

Anonyme 1988 : Dix ans de recherches archéologiques en Midi-Pyrénées. De l'âge du Fer aux temps barbares. Musée Saint-Raymond, oct. 1987-janv. 1988.

Arcelin 1973 : ARCELIN (P.), ARCELIN-PRADELLE (Ch.). - La nécropole protohistorique de la Catalane. Revue Archéologique de Narbonnaise, t. VI, 1973, p. 91-195, 51 fig.

Arcelin 1976 : ARCELIN (P.). - Les civilisations de l'âge du Fer en Provence. La Préhistoire Française, t. II, 1976, p. 657-675, 6 fig.

Arcelin 1978 : ARCELIN (P.), ARCELIN-PRADELLE (Ch.). - Une nécropole préromaine à Eyguières (Bouches-du-Rhône). Bulletin de l'Ecole Antique de Nîmes, 11-13, 1976-1978, p. 71-109, 14 fig. 
Arcelin 1979 a: ARCELIN-PRADELLE (Ch.). - La vie quotidienne, mœurs domestiques, habillement, armes. Au temps des Gaulois en Gaule méridionale. Dossiers de l'Archéologie, 35, 1979, p. 76-85.

Arcelin 1979 b : ARCELIN (P.). - La nécropole préromaine de l'Arcoule, comm. de Paradou (Bouches-du-Rhône). Documents d'Archéologie Méridionale, 2, 1979, p. 133-154, 24 fig.

Arcelin 1982 : ARCELIN (P.), ARCELIN-PRADELLE (Ch.), GASCO (Y.). - Le village protohistorique du Mont-Garou (Sanary, Var). Documents d'Archéologie Méridionale, 5, 1982, p. 53-137.

Arcelin 1985 : ARCELIN (P.), DEDET (B.). - Les enceintes protohistoriques du Midi de la Gaule des origines à la fin du Ile siècle av. n. è. Les enceintes protohistoriques de Gaule méridionale, ARALO, cahier 14, Caveirac, 1985, p. 11-35.

Arcelin-Pradelle 1982 : ARCELIN-PRADELLE (Ch.), DEDET (B.), PY (M). - La céramique grise monochrome en Languedoc. Revue Archéologique de Narbonnaise, t. XV, 1982, p. 18-67.

Arcelin-Pradelle 1984: ARCELIN-PRADELLE (Ch.). - La céramique grise monochrome en Provence. Revue Archéologique de Narbonnaise, suppl. 10, 1984, 224 p., 73 pl., 1 carte.

Audouze 1981 : AUDOUZE (F.), GAUCHER (G.). - Typologie des objets de l'âge du Bronze en France. fasc. VI, Epingles, Société Préhistorique Française, Paris, 1981, 113 p.

Aulas 1988 : AULAS (CH.). - Les amphores. In : VAGINAY (M.), GUICHARD (V.). - L'habitat gaulois de Feurs (Loire). Fouilles récentes. Documents d'Archéologie Française, ${ }^{\circ} 14$, Maison des Sciences de l'Homme, 1988. p. 87-90.

Bantelmann 1972: BANTELMANN (N.). - Fibeln vom Mittellatène schema im Rhein-MainMoselgebiet. Germania, 50, 1972, p. 98-110.

Barruol 1975: BARRUOL (G.). - Les peuples préromains du Sud-Est de la Gaule. Revue Archéologique de Narbonnaise, supplément $\mathrm{n}^{\circ}$ 1, 1975, $408 \mathrm{p}$.

Barruol 1985 : BARRUOL (G.). - Miroirs votifs découverts en Provence et dédiés à Séléné et à Aphrodite. Revue Archéologique de Narbonnaise, t. 18, 1985, p. 345-350.

Bats 1986: BATS (M.). - Le territoire de Marseille grecque: réflexions et problèmes. Etudes massaliètes, 1, 1986, $178 \mathrm{p}$.

Bats 1988 : BATS (M.). - La vaisselle et alimentation à Olbia de Provence (v. 350-v. 50 av. J.-C.), modèles culturels et catégories céramiques. Revue Archéologique de Narbonnaise, suppl. $\mathrm{n}^{\circ} 18,1988$, CNRS, 271 p., $72 \mathrm{pl}$.

Beck 1985 : BECK (F.), GUILLAUMET (J.-P.). - La métallurgie du bronze en pays éduen. Les âges du Fer dans la vallée de la Saône (VIIe-Ier siècle av. n. è), Revue Archéologique de l'Est, 6e supplément, 1985, p. 237-245, 7 fig.

Bedon 1984 : BEDON (R.). - Les carrières et les carriers de la Gaule romaine, Picard, 1984, 247 p.

Beeching 1985 : BEECHING (A.). VITAL (J.), DAL-PRA (G.). - La terrasse de la Brégoule à Soyons (Ardèche) - Une séquence majeure pour la protohistoire rhodanienne-, Archéologie en Ardèche, $\mathrm{n}^{\circ}$ 2. 1985, p. 4-12.

Bellon 1986 : BELLON (C.). BURNOUF (J.), MARTIN (J.-M.). - Premiers résultats des fouilles sur le site protohistorique de Gorge-de-Loup (Vaise. Lyon, Rhône). Revue Archéologique de l'Est, t. XXXVII, fasc. 3-4. 1986. p. 247-251. 5. fig.

Bellon 1989 : BELLON (C.). - Les importations, parures et objets divers. In : BURNOUF (J.), BELLON (C.), MARTIN (J.-M.), VEROT-BOURRELY (A.). - Lyon avant Lugdunum, un habitat du premier âge du Fer à Vaise. Aux origines de Lyon (Goudineau dir.), Documents d'Archéologie en Rhône-Alpes, $\mathrm{n}^{\circ} 2$, 1989, p. 19-21.

Bellon à paraître : BELLON (C.), PERRIN (F.). - La circulation des amphores massaliètes dans la moyenne vallée du Rhône aux VIe-Ve siècles av. n. è. Actes de la table-ronde CNRS de Lattes: 
“Diffusion chronologie des amphores massaliètes (VIeIer s. av. J.-C.).", 11 mars 1989, Etudes Massaliètes, 2, à paraître.

Beltz 1911 : BELTZ (R.). - Die Latènefibeln. Fünfter Bericht der Kommision fur prähistorische Typenkarten). Zeitschrift fur Ethnologie, 43, 1911. p. 664-817.

Benadik 1983: BENADIK (В.). - Manu keltisches gräberfeld (Bez. Nové Zámky). Fundkatalog. Materiala Archeologica. 1983, 167 p., LXI pl.

Benoit 1965 : BENOIT (F.) - Recherche sur l'hellénisation du Midi de la Gaule. Annales de la faculté des lettres, Aix-enProvence, 1965, 335 p., 50 pl., 16 fig.

Berger 1963: BERGER (L.). - Poseidonios Fragment 18: Ein Beitrag zur Deutung der Spâtkeltischen Viereckschanzen ? UrSchweiz, XXVII, 1963, 2/3, p. 26-28.

Biel 1987 : BIEL (J.). - Le tumulus princier celtique de Hochdorf. Trésors des princes celtes, Paris, 1987, p. 95-104.

Bocquet 1969 a : BOCQUET (A.). - L'Isère pré-et protohistorique. Gallia Préhistoire, t. XII, 1969, fas. 1. p. 121-258. 63 pl. et fasc. 2, p. 273-400, 119 pl.

Bocquet $1969 \mathrm{~b}$ : BOCQUET (A.). - Quelques gisements dauphinois et la voie du Col du Lautaret à la fin du premier âge du Fer. Cahiers Rhodaniens, t. XIII. 1966, p. 109-111.

Bocquet 1970 : BOCQUET (A.). - Catalogue des collections préhistoriques et protohistoriques du Musée Dauphinois. Grenoble, 1970. 2 vol.. 230 p., 89 pl.

Bocquet 1971: BOCQUET (A.). COLLARDELLE (M.). - Une épée de La Tène II provenant de Crémieu. Evocations. Bulletin du groupe d'études historiques et géographiques du Bas-Dauphiné, $\mathrm{n}^{\circ} 3,13 \mathrm{e}$ année, 1971, p. 1-3.

Bocquet 1976 : BOCQUET (A.), RAYMOND (J.). - Deux vases d'un abri sous-roche de Virignin (Ain). Etudes Préhistoriques, $\mathrm{n}^{\circ}$ 13, 1976, p. 33-35, 4 fig.

Bocquet 1984 : BOCQUET (A.), COLLARDELLE (M.). - Note sur une sépulture du deuxième âge du Fer découverte à Saint-Jean de Soudain (Isère). Revue Archéologique de Narbonnaise, t. XVIII. 1984. p. 323-326.

Bocquet 1986 : BOCQUET (A.). - L'archéologie de l'âge du Fer dans les Alpes du Nord. Les Celtes et les Alpes, catalogue d'exposition. Musée savoisien 9 mai-31 octobre, Chambéry. 1986, p. 13-9.

Bonnamour 1983 : BONNAMOUR (L.). - Les découvertes des âges du Fer dans le lit de la Saône (VIIe-Ier siècle av. n. è). La vallée de la Saône aux Ages du Fer (VIIe-Ier siècles av. n. è), catalogue de l'Exposition Château Saint-Michel de Rully, 12-29 mai 1983, p. 62-79.

Bonnamour 1985 a: BONNAMOUR (L.). - Découvertes archéologiques dans la Saône. Revue Archéologique de l'Est, t. XXXXI. fasc. 3-4. 1985, p. 237-253, 11 fig.

Bonnamour 1985 b : BONNAMOUR (L.). - Les sites de la Saône aux âges du Fer : problématique, les âges du Fer dans la vallée de la Saône (Vlle-Ier siècles av. n. è), Revue Archéologique de l'Est, 6e suppl., CNRS. 1985. p. 25-31.

Bonnet 1989 : BONNET (Ch.), ZOLLER (G.), BROILLET (Ph.), HALDIMANN (M.-A.), BAUD (Ch.-A.), KRAMAR (Ch.), SIMON (Ch.), OLIVE (CL). BILLAUD (Y.). - Les premiers ports de Genève. Archéologie Suisse, 12, 1, 1989, p. 2-24.

Bornatico 1957 : BORNATICO (J.). - La grotte du Gardon à Ambérieu-en-Bugey. Cahiers Rhodaniens. IV. 1957. p. 26-35.

Bouard 1987 : BOUARD (J.-M.). - La reconstitution du char d'Apremont. Trésors des princes celtes, Paris, 1987, p. 86-90.

Boucher 1980 : BOUCHER (J.-P.). - Chroniques archéologiques. Gallia, 1980, t. 38, fasc. 2, p. 532. 
Bouloumié 1977 : BOULOUMIÉ (B.). - Situles de bronze trouvées en Gaule (VIIe-IVe). Gallia, 35, 1977, p. 3-38.

Bouloumié 1988 : BOULOUMIÉ (B.). - Le symposium grécoétrusque et l'aristocratie celtique. Les princes celtes et la Méditerranée, Rencontres de l'Ecole de Louvre, La Documentation Française, 1988, p. 343-382.

Bouyer 1982 : BOUYER (M.). BUCHSENSZCHUTZ (O.). - La chronologie du village celtique des Arènes (Indre). Le deuxième âge du Fer en Auvergne et en Forez, Eds. J. Collis, R. Périchon, A. Duval. Saint-Etienne 1982. p. 72-89.

Bravard 1987 : BRAVARD (J.-P). - Le Rhône du Léman à Lyon. La manufacture, Lyon 1987, 451 p.

Briard 1976 : BRIARD (J.). - L'âge du Bronze en Europe barbare, Ed. des Hespérides, 1976.

Brulet 1982 : BRULET (R.). - Tournai capitale mérovingienne. Archéologia, n 166, mai 1982, p. 39-45.

Brun 1984 : BRUN (J.-P). - L'habitat de hauteur de SaintEstève (Evenos, Var). Bilan des recherches 1896-1976. Revue Archéologique de Narhonnaise, t. XVII, 1984, p. 1-28.

Brunaux 1985 a : BRUNAUX (J.-L.), GOGUEY (R.), GUILLAUMET (J.-L.), RAPIN (A.). - Le sanctuaire celtique de Mirebeau (Côte-d'Or). Les âges du Fer dans la vallée de la Saône (VII-Ier siècles av. n. è). Revue Archéologique de l'Est, 6e suppl., 1985, p. 79-111.

Brunaux 1985 b : BRUNAUX (J.-L.), MÉNIEL (P.), POPLIN (F.). - Gournay I. Les fouilles sur le sanctuaire et l'oppidum (1975-1984). Revue Archéologique de Picardie, 1985, 268 p., 112 pl.

Brunaux 1986 a : BRUNAUX (J.-L.). - La chronologie des armes laténiennes, "Gaule interne et Gaule méditerranéenne": confrontations chronologiques, 11-13 nov. 1986 Valbonne. Table-ronde CRA. décembre 1986, dactylographié.

Brunaux 1986 b : BRUNAUX (J.-L.). - Le sacrifié, le défunt et l'ancêtre. Actes du Ville colloque sur les âges du Fer, Aquitania, supplément n 1, 1986, p. 317-326.

Brunaux 1986 c : BRUNAUX (J.-L.). - Les Gaulois. Sanctuaires et rites, Collection des Hespérides, Editions Errance, 1986, 154 p.

Brunaux 1987 : BRUNAUX (J.-L.) - Les monnaies gauloises dans les sanctuaires. Mélanges offerts au Dr. Colbert de Beaulieu, Le Léopard d'Or, 1987, p. 157-162.

Brunella 1987 : BRUNELLA (PH.). - La nécropole de la fin de l'âge du Fer sur le site des résidences Sainte-Croix à Metz (Moselle). L'âge du Fer en Lorraine, Musée de Sarreguemines, Mai 1987, p. 60-68.

Buchsenschutz 1984 : BUCHSENSCHUTZ (0.). - Structures d'habitats et fortifications de l'âge du Fer en France septentrionale. Mémoires de la Société Préhistorique Française, t. 18, 1984, 249 p., 109 pl.

Buisson 1987 : BUISSON (A.). - Le dieu Mercure dans les campagnes lyonnaises et viennoises, Répertoire des témoignages. Art et Archéologie en Rhône-Alpes, 3,1987, p. 39-48.

Cahen-Delahay 1981 : CAHEN-DELAHAY (A.). - Habitats de La Tène dans les Ardennes belges. Les structures d'habitat à l'âge du Fer en Europe tempérée. Actes du Colloque de Châteauroux. 27-29 oct. 1977, Paris 1981. p. 61-66.

Cerchiaï 1988 : CERCHIAI (L.). - La situle de type Kurd dans la tombe 4461 de Pontecagnano. Les princes celtes et la Méditerranée. Rencontres de l'Ecole de Louvre, La Documentation Française, 1988, p. 103-108.

Chabot 1986 : CHABOT (L.). - Le territoire de Marseille et les oppida de la chaîne de la Nerthe (IleIer av. J. - C.). Etudes massaliètes, 1, Travaux du Centre C. Jullian, Université de Provence, 1986, p. 119-126. 
Chantre 1880 : CHANTRE (E.). - Etudes paléoethnologiques dans le bassin du Rhône. Premier âge du Fer, nécropoles et tumulus. Paris, Lyon. Baudry, 1880.

Chantre 1923 : CHANTRE (E.). - Le Camp retranché de Larina, commune d'Anoisin-Chatelan, près de Crémieux (Isère). Rhodania, Congrès de Vienne, 1923, p. 64-68.

Chapotat 1962 : CHAPOTAT (G.). - Le char processionnel de la Côte-Saint-André (Isère). Gallia, t. 20,1, p. 33-78.

Chapotat 1966 : CHAPOTAT (G.). - Exemplaires de céramique campanienne trouvés sur la colline de Sainte-Blandine à Vienne (Isère). Cahiers Rhodaniens, t. XIII, 1966, p. 137-143.

Chapotat 1970 : CHAPOTAT (G.). - Le matériel de La Tène III trouvé sur la colline de Sainte-Blandine. 2 volumes. Lyon, 1970, 186 p., LVI pl.

Chapotat 1973 : CHAPOTAT (G.). - Les dragages de Grigny (Rhône), Inventaires des trouvailles et études des épées de l'âge du Bronze. Revue Archéologique de l'Est, t. XXIV, fasc. 3-4, 1973, p. 341-359.

Charmasson 1981 : CHARMASSON (J.). - L'oppidum de SaintVincent-de-Gaujac (Gard). Archéologie en Languedoc, 4, 1981, p. 77-84.

Charvet 1882 : CHARVET (Dr.). - Armes et autres objets gaulois trouvés à Rives en 1882. Bulletin de l'Académie Delphinale, t. XVII, 1882. p. 295-315.

Chastel 1988 : CHASTEL (J.), DE KLINJ (H.), VITAL (J.) - L'habitat gallo-romain du Pré de La Cour à Montagnieu (Ain). Revue Archéologique de l'Est, t. XXXIX, 1-2,1988, p. 135-140.

Chauffin 1960 : CHAUFFIN (J.). - Le Camp de Larina, un nouveau jalon sur la route du vin. Rhodania, 1960, p. 27-50, VI pl.

Chaume 1987 : CHAUME (B.). - Vix. Trésors des princes celtes, Paris, 1987. p. 207-208.

Chausse 1977 : CHAUSSE (J.-C.), NICOLLET (F.). - La grotte du Trou de La Chuire. Evocations (MaiJuillet), 1977, p. 115120.

Chausserie-Laprée 1984 : CHAUSSERIE-LAPRÉE (J.), NIN (N.), DOMALLAIN (L.). - Le quartier de l'Isle à Martigues, six années de recherches archéologiques. Catalogue du Musée de Martigues, 1984, 64 p.

Chédeville 1980 : CHEDEVILLE (A.). - L'essor urbain et les hommes. La ville médiévale, des Carolingiens à la Renaissance. Histoire de la France Urbaine, 2, 1980, p. 103-141.

Chevillot 1976 : CHEVILLOT (C.). - Un atelier de bracelets en lignite décorés à Chalucet (SaintJean-Ligoure, Haute-Vienne). Bulletin de la Société Préhistorique Française, 1976, t. 73, Etudes et travaux, p. 422-436.

Chevillot 1982 : CHEVILLOT (C.). - Résultats d'une coupe de l'Agger septentrional du Camp de César à La Curade (comm. Couloumieix-Chamières, Dordogne). Le deuxième Age du Fer en Auvergne et en Forez. Eds. J. Collis, R. Périchon, A. Duval, Saint-Etienne, 1982, p. 115-144.

Chossenot 1989 : CHOSSENOT (M.). - L'habitat gaulois de La Tène finale de La Cheppe-Camp de Mourmelon (Marne). Architectures des âges des métaux, fouilles récentes. Dossiers de protohistoire, $\mathrm{n}^{\circ} 2,1988$, Ed. Errance, 1989, p. 101-110.

Christlein 1964 : CHRISTLEIN (R.). - Ein Bronzesiebfragment der Spätlatènezeit vom Zugmantel. Saalburg Jahrbuch, XXI, 1963-1964, p. 16-19.

Collis 1980 : COLLIS (J.). - Aulnat and Urbanization in France: a second interim report. Archeological Journal, vol. 137, 1980, p. 40-49,4 fig.

Combier 1970 : COMBIER (J.). - La céramique peinte du lac du Bourget (Savoie). Bulletin d'Etudes Préhistoriques alpines, t. II Aoste, 1970.

Combier 1972 : COMBIER (J.). - Figures zoomorphes et anthropomorphes. Etudes Préhistoriques, $\mathrm{n}^{\circ}$ 2, 1972, p. 41-44. 
Courbin 1976 : COURBIN (P.), GILLES (R.). - L'oppidum de Saint-Etienne-de-Dions, Saint-Marcel d'Ardèche. Néolithique et âges des métaux dans les Alpes Françaises, UISPP, 1976, livretguide A 9, p. 59-63.

Courtois 1976 : COURTOIS (J. -C.). - Les civilisations de l'âge du Fer dans les Alpes. La Préhistoire Française, t. Il, 1976, p. 708-723, 7 fig.

Cucherat 1960: CUCHERAT (C.). - Découverte d'un casque en bronze au bord du Rhône. Evocations, nov. déc. 1960, p. 41-43.

Curdy 1984: CURDY (PH.), BENKERT (A.), BERNAL (J.), MASSEREY (C.). - Intervention archéologique à Yverdon-les-Bains (VD), Rue de Philosophes : La Tène Finale - époque romaine précoce. Annuaire Suisse de Préhistoire et d'Archéologie, 1984, p. 123-136.

Dall'Aglio 1981 : DALL'AGLIO (P-L.), GU1SBERT1 (G.), GRUPPIONI (D.), VITALI (D.). - MonteBibele : aspetti archeologici, anthropologici e storici dell'insediamento preromano. Mélanges de l'Ecole Française de Rome, Antiquité, 93, 1, 1981, p. 1-29.

Daremberg 1969 : DAREMBERG (Ch.), SAGLIO (Edm.). - Dictionnaire des antiquités grecques et romaines d'après les textes et les monuments. t. 2. Graz, Austria, réédition. 1969.1 718p.

Daugas 1976 : DAUGAS (J.-P). MALACHER (F.). - Les civilisations de l'âge du Fer dans le Massif Central. La Préhistoire Française, t. II, 1976, p. 734-752, 5 ftg.

Daumas 1985 : DAUMAS (J.-C.), LAUDET (R.). - L'habitat du Bronze final des Gandus à SaintFerréol-Trente-Pas (Drôme). Etudes Préhistoriques, nº 10 (1981-1982), 1985, p. 1-32, 34 fig.

Davet 1967 : DAYET (M.). - Recherches archéologiques au Camp du Château (Salins), 1955-1959. Revue Archéologique de l'Est, t. 18, 1967, p. 52-97.

Debord 1982 : DEBORD (J.). - Premier bilan de huit années de fouilles à Villeneuve-Saint-Germain (Aisne), vallée de l'Aisne.

Cinq années de fouilles protohistoriques. Revue Archéologique de Picardie, 1982, p. 213-264.

Déchelette 1914 : DECHELETTE (J.). - Manuel d'Archéologie préhistorique, celtique et gallo-romaine. II, 3e partie, second âge du Fer ou époque de La Tène, 1914, 1689 p., 736 fig.

Dedet 1976 : DEDET (B.), PY (M.). - Introduction à l'étude de la protohistoire en Languedoc oriental. ARALO, cahier $\mathrm{n}^{\circ}$ 5, Caveirac, 1976, $142 \mathrm{p}$.

Dedet 1978 : DEDET (B.), MICHELOZZI (A.), PY (M.), RAYNAUD (J.-C.), TENDILLE (C.). - Ugernum, protohistoire de Beaucaire. ARALO. cahier $\mathrm{n}^{\circ}$ 6, Caveirac. 1978, $156 \mathrm{p}$.

Dedet 1985 : DEDET (B.), PY (M.). - L'occupation des rivages de l'étang de Maugio (Hérault) du Bronze final au premier âge du Fer. t. III, synthèses et annexes, ARALO, cahier $n^{\circ} 13$, Caveirac, 1985, 138 p.

Dedet 1987 : DEDET (B.). - Habitat et vie quotidienne en Languedoc au milieu de l'âge du Fer. L'habitat $\mathrm{n}^{\circ} 1 \mathrm{du}$ Plan de La Tour à Gailhan. Revue Archéologique de Narhonnaise, supplément 17, 1987,231 p., 114 fig.

Deléstrée 1977 : DELESTREE (L.-P.), DUVAL (A.). - Un coin monétaire inédit du Mont Beuvray. Antiquités Nationales, $\mathrm{n}^{\circ}$ 9, 1977, p. 45-47.

De Marinis 1987 : DE MARINIS (R.). - Fibule tardohallstattiane occidentali dell abitato etrusco del Forcello (Bagnolo S. Vito). Celti e etrusci nell'italia centro-settentrionale del Ve sec. a.-C. alla romanizzazione, Bologna 12-14 april 1985, Imola 1987, p. 89-99.

De Navarro 1972 : DE NAVARRO (J.-M.). - The finds from the site of La Tène. I, Scabbards and the Swords Found in them. London, 1972.

Deroc 1983: DEROC (A.). - Les monnaies gauloises d'argent de la vallée du Rhône. Etudes de Numismatique 2, Paris, 1983. 
Desbat 1989: DESBAT (A.), GENIN (M.), LAROCHE (C.), THIRION (PH.). - La chronologie des premières trames urbaines de Lyon. Aux origines de Lyon (Goudineau dir.). Documents d'Archéologie en Rhône-Alpes, n² 2, 1989, p. 95-118.

Détienne 1977 : DÉTIENNE (M.). - Dionysos mis à mort. Paris, 1977.

Détienne 1979 : DÉTIENNE (M.). VERNANT (J.-P.). - La cuisine du sacrifice en pays grec. Bibliothèque des Histoires, Gallimard, 1979, 336 p.

Devts 1983 : DEYTS (S.). - Les bois sculptés des sources de la Seine, Gallia. XLIIe suppl., CNRS. 1983.

Diderot 1771 : DIDEROT et D'ALEMBERT. - L'Encyclopédie ou dictionnaire raisonné des Sciences, des arts et des métiers. Recueil de Planches, sur les sciences, les arts libéraux, et les arts mécaniques, avec leur explication, Compact Edition, volume IV, t. XVIII-XXIII suite, 1146 p. Paris. M. DCC. LXXI, neuvième volume.

Dottin 1980 : DOTTIN (G.) - L'épopée celtique en Irlande. L'Arbre double. Les Presses d'aujourd'hui. 1980.

Drescher 1984 : DRESCHER (H.). - Bemerkungen zur Metallverarbeitung auf der Heuneburg und zu einigen besonderen Fundstiicken. In : SIEVERS (S.). - Die Kleinfunde der Heuneburg. Die Funde aus dem Grabungen 1950-1979. Heuneburgstudien, V, Mainz, 1984, p. 126-136.

Dusek 1966 : DUSEK (M.). - Thrakisches Graberfeld der hallstattzeit in Chotin. Archeologica slovaca fontes, t. VI, Bratislava, 1966,174 p., LXVIII Taf.

Durand 1979 : DURAND (J.-L.). - Bêtes grecques. In : DETIENNE (M.), VERNANT (J.-P.). - La cuisine du sacrifice en pays grec. 1979, p. 133-157.

Duval 1986: DUVAL (A.). LEHOCZKY (L.), SCHAAFF (U.). Zum keltischen von Amfreville. Archäologisches Korrespondenzblatt, 16, 1986, p. 83-84.

Duval 1977 : DUVAL (P.-M.). - Les Celtes. L'Univers des formes, 1977.

Egg 1986 : EGG (M.). - Zum "Fiistengrab" von Radkensburg (Südsteiermark). Jahrbuch des römischgermanischen Zentralmuzeums Mainz, vol. 33/1, 1986, p. 199-214.

Egloff 1980 : EGLOFF (M.). - La civilisation de La Tène dans le canton de Neuchatel. Helvetia Archeologia, 43/44, 1980, p. 139-151.

Eluère 1989 : ELUÈRE (Ch.), DRILHON (F.). DUDAY (H.), DUVAL (A.-R.). - L'or et l'argent de la tombe de Vix. Bulletin de la Société Préhistorique Française, 1989, t. 68/1, p. 10-32.

Ettlinger 1973 : ETTLINGER (E.). - Die Römisch Fibeln in der Schweiz. Berne, 1973. 197 p., 29 pl., 26 cartes.

Ferdière 1988 : FERDIÈRE (A.). - Les campagnes en Gaule romaine. Les techniques et les productions rurales en Gaule (52 av. J.-C. - 486 ap. J.-C). t. 2, Collection des Hespérides, Edition Errance, 1988, 284 p.

Feugère 1982 : FEUGÈRE (M.). - Elément d'un cadre en fer de La Tène Finale à Vienne (Isère). Revue Archéologique de Narbonnaise, t. XV, 1982, p. 162-176.

Feugère 1985 a : FEUGÈRE (M.). - Les fibules en Gaule méridionale de la conquête à la fin du Ve siècle après J.-C. Revue Archéologique de Narbonnaise, suppl. 12,1985, 509 p., 174 pl.

Feugère 1985 b : FEUGÈRE (M.). - Le seau en bois de la nécropole gauloise et gallo-romaine de Roanne. Cahiers Archéologiques de la Loire, 4-5, 1985, p. 71-78.

Feugère 1986 : FEUGÈRE (M.), GUILLOT (A.). - Fouilles de Bragny I, les petits objets dans leur contexte du Hallstatt Final. Revue Archéologique de l'Est, t. XXXVII. 1986. p. 159-221. 47 fig.

Feugère 1989 : FEUGÈRE (M.), PY (M.). - Les bracelets en verre de Nages (Gard) (Les Castels, fouilles 1958-1981). Le verre préromain en Europe occidentale, 1989, p. 153-167. 
Fischer à paraître : FISCHER (B.). - Les monnaies marseillaises et celtiques de Larina (Hières-surAmby, Isère). Les âges du Fer dans les Alpes. Actes du Xe colloque de l'AFEAF, Yenne-Chambéry 8-11 mai 1986.

Flouest 1977 : FLOUEST (J.-L.), STEAD. (L). - Une tombe de La Tène III à Hannogne (Ardennes). Mémoires de la Société d'Agriculture, de Commerce, des Sciences et des Arts du département de la Marne, 1977, p. 56-72, 5 fig., II pl.

Fogolani 1960 : FOGOLANI (G.). - Sanzeno nella Anaunia, Civilta del Ferro. 1960, p. 315 et ss.

Fournier 1989 : FOURNIER (CL). FOURNIER (J.), FOURNIER (J.). - Le poinçon monétaire gaulois d'Halloy-les-Pernois (Somme). Revue archéologique de Picardie, 1989, 1-2, p. 119122.

Furger-Gunti 1979 : FURGER-GUNTI (A.). - Die Ausgrabungen im Basler Munster I. Sàptkeltische und augustische Zeit. Basler Beitrage zu Ur-und frühgeschichte, 6, Derendingen-Solothurn, Habegger Verlag, 1979.

Furger-Gunti 1980 : FURGER-GUNTI (A.). BERGER (L.). - Katalog und Tafeln der Funde aus der spätkeltischen Siedlung Basel-Gasfabrik. Basler Beitrage Zu Ur-und Friihgeschichte, 7, Derendingcn Solothurn. Habegger Verlag. 1980, 450 p.. 175 pl.

Gaiffe 1985 : GAIFFE (O.). - La céramique grise à décor ondé dans le Centre-Est de la France : l'apport du Camp de Chassey. Revue Archéologique de l'Est, t. XXXVI, fasc. 3-4, 1985, p. 221-224.

Gallay 1972 : GALLAY (A.), HUBER (B.). - Nouveaux objets de l'âge du Bronze et du Fer provenant de la Saône. Revue Archéologique de l'Est, t. XIII, fasc. 3-4, 1972, p. 295-329, 13 pl.

Gauthier 1972 : GAUTHIER (M.-M.). - Emaux du Moyen-Age occidental, Paris, 1972.

Gauthier 1985 : GAUTHIER (M.). - Chroniques archéologiques. Gallia, 1985, t. 43. fasc. 2, p. 523-524.

Gebhard 1989 : GEBHARD (R.). - Pour une nouvelle typologie des bracelets celtiques en verre. Le verre préromain en Europe occidentale, 1989, p. 73-83.

Gendron 1986 : GENDRON (Ch.), GOMEZ DE SOTO (J.). - Le sanctuaire préromain de Faye-Labesse (Deux-Sèvres). Aquitania, supplément 1, 1986, p. 89-95, 12 fig.

Genin 1989 : GENIN (M.). PICON (M.). - Les amphores. In : MANDY (B.), SANDOZ G.), KRAUSZ (S.), GENIN (M.), PICON (M.), GODARD (C.), THIRION (Ph.), MONIN (M.). - Les fossés du plateau de La Sarra. Aux origines de Lyon (Goudineau dir.), Documents d'Archéologie en Rhône-Alpes, $\mathrm{n}^{\circ}$ 2, 1989, p. 50-62.

Gentric 1981 : GENTRIC (G.). - Circulation monétaire dans la basse vallée du Rhône (IIe-Ier s. av. J.-C.) d'après les monnaies de Bollène (Vaucluse). ARALO, cahier n 9. Caveirac, 1981, $107 \rho$, XVII pl.

Gerdsen 1985 : GERDSEN (H.). - Observations sur les tombes à épées de Chaveria (Jura) et de Concoeur-Corboin (Côte-d'Or). Les âges du Fer dans la vallée de la Saône (VIIe-Ier siècles avant notre ère). Revue Archéologique de l'Est, sixième supplément, 1985, p. 65-69.

Gomez de Soto 1988 : GOMEZ DE SOTO (J.), PAUTREAU (J.-P.). - Dans les pays d'Ouest, une aristocratie entre Hallstatt et Méditerranée. Les princes celtes et la Méditerranée, Rencontres de l'Ecole du Louvre, La Documentation Française, 1988, p. 57-69.

Goudineau 1975 : GOUDINEAU (Ch.). - Chroniques archéologiques. Gallia, 1973, t. 31, fasc. 2, p. 564.

Goudineau 1980 : GOUDINEAU (Ch.). - Les villes de la paix romaine. Histoire de la France Urbaine, 1, La ville antique (Duby dir.), 1980, p. 334-390.

Gran-Aymerich 1989 : GRAN-AYMERICH (J.-M.) - Les premières phases d'occupation du MontBeauvray. Données anciennes et recherches en cours. La civilisation de Hallstatt, bilan d'une rencontre. Rencontre internationale de Liège, Etudes et Recherches Archéologiques de l'Université de Liège, $n^{\circ}$ 36, 1989, p. 343-355. 
Gruel 1987 : GRUEL (K.), BARRAL (M.), VEILLON (M.). - Aléas de la frappe monétaire à l'époque gauloise. Rythmes de la production monétaire de l'Antiquité à nos jours. Paris, 10-12 janvier 1987, p. 67-74.

Gruet 1986: GRUET (M.). PASSINI (B.). - Le village ouvert des Pichelots. Pays de la Loire des Gaulois au Moyen-Age. Histoire et Archéologie, Les dossiers, n 106, 1986, p. 18-23.

Guichard 1988 : GUICHARD (V.). - Objets métalliques et autres mobiliers. In: VAGINAY (M.), GUICHARD (V.). - L'habitat gaulois de Feurs. Fouilles récentes (1978-1981). Documents d'Archéologie Française, $\mathrm{n}^{\circ}$ 14, Maison des Sciences de l'Homme, 1988, p. 149-163.

Guichard 1989 : GUICHARD (V.), BEFORT (J.-C.), DELPORTE (H.). - L'occupation protohistorique du Châtelard de Lijay (Loire). Cahiers Archéologiques de la Loire, 6, 1989, p. 19-45.

Guillaumet 1976 : GUILLAUMET (J.-P.). - La défaite des Helvètes. Histoire et archéologie. Les mouvements celtiques du Verne au Ier siècle av. n. è. (Duval P.-M./Kruta. V. éds), 1976, p. 195-200.

Guillaumet 1977 : GUILLAUMET (J.-P.). - Les passoires de la fin de La Tène en Gaule et dans le monde celtique. Gallia, t. 35. 1977, p. 239-248.

Guillaumet 1982 : GUILLAUMET (J.-P.). - Le matériel du tumulus de Celles (Cantal). Le deuxième âge du Fer en Auvergne et en Forez, Eds. J. Collis, R. Périchon, A. Duval, Saint-Etienne, 1982, p. 189-211.

Guillaumet 1983: GUILLAUMET (J.-P.). - Chalon-sur-Saône - Cabilonum-, marché et port principal des Eduens. La vallée de la Saône aux âges du Fer (VIIe-Ier siècle av. n. è), Catalogue de l'exposition Château Saint-Michel-de-Rully, 12-29 mai 1983, Société d'Histoire et d'Archéologie de Chalon-sur-Saône. 1983, p. 30-35.

Guillaumet 1984 : GUILLAUMET (J.-P.). - Les fibules de Bibracte, technique et typologie. Université de Dijon, 1984, 153 p., 70 pl.

Guillaumet 1986 : GUILLAUMET (J.-P.), PORTE (P.). - Redécouverte d'une tombe à char à Vernas/ Saint-Romain de Jalionas (Isère). Résumé des Communications du Xe colloque sur l'âge du Fer de L'AFEAF., Yenne-Chambéry, 8-11 mai 1986 (dactylographié).

Guillot 1966 : GUILLOT (J.-P.). - Recherches sur Aeria la celtique. Ogam, Tradition celtique, t. XVIII. fasc. 1-2, 1966. p. 87-95, 7 fig.

Guillot 1983 : GUILLOT (A.). - Le Petit-Chauvort, site de La Tène III. La Vallée de la Saône aux Ages du Fer (VIIe-Ier siècle av. n. è). Catalogue de l'exposition Château Saint-Michel de Rully. 12-29 mai 1983. Société d'Histoire et d'Archéologie de Chalon-sur-Saône, p. 23.

Gustin 1984: GUSTIN (M.). - Die Kelten in Yougoslawien. Jahrbuch des römisch-germanischen Zentralmuseums Mainz, vol. 31, 1984, p. 305-363, 31 fig.. 1 tabl.

Gustin 1985 : GUSTIN (M.). - Un char de combat à Brezice. Les tombes à char des princes et des guerriers celtes. Histoire et Archéologie, $\mathrm{n}^{\circ}$ 98, 1985, p. 70-75.

Hachmann 1960 : HACHMANN (R.). - Die chronologie der jüngeren Vorrömischen Eisenzeit. Bericht der Rômisch-germanischen Kommission, 41, 1960, 284 p.

Haevernick 1960: HAEVERNICK (Th.-E.). - Die Glasarmringe und Ringperlen der Mittel-und Spätlatènezeit auf dem Europaïschen Festland.. Bonn, 1960, 272 p.

Haffner 1979: HAFFNER (A.). - Zur absoluten Chronologie der Mittellatènezeit. Archeologisches Korrespondenzblatt, 9, 1979, p. 405-409.

Hatt 1976 : HATT (J.-J.), ROUALET (P.). - Le cimetière des Jogasses en Champagne et les origines de la civilisation de La Tène. Revue Archéologique de l'Est, t. XXVII, 1976, p. 421-448, 57 pl.

Hatt 1981 : HATT (J.-J.), ROUALET (P.). - Le cimetière des Jogasses en Champagne et les origines de la civilisation de La Tène. Revue Archéologique de l'Est, t. XXXII, 1981 p. 17-63, 37 pl.

Hodson 1968 : HODSON (F.-R.). - The La Tène cemetery at Münsingen-Rain. Acta Bernensia, V, Bern, 1968, 168 p., 122 pl., 1 tabl. 
Hudry 1955 : HUDRY (M.). - Une tombe du second âge du Fer à Saint-Laurent-la-Côte (Savoie). Gallia, 1955. t. XIII, fasc. 1, p. 89-90.

Jacobi 1974 : JACOBI (G.). - Werkzeug und Gerät ans dem Oppidum von Manching. Wiesbaden, 1974, 368 p., 107 fig.

Jacobi 1977 : JACOBI (G.). - Die Metallfunde vom Dünsberg. Materielen zur vor-und Friihgeschchiste von Hessen, 2, 1977.

Jannoray 1955 : JANNORAY (J.). - Ensérune. Paris, De Broccard, 1955.

Joffroy 1960 : JOFFROY (R.). - L'oppidum de Vi.x et la civilisation hallstattienne dans l'Est de la France. Société des Belles Lettres, Paris, 1960.

Joffroy 1976: JOFFROY (R.). - Les civilisations de l'âge du Fer en Bourgogne. La Préhistoire Française, t. Il, 1976, p. 816-825, 5 fig.

Kaenel 1983 a : KAENEL (G.), FABRE (S.). - La nécropole celtique de Gempenach/Champagny (District du Lac, FR.), fouilles de 1979. Annuaire Suisse de Préhistoire et d'Archéologie, volume 66. 1983, p. 189-213, 25 fig.

Kaenel 1983 b : KAENEL (G.), CURDY (Ph.). - Les fouilles du Mont-Vully. Archéologie Suisse, 6, 1983, p. 102-109.

Kaenel 1984 : KAENEL (G.), MULLER (F.), FURGER-GUNTI (A.). - L'occupation celtique du MontTerry (Jura) sur la base des collections jurassiennes. Annuaire Suisse de Préhistoire et d'Archéologie, vol. 67, 1984, p. 95-122, 9 fig.

Kaenel 1989 : KAENEL (G.), MULLER (F.). - A propos de certains types de bracelets en verre du Plateau suisse. Le verre préromain en Europe occidentale, 1989, p. 121-127.

Kimmig 1983 : KIMMIG (W.). - Die Griechische Kolonisation im Westlichen Mittelmeer Gebiet und ihre Wirkung auf diese Landschaften des Westlichen Mitteleuropa. Jahrbuch des römischgermanischen Zentralmuseums Main : t. 30, 1983, 5-78, 64 fig., 18 pl.

Kimmig 1987 : KIMMIG (W.). - Klein Aspergle. Trésors des princes celtes. Paris, 1987, p. 255-264.

Kleemann 1955 : KLEEMANN (O.). - Notices sur le commerce grec dans le domaine celtique. I, pointes de flèches helléniques trouvées en France. Revue Archéologique de l'Est, t. VI. fasc. 2, 1955, p. 146-152.

Klug 1985: KLUG (J.). - Sapropélitfunde Befestigen hallstattzeitlichen Hohensiedlung von Ihringen (Kr. Breisach. Hochschwartzwald). Archäologisches Nachrichten ans Baden, 34, 1985, p. 16-21.

Knauer 1969 : KNAUER (E.-R.). - Bronzekelle mit beweglichem Griff dans Berliner Museen Ber., N.F. XIX, 1969, p. 54-58.

Krämer 1964 : KRAMER (W.). - Das keltische Gräberfeld von Nebringen (Kr. Bohlingen). Stuttgart, 1964.

Krämer 1971 : KRAMER (W.). - Silberne Fibelpaare aus den letzten vorchristlichen Jahrundert. Germania, 49, 1-2, 1971, p. 111-132.

Kràmer 1985 : KRAMER (W.). - Die Grabfunde von Manching und die Latènezeitliche Flashgräbern in Siidbayern. Die Ausgrabungen in Manching, band 9,1985.

Krausz 1989 : KRAUSZ (S.). - Les ossements animaux. In : MANDY (B.) SANDOZ G.), KRAUSZ (S.), GENIN (M.), PICON (M.), GODARD (C.), THIRION (Ph.), MONIN (M.). - Les fossés du plateau de La Sarra. Aux origines de Lyon (Goudineau dir.). Documents d'Archéologie en Rhône-Alpes, n² 2, 1989, p. 44-50.

Kromer 1959 : KROMER (K.). - Das Gräberfeld von Hallstatt. 2 vol., Firenze, 1959. 
Kruta 1971 : KRUTA (V.). - Le trésor de Duchcov dans les collections tchécoslovaques. Usti nad Labem, 1971.

Kruta 1975 : KRUTA (V.). - L'Art celtique en Bohême. Les parures métalliques du Ve siècle au IIe siècle avant notre ère. Bibliothèque de l'Ecole Pratique des Hautes Etudes, IVe section, $384^{\mathrm{e}}$ volume, 1975, 302 p., XVIII pl., 6 cartes.

Kruta 1978 : KRUTA (V.), LESSING (E.), SZABO (M.). - Les Celtes. Hatier, Paris. 1978, 116 p., 116 ill.

Kruta 1980 : KRUTA (V.). - Les Boïens de Cispadane. Essai de paléoethnologie celtique. Etudes Celtiques, XVII. 1980. p. 7-32.

Kruta 1982 : KRUTA (V.). - L'Italie et l'Europe intérieure du Ve siècle au début du Ile siècle av. n. è. Savaria, 16, 1982, p. 203-221.

Kruta 1983 a : KRUTA (V.). - Faciès celtiques de la Cisalpine aux IVe et IIIe siècles av. n. è. Popoli e facies culturali celtiche a nord e a sud delle Alpi dal V al I secolo a. C., Atti del Colloquio Internazionale, Milano 14-16 nov 1980, (1983). p. 1-15.

Kruta 1983 b : KRUTA (V.). - Les Celtes orientaux et la Gaule, l'expansion des Celtes de la Gaule vers l'Orient. Histoire et Archéologie. Les dossiers, n 77,1983, p. 71-77.

Kruta 1985 : KRUTA (V.). - Le port d'anneaux de cheville en Champagne et le problème d'une immigration danubienne au IIIe siècle av. J.-C. Etudes Celtiques, t. XXII. 1985, p. 27-51.

Kruta 1986 a : KRUTA (V.). - Le corail, le vin et l'arbre de vie : observations sur l'art et la religion des Celtes du Ve au Ier siècle av. J.-C. Etudes Celtiques, t. XXIII. 1986, p. 7-32.

Kruta 1986 b : KRUTA (V.). - Les Celtes des Gaules d'après l'archéologie. Geschichte und Kultur der Kelten, Vorbereitungskonferenz 25.-28. Oktober 1982. Bonn, C. Winter, Universitatsverlag. Heidelberg. 1986. p. 33-51. 8 fig.

Kruta Poppi 1978 : KRUTA POPPI (L.). - Vestiges laténiens de la région de Modène. Etudes Celtiques, XV, 1978, p. 425-439.

Kruta Poppi 1979 : KRUTA POPPI (L.). - La sépulture de Ceretolo (province de Bologne) et le faciès boïen du IIIe av. n. è. Etudes Celtiques, XVI, 1979, p. 13-25.

Lagrand 1963 : LAGRAND (Ch.). - La céramique "pseudoionienne" dans la vallée du Rhône. Cahiers Rhodaniens, X, p. 37-82.

Lagrand 1973 : LAGRAND (Ch.), THALMANN (J. -P.). - Les habitats protohistoriques du Pè gue (Drôme), le sondage 8 (1957-1971). CDPA., Cahier n² 2, Grenoble, 1973, 158 p.. XXXIX pl.

Lagrand 1976 : LAGRAND (Ch.). - L'oppidum Saint-Marcel, Le Pègue (Drôme). Le Néolithique et les âges des métaux dans les Alpes Françaises, UISPP, livret A 9. 1976.

Lagrand 1979 : LAGRAND (Ch.). - Un nouvel habitat de la période de colonisation grecque, SaintPierre les Martigues (Bouches-du-Rhône). Documents d'Archéologie Méridionale, 2, 1979, p. 81-106.

Lamboglia 1952 : LAMBOGLIA (N.). - Per una classificazione preliminare della ceramica campana. Atti del I Congresso Internazionale di Studi Liguri, Bordighera, 1952, p. 139-206.

Landolfi 1987 : LANDOLFI (M.). - Prezence galliche nel piceno a sud del fiume ecino. Celti e etruschi nell Italia centro-settentrionale dal Ve secolo a. C alla romanizzazione, Bologne, 1987, p. 463 et ss.

Lasfargues 1984 : LASFARGUES (J.). - Archéologie en Rhône-Alpes (1983-1984), Protohistoire et monde gallo-romain, 10 ans de recherches. Musée de la civilisation gallo-romaine de Lyon, (Lasfargues dir.) 1983-1984, $176 \mathrm{p}$.

Lasfargues 1987 : LASFARGUES (J.). - Le char processionnel de la Côte-Saint-André (Isère). Trésors des princes celtes, Ed. réunion des Musées nationaux, 1987, p. 67-68.

La Tour 1892 : LA TOUR (H. De). - Atlas de monnaies gauloises. Paris, 1892. 
Lefèbvre 1985 : LEFÈBVRE (CL.). - Jastres, Lussas (Ardèche). Les enceintes protohistoriques de Gaule méridionale, ARALO, cahier 14, Caveirac, 1985, p. 97-101.

Leman-Delerive 1986 : LEMAN-DELERIVE (G.). - Plaque émaillée de Paillart (Oise). Gallia, 44, 1986, p. 29-53.

Lerat 1979 : LERAT (L.). - Les fibules d'Alésia dans les Musées d'Alise-Sainte-Reine. Biblio. Pro Alésia VII, Université de Dijon, 1979, 123 p., XXXVI pl.

Le Roux 1986 : LE ROUX (F.), GUYONVARC'H (Ch.-J.). - Les druides. Editions Ouest-France, 1986, $448 \mathrm{p}$.

Loriot 1988 : LORIOT (X.), REMY (B.). - Corpus des trésors monétaires antiques de France (dir. Loriot/ Nony). Rhône-Alpes, t. V. 2, Société française de numismatique, Paris, 1988, 118 p.

Loth 1979: LOTH (J.). - Les Mabinogion, contes bardiques gallois. L'Arbre double, Les Presses d'Aujourd'hui, 1979, $286 \mathrm{p}$.

Louis 1958 : LOUIS (M.), TAFFANEL (O.), TAFFANEL (J.). - Le premier âge du Fer languedocien, $2^{\circ}$ partie, les nécropoles à incinérations. Bordighera-Montpellier, 1958.

Maier 1970: MAIER (F.). - Die bemalte Spätlatene-keramik von Munching. Die Ausgrabungen im Manching, band 3, Wiesbaden, Steiner, 1970, 240 p., 112 taf.

Mahr 1981 : MAHR (G.), MIRON (A.). - Das Brandgraberfeld von Horath. Trierer Zeitschrift, vol. 43/44, 1980/1981, p. 7-262, 78 pl.

Malacher 1987 : MALACHER (F.). - Découverte d'un coin monétaire à Corent (Puy-de-Dôme). Bulletin de la Société Française de Numismatique, 42e année, n 9, mai 1987, p. 275-276.

Marcadal 1985 : MARCADAL (Y.). - La seule tombe à char d'Aquitaine. Les tombes à char des princes et des guerriers celtes. Histoire et Archéologie, n98, 1985, p. 76-80.

Marïen 1958 : MARIEN (M.E.). - Trouvailles du champ d'Urne et des tombelles hallstattiennes de Court - St-Etienne. Bruxelles 1958.

Markale 1971 : MARKALE (J.). - L'épopée celtique d'Irlande, Paris, 1971.

Martin-Kilscher 1981: MARTIN-KILSCHER (S.). - Das Keltische Gräberfeld vom Vevey VD. Annuaire Suisse de Préhistoire et d'Archéologie, vol. 64, 1981, p. 107-156, 35 fig.

Michelucci 1978 : MICHELUCCI (M.). - Talamone. Ripostiglio Vivarelli-Strozzi. Ripostiglio del Genio militare. I Galli e l'Italia. Soprintenza archeologica di Roma, De Lucca, Rome, 1978, p. 207-220.

Millotte 1963 : MILLOTTE (J.-P.). - Le Jura et les plaines de la Saône aux âges des Métaux. Annales Littéraires de la faculté de Besançon, vol. 59, archéo. 16, Les Belles-Lettres. Paris. 1963, 452 p., 77 pl.. 6 cartes.

Millotte 1976 : MILLOTTE (J.-P). - Les civilisations de l'âge du Fer dans le Jura. La Préhistoire Française, t. II. 1976, p. 724-733, 5 fig.

Millotte 1983 : MILLOTTE (J.-P). - Les sépultures des âges du Fer dans la vallée de la Saône supérieure. La vallée de la Saône aux âges du Fer (VIIe-Ier siècle av. n. è.). Catalogue de l'exposition Château Saint-Michel-de-Rully, 12-29 mai 1983. Société d'Histoire et d'Archéologie de Chalon-surSaône, 1983, p. 5-13.

Mohen 1979 : MOHEN (J.-P). - La présence celtique dans le Sud-Ouest de l'Europe. Les mouvements celtiques du Ve au Ier siècle av. n. è, P-M. Duval et V. Kruta (Eds), 1979, p. 29-48, 11 fig.

Mohen 1988 : MOHEN (J.-P). - La circulation des matières précieuses : l'ambre, l'étain, le corail et l'ivoire. Les princes celtes et la Méditerranée. Rencontres de l'Ecole du Louvre, La Documentation Française. 1988, p. 221-227. 
Moosleitner 1974 : MOOSLEITNER (F.), PAULI (L.), PENNINGER (E.). - Der Diirrnberg bei Hallein II, Katalog der Grabfunde aus der Hallstatt und Latènezeit. Münchner Beitrâge zur-vor und Frühgeschichte, Band 17, Munich, 1974.

Morel 1978 : MOREL (J.-P.). - A propos des céramiques campaniennes de France et d'Espagne. Archéologie en Languedoc, 1, 1978, p. 158-162.

Morel 1985 : MOREL (J.-P). - La céramique campanienne en Gaule interne. Les âges du Fer dans la vallée de la Saône, Revue Archéologique de l'Est, 6'suppl., 1985, p. 181-187.

Morel 1988 : MOREL (J.-P). - Céramiques à vernis noir. In: VAGINAY (M.), GUICHARD (V.). L'habitat gaulois de Feurs (Loire). Fouilles récentes. Documents d'Archéologie Française, nº 14, Maison des Sciences de l'Homme, 1988, p. 91-96.

Millier 1904 : MULLER (H.). - Présentation d'objets. Bulletin de la Société Dauphinoise d'Ethnologie et d'Archéologie, 1904, p. 147-152.

Millier 1913 : MULLER (H.). - Tombes gauloises de la Tène II découvertes au pied des Balmes de Voreppe (Isère). Bulletin de la Société Dauphinoise d'Ethnologie et d'Archéologie, t. 20, n 2-3, 1913, p. 105-113.

Millier 1931 : MULLER (H.). - Mobilier d'une sépulture gauloise découverte près de Crémieu. Bulletin de la Société Dauphinoise d'Ethnologie et d'Archéologie, t. 28. fasc. 1-4, 1931, p. 6-7.

Müller-Karpe 1974 : MULLER-KARPE (A.). - Handhuch der Vorgeschichte. Miinchen, 1974.

Miiller-Karpe 1977 : MULLER-KARPE (A.), MULLER-KARPE (M.). - Neue Latènezeitliche Funde aus dem Heidetrânkoppidum. Germania, 55, 1977, p. 33-63, 10 pl.

Nicolardot 1988 : NICOLARDOT (J.-P.). - Traditions et originalités des habitats du premier âge du Fer en Bourgogne. Les princes celtes et la Méditerranée, Rencontres de l'Ecole du Louvre, La Documentation Française. 1988, p. 111-128.

Nicolas 1971 : NICOLAS (A.). - La céramique peinte protohistorique de Moras-en-Valloire. Revue Archéologique de l'Est, t. XXII, 1971, p. 301-304.

Nicollet 1975 : NICOLLET (F.). - Sauvetage archéologique du site de la grotte de La Chuire (Camp de Larina). Etude Galloromaine, $\mathrm{n}^{\circ}$ 1, 1975 (dactylo. 22 p.).

Nicollet 1976 : NICOLLET (F.), CHAUSSE (J.-C.). - Sauvetage archéologique du site de la grotte de La Chuire (Camp de Larina). Etude Gallo-romaine, n² 2, 1976 (dactylographié 60 p.).

Odiot à paraître : ODIOT (Th.). - Les oppida du Tricastin. Les âges du Fer dans les Alpes. Actes du Xe colloque de l'AFEAF, Yenne-Chambéry 8-11 mai 1986.

Oggiano-Bitar 1985 : OGGIANO-BITAR (H.). - Bronzes figurés antiques des Bouches-du-Rhône. Gallia, XLIII ${ }^{\mathrm{e}}$ suppl., CNRS, 1985.

Parruzot 1977 : PARRUZOT (P.), DELINON (M). - La nécropole gauloise de Gringalet à Serguines (Yonne), Les petits enclos carrés et les sépultures isolées. Les Sénons axant la conquête à la lumière des dernières découvertes, Habitats, commerce, sépultures, Actes du colloque de La Tène tenu à Sens le 15 mai 1977, Société Archéologique de Sens, fasc. 21, 1977, p. 55-66.

Paulik 1976 : PAULIK (J.). - Keltské Hradisko Pohanská v plaveckom podhradi. Slovenské narodné Muzeum, archeologicky Ustav, III, 1976.

Pélatan 1986 : PÉLATAN (J. -P.). - L'oppidum de Larina (Isère). Revue Archéologique Sites, $\mathrm{n}^{\circ} 31$ (hors série), 1986, 102 p., LUI pl., XVIII photos.

Pelletier 1966 : PELLETIER (A.). - De la Vienne gauloise à la Vienne romaine. Essai d'étude stratigraphique. Cahiers Rhodaniens, t. XIII, 1966. p. 144-154.

Penninger 1972 : PENNINGER (E.). - Der Dürrnberg bei Hallein I. Katalog der Grabfunde aus der Hallstatt und Latènezeit, Munich, 1972128 p., 120 Taf. 
Penninger 1987 : PENNINGER (E.). - Hallein, la tombe 44 du Diirrnberg. Trésors des princes celtes, Paris, 1987, p. 232-243.

Périchon 1974 : PERICHON (R.). - La céramique peinte celtique et gallo-romaine en Forez et dans le Massif Central. Centre d'études foréziennes, thèses et mémoires nº 6, éd. Horvath, 1974, 146 p., 20 fig.

Périn 1981 : PERIN (P.). - L'assimilation ethnique. Les Francs. Histoire et Archéologie, $\mathrm{n}^{\circ}$ 56, 1981.

Perraud 1971 : PERRAUD (A.). - Catalogue des collections archéologiques du Musée de Briord (Ain). La Physiophile, $\mathrm{n}^{\circ}$ 75, décembre 1971, p. 1-80, 29 pl.

Perrin 1974 : PERRIN (M.). - La fosse hallstattienne des Joncs à Tournus (Saône-et-Loire). Bulletin de la Société des Amis des Arts et des Sciences de Tournus, t. LXXII, 1974, p. 3-113, 21 pl.

Perrin 1988 : PERRIN (F.). - Le site de La Chuire à Larina (Isère) et le contexte régional de l'âge du Fer. Mémoire de l'Ecole Pratique des Hautes Etudes, IVe section, sciences historiques et philologiques, sous la direction de M. V. Kruta, 1988.

Perrin à paraître : PERRIN (F.). - Le site de La Chuire (Camp de Larina, Hières-sur-Amby, Isère) et l'Isle Crémieu à l'âge du Fer. Les âges du Fer dans les Alpes. Actes du Xe colloque de l'AFEAF, YenneChambéry 8-11 mai 1986.

Perrichet-Thomas 1975 : PERRICHET-THOMAS (C.), GABET (C.), FAVRE (M.). - Le site à sel de ludène à Loire-Les-Marais (Charente-Maritime. Bulletin de la Société de Géographie de Rochefort, III, $2^{\circ}$ série, $\mathrm{n}^{\circ} 7,1975$. p. 226-242.

Pic 1906 : PIC (J.-L.). - Le Hradischt de Stradonitz en Bohême. Leipzig, 1906.

Pingel 1969: PINGEL (V.). - Jungerkeltische Keramik vom Cayla bei Mailhac (Aude) und von Ensérune. Marburger Beiträge zur Archaölogie der Kelten, Festschrift fiir W. Dehn, Rudolf Habelt Verlag GMBH, Bonn, 1969, p. 145-154.

Pingel 1971 : PINGEL (V.). - Die glatte Drehscheiben-keramik von Manching. Die Ausgrabungen auf Manching, band 4, 1971, Wiesbaden. 205 p.

Piton 1985 : PITON (D.), DILLY (G.). - Le fanum des Chatelets de Vendeuil-Caply (Oise). Revue Archéologique de Picardie, $\mathrm{n}^{\circ}$ 1-2, 1985. p. 25-47.

Polenz 1982 : POLENZ (H.). - Miinzen in latènezeitlichen Grâbern Mitteleuropas aus der zeit zwischen 300 vor Christi Geburt. Bayerische Vorgeschits-blàtter, 47, 1982, p. 27-223.

Porte 1980 : PORTE (P.). - L'oppidum et l'habitat mérovingien de Larina (commune de Hières sur Amby, Isère). Mémoire de Maîtrise d'histoire, Université d'Aix-en-Provence, 2 vol., 1980.

Poulain 1960 : POULAIN-JOSIEN (Th.). - Etude de la faune provenant d'un dépotoir de La Tène à Larina-Chatelans (Isère). Rhodania, 1960. p. 51-63.

Prades 1985 : PRADES (H.). - L'occupation des rivages de l'étang de Maugio (Hérault) du Bronze final au premier âge du Fer, t.I, ARALO, cahier n 11, Caveirac, 1985, 140 p.

Prieur 1977: PRIEUR (J.). - La Savoie antique. Mémoire et documents publiés par la Société savoisiennne d'Histoire et d'Archéologie, t. LXXXVI, 1977, 178 p.

Primas 1974 : PRIMAS (M.). - Die Hallstattzeit im alpinen Raum. Archäologie der Schweiz, band IV, 1974, p. 35-46, 9 pl., 1 carte.

Py 1974 : PY (M.). - Le problème des Volques Arécomiques à la lumière des résultats actuels de la recherche archéologique. Miscelanea Arqueologica, II, Barcelona, 1974, p. 209-253, 23 fig.

Py 1978 a : PY (M.). - L'oppidum des Castels à Nages (Gard), fouilles de 1958-1974, XXXVe suppl. Gallia, CNRS, 1978.

Py 1978 b : PY (M.). - Quatre siècles d'amphore massaliète. Essai de classification des bords. Figlina, 3, 1978, p. 1-23, 14 fig. 
Py 1979 : PY (M.). - Agriculture et artisanat, l'essor économique du IIIe au le siècle. Au temps des Gaulois en Gaule méridionale. Dossiers de l'Archéologie, n 35, 1979, p. 86-98.

Py 1984 : PY (M.). - La Liquière, Calvisson, Gard. Village du premier âge du Fer en Languedoc Oriental. Revue Archéologique de Narbonnaise, supplément 11, CNRS, 1984.

Rajot 1985 : RAJOT (J.-L.). - Le site hallstattien de Charmes à Mancey (Saône-et-Loire). Bulletin de la Société des Amis des Arts et des Sciences de Tournus, t. LXXXIV, 1985, p. 137-199, 31 fig.

Ramseyer 1983 : RAMSEYER (D.). - Châtillon-sur-Glâne, un habitat de hauteur du Hallstatt Final : synthèse de huit années de fouilles (1974-1981). Annuaire Suisse de Préhistoire et d'Archéologie. vol. 66, 1983, p. 161-188, 28 fig.

Rapin 1983 : RAPIN (A.). - L'armement du guerrier celte au 2e âge du Fer. L'art celtique en Gaule. Collections des Musées de Province, 1983/1984, p. 69-79.

Rapin 1986 : RAPIN (A.). - La nécropole de Tartigny (Oise) : étude du mobilier métallique. Revue Archéologique de Picardie, 3/4, 1986, p. 59-78.

Rapin 1987 : RAPIN (A.), SCHWALLER (M.). - Contribution à l'étude de l'armement celtique : la tombe 163 d'Ensérune. Revue Archéologique de Narbonnaise, t. 20. 1987. p. 155-183.

Rapin 1988 : RAPIN (A.). - Boucliers et lances, Gournay II. Revue Archéologique de Picardie, 1988, 245 p.

Raynard 1819: RAYNARD (M.). - Recherches sur un mors de bride antique. Compte-rendu des travaux de la Société Royale d'Agriculture, Histoire Naturelle et Arts Utiles de Lyon, (Lyon), 1819. p. 192-197.

Raynaud 1983 : RAYNAUD (Cl.), ROUX (J.-C.). - L'oppidum des Gardies à Pignan (Hérault). VIe-Ve siècle av. J.-C. Documents d'Archéologie Méridionale, 6, 1983, p. 23-65,40 fig.

Rémy 1971 : RÉMY (B.). - Les Allobroges, population et religion. Recherches épigraphiques. Thèse de 3e cycle, Université de Lyon II, 3 vol., 1971.

Rey-Vodoz 1986 : REY-VODOZ (R.). - Les fibules galloromaines de Martigny (VS, Suisse). Annuaire Suisse de Préhistoire et d'Archéologie, vol. 69, 1986, p. 149-198, 14 pl., 5 fig.

Ridgway 1979 : RIDGWAY (F.-R.). - The Este and Golasecca cultures : a chronogical guide. Italy before the Romans, The Iron Age, Orientalising and etruscan periods. D. and F.-R. Ridgway (éds), Academic Press, New-York - Los Angeles-San Francisco, 1979, p. 419-487, 54 fig.

Rochna 1984 : ROCHNA (O.), MADLER (K.). - Das Tonschiefer-sapropélit. Gagat-und Wasmaterial der Heuneburg. In: SIEVERS (S.).-Die Kleinfunde der Heuneburg. Die Funde aus dem Grabungen 1950-1979. Heuneburgstudien, V, Mainz, 1984, p. 91-94. .

Roulière-Lambert 1987 : ROULIERE-LAMBERT (M.-J.). - Les tumulus de Conliège à la Croix-desMonceaux. Trésors des princes celtes, Paris, 1987, p. 203-206.

Ruoff 1974 : RUOFF (U.). - Zur Frage der Kontinuität zwischen Bronze-und Eisenzeit in der Schweiz. Bern, 1974, 137 p. 54 Taf.

Rybova 1983 : RYBOVA (A.), MOTYKOVA (K.). - Der Eisendepotfunde der Latènezeit von Kolín. Památcky Archeologické, t. LXXIV, 1983, p. 96-174.

Sandoz 1988 : SANDOZ (G.) THIRION (Ph.). - Vénissieux. Z.A.C. Du Vieux Bourg. Rapport d'activité DRAH Rhône-Alpes, mai 1988, 18 p., XXI pl., dactylographié.

Sandoz 1989 : SANDOZ (G.). - Céramique domestique, fibules, monnaies et mobilier divers. In : MANDY (B.), SANDOZ G.), KRAUSZ (S.), GENIN (M.), PICON (M.), GODARD (C.), THIRION (Ph.), MONIN (M.). - Les fossés du plateau de La Sarra. Aux origines de Lyon (Goudineau dir.). Documents d'Archéologie en Rhône-Alpes, n² 2, 1989, p. 67-76. 
Schaeffer 1930 : SCHAEFFER (F. A. C.). - Les tertres funéraires préhistoriques de la forêt de Haguenau, II. Les tertres de l'âge du Fer. Haguenau. 1930.

Sciau 1982 : SCIAU (G.), RICHARD (J.-Cl.). - Un coin monétaire celtique découvert à La Lagaste (Pomas et Rouffiac, Aude). Cahiers Numismatiques, n 73, septembre 1982, p. 166-169.

Schwab 1973 : SCHWAB (H.). MULLER (R.). - Le passé du Seeland sous un jour nouveau. Découvertes et fouilles archéologiques au cours de la 2e correction des eaux du Jura, Fribourg 1973, p. 59-70.

Schwab 1981 : SCHWAB (H.). - Deux nécropoles laténiennes à Gumefens, RN 12 Archéologie. Exploration archéologique de la RN 12 dans le canton de Fribourg, Fribourg, 1981, p. 15-20.

Schwab 1983 : SCHWAB (H.). - Die Sondiergrabungen 1978 auf dem Mont-Vully. Jahrbuch des römisch-germanischen Zentralmuseums Mainz, vol. 30, 1983, p. 233-264, 20 fig.

Schwartz 1975: SCHWARTZ (K.). - Die Geschichte eines Keltische Temenos im Nordliche Alpenvorland. Ausgrabungen im Deutschland, Mainz, I, 1975, p. 324-358.

Scotto 1985 : SCOTTO (R.-F.). - La céramique grise à décor ondé de Montmorot (Jura). Les âges du Fer dans la vallée de la Saône, Revue Archéologique de l'Est, 6e suppl. 1985, p. 45-51.

Sievers 1984 : SIEVERS (S.). - Die Kleinfunde der Heuneburg. Die Funde aus den Grabungen 1950-1979. Heuneburgstudien, V, Mainz, 1984, 2 vol., 256 p., 250 pl.

Sigaut 1988 : SIGAUT (F.). - L'évolution technique des agricultures européennes avant l'époque industrielle. Revue Archéologique du Centre de la France, t. 27, fasc. 1, 1988, p. 741.

Simonnet 1982 : SIMONNET (L.). - Aspects du gisement de La Tène de Marcilhac (comm. de SaintPaulien, Haute-Loire). Le deuxième âge du Fer en Auvergne et en Forez, Eds. J. Collis, R. Périchon, À. Duval, Saint-Etienne, 1982, p. 97-105.

Snodgrass 1964 : SNODGRASS (A.). - Early greek armour and weapons. Edimburgh University Press. 1964.

Solier 1976 : SOLIER (Y.), RANCOULE (G.), PASSELAC (M.). - La nécropole de Las Peyros VIe siècle av. n. è à Couffoulens (Aude). Revue Archéologique de Narbonnaise, suppl. 6, CNRS, 1976.

Spindler 1976 : SPINDLER (K.). - Magdalenenberg IV. Der hallstattzeitliche Fiirstgrabhiigel bei Villigen im Schwartzwald, 1976, 84 p., 144 taf.

Spitzing 1984: SPITZING (T.). - Der Eisendepotfunde von Mengen, Fr. BreisgauHochschwartzwald. Archäologischen Nachrichten aus Baden, 32, 1984, p. 20-27, 7 pl.

Stockli 1975 : STOCKLI (W.-E.). - Chronologie der Jüngerenzeit im Tessin. Antiqua 2, Bâle, 1975, 188 p., $50 \mathrm{pl}$.

Sulimirski 1961 : SULIMIRSKI (T.). - Die Scythen in Mittelund Westeuropa. Bericht über den V. internazionalen kongress fur vor-und Friihgeschichte (Hambourg 1958), Berlin. 1961. p. 793-799.

Suter 1984 : SUTER (P.-J.). - Neuere MittellateneGrabkomplexe aus dem Kanton Bern. Annuaire Suisse de Préhistoire et d'Archéologie, vol. 67, 1984, p. 73-93, 13 fig.

Szabó 1983 : SZABó (M.). - La migration des Celtes. Histoire et Archéologie. n 77, 1983, p. 12-19.

Taffanel 1967 : TAFFANEL (O.), TAFFANEL (J.). - Les épées à sphères à Mailhac. Gallia, t. XXV, fasc. 1, 1967, p. 1-10.

Tendille 1978 : TENDILLE (C.). - Les fibules protohistoriques de la région nîmoise. Documents d'Archéologie Méridionale, 1, 1978, p. 77-112.

Tendille 1980 : TENDILLE (C.). - Mobiliers protohistoriques de la région nîmoise : autres objets de parures et d'habillement. Documents d'Archéologie Méridionale, 3, 1980, p. 95-124.

Tendille 1982: TENDILLE (C.). - Mobiliers métalliques protohistoriques de la région nîmoise : instruments et outils divers (V). Documents d'Archéologie Méridionale, 5, 1982, p. 33-52, 10 fig. 
Tendille 1983: TENDILLE (C.). - Le mobilier métallique. In: RAYNAUD (Cl.), ROUX (J.-C.). L'oppidum des Gardies à Pignan (Hérault), VIe-Ve siècle av. J.-C. Documents d'Archéologie Méridionale, 6, 1983, p. 52-60.

Thévenot 1983 : THEVENOT (J.-P). - Le Camp de Chassey. La vallée de la Saône aux âges du Fer (VIIeIe siècles av. n. è). Catalogue de l'exposition, Château Saint-Michel de Rully, 12-29 mai 1983, p. 26-29.

Tisserand 1980 : TISSERAND (G.). - Les ex-votos du site de Flaviers à Mouzon (Ardennes). Revue Archéologique de l'Est, t. XXXI, fasc. 1-2, 1980, p. 61-73.

Tizzoni 1987 : TIZZONI (M.). - Les épées laténiennes estampillées de Lombardie. Les Celtes et l'Italie, Dossiers de l'Archéologie, n 112, janv. 1987, p. 70-73.

Todorovic 1972 : TODOROVIC (J.). - Praistorijska Karaburma I. Nekropola mladeg vozdenog doba, Belgrade, 1972.

Todorovic 1974 : TODOROVIC (J.). - Scordisci. Belgrade, 1974, 295 p.

Treffort 1986 : TREFFORT (J. L.), VORUZ (J. L.). - La grotte du Gardon à Ambérieu-en-Bugey (Ain) : un site exceptionnel. Cahiers René de Lucinges, $\mathrm{n}^{\circ} 2,1986$.

Trümpler 1957 : TRUMPLER (D.), BERARD (CL.), SAUTER (M.-R.). - Tombes de La Tène C trouvées dans le village du Levron (Comm. de Vollèges, Valais). Archives Suisses d'Anthropologie Générale, $\mathrm{t}$. XXII, n 1, 1957, p. 55-75.

Tschumi 1929 : TSCHUMI (O.). - Der Massenfund von Tiefenau auf der Engehalbinsel bei Bern. Einundzwangzister Jahrbericht der Schweizerischen Gesellschaft fiir Urgeschichte, 1929, p. 131-148.

Tschumi 1940 : TSCHUMI (O.). - Die Ur-und friihgeschichtliche fundstelle von Port in am nidau (Kanton bern). Verlag der heimatkundekommission seeland, Biel, 1940.

Vaginay 1984: VAGINAY (M.), GUICHARD (V.). - Une fosse de La Tène moyenne à Goincet (Poncins, Loire). Revue Archéologique de l'Est, t. 35, fasc. 3-4, 1984, p. 191-226, 20 fig.

Vaginay 1988 : VAGINAY (M.). GUICHARD (V.). - L'habitat gaulois de Feurs (Loire). Fouilles récentes. Documents d'Archéologie Française, n 14, Maison des Sciences de l'Homme, 1988, 200 p., 153 fig.

Vaginay 1988 : VAGINAY (M.). - Les oppida de La Loire ; Joeuvre et le Crêt-Châtelard : recherches récentes ; Cahiers Archéologiques de la Loire, 6,1989, p. 47-67.

Vallier 1879: VALLIER (G.). - Découverte de monnaies gauloises à Moirans (Isère) (Avril 1879), Grenoble, 1879.

Vaussanvin 1978 : VAUSSANVIN (H.). - Les importations de céramiques à vernis noir dans la moyenne vallée de la Saône. Archéologie en Languedoc, 1, 1978, p. 139-148.

Venclovâ 1989 : VENCLOVA (N.). - La parure celtique en verre en Europe centrale. Le verre préromain en Europe occidentale, 1989, p. 85-97.

Verger 1988: VERGER (S.), GUILLAUMET (J.-P.). - Les tumulus de Saint-Romain-de-Jalionas (Isère). Premières observations. Les princes celtes et la Méditerranée, Rencontres de l'Ecole du Louvre. La Documentation Française, 1988, p. 231 - 240.

Veter 1976 : VETER (A.), LAMOTHE (M.-J.). - Le livre de l'outil, Ed. hier et demain. 1976.

Verchère de Reffye 1864 : VERCHERE DE REFFYE. - Les armes d'Alise. Revue Archéologique, II, 1864 .

Vidal 1976 : VIDAL (M.). - Le seau en bois orné de Vieille-Toulouse (Haute-Garonne). Gallia. t. 34, 1976, p. 167-200.

Vignard 1961 : VIGNARD (M.). - Essai d'inventaire archéologique de la Drôme, les trouvailles isolées de l'âge du Bronze. Ogam, t. XIII, fasc. 1, n 73, 1961, p. 25-46.

Villard 1960 : VILLARD (F.). - La céramique grecque de Marseille, Paris, 1960, 177 p., 58 pl. 
Villard 1988 : VILLARD (F.). - Des vases grecs chez les Celtes. Les princes celtes et la Méditerranée, Rencontres de l'Ecole du Louvre, La Documentation Fraçaise, 1988, p. 333-341.

Viollier 1916 : VIOLLIER (D.). - Les sépultures du second âge du Fer sur le Plateau Suisse, Genève, 1916.

Vital 1984 : VITAL (J.). - Sites et industries de l'âge du Bronze dans le défilé de Donzère (Drôme). Thèse de 3e cycle, Université de Bordeaux I, 2 vol.. 1984 (dactylographié).

Vital 1986 : VITAL (J.), VORUZ (J.-L.). - Les tombes à incinérations de Chamboux à Montalieu-Vercieu (Isère). Résumé des communications $\mathrm{du}^{\mathrm{Xe}}$ Colloque sur l'âge du Fer de L’AFEAF, Yenne-Chambéry, 8-11 mai 1986, p. 6-7.

Vital 1988 : VITAL (J.). - Un four-dépotoir du VIIIe/VIIe siècle av. J.-C. à Sinzelles-Caramontron (comm. de Polignac, Haute-Loire). Revue Archéologique du Centre de la France, t. 27, fasc. 1, 1988, p. $43-60$

Vitali 1985 : VITALI (D.). - Gisements miniers et objets celtiques à Monte-Bibele (province de Bologne), quelques considérations préliminaires. Les âges du Fer dans la vallée de la Saône. Revue Archéologique de l'Est, 6e suppl., 1985, p. 263-269, 7 fig.

Von Kaenel 1981 : VON KAENEL (H. -M.). - Zum Massalia-Obol aus grab 22. In : MARTIN-KILSCHER (S.). - Das Keltische Grâberfeld vom Vevey VD. Annuaire Suisse de Préhistoire et d'Archéologie, vol. 64, 1981, p. 119-120.

Vouga 1923 : VOUGA (P.). - Trousse d'outils à La Tène. Genava, Bulletin du Musée d'Art et d'Histoire, 1, 1923, p. 113-117, 3 fig.

Vuaillat 1981 : VUAILLAT (D.), LAMBERT (G.). - Essai de description formelle sur les épées hallstattiennes de l'Est de la France. Approche d'une méthode de gestion de l'information. Revue d'Archéométrie, nº 5, 1981, p. 199-215.

Waldhauser 1974 : WALDHAUSER (J.). - Die keltische Viereckschanzen in Böhmen. The Celts in Central Europe, Szekesfehèrvar, 1974, p. 235-244.

Werner 1954 : WERNER (J.). - Die Bronzekanne von Kelheim. Bayerische vorgeschichtblatter, 20, 1954, p. 43-73.

Werner 1955: WERNER (J.). - Die Nauheimer Fibel. Jahrbuch des rômisch-germanischen Zentralmuseums Mainz, 2, 1955, p. 170-195.

Werner 1979 : WERNER (J.). - Spates Keltentum zwischen Röm und Germanien. Miinchen, 1979, 220 p.

Willaume 1977 : WILLAUME (M.) et alii. - La nécropole de Mainville à Bromeilles (Loiret). Revue Archéologique du Loiret, 3,1977, p. 54-55.

Willaume 1987 : WILLAUME (M.). - Les objets de la vie quotidienne. Archéologie d'Entremont, Musée Granet, 1987.

Wilson 1985 : WILSON (D.). - La Tapisserie de Bayeux. Edition Albin Michel, 1985.

Wyss 1975 : WYSS (R.). - Sépultures, sanctuaires, sacrifices et leurs relations avec l'habitat en Suisse à l'époque celtique. L'habitat et la nécropole à l'âge du Fer en Europe occidentale et centrale, P.M. DUVAL, V. KRUTA éds, Paris, 1975, p. 75-86. 


\section{Crédits illustrations}

\section{Dessin, plans, graphiques et cartes de répartition}

1 F. Perrin, C. Plantevin : fig. 2, 3, 8, 9, 14,-18, 20-22, 24-33, 35, 36, 38, 40-41, 43-45, 47, 49-51, 54-65, 68, 69, 70, 72, 74, 76-78, 80-84, 86-93, 95-99, 101-144, 147, 148.

Maison du patrimoine de Hières-sur-Amby : fig. 4,5 .

M. Feugère : fig. 6.

\section{Photographies}

2 Musée de la Civilisation Gallo-Romaine de Lyon :

F. Leyge, Ch. Thioc : fig. 7, 19, 34, 37, 39, 42, 46, 48, 52-53, 66, 67, 71,73, 75, 79, 85, 94, 100.

Ch. Thioc: Photos de couverture.

Musée Dauphinois de Grenoble :

B. Roche : fig. 23.

C. Bellon : fig. $1,13$.

K. Gruel : fig. 12.

V. Guichard : fig. 10, 11, 145, 146. 